\title{
PYROLYSIS OF BLACK LIQUOR IN A HIGH-INTENSITY ACOUSTIC FIELD
}

\author{
A Thesis Submitted by
}

Steven A. Koepke

B.S. 1991, University of Minnesota

M.S. 1993, Institute of Paper Science and Technology

in partial fulfillment of the requirements of the Institute of Paper Science and Technology

for the degree of Doctor of Philosophy Atlanta, Georgia

Publication Rights reserved by the Institute of Paper Science and Technology 


\title{
PYROLYSIS OF BLACK LIQUOR IN A HIGH-INTENSITY ACOUSTIC FIELD
}

\author{
A Thesis Submitted by
}

Steven A. Koepke

B.S. 1991, University of Minnesota

M.S. 1993, Institute of Paper Science and Technology

in partial fulfillment of the requirements of the Institute of Paper Science and Technology

for the degree of Doctor of Philosophy Atlanta, Georgia

Publication Rights reserved by the Institute of Paper Science and Technology 
ABSTRACT

LIST OF FIGURES

LIST OF TABLES

NOMENCLATURE

[1] INTRODUCTION

[2] LITERATURE REVIEW

[2.1] GENERAL MECHANISM OF BIOMASS PYROLYSIS

[2.1.1] Effects of Temperature, Heating Rate, and Holding Time

[2.1.2] Influence of Mass Transfer Rate of Products

[2.2] EXPERIMENTAL STUDIES OF BIOMASS PYROLYSIS

[2.2.1] Types of Reactors

[2.2.2] Pyrolysis of Cellulose, Hemicellulose, Hydroxy Acids, Lignin, Wood, and Coal

[2.2.3] Pyrolysis of Black Liquor

[2.3] PROPAGATION OF ACOUSTIC WAVES 32

[2.3.1] Traveling Waves

[2.3.2] Resonant Standing Wave in a Tube

[2.4] ACOUSTIC ENHANCEMENT OF HEAT AND MASS TRANSFER RATES 37

[2.4.1] Role of Acoustic Velocity

[2.4.2] Role of Acoustic Pressure

[3] ANALYSIS OF THE PROBLEM AND THESIS OBJECTIVES

[4] EXPERIMENTAL

[4.1] EXPERIMENTAL REACTOR

[4.1.1] Reactor Tube and Support Frame $\quad 55$

[4.1.2] Acoustic Compression Driver and Air Purge $\quad 58$

[4.1.3] Horizontal Trombone Tube $\quad 58$

[4.1.4] Secondary Gas Preheater and $45^{\circ}$ Elbow Section 59

[4.1.5] Particle Feeder and 90 ${ }^{\circ}$ Elbow Section $\quad 59$

[4.1.6] Vertical Heated Pyrolysis Tube 63

[4.1.7] Acoustic Decoupler/Char Collector 66

[4.1.8] Pyrolysis Gas Analysis System 67

[4.1.9] Gas and Particle Flow Imaging System 69

[4.1.10] Data Acquisition System $\quad 70$

[4.2] DESIGN OF PYROLYSIS EXPERIMENTS

[4.3] REACTOR OPERATING PROCEDURE

[5] RESULTS AND DISCUSSION

[5.1] RESULTS OF PYROLYSIS EXPERIMENTS

[5.1.1] Analysis of Pyrolysis Products $\quad 84$

[5.1.2] Char Analysis $\quad 85$

[5.1.2.1] Char Yields from Inflight Particle Pyrolysis Experiments 85 
[5.1.2.2] Char Chemical Composition $\quad 89$

[5.1.2.3] Kinetics of Carbon Conversion to Char and Volatiles 97

$\begin{array}{ll}\text { [5.1.2.4] Conclusions } & 99\end{array}$

[5.1.3] SEM Analysis of Char Particles 99

[5.1.3.1] Morphology of Char Particles Obtained at a Gas Temperature of $\mathbf{4 0 0}^{\circ} \mathrm{C}$

[5.1.3.2] Morphology of Char Particles Obtained at a Gas Temperature of $550^{\circ} \mathrm{C}$

[5.1.3.3] Morphology of Char Particles Obtained at a Gas Temperature of $\mathbf{7 0 0}^{\circ} \mathrm{C} \quad 113$

$\begin{array}{ll}\text { [5.1.3.4] Conclusions } & 117\end{array}$

[5.1.4] SEM Analysis of Glass-fiber Filters 118

[5.1.4.1] Morphology of Tar Material Obtained at a Gas Temperature of $400^{\circ} \mathrm{C}$

[5.1.4.2] Morphology of Tar Material Obtained at a Gas Temperature of $550^{\circ} \mathrm{C}$

[5.1.4.3] Morphology of Tar Material Obtained at a Gas Temperature of $550^{\circ} \mathbf{C} \quad 126$

$\begin{array}{ll}\text { [5.1.4.4] Conclusions } & 130\end{array}$

[5.1.5] FT-IR Analysis of Tarry Liquid and Fume Coated Glass-fiber Filters 131

[5.1.5.1] Chemical Composition of Material Obtained at a Gas Temperature of $400^{\circ} \mathrm{C}$

133

[5.1.5.2] Chemical Composition of Material Obtained at a Gas Temperature of $550^{\circ} \mathrm{C}$

[5.1.5.3] Chemical Composition of Material Obtained at a Gas Temperature of $700^{\circ} \mathrm{C}$

[5.1.5.4] Conclusions

[5.1.6.1] $\mathrm{CO}$ and $\mathrm{CO}_{2}$ Yields Obtained From Non-sticking, Inflight Particle Experiments

[5.1.6.2] $\mathrm{CO}$ and $\mathrm{CO}_{2}$ Obtained From Inflight Particle Pyrolysis Experiments at $\geq 158 \mathrm{~dB}$

[5.1.6.3] Effects of Secondary Gas Space-time and Particle Residence Time on Primary and Secondary $\mathrm{CO}$ and $\mathrm{CO}_{2}$ Yields Obtained at a Gas Temperature of $400^{\circ} \mathrm{C}$

[5.1.6.4] Effects of Secondary Gas Space-time and Particle Residence Time on Primary and Secondary $\mathrm{CO}$ and $\mathrm{CO}_{2}$ Yields Obtained at a Gas Temperature of $550^{\circ} \mathrm{C}$ [5.1.6.4.1] Primary $\mathrm{CO}$ and $\mathrm{CO}_{2}$ Yields 156 [5.1.6.4.2] Secondary $\mathrm{CO}$ and $\mathrm{CO}_{2}$ Yields 158 [5.1.6.4.3] Effect of Tar Polymerization on Secondary $\mathrm{CO}_{2}$ Yields

[5.1.6.4] Effect of Gasification on $\mathrm{CO}$ and $\mathrm{CO}_{2}$ Yields Obtained at Gas Temperatures of 550 and $700^{\circ} \mathrm{C}$ 
[5.2] GAS AND PARTICLE FLOW ANALYSIS 169

[5.2.1] Estimation of Particle Residence Time Using the Diode Laser System 169

[5.2.2] High- and Low-Speed Video Imaging of Gas and Particle Flows in

$\begin{array}{ll}\text { Simulated Pyrolysis Tube } & 170\end{array}$

$\begin{array}{ll}\text { [5.2.3] Conclusions } & 178\end{array}$

[6] CONCLUSIONS 179

[7] LITERATURE CITED 182

[8] ACKNOWLEDGEMENTS 191

[A1] APPENDIX 1. A LIST OF MAJOR EXPERIMENTAL EQUIPMENT 192

[A2] APPENDIX 2. DATA ACQUISITION COMPUTER PROGRAM 195

[A3] APPENDIX 3. PREPARATION OF BLACK LIQUOR PARTICLES 202

[A4] APPENDIX 4. CHAR COLLECTION, TAR EXTRACTION, CHEMICAL

COMPOSITION, AND UNCERTAINTY ANALYSIS 203

[A4.1] CHAR COLLECTION 203

[A4.2] TAR EXTRACTION FROM CHAR 204

[A4.3] CHAR CHEMICAL COMPOSITION AND UNCERTAINTY ANALYSIS 205

[A5] APPENDIX 5. CALCULATION OF CO AND $\mathrm{CO}_{2}$ YIELDS AND

UNCERTAINTY ANALYSIS $\quad 216$

[A5.1] PARTICLE FEEDER CALIBRATION 216

[A5.2] CALCULATION OF ACTUAL CO AND $\mathrm{CO}_{2}$ YIELDS FROM

MEASURED CO AND $\mathrm{CO}_{2}$ CONCENTRATIONS 217

[A5.3] CALCULATION OF ESTIMATED $\mathrm{CO}_{2}$ YIELD FROM

ESTIMATED CO $\mathrm{C}_{2}$ CONCENTRATION 220

[A6] APPENDIX 6. SEM IMAGING AND FT-IR ANALYSIS METHODS OF

TARRY LIQUID AND FUME ON GLASS-FIBER FILTERS 253

[A6.1] SEM IMAGING 253

[A6.2] FT-IR ANALYSIS 253

[A7] APPENDIX 7. THERMOCOUPLE TEMPERATURE MEASUREMENTS AND ERROR ANALYSIS $\quad 255$

[A8] APPENDIX 8. AMPLITUDES OF MEASURED ACOUSTIC PRESSURE

AND CALCULATED ACOUSTIC VELOCITY IN THE HEATED

PYROLYSIS TUBE

[A9] APPENDIX 9. MEASURED PARTICLE RESIDENCE TIMES IN THE

PYROLYSIS TUBE IN COLD FLOW EXPERIMENTS

[A9.1] ESTIMATION OF CHAR PARTICLE DENSITY

[A9.2] AMPLITUDES OF MEASURED ACOUSTIC PRESSURE AND

CALCULATED ACOUSTIC VELOCITY IN THE PYROLYSIS TUBE 283

[A9.3] MEASURED PARTICLE RESIDENCE TIMES 285

[A10] APPENDIX 10. NUMERICAL MODELING 291

[A10.1] PURPOSE AND LIMITATIONS OF NUMERICAL MODELS 291

[A10.2] FORMULATION OF MODEL TO ESTIMATE MEAN PARTICLE

RESIDENCE

282

282

[A10.2.1] Model Estimation of Mean Char Particle Residence Time in the Pyrex Tube Measured During Gas and Particle Flow Imaging Studies 
[A10.2.2] Model Estimation of Mean Char Particle Residence Time in Heated Pyrolysis Tube During Pyrolysis Experiments

[A10.3] FORMULATION OF MODEL TO ESTIMATE PARTICLE

HEATUP RATES TO PEAK GAS TEMPERATURE

[A10.4] FORMULATION OF KINETIC MODEL TO ESTIMATE CARBON CONVERSION TO CHAR AND VOLATILES

[A11] APPENDIX 11. MISCELLANEOUS CALCULATIONS

[A11.1] SECONDARY GAS ACTUAL SPACE-TIME

[A11.2] ACOUSTIC CONDITIONS FOR A QUASI STEADY-STATE

FLOW FIELD AROUND 106-125 $\mu \mathrm{m}$ DIAMETER PARTICLES 


\begin{abstract}
The overall objective of this dissertation was to understand how high-intensity acoustic oscillation influence the pyrolysis of dry, 105-125 $\mu \mathrm{m}$ diameter, black liquor particles with respect to their chemical and physical transformation to pyrolytic products. Specifically, the effects of increased rates of particle heatup to peak temperature and mass transport of products from the particle on the yields of char, tar, and gases were investigated.
\end{abstract}

Particles were pyrolyzed in an entrained flow reactor fitted with acoustic wave generation equipment. Particle pyrolyses were conducted inflight and in semi-batch mode at gas temperatures between $400-700^{\circ} \mathrm{C}$. Residence times of inflight particles, tar aerosol, and tar vapor in the reactor were controlled by varying both the heated length of the reactor and the flowrate of nitrogen. In semi-batch mode, particles were retained on a steel-wool-plug to obtain data at long residence times. Acoustic amplitudes ranged from 146-160 dB and frequencies ranged from $310-1000 \mathrm{~Hz}$.

Experimental data collected include char yield, fraction of the carbon in black liquor as total and carbonate carbon in the char, SEM images of char particles, FT-IR spectra and SEM images of material filtered from the product gas, $\mathrm{CO}$ and $\mathrm{CO}_{2}$ yields, and high- and low-speed video of smoke-laden gas and particle flows in the reactor. Theoretical analyses were done to estimate particle residence time, particle heatup rate, and the pyrolytic conversion of carbon in the black liquor to char and total volatiles. 
It was found that at a gas temperature of $400^{\circ} \mathrm{C}$, acoustics did not affect char or $\mathrm{CO}$ and $\mathrm{CO}_{2}$ yields due to too low temperature for progression of tar secondary reactions. At a gas temperature of $550^{\circ} \mathrm{C}$, char yield was reduced by $10 \%$ and $\mathrm{CO}$ and $\mathrm{CO}_{2}$ gas yields were increased by $40-500 \%$ and $40-1000 \%$, respectively, with an acoustic field under various particle reaction (residence) times. At a gas temperature of $700^{\circ} \mathrm{C}, \mathrm{CO}_{2}$ yield increased by $30-80 \%$ with an acoustic field, whereas $\mathrm{CO}$ and char yields were about the same. The results of char and gas yields also show that acoustic effects were more enhanced during the initial particle heatup period. The fact that acoustics selectively enhanced the two slightly endothermic reactions, organic carbon reduction and inorganic (carbonate) carbon formation, indicates that acoustics increased the heat transfer from the surrounding gas to the particles. The fact that acoustics most significantly increased $\mathrm{CO}_{2}$ yield and reduced char yield at a gas temperature of $550^{\circ} \mathrm{C}$, at which reactive tars may undergo secondary cracking to form $\mathrm{CO}_{2}$ or polymerize into char unless the tar can escape, indicates that acoustics enhanced the transport of reactive tar species away from the pyrolyzing particle. At a higher temperature of $700^{\circ} \mathrm{C}$, lack of reduction of char yield with acoustics indicates a critical heating rate has been attained with or without acoustics and that secondary cracking of reactive tar functional groups to form $\mathrm{CO}_{2}$ is more favored than tar polymerization into char. SEM analysis of the char surfaces revealed that particles swelled much more and large bubbles were formed at the particle surface when particles were pyrolyzed with acoustic fields, further verifying the enhanced heat and mass transfer between the particle surfaces and the surrounding gas. 


\section{LIST OF FIGURES}

Figure 1. Four stages of burning of a black liquor droplet.

Figure 2. A schematic diagram of the general mechanism of biomass pyrolysis.

Figure 3. A schematic diagram of the retort furnace reactor, heated grid reactor, and entrained flow reactor.

Figure 4. A schematic diagram of a sinusoidal acoustic wave of amplitude $\hat{a}$, wavelength $\lambda$, and velocity $c$ traveling through a medium in coordinates of time $t$ and distance $x$ away from the origin O. EE' shows the particles of the medium at their equilibrium positions. DD' shows the displacement of the particles of the medium undergoing simple harmonic motion at an instant $t=0$ as the wave passes to the right. vv' shows the velocities of the particles of the medium at an instant $t=0$. Curve along OX is the wave form of the displacement of the particles of the medium at an instant $t=0$. Curve along $\mathrm{OX}^{\prime}$ is the waveform of the acoustic pressure at an instant $t=0$.

Figure 5. A schematic diagram of the reflection of an acoustic wave at the open end of a tube reactor. (a) $t=0$ and (b) $t=$ time at $1 / 4$ period later.

Figure 6. An illustration of acoustic streaming of particles of a medium about a cylinder showing inner and outer streaming vortices.

Figure 7. An illustration of quasi steady-state flow reversal and wake shedding from a cylinder at different times $\chi$ during an oscillation cycle ( $\chi$ spans from $0-1$ during one cycle). Shaded areas represent the schlieren image of water vapor that has evaporated from the surface of a sintered cylinder. The oscillatory flow velocity is a maximum at $\chi=0,0.5$, and 1 and a minimum at $\chi=0.25$ and 0.75 . Peak oscillatory velocities were between $63-75 \mathrm{~m} / \mathrm{s}$.

Figure 8. An illustration of two main acoustic streaming vortices inside of a tube containing a resonant axial acoustic field with mean flow.

Figure 9. A schematic diagram of the experimental facility.

Figure 10. Photographs of the reactor showing gas cylinder side and instrumentation side.

(a) acoustic compression drivers, (b) product gas exhaust, (c) trombone tube,

(d) particle injection $90^{\circ}$ elbow, (e) pyrolysis section, (f) acoustic decoupler and $\mathrm{N}_{2}$ gas quench, (g) diode laser for particle residence time determinations, (h) particle feeder, (i) $\mathrm{N}_{2}$ gas preheater and $45^{\circ}$ elbow, (j) heater and sound generation instrumentation, $(\mathrm{k})$ trombone tube, and (l) air regulation for vacuum ejector. 
Figure 11. A photograph and schematic diagram of the particle feeder. (a) off-take tube, (b) top carrier gas, (c) top tube, (d) o-ring seal, (e) inverted cone, (f) feed vial,

(g) sintered distributor plate, (h) bottom carrier gas, (i) screwjack, and

(j) electric screwjack drive motor.

Figure 12. A schematic diagram of the $90^{\circ}$ elbow section. (a) acoustic pressure probe port, (b) inner particle injector tube, (c) cooling water inlet, (d) cooling water outlet, (e) particle injector assembly, (f) graphite gaskets, (g) preheated $\mathrm{N}_{2}$ inlet, (h) $45^{\circ}$ elbow section, (i) plate heaters, (j) flow vane, (k) thermocouple, and (l) pyrolysis tube section.

Figure 13. A schematic diagram of the acoustic pressure probe and calibration system. (a) piston with o-ring seal, (b) reference pressure transducer, (c) pressure probe, (d) water outlet, (e) water inlet, (f) probe pressure transducer, and (g) semi-infinite tube.

Figure 14. A photograph of the pyrolysis section. (a) ceramic heater, (b) thermocouple,

(b) heater power supply junction box, (d) optical port, and

(e) acoustic decoupler.

Figure 15. A schematic diagram of the diode laser system for measuring the residence time of a pulse of particles in the pyrolysis tube.

Figure 16. A schematic diagram of the acoustic decoupler/char collector. (a) pyroylsis tube, (b) expansion chamber lid, (c) flange gasket, (d) $\mathrm{N}_{2}$ quench, (e) thermocouple, (f) tube to static pressure transducer, (g) teflon flange seal and tar and fume filter, (h) product gas exhaust tube, and (i) char collection zone.

Figure 17. A schematic diagram of the pyrolysis gas analysis system. 68

Figure 18. A schematic diagram of the gas and particle flow imaging system. 70

Figure 19. A schematic diagram of pyrolytic processes occurring in the acoustic reactor.

Figure 20. Char yields obtained from non-sticking, inflight particle pyrolysis experiments with and without an acoustic field of $146-154 \mathrm{~dB}$ and $310-1000 \mathrm{~Hz}$ at a gas temperature of $550^{\circ} \mathrm{C}$. Pyrolysis tube and secondary gas flow configurations were: $0.18,0.48$, and $0.81 \mathrm{~m}$ heated length and 20 slpm preheated $\mathrm{N}_{2}$, and $0.81 \mathrm{~m}$ heated length and 5 and 10 slpm preheated $\mathrm{N}_{2}$.

Figure 21. Char yields obtained from non-sticking, inflight particle pyrolysis experiments with and without an acoustic field of $151 \mathrm{~dB}$ and $950-990 \mathrm{~Hz}$ at gas temperatures of 400 and $700^{\circ} \mathrm{C}$. Pyrolysis tube and secondary gas flow configurations were: $0.18,0.48$, and $0.81 \mathrm{~m}$ heated length and $20 \mathrm{slpm}$ preheated $\mathrm{N}_{2}$. 
Figure 22. Wt\% of BLS, or percent of the carbon in BLS, as total carbon in char obtained from non-sticking, inflight particle pyrolysis experiments with and without an acoustic field of $151 \mathrm{~dB}$ and $970-1000 \mathrm{~Hz}$ at a gas temperature of $550^{\circ} \mathrm{C}$. Pyrolysis tube and secondary gas flow configurations were: $0.18,0.48$, and $0.81 \mathrm{~m}$ heated lengths and 20 slpm preheated $\mathrm{N}_{2}$, and $0.81 \mathrm{~m}$ heated length and $5 \mathrm{slpm}$ preheated $\mathrm{N}_{2}$.

Figure 23. $\mathrm{Wt} \%$ of BLS, or percent of the carbon in BLS, as carbonate carbon in char obtained from non-sticking, inflight particle pyrolysis experiments with and without an acoustic field of $151 \mathrm{~dB}$ and $970-1000 \mathrm{~Hz}$ at a gas temperature of $550^{\circ} \mathrm{C}$. Pyrolysis tube and secondary gas flow configurations were: 0.18 , 0.48 , and $0.81 \mathrm{~m}$ heated lengths and 20 slpm preheated $\mathrm{N}_{2}$, and $0.81 \mathrm{~m}$ heated length and 5 slpm preheated $\mathrm{N}_{2}$.

Figure 24. $\mathrm{Wt} \%$ of BLS, or percent of the carbon in BLS, as organic carbon in char obtained from non-sticking, inflight particle pyrolysis experiments with and without an acoustic field of $151 \mathrm{~dB}$ and $970-1000 \mathrm{~Hz}$ at a gas temperature of $550^{\circ} \mathrm{C}$. Pyrolysis tube and secondary gas flow configurations were: $0.18,0.48$, and $0.81 \mathrm{~m}$ heated lengths and 20 slpm preheated $\mathrm{N}_{2}$, and $0.81 \mathrm{~m}$ heated length and $5 \mathrm{slpm}$ preheated $\mathrm{N}_{2}$.

Figure 25. Wt\% of BLS, or percent of the carbon in BLS, as total carbon in char obtained from non-sticking, inflight particle pyrolysis experiments with and without an acoustic field of $151 \mathrm{~dB}$ and $950-990 \mathrm{~Hz}$ at a gas temperature of $700^{\circ} \mathrm{C}$. Pyrolysis tube and secondary gas flow configurations were: $0.18,0.48$, and $0.81 \mathrm{~m}$ heated lengths and 20 slpm preheated $\mathrm{N}_{2}$.

Figure 26. Wt\% of BLS, or percent of the carbon in BLS, as carbonate carbon in char obtained from non-sticking, inflight particle pyrolysis experiments with and without an acoustic field of $151 \mathrm{~dB}$ and $950-990 \mathrm{~Hz}$ at a gas temperature of $700^{\circ} \mathrm{C}$. Pyrolysis tube and secondary gas flow configurations were: 0.18 , 0.48 , and $0.81 \mathrm{~m}$ heated lengths and $20 \mathrm{slpm}$ preheated $\mathrm{N}_{2}$.

Figure 27. $\mathrm{Wt} \%$ of BLS, or percent of the carbon in BLS, as organic carbon in char obtained from non-sticking, inflight particle pyrolysis experiments with and without an acoustic field of $151 \mathrm{~dB}$ and $950-990 \mathrm{~Hz}$ at a gas temperature of $700^{\circ} \mathrm{C}$. Pyrolysis tube and secondary gas flow configurations were: 0.18 , 0.48 , and $0.81 \mathrm{~m}$ heated lengths and 20 slpm preheated $\mathrm{N}_{2}$.

Figure 28. A comparison of the percent of the carbon in BLS as total carbon in the char estimated with a two parallel, first-order, irreversible reaction kinetics model and measured with and without an acoustic field of $151 \mathrm{~dB}$ and $950-1000 \mathrm{~Hz}$ under conditions of $0.21-1.26 \mathrm{~s}$ particle residence time and secondary gas temperatures of 550 and $700^{\circ} \mathrm{C}$. 
Figure 29. SEM images of char particles obtained with an acoustic field of $151 \mathrm{~dB}$ and $960 \mathrm{~Hz}(\mathrm{RAC1119})$ under reactor conditions of $400^{\circ} \mathrm{C}, 0.81 \mathrm{~m}$ pyrolysis tube heated length, $1.10 \mathrm{~s}$ particle residence time, and $2.10 \mathrm{~s}$ secondary gas space-time.

Figure 30. SEM images of char particles obtained without acoustics (RNAC1113) under conditions of $400^{\circ} \mathrm{C}, 0.81 \mathrm{~m}$ pyrolysis tube heated length, $0.86 \mathrm{~s}$ particle residence time, and $2.10 \mathrm{~s}$ secondary gas space-time.

Figure 31. A SEM image of a single char particle obtained with an acoustic field of $151 \mathrm{~dB}$ and $1000 \mathrm{~Hz}$ (RAC1107) under reactor conditions of $550^{\circ} \mathrm{C}, 0.18 \mathrm{~m}$ pyrolysis tube heated length, $0.27 \mathrm{~s}$ particle residence time, and $0.38 \mathrm{~s}$ secondary gas space-time.

Figure 32. A SEM image of a single char particle obtained without acoustics (RNAC1105) under reactor conditions of $550^{\circ} \mathrm{C}, 0.18 \mathrm{~m}$ pyrolysis tube heated length, $0.23 \mathrm{~s}$ particle residence time, and $0.38 \mathrm{~s}$ secondary gas space-time.

Figure 33. A SEM image of a single char particle obtained with an acoustic field of $151 \mathrm{~dB}$ and $970 \mathrm{~Hz}$ (RAC1108) under reactor conditions of $550^{\circ} \mathrm{C}, 0.48 \mathrm{~m}$ pyrolysis tube heated length, $0.70 \mathrm{~s}$ particle residence time, and $1.02 \mathrm{~s}$ secondary gas space-time.

Figure 34. A SEM image of a single char particle obtained with an acoustic field of $151 \mathrm{~dB}$ and $990 \mathrm{~Hz}$ (RAC925B) under reactor conditions of $550^{\circ} \mathrm{C}, 0.81 \mathrm{~m}$ pyrolysis tube heated length, $1.26 \mathrm{~s}$ particle residence time, and $1.72 \mathrm{~s}$ secondary gas space-time.

Figure 35. A SEM image of a single char particle obtained without acoustics (RNA21105) under reactor conditions of $550^{\circ} \mathrm{C}, 0.48 \mathrm{~m}$ pyrolysis tube heated length, $0.54 \mathrm{~s}$ particle residence time, and $1.02 \mathrm{~s}$ secondary gas space-time.

Figure 36. A SEM image of a single char particle obtained without acoustics (RNAC918) under reactor conditions of $550^{\circ} \mathrm{C}, 0.81 \mathrm{~m}$ pyrolysis tube heated length, $0.90 \mathrm{~s}$ particle residence time, and $1.72 \mathrm{~s}$ secondary gas space-time.

Figure 37. A SEM image of a single char particle obtained with an acoustic field of $158 \mathrm{~dB}$ and $970 \mathrm{~Hz}$ (RAC1207) under reactor conditions of $550^{\circ} \mathrm{C}, 0.81 \mathrm{~m}$ pyrolysis tube heated length, at least $1.37 \mathrm{~s}$ particle residence time (some particles stuck to pyrolysis tube wall), and $1.72 \mathrm{~s}$ secondary gas space-time.

Figure 38. A SEM image of a single char particle obtained without acoustics (RNAC927) under reactor conditions of $550^{\circ} \mathrm{C}, 0.81 \mathrm{~m}$ pyrolysis tube heated length, $2.77 \mathrm{~s}$ particle residence time, and $6.59 \mathrm{~s}$ secondary gas space-time. 
Figure 39. A SEM image of a single char particle obtained with an acoustic field of $151 \mathrm{~dB}$ and $980 \mathrm{~Hz}(\mathrm{RAC1226})$ under reactor conditions of $550^{\circ} \mathrm{C}, 0.81 \mathrm{~m}$ pyrolysis tube heated length, $3.69 \mathrm{~s}$ particle residence time, and $6.59 \mathrm{~s}$ secondary gas space-time.

Figure 40. A SEM image of a single char particle obtained with an acoustic field of $158 \mathrm{~dB}$ and $970 \mathrm{~Hz}(\mathrm{RAC} 1224)$ under reactor conditions of $550^{\circ} \mathrm{C}, 0.81 \mathrm{~m}$ pyrolysis tube heated length, very long particle residence time due to particle levitation and sticking to pyrolysis tube wall, and $6.59 \mathrm{~s}$ secondary gas space-time.

Figure 41. A SEM image of the surface of a char particle obtained with an acoustic field of $151 \mathrm{~dB}$ and $980 \mathrm{~Hz}(\mathrm{RAC1226})$ under reactor conditions of $550^{\circ} \mathrm{C}$, $0.81 \mathrm{~m}$ pyrolysis tube heated length, $3.69 \mathrm{~s}$ particle residence time, and 6.59 s secondary gas space-time.

Figure 42. A SEM image of the surface of a char particle obtained with an acoustic field of $158 \mathrm{~dB}$ and $970 \mathrm{~Hz}(\mathrm{RAC1224})$ under reactor conditions of $550^{\circ} \mathrm{C}$, $0.81 \mathrm{~m}$ pyrolysis tube heated length, very long particle residence time due to particle levitation and sticking to pyrolysis tube wall, and $6.59 \mathrm{~s}$ secondary gas space-time.

Figure 43. A SEM image of the surface of a char particle obtained with an acoustic field of $151 \mathrm{~dB}$ and $970 \mathrm{~Hz}(\mathrm{RAC} 1108)$ under reactor conditions of $550^{\circ} \mathrm{C}$, $0.48 \mathrm{~m}$ pyrolysis tube heated length, $0.70 \mathrm{~s}$ average particle residence time, and $1.02 \mathrm{~s}$ secondary gas space-time.

Figure 44. A SEM picture of the exterior surface of the char structure obtained with a steel-wool-plug (RNAC1019) located at $0.13 \mathrm{~m}$ downstream from the particle injection point under reactor conditions of $550^{\circ} \mathrm{C}, 0.81 \mathrm{~m}$ pyrolysis tube heated length, and $3.39 \mathrm{~s}$ secondary gas space-time.

Figure 45. A SEM picture of the exterior surface of a steel-wool-fiber (RNAC1019) located near the pyrolysis tube wall away from the tar product flow obtained with the steel-wool-plug located at $0.13 \mathrm{~m}$ downstream from the particle injection point under reactor conditions of $550^{\circ} \mathrm{C}, 0.81 \mathrm{~m}$ pyrolysis tube heated length, and $3.39 \mathrm{~s}$ secondary gas space-time.

Figure 46. A SEM picture of the exterior surface of a steel-wool-fiber (RNAC1019) located near the pyrolysis tube wall away from the tar product flow obtained with the steel-wool-plug located at $0.13 \mathrm{~m}$ downstream from the particle injection point under reactor conditions of $550^{\circ} \mathrm{C}, 0.81 \mathrm{~m}$ pyrolysis tube heated length, and $3.39 \mathrm{~s}$ secondary gas space-time. 
Figure 47. A SEM picture of the interior surface of the char structure obtained with a steel-wool-plug (RNAC1019) located at $0.13 \mathrm{~m}$ downstream from the particle injection point under reactor conditions of $550^{\circ} \mathrm{C}, 0.81 \mathrm{~m}$ pyrolysis tube heated length, and $3.39 \mathrm{~s}$ secondary gas space-time.

Figure 48. A SEM image of a single char particle obtained with an acoustic field of $151 \mathrm{~dB}$ and $960 \mathrm{~Hz}(\mathrm{RAC1} 126 \mathrm{~A})$ under reactor conditions of $700^{\circ} \mathrm{C}$, $0.18 \mathrm{~m}$ pyrolysis tube heated length, $0.25 \mathrm{~s}$ particle residence time, and 0.32 s secondary gas space-time.

Figure 49. A SEM image of a single char particle obtained without acoustics (RNAC1123) under reactor conditions of $700^{\circ} \mathrm{C}, 0.18 \mathrm{~m}$ pyrolysis tube heated length, $0.21 \mathrm{~s}$ particle residence time, and $0.32 \mathrm{~s}$ secondary gas space-time.

Figure 50. A SEM image of a single char particle obtained with an acoustic field of $151 \mathrm{~dB}$ and $990 \mathrm{~Hz}(\mathrm{RAC1130})$ under reactor conditions of $700^{\circ} \mathrm{C}, 0.48 \mathrm{~m}$ pyrolysis tube heated length, $0.64 \mathrm{~s}$ particle residence time, and $0.86 \mathrm{~s}$ secondary gas space-time.

Figure 51. A SEM image of a single char particle obtained with an acoustic field of $151 \mathrm{~dB}$ and $950 \mathrm{~Hz}(\mathrm{RAC1} 126 \mathrm{~B})$ under reactor conditions of $700^{\circ} \mathrm{C}, 0.81 \mathrm{~m}$ pyrolysis tube heated length, $1.15 \mathrm{~s}$ particle residence time, and $1.46 \mathrm{~s}$ secondary gas space-time.

Figure 52. A SEM image of a single char particle obtained without acoustics (RNAC1127) under reactor conditions of $700^{\circ} \mathrm{C}, 0.48 \mathrm{~m}$ pyrolysis tube heated length, $0.49 \mathrm{~s}$ particle residence time, and $0.86 \mathrm{~s}$ secondary gas space-time.

Figure 53. A SEM image of a single char particle obtained without acoustics (RNAC1122) under reactor conditions of $700^{\circ} \mathrm{C}, 0.81 \mathrm{~m}$ pyrolysis tube heated length, $0.82 \mathrm{~s}$ particle residence time, and $1.46 \mathrm{~s}$ secondary gas space-time.

Figure 54. A SEM image of tarry liquid coated glass-fiber filter obtained without acoustics (RNAC1113) under reactor conditions of $400^{\circ} \mathrm{C}, 0.81 \mathrm{~m}$ pyrolysis tube heated length, $0.85 \mathrm{~s}$ average particle residence time, and $2.10 \mathrm{~s}$ preheated secondary gas space-time.

Figure 55. A SEM image of tarry liquid coated glass-fiber filter obtained without acoustics (RNAC1105) under reactor conditions of $550^{\circ} \mathrm{C}, 0.18 \mathrm{~m}$ pyrolysis tube heated length, 0.23 or $0.54 \mathrm{~s}$ particle residence time, and 0.32 or $1.02 \mathrm{~s}$ secondary gas space-time. 
Figure 56. A SEM image of tarry liquid coated glass-fiber filter obtained with an acoustic field of $151 \mathrm{~dB}$ and $1000 \mathrm{~Hz}$ (RAC1107) under reactor conditions of $550^{\circ} \mathrm{C}, 0.18 \mathrm{~m}$ pyrolysis tube heated length, $0.27 \mathrm{~s}$ particle residence time, and $0.32 \mathrm{~s}$ secondary gas space-time.

Figure 57. A SEM image of tar fume coated glass-fiber filter obtained without acoustics (RNAC918) under reactor conditions of $550^{\circ} \mathrm{C}, 0.81 \mathrm{~m}$ pyrolysis tube heated length, $0.90 \mathrm{~s}$ particle residence time, and $1.72 \mathrm{~s}$ secondary gas space-time.

Figure 58. A SEM image of tar fume coated glass-fiber filter obtained with an acoustic field of $151 \mathrm{~dB}$ and $970 \mathrm{~Hz}$ (RAC1108) under reactor conditions of $550^{\circ} \mathrm{C}$, $0.48 \mathrm{~m}$ pyrolysis tube heated length, $0.70 \mathrm{~s}$ particle residence time, and $1.02 \mathrm{~s}$ secondary gas space-time.

Figure 59. A SEM image of tar fume coated glass-fiber filter obtained with an acoustic Field of $151 \mathrm{~dB}$ and $990 \mathrm{~Hz}$ (RAC925B) under reactor conditions of $550^{\circ} \mathrm{C}$, $0.81 \mathrm{~m}$ pyrolysis tube heated length, $1.26 \mathrm{~s}$ particle residence time, and $1.72 \mathrm{~s}$ secondary gas space-time.

Figure 60. A SEM image of tar fume and carbon fibril coated glass-fiber filter obtained with an acoustic field of $151 \mathrm{~dB}$ and $980 \mathrm{~Hz}$ (RAC1226) under reactor conditions of $550^{\circ} \mathrm{C}, 0.81 \mathrm{~m}$ pyrolysis tube heated length, $3.69 \mathrm{~s}$ particle residence time, and $6.59 \mathrm{~s}$ secondary gas space-time. Carbon fibrils resemble elongated, blade-like objects compared to tar fume pebble-like objects.

Figure 61. A SEM image of tarry liquid covered tar fume clumps that the coated glass-fiber filter obtained with an acoustic field of $158 \mathrm{~dB}$ and $970 \mathrm{~Hz}$ (RAC1224) under reactor conditions of $550^{\circ} \mathrm{C}, 0.81 \mathrm{~m}$ pyrolysis tube heated length, very long particle residence time due to particle levitation and sticking to pyrolysis tube wall, and $6.59 \mathrm{~s} \mathrm{secondary} \mathrm{gas} \mathrm{space-time.}$

Figure 62. A SEM image of tar fume coated glass-fiber filter obtained with an acoustic field of $158 \mathrm{~dB}$ and $970 \mathrm{~Hz}$ (RAC1230) under reactor conditions of $550^{\circ} \mathrm{C}$, $0.81 \mathrm{~m}$ pyrolysis tube heated length, $3.91 \mathrm{~s}$ particle residence time, $3.39 \mathrm{~s}$ secondary gas space-time, and $10 \mathrm{~s}$ on and $10 \mathrm{~s}$ off pulsed feeding of BLS particles.

Figure 63. A SEM image of a typical tarry liquid coated glass-fiber filter obtained with a steel-wool-plug at $0.13 \mathrm{~m}$ acoustic field (RNAC1019) under reactor conditions of $550^{\circ} \mathrm{C}, 0.81 \mathrm{~m}$ pyrolysis tube heated length, and $3.39 \mathrm{~s}$ secondary gas space-time. 
Figure 64. A SEM image of tar coated glass-fiber filter obtained without acoustics (RNAC1123) under reactor conditions of $700^{\circ} \mathrm{C}, 0.18 \mathrm{~m}$ pyrolysis tube heated length, $0.21 \mathrm{~s}$ particle residence time, and $0.32 \mathrm{~s}$ secondary gas space-time.

Figure 65. A SEM image of fume coated glass-fiber filter obtained without acoustics (RNAC1127) under reactor conditions of $700^{\circ} \mathrm{C}, 0.48 \mathrm{~m}$ pyrolysis tube heated length, $0.49 \mathrm{~s}$ particle residence time, and $0.86 \mathrm{~s}$ secondary gas space-time.

Figure 66. A SEM image of fume coated glass-fiber filter obtained without acoustics (RNAC1122) under reactor conditions of $700^{\circ} \mathrm{C}, 0.81 \mathrm{~m}$ pyrolysis tube heated length, $0.82 \mathrm{~s}$ particle residence time, and $1.46 \mathrm{~s}$ secondary gas space-time.

Figure 67. A SEM image of fume coated glass-fiber filter obtained with an acoustic field of $151 \mathrm{~dB}$ and $960 \mathrm{~Hz}$ (RAC1126A) under reactor conditions of $700^{\circ} \mathrm{C}, 0.18 \mathrm{~m}$ pyrolysis tube heated length, $0.25 \mathrm{~s}$ particle residence time, and $0.32 \mathrm{~s}$ secondary gas space-time.

Figure 68. A SEM image of fume coated glass-fiber filter obtained with an acoustic field of $151 \mathrm{~dB}$ and $990 \mathrm{~Hz}$ (RAC1127) under reactor conditions of $700^{\circ} \mathrm{C}$, $0.48 \mathrm{~m}$ pyrolysis tube heated length, $0.64 \mathrm{~s}$ particle residence time, and 0.86 s secondary gas space-time.

Figure 69. A SEM image of fume coated glass-fiber filter obtained with an acoustic field of $151 \mathrm{~dB}$ and $950 \mathrm{~Hz}(\mathrm{RAC1} 130 \mathrm{~B})$ under reactor conditions of $700^{\circ} \mathrm{C}$, $0.81 \mathrm{~m}$ pyrolysis tube heated length, $1.15 \mathrm{~s}$ particle residence time, and $1.46 \mathrm{~s}$ secondary gas space-time.

Figure 70. A FT-IR spectrum of a clean glass-fiber filter.

Figure 71. A FT-IR spectrum of tarry liquid coated glass-fiber filter obtained without acoustics (RNAC1113) under reactor conditions of $400^{\circ} \mathrm{C}, 0.81 \mathrm{~m}$ pyrolysis tube heated length, $0.86 \mathrm{~s}$ particle residence time, and $2.10 \mathrm{~s}$ secondary gas space-time.

Figure 72. A FT-IR spectrum of tarry liquid coated glass-fiber filter obtained with an acoustic field of $151 \mathrm{~dB}$ and $960 \mathrm{~Hz}$ (RAC1119) under reactor conditions of $400^{\circ} \mathrm{C}, 0.81 \mathrm{~m}$ pyrolysis tube heated length, $1.10 \mathrm{~s}$ particle residence time, and $2.10 \mathrm{~s}$ secondary gas space-time.

Figure 73. A FT-IR spectrum of tar coated glass-fiber filter obtained without acoustics (RNAC1105) under reactor conditions of $550^{\circ} \mathrm{C}, 0.18 \mathrm{~m}$ pyrolysis tube heated length, $0.23 \mathrm{~s}$ particle residence time, and $0.38 \mathrm{~s}$ secondary gas space-time. 
Figure 74. A FT-IR spectrum of tarry liquid coated glass-fiber filter obtained without acoustics (RNA21105) under reactor conditions of $550^{\circ} \mathrm{C}, 0.48 \mathrm{~m}$ pyrolysis tube heated length, $0.54 \mathrm{~s}$ particle residence time, and $1.02 \mathrm{~s}$ secondary gas space-time.

Figure 75. A FT-IR spectrum of tarry liquid coated glass-fiber filter obtained with an acoustic field of $151 \mathrm{~dB}$ and $1000 \mathrm{~Hz}$ (RAC1107) under reactor conditions of $550^{\circ} \mathrm{C}, 0.18 \mathrm{~m}$ pyrolysis tube heated length, $0.27 \mathrm{~s}$ particle residence time, and $0.38 \mathrm{~s}$ secondary gas space-time.

Figure 76. A FT-IR spectrum of tar fume coated glass-fiber filter obtained without acoustics (RNAC918) under reactor conditions of $550^{\circ} \mathrm{C}, 0.81 \mathrm{~m}$ pyrolysis tube heated length, $0.90 \mathrm{~s}$ particle residence time, and $1.72 \mathrm{~s}$ secondary gas space-time.

Figure 77. A FT-IR spectrum of tar fume coated glass-fiber filter obtained without acoustics (RNAC927) under reactor conditions of $550^{\circ} \mathrm{C}, 0.81 \mathrm{~m}$ pyrolysis tube heated length, $2.77 \mathrm{~s}$ particle residence time, and $6.59 \mathrm{~s}$ secondary gas space-time.

Figure 78. A FT-IR spectrum of tar fume coated glass-fiber filter obtained with an acoustic field of $151 \mathrm{~dB}$ and $970 \mathrm{~Hz}$ (RAC1108) under reactor conditions of $550^{\circ} \mathrm{C}$, $0.18 \mathrm{~m}$ pyrolysis tube heated length, 0.70 particle residence time, and $1.02 \mathrm{~s}$ secondary gas space-time.

Figure 79. A FT-IR spectrum of tar fume coated glass-fiber filter obtained with an acoustic field of $151 \mathrm{~dB}$ and $990 \mathrm{~Hz}$ (RAC925B) under reactor conditions of $550^{\circ} \mathrm{C}$, $0.81 \mathrm{~m}$ pyrolysis tube heated length, $1.26 \mathrm{~s}$ particle residence time, and $1.72 \mathrm{~s}$ secondary gas space-time.

Figure 80. A FT-IR spectrum of tar fume coated glass-fiber filter obtained with an acoustic field of $158 \mathrm{~dB}$ and $970 \mathrm{~Hz}\left(\mathrm{RAC1207)}\right.$ ) under reactor conditions of $550^{\circ} \mathrm{C}$, $0.81 \mathrm{~m}$ pyrolysis tube heated length, particle residence time of at least $1.37 \mathrm{~s}$, and $1.72 \mathrm{~s}$ secondary gas space-time.

Figure 81. A FT-IR spectrum of typical tar coated glass-fiber filter obtained with a steel-wool-plug located at $0.13 \mathrm{~m}$ downstream from the particle injection point (RNAC1019) under conditions of $550^{\circ} \mathrm{C}, 0.81 \mathrm{~m}$ pyrolysis tube heated length, and $3.39 \mathrm{~s}$ secondary gas space-time.

Figure 82. A FT-IR spectrum of tar coated glass-fiber filter obtained with an acoustic field of $151 \mathrm{~dB}$ and $960 \mathrm{~Hz}$ (RAC1206) and a steel-wool-plug located at $0.75 \mathrm{~m}$ under reactor conditions of $550^{\circ} \mathrm{C}, 0.81 \mathrm{~m}$ pyrolysis tube heated length, and $1.72 \mathrm{~s}$ secondary gas space-time. 
Figure 83. A FT-IR spectrum of tarry liquid coated glass-fiber filter obtained without acoustics (RNAC1123) under reactor conditions of $700^{\circ} \mathrm{C}, 0.18 \mathrm{~m}$ pyrolysis tube heated length, $0.21 \mathrm{~s}$ particle residence time, and $0.32 \mathrm{~s}$ secondary gas space-time.

Figure 84. A FT-IR spectrum of tar fume glass-fiber filter obtained without acoustics (RNAC1127) under reactor conditions of $700^{\circ} \mathrm{C}, 0.48 \mathrm{~m}$ pyrolysis tube heated length, $0.49 \mathrm{~s}$ particle residence time, and $0.86 \mathrm{~s}$ secondary gas space-time.

Figure 85. A FT-IR spectrum of tar and $\mathrm{Na}_{2} \mathrm{CO}_{3}$ fume coated glass-fiber filter obtained without acoustics (RNAC1122) under reactor conditions of $700^{\circ} \mathrm{C}, 0.81 \mathrm{~m}$ pyrolysis tube heated length, $0.82 \mathrm{~s}$ particle residence time, and $1.46 \mathrm{~s}$ secondary gas space-time.

Figure 86. A FT-IR spectrum of tar and $\mathrm{Na}_{2} \mathrm{CO}_{3}$ fume coated glass-fiber filter obtained with an acoustic field of $151 \mathrm{~dB}$ and $960 \mathrm{~Hz}$ (RAC1126A) under reactor conditions of $700^{\circ} \mathrm{C}, 0.18 \mathrm{~m}$ pyrolysis tube heated length, $0.25 \mathrm{~s}$ particle residence time, and $0.32 \mathrm{~s}$ secondary gas space-time.

Figure 87. A FT-IR spectrum of tar and $\mathrm{Na}_{2} \mathrm{CO}_{3}$ fume coated glass-fiber filter obtained with an acoustic field of $151 \mathrm{~dB}$ and $990 \mathrm{~Hz}$ (RAC1127) under reactor conditions of $700^{\circ} \mathrm{C}, 0.48 \mathrm{~m}$ pyrolysis tube heated length, $0.64 \mathrm{~s}$ particle residence time, and $0.86 \mathrm{~s}$ secondary gas space-time.

Figure 88. A FT-IR spectrum of tar and $\mathrm{Na}_{2} \mathrm{CO}_{3}$ fume coated glass-fiber filter obtained with an acoustic field of $151 \mathrm{~dB}$ and $950 \mathrm{~Hz}$ (RAC1126B) under reactor conditions of $700^{\circ} \mathrm{C}, 0.81 \mathrm{~m}$ pyrolysis tube heated length, $1.15 \mathrm{~s}$ particle residence time, and $1.46 \mathrm{~s}$ secondary gas space-time.

Figure 89. A FT-IR spectrum of $\mathrm{Na}_{2} \mathrm{CO}_{3}$ fume coated glass-fiber filter obtained with an acoustic field of $160 \mathrm{~dB}$ and $950 \mathrm{~Hz}$ (RAC1130C) under reactor conditions of $700^{\circ} \mathrm{C}, 0.81 \mathrm{~m}$ pyrolysis tube heated length, at least $1.37 \mathrm{~s}$ particle residence time, and $1.46 \mathrm{~s}$ secondary gas space-time.

Figure 90. CO yields obtained from the non-sticking, inflight particle pyrolysis experiments with and without an acoustic field of 146-154 dB and $310-1000 \mathrm{~Hz}$ at a gas temperature of $550^{\circ} \mathrm{C}$. Pyrolysis tube and secondary gas flow configurations were: $0.18,0.48$, and $0.81 \mathrm{~m}$ heated lengths and 20 slpm preheated $\mathrm{N}_{2}$, and $0.81 \mathrm{~m}$ heated length and 5, 10, and $20 \mathrm{slpm}$ preheated $\mathrm{N}_{2}$. 
Figure 91. $\mathrm{CO}_{2}$ yields obtained from the non-sticking, inflight particle pyrolysis experiments with and without an acoustic field of 146-154 dB and 310$1000 \mathrm{~Hz}$ at a gas temperature of $550^{\circ} \mathrm{C}$. Pyrolysis tube and secondary gas flow configurations were: $0.18,0.48$, and $0.81 \mathrm{~m}$ heated lengths and 20 slpm preheated $\mathrm{N}_{2}$, and $0.81 \mathrm{~m}$ heated length and 5, 10, and $20 \mathrm{slpm}$ preheated $\mathrm{N}_{2}$.

Figure 92. CO yields obtained from the non-sticking, inflight particle pyrolysis experiments with and without an acoustic field of $151 \mathrm{~dB}$ and $950-990 \mathrm{~Hz}$ at gas temperatures of 400 and $700^{\circ} \mathrm{C}$. Pyrolysis tube and secondary gas flow configurations were: $0.18,0.48$, and $0.81 \mathrm{~m}$ heated lengths and $20 \mathrm{slpm}$ preheated $\mathrm{N}_{2}$, and $0.81 \mathrm{~m}$ heated length and 5, 10, and 20 slpm preheated $\mathrm{N}_{2} .151$

Figure 93. $\mathrm{CO}_{2}$ yields obtained from the non-sticking, inflight particle pyrolysis experiments with and without an acoustic field of $151 \mathrm{~dB}$ and $950-990 \mathrm{~Hz}$ at gas temperatures of 400 and $700^{\circ} \mathrm{C}$. Pyrolysis tube and secondary gas flow configurations were: $0.18,0.48$, and $0.81 \mathrm{~m}$ heated lengths and $20 \mathrm{slpm}$ preheated $\mathrm{N}_{2}$, and $0.81 \mathrm{~m}$ heated length and 5, 10, and $20 \mathrm{slpm}$ preheated $\mathrm{N}_{2} .152$

Figure 94. $\quad \mathrm{CO}$ and $\mathrm{CO}_{2}$ yields obtained from inflight, particle pyrolysis experiments and steel-wool-plug experiments conducted at a gas temperature of $550^{\circ} \mathrm{C}$ with steel-wool-plug located $0.13 \mathrm{~m}$ downstream from the particle injection point. Pyrolysis tube and secondary gas flow configurations were: (a) $0.18 \mathrm{~m}$ heated length and 20 slpm secondary gas; (b) $0.18 \mathrm{~m}$ heated length and $10 \mathrm{slpm}$ preheated $\mathrm{N}_{2}$; (c) $0.48 \mathrm{~m}$ heated length and 20 slpm preheated $\mathrm{N}_{2}$; (d) $0.81 \mathrm{~m}$ heated length and $20 \mathrm{slpm}$ preheated $\mathrm{N}_{2} ;$ (e) $0.81 \mathrm{~m}$ heated length and $10 \mathrm{slpm}$ preheated $\mathrm{N}_{2}$; and (f) $0.81 \mathrm{~m}$ heated length and 5 slpm preheated $\mathrm{N}_{2}$.

Figure 95. An illustration of deposition and accumulation of BLS particles at different times during a typical steel-wool-plug experiment.

Figure 96. Estimated mean $\mathrm{CO}_{2}$ yields obtained from inflight particle experiments and steel-wool-plug experiments conducted at a gas temperature of $550^{\circ} \mathrm{C}$ with steel-wool-plug located $0.13 \mathrm{~m}$ downstream from the particle injection point. Pyrolysis tube and secondary gas flow configurations were: (a) $0.18 \mathrm{~m}$ heated length and 20 slpm secondary gas; (b) $0.18 \mathrm{~m}$ heated length and $10 \mathrm{slpm}$ preheated $\mathrm{N}_{2}$; (c) $0.48 \mathrm{~m}$ heated length and 20 slpm preheated $\mathrm{N}_{2}$; (d) $0.81 \mathrm{~m}$ heated length and $20 \mathrm{slpm}$ preheated $\mathrm{N}_{2} ;$ (e) $0.81 \mathrm{~m}$ heated length and 10 slpm preheated $\mathrm{N}_{2}$; and (f) $0.81 \mathrm{~m}$ heated length and 5 slpm preheated $\mathrm{N}_{2}$.

Figure 97. High-speed video images of inflight char particles in the first $0.185 \mathrm{~m}$ section of simulated pyrolysis tube following the particle injection tube exit using secondary gas flowrate of $56 \mathrm{slpm}$ cold air at a temperature of $20^{\circ} \mathrm{C}$ (a) without acoustics, (b) with an acoustic field of $151 \mathrm{~dB}$ and $970 \mathrm{~Hz}$, and (c) with an acoustic field of $158 \mathrm{~dB}$ and $970 \mathrm{~Hz}$. 
Figure 98. High-speed video images of inflight char particles in $0.185 \mathrm{~m}$ section of simulated pyrolysis tube following the particle injection tube exit using secondary gas flowrate of 14 slpm cold air at a temperature of $20^{\circ} \mathrm{C}$ (a) without acoustics, (b) with an acoustic field of $151 \mathrm{~dB}$ and $970 \mathrm{~Hz}$, and (c) with an acoustic field of $158 \mathrm{~dB}$ and $970 \mathrm{~Hz}$.

Figure 99. Low-speed video images of $\mathrm{N}_{2}$ carrier gas jet in $0.09 \mathrm{~m}$ long section of pyrex glass tube following the particle injection point: (a) without acoustics using a secondary gas flowrate of 14 slpm cold air, (b) without acoustics using a secondary gas flowrate of 56 slpm cold air, and (c) with an acoustic field of $151 \mathrm{~dB}$ and $970 \mathrm{~Hz}$ using secondary gas flowrates of 14 or 56 slpm cold air.

Figure 100. A high-speed video image of particles in the pyrex glass tube levitated at 0.19-0.22 $\mathrm{m}$ downstream of particle injection tube exit obtained with an acoustic field of $159 \mathrm{~dB}$ and $970 \mathrm{~Hz}$ for a 14 slpm flowrate of cold air.

Figure 101. Low-speed video images of particles in the pyrex glass tube (a) obtained between $0.15-0.27 \mathrm{~m}$ downstream from particle injection point with or without an acoustic field of $151 \mathrm{~dB}$ and $970 \mathrm{~Hz}$ and secondary airflowrates of 14 or 56 slpm, (b) showing levitation between 0.19-0.22 m downstream from particle injection point with an acoustic field of $159 \mathrm{~dB}$ and $970 \mathrm{~Hz}$ and secondary air flowrate of $14 \mathrm{slpm}$, (c) showing levitation between 0.01-0.08 $\mathrm{m}$ downstream from the particle injection point with an acoustic field of $161 \mathrm{~dB}$ and $340 \mathrm{~Hz}$ and a flowrate of 14 slpm, and (d) obtained between $0.15-0.27 \mathrm{~m}$ downstream from the particle injection point with an acoustic field of $159 \mathrm{~dB}$ and $970 \mathrm{~Hz}$ and a secondary air flowrate of $56 \mathrm{slpm}$.

Figure A3.1. A flowchart of particle preparation.

Figure A5.1. Feedrate of BLS particles versus dial setting of screw jack motor speed. Calibration conditions: bulk density of BLS $=855 \mathrm{~kg} / \mathrm{m}^{3}, 13 \mathrm{~g}$ of BLS initially in feeder vial, and $5 \mathrm{~g}$ of BLS fed.

Figure A5.2. Profiles of $\mathrm{CO}$ and $\mathrm{CO}_{2}$ concentrations in the pyrolysis gas obtained without acoustics (RNAC1113) under reactor conditions of $400^{\circ} \mathrm{C}$, $0.81 \mathrm{~m}$ pyrolysis tube heated length, $0.86 \mathrm{~s}$ particle residence time, and $2.10 \mathrm{~s}$ secondary gas space-time.

Figure A5.3. Profiles of $\mathrm{CO}$ and $\mathrm{CO}_{2}$ concentrations in the pyrolysis gas obtained in an acoustic field of $151 \mathrm{~dB}$ and $960 \mathrm{~Hz}$ (RAC1119) under reactor conditions of $400^{\circ} \mathrm{C}, 0.81 \mathrm{~m}$ pyrolysis tube heated length, $1.10 \mathrm{~s}$ particle residence time, and $2.10 \mathrm{~s}$ secondary gas space-time. 
Figure A5.4. Profiles of $\mathrm{CO}$ and $\mathrm{CO}_{2}$ concentrations in the pyrolysis gas obtained in an acoustic field of $154 \mathrm{~dB}$ and $960 \mathrm{~Hz}(\mathrm{RAC1009})$ under reactor conditions of $400^{\circ} \mathrm{C}, 0.81 \mathrm{~m}$ pyrolysis tube heated length, $0.94 \mathrm{~s}$ particle residence time, and $1.70 \mathrm{~s}$ secondary gas space-time.

Figure A5.5. Profiles of $\mathrm{CO}$ and $\mathrm{CO}_{2}$ concentrations in the pyrolysis gas obtained with a steel-wool-plug located at $0.13 \mathrm{~m}$ (RNAC1111) under reactor conditions of $400^{\circ} \mathrm{C}, 0.18 \mathrm{~m}$ pyrolysis tube heated length, and $0.47 \mathrm{~s}$ secondary gas space-time.

Figure A5.6. Profiles of $\mathrm{CO}$ and $\mathrm{CO}_{2}$ concentrations in the pyrolysis gas obtained with a steel wool plug located at $0.13 \mathrm{~m}$ (RNAC2111) under reactor conditions of $400^{\circ} \mathrm{C}, 0.18 \mathrm{~m}$ pyrolysis tube heated length, and $0.47 \mathrm{~s}$ secondary gas space-time.

Figure A5.7. Profiles of $\mathrm{CO}$ and $\mathrm{CO}_{2}$ concentrations in the pyrolysis gas obtained with a steel wool plug located at $0.13 \mathrm{~m}$ (RNAC1112) under reactor conditions of $400^{\circ} \mathrm{C}, 0.81 \mathrm{~m}$ pyrolysis tube heated length, and $2.10 \mathrm{~s}$ secondary gas space-time.

Figure A5.8. Profiles of $\mathrm{CO}$ and $\mathrm{CO}_{2}$ concentrations in the pyrolysis gas obtained without an acoustic field (RNAC1105) under reactor conditions of $550^{\circ} \mathrm{C}, 0.18 \mathrm{~m}$ pyrolysis tube heated length, $0.23 \mathrm{~s}$ particle residence time, and $0.38 \mathrm{~s}$ secondary gas space-time.

Figure A5.9. Profiles of $\mathrm{CO}$ and $\mathrm{CO}_{2}$ concentrations in the pyrolysis gas obtained without an acoustic field (RNAC21105) under reactor conditions of $550^{\circ} \mathrm{C}, 0.48 \mathrm{~m}$ pyrolysis tube heated length, $0.54 \mathrm{~s}$ particle residence time, and $1.02 \mathrm{~s}$ secondary gas space-time.

Figure A5.10. Profiles of $\mathrm{CO}$ and $\mathrm{CO}_{2}$ concentrations in the pyrolysis gas obtained without an acoustic field (RNAC912) under reactor conditions of $550^{\circ} \mathrm{C}, 0.81 \mathrm{~m}$ pyrolysis tube heated length, $20 \mathrm{slpm} \mathrm{N}_{2}$ quench, $0.90 \mathrm{~s}$ particle residence time, and $1.72 \mathrm{~s}$ secondary gas space-time.

Figure A5.11. Profiles of $\mathrm{CO}$ and $\mathrm{CO}_{2}$ concentrations in the pyrolysis gas obtained without an acoustic field (RNAC918) under reactor conditions of $550^{\circ} \mathrm{C}, 0.81 \mathrm{~m}$ pyrolysis tube heated length, $20 \mathrm{slpm} \mathrm{N}_{2}$ quench, $0.90 \mathrm{~s}$ particle residence time, and $1.72 \mathrm{~s}$ secondary gas space-time.

Figure A5.12. Profiles of $\mathrm{CO}$ and $\mathrm{CO}_{2}$ concentrations in the pyrolysis gas obtained without an acoustic field (RNAC919A) under reactor conditions of $550^{\circ} \mathrm{C}, 0.81 \mathrm{~m}$ pyrolysis tube heated length, $20 \mathrm{slpm} \mathrm{N}_{2}$ quench, $0.90 \mathrm{~s}$ particle residence time, and $1.72 \mathrm{~s}$ secondary gas space-time. 
Figure A5.13. Profiles of $\mathrm{CO}$ and $\mathrm{CO}_{2}$ concentrations in the pyrolysis gas obtained without an acoustic field (RNAC927B) under reactor conditions of $550^{\circ} \mathrm{C}, 0.81 \mathrm{~m}$ pyrolysis tube heated length, $1.58 \mathrm{~s}$ particle residence time, and $3.39 \mathrm{~s}$ secondary gas space-time.

Figure A5.14. Profiles of $\mathrm{CO}$ and $\mathrm{CO}_{2}$ concentrations in the pyrolysis gas obtained without an acoustic field (RNAC927) under reactor conditions of $550^{\circ} \mathrm{C}, 0.81 \mathrm{~m}$ pyrolysis tube heated length, $2.77 \mathrm{~s}$ particle residence time, and $6.59 \mathrm{~s}$ secondary gas space-time.

Figure A5.15. Profiles of $\mathrm{CO}$ and $\mathrm{CO}_{2}$ concentrations in the pyrolysis gas obtained without an acoustic field of $146 \mathrm{~dB}$ and $1000 \mathrm{~Hz}$ (RAC925) under reactor conditions of $550^{\circ} \mathrm{C}, 0.81 \mathrm{~m}$ pyrolysis tube heated length, $1.23 \mathrm{~s}$ particle residence time, and $1.72 \mathrm{~s}$ secondary gas space-time.

Figure A5.16. Profiles of $\mathrm{CO}$ and $\mathrm{CO}_{2}$ concentrations in the pyrolysis gas obtained with an acoustic field of $151 \mathrm{~dB}$ and $950 \mathrm{~Hz}(\mathrm{RAC1106})$ under reactor conditions of $550^{\circ} \mathrm{C}, 0.18 \mathrm{~m}$ pyrolysis tube heated length, and $0.38 \mathrm{~s}$ secondary gas space-time.

Figure A5.17. Profiles of $\mathrm{CO}$ and $\mathrm{CO}_{2}$ concentrations in the pyrolysis gas obtained with an acoustic field of $151 \mathrm{~dB}$ and $1000 \mathrm{~Hz}$ (RAC1107) under reactor conditions of $550^{\circ} \mathrm{C}, 0.18 \mathrm{~m}$ pyrolysis tube heated length, $0.27 \mathrm{~s}$ particle residence time, and $0.38 \mathrm{~s}$ secondary gas space-time.

Figure A5.18. Profiles of $\mathrm{CO}$ and $\mathrm{CO}_{2}$ concentrations in the pyrolysis gas obtained with an acoustic field of $151 \mathrm{~dB}$ and $970 \mathrm{~Hz}$ (RAC1108) under reactor conditions of $550^{\circ} \mathrm{C}, 0.48 \mathrm{~m}$ pyrolysis tube heated length, $0.70 \mathrm{~s}$ particle residence time, and $1.02 \mathrm{~s}$ secondary gas space-time.

Figure A5.19. Profiles of $\mathrm{CO}$ and $\mathrm{CO}_{2}$ concentrations in the pyrolysis gas obtained with an acoustic field of $151 \mathrm{~dB}$ and $990 \mathrm{~Hz}$ (RAC925B) under reactor conditions of $550^{\circ} \mathrm{C}, 0.81 \mathrm{~m}$ pyrolysis tube heated length, $1.26 \mathrm{~s}$ particle residence time, and $1.72 \mathrm{~s}$ secondary gas space-time.

Figure A5.20. Profiles of $\mathrm{CO}$ and $\mathrm{CO}_{2}$ concentrations in the pyrolysis gas obtained with an acoustic field of $151 \mathrm{~dB}$ and $980 \mathrm{~Hz}(\mathrm{RAC1230B})$ under reactor conditions of $550^{\circ} \mathrm{C}, 0.81 \mathrm{~m}$ pyrolysis tube heated length, $10 \mathrm{slpm} \mathrm{N}_{2}$ quench, $2.22 \mathrm{~s}$ particle residence time, and $3.39 \mathrm{~s}$ secondary gas space-time.

Figure A5.21. Profiles of $\mathrm{CO}$ and $\mathrm{CO}_{2}$ concentrations in the pyrolysis gas obtained with an acoustic field of $151 \mathrm{~dB}$ and $980 \mathrm{~Hz}$ (RAC1226) under reactor conditions of $550^{\circ} \mathrm{C}, 0.81 \mathrm{~m}$ pyrolysis tube heated length, $15 \mathrm{slpm} \mathrm{N}_{2}$ quench, $3.69 \mathrm{~s}$ particle residence time, and $6.59 \mathrm{~s}$ secondary gas space-time. 
Figure A5.22. Profiles of $\mathrm{CO}$ and $\mathrm{CO}_{2}$ concentrations in the pyrolysis gas obtained with an acoustic field of $151 \mathrm{~dB}$ and $310 \mathrm{~Hz}$ (RAC1231A) under reactor conditions of $550^{\circ} \mathrm{C}, 0.81 \mathrm{~m}$ pyrolysis tube heated length, $1.26 \mathrm{~s}$ particle residence time, and $1.72 \mathrm{~s}$ secondary gas space-time.

Figure A5.23. Profiles of $\mathrm{CO}$ and $\mathrm{CO}_{2}$ concentrations in the pyrolysis gas obtained with an acoustic field of $151 \mathrm{~dB}$ and $310 \mathrm{~Hz}$ (RAC1231B) under reactor conditions of $550^{\circ} \mathrm{C}, 0.81 \mathrm{~m}$ pyrolysis tube heated length, $10 \mathrm{slpm} \mathrm{N}_{2}$ quench, $2.18 \mathrm{~s}$ particle residence time, and $3.39 \mathrm{~s}$ secondary gas space-time.

Figure A5.24. Profiles of $\mathrm{CO}$ and $\mathrm{CO}_{2}$ concentrations in the pyrolysis gas obtained with an acoustic field of $151 \mathrm{~dB}$ and $310 \mathrm{~Hz}$ (RAC1231C) under reactor conditions of $550^{\circ} \mathrm{C}, 0.81 \mathrm{~m}$ pyrolysis tube heated length, $15 \mathrm{slpm} \mathrm{N}_{2}$ quench, $3.57 \mathrm{~s}$ particle residence time, and $6.59 \mathrm{~s}$ secondary gas space-time.

Figure A5.25. Profiles of $\mathrm{CO}$ and $\mathrm{CO}_{2}$ concentrations in the pyrolysis gas obtained with an acoustic field of $154 \mathrm{~dB}$ and $1010 \mathrm{~Hz}$ (RAC1028) under reactor conditions of $550^{\circ} \mathrm{C}, 0.18 \mathrm{~m}$ pyrolysis tube heated length, $0.00 \mathrm{~s}$ particle residence time, and $0.38 \mathrm{~s}$ secondary gas space-time.

Figure A5.26. Profiles of $\mathrm{CO}$ and $\mathrm{CO}_{2}$ concentrations in the pyrolysis gas obtained with an acoustic field of $154 \mathrm{~dB}$ and $950 \mathrm{~Hz}$ (RAC912) under reactor conditions of $550^{\circ} \mathrm{C}, 0.81 \mathrm{~m}$ pyrolysis tube heated length, $20 \mathrm{slpm} \mathrm{N}_{2}$ quench, $1.29 \mathrm{~s}$ particle residence time, and $1.72 \mathrm{~s}$ secondary gas space-time.

Figure A5.27. Profiles of $\mathrm{CO}$ and $\mathrm{CO}_{2}$ concentrations in the pyrolysis gas obtained with an acoustic field of $154 \mathrm{~dB}$ and $990 \mathrm{~Hz}$ (RAC926) under reactor conditions of $550^{\circ} \mathrm{C}, 0.81 \mathrm{~m}$ pyrolysis tube heated length, $1.29 \mathrm{~s}$ particle residence time, and $1.72 \mathrm{~s}$ secondary gas space-time.

Figure A5.28. Profiles of $\mathrm{CO}$ and $\mathrm{CO}_{2}$ concentrations in the pyrolysis gas obtained with an acoustic field of $154 \mathrm{~dB}$ and $990 \mathrm{~Hz}$ (RAC930) under reactor conditions of $550^{\circ} \mathrm{C}, 0.81 \mathrm{~m}$ pyrolysis tube heated length, $2.27 \mathrm{~s}$ particle residence time, and $3.39 \mathrm{~s}$ secondary gas space-time.

Figure A5.29. Profiles of $\mathrm{CO}$ and $\mathrm{CO}_{2}$ concentrations in the pyrolysis gas obtained with an acoustic field of $154 \mathrm{~dB}$ and $1010 \mathrm{~Hz}$ (RAC1014) under reactor conditions of $530^{\circ} \mathrm{C}, 0.81 \mathrm{~m}$ pyrolysis tube heated length, $1.29 \mathrm{~s}$ particle residence time, and 1.76 s secondary gas space-time.

Figure A5.30. Profiles of $\mathrm{CO}$ and $\mathrm{CO}_{2}$ concentrations in the pyrolysis gas obtained with an acoustic field of $154 \mathrm{~dB}$ and $960 \mathrm{~Hz}$ (RAC1227A) under reactor conditions of $550^{\circ} \mathrm{C}, 0.81 \mathrm{~m}$ pyrolysis tube heated length, $15 \mathrm{slpm} \mathrm{N}_{2}$ quench, $3.88 \mathrm{~s}$ particle residence time, and $6.59 \mathrm{~s}$ secondary gas space-time. 
Figure A5.31. Profiles of $\mathrm{CO}$ and $\mathrm{CO}_{2}$ concentrations in the pyrolysis gas obtained with an acoustic field of $158 \mathrm{~dB}$ and $970 \mathrm{~Hz}$ (RAC1207) under reactor conditions of $550^{\circ} \mathrm{C}, 0.81 \mathrm{~m}$ pyrolysis tube heated length, at least $1.37 \mathrm{~s}$ particle residence time, and $1.72 \mathrm{~s}$ secondary gas space-time.

Figure A5.32. Profiles of $\mathrm{CO}$ and $\mathrm{CO}_{2}$ concentrations in the pyrolysis gas obtained with an acoustic field of $159.5 \mathrm{~dB}$ and $970 \mathrm{~Hz}$ (RAC1227B) under reactor conditions of $550^{\circ} \mathrm{C}, 0.81 \mathrm{~m}$ pyrolysis tube heated length, $10 \mathrm{slpm} \mathrm{N}_{2}$ quench, at least $3.91 \mathrm{~s}$ particle residence time, and $3.39 \mathrm{~s}$ secondary gas space-time.

Figure A5.33. Profiles of $\mathrm{CO}$ and $\mathrm{CO}_{2}$ concentrations in the pyrolysis gas obtained with an acoustic field of $159.5 \mathrm{~dB}$ and $970 \mathrm{~Hz}$ (RAC1230) under reactor conditions of $550^{\circ} \mathrm{C}, 0.81 \mathrm{~m}$ pyrolysis tube heated length, $10 \mathrm{slpm} \mathrm{N}_{2}$ quench, $0.00 \mathrm{~s}$ particle residence time, at least $3.39 \mathrm{~s}$ secondary gas space-time, and pulsed feeding of BLS particles.

Figure A5.34. Profiles of $\mathrm{CO}$ and $\mathrm{CO}_{2}$ concentrations in the pyrolysis gas obtained with an acoustic field of $158 \mathrm{~dB}$ and $970 \mathrm{~Hz}$ (RAC1224) under reactor conditions of $550^{\circ} \mathrm{C}, 0.81 \mathrm{~m}$ pyrolysis tube heated length, $15 \mathrm{slpm} \mathrm{N}_{2}$ quench, very long particle residence time, and $6.59 \mathrm{~s}$ secondary gas space-time.

Figure A5.35. Profiles of $\mathrm{CO}$ and $\mathrm{CO}_{2}$ concentrations in the pyrolysis gas obtained with a steel-wool-plug located at $0.13 \mathrm{~m}$ (RNAC1017) under reactor conditions of $550^{\circ} \mathrm{C}, 0.18 \mathrm{~m}$ pyrolysis tube heated length, and $0.38 \mathrm{~s}$ secondary gas space-time.

Figure A5.36. Profiles of $\mathrm{CO}$ and $\mathrm{CO}_{2}$ concentrations in the pyrolysis gas obtained with a steel-wool-plug located at $0.13 \mathrm{~m}$ (RNAC1012) under reactor conditions of $550^{\circ} \mathrm{C}, 0.18 \mathrm{~m}$ pyrolysis tube heated length, and $0.75 \mathrm{~s}$ secondary gas space-time.

Figure A5.37. Profiles of $\mathrm{CO}$ and $\mathrm{CO}_{2}$ concentrations in the pyrolysis gas obtained with a steel-wool-plug located at $0.13 \mathrm{~m}$ (RNAC1023) under reactor conditions of $550^{\circ} \mathrm{C}, 0.81 \mathrm{~m}$ pyrolysis tube heated length, and $1.72 \mathrm{~s}$ secondary gas space-time.

Figure A5.38. Profiles of $\mathrm{CO}$ and $\mathrm{CO}_{2}$ concentrations in the pyrolysis gas obtained with a steel-wool-plug located at $0.13 \mathrm{~m}$ (RNAC1019) under reactor conditions of $550^{\circ} \mathrm{C}, 0.81 \mathrm{~m}$ pyrolysis tube heated length, and $3.39 \mathrm{~s}$ secondary gas space-time.

Figure A5.39. Profiles of $\mathrm{CO}$ and $\mathrm{CO}_{2}$ concentrations in the pyrolysis gas obtained with a steel-wool-plug located at $0.13 \mathrm{~m}$ (RNAC1024) under reactor conditions of $550^{\circ} \mathrm{C}, 0.81 \mathrm{~m}$ pyrolysis tube heated length, and $3.39 \mathrm{~s}$ secondary gas space-time. 
Figure A5.40. Profiles of $\mathrm{CO}$ and $\mathrm{CO}_{2}$ concentrations in the pyrolysis gas obtained with a steel-wool-plug located at $0.13 \mathrm{~m}$ (RNAC1226) under reactor conditions of $550^{\circ} \mathrm{C}, 0.81 \mathrm{~m}$ pyrolysis tube heated length, $15 \mathrm{slpm} \mathrm{N}_{2}$ quench, and $6.59 \mathrm{~s}$ secondary gas space-time.

Figure A5.41. Profiles of $\mathrm{CO}$ and $\mathrm{CO}_{2}$ concentrations in the pyrolysis gas obtained with a steel-wool-plug located at $0.75 \mathrm{~m}$ (RNAC923) under reactor conditions of $550^{\circ} \mathrm{C}, 0.81 \mathrm{~m}$ pyrolysis tube heated length, and $1.72 \mathrm{~s}$ secondary gas space-time.

Figure A5.42. Profiles of $\mathrm{CO}$ and $\mathrm{CO}_{2}$ concentrations in the pyrolysis gas obtained with a steel-wool-plug located at $0.75 \mathrm{~m}$ and an acoustic field of $151 \mathrm{~dB}$ and $960 \mathrm{~Hz}$ (RAC1206) under reactor conditions of $550^{\circ} \mathrm{C}, 0.81 \mathrm{~m}$ pyrolysis tube heated length, and $3.39 \mathrm{~s}$ secondary gas space-time.

Figure A5.43. Profiles of $\mathrm{CO}$ and $\mathrm{CO}_{2}$ concentrations in the pyrolysis gas obtained without an acoustic field (RNAC1123) under reactor conditions of $700^{\circ} \mathrm{C}, 0.18 \mathrm{~m}$ pyrolysis tube heated length, $0.21 \mathrm{~s}$ particle residence time, and $0.32 \mathrm{~s}$ secondary gas space-time.

Figure A5.44. Profiles of $\mathrm{CO}$ and $\mathrm{CO}_{2}$ concentrations in the pyrolysis gas obtained without an acoustic field (RNAC1127) under reactor conditions of $700^{\circ} \mathrm{C}, 0.48 \mathrm{~m}$ pyrolysis tube heated length, $0.82 \mathrm{~s}$ particle residence time, and $0.86 \mathrm{~s}$ secondary gas space-time.

Figure A5.45. Profiles of $\mathrm{CO}$ and $\mathrm{CO}_{2}$ concentrations in the pyrolysis gas obtained without an acoustic field (RNAC1122) under reactor conditions of $550^{\circ} \mathrm{C}, 0.81 \mathrm{~m}$ pyrolysis tube heated length, $10 \mathrm{slpm} \mathrm{N}_{2}$ quench, $0.82 \mathrm{~s}$ particle residence time, and $1.46 \mathrm{~s}$ secondary gas space-time.

Figure A5.46. Profiles of $\mathrm{CO}$ and $\mathrm{CO}_{2}$ concentrations in the pyrolysis gas obtained in an acoustic field of $151 \mathrm{~dB}$ and $960 \mathrm{~Hz}$ (RAC1126A) under reactor conditions of $700^{\circ} \mathrm{C}, 0.18 \mathrm{~m}$ pyrolysis tube heated length, $0.25 \mathrm{~s}$ particle residence time, and 0.32 s secondary gas space-time.

Figure A5.47. Profiles of $\mathrm{CO}$ and $\mathrm{CO}_{2}$ concentrations in the pyrolysis gas obtained in an acoustic field of $151 \mathrm{~dB}$ and $960 \mathrm{~Hz}$ (RAC1127) under reactor conditions of $700^{\circ} \mathrm{C}, 0.48 \mathrm{~m}$ pyrolysis tube heated length, $0.64 \mathrm{~s}$ particle residence time, and 0.86 s secondary gas space-time.

Figure A5.48. Profiles of $\mathrm{CO}$ and $\mathrm{CO} 2$ concentrations in the pyrolysis gas obtained in an acoustic field of $151 \mathrm{~dB}$ and $990 \mathrm{~Hz}$ (RAC1130) under reactor conditions of $700^{\circ} \mathrm{C}, 0.48 \mathrm{~m}$ pyrolysis tube heated length, $0.64 \mathrm{~s}$ particle residence time, and $0.86 \mathrm{~s}$ secondary gas space-time. 
Figure A5.49. Profiles of $\mathrm{CO}$ and $\mathrm{CO}_{2}$ concentrations in the pyrolysis gas obtained in an acoustic field of $151 \mathrm{~dB}$ and $950 \mathrm{~Hz}(\mathrm{RAC1126B})$ under reactor conditions of $700^{\circ} \mathrm{C}, 0.81 \mathrm{~m}$ pyrolysis tube heated length, $10 \mathrm{slpm} \mathrm{N}_{2}$ quench, $1.15 \mathrm{~s}$ particle residence time, and $1.46 \mathrm{~s}$ secondary gas space-time.

Figure A5.50. Profiles of $\mathrm{CO}$ and $\mathrm{CO}_{2}$ concentrations in the pyrolysis gas obtained in an acoustic field of $151 \mathrm{~dB}$ and $950 \mathrm{~Hz}$ (RAC1130B) under reactor conditions of $700^{\circ} \mathrm{C}, 0.81 \mathrm{~m}$ pyrolysis tube heated length, $1.15 \mathrm{~s}$ particle residence time, and $1.46 \mathrm{~s}$ secondary gas space-time.

Figure A5.51. Profiles of $\mathrm{CO}$ and $\mathrm{CO}_{2}$ concentrations in the pyrolysis gas obtained in an acoustic field of $160 \mathrm{~dB}$ and $950 \mathrm{~Hz}$ (RAC1130C) under reactor conditions of $700^{\circ} \mathrm{C}, 0.81 \mathrm{~m}$ pyrolysis tube heated length, very long particle residence time, and $1.46 \mathrm{~s}$ secondary gas space-time.

Figure A5.52. Profiles of $\mathrm{CO}$ and $\mathrm{CO}_{2}$ concentrations in the pyrolysis gas obtained in an acoustic field of $160 \mathrm{~dB}$ and $950 \mathrm{~Hz}(\mathrm{RAC1205})$ under reactor conditions of $700^{\circ} \mathrm{C}, 0.81 \mathrm{~m}$ pyrolysis tube heated length, $10 \mathrm{slpm} \mathrm{N}_{2}$ quench, very long particle residence time, and $2.87 \mathrm{~s}$ secondary gas space-time.

Figure A5.53. Profiles of $\mathrm{CO}$ and $\mathrm{CO}_{2}$ concentrations in the pyrolysis gas obtained with a steel-wool-plug located at $0.13 \mathrm{~m}$ (RNAC1124) under reactor conditions of $700^{\circ} \mathrm{C}, 0.18 \mathrm{~m}$ pyrolysis tube heated length, and $0.32 \mathrm{~s}$ secondary gas space-time.

Figure A5.54. Profiles of $\mathrm{CO}$ and $\mathrm{CO}_{2}$ concentrations in the pyrolysis gas obtained with a steel-wool-plug located at $0.13 \mathrm{~m}$ (RNAC1125) under reactor conditions of $700^{\circ} \mathrm{C}, 0.81 \mathrm{~m}$ pyrolysis tube heated length, 10 slpm $\mathrm{N}_{2}$ quench, and $1.46 \mathrm{~s}$ secondary gas space-time.

Figure A5.55. Profiles of $\mathrm{CO}$ and $\mathrm{CO}_{2}$ concentrations in the pyrolysis gas obtained with a steel-wool-plug located at $0.75 \mathrm{~m}$ (RNAC1204) under reactor conditions of $700^{\circ} \mathrm{C}, 0.81 \mathrm{~m}$ pyrolysis tube heated length, and $1.46 \mathrm{~s}$ secondary gas space-time.

Figure A8.1. Profiles of the measured acoustic pressure amplitude $(+)$ and the calculated acoustic velocity amplitude $(-)$ in the pyrolysis tube obtained with an acoustic field of $151 \mathrm{~dB}$ and $960 \mathrm{~Hz}$ (RAC1119) under reactor conditions of $400^{\circ} \mathrm{C}, 0.81 \mathrm{~m}$ pyrolysis tube heated length, $0.86 \mathrm{~s}$ particle residence time, and $2.10 \mathrm{~s}$ secondary gas space-time.

Figure A8.2. Profiles of the measured acoustic pressure amplitude $(+)$ and the calculated acoustic velocity amplitude $(-)$ in the pyrolysis tube obtained with an acoustic field of $154 \mathrm{~dB}$ and $970 \mathrm{~Hz}$ (RAC1009) under reactor conditions of $400^{\circ} \mathrm{C}, 0.81 \mathrm{~m}$ pyrolysis tube heated length, $1.10 \mathrm{~s}$ particle residence time, and $1.70 \mathrm{~s}$ secondary gas space-time. 
Figure A8.3. Profiles of the measured acoustic pressure amplitude $(+)$ and the calculated acoustic velocity amplitude $(-)$ in the pyrolysis tube obtained with an acoustic field of $146 \mathrm{~dB}$ and $1000 \mathrm{~Hz}$ (RAC925) under reactor conditions of $550^{\circ} \mathrm{C}, 0.81 \mathrm{~m}$ pyrolysis tube heated length, $1.23 \mathrm{~s}$ particle residence time, and $1.72 \mathrm{~s}$ secondary gas space-time.

Figure A8.4. Profiles of the measured acoustic pressure amplitude $(+)$ and the calculated acoustic velocity amplitude $(-)$ in the pyrolysis tube obtained with an acoustic field of $151 \mathrm{~dB}$ and $950 \mathrm{~Hz}$ (RAC1106) under reactor conditions of $550^{\circ} \mathrm{C}, 0.18 \mathrm{~m}$ pyrolysis tube heated length, and $0.38 \mathrm{~s}$ secondary gas space-time.

Figure A8.5. Profiles of the measured acoustic pressure amplitude $(+)$ and the calculated acoustic velocity amplitude $(-)$ in the pyrolysis tube obtained with an acoustic field of $151 \mathrm{~dB}$ and $1000 \mathrm{~Hz}$ (RAC1107) under reactor conditions of $550^{\circ} \mathrm{C}, 0.18 \mathrm{~m}$ pyrolysis tube heated length, $0.27 \mathrm{~s}$ particle residence time, and $0.38 \mathrm{~s}$ secondary gas space-time.

Figure A8.6. Profiles of the measured acoustic pressure amplitude $(+)$ and the calculated acoustic velocity amplitude $(-)$ in the pyrolysis tube obtained with an acoustic field of $151 \mathrm{~dB}$ and $970 \mathrm{~Hz}$ (RAC1108) under reactor conditions of $550^{\circ} \mathrm{C}, 0.48 \mathrm{~m}$ pyrolysis tube heated length, $0.70 \mathrm{~s}$ particle residence time, and $1.02 \mathrm{~s}$ secondary gas space-time.

Figure A8.7. Profiles of the measured acoustic pressure amplitude $(+)$ and the calculated acoustic velocity amplitude $(-)$ in the pyrolysis tube obtained with an acoustic field of $151 \mathrm{~dB}$ and $990 \mathrm{~Hz}$ (RAC925B) under reactor conditions of $550^{\circ} \mathrm{C}, 0.81 \mathrm{~m}$ pyrolysis tube heated length, $1.26 \mathrm{~s}$ particle residence time, and $1.72 \mathrm{~s}$ secondary gas space-time.

Figure A8.8. Profiles of the measured acoustic pressure amplitude $(+)$ and the calculated acoustic velocity amplitude $(-)$ in the pyrolysis tube obtained with an acoustic field of $151 \mathrm{~dB}$ and $980 \mathrm{~Hz}$ (RAC1230B) under reactor conditions of $550^{\circ} \mathrm{C}, 0.81 \mathrm{~m}$ pyrolysis tube heated length, $2.22 \mathrm{~s}$ particle residence time, and $3.39 \mathrm{~s}$ secondary gas space-time.

Figure A8.9. Profiles of the measured acoustic pressure amplitude $(+)$ and the calculated acoustic velocity amplitude $(-)$ in the pyrolysis tube obtained with an acoustic field of $151 \mathrm{~dB}$ and $980 \mathrm{~Hz}$ (RAC1226) under reactor conditions of $550^{\circ} \mathrm{C}, 0.81 \mathrm{~m}$ pyrolysis tube heated length, $3.69 \mathrm{~s}$ particle residence time, and $6.59 \mathrm{~s}$ secondary gas space-time. 
Figure A8.10. Profiles of the measured acoustic pressure amplitude $(+)$ and the calculated acoustic velocity amplitude $(-)$ in the pyrolysis tube obtained with an acoustic field of $151 \mathrm{~dB}$ and $310 \mathrm{~Hz}$ (RAC1231A) under reactor conditions of $550^{\circ} \mathrm{C}, 0.81 \mathrm{~m}$ pyrolysis tube heated length, $1.26 \mathrm{~s}$ particle residence time, and $1.72 \mathrm{~s}$ secondary gas space-time.

Figure A8.11. Profiles of the measured acoustic pressure amplitude $(+)$ and the calculated acoustic velocity amplitude $(-)$ in the pyrolysis tube obtained with an acoustic field of $151 \mathrm{~dB}$ and $310 \mathrm{~Hz}(\mathrm{RAC} 1231 \mathrm{~B})$ under reactor conditions of $550^{\circ} \mathrm{C}, 0.81 \mathrm{~m}$ pyrolysis tube heated length, $2.18 \mathrm{~s}$ particle residence time, and $3.39 \mathrm{~s}$ secondary gas space-time.

Figure A8.12. Profiles of the measured acoustic pressure amplitude $(+)$ and the calculated acoustic velocity amplitude $(-)$ in the pyrolysis tube obtained with an acoustic field of $151 \mathrm{~dB}$ and $310 \mathrm{~Hz}$ (RAC1231C) under reactor conditions of $550^{\circ} \mathrm{C}, 0.81 \mathrm{~m}$ pyrolysis tube heated length, $3.57 \mathrm{~s}$ particle residence time, and $6.59 \mathrm{~s}$ secondary gas space-time.

Figure A8.13. Profiles of the measured acoustic pressure amplitude $(+)$ and the calculated acoustic velocity amplitude $(-)$ in the pyrolysis tube obtained with an acoustic field of $154 \mathrm{~dB}$ and $1010 \mathrm{~Hz}$ (RAC1028) under reactor conditions of $550^{\circ} \mathrm{C}, 0.18 \mathrm{~m}$ pyrolysis tube heated length, and $0.38 \mathrm{~s}$ secondary gas space-time.

Figure A8.14. Profiles of the measured acoustic pressure amplitude $(+)$ and the calculated acoustic velocity amplitude $(-)$ in the pyrolysis tube obtained with an acoustic field of $154 \mathrm{~dB}$ and $950 \mathrm{~Hz}$ (RAC912) under reactor conditions of $550^{\circ} \mathrm{C}, 0.81 \mathrm{~m}$ pyrolysis tube heated length, $1.29 \mathrm{~s}$ particle residence time, and $1.72 \mathrm{~s}$ secondary gas space-time.

Figure A8.15. Profiles of the measured acoustic pressure amplitude $(+)$ and the calculated acoustic velocity amplitude (-) in the pyrolysis tube obtained with an acoustic field of $154 \mathrm{~dB}$ and $990 \mathrm{~Hz}$ (RAC926) under reactor conditions of $550^{\circ} \mathrm{C}, 0.81 \mathrm{~m}$ pyrolysis tube heated length, $1.29 \mathrm{~s}$ particle residence time, and $1.72 \mathrm{~s}$ secondary gas space-time.

Figure A8.16. Profiles of the measured acoustic pressure amplitude $(+)$ and the calculated acoustic velocity amplitude $(-)$ in the pyrolysis tube obtained with an acoustic field of $154 \mathrm{~dB}$ and $1000 \mathrm{~Hz}$ (RAC1014) under reactor conditions of $530^{\circ} \mathrm{C}, 0.81 \mathrm{~m}$ pyrolysis tube heated length, $1.29 \mathrm{~s}$ particle residence time, and $1.76 \mathrm{~s}$ secondary gas space-time. 
Figure A8.17. Profiles of the measured acoustic pressure amplitude $(+)$ and the calculated acoustic velocity amplitude $(-)$ in the pyrolysis tube obtained with an acoustic field of $154 \mathrm{~dB}$ and $990 \mathrm{~Hz}$ (RAC930) under reactor conditions of $550^{\circ} \mathrm{C}, 0.81 \mathrm{~m}$ pyrolysis tube heated length, $2.27 \mathrm{~s}$ particle residence time, and $3.39 \mathrm{~s}$ secondary gas space-time.

Figure A8.18. Profiles of the measured acoustic pressure amplitude $(+)$ and the calculated acoustic velocity amplitude $(-)$ in the pyrolysis tube obtained with an acoustic field of $154 \mathrm{~dB}$ and $960 \mathrm{~Hz}$ (RAC1227A) under reactor conditions of $550^{\circ} \mathrm{C}, 0.81 \mathrm{~m}$ pyrolysis tube heated length, $3.88 \mathrm{~s}$ particle residence time, and $6.59 \mathrm{~s}$ secondary gas space-time.

Figure A8.19. Profiles of the measured acoustic pressure amplitude $(+)$ and the calculated acoustic velocity amplitude $(-)$ in the pyrolysis tube obtained with an acoustic field of $158 \mathrm{~dB}$ and $970 \mathrm{~Hz}$ (RAC1207) under reactor conditions of $550^{\circ} \mathrm{C}, 0.81 \mathrm{~m}$ pyrolysis tube heated length, at least $1.37 \mathrm{~s}$ particle residence time, and $1.72 \mathrm{~s}$ secondary gas space-time.

Figure A8.20. Profiles of the measured acoustic pressure amplitude $(+)$ and the calculated acoustic velocity amplitude $(-)$ in the pyrolysis tube obtained with an acoustic field of $159.5 \mathrm{~dB}$ and $970 \mathrm{~Hz}$ (RAC1227B) under reactor conditions of $550^{\circ} \mathrm{C}, 0.81 \mathrm{~m}$ pyrolysis tube heated length, at least $3.91 \mathrm{~s}$ particle residence time, and $3.39 \mathrm{~s}$ secondary gas space-time.

Figure A8.21. Profiles of the measured acoustic pressure amplitude $(+)$ and the calculated acoustic velocity amplitude $(-)$ in the pyrolysis tube obtained with an acoustic field of $159.5 \mathrm{~dB}$ and $970 \mathrm{~Hz}$ (RAC1230) under reactor conditions of $550^{\circ} \mathrm{C}, 0.81 \mathrm{~m}$ pyrolysis tube heated length, at least $3.91 \mathrm{~s}$ particle residence time, $3.39 \mathrm{~s}$ secondary gas space-time, and pulsed feeding of BLS particles.

Figure A8.22. Profiles of the measured acoustic pressure amplitude $(+)$ and the calculated acoustic velocity amplitude $(-)$ in the pyrolysis tube obtained with an acoustic field of $158 \mathrm{~dB}$ and $970 \mathrm{~Hz}$ (RAC1224) under reactor conditions of $550^{\circ} \mathrm{C}, 0.81 \mathrm{~m}$ pyrolysis tube heated length, very long particle residence time, and 6.59 s secondary gas space-time.

Figure A8.23. Profiles of the measured acoustic pressure amplitude $(+)$ and the calculated acoustic velocity amplitude $(-)$ in the pyrolysis tube obtained with an acoustic field of $151 \mathrm{~dB}$ and $960 \mathrm{~Hz}$ (RAC1206) and a steel wool plug located at $0.75 \mathrm{~m}$ under reactor conditions of $550^{\circ} \mathrm{C}, 0.81 \mathrm{~m}$ pyrolysis tube heated length, very long particle residence time, and $3.39 \mathrm{~s}$ secondary gas space-time. 
Figure A8.24. Profiles of the measured acoustic pressure amplitude $(+)$ and the calculated acoustic velocity amplitude $(-)$ in the pyrolysis tube obtained with an acoustic field of $151 \mathrm{~dB}$ and $960 \mathrm{~Hz}$ (RAC1126A) under reactor conditions of $700^{\circ} \mathrm{C}, 0.18 \mathrm{~m}$ pyrolysis tube heated length, $0.25 \mathrm{~s}$ particle residence time, and $0.32 \mathrm{~s}$ secondary gas space-time.

Figure A8.25. Profiles of the measured acoustic pressure amplitude $(+)$ and the calculated acoustic velocity amplitude $(-)$ in the pyrolysis tube obtained with an acoustic field of $151 \mathrm{~dB}$ and $990 \mathrm{~Hz}$ (RAC1127) under reactor conditions of $700^{\circ} \mathrm{C}, 0.48 \mathrm{~m}$ pyrolysis tube heated length, $0.64 \mathrm{~s}$ particle residence time, and $0.86 \mathrm{~s}$ secondary gas space-time.

Figure A8.26. Profiles of the measured acoustic pressure amplitude $(+)$ and the calculated acoustic velocity amplitude $(-)$ in the pyrolysis tube obtained with an acoustic field of $151 \mathrm{~dB}$ and $990 \mathrm{~Hz}(\mathrm{RAC1130})$ under reactor conditions of $700^{\circ} \mathrm{C}, 0.48 \mathrm{~m}$ pyrolysis tube heated length, $0.64 \mathrm{~s}$ particle residence time, and $0.86 \mathrm{~s}$ secondary gas space-time.

Figure A8.27. Profiles of the measured acoustic pressure amplitude $(+)$ and the calculated acoustic velocity amplitude $(-)$ in the pyrolysis tube obtained with an acoustic field of $151 \mathrm{~dB}$ and $950 \mathrm{~Hz}$ (RAC1126B) under reactor conditions of $700^{\circ} \mathrm{C}, 0.81 \mathrm{~m}$ pyrolysis tube heated length, $1.15 \mathrm{~s}$ particle residence time, and $1.46 \mathrm{~s}$ secondary gas space-time.

Figure A8.28. Profiles of the measured acoustic pressure amplitude $(+)$ and the calculated acoustic velocity amplitude $(-)$ in the pyrolysis tube obtained with an acoustic field of $151 \mathrm{~dB}$ and $950 \mathrm{~Hz}$ (RAC1130B) under reactor conditions of $700^{\circ} \mathrm{C}, 0.81 \mathrm{~m}$ pyrolysis tube heated length, $1.15 \mathrm{~s}$ particle residence time, and $1.46 \mathrm{~s}$ secondary gas space-time.

Figure A8.29. Profiles of the measured acoustic pressure amplitude $(+)$ and the calculated acoustic velocity amplitude $(-)$ in the pyrolysis tube obtained with an acoustic field of $160 \mathrm{~dB}$ and $950 \mathrm{~Hz}$ (RAC1130C) under reactor conditions of $700^{\circ} \mathrm{C}, 0.81 \mathrm{~m}$ pyrolysis tube heated length, very long particle residence time, and $1.46 \mathrm{~s}$ secondary gas space-time.

Figure A8.30. Profiles of the measured acoustic pressure amplitude $(+)$ and the calculated acoustic velocity amplitude $(-)$ in the pyrolysis tube obtained with an acoustic field of $160 \mathrm{~dB}$ and $950 \mathrm{~Hz}$ (RAC1205) under reactor conditions of $700^{\circ} \mathrm{C}, 0.81 \mathrm{~m}$ pyrolysis tube heated length, very long particle residence time, and $2.87 \mathrm{~s}$ secondary gas space-time.

Figure. A9.1. Profiles of the measured acoustic pressure amplitude and the calculated acoustic velocity amplitude inside the pyrex tube obtained with an acoustic field of $151 \mathrm{~dB}_{\mathrm{rms}}$ and frequency of $970 \mathrm{~Hz}$. 
Figure. A9.2. Profiles of the measured acoustic pressure amplitude and the calculated acoustic velocity amplitude inside the pyrex tube obtained with an acoustic field of $159 \mathrm{~dB}_{\mathrm{rms}}$ and frequency of $970 \mathrm{~Hz}$.

Figure. A9.3. Profiles of the measured acoustic pressure amplitude and the calculated acoustic velocity amplitude inside the pyrex tube obtained with an acoustic field of $151 \mathrm{~dB}_{\mathrm{rms}}$ and frequency of $340 \mathrm{~Hz}$.

Figure. A9.4. Profiles of the measured acoustic pressure amplitude and the calculated acoustic velocity amplitude inside the pyrex tube obtained with an acoustic field of $159 \mathrm{~dB}_{\mathrm{rms}}$ and frequency of $340 \mathrm{~Hz}$.

Figure A10.1. A schematic diagram of the gravitational, downward steady flow drag, and levitational forces exerted on levitating particle.

Figure A10.2. A schematic diagram of the levitational force, acoustic pressure, and approximate regions of particle levitation in the pyrolysis tube.

Figure A10.3. Model predicted dynamics of inflight char particles in pyrolysis tube obtained without acoustics for $V_{S T P}=56 \mathrm{slpm}$ air, $=20^{\circ} \mathrm{C}, T_{g}=1.175 \mathrm{~kg} / \mathrm{m}^{3}$, $v_{g}=1.535 \times 10^{-5} \mathrm{~m}^{2} / \mathrm{s}, m_{p}(z)=7.11 \times 10^{-10} \mathrm{~kg}, d_{p}(z)=150 \mu \mathrm{m}$, and $\rho_{p}(z)=402 \mathrm{~kg} / \mathrm{m}^{3}$.

Figure A10.4. Model predicted dynamics of inflight char particles in pyrolysis tube obtained without acoustics for $V_{S T P}=14$ slpm air, $T_{g}=20^{\circ} \mathrm{C}$, $\rho_{g}=1.175 \mathrm{~kg} / \mathrm{m}^{3}, v_{g}=1.535 \times 10^{-5} \mathrm{~m}^{2} / \mathrm{s}, m_{p}(z)=7.11 \times 10^{-10} \mathrm{~kg}$, $d_{p}(z)=150 \mu \mathrm{m}$, and $\rho_{p}(z)=402 \mathrm{~kg} / \mathrm{m}^{3}$.

Figure A10.5. Model predicted dynamics of inflight char particles in pyrolysis tube obtained with an acoustic field of $151 \mathrm{~dB}\left(\hat{u}_{g}=2.5 \mathrm{~m} / \mathrm{s}\right)$ and $970 \mathrm{~Hz}$ for $V_{S T P}=56 \mathrm{slpm}$ air, $T_{g}=20^{\circ} \mathrm{C}, \rho_{g}=1.175 \mathrm{~kg} / \mathrm{m}^{3}, v_{g}=1.535 \times 10^{-5} \mathrm{~m}^{2} / \mathrm{s}$, $m_{p}(z)=7.11 \times 10^{-10} \mathrm{~kg}, d_{p}(z)=150 \mu \mathrm{m}$, and $\rho_{p}(z)=402 \mathrm{~kg} / \mathrm{m}^{3}$.

Figure A10.6. Model predicted dynamics of inflight char particles in pyrolysis tube obtained with an acoustic field of $151 \mathrm{~dB}\left(\hat{u}_{g}=2.5 \mathrm{~m} / \mathrm{s}\right)$ and $970 \mathrm{~Hz}$ for $V_{S T P}=14 \mathrm{slpm}$ air, $T_{g}=20^{\circ} \mathrm{C}, \rho_{g}=1.175 \mathrm{~kg} / \mathrm{m}^{3}, v_{g}=1.535 \times 10^{-5} \mathrm{~m}^{2} / \mathrm{s}$, $m_{p}(z)=7.11 \times 10^{-10} \mathrm{~kg}, d_{p}(z)=150 \mu \mathrm{m}$, and $\rho_{p}(z)=402 \mathrm{~kg} / \mathrm{m}^{3}$.

Figure A10.7. Model predicted dynamics of inflight char particles in pyrolysis tube obtained with an acoustic field of $159 \mathrm{~dB}\left(\hat{u}_{g}=6.4 \mathrm{~m} / \mathrm{s}\right)$ and $970 \mathrm{~Hz}$ for $V_{S T P}=56 \mathrm{slpm}$ air, $T_{g}=20^{\circ} \mathrm{C}, \rho_{g}=1.175 \mathrm{~kg} / \mathrm{m}^{3}, v_{g}=1.535 \times 10^{-5} \mathrm{~m}^{2} / \mathrm{s}$, $m_{p}(z)=7.11 \times 10^{-10} \mathrm{~kg}, d_{p}(z)=150 \mu \mathrm{m}$, and $\rho_{p}(z)=402 \mathrm{~kg} / \mathrm{m}^{3}$. 
Figure A10.8. Model predicted dynamics of inflight char particles in pyrolysis tube obtained with an acoustic field of $159 \mathrm{~dB}\left(\hat{u}_{g}=6.4 \mathrm{~m} / \mathrm{s}\right)$ and $970 \mathrm{~Hz}$ for $V_{\text {STP }}=14 \mathrm{slpm}$ air, $T_{g}=20^{\circ} \mathrm{C}, \rho_{g}=1.175 \mathrm{~kg} / \mathrm{m}^{3}, v_{g}=1.535 \times 10^{-5} \mathrm{~m}^{2} / \mathrm{s}$, $m_{p}(z)=7.11 \times 10^{-10} \mathrm{~kg}, d_{p}(z)=150 \mu \mathrm{m}$, and $\rho_{p}(z)=402 \mathrm{~kg} / \mathrm{m}^{3}$.

Figure A10.9. Model predicted dynamics of inflight BLS particles in pyrolysis tube obtained without acoustics (RNAC1113) for $V_{S T P}=20 \mathrm{slpm} \mathrm{N}{ }_{2}, T_{g}=400^{\circ} \mathrm{C}$, $\rho_{g}=0.5028 \mathrm{~kg} / \mathrm{m}^{3}, v_{g}=3.484 \times 10^{-5} \mathrm{~m}^{2} / \mathrm{s}, d_{p}(0)=115 \mu \mathrm{m}$, $m_{p}(0)=7.4855 \times 10^{-10} \mathrm{~kg}, \rho_{p}(0)=940 \mathrm{~kg} / \mathrm{m}^{3}, D_{p}(0.81)=150 \mu \mathrm{m}$, and $M_{p}(0.81)=0.96$.

Figure A10.10. Model predicted dynamics of inflight BLS particles in pyrolysis tube obtained with an acoustic field of $151 \mathrm{~dB}\left(\hat{u}_{g}=3.9 \mathrm{~m} / \mathrm{s}\right.$ for RAC1119) and $970 \mathrm{~Hz}$ for $V_{\text {STP }}=20 \mathrm{slpm} \mathrm{N}, T_{g}=400^{\circ} \mathrm{C}, \rho_{g}=0.5028 \mathrm{~kg} / \mathrm{m}^{3}$, $v_{g}=3.484 \times 10^{-5} \mathrm{~m}^{2} / \mathrm{s}, d_{p}(0)=115 \mu \mathrm{m}, m_{p}(0)=7.4855 \times 10^{-10} \mathrm{~kg}$, $\rho_{p}(0)=940 \mathrm{~kg} / \mathrm{m}^{3}, D_{p}(0.81)=225 \mu \mathrm{m}$, and $M_{p}(0.81)=0.934$.

Figure A10.11. Model predicted dynamics of inflight BLS particles in pyrolysis tube obtained with an acoustic field of $151 \mathrm{~dB}\left(\hat{u}_{g}=3.9 \mathrm{~m} / \mathrm{s}\right.$ for RAC1009) and $970 \mathrm{~Hz}$ for $V_{S T P}=24.9 \mathrm{slpm} \mathrm{N}_{2}, T_{g}=400^{\circ} \mathrm{C}, \rho_{g}=0.5028 \mathrm{~kg} / \mathrm{m}^{3}$, $\nu_{g}=3.484 \times 10^{-5} \mathrm{~m}^{2} / \mathrm{s}, d_{p}(0)=115 \mu \mathrm{m}, m_{p}(0)=7.4855 \times 10^{-10} \mathrm{~kg}$, $\rho_{p}(0)=940 \mathrm{~kg} / \mathrm{m}^{3}, D_{p}(0.81)=225 \mu \mathrm{m}$, and $M_{p}(0.81)=0.934$ (assumed to be the same as RAC11119; char yield could not be obtained because some particles stuck to pyrolysis tube wall).

Figure A10.12 Model predicted dynamics of inflight BLS particles in pyrolysis tube obtained without an acoustic field for $V_{S T P}=20 \mathrm{slpm} \mathrm{N}, T_{g}=550^{\circ} \mathrm{C}$, $\rho_{g}=0.4103 \mathrm{~kg} / \mathrm{m}^{3}, v_{g}=8.69 \times 10^{-5} \mathrm{~m}^{2} / \mathrm{s}, d_{p}(0)=115 \mu \mathrm{m}$, $m_{p}(0)=7.4855 \times 10^{-10} \mathrm{~kg}, \rho_{p}(0)=940 \mathrm{~kg} / \mathrm{m}^{3}, D_{p}(\geq 0.18)=275 \mu \mathrm{m}$, $M_{p}(0.18)=0.847, M_{p}(0.48)=0.806$, and $M_{p}(0.81)=0.772$.

Figure A10.13. Model predicted dynamics of inflight BLS particles in pyrolysis tube obtained without an acoustic field for $V_{S T P}=10 \mathrm{slpm} \mathrm{N}, T_{g}=550^{\circ} \mathrm{C}$, $\rho_{g}=0.4103 \mathrm{~kg} / \mathrm{m}^{3}, v_{g}=8.69 \times 10^{-5} \mathrm{~m}^{2} / \mathrm{s}, d_{p}(0)=115 \mu \mathrm{m}$, $m_{p}(0)=7.4855 \times 10^{-10} \mathrm{~kg}, \rho_{p}(0)=940 \mathrm{~kg} / \mathrm{m}^{3}, D_{p}(\geq 0.103)=275 \mu \mathrm{m}$, $M_{p}(0.18)=0.834, M_{p}(0.48)=0.788$, and $M_{p}(0.81)=0.756$.

Figure A10.14. Model predicted dynamics of inflight BLS particles in pyrolysis tube obtained without an acoustic field for $V_{S T P}=5 \operatorname{slpm~} \mathrm{N}_{2}, T_{g}=550^{\circ} \mathrm{C}$, $\rho_{g}=0.4103 \mathrm{~kg} / \mathrm{m}^{3}, v_{g}=8.69 \times 10^{-5} \mathrm{~m}^{2} / \mathrm{s}, d_{p}(0)=115 \mu \mathrm{m}$, $m_{p}(0)=7.4855 \times 10^{-10} \mathrm{~kg}, \rho_{p}(0)=940 \mathrm{~kg} / \mathrm{m}^{3}, D_{p}(z \geq 0.076)=275 \mu \mathrm{m}$, $M_{P}(0.18)=0.814, M_{P}(0.48)=0.783$, and $M_{P}(0.81)=0.756$. 
Figure A10.15. Model predicted dynamics of inflight BLS particles in pyrolysis tube obtained with an acoustic field of $146 \mathrm{~dB}\left(\hat{u}_{g}=4.1 \mathrm{~m} / \mathrm{s}\right.$ for RAC1107) and $1000 \mathrm{~Hz}$ for $V_{S T P}=20 \mathrm{slpm} \mathrm{N}, T_{g}=550^{\circ} \mathrm{C}, \rho_{g}=0.4103 \mathrm{~kg} / \mathrm{m}^{3}$, $v_{g}=8.69 \times 10^{-5} \mathrm{~m}^{2} / \mathrm{s}, d_{p}(0)=115 \mu \mathrm{m}, m_{p}(0)=7.4855 \times 10^{-10} \mathrm{~kg}$, $\rho_{p}(0)=940 \mathrm{~kg} / \mathrm{m}^{3}, D_{p}(\geq 0.136)=275 \mu \mathrm{m}, M_{p}(0.18)=0.843$, $M_{p}(0.48)=0.794$, and $M_{p}(0.81)=0.751$.

Figure A10.16. Model predicted dynamics of inflight BLS particles in pyrolysis tube obtained with an acoustic field of $151 \mathrm{~dB}\left(\hat{u}_{g}=4.1 \mathrm{~m} / \mathrm{s}\right.$ for RAC1107) and $1000 \mathrm{~Hz}$ for $V_{S T P}=20 \mathrm{slpm} \mathrm{N}_{2}, T_{g}=550^{\circ} \mathrm{C}, \rho_{g}=0.4103 \mathrm{~kg} / \mathrm{m}^{3}$, $v_{g}=8.69 \times 10^{-5} \mathrm{~m}^{2} / \mathrm{s}, d_{p}(0)=115 \mu \mathrm{m}, m_{p}(0)=7.4855 \times 10^{-10} \mathrm{~kg}$, $\rho_{p}(0)=940 \mathrm{~kg} / \mathrm{m}^{3}, D_{p}(\geq 0.18)=300 \mu \mathrm{m}, M_{p}(0.18)=0.762$, $M_{p}(0.48)=0.723$, and $M_{p}(0.81)=0.706$.

Figure A10.17. Model predicted dynamics of inflight BLS particles in pyrolysis tube obtained with an acoustic field of $151 \mathrm{~dB}\left(\hat{u}_{g}=4.1 \mathrm{~m} / \mathrm{s}\right.$ for RAC1107) and $1000 \mathrm{~Hz}$ for $V_{S T P}=10 \mathrm{slpm} \mathrm{N}, T_{g}=550^{\circ} \mathrm{C}, \rho_{g}=0.4103 \mathrm{~kg} / \mathrm{m}^{3}$, $v_{g}=8.69 \times 10^{-5} \mathrm{~m}^{2} / \mathrm{s}, d_{p}(0)=115 \mu \mathrm{m}, m_{p}(0)=7.4855 \times 10^{-10} \mathrm{~kg}$, $\rho_{p}(0)=940 \mathrm{~kg} / \mathrm{m}^{3}, D_{p}(\geq 0.129)=300 \mu \mathrm{m}, M_{p}(0.18)=0.751$, $M_{p}(0.48)=0.706$, and $M_{p}(0.81)=0.673$.

Figure A10.18. Model predicted dynamics of inflight BLS particles in pyrolysis tube obtained with an acoustic field of $151 \mathrm{~dB}\left(\hat{u}_{g}=4.1 \mathrm{~m} / \mathrm{s}\right.$ for RAC1107) and $1000 \mathrm{~Hz}$ for $V_{S T P}=5 \mathrm{slpm} \mathrm{N}_{2}, T_{g}=550^{\circ} \mathrm{C}, \rho_{g}=0.4103 \mathrm{~kg} / \mathrm{m}^{3}$, $v_{g}=8.69 \times 10^{-5} \mathrm{~m}^{2} / \mathrm{s}, d_{p}(0)=115 \mu \mathrm{m}, m_{p}(0)=7.4855 \times 10^{-10} \mathrm{~kg}$, $\rho_{p}(0)=940 \mathrm{~kg} / \mathrm{m}^{3}, M_{p}(0.18)=0.735, M_{p}(0.48)=0.706, M_{p}(0.81)=0.687$, and $D_{p}(z \geq 0.111)=300 \mu \mathrm{m}$.

Figure A10.19. Model predicted dynamics of inflight BLS particles in pyrolysis tube obtained with an acoustic field of $151 \mathrm{~dB}\left(\hat{u}_{g}=4.1 \mathrm{~m} / \mathrm{s}\right.$ for RAC1231A) and $310 \mathrm{~Hz}$ for $V_{S T P}=20 \operatorname{slpm~} \mathrm{N}_{2}, T_{g}=550^{\circ} \mathrm{C}, \rho_{g}=0.4103 \mathrm{~kg} / \mathrm{m}^{3}$, $v_{g}=8.69 \times 10^{-5} \mathrm{~m}^{2} / \mathrm{s}, d_{p}(0)=115 \mu \mathrm{m}, m_{p}(0)=7.4855 \times 10^{-10} \mathrm{~kg}$, $\rho_{p}(0)=940 \mathrm{~kg} / \mathrm{m}^{3}, M_{p}(0.18)=0.762, M_{p}(0.48)=0.745, M_{p}(0.81)=0.728$, and $D_{p}(z \geq 0.176)=300 \mu \mathrm{m}$.

Figure A10.20. Model predicted dynamics of inflight BLS particles in pyrolysis tube obtained with an acoustic field of $151 \mathrm{~dB}\left(\hat{u}_{g}=4.1 \mathrm{~m} / \mathrm{s}\right.$ for RAC1231B) and $310 \mathrm{~Hz}$ for $V_{S T P}=10 \mathrm{slpm} \mathrm{N}_{2}, T_{g}=550^{\circ} \mathrm{C}, \rho_{g}=0.4103 \mathrm{~kg} / \mathrm{m}^{3}$, $v_{g}=8.69 \times 10^{-5} \mathrm{~m}^{2} / \mathrm{s}, d_{p}(0)=115 \mu \mathrm{m}, m_{p}(0)=7.4855 \times 10^{-10} \mathrm{~kg}$, $\rho_{p}(0)=940 \mathrm{~kg} / \mathrm{m}^{3}, M_{p}(0.18)=0.758, M_{p}(0.48)=0.733, M_{p}(0.81)=0.705$, and $D_{p}(z \geq 0.128)=300 \mu \mathrm{m}$. 
Figure A10.21. Model predicted dynamics of inflight BLS particles in pyrolysis tube obtained with an acoustic field of $151 \mathrm{~dB}\left(\hat{u}_{g}=4.1 \mathrm{~m} / \mathrm{s}\right.$ for RAC1231C) and $310 \mathrm{~Hz}$ for $V_{S T P}=5 \mathrm{slpm} \mathrm{N}, T_{g}=550^{\circ} \mathrm{C}, \rho_{g}=0.4103 \mathrm{~kg} / \mathrm{m}^{3}$, $v_{g}=8.69 \times 10^{-5} \mathrm{~m}^{2} / \mathrm{s}, d_{p}(0)=115 \mu \mathrm{m}, m_{p}(0)=7.4855 \times 10^{-10} \mathrm{~kg}$ $\rho_{p}(0)=940 \mathrm{~kg} / \mathrm{m}^{3}, M_{p}(0.18)=0.757, M_{p}(0.48)=0.735, M_{p}(0.81)=0.711$, and $D_{p}(z \geq 0.109)=300 \mu \mathrm{m}$.

Figure A10.22. Model predicted dynamics of inflight BLS particles in pyrolysis tube obtained with an acoustic field of $154 \mathrm{~dB}\left(\hat{u}_{g}=5.5 \mathrm{~m} / \mathrm{s}\right.$ for RAC926) and $990 \mathrm{~Hz}$ for $V_{S T P}=20 \mathrm{slpm} \mathrm{N}_{2}, T_{g}=550^{\circ} \mathrm{C}, \rho_{g}=0.4103 \mathrm{~kg} / \mathrm{m}^{3}$, $v_{g}=8.69 \times 10^{-5} \mathrm{~m}^{2} / \mathrm{s}, d_{p}(0)=115 \mu \mathrm{m}, m_{p}(0)=7.4855 \times 10^{-10} \mathrm{~kg}$, $\rho_{p}(0)=940 \mathrm{~kg} / \mathrm{m}^{3}, M_{p}(0.18)=0.768, M_{p}(0.48)=0.73, M_{p}(0.81)=0.695$, and $D_{p}(z \geq 0.185)=300 \mu \mathrm{m}$.

Figure A10.23. Model predicted dynamics of inflight BLS particles in pyrolysis tube obtained with an acoustic field of $154 \mathrm{~dB}\left(\hat{u}_{g}=5.5 \mathrm{~m} / \mathrm{s}\right.$ for RAC930) and $990 \mathrm{~Hz}$ for $V_{S T P}=10 \mathrm{slpm} \mathrm{N}_{2}, T_{g}=550^{\circ} \mathrm{C}, \rho_{g}=0.4103 \mathrm{~kg} / \mathrm{m}^{3}$, $v_{g}=8.69 \times 10^{-5} \mathrm{~m}^{2} / \mathrm{s}, \quad d_{p}(0)=115 \mu \mathrm{m}, m_{p}(0)=7.4855 \times 10^{-10} \mathrm{~kg}$, $\rho_{p}(0)=940 \mathrm{~kg} / \mathrm{m}^{3}, M_{p}(0.18)=0.756, M_{p}(0.48)=0.716, M_{p}(0.81)=0.673$ and $D_{p}(z \geq 0.135)=300 \mu \mathrm{m}$.

Figure A10.24. Model predicted dynamics of inflight BLS particles in pyrolysis tube obtained with an acoustic field of $154 \mathrm{~dB}\left(\hat{u}_{g}=5.5 \mathrm{~m} / \mathrm{s}\right.$ for RAC1227A) and $960 \mathrm{~Hz}$ for $V_{S T P}=5 \mathrm{slpm} \mathrm{N}, T_{g}=550^{\circ} \mathrm{C}, \rho_{g}=0.4103 \mathrm{~kg} / \mathrm{m}^{3}$, $v_{g}=8.69 \times 10^{-5} \mathrm{~m}^{2} / \mathrm{s}, d_{p}(0)=115 \mu \mathrm{m}, m_{p}(0)=7.4855 \times 10^{-10} \mathrm{~kg}$, $\rho_{p}(0)=940 \mathrm{~kg} / \mathrm{m}^{3}, M_{p}(0.18)=0.755, M_{p}(0.48)=0.716, M_{p}(0.81)=0.673$, and $D_{p}(z \geq 0.124)=300 \mu \mathrm{m}$.

Figure A10.25. Model predicted dynamics of inflight BLS particles in pyrolysis tube obtained with an acoustic field of $158 \mathrm{~dB}\left(\hat{u}_{g}=10.3 \mathrm{~m} / \mathrm{s}\right.$ for RAC1207) and $970 \mathrm{~Hz}$ for $V_{S T P}=20 \mathrm{slpm} \mathrm{N}, T_{g}=550^{\circ} \mathrm{C}, \rho_{g}=0.4103 \mathrm{~kg} / \mathrm{m}^{3}$, $v_{g}=8.69 \times 10^{-5} \mathrm{~m}^{2} / \mathrm{s}, d_{p}(0)=115 \mu \mathrm{m}, m_{P}(0)=7.4855 \times 10^{-10} \mathrm{~kg}$, $\rho_{p}(0)=940 \mathrm{~kg} / \mathrm{m}^{3}, M_{p}(0.18)=0.761, M_{p}(0.48)=0.708, M_{p}(0.81)=0.651$, and $D_{p}(z \geq 0.173)=300 \mu \mathrm{m}$.

Figure A10.26. Model predicted dynamics of inflight BLS particles in pyrolysis tube obtained with an acoustic field of $159.5 \mathrm{~dB}\left(\hat{u}_{g}=11.5 \mathrm{~m} / \mathrm{s}\right.$ for RAC1227B) and $970 \mathrm{~Hz}$ for $V_{S T P}=10 \mathrm{slpm} \mathrm{N}_{2}, T_{g}=550^{\circ} \mathrm{C}, \rho_{g}=0.4103 \mathrm{~kg} / \mathrm{m}^{3}$, $v_{g}=8.69 \times 10^{-5} \mathrm{~m}^{2} / \mathrm{s}, d_{p}(0)=115 \mu \mathrm{m}, m_{p}(0)=7.4855 \times 10^{-10} \mathrm{~kg}$, $\rho_{p}(0)=940 \mathrm{~kg} / \mathrm{m}^{3}, M_{p}(0.18)=0.753, M_{p}(0.48)=0.70, M_{p}(0.81)=0.642$, and $D_{p}(z \geq 0.129)=300 \mu \mathrm{m}$. 
Figure A10.27. Model predicted dynamics of inflight BLS particles in pyrolysis tube obtained with an acoustic field of $159.5 \mathrm{~dB}\left(\hat{u}_{g}=11.5 \mathrm{~m} / \mathrm{s}\right.$ for RAC1224) and $970 \mathrm{~Hz}$ for $V_{S T P}=5 \mathrm{slpm} \mathrm{N}_{2}, T_{g}=550^{\circ} \mathrm{C}, \rho_{g}=0.4103 \mathrm{~kg} / \mathrm{m}^{3}$, $\nu_{g}=8.69 \times 10^{-5} \mathrm{~m}^{2} / \mathrm{s}, d_{p}(0)=115 \mu \mathrm{m}, m_{p}(0)=7.4855 \times 10^{-10} \mathrm{~kg}$, $\rho_{p}(0)=940 \mathrm{~kg} / \mathrm{m}^{3}, M_{p}(0.18)=0.758, M_{p}(0.81)=0.629$, and $D_{P}(z \geq 0.0 .98)=300 \mu \mathrm{m}$.

Figure A10.28. Model predicted dynamics of inflight BLS particles in pyrolysis tube obtained without an acoustic field for $V_{S T P}=20 \mathrm{slpm} \mathrm{N}, T_{g}=700^{\circ} \mathrm{C}$, $\rho_{g}=0.3469 \mathrm{~kg} / \mathrm{m}^{3}, \nu_{g}=1.14 \times 10^{-4} \mathrm{~m}^{2} / \mathrm{s}, d_{p}(0)=115 \mu \mathrm{m}$, $m_{P}(0)=7.4855 \times 10^{-10} \mathrm{~kg}, \rho_{P}(0)=940 \mathrm{~kg} / \mathrm{m}^{3}, D_{P}(0.18)=300 \mu \mathrm{m}$, $D_{p}(\geq 0.48)=600 \mu \mathrm{m}, M_{p}(0.18)=0.76, M_{p}(0.48)=0.705$, and $M_{p}(0.81)=0.688$.

Figure A10.29. Model predicted dynamics of inflight BLS particles in pyrolysis tube obtained with an acoustic field of $151 \mathrm{~dB}\left(\hat{u}_{g}=4.5 \mathrm{~m} / \mathrm{s}\right.$ for RAC1126A) and $960 \mathrm{~Hz}$ for $V_{S T P}=20 \mathrm{slpm} \mathrm{N}_{2}, T_{g}=700^{\circ} \mathrm{C}, \rho_{g}=0.3469 \mathrm{~kg} / \mathrm{m}^{3}$, $v_{g}=1.14 \times 10^{-4} \mathrm{~m}^{2} / \mathrm{s}, d_{p}(0)=115 \mu \mathrm{m}, m_{p}(0)=7.4855 \times 10^{-10} \mathrm{~kg}$, $\rho_{p}(0)=940 \mathrm{~kg} / \mathrm{m}^{3}, D_{p}(0.18)=550 \mu \mathrm{m}, D_{P}(\geq 0.48)=600 \mu \mathrm{m}$, $M_{p}(0.18)=0.738, M_{p}(0.48)=0.687$, and $M_{p}(0.81)=0.668$.

Figure A10.30. Model predicted heatup of inflight BLS particles to a peak gas temperature of $400^{\circ} \mathrm{C}$. Particle temperatures estimated (a) without acoustics (RNAC1113) and (b) with an acoustic field of $151 \mathrm{~dB}$ and $960 \mathrm{~Hz}$ (RAC1119) using experimental gas temperatures obtained (c) with and (d) without acoustics. (e) Particle temperature estimated assuming a uniform gas temperature of $400^{\circ} \mathrm{C}$ and an acoustic field of $151 \mathrm{~dB}$ and $960 \mathrm{~Hz}$.

Figure A10.31. Model predicted heatup of inflight BLS particles to a peak gas temperature of $550^{\circ} \mathrm{C}$. Particle temperatures calculated (a) without an acoustic field (RNAC1105) and (b) with an acoustic field of $151 \mathrm{~dB}$ and $1000 \mathrm{~Hz}$ (RAC1107) using experimental gas temperatures obtained (c) with and (d) without acoustics. Particle temperature calculated (e)assuming $T_{g}(z)=550^{\circ} \mathrm{C}, \varepsilon=0.4$, and an acoustic field of $151 \mathrm{~dB}$ and $1000 \mathrm{~Hz}$. (f) Particle temperature calculated assuming $T_{g}(z)=550^{\circ} \mathrm{C}, \varepsilon=0.4$, $T_{g}(z)$ and an acoustic field of $159 \mathrm{~dB}$ and $970 \mathrm{~Hz}$. 
Figure A10.32. Model predicted (a) Nu or Sh without an acoustic field, (b) Nuac or Shac with an acoustic field of $151 \mathrm{~dB}$ and $1000 \mathrm{~Hz}$ (RAC1107), and (c) $\mathrm{Nu} a c$ or Shac with an acoustic field of $159 \mathrm{~dB}$ and $970 \mathrm{~Hz}$ in which $\hat{u}_{s w}$ was to occur at the particle injection tube exit, during particle heatup to a peak gas temperature of $550^{\circ} \mathrm{C}$. Measured gas temperatures were used for all cases.

Figure A10.33. Model predicted heatup of inflight BLS particles to a peak gas temperature of $550^{\circ} \mathrm{C}$. Particle temperatures estimated (a) without an acoustic field (RNAC1105) using experimental gas temperatures; (b) with an acoustic field of $151 \mathrm{~dB}$ and $1000 \mathrm{~Hz}$ (RAC1107), assuming $T_{g}(z)=550^{\circ} \mathrm{C}$ and $\varepsilon=1$; and (c) due to radiative heating using a pyrolysis tube wall temperature of $570^{\circ} \mathrm{C}$ and $\varepsilon=1$.

Figure A10.34. Model predicted heatup of inflight BLS particles to a peak gas temperature of $700^{\circ} \mathrm{C}$. Particle temperatures calculated (a) without acoustics (RNAC1123) and (b) with an acoustic field of $151 \mathrm{~dB}$ and $960 \mathrm{~Hz}$ (RAC1126A) using experimental gas temperatures obtained (c) with and (d) without acoustics.

Figure A12.1. A schematic diagram of the ejector. 


\section{LIST OF TABLES}

Table 1. Elemental analyses of BLS from the hardwood soda-AQ black liquor used in this study by Galbraith Labs, Knoxville, TN and from different softwood kraft black liquors (Frederick and Hupa, 1993).

Table 2. Chemical composition of a birch hardwood soda-AQ black liquor and a pine softwood kraft black liquor (Alen et al., 1995).

Table 3. The operating characteristics and applications of the retort furnace reactor, heated grid reactor, and entrained flow reactor used in pyrolysis studies.

Table 4. Thermogravimetric analysis of biomass materials at slow heating rates $\left(<1^{\circ} \mathrm{C} / \mathrm{s}\right)$.

Table 5. Laboratory studies of biomass pyrolysis that used a RFR, HGR, or EFR.

Table 6. Product yields from the batch and steady-state pyrolyses of kraft black liquor at constant temperatures between $400-900^{\circ} \mathrm{C}$ (Brink et al., 1967 and 1970).

Table 7. Char, tar, and gas yields after $15 \mathrm{~min}$ pyrolysis at furnace temperatures between $490-740^{\circ} \mathrm{C}$ (Bhattacharya et al., 1986).

Table 8. Char pyrolysis yield, composition, and bulk density from slow heating at $0.3^{\circ} \mathrm{C} / \mathrm{s}$ to a peak temperature of $700^{\circ} \mathrm{C}$ and $120 \mathrm{~s}$ holding time and from fast heating at $715 \pm 175^{\circ} \mathrm{C} / \mathrm{s}$ to a peak temperature of $750 \pm 50^{\circ} \mathrm{C}$ and $9 \mathrm{~s}$ holding time (Arpiainen et al., 1992).

Table 9. Yields of char and carbon in the char from the pyrolysis of black liquor at furnace temperatures between $700-900^{\circ} \mathrm{C}$ (Backman et al., 1992).

Table 10. Pine kraft BLS pyrolysis conditions and product yields (Alen et al., 1994 and Arpiainen et al., 1995a and 1995b).

Table 11. Product yields from the pyrolysis of dry 90-125 $\mu \mathrm{m}$ diameter pine kraft BLS particles at estimated particle residence times between 0.3-1.7 s (Frederick et al., 1995a and Carangal et al., 1995).

Table 12. Yields of char, fume, and sodium contained in the fume from pyrolysis of an industrial kraft black liquor (Backman et al., 1996).

Table 13. Experimental and theoretical studies of acoustic enhancement of heat and mass transfer.

Table 14. A list of experimental variables. 
Table 15. A list of experiments to collect BLS pyrolytic product yield data.

Table 16. Particle flow configurations through the reactor with a steel wool plug.

Table 17. A list of chemical species and their corresponding peaks on FT-IR spectra of tar and fume coated glass-fiber filters

(Pouchert, 1985 and Solomons, 1988).

Table A4.1. Mass of chars, RNAC918 and RAC925B, after soxhlet extraction of tar in tetrahydrofuran for 2 and 18 hours.

Table A4.2. Comparison of a known sample, containing organic and carbonate carbon, with measured result from Huffman Laboratories, Inc., Golden, CO.

Table A4.3. Char analysis results (measured with covered sample boat unless indicated otherwise) from Huffman Laboratories, Inc., Golden, CO.

Table A4.4. Measured quantities of BLS fed, char collected, and total, carbonate, and organic carbon in the char.

Table A5.1. CO yields calculated from measured $\mathrm{CO}$ concentration in the pyrolysis gas.

Table A5.2. $\quad \mathrm{CO}_{2}$ yields calculated from measured $\mathrm{CO}_{2}$ concentrations and estimated $\mathrm{CO}_{2}$ concentrations in the pyrolysis gas.

Table A7.1. Pyrolysis tube wall and gas temperatures measured with thermocouples (not corrected for conduction and radiation errors).

Table A7.2. Centerline gas temperatures measured with a $1.59 \mathrm{~mm}$ sheath diameter thermocouple inserted through the particle injection tube (not corrected for conduction and radiation errors).

Table A7.3. Centerline gas temperature measured with a $3.18 \mathrm{~mm}$ sheath diameter thermocouple inserted through the particle injection tube and the corresponding near-centerline gas temperature measured with a pyrolysis tube thermocouple (not corrected for conduction and radiation errors).

Table A7.4. Centerline and average velocity of preheated $\mathrm{N}_{2}$ in the pyrolysis tube at temperatures of 550 and $700^{\circ} \mathrm{C}$ for laminar flow.

Table A7.5. Thermal conduction and radiation errors of the measured gas and pyrolysis tube wall temperatures.

Table A8.1. Output voltage of probe acoustic pressure transducer corresponding to the acoustic pressure measured by reference transducer. 
Table A8.2. Values of variables used to calculate acoustic pressure amplitudes of the standing wave.

Table A9.1. Residence times of a pulse of BLS particles in the $0.95 \mathrm{~m}$ pyrolysis tube obtained with and without acoustics using a secondary air flowrate of $56 \mathrm{slpm}$.

Table A9.2. Mean velocities of individual particles in the pyrex, simulated pyrolysis tube at distances of $0.045-0.085,0.05-0.175$, and $0.145-0.185 \mathrm{~m}$ from the particle injection point obtained with and without an acoustic field of $151 \mathrm{~dB}$ and $970 \mathrm{~Hz}$ using a secondary air flowrate of $56 \mathrm{slpm}$.

Table A9.3. Mean velocities of individual particles in the pyrex, simulated pyrolysis tube at distances of $0.045-0.085,0.05-0.175$, and $0.145-0.185 \mathrm{~m}$ from the particle injection point obtained with and without an acoustic field of $151 \mathrm{~dB}$ and $970 \mathrm{~Hz}$ using a secondary air flowrate of 14 slpm.

Table A9.4. Mean velocities of individual particles in the pyrex, simulated pyrolysis tube at distances of $0.045-0.085,0.05-0.175$, and $0.145-0.185 \mathrm{~m}$ from the particle injection point obtained with an acoustic field of $159 \mathrm{~dB}$ and $970 \mathrm{~Hz}$ using a secondary air flowrate of $56 \mathrm{slpm}$.

Table A9.5. Mean particle residence times in the $0.18 \mathrm{~m}$ simulated pyrolysis tube calculated using the mean particle velocities between $0.05-0.175 \mathrm{~m}$ downstream of the particle injection point with and without an acoustic field of 151 or $159 \mathrm{~dB}$ and $970 \mathrm{~Hz}$ using secondary air flowrates between 14-56 slpm.

Table A10.1. Estimated mean residence times of inflight particles in the heated pyrolysis tube for pyrolysis experiments conducted with and without an acoustics.

Table A11.1 Biot number of $125 \mu \mathrm{m}$ diameter BLS particles calculated at temperatures of 550 and $700^{\circ} \mathrm{C}$ and relative slip velocities between $4.3-11 \mathrm{~m} / \mathrm{s}$. 
xxxiv

\section{NOMENCLATURE}

\section{ROMAN SYMBOLS}

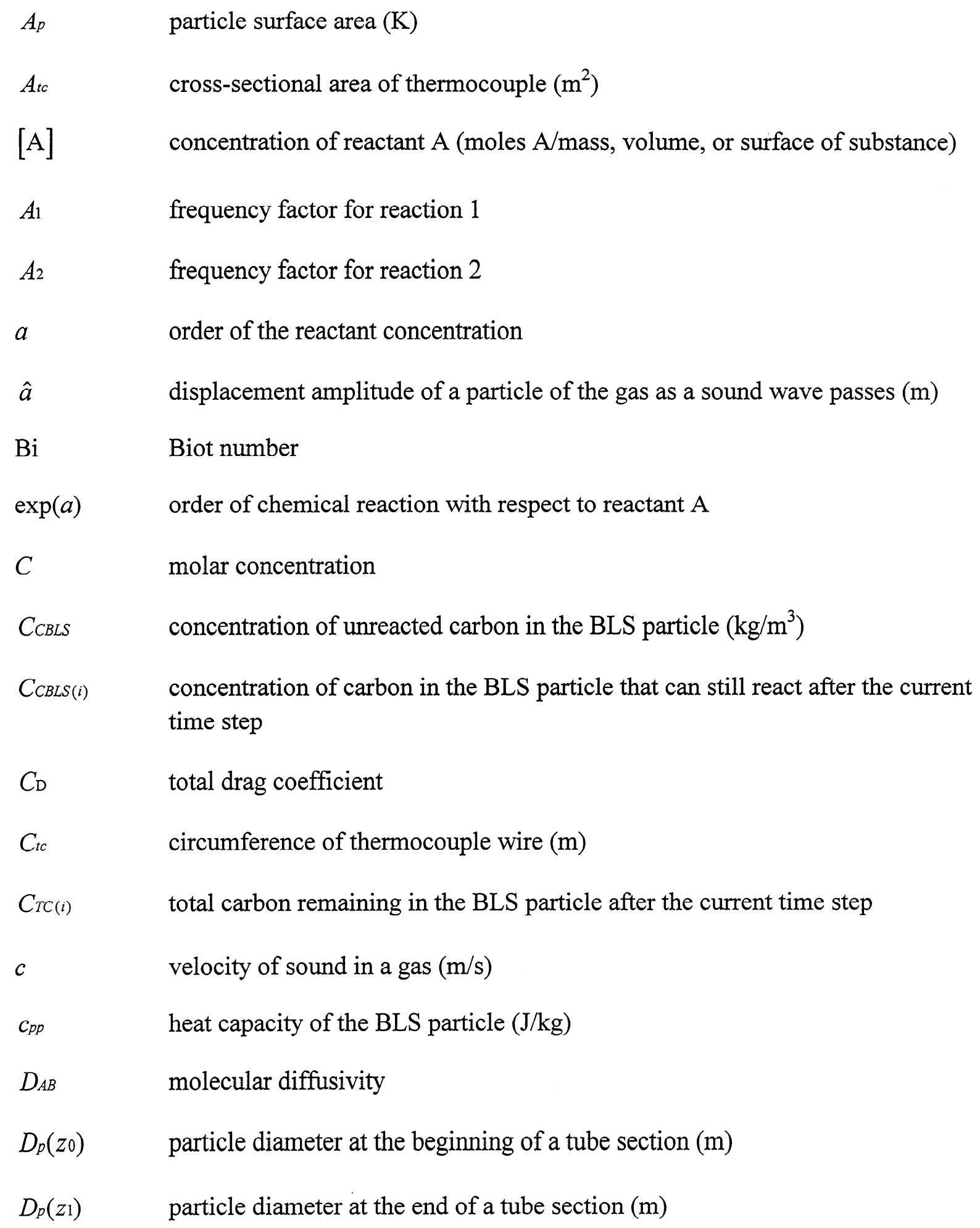




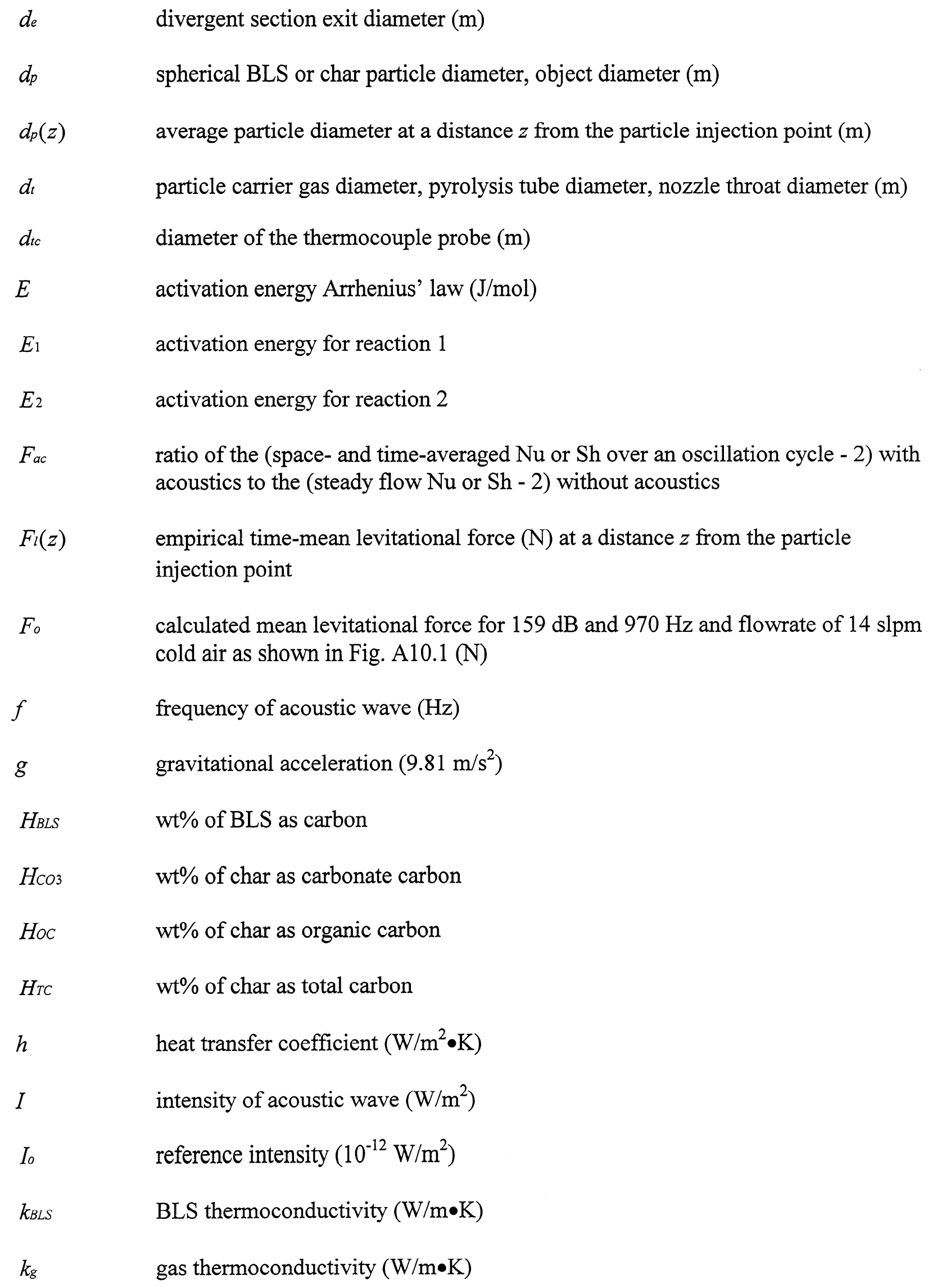




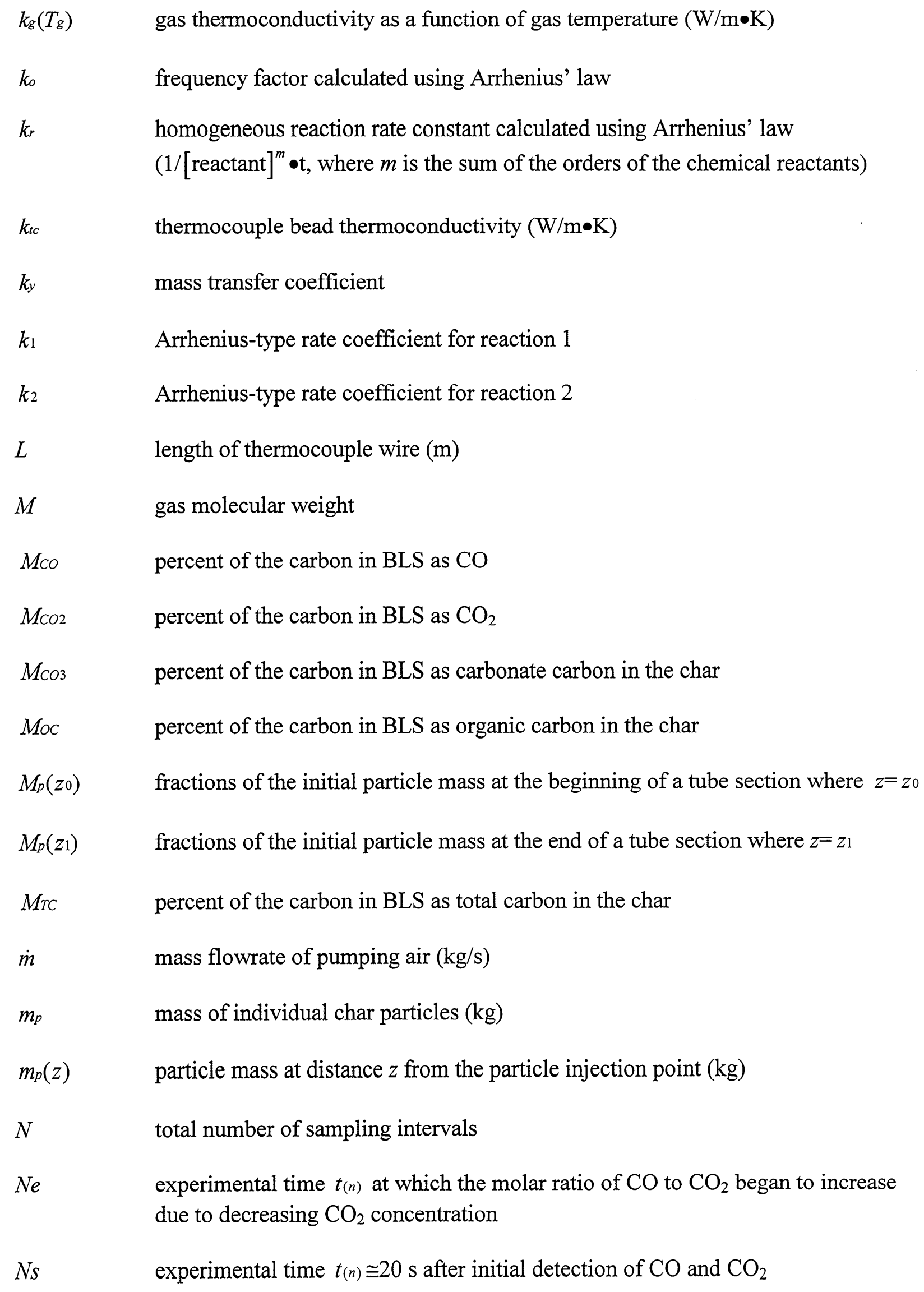




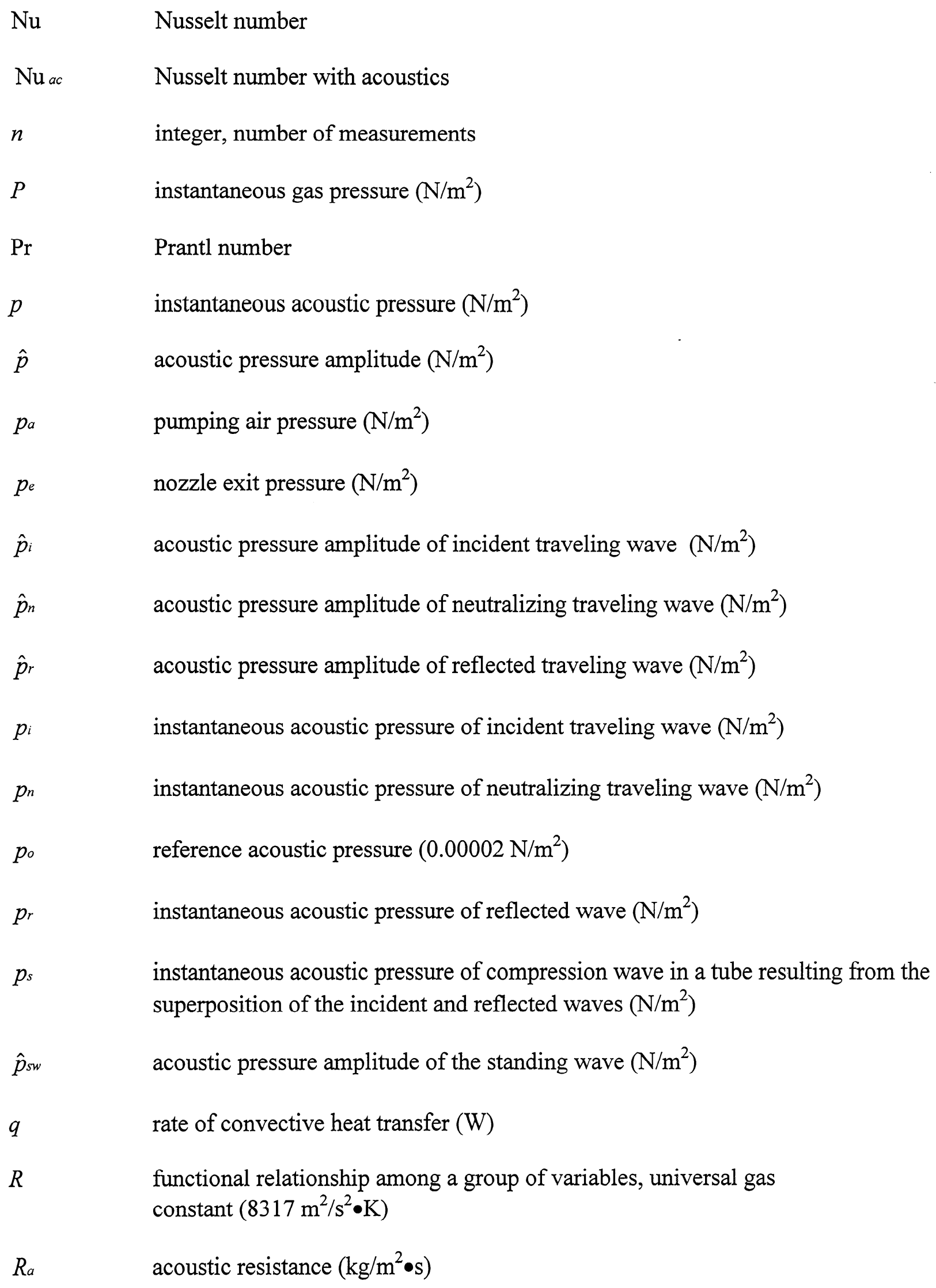


$\mathrm{Re}_{p} \quad$ particle Reynolds number, object Reynolds number

$r$

$r \mathrm{~B}$

$r_{d}(z)$

$r t$

$S_{1}$

$S_{2}$

Sc

Sh

$S_{(i)}$

SPL

$s$

$T$

$T_{g}$

$T_{g}\left(z_{0}\right)$

$T_{g}\left(z_{1}\right)$

$T_{m}$

$T r$

$T_{s}$

$T_{w}$ radial distance from the pyrolysis tube centerline

rate of product B formed (mol B formed $/ \mathrm{kg}, \mathrm{m}^{3}$, or $\mathrm{m}^{2}$ of substance•time)

maximum particle radial dispersion distance at a distance $z$ from the particle injection point $(\mathrm{m})$

radius of the pyrolysis tube

concentration of unreactive carbon formed that remains in the BLS particle via reaction 1

concentration of unreactive carbon formed that remains in the BLS particle via reaction 2

Schmidt number

Sherwood number

fraction of unreactive carbon in BLS as volatiles at the current time step

sound pressure level (decibels)

sample standard deviation, integration variable in Basset history integral in Eq. 25 (s)

temperature $(\mathrm{K})$

gas temperature $(\mathrm{K})$

gas temperature at the beginning of a tube section where $z=z_{0}(\mathrm{~K})$

gas temperature at the end of a tube section where $z=z_{1}(\mathrm{~K})$

minimum temperature at which the cracking reactions can occur in biomass materials $(\mathrm{K})$

temperature of the preheated $\mathrm{N}_{2}$ in the pyrolysis tube $(\mathrm{K})$

particle surface temperature, thermocouple temperature $(\mathrm{K})$

wall temperature $(\mathrm{K})$

Student's t-statistic, time (s) 
xxxix

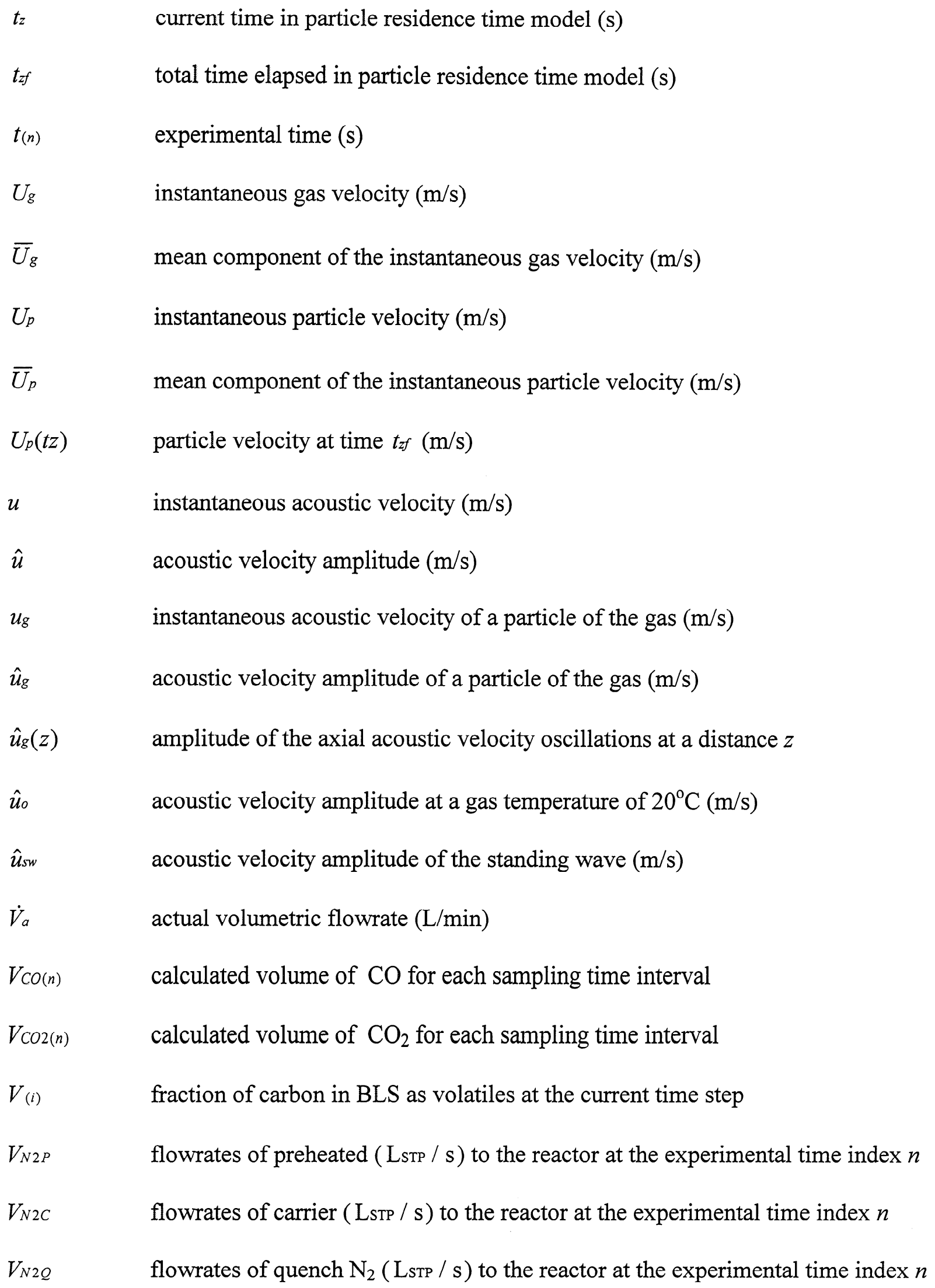




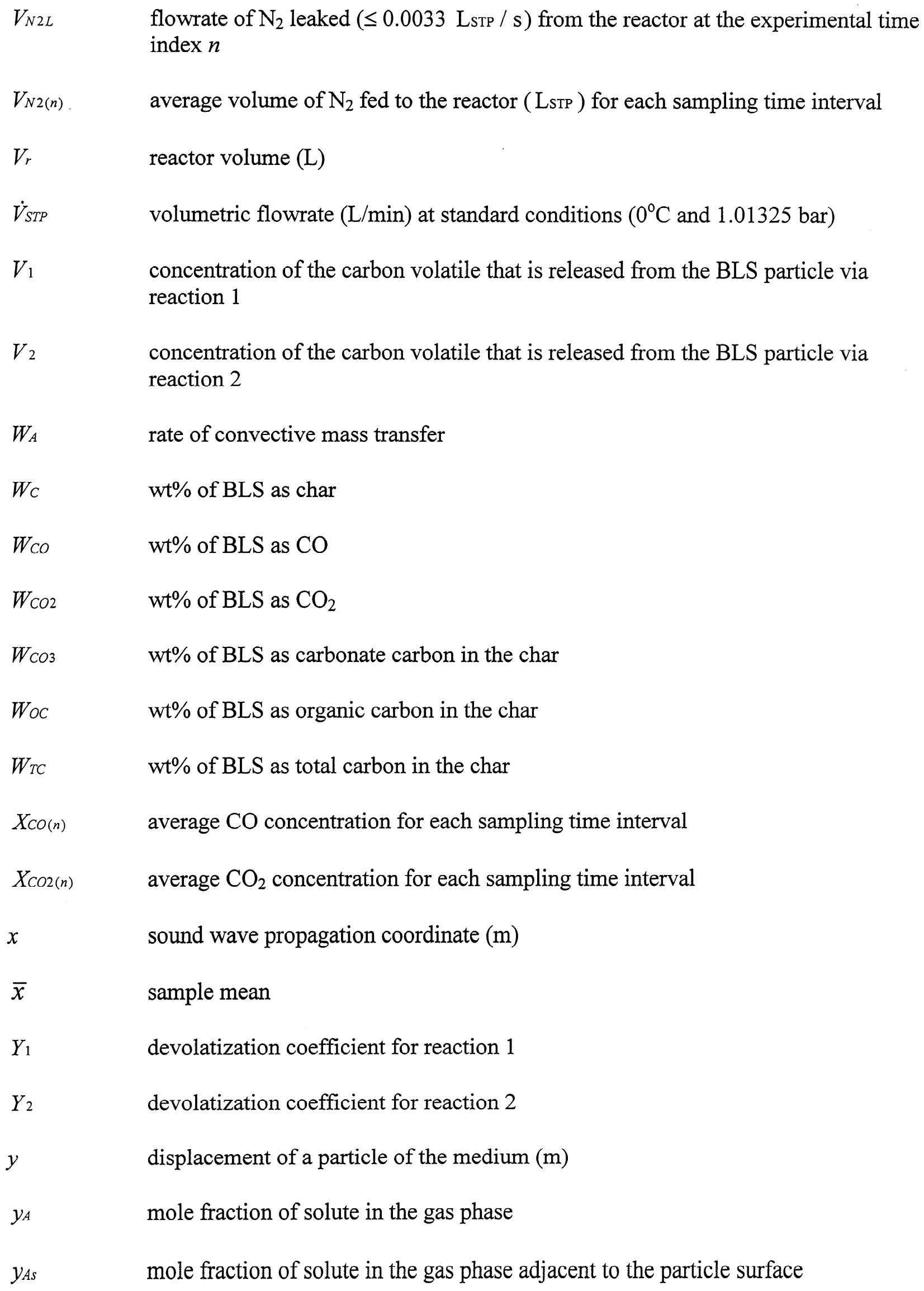




\section{GREEK SYMBOLS}

$\Delta \mathrm{A}$

$\Delta \mathrm{H}$

$\Delta t z$

$\Gamma$

$\gamma$

$\varepsilon$

$\lambda$

$\lambda_{1 / 4}$

$\mu \quad$ population mean

axial distance traveled by a particle downstream from the injection point into the pyrolysis tube (m)

axial distance between the particle injection point and the nearest downstream acoustic pressure anti-node (m)

distance from the particle injection tube exit to the position of acoustic pressure measurements on the standing wave $(\mathrm{m})$

distance $z$ from particle injection point to where the primary gas jet is completely mixed with the secondary gas stream $(0.15 \mathrm{~m})$

distance from the particle injection tube exit to the position of maximum acoustic pressure on the standing wave $(\mathrm{m})$

total distance traversed by a particle from its injection to time $t_{z f}$ axial distance traveled by a particle up to the start of a tube section (m) axial distance traveled by a particle up to the end of a tube section (m) sphere term in Eq. 25

time increment (s)

preheated $\mathrm{N}_{2}$ actual space-time (s)

ratio of the gas specific heat at constant pressure to the gas specific heat at constant volume

emissivity

$\lambda \quad$ wavelength of sound wave $(\mathrm{m})$

distance between pressure nodes or pressure anti-nodes (m) 


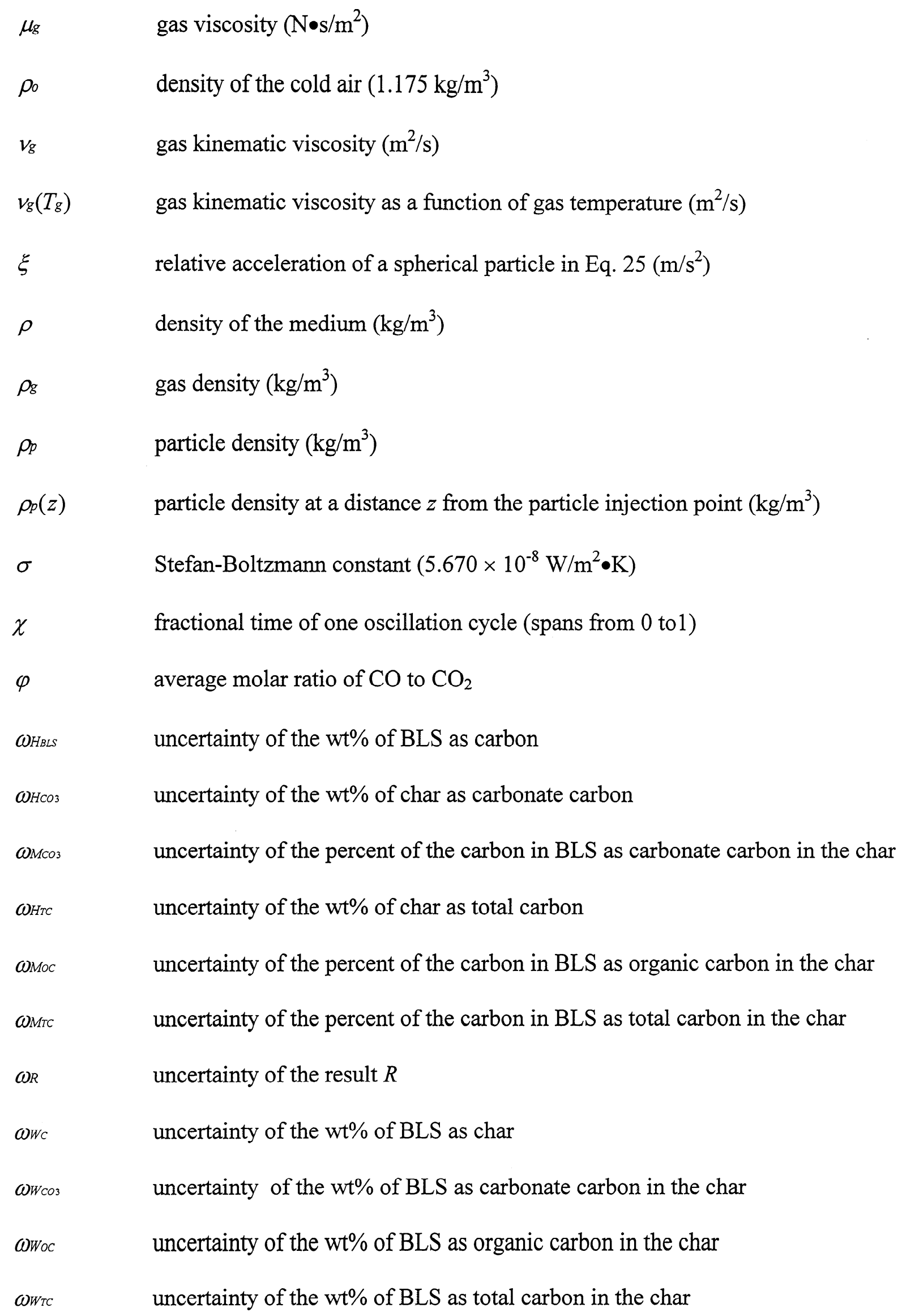




\section{[1] INTRODUCTION}

Black liquor, an aqueous solution containing dissolved organic and inorganic solids (BLS), is a by-product of the kraft pulping process. During pulping about $50 \%$ of the wood dissolves into the caustic pulping solution containing sodium hydroxide and sodium sulfide. The dissolved organic material is a complex substance derived from cellulose, hemicelluloses, lignin, and extractives in the wood. Resin and fatty acids are extracted directly from the wood. Hydroxy acids, acetic acid, and formic acid are degradation products of hemicelluloses and some of the cellulose (Alen and Sjorstrom, 1980). Sodium lignate macromolecules, termed alkali lignin, are formed when sodium reacts with lignin undergoing extraction from the wood (Blackwell and King, 1985). Sodium lignate macromolecules are mostly comprised of phenyl propane units. Ionized phenolic and carboxylic groups prevent the macromolecules from agglomerating and precipitating. Sodium forms ionic bonds with alkali lignin, hydroxy acids, extractives, and other inorganic ions.

Currently, black liquor is evaporated to about $60-80 \%$ solids and combusted in a recovery boiler in the form of a spray to generate steam and electricity and recover pulping chemicals. The understanding of the combustion of black liquor spray in a recovery boiler is very limited. Laboratory studies indicate that a black liquor droplet burns in four stages as shown in Fig. 1 (Adams and Frederick, 1988). Devolatization or thermal decomposition of BLS to form char, tars, liquids, and gases is initiated when enough of the water has evaporated to allow the solids to attain $200^{\circ} \mathrm{C}$ (Brink et al. 1967). In the presence of oxygen, volatile products ignite and a flame engulfs the droplet. Devolatization proceeds faster in gases with high oxygen contents, because tars, liquids, and gases burn faster and release more heat. The burning droplet can swell to more 
than 20 times its initial volume before solidifying into a char residue containing about $20-25 \%$ fixed carbon and $75-80 \%$ inorganic material. Char burning begins when the flame disappears and heterogeneous combustion occurs at the surface. As carbon in the char is consumed, the particle shrinks and finally collapses, leaving an inorganic smelt bead (Grace, 1992). The smelt bead is comprised of sodium carbonate and sodium sulfate (Bergholm 1963).

1) Water evaporation

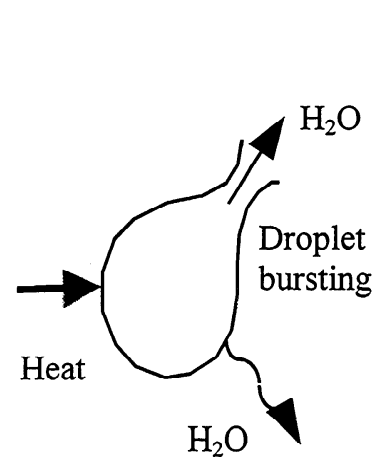

2) Devolatization

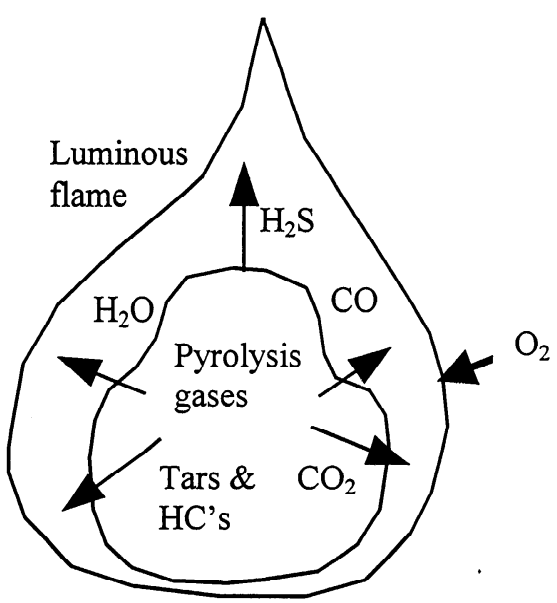

3) Char oxidation

4) Smelt coalescence

Figure 1. Four stages of burning of a black liquor droplet.

Research has been ongoing to develop of an economical and energy efficient black liquor gasification process that can replace the recovery boiler. One aspect of this research focuses on the initial devolatization stage of gasification. When BLS are gasified, devolatization and char carbon gasification are conducted with a substoichiometric amount of oxygen needed for complete combustion of the carbon in order to produce $\mathrm{CO}$ fuel in favor of $\mathrm{CO}_{2} \cdot \mathrm{CO}_{2}$ or steam are the gasifying agents. The product gas is combusted to supply heat for the process and to generate steam and electricity. The devolatization stage is termed pyrolysis when conducted without additional oxygen. 
The behavior and yield of the black liquor devolatization products dictate the energy requirements and processing conditions for gasifying the char carbon (Brink and Thomas, 1975). Char carbon gasification reactions require more energy input and proceed more slowly than do pyrolysis reactions. Hence, gasification would be more energy efficient if more of the carbon in BLS were converted to combustible gases instead of char during pyrolysis. Gasification reactions proceed very rapidly at high gas temperatures $\left(>900^{\circ} \mathrm{C}\right)$ found in a recovery boiler or Chemrec gasifier (Stigsson and Hesseborn, 1995). However, corrosion is severe at temperatures above the smelt melting point which necessitates very costly, specialized process equipment. Gasification conducted at gas temperatures below the smelt melting point $\left(\sim 700-800^{\circ} \mathrm{C}\right)$ would be more energy efficient and require less costly processing equipment. Because gasification reactions proceed more slowly at $700-800^{\circ} \mathrm{C}$, the study of how the pyrolysis process variables affect pyrolytic product yields is important to making black liquor gasification more energy efficient and economical, especially for low temperature gasification processes.

It is known from studies of wood and coal pyrolysis using small $<125 \mu \mathrm{m}$ diameter particles that the process variables such as substrate peak temperature, substrate heatup rate, substrate holding time at peak temperature, and mass transfer rate of products away from the substrate can affect the relative proportions of char, tar, liquids, and gases. In this dissertation, the substrate heatup rate of is defined as the increase of substrate temperature versus time. The effects of the process variables on the product distribution inherently depend on the particle dimensions, pyrolysis reaction kinetics, and chemical and morphological changes that occur during pyrolysis. Although several studies have pyrolyzed $<125 \mu \mathrm{m}$ diameter kraft BLS particles at relatively high particle heatup rates using various techniques (Alen et al., 1992 and 1994; Arpiainen et al., 1995a and b; Carangal et al., 1995; Backman et al., 1992; Bergholm, 1963; 
Frederick et al., 1995a), the results were not conclusive to quantify whether or not increased rates of particle heatup can reduce char yields and affect the relative yields of tar, liquid, and gases. The effect of the mass transfer rate of products from the particle on pyrolytic product yields was not investigated in any of these studies. A study of BLS pyrolysis under severe conditions that promote rapid particle heatup and high mass transfer rates of products from the particle would better define the constraints imposed by the pyrolytic process variables on low temperature black liquor gasification processes.

Many laboratory apparatus are available for the study of BLS particle pyrolysis. However, common types of apparatus that can rapidly heat $100 \mu \mathrm{m}$ diameter BLS particles are not able to modify the gas-film boundary layer around the particle in order to increase the mass transport of pyrolytic products from the particle surface to the bulk gas phase (Serio et al., 1992). One possible way to significantly increase the rates of BLS particle heatup and mass transport of pyrolytic products (internally and externally) is to pyrolyze small particles while they are inflight in the presence of a high-intensity acoustic field. Numerous studies have shown that highintensity acoustic oscillations or sound waves can increase convective mass, momentum, and heat transfer between gas and solid or liquid phases, resulting in more efficient evaporation and combustion. Some examples are combustion of coal (Gupta and Rajan, 1991; Lyman and Sabnis, 1982; Severyanin, 1969; Carvalho et al., 1987) and gasoline and diesel fuel droplets (Blaszcyk, 1991); sublimation of naphthalene spheres (Hodgins et al., 1957); and evaporation of water sprays (Rawson, 1988) and water and methanol droplets (Sujith, 1994). Acoustic enhancement of heat and mass transfer varies from several percent to several orders of magnitude depending on the bulk flow characteristics (Hodgins et al., 1957; Cheng and Fand, 1963; Ha and Yavuzkurtz, 1993a and b), amplitude and frequency of the acoustically-induced gas pressure and 
velocity oscillations (Al Taweel and Landau, 1979; Celik and Wang, 1991; Fand and Kaye, 1960; Ha and Yavuzkurt, et al., 1989), and location of the process relative to the pressure nodes in a resonant standing wave (Arpaci et al., 1990 and 1991).

This dissertation was undertaken to understand how high-intensity acoustic oscillations influence the inflight pyrolysis of BLS particles with respect to their chemical and physical transformation to char and volatile products. Soda-AQ BLS was used in this study as a surrogate for kraft BLS in order to preclude generation of malodorous sulfur gases due to complex pyrolysis reactions between sulfur and carbon produce (Forssen et al., 1992), corrosion problems in the reactor, and liquor handling problems. The results obtained from studying the pyrolysis of soda-AQ BLS should apply to kraft BLS because the liquors are chemically similar, as shown in Tables 1 and 2 .

Table 1. Elemental analyses of BLS from the hardwood soda-AQ black liquor used in this study by Galbraith Labs, Knoxville, TN and from different softwood kraft black liquors (Frederick and Hupa 1993).

\begin{tabular}{|l|r|r|}
\hline \multirow{2}{*}{ Element } & \multicolumn{2}{|c|}{ Wt\% of BLS } \\
\cline { 2 - 3 } & \multicolumn{1}{|c|}{ HW soda-AQ } & \multicolumn{1}{c|}{ Pine SW kraft } \\
\hline Carbon & $39.37\left(39.52^{\mathrm{a}}\right)$ & $30.1-39.8$ \\
\hline Hydrogen & 3.6 & $3.5-4.2$ \\
\hline Oxygen & 34.45 & $33.1-37.3$ \\
\hline Sodium & 21.23 & $15.5-20$ \\
\hline Sulfur & - & $4-6.8$ \\
\hline Potassium & 0.9 & $0.1-2.5$ \\
\hline Chlorine & 0.45 & $0.3-.9$ \\
\hline
\end{tabular}

a Mean of four total carbon measurements by Huffman Labs, Inc., Golden, $\mathrm{CO}$ and one total carbon measurement by Galbraith Labs, Inc.

b By difference. 
Table 2. Chemical composition of a birch hardwood soda-AQ black liquor and a pine softwood kraft black liquor (Alen et al. 1995).

\begin{tabular}{|l|r|r|}
\hline \multirow{2}{*}{ Constituent } & \multicolumn{2}{|c|}{ Wt\% of BLS } \\
\cline { 2 - 3 } & Birch HW soda-AQ & Pine SW kraft \\
\hline Alkali lignin & 32.6 & 43.9 \\
\hline Hydroxy acids & 17.1 & 18.9 \\
\hline Acetic acid & 12.6 & 4.7 \\
\hline Formic acid & 5.1 & 7.1 \\
\hline Other organics & 12.9 & 3 \\
\hline Sodium & 16.5 & 17.3 \\
\hline Unidentified & 3.2 & 5.1 \\
\hline
\end{tabular}

A study of the pyrolysis of soda-AQ BLS particles in an intense acoustic field would answer two important questions: (1) To what extent can organic carbon conversion to gas phase constituents be increased by using acoustic oscillations to simultaneously enhance the rates of particle heatup and mass transport of products from the pyrolyzing particle? (2) Through what mechanisms do acoustic oscillations affect conversion, for instance, faster particle heatup, greater mass transfer of reactive products away the particle, and longer residence times of BLS particles, fume, and vapor phase products due to the change of fluid dynamics by the acoustics? 


\section{[2] LITERATURE REVIEW}

The purpose of this literature review is to provide an understanding of how the process variables and an acoustic field can affect the pyrolysis of soda-AQ black liquor. First, the well studied effects of the process variables on the general pyrolysis mechanism of materials related to black liquor such as cellulose, hemicellulose, lignin, hydroxy acids, wood, and coal will be explained. Second, the limited studies on black liquor pyrolysis will be presented. Third, background theory of acoustic wave propagation and several experimental and theoretical studies concerning the effects of a resonant acoustic field on the rates of mass and energy transport and the particle terminal velocity will be presented.

\section{[2.1] GENERAL MECHANISM OF BIOMASS PYROLYSIS}

Limited studies have been conducted on the black liquor pyrolysis mechanism. However, black liquor pyrolysis can be understood through the understanding of the pyrolysis of biomass such as wood and its cellulose, hemicellulose, and lignin components (Wenzyl, 1970) and coal (Smoot, 1993). Biomass pyrolysis reactions can occur over a wide range of temperatures, and the products formed at earlier stages can undergo further transformation and decomposition in a series of parallel and consecutive, competing, homogeneous or heterogeneous-phase reactions (Elder and Soltes, 1981), as shown in Fig. 2. 


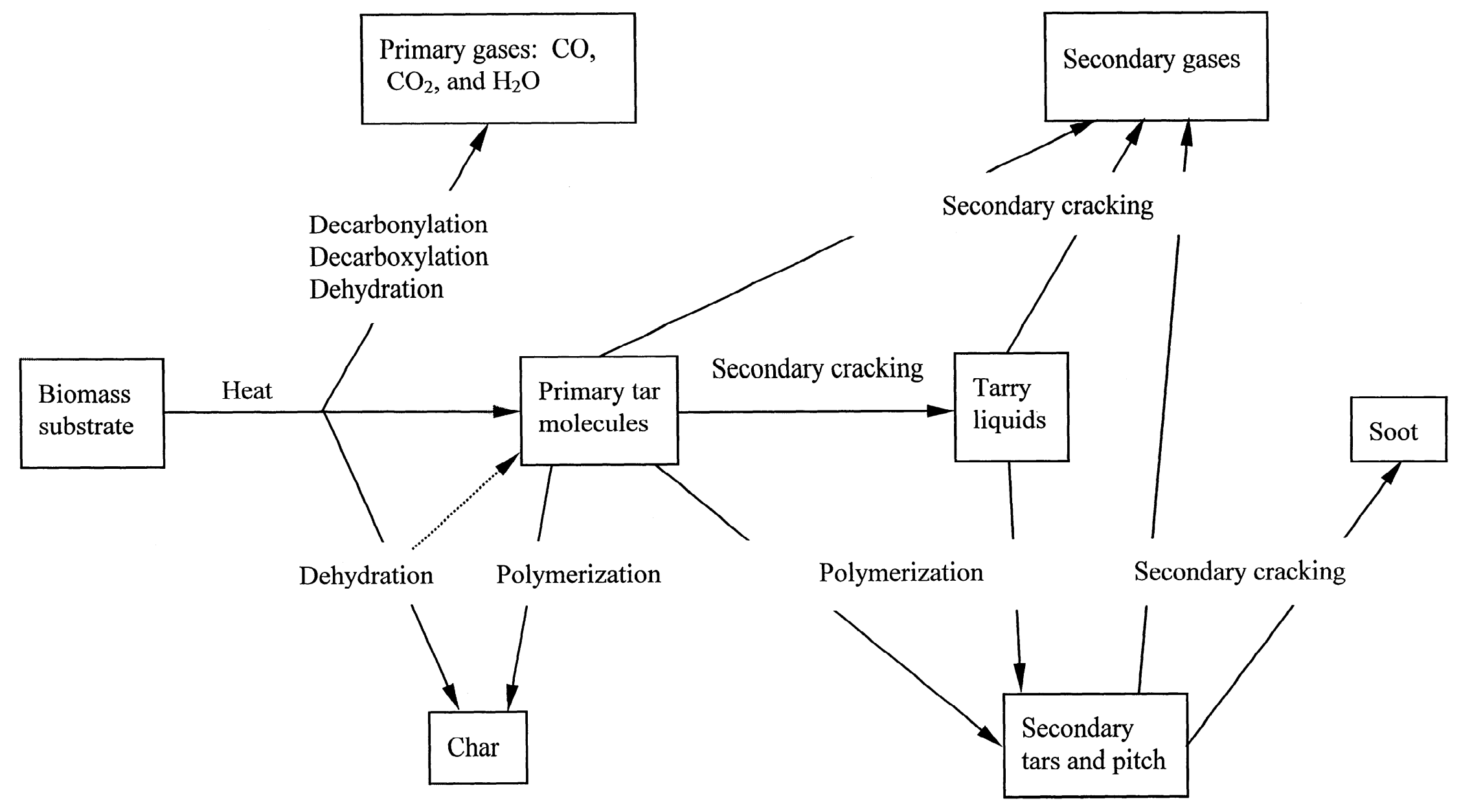

Figure 2. A schematic diagram of the general mechanism of biomass pyrolysis. 
When the temperature of a biomass material exceeds $200^{\circ} \mathrm{C}$, chemical bonds of the substrate start to break, which divides the substrate into large molecular weight fragments and $\mathrm{CO}, \mathrm{CO}_{2}$, and $\mathrm{H}_{2} \mathrm{O}$ (Shafizadeh, 1982). $\mathrm{CO}, \mathrm{CO}_{2}$, and $\mathrm{H}_{2} \mathrm{O}$ are formed by decarbonylation, decarboxylation, and dehydration reactions, respectively. As the substrate temperature increases above about $300^{\circ} \mathrm{C}$, further bond breaking continues to divide or crack the large molecular weight fragments into gases and primary tar molecules (Bergougnou and Graham, 1984). Primary tars may recombine or repolymerize to form char, or may undergo secondary cracking to form secondary tars, tarry liquids, gases, and soot depending on the temperature and the contact time with other primary tars and the charring substrate. The char residue is a mixture of polymerized primary tar molecules, dehydrated fragments, tarry liquids, and soot. Secondary tars and tarry liquids may further crack or polymerize within the substrate or in the surrounding gas if the gas temperature is equal to that of the substrate. Increasing the holding time of tars and liquids in the hot bulk gas can promote further secondary polymerization and cracking reactions (Bartle et al., 1990; Boroson et al., 1989a and b; Brink et al., 1970; Howard et al., 1987; Khan, 1989). At sufficiently high temperatures with long enough holding times, tars and liquids will eventually fragment into $\mathrm{CO}, \mathrm{CO}_{2}, \mathrm{H}_{2}, \mathrm{H}_{2} \mathrm{O}$, and $\mathrm{CH}_{4}$ (Elder and Soltes, 1981).

\section{[2.1.1] Effects of Temperature, Heating Rate, and Holding Time}

The substrate peak temperature, heating rate, and holding time at the peak temperature influence competing pyrolytic reaction pathways and dictate the yields of char, tar, liquids, and gases. The individual pyrolytic cracking and polymerization, homogeneous phase reactions of biomass materials are under kinetic control rather than equilibrium control (Anthony et al., 1975 and Bergougnou and Graham, 1984). A homogenous reaction is under kinetic control when the 
quantities of reaction products are determined by the relative rates of competing reactions rather than by their relative thermodynamic stabilities (Solomons, 1988). For a typical biomass solid material, the global kinetics of the pyrolytic reactions are characterized by three stages: an initial slow induction period, a period of accelerated reaction, and a period during which reaction slows down (Lin, 1974).

Chemical reaction kinetics can be used to explain the effect of temperature, heating rate, and holding time at peak temperature on pyrolytic reactions. For a single homogeneous reaction, such as reactant $\mathrm{A}$ cracking to produce $\mathrm{B}$ and $\mathrm{C}$, the product $\mathrm{B}$ formation rate $r_{\mathrm{B}}$ can be expressed as,

$$
r \mathrm{~B}=\frac{d[\mathrm{~B}]}{d t}=k_{r}[\mathrm{~A}]^{a},
$$

where the power $a$ is the order of the reactant concentration [A] determined from experimental data (Levenspiel, 1972). The rate constant $k_{r}$ can be calculated using Arrhenius' law

$$
k_{r}=k_{o} e^{-E / R T},
$$

where $k_{o}$ is the frequency factor, and $E$ is the activation energy. For all reactions in which covalent bonds are broken, the reactants must first overcome an activation energy at a transitionary state between the reactants and the products (Solomons, 1988). The activation energy is the difference in potential energy of the reactants between their fundamental state and high-energy transition state. The activation energy must come from an external source. The heat of reaction is the difference in potential energy between reactants and products. Exothermic reactions release energy to the environment because the potential energy of the product is lower 
than that of the reactant, while endothermic reactions require additional energy input to react because the potential energy of the product is higher than that of the reactant state. In summary, reactions that have lower activation energies occur at lower temperatures, and their reaction rates are less sensitive to temperature.

Many polymerization and cracking reactions of primary and secondary tars have different activation energies, and their net heat of reaction as a whole is approximately zero (Shafizadeh, 1985). Generally, the polymerization reactions are slightly exothermic. They have lower activation energies than that of the cracking reactions which are usually endothermic. For biomass materials, there is a minimum temperature $T_{m}$ corresponding to necessary activation energy at which cracking reactions can proceed. When the temperature of a biomass substrate is slowly increased to the peak temperature, more char will be produced. The sequence of consecutive polymerization reactions has more time to proceed before facing competition from cracking reactions, which start to proceed at $T_{m}$. Rapidly increasing the temperature of the substrate to peak temperatures above $T_{m}$ can increase the yields of tar, liquids, and gases over char by allowing alternative cracking reactions with higher activation energies to proceed before significant polymerization results (Darivakis et al., 1994).

\section{[2.1.2] Influence of Mass Transfer Rate of Products}

A solid biomass substrate can soften or even melt during pyrolysis, which transforms the solid into a heterogeneous mixture of solidifying char, tar, tarry liquids, and gases. Rapid generation of gases within the substrate increases the internal pressure, which acts as a driving force for transport of gases and reactive tar and volatiles through the continuously changing network of interconnected pores within the substrate (Darivakis et al., 1994). Bubbles of 
noncondensable gas that may contain reactive tar and volatiles can also diffuse through any molten portions of the substrate (Serio et al., 1992).

Furthermore, reactive tar and tarry liquids can react with the charring structure to form additional char, or react with one another to form soot deposits, if they do not escape from the interior or exterior surface of the substrate before polymerization occurs. The prompt escaping of tar and volatiles from the exterior surface may be limited by their transport through the surrounding gas-film layer (Freihaut et al., 1989; Lilly et al., 1985). The rates of heterogeneous, secondary reactions of primary tar with the charring substrate depend on the reaction kinetics, instantaneous concentration of products, and contact time of the product with the substrate. Lower instantaneous concentrations of the reactive pyrolytic products can decrease the rates of polymerization reactions (Howard et al., 1989). Shorter contact time can reduce the amount of products that polymerize into the substrate (Anthony et al., 1975; Fletcher, 1989). Consequently, higher mass transfer rates of products are necessary to prevent increased volatiles holdup inside the substrate or on its surface when the rate of volatiles generation increases due to rapid substrate heatup to high temperatures.

\section{[2.2] EXPERIMENTAL STUDIES OF BIOMASS PYROLYSIS}

\section{[2.2.1] Types of Reactors}

Finely, pulverized biomass particles are often used in industrial combustion, gasification, and pyrolysis processes. Therefore, many laboratory studies on the pyrolysis of small biomass particles have been conducted. Three commonly used laboratory pyrolysis apparatus are illustrated in Fig. 3. Table 3 describes their operating parameters and applications in various 
pyrolysis studies. Other apparatus include fluidized beds, single particle heating lasers, and curie point heated tube reactors (Serio et al., 1992). Each apparatus has been designed to control one or more of the process variables, so that the effect of each variable on product yield can be determined.

Retort Furnace Reactor (RFR)

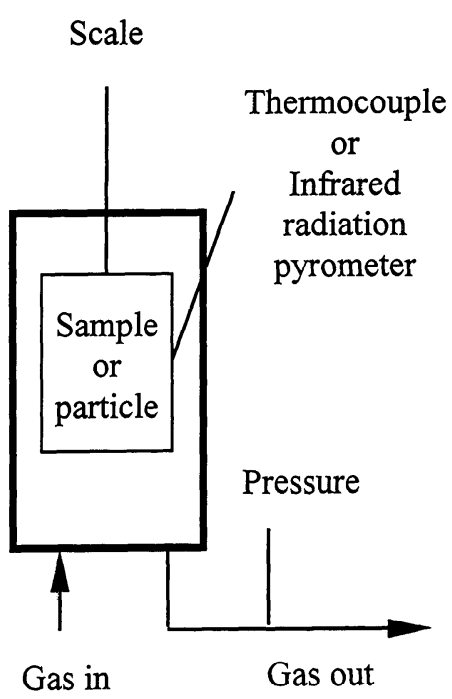

Heated Grid Reactor (HGR)

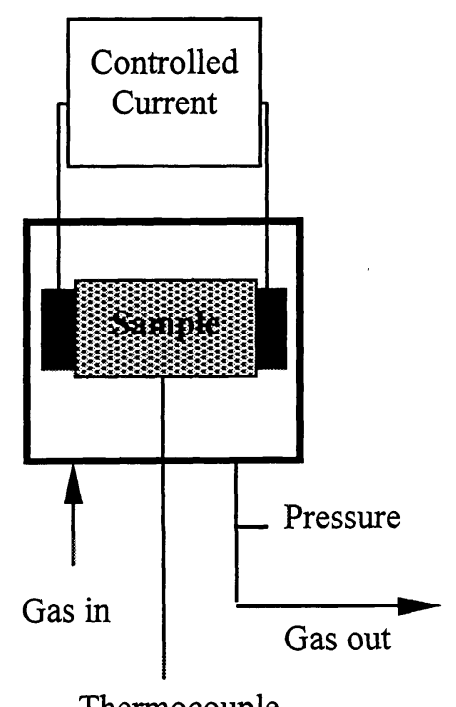

Entrained Flow Reactor (EFR)

Particles and carrier gas in

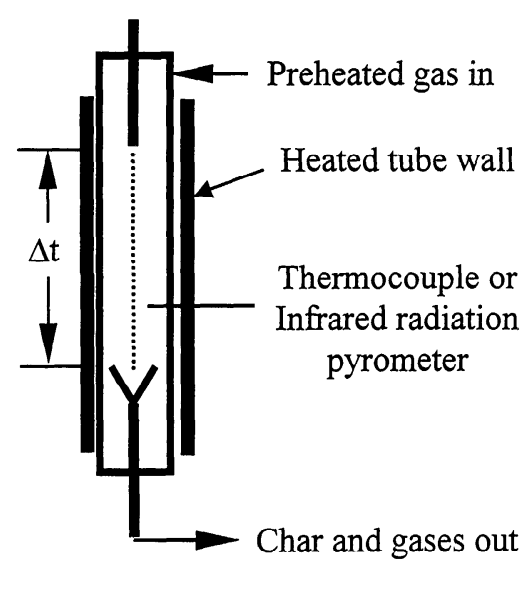
Thermocouple

Figure 3. A schematic diagram of the retort furnace reactor, heated grid reactor, and entrained flow reactor. 
Table 3. The operating characteristics and applications of the retort furnace reactor, heated grid reactor, and entrained flow reactor used in pyrolysis studies.

\begin{tabular}{|c|c|c|c|}
\hline & Retort furnace reactor & Heated grid reactor & Entrained flow reactor \\
\hline Sample size & $\begin{array}{l}\text { Crucible capacity or } 1.5-3 \mathrm{~mm} \\
\text { particle suspended on } \\
\text { thermocouple or thin rod }\end{array}$ & $\begin{array}{l}\text { Typically }<100 \mathrm{mg} \text { of } 40-120 \mu \mathrm{m} \\
\text { diameter particles spread thinly on } \\
\text { wire mesh heating element }\end{array}$ & $\begin{array}{l}\text { Typically } 100 \mu \mathrm{m} \text { diameter } \\
\text { particles; solids feedrate }<1 \mathrm{~g} / \mathrm{min}\end{array}$ \\
\hline $\begin{array}{l}\text { Gas } \\
\text { temperature }\end{array}$ & Same as furnace temperature & Near room temperature & Same as furnace temperature \\
\hline $\begin{array}{l}\text { Sample } \\
\text { temperature }\end{array}$ & $\begin{array}{l}\text { Attains gas temperature by } \\
\text { radiation and convection; can be } \\
\text { measured by thermocouple of IR } \\
\text { pyrometer }\end{array}$ & $\begin{array}{l}\text { Attains the temperature of the } \\
\text { thermocouple attached to the wire } \\
\text { mesh grid by radiation and } \\
\text { conduction }\end{array}$ & $\begin{array}{l}\text { Attains the reactor temperature by } \\
\text { convection and radiation }\end{array}$ \\
\hline Gas pressure & Vacuum to several atmospheres & Vacuum to several atmospheres & $\begin{array}{l}\text { Usually operated near one } \\
\text { atmosphere }\end{array}$ \\
\hline $\begin{array}{l}\text { Batch or } \\
\text { continuous }\end{array}$ & Batch and continuous & Batch & Continuous \\
\hline $\begin{array}{l}\text { Sample } \\
\text { heating rate }\end{array}$ & $\begin{array}{l}\text { Usually }<100^{\circ} \mathrm{C} / \mathrm{s} \text { for crucible; } \\
\text { uneven heating of } 1.5-3 \mathrm{~mm} \\
\text { particles usually }<1000^{\circ} \mathrm{C} / \mathrm{s}\end{array}$ & $\begin{array}{l}<1000^{\circ} \mathrm{C} / \mathrm{s} ; \text { measured sample } \\
\text { temperature is uncertain for } \\
>1000^{\circ} \mathrm{C} / \mathrm{s}\end{array}$ & $\begin{array}{l}\text { Several } 1000^{\circ} \mathrm{C} / \mathrm{s} \text { depending on the } \\
\text { temperatures of the preheated gas } \\
\text { and the furnace wall }\end{array}$ \\
\hline $\begin{array}{l}\text { Sample } \\
\text { residence time }\end{array}$ & $\begin{array}{l}\text { Time to attain the maximum } \\
\text { temperature and additional holding } \\
\text { time }\end{array}$ & $\begin{array}{l}\text { Typically }<1 \mathrm{~s} \text { to attain the peak } \\
\text { temperature followed by any } \\
\text { additional holding time and relatively } \\
\text { short cooling time }\end{array}$ & $\begin{array}{l}\text { Time for particle and gas to travel } \\
\text { between injection and collection } \\
\text { probes }\end{array}$ \\
\hline Advantages & $\begin{array}{l}\text { Can control sample residence time } \\
\text { and measure temperature for small } \\
\text { sample masses }\end{array}$ & $\begin{array}{l}\text { Can determine volatile evaporative } \\
\text { transport limitations by varying the } \\
\text { pressure; cool bulk gas minimizes } \\
\text { volatile cracking reactions in the gas } \\
\text { phase once the vapors leave the hot } \\
\text { grid region }\end{array}$ & $\begin{array}{l}\text { Can study particle pyrolysis and } \\
\text { secondary volatile cracking } \\
\text { reactions at very high heating rates }\end{array}$ \\
\hline
\end{tabular}


Table 3 (Continued). The operating characteristics and applications of the retort furnace reactor, heated grid reactor, and entrained flow reactor used in pyrolysis studies.

\begin{tabular}{|l|l|l|l|}
\hline & \multicolumn{1}{|c|}{ Retort furnace reactor } & \multicolumn{1}{c|}{ Heated grid reactor } & \multicolumn{1}{c|}{ Entrained flow reactor } \\
\hline Disadvantages & $\begin{array}{l}\text { Unable to study rapid heating } \\
\text { effects; hot bulk gas allows } \\
\text { secondary volatile cracking } \\
\text { reactions in batch or continuous } \\
\text { mode; and batch mode promotes } \\
\text { reaction of volatiles with the } \\
\text { sample }\end{array}$ & $\begin{array}{l}\text { Lower heating rates than entrained } \\
\text { flow reactors; cannot change the gas } \\
\text { flow field to affect convective mass } \\
\text { transfer rates because grid can cool } \\
\text { nonuniformly and grid can affect gas } \\
\text { flow characteristics }\end{array}$ & $\begin{array}{l}\text { Difficult to know exact residence } \\
\text { time and temperature of an } \\
\text { individual particle, so must rely on } \\
\text { fluid mechanics model or uncertain } \\
\text { IR pyrometer measurement. } \\
\text { Cannot change the flow field to } \\
\text { affect convective heat and mass } \\
\text { transfer rates }\end{array}$ \\
\hline Used by & $\begin{array}{l}\text { Avni (1985); Backman et al. } \\
\text { (1992); Mackay and Roberts } \\
\text { (1982); Brink et al. (1967 and } \\
\text { 1970); Howard et al. (1987) }\end{array}$ & $\begin{array}{l}\text { Anthony et al. (1975); Gavalas and } \\
\text { Iatridis (1979); Alen et al. (1992); } \\
\text { Gibbens-Matham and Kandiyoti } \\
\text { (1988); Niksa et al. (1982); } \\
\text { Freihaut et al. (1982) }\end{array}$ & $\begin{array}{l}\text { Kobayashi et al. (1976); Fletcher } \\
\text { (1989); Frederick et al. (1995a) }\end{array}$ \\
\hline
\end{tabular}




\section{[2.2.2] Pyrolysis of Cellulose, Hemicellulose, Hydroxy Acids, Lignin, Wood, and Coal}

Each biomass material has different thermal properties and pyrolytic behavior, and exhibits different relative yields of char, tar, liquids, and gases. Thermogravimetric analysis in RFR at slow heating rates $\left(<1^{\circ} \mathrm{C} / \mathrm{s}\right)$ indicates that biomass materials pyrolyze in several phases as shown in Table 4. Table 5 describes several laboratory studies of biomass pyrolysis using a RFR, HGR, or EFR.

Table 4. Thermogravimetric analysis of biomass materials at slow heating rates $\left(<1^{\circ} \mathrm{C} / \mathrm{s}\right)$.

\begin{tabular}{|c|c|c|}
\hline Reference & Material & Pyrolysis behavior \\
\hline $\begin{array}{l}\text { Elder and } \\
\text { Soltes (1981) }\end{array}$ & Cellulose & $\begin{array}{l}\text { Gases and an aqueous distillate containing organic acids are } \\
\text { generated below } 240^{\circ} \mathrm{C} \text {; gases and tar are rapidly evolved } \\
\text { between } 240-400^{\circ} \mathrm{C} \text {; and char residue forms above } 400^{\circ} \mathrm{C} \text {. }\end{array}$ \\
\hline Hurd (1929) & Hydroxy acids & $\begin{array}{l}\text { Starts to decompose above } 240^{\circ} \mathrm{C} \text { to form lactic acid that } \\
\text { may decompose into polylactide residue, an aldehyde, } \mathrm{CO} \text {, } \\
\text { and } \mathrm{H}_{2} \mathrm{O} \text { at higher temperature. }\end{array}$ \\
\hline $\begin{array}{l}\text { Wenzyl } \\
(1970)\end{array}$ & Hemicelluloses & $\begin{array}{l}\text { Decomposes at temperatures between } 200-260^{\circ} \mathrm{C} \text { and forms } \\
\text { mostly volatile products. }\end{array}$ \\
\hline $\begin{array}{l}\text { Allen and } \\
\text { Mattile (1971) }\end{array}$ & Lignin & $\begin{array}{l}\text { Decomposes between } 280-480^{\circ} \mathrm{C} \text { and yields } 55 \mathrm{wt} \% \text { char, } \\
20 \mathrm{wt} \% \text { aqueous distillate, } 15 \mathrm{wt} \% \text { tar, and } 12 \mathrm{wt} \% \text { gas. }\end{array}$ \\
\hline $\begin{array}{l}\text { Deglise and } \\
\text { Magne (1987) } \\
\text { And } \\
\text { Shafizadeh } \\
\text { (1985) }\end{array}$ & Wood & $\begin{array}{l}\text { Pyrolyzes similar to the pyrolyses of its individual } \\
\text { components: chemically bonded water is released between } \\
130-200^{\circ} \mathrm{C} \text {; hemicelluloses decompose between } 200-280^{\circ} \mathrm{C} \text {; } \\
\text { cellulose decomposition into mainly volatile products } \\
\text { reaches a maximum at } 320^{\circ} \mathrm{C} \text {; and lignin decomposes into } \\
\text { condensable vapors and forms a carbonaceous char up to } \\
\text { about } 450^{\circ} \mathrm{C} \text {. }\end{array}$ \\
\hline $\begin{array}{l}\text { Dutta and } \\
\text { Wen (1979) } \\
\text { And } \\
\text { Hurd (1929) }\end{array}$ & Bituminous coal & $\begin{array}{l}\text { Swells like black liquor during heatup. Gases and light } \\
\text { volatiles start to evolve between } 150-200^{\circ} \mathrm{C} \text { and reach a } \\
\text { maximum between } 350-450^{\circ} \mathrm{C} \text {; tar and liquid volatiles are } \\
\text { released between } 400-600^{\circ} \mathrm{C} \text {; and a carbonaceous char } \\
\text { slowly forms up to } 900-950^{\circ} \mathrm{C} \text {. }\end{array}$ \\
\hline
\end{tabular}


Table 5. Laboratory studies of biomass pyrolysis that used a RFR, HGR, or EFR.

\begin{tabular}{|c|c|c|}
\hline Study & Material & Pyrolysis apparatus, experimental conditions, and results \\
\hline $\begin{array}{l}\text { Mackay and } \\
\text { Roberts (1982) }\end{array}$ & Cellulose & $\begin{array}{l}\text { RFR. When cellulose was heated to } 700^{\circ} \mathrm{C} \text {, char yield was } 17 \mathrm{wt} \% \text { at a heating rate of } 25^{\circ} \mathrm{C} / \mathrm{min} \\
\text { compared to } 25 \mathrm{wt} \% \text { at a heating rate of } 1^{\circ} \mathrm{C} / \mathrm{min} \text {. }\end{array}$ \\
\hline $\begin{array}{l}\text { Hajaligol } \\
\text { et al. (1982) }\end{array}$ & Cellulose & $\begin{array}{l}\text { HGR. Char yield was } 3-6 \mathrm{wt} \% \text { of dry cellulose when } 100 \mu \mathrm{m} \text { thick strips were heated at } 100- \\
1000^{\circ} \mathrm{C} / \mathrm{s} \text { to peak temperatures between } 500-1000^{\circ} \mathrm{C} \text {. An additional } 2-30 \mathrm{~s} \text { holding time were } \\
\text { required to complete the pyrolysis after heating to peak temperatures between } 500-800^{\circ} \mathrm{C} \text {. At } \\
\text { pressures above } 1.36 \mathrm{bar} \text {, char and gas yields were higher while tar yield was lower. A tarry liquid } \\
\text { accounted for } 40 \text { to } 83 \mathrm{wt} \% \text { of the volatiles above } 400^{\circ} \mathrm{C} \text {. Above } 750^{\circ} \mathrm{C} \text {, CO was the dominant gas } \\
\text { product produced by cracking of the tarry liquid. }\end{array}$ \\
\hline $\begin{array}{l}\text { Snow et al. } \\
(1982)\end{array}$ & Lignin & $\begin{array}{l}\text { RFR. Char yield was unchanged when lignin with the addition of } 2 \mathrm{wt} \% \text { sodium chloride was } \\
\text { slowly heated to peak temperatures between } 200-450^{\circ} \mathrm{C} \text {. }\end{array}$ \\
\hline $\begin{array}{l}\text { Gavalas and } \\
\text { Iatridis (1979) }\end{array}$ & Lignin & $\begin{array}{l}\text { HGR. Char yield was } 35-78 \mathrm{wt} \% \text { of dry lignin when lignin was rapidly heated to peak temperatures } \\
\text { between } 400-700^{\circ} \mathrm{C} \text {. Yields of } \mathrm{CO}, \mathrm{CO}_{2} \text {, and } \mathrm{CH}_{4} \text { increased at high temperatures and long holding } \\
\text { times. }\end{array}$ \\
\hline $\begin{array}{l}\text { Avni et al. } \\
(1985)\end{array}$ & $\begin{array}{l}\text { Alkali } \\
\text { lignin }\end{array}$ & $\begin{array}{l}\text { In nitrogen at } 1.01 \text { bar, char yield was } 22-37 \mathrm{wt} \% \text { of dry lignin when lignin was heated at } 600^{\circ} \mathrm{C} / \mathrm{s} \text { to } \\
\text { peak temperatures between } 500-900^{\circ} \mathrm{C} \text { in } \mathrm{HGR} \text {. At } 0.001 \text { bar, char yield further decreased by } 4-10 \\
\text { wt } \% \text { and tar yield increased by } 6-20 \mathrm{wt} \% \text {. At } 1.01 \text { bar, char yield was } 40-50 \mathrm{wt} \% \text { when lignin was } \\
\text { heated at } 10^{\circ} \mathrm{C} / \mathrm{min} \text { to peak temperatures between } 500-900^{\circ} \mathrm{C} \text { in a RFR. }\end{array}$ \\
\hline $\begin{array}{l}\text { Howard et al. } \\
(1985 b)\end{array}$ & $\begin{array}{l}\text { Sweet gum } \\
\text { hardwood } \\
\text { milled- } \\
\text { lignin }\end{array}$ & $\begin{array}{l}\mathrm{HGR} .100 \mu \mathrm{m} \text { thick flakes were heated at } 1000^{\circ} \mathrm{C} / \mathrm{s} \text { to peak temperatures between } 500-1100^{\circ} \mathrm{C} \text {. } \\
\text { Char yield decreased rapidly after } 420^{\circ} \mathrm{C} \text { to approach a minimum of } 15 \mathrm{wt} \% \text { of dry lignin at } 620^{\circ} \mathrm{C} \text {. } \\
\text { Above } 523^{\circ} \mathrm{C} \text {, tar was the major pyrolysis product with a maximum yield of } 53 \mathrm{wt} \% \text { at } 626^{\circ} \mathrm{C} \text {. } \\
\text { Above } 575^{\circ} \mathrm{C} \text {, CO was the dominant gas produced by tar cracking. }\end{array}$ \\
\hline $\begin{array}{l}\text { Howard et al. } \\
(1985 \mathrm{a})\end{array}$ & $\begin{array}{l}\text { Sweet gum } \\
\text { hardwood }\end{array}$ & $\begin{array}{l}\text { HGR. A thin layer of } 48-88 \mu \mathrm{m} \text { diameter particles was heated at } 1000^{\circ} \mathrm{C} / \mathrm{s} \text { to peak temperatures } \\
\text { between } 500-1100^{\circ} \mathrm{C} \text {. Char yield decreased rapidly after the substrate attained } 420^{\circ} \mathrm{C} \text { to approach a } \\
\text { minimum of } 7 \mathrm{wt} \% \text { of dry wood at } 620^{\circ} \mathrm{C} \text {. Above } 523^{\circ} \mathrm{C} \text {, tar was the major pyrolysis product with a } \\
\text { maximum yield of } 55 \mathrm{wt} \% \text { at } 626^{\circ} \mathrm{C} \text {. Above } 575^{\circ} \mathrm{C}, \mathrm{CO} \text { was the dominant gas produced by } \\
\text { cracking of the primary tar. }\end{array}$ \\
\hline $\begin{array}{l}\text { Diebold and } \\
\text { Scahill (1985) }\end{array}$ & Wood & $\begin{array}{l}\text { Wood was contacted with a red hot metal surface at a temperature of } 1000^{\circ} \mathrm{C} \text { and vapor products } \\
\text { were immediately vacuumed away. This ablative-like pyrolysis showed char formation results from } \\
\text { the polymerization of primary tar vapors. }\end{array}$ \\
\hline
\end{tabular}


Table 5 (Continued). Laboratory studies of biomass pyrolysis that used a RFR, HGR, or EFR.

\begin{tabular}{|c|c|c|}
\hline Study & Material & Pyrolysis apparatus, experimental conditions, and results \\
\hline $\begin{array}{l}\text { Boroson et al. } \\
(1989 \mathrm{a} \text { and } \mathrm{b})\end{array}$ & $\begin{array}{l}\text { Sweet gum } \\
\text { hardwood tar }\end{array}$ & $\begin{array}{l}\text { Vapor phase cracking of tar was studied using two RFR in series. At a gas temperature of } 550^{\circ} \mathrm{C} \text { in } \\
\text { first RFR, primary yields of } \mathrm{CO}, \mathrm{CO}_{2} \text {, and tar were } 3.2,6.8 \text {, and } 52.8 \mathrm{wt} \% \text { of dry wood, respectively. } \\
\text { At a gas temperature of } 600^{\circ} \mathrm{C} \text { compared to } 800^{\circ} \mathrm{C} \text { in the second RFR, yields of } \mathrm{CO} \text { increased from } \\
14.7 \text { to } 35.7 \mathrm{wt} \%, \mathrm{CO}_{2} \text { increased from } 9.7 \text { to } 13.2 \mathrm{wt} \% \text {, and tar decreased from } 36.6 \text { to } 6.1 \mathrm{wt} \% \text { for } \\
\text { residence time of } 1-1.2 \mathrm{~s} \text {. Tar was passed through a } 0.2-0.12 \mathrm{~m} \text { packed bed of char from the same } \\
\text { wood to study heterogeneous cracking. At gas temperatures between } 400-600^{\circ} \mathrm{C} \text { heterogeneous } \\
\text { conversion was a constant } 14 \pm 7 \mathrm{wt} \% \text { of the tar. Yields of } \mathrm{CO} \text { increased by } 0.7 \mathrm{wt} \% \text { of wood and } \\
\mathrm{CO}_{2} \text { increased by } 2.1-3.1 \mathrm{wt} \% \text {. }\end{array}$ \\
\hline $\begin{array}{l}\text { Cuello et al. } \\
(1985)\end{array}$ & Wood tar & $\begin{array}{l}\text { RFR. Tar was contacted with } \mathrm{Na}_{2} \mathrm{CO}_{3} \text { at temperatures between } 550-850^{\circ} \mathrm{C} \text {. Rate of tar conversion to } \\
\text { gases increased substantially. The ultimate yield of gases increased slightly. }\end{array}$ \\
\hline $\begin{array}{l}\text { Anthony et al. } \\
\text { (1974) }\end{array}$ & $\begin{array}{l}\text { Lignite and } \\
\text { bituminous } \\
\text { coal }\end{array}$ & $\begin{array}{l}\text { HGR. Char yields from swelling bituminous coal particles, initially } 70 \mu \mathrm{m} \text { diameter, decreased from } \\
62.5 \text { to } 42 \mathrm{wt} \% \text { when ambient pressure was reduced from } 101-0.001 \text { bar. Char yields decreased with } \\
\text { the decrease of particle size. Particle heatup at } 100-10,000^{\circ} \mathrm{C} / \mathrm{s} \text { reduced char yield slightly. The rate } \\
\text { of particle heatup did not affect lignite coal char yield. }\end{array}$ \\
\hline $\begin{array}{l}\text { Freihaut et al. } \\
(1982)\end{array}$ & $\begin{array}{l}\text { Bituminous } \\
\text { coal }\end{array}$ & $\begin{array}{l}\text { HGR. Tar evolution at } 1.01 \text { bar was accompanied by substantial particle swelling and formation of } \\
\text { bubbles that quickly ruptured; particles tended to flow together and seep into the holes between the } \\
\text { mesh wires. Tar evolution in a vacuum resembled a sublimation process with very little swelling. }\end{array}$ \\
\hline $\begin{array}{l}\text { Niksa et al. } \\
(1982)\end{array}$ & $\begin{array}{l}\text { Bituminous } \\
\text { coal }\end{array}$ & $\begin{array}{l}\text { HGR. Char yields in a vacuum decreased by } 3-10 \mathrm{wt} \% \text { of dry-ash free coal at heating rates of } 1000- \\
10,000^{\circ} \mathrm{C} / \mathrm{s} \text { compared to } 100^{\circ} \mathrm{C} / \mathrm{s} \text { under peak temperatures between } 500-1000^{\circ} \mathrm{C} \text {. Heating rate was } \\
\text { most influential when temperatures were greater than } 675^{\circ} \mathrm{C} .50 \mu \mathrm{m} \text { diameter particles pyrolyzed } \\
\text { faster than did } 125 \mu \mathrm{m} \text { diameter particles. }\end{array}$ \\
\hline $\begin{array}{l}\text { Lilly et al. } \\
(1985)\end{array}$ & $\begin{array}{l}\text { Bituminous } \\
\text { coal }\end{array}$ & $\begin{array}{l}\text { HGR. } 75 \mu \mathrm{m} \text { diameter particles were heated at } 1000^{\circ} \mathrm{C} / \mathrm{s} \text { to peak temperatures between } 500-900^{\circ} \mathrm{C} \text {. } \\
\text { At } 500^{\circ} \mathrm{C} \text {, char yields were } 80 \text { and } 65 \mathrm{wt} \% \text { of dry-ash free coal at } 1.64 \text { and } 0.0004 \text { bar, respectively. } \\
\text { At } 750^{\circ} \mathrm{C} \text {, char yields were } 58 \text { and } 47 \mathrm{wt} \% \text { at } 1.64 \text { and } 0.0004 \text { bar, respectively. Char yields were } \\
\text { unchanged when the particles were heated to higher temperatures. }\end{array}$ \\
\hline
\end{tabular}


Table 5 (Continued). Laboratory studies of biomass pyrolysis that used a RFR, HGR, or EFR.

\begin{tabular}{|c|c|c|}
\hline Study & Material & Pyrolysis apparatus, experimental conditions, and results \\
\hline $\begin{array}{l}\text { Gibbens- } \\
\text { Matham and } \\
\text { Kandiyoti } \\
\text { (1988) }\end{array}$ & $\begin{array}{l}\text { Bituminous } \\
\text { coal }\end{array}$ & $\begin{array}{l}\text { HGR. A thin layer of } 100-150 \mu \mathrm{m} \text { particles was heated to peak temperatures between } 450-950^{\circ} \mathrm{C} \text { in } \\
\text { helium at } 1.2 \mathrm{bar} \text {. For } 30 \mathrm{~s} \text { holding time at peak temperature, char yields were } 45-62 \mathrm{wt} \% \text { of dry-ash } \\
\text { free coal at } 1000^{\circ} \mathrm{C} / \mathrm{s} \text { compared to } 52-62 \mathrm{wt} \% \text { at } 1^{\circ} \mathrm{C} / \mathrm{s} \text {. Without additional holding time, char yields } \\
\text { at } 1000^{\circ} \mathrm{C} / \mathrm{s} \text { were higher below } 650^{\circ} \mathrm{C} \text { and lower between } 650-950^{\circ} \mathrm{C} \text { than the yields at } 1{ }^{\circ} \mathrm{C} \text {. Mass } \\
\text { transport of products using a slow gas sweep velocity }(0.1 \mathrm{~m} / \mathrm{s}) \text { had little effect on char yield. }\end{array}$ \\
\hline $\begin{array}{l}\text { Fletcher } \\
(1989)\end{array}$ & $\begin{array}{l}\text { Bituminous } \\
\text { coal }\end{array}$ & $\begin{array}{l}\text { EFR. Particle residence time }(0.3 \mathrm{~s}) \text { was calculated from measured velocities. Particle temperatures } \\
\text { were measured above } 570^{\circ} \mathrm{C} \text { to within } \pm 50^{\circ} \mathrm{C} \text { with an IR pyrometer. The } 63-75 \mu \mathrm{m} \text { particles attained } \\
770 \text { or } 970^{\circ} \mathrm{C} \text { only slightly faster than did the } 106-125 \mu \mathrm{m} \text { particles. For the } 63-75 \mu \mathrm{m} \text { particles } \\
\text { minimum char yields of } 50 \mathrm{wt} \% \text { dry coal were obtained after } 0.17 \mathrm{~s} \text { at } 970^{\circ} \mathrm{C} \text { and after } 0.27 \mathrm{~s} \text { at } \\
770^{\circ} \mathrm{C} \text {. For the } 106-125 \mu \mathrm{m} \text { particles minimum char yields of } 60 \mathrm{wt} \% \text { were obtained after } 0.25 \mathrm{~s} \text { at } \\
970^{\circ} \mathrm{C} \text { and after } 0.32 \mathrm{~s} \text { at } 770^{\circ} \mathrm{C} \text {. For both size fractions, fast heatup to } 770^{\circ} \mathrm{C} \text { decreased the time for } \\
\text { complete conversion. They suggested that internal transport of products was more limited in the } \\
\text { larger particles. }\end{array}$ \\
\hline $\begin{array}{l}\text { Griffen et al. } \\
\text { (1993) }\end{array}$ & $\begin{array}{l}\text { Bituminous } \\
\text { coal }\end{array}$ & $\begin{array}{l}\text { Used a refined version of the HGR built by Anthony et al. (1975). Char yields decreased linearly } \\
\text { from } 56 \text { to } 48 \mathrm{wt} \% \text { of dry-ash free coal when either } 63-75 \text { or } 106-125 \mu \text { m particle size fractions were } \\
\text { heated at } 10-20,000^{\circ} \mathrm{C} / \mathrm{s} \text { to a peak temperature of } 800^{\circ} \mathrm{C} \text { under an ambient pressure of } 1.01 \text { bar with } \\
\text { no additional holding time. Tar yields increased from } 26 \text { to } 33 \mathrm{wt} \% \text { when the } 63-75 \mu \mathrm{m} \text { particles } \\
\text { were heated at } 20,000^{\circ} \mathrm{C} / \mathrm{s} \text { compared to } 200^{\circ} \mathrm{C} / \mathrm{s} \text {. Tar yields were slightly lower for the } 106-125 \mu \mathrm{m} \\
\text { particles for heating rates }>1000^{\circ} \mathrm{C} / \mathrm{s} \text {. They postulated that rapid heating can increase the interior } \\
\text { concentration gradients of the mobile volatile species, enhancing their transport through the particle, } \\
\text { because neither particle size or maximum temperature affected the minimum char yield. }\end{array}$ \\
\hline $\begin{array}{l}\text { Howard et al. } \\
\text { (1987) }\end{array}$ & $\begin{array}{l}\text { Bituminous } \\
\text { coal tar }\end{array}$ & $\begin{array}{l}\text { Vapor phase cracking of tar was studied using two RFR in series. Primary tar yield was } 24 \mathrm{wt} \% \text { of } \\
\text { dry coal at a gas temperature of } 550^{\circ} \mathrm{C} \text { in first RFR. Tar yields decreased from } 20.5 \text { to } 9.7 \mathrm{wt} \% \text { at } \\
\text { temperatures of } 600 \text { and } 900^{\circ} \mathrm{C} \text {, respectively, with a residence time of } 0.6 \mathrm{~s} \text { in the second RFR. } \\
\text { Increasing the tar residence time to } 3.9 \mathrm{~s} \text { promoted the cracking of an additional } 10-18 \mathrm{wt} \% \text { of tar at } \\
\text { temperatures between } 600-900^{\circ} \mathrm{C} \text {. }\end{array}$ \\
\hline $\begin{array}{l}\text { Bartle et al. } \\
\text { (1990) }\end{array}$ & Coal & $\begin{array}{l}\text { Vapor phase cracking of tar was studied in the freeboard of a fluidized bed reactor. The freeboard is } \\
\text { the solids free region above the fluidized bed. Cracking reduced tar yields by } 1.5,3 \text {, and } 6.4 \mathrm{wt} \% \text { dry } \\
\text { ash free coal at temperatures of } 500,580 \text { and } 750^{\circ} \mathrm{C} \text {, respectively. }\end{array}$ \\
\hline
\end{tabular}


The effects of the process variables on the pyrolytic product yields from biomass are summarized as follows:

- Smaller particles heat up faster and more uniformly and pyrolyze in a shorter time than do larger particles.

- Slow particle heatup to the peak temperature usually decreases tar yield and correspondingly increases the char yield. Primary gas yields may not be affected.

- Pyrolyzing smaller particles yields less char, because tar will have a short travel distance to the exterior surface, which reduces the contact time of the tar with the charring substrate.

- Pyrolyzing smaller particles at reduced ambient pressure increases the tar yield and correspondingly decreases the char yield by shortening the contact time of tar molecules with the charring substrate. Reducing the ambient pressure increases the driving force for internal tar transport by increasing the relative pressure drop from the substrate center to its surface, increasing the amount of tar molecules that evaporate and then diffuse into gas bubbles traveling to the surface, and increasing the evaporation rate of tar molecules from surface through the gas-film boundary layer.

- At longer residence times $(>0.5 \mathrm{~s})$ and higher gas temperatures $\left(>500^{\circ} \mathrm{C}\right)$, tars that have escaped from the pyrolyzing substrate into the hot gas phase can undergo secondary cracking to produce gases. 


\section{[2.2.3] Pyrolysis of Black Liquor}

Black liquor pyrolysis has been extensively studied. The results are not conclusive whether increased rates of particle heatup or mass transfer of pyrolytic products from the substrate can decrease char yields and increase yields of tar and gases. The effect of increased mass transfer rate of pyrolytic products from the substrate on the yields of char, tar, and gases has not been studied.

Bergholm (1963) pyrolyzed dried sodium sulfite pulping liquor particles in an EFR at gas temperatures between $600-900^{\circ} \mathrm{C}$ and found that carbon releases were 65,45 , and $30 \%$ for the 10,100 , and $200 \mu \mathrm{m}$ diameter particles, respectively. He suggested that the increased carbon release from the smaller particles was due faster particle heatup rate to peak temperature.

Brink et al. (1967) pyrolyzed 65\% solids, kraft black liquor in a RFR in batch mode. The reactor vessel pressure was maintained near 1.01 bar by bleeding off gases as they formed. Gas chromatography was used to identify and quantify gas and liquid products. Later, they conducted experiments under continuous conditions at constant temperatures between $400-1000^{\circ} \mathrm{C}$ (Brink et al., 1970). Concentrated black liquor was injected into the reactor at a constant flowrate, and product gases were simultaneously withdrawn at a constant flowrate. Table 6 shows their product yields from the batch and continuous pyrolyses of kraft black liquor. At higher reactor temperatures, tarry liquid and gas yields were higher and char yields were lower. 
Table 6. Product yields from the batch and steady-state pyrolyses of kraft black liquor at constant temperatures between $400-900^{\circ} \mathrm{C}$ (Brink et al., 1967 and 1970).

\begin{tabular}{|l|r|r|}
\hline \multirow{2}{*}{ Product } & \multicolumn{2}{|c|}{ Wt\% of BLS } \\
\cline { 2 - 3 } & \multicolumn{1}{|c|}{ Batch } & \multicolumn{1}{c|}{ Continuous } \\
\hline Char residue & $57-70$ & - \\
\hline Tarry liquid & $3-10$ & - \\
\hline Water & $15-25$ & $5-33$ \\
\hline $\mathrm{CO}$ & $1.3-5.5$ & $3-20$ \\
\hline $\mathrm{CO}_{2}$ & $0.9-4$ & $1-2$ \\
\hline $\mathrm{CH}_{4}$ & $0.1-1.5$ & $0-3$ \\
\hline $\mathrm{H}_{2}$ & $0-0.8$ & - \\
\hline Other hydrocarbon gases & $<0.8$ & - \\
\hline Sulfur containing gases & $<2.5$ & \\
\hline
\end{tabular}

Bolker et al. (1982) used thermogravimetry to determine the weight loss of a dried kraft black liquor at a heating rate of $4.6^{\circ} \mathrm{C} / \mathrm{min}$ to peak temperatures up to $1000^{\circ} \mathrm{C}$. Char yield was unchanged up to $260^{\circ} \mathrm{C}$, then decreased rapidly to $55 \mathrm{wt} \%$ at $350^{\circ} \mathrm{C}$, gradually to $40 \mathrm{wt} \%$ at $675^{\circ} \mathrm{C}$, and rapidly to $6 \mathrm{wt} \%$ at $800^{\circ} \mathrm{C}$.

Kubes (1984) performed differential thermal analysis of various black liquors between $40-400^{\circ} \mathrm{C}$ and found that softwood black liquors had higher activation energies than did hardwood black liquors. The reported activation energy for pyrolysis was determined from the global resultant of the various unknown reactions. The activation energy for all the liquors increased with higher ratios of inorganics to organics. The higher activation energy of some of the softwood black liquors was thought to result from resins in the various softwood species.

Bhattacharya et al. (1986) pyrolyzed black liquor in a quartz tube furnace that was continuously purged with $60 \mathrm{~mL} / \mathrm{min}$ of nitrogen gas to remove the volatile products. The furnace was preheated to a maximum temperature between $490-740^{\circ} \mathrm{C}$. Then a crucible containing about $2 \mathrm{~g}$ of dried liquor solids was inserted into the furnace and held for up to $15 \mathrm{~min}$ 
in order to completely pyrolyze the sample. The sample heating rate was not reported. Table 7 shows the yields of char, tar, and gases attained after 15 min pyrolysis.

Table 7. Char, tar, and gas yields after 15 min pyrolysis at furnace temperatures between $490-740^{\circ} \mathrm{C}$ (Bhattacharya et al., 1986).

\begin{tabular}{|l|r|r|}
\hline Product & \multicolumn{1}{|c|}{ Wt\% of BLS } & Gas concentration, vol\% \\
\hline Char & $48-51$ & - \\
\hline $\mathrm{Tar}$ & $33-36$ & - \\
\hline $\mathrm{CO}$ & - & $32-39$ \\
\hline $\mathrm{CO}_{2}$ & - & $31-33$ \\
\hline $\mathrm{H}_{2}$ & - & $3-5.2$ \\
\hline $\mathrm{CH}_{4}$ & - & $2-3$ \\
\hline
\end{tabular}

Li and van Heiningen (1990) used thermogravimetry to determine sodium loss during pyrolysis of kraft black liquor in $\mathrm{N}_{2}$ and gasification in a mixture of $\mathrm{CO}, \mathrm{CO}_{2}$, and He. The dried liquor solids were heated at $20^{\circ} \mathrm{C} / \mathrm{min}$ to $800^{\circ} \mathrm{C}$. Char yield after the first period of rapid weight loss was $74 \mathrm{wt} \%$ at $450^{\circ} \mathrm{C}$. The char yield gradually decreased to $70 \mathrm{wt} \%$ at $675^{\circ} \mathrm{C}$, then decreased rapidly to $59 \mathrm{wt} \%$ at $800^{\circ} \mathrm{C}$, and finally decreased to $29 \mathrm{wt} \%$ after several minutes of holding at the peak temperature. Pyrolysis of the organics was suggested to occur during the first period of weight loss. The weight loss above $675^{\circ} \mathrm{C}$, often called the second period of weight loss, was attributed to the decomposition of sodium carbonate $\left(\mathrm{Na}_{2} \mathrm{CO}_{3}\right)$ as given by,

$$
\begin{aligned}
& \mathrm{Na}_{2} \mathrm{CO}_{3}+2 \mathrm{C} \rightleftarrows 2 \mathrm{Na}+3 \mathrm{C} \\
& \mathrm{Na}_{2} \mathrm{CO}_{3}+\mathrm{C} \rightleftarrows 2 \mathrm{Na}+\mathrm{CO}+\mathrm{CO}_{2} .
\end{aligned}
$$

In addition, the second period of weight loss may have been enhanced by reduction of sodium sulfate $\left(\mathrm{Na}_{2} \mathrm{SO}_{4}\right)$ by char carbon (Cameron and Grace 1985) as given by, 


$$
\mathrm{Na}_{2} \mathrm{SO}_{4}+\mathrm{C} \rightleftarrows \mathrm{Na}_{2} \mathrm{~S}+\mathrm{CO} \text { (or } \mathrm{CO}_{2} \text { ). }
$$

Sodium in the char decreased from 19 to $4 \mathrm{wt} \%$ and carbonate ion in the char decreased from 23 to $3 \mathrm{wt} \%$ after holding for several minutes above $675^{\circ} \mathrm{C}$. Decomposition of $\mathrm{Na}_{2} \mathrm{CO}_{3}$ was suppressed when pyrolysis was carried out in a gas mixture containing $10 \% \mathrm{CO}$ and $90 \% \mathrm{He}$.

Verrill (1992) studied the pyrolytic loss of sodium from $5 \mathrm{mg}$ droplets of concentrated kraft black liquor that were suspended on a wire and inserted into a tube furnace. Gas containing $5 \% \mathrm{CO}$ and $95 \% \mathrm{~N}_{2}$ flowed past the droplet with a velocity between $0.61-1.83 \mathrm{~m} / \mathrm{s}$. The droplets were exposed to the hot furnace gases for up to $30 \mathrm{~s}$. It was found that pyrolysis was completed within 1-3 s, as indicated by the cessation of rapid swelling and solidification of the molten particle into a friable char. Droplet heating rates were about $100-200^{\circ} \mathrm{C} / \mathrm{s}$. Approximately $5-30 \mathrm{wt} \%$ of the sodium was released. Over the range of exposure times, char yields were between $75-86 \mathrm{wt} \%$ at 600 and $750^{\circ} \mathrm{C}$ and between $61-64 \mathrm{wt} \%$ at $900^{\circ} \mathrm{C}$. He suggested that physical ejection of particulate containing sodium and organic material, observed during the period of rapid swelling and gas evolution, was responsible for most of the sodium loss during combustion. Bjorkman (1968) observed similar violent swelling during the pyrolysis of sodiumbase sulfite liquors.

Miller (1986) pyrolyzed 40-45 mg black liquor droplets in a RFR with preheated gas flow and reported that a higher heat flux which resulted in a faster particle heatup rate to studied peak temperatures of 400 and $500^{\circ} \mathrm{C}$ increased the rates of swelling and generation of $\mathrm{CO}$ and $\mathrm{CO}_{2}$. He also reported that the chemical composition can affect the maximum swollen volume. The lignin in the black liquor was separated into several molecular weight fractions. The maximum swollen volume was highest when the lowest molecular weight lignin fraction was pyrolyzed. 
He suggested that the viscosity of the pyrolyzing melt comprised of the lowest molecular weight lignin fraction was lower.

Alen et al. (1992) used a HGR to pyrolyze pine and birch black liquors made by the kraft and soda-AQ pulping processes. Approximately $300 \mathrm{mg}$ of dried finely ground solids were heated at $715 \pm 175^{\circ} \mathrm{C} / \mathrm{s}$ to a peak temperature of $750 \pm 50^{\circ} \mathrm{C}$ and held for $9 \mathrm{~s}$. Different samples from the same black liquors were also heated in a RFR at $0.03^{\circ} \mathrm{C} / \mathrm{s}$ to a peak temperature of $700^{\circ} \mathrm{C}$ and held for $120 \mathrm{~s}$. Char pyrolysis yield, composition, bulk density, and BET surface area are shown in Table 8 . The bulk densities of the chars from the rapidly heated liquors were much lower, and the BET surface areas were higher than that of the slowly heated liquors, indicating that heatup rate affected the char morphology of black liquor in the same manner as it did for bituminous coal (Freihaut et al, 1982). Faster heatup rate did not increase sodium release.

However, the results were not conclusive to quantify the effect of rapid heating on char yields.

Table 8. Char pyrolysis yield, composition, and bulk density from slow heating at $0.3^{\circ} \mathrm{C} / \mathrm{s}$ to a peak temperature of $700^{\circ} \mathrm{C}$ and $120 \mathrm{~s}$ holding time and from fast heating at $715 \pm 175^{\circ} \mathrm{C} / \mathrm{s}$ to a peak temperature of $750 \pm 50^{\circ} \mathrm{C}$ and $9 \mathrm{~s}$ holding time (Arpiainen et al., 1992).

\begin{tabular}{|c|c|c|c|c|c|c|c|c|}
\hline \multirow[t]{2}{*}{ Char properties } & \multicolumn{2}{|c|}{ Pine kraft } & \multicolumn{2}{|c|}{ Birch kraft } & \multicolumn{2}{|c|}{ Pine soda-AQ } & \multicolumn{2}{|c|}{ Birch soda-AQ } \\
\hline & Slow & Fast & Slow & Fast & Slow & Fast & Slow & Fast \\
\hline Yield, $w t \%$ of BLS & $57 \pm 8$ & $51 \pm 5$ & $72 \pm 2$ & $69 \pm 4$ & $64 \pm 2$ & $59 \pm 4$ & $66 \pm 2$ & $59 \pm 4$ \\
\hline $\mathrm{Na}, \mathrm{wt} \%$ of $\mathrm{BLS}$ & 24.4 & 22.4 & 28 & 28.1 & 21.8 & 22.8 & 24.9 & 25.6 \\
\hline $\mathrm{S}, \mathrm{wt} \%$ of BLS & 0.97 & 3.5 & 2.41 & 6.4 & - & - & - & - \\
\hline $\mathrm{SO}_{4}^{2-}, \mathrm{wt} \%$ of $\mathrm{BLS}$ & 1.76 & 9.5 & 4.21 & 15.1 & - & - & - & - \\
\hline BET surface area, $\mathrm{m}^{2} / \mathrm{g}$ & 90 & 223 & 24 & - & 16 & 93 & 12 & 92 \\
\hline Bulk density, $\mathrm{kg} / \mathrm{m}^{3}$ & 157 & 58 & 245 & 254 & 398 & 59 & 411 & 71 \\
\hline
\end{tabular}

Backman et al. (1992) suspended individual 4-20 mg droplets of concentrated pine kraft black liquor on a wire and pyrolyzed them in a RFR preheated to 700,800 , or $900^{\circ} \mathrm{C}$. Pyrolysis 
was conducted in $5 \% \mathrm{CO}$ and $95 \% \mathrm{~N}_{2}$ in order to suppress $\mathrm{Na}_{2} \mathrm{CO}_{3}$ decomposition. Droplet heating rates were about $100-300^{\circ} \mathrm{C} / \mathrm{s}$. Table 9 shows the yields of char and total carbon in the char after 5 and $60 \mathrm{~s}$ pyrolysis. The decrease in char yield obtained at $900^{\circ} \mathrm{C}$ and a holding time of $5 \mathrm{~s}$ was attributed to faster droplet heatup rate than was achieved at $700^{\circ} \mathrm{C}$ and a holding time of $5 \mathrm{~s}$. They also reported that for four different pine kraft black liquors, $37-87 \%$ of the organic carbon in BLS was converted to volatiles at a gas temperature of $800^{\circ} \mathrm{C}$.

Table 9. Yields of char and carbon in the char from the pyrolysis of black liquor at furnace temperatures between $700-900^{\circ} \mathrm{C}$ (Backman et al., 1992).

\begin{tabular}{|r|r|l|ll|}
\hline Gas temp., ${ }^{\mathbf{~}} \mathbf{C}$ & Time, $\mathbf{s}$ & $\begin{array}{l}\text { Char, } \\
\text { wt\% of BLS }\end{array}$ & $\begin{array}{l}\text { Total C in char, } \\
\text { \% of the C in BLS }\end{array}$ & 71 \\
\hline 700 & 5 & 74 & \\
\hline 700 & 60 & 62 & 62 \\
\hline 800 & 5 & 68 & 32 \\
\hline 800 & 60 & 51 & 44 \\
\hline 900 & 5 & 58 & 12 \\
\hline 900 & 60 & 40 & & \\
\hline
\end{tabular}

Frederick et al. (1994) proposed that the lower char yields at $900^{\circ} \mathrm{C}$, observed by Backman et al. (1992), were due to $\mathrm{Na}_{2} \mathrm{CO}_{3}$ decomposition and $\mathrm{Na}_{2} \mathrm{SO}_{4}$ reduction by carbon in the char. When the concentration of $\mathrm{CO}$ in the pyrolysis gas was increased from 5 to $50 \%$, the carbon retained in the char increased from 12 to $40 \%$ of the carbon in BLS. The rate of carbon release decreased with increased $\mathrm{CO}$ concentration in the pyrolysis gas.

Gairns et al. (1994) suspended individual droplets of concentrated, mixed-hardwood kraft black liquor on a wire and exposed them to He for $60 \mathrm{~s}$ in a RFR preheated to $400-900^{\circ} \mathrm{C}$. Char yields were between $66-70 \mathrm{wt} \%$ of BLS between $500-700^{\circ} \mathrm{C}$, and decreased to $40 \mathrm{wt} \%$ of BLS at $800^{\circ} \mathrm{C}$. Decomposition of $\mathrm{Na}_{2} \mathrm{CO}_{3}$ and reduction of $\mathrm{Na}_{2} \mathrm{SO}_{4}$ by char carbon was thought to be 
responsible for the low char yields beyond $800^{\circ} \mathrm{C}$. The $\mathrm{CO}_{2}$ yields were $4-10$ and $10-28 \%$ of the carbon in BLS at 700 and $900^{\circ} \mathrm{C}$, respectively.

Alen et al. (1994 and 1995) and Arpiainen et al. (1995) used their HGR to pyrolyze $100 \mathrm{mg}$ of $105 \mu \mathrm{m}$ diameter, pine kraft BLS particles. Particles were heated at $1000^{\circ} \mathrm{C} / \mathrm{s}$ to peak temperatures between $400-900^{\circ} \mathrm{C}$ and held for several seconds. Additionally, pyrolysis was conducted under pressures of 2 and 21 bar for peak temperatures of 675 and $975^{\circ} \mathrm{C}$. Table 10 lists the pyrolysis conditions and their corresponding product yields. Char yields were essentially the same above $500^{\circ} \mathrm{C}$, and more of the tar was converted to gases at higher temperatures and longer holding times. Their results suggested that pyrolysis of $105 \mu \mathrm{m}$ diameter particles was completed before the particle temperature attained $650-750^{\circ} \mathrm{C}$, as suggested by Hupa et al. (1987) for large droplets. High pressure reduced the rate of $\mathrm{Na}_{2} \mathrm{CO}_{3}$ decomposition under longer holding times at $900^{\circ} \mathrm{C}$.

Table 10. Pine kraft BLS pyrolysis conditions and product yields (Alen et al., 1994 and Arpiainen et al., 1995a and 1995b).

\begin{tabular}{|c|c|c|c|c|c|c|c|c|c|}
\hline \multirow{2}{*}{$\begin{array}{l}\text { Grid } \\
\text { temp., }{ }^{\circ} \mathrm{C}\end{array}$} & \multirow{2}{*}{\begin{tabular}{|l|} 
Holding \\
time, $s$
\end{tabular}} & \multirow{2}{*}{$\begin{array}{l}\begin{array}{l}\text { Pres., } \\
\text { bar }\end{array} \\
\end{array}$} & \multicolumn{7}{|c|}{ Wt\% of BLS } \\
\hline & & & Char $^{\mathbf{a}}$ & Tar & $\mathrm{CO}$ & $\mathrm{CO}_{2}$ & $\mathbf{H}_{2}$ & $\mathrm{C}_{1}-\mathrm{C}_{3} \mathrm{HCs}$ & $\mathrm{Na}_{2} \mathrm{CO}_{3}$ \\
\hline 400 & 30 & 2 & 75 & 17 & 1.3 & 4.5 & 0 & 0.2 & \\
\hline 500 & 30 & 2 & 69 & 19 & 1.7 & 5.6 & 0.2 & 1.1 & \\
\hline 600 & 30 & 2 & 71 & 16 & 2.2 & 6.8 & 0.4 & 1.8 & \\
\hline 675 & $5-40$ & $2-21$ & $67-69$ & $8-15$ & $4.6-6$ & $9.2-10$ & $1.2-1.8$ & $3.5-5.8$ & 38.4 \\
\hline 900 & 1 & 2 & $66-68$ & $10-15$ & 13.8 & 3.2 & 1.7 & 3.5 & 36.5 \\
\hline 900 & 20 & 2 & $46-48$ & $10-15$ & 29 & 1.5 & 2.9 & 3.5 & 23.4 \\
\hline 900 & 1 & 21 & $66-68$ & $10-15$ & 8.6 & 7.5 & 1.2 & 5 & 38.4 \\
\hline 900 & 20 & 21 & $60-63$ & $10-15$ & 17.5 & 4.8 & 1.9 & 4.8 & 31.5 \\
\hline
\end{tabular}

a Error limits of $\pm 2-3 \mathrm{wt} \%$ of BLS 
Frederick et al. (1995a) and Carangal et al. (1995) studied the pyrolysis of 90-125 $\mu \mathrm{m}$ pine kraft BLS particles in an EFR preheated to $700-1100^{\circ} \mathrm{C}$. Preheated $\mathrm{N}_{2}$ was introduced into the reaction tube through a flow straightener; the flow was assumed laminar through the reaction tube. Particles were entrained in $\mathrm{N}_{2}$ carrier gas and then fed to the reactor at $0.5 \mathrm{~g} / \mathrm{min}$. Char and fume were removed from the pyrolysis gas by a cyclone and filter. A Fourier transform infrared spectrometer was used to analyze the pyrolysis gases for $\mathrm{CO}, \mathrm{CO}_{2}, \mathrm{CH}_{4}$, ethylene, acetylene, formaldehyde, acetaldehyde, methanol, propylene, butadiene, carbonyl sulfide, methyl mercaptan, and dimethyl sulfide; however, only $\mathrm{CO}$ and $\mathrm{CO}_{2}$ were prominent at $700^{\circ} \mathrm{C}$. Tar yield was calculated as being the difference between the char and gas yields. Particle heating rates were $4,400^{\circ} \mathrm{C} / \mathrm{s}$ to a peak temperature of $700^{\circ} \mathrm{C}$ and $13,000^{\circ} \mathrm{C} / \mathrm{s}$ to a peak temperature of $1100^{\circ} \mathrm{C}$, and particle residence times were between $0.3-1.7 \mathrm{~s}$. Table 11 shows the product yields for residence times between $0.3-1.5 \mathrm{~s}$ and peak temperatures between $700-1100^{\circ} \mathrm{C}$. Both studies suggested that decomposition of $\mathrm{Na}_{2} \mathrm{CO}_{3}$ and reduction of $\mathrm{Na}_{2} \mathrm{SO}_{4}$ by char carbon also were responsible for the gradual decrease in char yields with longer residence times for the 90-125 $\mu \mathrm{m}$ diameter particles. However, in another study Frederick et al. (1995b) reported that very little sodium was released at temperatures between $700-900^{\circ} \mathrm{C}$. The amount of inorganic fume on the filter was between $1-3 \mathrm{wt} \%$ of BLS. The amount of sodium in the fume was between $2-4 \%$ of the sodium in BLS. 
Table 11. Product yields from the pyrolysis of 90-125 $\mu \mathrm{m}$ diameter pine kraft BLS particles at estimated particle residence times between 0.3-1.7 s (Frederick et al., 1995a and Carangal et al., 1995).

\begin{tabular}{|l|r|r|r|}
\hline \multirow{2}{*}{ Pyrolysis product } & \multicolumn{3}{|c|}{ Gas temperature } \\
\cline { 2 - 4 } & $\mathbf{7 0 0}{ }^{\mathbf{0}} \mathbf{C}$ & $\mathbf{9 0 0}{ }^{\circ} \mathbf{C}$ & $\mathbf{1 1 0 0}{ }^{\mathbf{C}} \mathbf{C}$ \\
\hline Char, wt\% of BLS & $50-70$ & $37-59$ & $20-45$ \\
\hline Total C in char, \% of the C in BLS & $50-68$ & $36-58$ & $20-45$ \\
\hline $\mathrm{CO}_{3}{ }^{2-}$ in char, \% of the C in BLS & $4.5-9.5$ & $4.5-12.5$ & $2-8$ \\
\hline Tar, \% of the C in BLS & $30-35$ & $30-45$ & $0-45$ \\
\hline Total gas, \% of the C in BLS & $0.5-15$ & $2-22$ & $10-80$ \\
\hline $\mathrm{CO}, \%$ of the C in BLS & $0-3.5$ & $0-7$ & $3-68$ \\
(as wt\% of BLS) & $(0-2.9)$ & $(0-5.7)$ & $(2.4-55.4)$ \\
\hline $\mathrm{CO}_{2}, \%$ of the C in BLS & $0.5-7.5$ & $2-9.5$ & $5-16$ \\
(as wt\% of BLS) & $0.64-9.6)$ & $(2.6-12.2)$ & $(6.4-20.5)$ \\
\hline $\mathrm{CH}_{4}, \%$ of the C in BLS & $0-1$ & $0-4$ & $2-7$ \\
(as wt\% of BLS) & $(0-0.47)$ & $(0-1.86)$ & $(0.93-3.26)$ \\
\hline
\end{tabular}

Backman et al. (1996) used their HGR in conjunction with an electrical low pressure impactor (ELPI) to measure fume release with time during the pyrolysis of an industrial kraft black liquor. The liquor was painted on the grid and then oven-dried. Typical sample weight was about $10 \mathrm{mg}$. The sample was heated at $3000^{\circ} \mathrm{C} / \mathrm{s}$ to peak temperatures between $400-820^{\circ} \mathrm{C}$ and held for $10 \mathrm{~s}$. The yields of char, fume particles, and sodium contained in the fume are shown in Table 12. At peak temperatures between $400-600^{\circ} \mathrm{C}$, the rate of fume released with time was a single peak distribution with a maximum at $2 \mathrm{~s}$ into the run and a span of about $5 \mathrm{~s}$. The collected material was thought to be tar because very little sodium was found. At $700^{\circ} \mathrm{C}$ the time-dependent fume release had two peaks. The first peak was identical to the single peak in the experiments conducted between $400-600^{\circ} \mathrm{C}$. A second peak, which overlapped the first one, became detectable after $5 \mathrm{~s}$ and gradually increased until the grid power was shut off. Much more sodium was found in the fume obtained using a peak temperature of $700^{\circ} \mathrm{C}$. Backman et al. (1995) reported that pyrolytic volatiles yields in the HGR at atmospheric or pressurized 
conditions were always greater than those in the single droplet RFR for the 15 different black liquors studied. High pyrolytic volatiles yields from the HGR were attributed to fast particle heating.

Table 12. Yields of char, fume, and sodium contained in fume from pyrolysis of an industrial kraft black liquor (Backman et al., 1996).

\begin{tabular}{|l|r|r|r|r|r|}
\hline \multirow{2}{*}{ Pyrolysis product } & \multicolumn{5}{|c|}{ Grid temperature } \\
\cline { 2 - 6 } & $\mathbf{4 0 0}^{\circ} \mathbf{C}$ & $\mathbf{5 5 0}^{\mathbf{}} \mathbf{C}$ & $\mathbf{6 0 0}^{\mathbf{}} \mathbf{C}$ & $\mathbf{7 0 0}^{\circ} \mathbf{C}$ & $\mathbf{8 2 0}^{\circ} \mathbf{C}$ \\
\hline Char, wt\% of BLS & 80 & 79 & 77 & 71.2 & 71.5 \\
\hline Fume, wt\% of BLS & 1.54 & 1.52 & 2.04 & 6.6 & 4.5 \\
\hline Na in fume, \% of the Na in BLS & $<0.3$ & 0.67 & 0.4 & 4.23 & 3.3 \\
\hline
\end{tabular}

The effects of the process variables on pyrolytic product yields from black liquor are summarized as follows:

- The first period of BLS weight loss results from the pyrolysis of organic material. For small diameter dried particles $(\sim 100 \mu \mathrm{m})$, pyrolysis of a large fraction of the organics was completed between $450-500^{\circ} \mathrm{C}$. Pyrolysis is nearly complete within $0.3 \mathrm{~s}$ at high temperatures $\left(>700^{\circ} \mathrm{C}\right)$.

- A second period of BLS weight loss results in part by pyrolytic cracking between $700-900^{\circ} \mathrm{C}$, but results primarily by decomposition of $\mathrm{Na}_{2} \mathrm{CO}_{3}$ or reduction of $\mathrm{Na}_{2} \mathrm{SO}_{4}$ above $900^{\circ} \mathrm{C}$ with longer holding time.

- At relatively high temperatures $\left(>700^{\circ} \mathrm{C}\right)$ with longer residence times $(0.3-1.5 \mathrm{~s})$, tar and liquid aerosol or vapor products that have escaped from a pyrolyzing pine kraft black liquor particle can crack to produce gases. 
- There is considerable variability in the product yields from the BLS pyrolysis studies. It cannot be concluded whether rapid heatup of small BLS particles in an EFR or HGR results in decreased char yields.

Concluding the first two sections of this literature review, it has been shown that:

- Data are not available to allow calculation of pyrolytic product yields under conditions of rapid heatup of small particles. It is not known whether rapid heatup of small BLS particles can reduce char yields and increase tar and gas yields.

- Little is known whether longer residence time at low temperatures between $400-700^{\circ} \mathrm{C}$ can enhance secondary cracking of pyrolytic tar to gases.

- The role of mass transfer during pyrolysis of small biomass particles is not well understood. For small particles of approximately $100 \mu \mathrm{m}$ diameter or less, limitation of mass transport of products through the gas-film boundary layer has not been investigated by substantially increasing the slip velocity between the particle and gas. The effect of oscillating pressure on internal mass transport of pyrolytic products from biomass has not been investigated.

As a result, the effects of rapid particle heatup and increased mass transport of products on the pyrolytic product yields from small BLS particles cannot be theoretically predicted. The effects of increased rates of particle heatup and mass transport of products from the particle on the pyrolytic product yields from small BLS particles will be investigated by application of an acoustic field. The theory of acoustic wave propagation and several studies concerning the effects of a resonant acoustic field on the rates of mass and energy transport and particle dynamics will be presented in the next section of this literature review. 


\section{[2.3] PROPAGATION OF ACOUSTIC WAVES}

\section{[2.3.1] Traveling Waves}

Acoustic waves are pressure pulsations superimposed on an existing pressure (Colby, 1958). They are longitudinal waves generated by vibration of a material body. Acoustic waves propagate in a spherical, uniform pattern away from a point source. Particles of the medium oscillate back and forth in the direction of wave propagation. Far away from a point source, the radius of the spherical wave is so large that the wave front can be considered planar. When a sinusoidal acoustic wave passes through a given location, particles of the medium move in the same direction with the same velocity, undergoing compression or rarefaction as illustrated in Fig. 4.

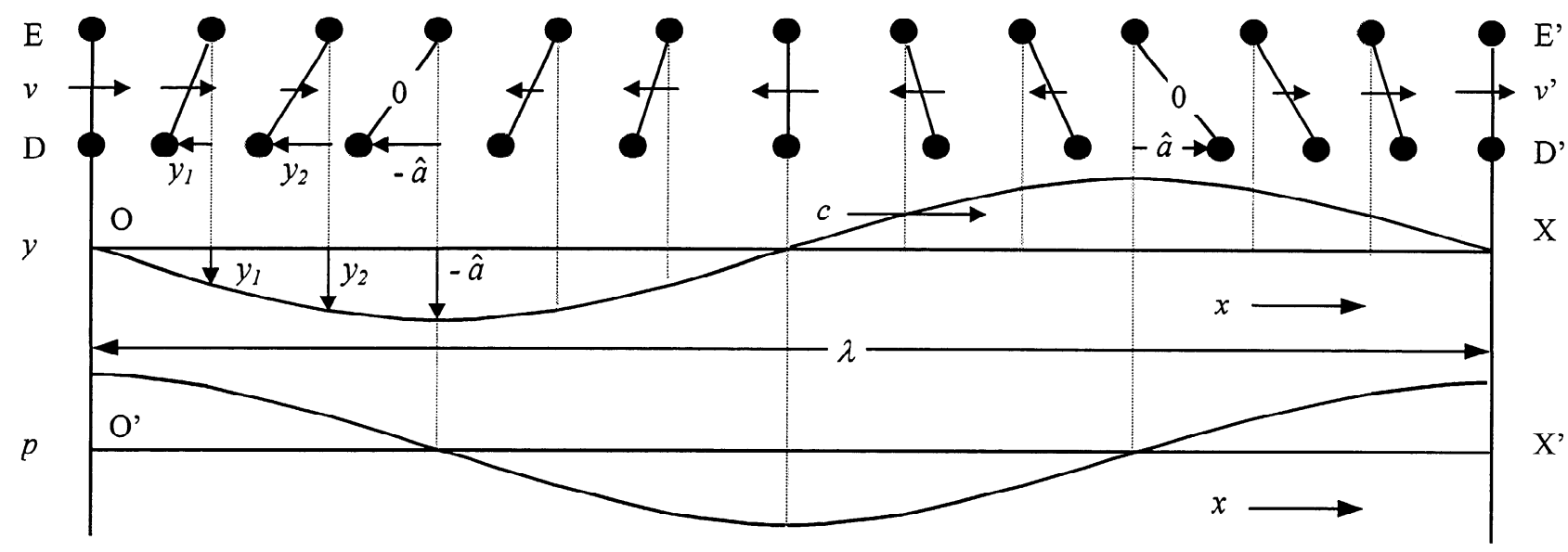

Figure 4. A schematic diagram of an sinusoidal acoustic wave of amplitude $\hat{a}$, wavelength $\lambda$, and velocity $c$ traveling through a medium in coordinates of time $t$ and distance $x$ away from the origin $\mathrm{O}$. EE' shows the particles of the medium at their equilibrium positions. DD' shows the displacement of the particles of the medium undergoing simple harmonic motion at an instant $t=0$ as the wave passes to the right. vv' shows the velocities of the particles of the medium at an instant $t=0$. Curve along OX is the wave form of the displacement of the particles of the medium at an instant $t=0$. Curve along OX' is the waveform of the acoustic pressure at an instant $t=0$. 
The displacement $y$ of a particle of the medium can be expressed as,

$$
y=\hat{a} \sin \left(2 \pi f t-\frac{2 \pi x}{\lambda}\right)
$$

where $x$ is the wave propagation coordinate, $\hat{a}$ is the amplitude of the particle displacement, $f$ is the frequency, $\lambda$ is the wavelength, $t$ is the time, and $c$ is the speed of sound in a medium which for a gas can be expressed as,

$$
c=\sqrt{\frac{\gamma R T_{g}}{M}}
$$

where $\gamma$ is the ratio of the specific heat at constant pressure to the specific heat at constant volume, $T_{g}$ is the absolute temperature, $R$ is the universal gas constant, and $M$ is the molecular weight of the medium. The medium particle velocity $u$ referred to as the instantaneous acoustic velocity can be expressed as,

$$
u=\frac{d y}{d t}=2 \pi f a ̂ \cos \left(2 \pi f t-\frac{2 \pi f x}{c}\right) .
$$

The acoustic pressure $p$, which is the dynamic pressure of the medium above or below its equilibrium pressure caused by wave propagation, can be expressed in terms of the compression of the medium as,

$$
p=\hat{p} \cos \left(2 \pi f t-\frac{2 \pi f x}{c}\right)
$$


where $\hat{p}$ is the amplitude. A positive acoustic pressure indicates a compression, and a negative pressure indicates a rarefaction. At any given instant, the waveforms of the acoustic pressure $p(x, t)$ and the displacement $y(x, t)$ are $90^{\circ}$ out of phase.

The ratio of the amplitudes of the acoustic pressure over that of the acoustic velocity is defined as the acoustic resistance $R a$,

$$
R_{a}=\rho c=\frac{\hat{p}}{\hat{u}},
$$

where $\rho$ is the density of the medium.

The intensity of an acoustic wave $I$, which is the rate of energy transfer or work done by the pressure wave across a unit area perpendicular to the direction of wave propagation, can be expressed as,

$$
I=\frac{p^{2}}{2 \rho c}
$$

The intensity often varies over several orders of magnitude and is expressed as the sound pressure level $S P L$ in decibel units,

$$
S P L=10 \log \frac{I}{I_{o}}=20 \log \frac{p}{p_{o}},
$$

where the reference pressure $p_{0}$ is $0.00002 \mathrm{~N} / \mathrm{m}^{2}$. 


\section{[2.3.2] Resonant Standing Wave in a Tube}

For combustion applications, high-intensity acoustic oscillations can be generated inside a tubular reactor by exciting a resonant standing plane wave along the tube axis. Acoustic pressure pulsations that excite the resonant axial standing wave may come from an electrical acoustic driver or from the periodic combustion of fuel (Belles et al., 1986). In a tubular reactor containing a gas, a sudden change in the acoustic resistance at an open end will cause the incident wave to be reflected (Colby, 1958) as shown in Fig. 5.

(a)

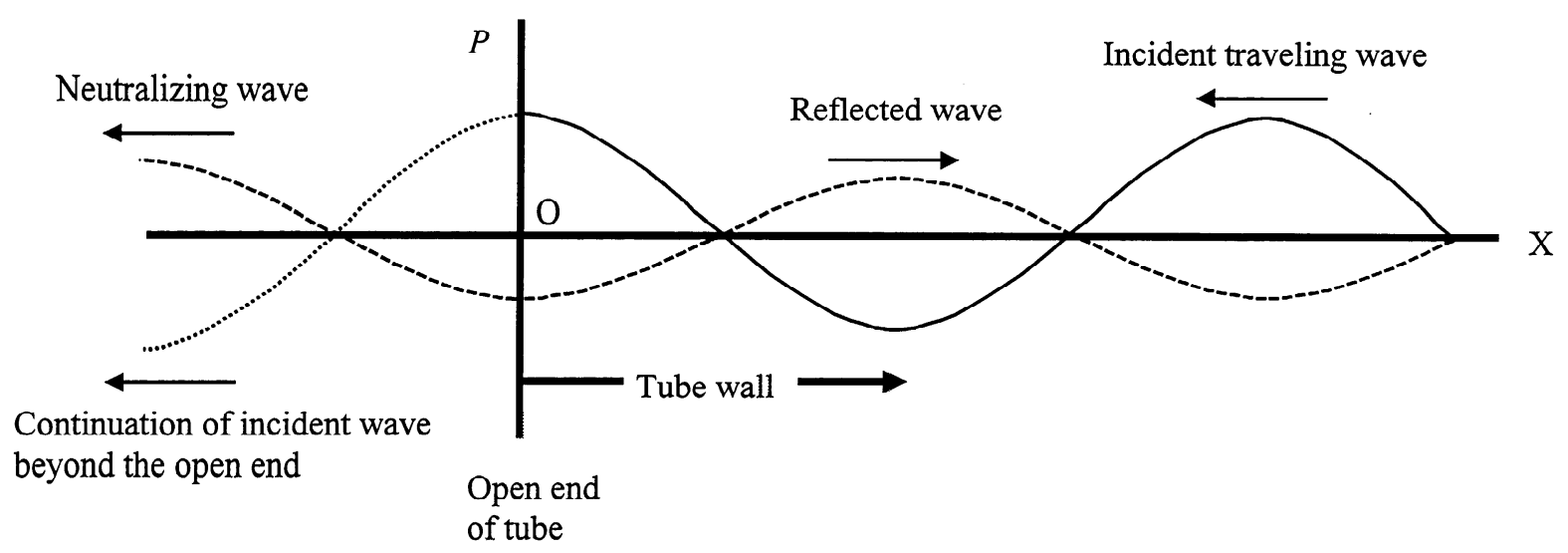

(b) Continuation of incident wave beyond the open end

Tube wall

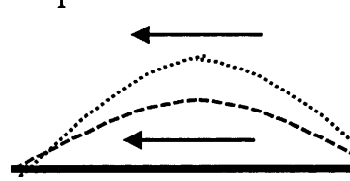

Neutralizing wave
$P$

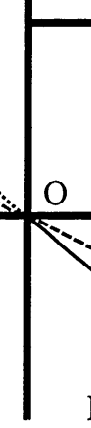

$\longrightarrow$

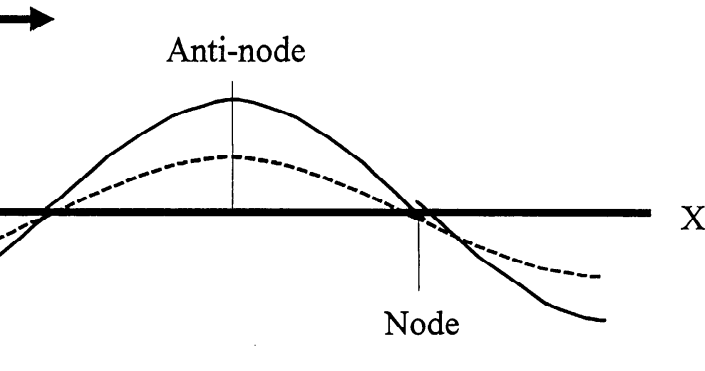

Incident traveling wave

Open end

of tube

Figure 5. A schematic diagram of the reflection of an acoustic wave at the open end of a tube reactor. (a) $t=0$ and (b) $t=$ time at $1 / 4$ period later. 
When a plane wave traveling in a tube encounters the open end, the positive pressure in a compression that has been exerted against the tube wall is suddenly released to normal as the gas rushes out, initiating rarefaction waves in both directions from the open end, as shown in Fig. 5a. Conversely, as the gas rushes into the tube upon the arrival of a rarefaction of the traveling wave in the tube at the open end, a compression wave is started in both directions, as shown in Fig. $5 \mathrm{~b}$. The reflected wave travels to the tube and its neutralizing companion wave travels in the opposite direction. At the open end, compressions of the incident wave, reflected wave, and neutralizing wave are in phase with each other.

The pressure $p_{i}$ of the plane wave at $t=0$ that is traveling toward the open end at $x=0$ can be expressed in terms of the compression of the gas as,

$$
p_{i}=\hat{p}_{i} \cos \left(2 \pi f t+\frac{2 \pi f x}{c}\right) .
$$

The pressure $p_{n}$ of the neutralizing wave that travels in the same direction as the incident wave and partially interferes with its continuation beyond the open end can be expressed in terms of the compression of the gas as,

$$
p_{n}=-\hat{p}_{r} \cos \left(2 \pi f t+\frac{2 \pi f x}{c}\right),
$$

and the acoustic pressure $p_{r}$ of the companion reflected wave, can be expressed in terms of the compression of the gas as,

$$
p_{r}=-\hat{p}_{r} \cos \left(2 \pi f t-\frac{2 \pi f x}{c}\right),
$$


where $\hat{p}_{r}$ does not equal $\hat{p}_{i}$ because not all of the energy in the incident wave is reflected back into the tube. More specifically, the change in the acoustic resistance is not infinite at the open end. The compression pressure $p_{s}$ in the tube resulting from superposition of the incident and reflected waves can be expressed in terms of the compression of a gas as,

$$
p_{s}=p_{i}+p_{r}=\left(\hat{p}_{i}-\hat{p}_{r}\right) \cos \left(2 \pi f t+\frac{2 \pi f x}{c}\right)-\left[2 \hat{p}_{r} \sin \left(\frac{2 \pi f x}{c}\right)\right] \sin (2 \pi f t),
$$

in which the first term represents the traveling wave that emerges from the open end of the tube of amplitude $\left(\hat{p}_{i}-\hat{p}_{r}\right)$, and the second term represents a standing wave in the tube of amplitude $2 \hat{p}_{r} \sin (2 \pi f x / c)$. The acoustic pressure is a minimum at a node and a maximum at an anti-node, as shown in Fig. $5 \mathrm{~b}$. The pressure nodes $\mathrm{N}$ are located at distances $x=n \lambda / 2$ from the open end, where $n$ is an integer, and the acoustic pressure anti-nodes are located at distances $x=(2 n+1) \lambda / 4$. The acoustic velocity nodes and anti-nodes are $90^{\circ}$ out of phase with the acoustic pressure nodes and anti-nodes, respectively.

\section{[2.4] ACOUSTIC ENHANCEMENT OF HEAT AND MASS TRANSFER RATES}

\section{[2.4.1] Role of Acoustic Velocity}

Acoustic enhancement of convective heat and mass transfer depends on whether acoustic streaming or quasi steady-state flow conditions exist around the object. Acoustic streaming is the generation of a non-zero mean motion of the particles of a medium by an oscillatory flowfield (Lighthill, 1978). Fig. 6 illustrates acoustic streaming of the particles of a medium around a cylinder as observed by Andrade (1931), who vibrated a cylinder back and forth in still air with 
tobacco smoke, and by Schlichting (1960), who vibrated a cylinder in water and derived a mathematical solution for the observed flow patterns. The flow field around an object in oscillatory flow is only considered to be quasi steady when steady-state conditions corresponding to the instantaneous slip velocity are achieved. Fig. 7 illustrates quasi steady-state flow reversal and wake shedding as observed by Arpaci et al. (1991), who used high-speed laser schlieren video to investigate the evaporation of water from a sintered cylinder during a gas oscillation cycle.

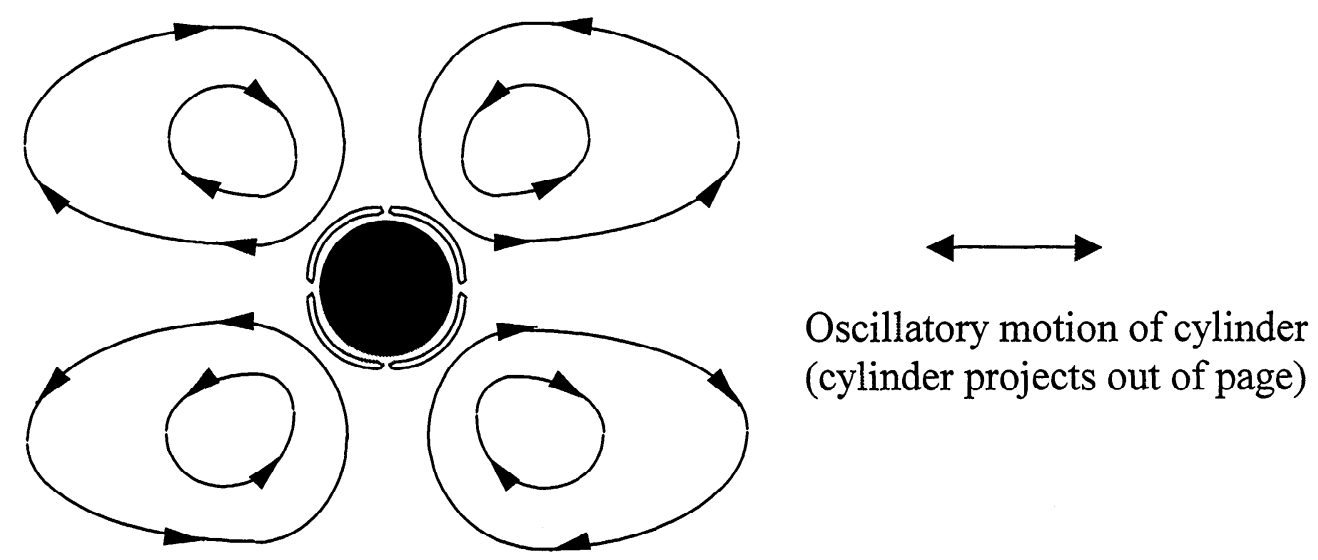

Figure 6. An illustration of acoustic streaming of particles of the medium about a cylinder showing inner and outer streaming vortices. 


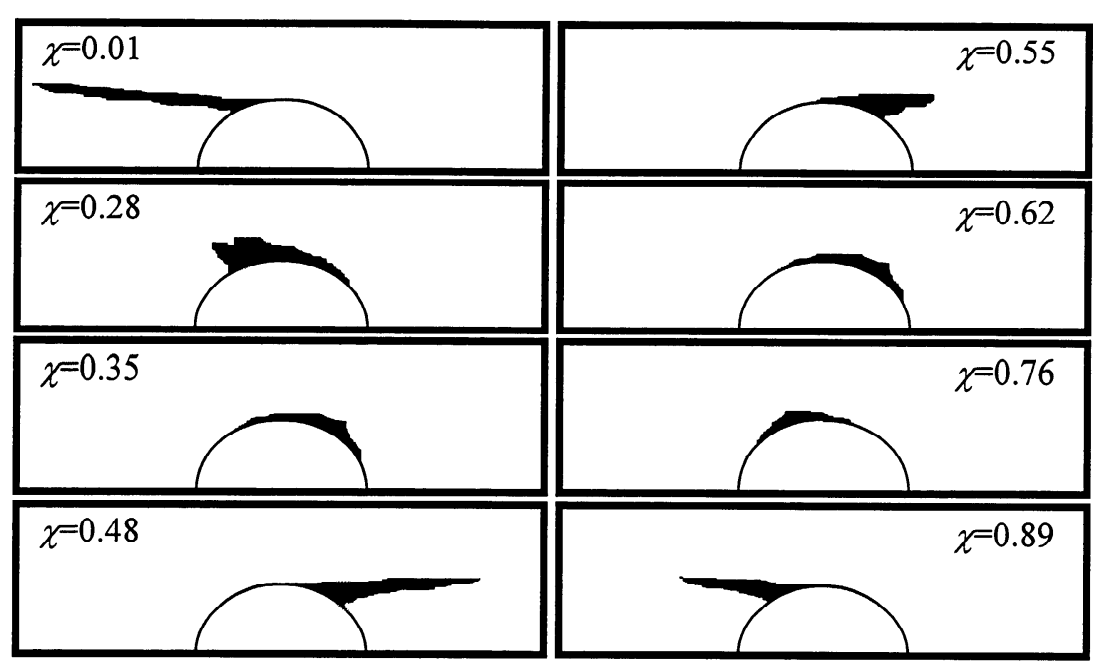

Figure 7. An illustration of quasi steady-state flow reversal and wake shedding from a cylinder at different times $\chi$ during an oscillation cycle ( $\chi$ spans from $0-1$ during one cycle). Shaded areas represent the schlieren image of water vapor that has evaporated from the surface of a sintered cylinder. The oscillatory flow velocity is a maximum at $\chi=0,0.5$, and 1 and a minimum at $\chi=0.25$ and 0.75 . Peak oscillatory velocities were between $63-75 \mathrm{~m} / \mathrm{s}$.

Al Taweel and Landau (1976) summarized several investigations concerning the convective mass transfer between solid spheres and oscillating fluids for acoustic streaming and quasi steady-state flow conditions. Mass transfer correlations were based on the ratio of the displacement amplitude $\hat{a}$ of the oscillating flow to the sphere diameter $d_{p}$. When $\hat{a} / d_{p}<0.75$, mass transfer occurs by acoustic streaming for frequencies between $1-10^{6} \mathrm{~Hz}$. When $\hat{a} / d_{p} \geq 0.75$, mass transfer is controlled by the oscillatory slip velocity and quasi steady-state mass, momentum, and energy transport conditions. To explain the transition from acoustic streaming to quasi steady-state control of mass transfer, Al Taweel and Landau noted that an accelerating body must travel a certain distance before wake separation can occur, and that wake separation can be suppressed by reversing the flow before separation occurs. For $\hat{a} / d_{p} \leq 0.75$, flow always reverses before the wake can separate. For $\hat{a} / d_{p}>0.75$, wake separation cannot be suppressed before the flow reverses direction. 
Transition from a laminar to turbulent boundary layer around a cylinder was observed to occur in a high-intensity acoustic field of 163-172 dB and 65-105 Hz (Arpaci et al., 1991). Boulard and Malherbe (1988) observed turbulent velocity fluctuations of $0.5-1 \mathrm{~m} / \mathrm{s}$ in a particleseeded gas flow with a resonant acoustic field of $152 \mathrm{~dB}$ and $1000 \mathrm{~Hz}$. Therefore, a quasi-steady analysis of the heat, mass, and momentum transfer between a sphere and a gas in oscillation due to an acoustic field is only an approximation.

The BLS particles used in this study will experience a quasi steady-state flow field, as calculated in Appendix 11. Assuming quasi-steady laminar flow, the rates of convective heat $q$ and mass transfer $W_{A}$ between a spherical particle and a gas in oscillation can be calculated using the following equations:

$$
\begin{aligned}
& q=h A_{p}\left(T_{g}-T_{s}\right) \\
& W_{A}=k_{y} A_{p}\left(y_{A s}-y_{A}\right),
\end{aligned}
$$

where $A_{p}$ is the particle surface area, $T_{s}$ is the particle surface temperature, $T_{g}$ is the bulk gas temperature, $y_{A s}$ is the mole fraction of solute in the gas phase adjacent to the particle surface, and $y_{A}$ is the mole fraction of solute in the gas phase, and $h$ and $k_{y}$ are the heat and mass transfer coefficients, respectively, which can be expressed as,

$$
\begin{aligned}
& h=\frac{\mathrm{Nu} k_{g}}{d_{p}} \\
& k_{y}=\frac{\operatorname{Sh} C D_{A B}}{d_{p}}
\end{aligned}
$$


where $k_{g}$ is the gas thermoconductivity, $C$ is the molar concentration, and $D_{A B}$ is the molecular diffusivity, $\mathrm{Nu}$ is the Nusselt number, and the $\mathrm{Sh}$ is the Sherwood number (Bennet and Myers 1974; Bird et al. 1960; DeWitt and Incropera 1990). Commonly used Nussult and Sherwood number correlations for forced convection around a sphere (Marshall and Ranz, 1952), which are applicable to quasi steady laminar flow conditions, are given by,

$$
\begin{aligned}
& \mathrm{Nu}=2+0.6 \operatorname{Re}_{p}{ }^{1 / 2} \operatorname{Pr}^{1 / 3} \\
& \mathrm{Sh}=2+0.6 \operatorname{Re}_{p}^{1 / 2} \operatorname{Sc}^{1 / 3}
\end{aligned}
$$

where $\operatorname{Re}_{p}$ is the particle Reynolds number, Pr is the Prantl number, and Sc is the Schmidt number. The particle Reynolds number can be expressed as,

$$
\operatorname{Re}_{p}=\frac{\left|U_{g}-U_{p}\right| d_{p}}{v_{g}},
$$

where $U_{g}$ is the instantaneous gas velocity, $U_{p}$ is the instantaneous particle velocity, and $v_{g}$ is the kinematic viscosity of the gas. For a spherical particle, both Ha and Yavuzkurt (1993b) and Gauvin and Sayegh (1979) derived similar expressions for the fractional increase $F_{a c}$ in the ratio of the (space- and time-averaged $\mathrm{Nu}$ or Sh over an oscillation cycle -2) with acoustics the (steady flow $\mathrm{Nu}$ or $\mathrm{Sh}-2$ ) without acoustics which can be expressed as,

$$
F_{a c}=0.7628 \sqrt{\frac{\hat{u}_{g}}{\left|U_{g}-U_{P}\right|}}+0.1372,
$$


where $\hat{u}_{g}$ is velocity amplitude of the gas oscillations. Space-averaging refers to the average $\mathrm{Nu}$ for the entire surface of the sphere, and time averaging refers to the average $\mathrm{Nu}$ over one oscillation cycle.

The slip velocity $U_{g}-U_{p}$ is determined by the degree to which a particle is entrained in the gas oscillations (Rudinger, 1980). A fully entrained particle has a zero slip velocity and oscillates in phase with the gas oscillations. A particle that is not entrained and does not oscillate has a slip velocity equal to the sum of the mean flow velocity and the velocity of the gas oscillations.

Modified forms of the equation for unsteady motion of a rigid spherical particle, derived by Basset (1888) for creeping flow conditions (i.e., $\operatorname{Re}_{p}<0.1$ and Stokes drag), have been used to calculate the velocity of a sphere falling through a high-intensity, vertical, resonant axial acoustic field. Basset's equation can be expressed as,

$$
\begin{array}{r}
\frac{1}{6} \pi d_{p}^{3} \rho_{p} \frac{d U_{p}}{d t}=C_{\mathrm{D}} \bullet \frac{1}{2} \rho_{g}\left(U_{g}-U_{p}\right)\left|U_{g}-U_{p}\right| \bullet \frac{1}{4} \pi d_{p}^{2}-\frac{1}{6} \pi d_{p}^{3} \frac{\partial P}{\partial x}+\Delta_{\mathrm{A}} \frac{1}{2} \bullet \frac{1}{6} \pi d_{p}^{3} \rho_{g} \xi \\
+\Delta_{\mathrm{H}} \frac{3}{2} d_{p}{ }^{2} \sqrt{\pi \rho_{g} \mu_{g}} \int_{0}^{t} \frac{\xi}{\sqrt{t-s}} d s+\frac{1}{6} \pi d_{p}^{3} \rho_{p} g+\text { external force }
\end{array}
$$

where $P$ is the gas pressure, $t$ and $x$ are the time and position coordinates, $C_{D}$ is the Stokes drag coefficient, $\Delta_{\mathrm{A}}$ and $\Delta_{\mathrm{H}}$ are empirical unsteady drag coefficients, $\rho_{p}$ and $\rho_{g}$ are sphere and gas densities, $d_{p}$ is the sphere diameter, $\mu_{g}$ is the gas viscosity, $\xi$ is the relative acceleration of the sphere, $g$ is the gravitational acceleration, and $s$ is the integration variable (Rudinger, 1980 and Clift et al. 1978). The term on the left-hand side represents the product of the mass of the sphere and its acceleration. The first term on the right-hand side is the viscous drag force exerted by the 
gas on the particle. The second term represents the force from the pressure gradient in the gas surrounding the sphere. The third term represents the force due to acceleration of the apparent mass of the sphere relative to the gas. The apparent mass of the sphere is the sum of the mass of the sphere and the mass of surrounding gas carried by the sphere when it accelerates. The fourth term is the force associated with continual adjustment of the accelerated flow pattern to the steady flow pattern. This force is represented by the Basset history integral, which accounts for past acceleration weighted as $(t-s)^{-1 / 2}$, where $(t-s)$ is the time elapsed since the past acceleration. The fifth term is the gravitational force acting downwards on the particle, where the particle and gas velocities are positive downwards. According to Rudinger (1980), the carried mass, pressure gradient, and Basset history terms are commonly neglected except for high pressures, very low density (hollow) particles, or very high frequencies $(10 \mathrm{kHz})$.

The terminal velocity of free falling particles in an acoustic field can be obtained by solving Eq. 25 when $d U_{P} / d t=0$. Schoneborn (1975) calculated the particle terminal velocity through a vertical oscillatory flow field by varying $\Delta_{\mathrm{A}}$ and $\Delta_{\mathrm{H}}$ in Eq. 25. Calculated particle terminal velocities, based on modified empirical drag coefficients, were correlated with experimental observations of different wake shedding phenomena and terminal velocity reductions over a range of oscillation frequencies. Sujith (1994) measured terminal velocities of individual 50-250 $\mu \mathrm{m}$ water droplets allowed to fall from rest in still air and in a resonant axial acoustic field. Droplet terminal velocities for an acoustic velocity amplitude of $3.1 \mathrm{~m} / \mathrm{s}$ with frequencies between $320-975 \mathrm{~Hz}$ were $10-35 \%$ lower than in still air. A numerical analysis, which included all of the terms Eq. 25, predicted droplet terminal velocities that were slightly lower than those measured in an acoustic field. 
At high acoustic velocity amplitudes, the acoustic pressure exerted on a particle may be sufficient to overcome gravity so that a particle can be levitated (Doinikov, 1996; King, 1934). There is considerable disagreement between these authors as to the magnitude and direction of the time-mean radiation pressure for a given particle diameter and acoustic pressure amplitude and frequency. King derived an expression for the radiation pressure, which did not account for viscous dissipation due to particle oscillations, and determined that for $\rho_{g} / \rho_{p}<2.5$ particles should be levitated from the acoustic pressure node to $\lambda / 8$ downstream from that node in a vertical resonant axial acoustic field. Doinikov derived an expression for the radiation pressure, which accounted for viscous and thermal dissipation due to particle oscillations and determined that for $\rho_{g} / \rho_{p}<1$ particles should be levitated from the acoustic pressure anti-node to $\lambda / 8$ downstream from that anti-node in a vertical resonant axial acoustic field. The sign and the magnitude of the radiation pressure derived by Doinikov were opposite to and about 9 orders of magnitude larger, respectively, than that derived by King, as calculated in Appendix 11. Because the radiation pressure is a second order effect in the wave equation, the radiation pressure force exerted on particles at different sound pressure levels can are related by the product of the gas density and the square of the acoustic velocity (Bate and Stephens, 1950).

Westervelt (1951 and 1993) theorized that Oseen-type drag force may increase the drag coefficient such that particles may appear to levitate against gravity when sinusoidal oscillations of two harmonically related acoustic waves, such as in a resonant standing wave, are sufficiently out of phase with each other. The result of the superposition of the two wave forms is a periodic time-mean velocity component whose direction is opposite to the direction of the radiation pressure force derived by King (1934). The Oseen-type drag force was expressed in terms of a 
drag coefficient based on the oscillatory component of the gas velocity. The magnitude of the force is proportional to the product of the gas density and the square of the time-mean velocity component. The direction of the force depends on the phase difference between the two harmonically related acoustic waves. The theory of Oseen-type drag force in an acoustic field has not been sufficiently developed to calculate the magnitude of the force. However, the magnitude of the Oseen-type drag force would be expected to be greatest near the velocity antinode of the resonant axial acoustic field at its driven frequency.

Purdy (1963), while using tobacco smoke as a flow tracer, observed two main standing vortices in the presence of mean flow through a glass tube as illustrated in Fig. 8. The axial component of the recirculation velocity was greatest at a distance of $\lambda / 8$ downstream from the nearest acoustic pressure anti-node. The main vortices that circulated in the counter direction of the steady flow were located near the wall in a greatly reduced size. The thickness of the main vortices that circulated in the direction of the steady flow was dependent on the ratio of the mean steady flow velocity to the acoustic velocity amplitude.

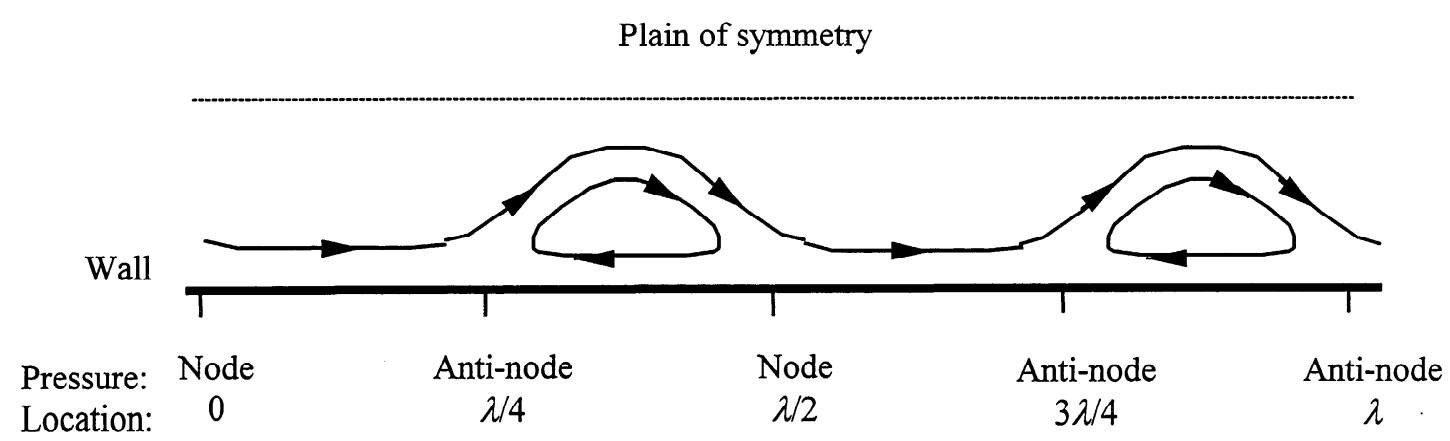

Figure 8. An illustration of two main acoustic streaming vortices inside of a tube containing a resonant axial acoustic field with mean flow. 


\section{[2.4.2] Role of Acoustic Pressure}

Acoustic pressure pulsations, which are most severe at a pressure anti-node in a resonant acoustic field, were reported to significantly increase the rates of internal mass transfer through a thin potato slice and a moistened sheet of paper (Bartolome et al., 1969 and Borisov and Gynkina, 1962). In a review of those studies, Arpaci et al. (1991) postulated that mass transport of water vapor from the potato slice and paper was enhanced because compressing and expanding gas can enter and leave the porous body, increasing.gas-phase mixing and liquid evaporation inside the body. It is pointed out that the pressure pulsations may have been misinterpreted to increase internal mass transport because at the high sound pressure levels used in those studies, the velocity anti-nodes of the standing wave harmonics can be large even at the pressure anti-nodes. Enhanced convective mass transport of vapor at a harmonic anti-node also could have significantly increased the drying rate compared to that observed without acoustics.

Table 13 describes several studies of acoustic enhancement of heat and mass transfer. 
Table 13. Experimental and theoretical studies of acoustic enhancement of heat and mass transfer.

\begin{tabular}{|c|c|c|}
\hline Study & Measured or modeled variables & Results and conclusions \\
\hline $\begin{array}{l}\text { Hodgins et al. } \\
\text { (1957) }\end{array}$ & $\begin{array}{l}\text { Sublimation rate of naphthalene coated on a } 7.9 \mathrm{~mm} \\
\text { diameter glass sphere that was suspended on a wire and } \\
\text { placed at a pressure node. } \mathrm{SPL}=160 \mathrm{~dB} \text { and } \\
\mathrm{f}=100-700 \mathrm{~Hz} \text {. }\end{array}$ & $\begin{array}{l}\text { Rates were enhanced by } 220 \% \text { and } 100 \% \text { with } \\
\text { acoustics for a } 14 \text { and } 56 \text { slpm mean air flowrate past } \\
\text { the sphere, respectively, compared to that in steady } \\
\text { flow at the same Re without acoustics. }\end{array}$ \\
\hline $\begin{array}{l}\text { Fand and Kaye } \\
(1960)\end{array}$ & $\begin{array}{l}\text { Heat transfer rate from a } 19 \mathrm{~mm} \text { diameter cylinder that } \\
\text { was heated to } 110^{\circ} \mathrm{C} \text { and positioned at a pressure node, } \\
\text { transversely to the acoustic wave propagation. } \\
\mathrm{SPL}=142-141 \mathrm{~dB} \text { and } \mathrm{f}=1100-4890 \mathrm{~Hz} \text {. }\end{array}$ & $\begin{array}{l}\text { Rate was } 300 \% \text { greater at } 151 \mathrm{~dB} \text { and } 2130 \mathrm{~Hz} \text { than } \\
\text { that without acoustics and only free convection. } \\
\text { Acoustic streaming vortices were observed above } \\
140 \mathrm{~dB} \text { using tobacco smoke. }\end{array}$ \\
\hline $\begin{array}{l}\text { Borisov and } \\
\text { Gynkina (1962) }\end{array}$ & $\begin{array}{l}\text { Drying rate of moist paper at a pressure node and } \\
\text { anti-node. } S P L=143-160 \mathrm{~dB} \text { and } \mathrm{f}=1080 \mathrm{~Hz} \text {. }\end{array}$ & $\begin{array}{l}\text { Rate was } 900 \% \text { greater at a pressure anti-node at } \\
163 \mathrm{~dB} \text { than that without sound. The drying rate was } \\
\text { slightly lower at a node at } 143 \mathrm{~dB} \text {. }\end{array}$ \\
\hline $\begin{array}{l}\text { Cheng and Fand } \\
\text { (1963) }\end{array}$ & $\begin{array}{l}\text { Heat transfer rate from Fand and Kaye's }(1960) \text { cylinder } \\
\text { in a crossflow that was perpendicular to the sound } \\
\text { propagation. } S P L=130-150 \mathrm{~dB} \text { and } \mathrm{f}=1100-1500 \mathrm{~Hz} \text {. } \\
\text { Crossflow } \mathrm{Re}=1000-10,000 .\end{array}$ & $\begin{array}{l}\text { Rates increased } 25 \% \text { with acoustics compared to that } \\
\text { without acoustics at crossflow } \mathrm{Re}=1000 \text {, due to } \\
\text { acoustic streaming, and } \mathrm{Re}=10,000 \text {, due to a } \\
\text { resonance interaction between the acoustic } \\
\text { oscillations and vortex shedding from the cylinder. }\end{array}$ \\
\hline $\begin{array}{l}\text { Bartolome et al. } \\
\text { (1969) }\end{array}$ & $\begin{array}{l}\text { Drying rate of potato cylinders placed in a pressure node } \\
\text { and anti-node. SPL }=118-141 \mathrm{~dB} \text { and } \mathrm{f}=700-10,000 \mathrm{~Hz} \text {. }\end{array}$ & $\begin{array}{l}\text { Time-averaged rates were up to } 250 \% \text { greater with } \\
\text { acoustics compared to those without acoustics. } \\
\text { Below } 2500 \mathrm{~Hz} \text {, enhancement was greatest at a } \\
\text { pressure anti-node. Maximum enhancement occurred } \\
\text { at } 8100 \mathrm{~Hz} \text { without respect to location in the acoustic } \\
\text { field. }\end{array}$ \\
\hline $\begin{array}{l}\text { Lyman and } \\
\text { Sabnis } \\
(1982)\end{array}$ & $\begin{array}{l}\text { Combustion of a } 1.3 \text { and } 2.4 \mathrm{~mm} \text { diameter coal particle } \\
\text { that was suspended on a rod and placed at a pressure } \\
\text { node. SPL }=140 \mathrm{~dB} \text { and } \mathrm{f}=54 \text { and } 130 \mathrm{~Hz} \text {. Burning time } \\
\text { was determined by monitoring the intensity of emitted } \\
\text { radiation. }\end{array}$ & $\begin{array}{l}\text { Reduction in burning time with acoustics compared } \\
\text { to that without acoustics varied between } 50 \% \text { for a } \\
1.3 \mathrm{~mm} \text { diameter particle at } 54 \mathrm{~Hz} \text { and } 10 \% \text { for a } \\
2.4 \mathrm{~mm} \text { diameter particle at } 130 \mathrm{~Hz} \text {. Enhanced } \\
\text { burning was attributed to an increased oxygen } \\
\text { transfer rate through the gas-film boundary layer. }\end{array}$ \\
\hline
\end{tabular}


Table 13 (Continued). Experimental and theoretical studies of acoustic enhancement of heat and mass transfer.

\begin{tabular}{|c|c|c|}
\hline Study & Measured or modeled variables & Results and conclusions \\
\hline $\begin{array}{l}\text { Boulard and } \\
\text { Malherbe } \\
\text { (1988) }\end{array}$ & $\begin{array}{l}\text { Velocity of turbulent fluctuations during an oscillation cycle } \\
\text { at a pressure node. SPL }=150-163 \mathrm{~dB} \text { and } \mathrm{f}=1000 \mathrm{~Hz} \text {. } \\
\text { Laser velocimetry was used to measure the velocity of } \\
0.4 \mu \mathrm{m} \text { diameter particles in the flow of } 12 \mathrm{~cm} / \mathrm{s} \text {. }\end{array}$ & $\begin{array}{l}\text { At } 163 \mathrm{~dB} \text {, longitudinal velocity at a pressure } \\
\text { node was } 15 \mathrm{~m} / \mathrm{s} \text {, and turbulent velocity } \\
\text { fluctuations averaged } 3 \mathrm{~m} / \mathrm{s} \text { with spikes up to } \\
6 \mathrm{~m} / \mathrm{s} \text {. At } 152 \mathrm{~dB} \text {, turbulent velocity fluctuations } \\
\text { were } 0.5-1 \mathrm{~m} / \mathrm{s} \text {. Smallest eddy diameters were } \\
\text { calculated to be } 52 \mu \mathrm{m} \text { at } 153 \mathrm{~dB} \text { and } 100 \mu \mathrm{m} \text { at } \\
163 \mathrm{~dB} \text {. }\end{array}$ \\
\hline $\begin{array}{l}\text { Rawson } \\
(1988)\end{array}$ & $\begin{array}{l}\text { Evaporation rate of water droplets falling in an a resonant } \\
\text { axial acoustic field. SPL }=152 \mathrm{~dB} \text { and } \mathrm{f}=1100-1300 \mathrm{~Hz} \text {. }\end{array}$ & $\begin{array}{l}\text { Rate increased } 30 \% \text { with acoustics compared to } \\
\text { that without acoustics. }\end{array}$ \\
\hline $\begin{array}{l}\text { Ha et al. } \\
\text { (1989) }\end{array}$ & $\begin{array}{l}\text { Combustion of } 20-70 \mu \mathrm{m} \text { diameter coal particles in a flat } \\
\text { flame burner located at a pressure node. SPL }=140-150 \mathrm{~dB} \\
\text { and } \mathrm{f}=560-2000 \mathrm{~Hz} \text {. Burning rates were indirectly obtained } \\
\text { by measuring the light emitted from the flame. }\end{array}$ & $\begin{array}{l}\text { Average values of the light intensity were } 250- \\
300 \% \text { higher at } 145-150 \mathrm{~dB} \text { and frequency of } \\
2000 \mathrm{~Hz} \text { than that without acoustics. }\end{array}$ \\
\hline $\begin{array}{l}\text { Ha et al. } \\
(1993 \mathrm{a} \text { and } \mathrm{b})\end{array}$ & $\begin{array}{l}\text { Calculation of space- and time-averaged quasi steady } \mathrm{Nu} \text { in } \\
\text { the presence of acoustics for either free convection or forced } \\
\text { flow using the two-dimensional, unsteady conservation of } \\
\text { mass, momentum, and energy equations for laminar flow } \\
\text { past a sphere. }\end{array}$ & $\begin{array}{l}\text { (Nu with acoustics }-2), \text { when normalized to the } \\
\text { steady flow }(\mathrm{Nu} \text { without acoustics }-2) \text {, increased } \\
85 \% \text { when } \hat{u}_{g} /\left|U_{g}-U_{p}\right|=5 \text { and decreased } 10 \% \\
\text { when } \hat{u}_{g} /\left|U_{g}-U_{p}\right| \leq 1 \text {. For free convection, } \mathrm{Nu} \\
\text { increased } 300 \% \text { with acoustics. }\end{array}$ \\
\hline $\begin{array}{l}\text { Arpaci et al. } \\
(1990)\end{array}$ & $\begin{array}{l}\text { Calculation of the evaporation rate of a } 100 \mu \mathrm{m} \text { diameter } \\
\text { water droplet in an oscillating gas flow field using Eq. } 25 \\
\text { and a quasi steady-state heat, mass, and momentum transfer } \\
\text { analysis. Acoustic velocities were between } 50-100 \mathrm{~m} / \mathrm{s} \text {. }\end{array}$ & $\begin{array}{l}\text { Rates in an oscillating gas flow field were over } \\
160 \% \text { greater than that for steady flow at the same } \\
\text { Re number. }\end{array}$ \\
\hline $\begin{array}{l}\text { Arpaci et al. } \\
\text { (1991) }\end{array}$ & $\begin{array}{l}\text { Evaporation rate of water from a sintered cylinder located at } \\
\text { a pressure node of an oscillating standing wave that was } \\
\text { excited in a pulse combustor. SPL }=163-172 \mathrm{~dB} \text { and } \\
\mathrm{f}=65-105 \mathrm{~Hz} \text {. Calculation of evaporation rate using a quasi } \\
\text { steady-state heat, mass, and momentum transfer analysis } \\
\text { and Eq. } 25 \text {. }\end{array}$ & $\begin{array}{l}\text { Experimental rate was } 100 \% \text { greater for } \\
\text { oscillating flow than that in steady flow at the } \\
\text { same cylinder Re. A } 25 \% \text { underprediction of the } \\
\text { experimental rate by quasi-steady analysis was } \\
\text { attributed to acoustically generated turbulence. }\end{array}$ \\
\hline
\end{tabular}


Table 13 (Continued). Experimental and theoretical studies of acoustic enhancement of heat and mass transfer.

\begin{tabular}{|c|c|c|}
\hline Study & Measured or modeled variables & Results and conclusions \\
\hline $\begin{array}{l}\text { Blasczyk } \\
\text { (1991) }\end{array}$ & $\begin{array}{l}\text { Combustion of a } 2-2.5 \mathrm{~mm} \text { diameter gasoline and } \\
\text { diesel fuel droplet that was suspended on a wire, } \\
\text { which was attached to an electronic scale. } \\
\mathrm{SPL}=100-115 \mathrm{~dB} \text { and } \mathrm{f}=100-5000 \mathrm{~Hz} \text {. Droplet } \\
\text { weight loss with time was recorded. }\end{array}$ & $\begin{array}{l}\text { Burning times decreased by } 14 \% \text { with acoustics at } \\
\mathrm{f}=100-275 \mathrm{~Hz} \text { compared to that without acoustics in still } \\
\text { air. Burning times were decreased by } 8 \% \text { for } \\
\mathrm{f}=700-5000 \mathrm{~Hz} \text {. }\end{array}$ \\
\hline $\begin{array}{l}\text { Celik and Wang } \\
\text { (1991) }\end{array}$ & $\begin{array}{l}\text { Calculation of the heat transfer rate from a hot gas } \\
\text { to a single } 10-100 \mu \mathrm{m} \text { diameter coal particle in an } \\
\text { oscillating gas flow field using Eq. } 25 \text { and a quasi } \\
\text { steady-state heat, mass, and momentum transfer } \\
\text { analysis. Acoustic velocity was } 70 \mathrm{~m} / \mathrm{s} \text {. Gas } \\
\text { temperature was } 525^{\circ} \mathrm{C} \text {. }\end{array}$ & $\begin{array}{l}\text { Rate was enhanced by } 300 \% \text { with sound compared to that } \\
\text { in steady flow without sound at the same mean flow Re. } \\
100 \mu \mathrm{m} \text { diameter particles were not entrained in the flow. } \\
10 \mu \mathrm{m} \text { diameter particles were completely entrained in } \\
\text { the flow. }\end{array}$ \\
\hline $\begin{array}{l}\text { Ha et al. } \\
\text { (1991 a and b) }\end{array}$ & $\begin{array}{l}\text { Calculation of char burnout time for a single } \\
100 \mu \mathrm{m} \text { diameter coal or coal-water slurry particle } \\
\text { in an oscillating gas flow field using Eq. } 26 \text { and a } \\
\text { quasi steady-state heat, mass, and momentum } \\
\text { transfer analysis. Nu and Sh numbers from (Ha, } \\
1990) \text { were used in a coal combustion model } \\
\text { developed by Baxter et al. }(1985) \text {. } \\
\text { SPL=160-170 dB and } \mathrm{f}=2000 \mathrm{~Hz} \text {. } \\
\end{array}$ & $\begin{array}{l}\text { Char burnout time decreased by } 15.7 \text { and } 30.2 \% \text { at } 160 \\
\text { and } 170 \mathrm{~dB} \text {, respectively, compared to that without sound } \\
\text { at the same flow Re. Char burnout times were slightly } \\
\text { longer for the coal-water slurry particles with sound than } \\
\text { that without sound. }\end{array}$ \\
\hline $\begin{array}{l}\text { Sujith } \\
(1994)\end{array}$ & $\begin{array}{l}\text { Measured evaporation rate of } 50-250 \mu \mathrm{m} \text { diameter } \\
\text { water and methanol droplets. SPL } \leq 160 \mathrm{~dB} \text { and } \\
\mathrm{f}=320-1240 \mathrm{~Hz} \text {. A quasi steady-state heat, mass, } \\
\text { and momentum transfer analysis was conducted } \\
\text { using Eq. } 25 \text {. }\end{array}$ & $\begin{array}{l}\text { Evaporation rate of methanol was enhanced by } 100 \% \text { at } \\
160 \mathrm{~dB} \text { and } 1240 \mathrm{~Hz} \text { compared to that without acoustics. } \\
\text { The quasi steady-state analysis over predicted the } \\
\text { evaporation rate but the trends were the same over the } \\
\text { range of droplet sizes studied. }\end{array}$ \\
\hline
\end{tabular}


The effects of acoustic oscillations on an inflight particle are summarized as follows:

- A particle falling through a resonant standing wave in a vertical tube will experience regions of maximum (anti-node) and minimum (node) oscillatory velocity and pressure. The pressure anti-node is $90^{\circ}$ out-of-phase with the velocity anti-node.

- The rates of convective heat and mass transfer can be enhanced up to several hundred percent depending on the slip velocity between a particle and a gas. The slip velocity depends on the degree of particle entrainment in the acoustically-induced gas oscillations. Enhancement increases with increasing acoustic velocity at a pressure node in a resonant standing wave and with decreasing steady flow velocity. Oscillation frequency has little effect on enhancement.

- Results of studies are inconclusive whether pressure pulsations increase the rate of internal mass transfer of vapor through porous media.

- The particle terminal velocity can be reduced at high sound pressure levels. Particles will levitate if the acoustic radiation pressure or Oseen-type drag force on a particle is greater than the gravitational force.

- Acoustic streaming of the medium within a tube can cause standing vortices and turbulence. Though it has not been studied, apparently due to lack of industrial application, acousticallyinduced turbulence and standing vortices superimposed on the mean flow could increase the back mixing and residence time of aerosol and vapor in a tube. 


\section{[3] ANALYSIS OF THE PROBLEM AND THESIS OBJECTIVES}

Much research has been conducted on black liquor pyrolysis as discussed in the Literature

Review:

- The results from these studies were inconclusive on whether rapid particle heatup can increase the conversion of carbon in BLS to tars and gases.

- The possibility of mass transfer limitations on the escape of tar from a small, dry BLS particle has not been studied.

- The experimental systems used in all of the black liquor pyrolysis studies were not able to isolate the effects of particle heatup rate, mass transfer rate of pyrolytic products from the particle, or chemical kinetics on the yields of char, tar, and gaseous products. Those rapid particle heatup experiments could produced more tar; however, tar molecules may have polymerize to form char within or on the surface of particles (EFR experiments) or within particles and on the hot wire grid (HGR experiments), rather than escaped into the bulk gas.

- At longer residence times between $0.3-1.5 \mathrm{~s}$ and gas temperatures between $700-1100^{\circ} \mathrm{C}$, tar aerosol and vapor products that have escaped from BLS particle can undergo secondary cracking to gases. It is not known whether increased exposure times at gas temperatures below $700^{\circ} \mathrm{C}$ can enhance the conversion of tar carbon to gases. 
A better understanding of the effects of heat and mass transfer on the pyrolytic yields of char and gaseous products from BLS is needed to develop more detailed pyrolysis reaction models and to better define the constraints imposed by the process variables on low temperature black liquor gasification processes.

It was shown in the Literature Review that high-intensity acoustic oscillations can increase convective mass, momentum, and heat transfer between gas and solid or liquid phases. One possible way to significantly increase both the rates of particle heatup and convective mass transport of tar from the particle is to pyrolyze small biomass particles while they are inflight in the presence of a high-intensity acoustic field. An experimental system using acoustic oscillations to create conditions that promote increased heat flux to particles and volatile efflux from particles without increasing the peak temperature, varying the particle size, or changing the gas pressure, would provide a means determine the degree to which convective transport processes influence BLS pyrolysis. The effect of increased rates of particle heatup and mass transfer of tar through the gas-film boundary layer could be determined by measuring char and primary gas yields obtained at different gas temperatures and over a range of slip velocities between the BLS particle and the oscillating gas.

The effect of increased exposure time of tar aerosols and vapors at gas temperatures below $700^{\circ} \mathrm{C}$ could be determined by measuring secondary gas yields over a range of gas spacetimes in a tube reactor with steady mean flow. Gas space-time is defined as the ratio of the reactor volume to the volumetric flowrate of gas fed to the reactor. The effect of acousticallyinduced turbulence and standing vortices on extending tar aerosol and vapor residence time in a 
tube reactor with a steady mean flow could be quantified by measuring the secondary gas yield over a range of gas space-times and acoustic amplitudes and frequencies.

The overall objective of this dissertation is to understand how high-intensity acoustic oscillations influence the inflight pyrolysis of BLS particles with respect to their chemical and physical transformation to char, tar, and gases. Pyrolysis temperatures were restricted to levels below the inorganic melting point, which are of interest to low temperature gasification processes. Particle diameters were restricted to $106-125 \mu \mathrm{m}$ to prevent a large temperature gradient between the surface and center of the particle during heatup to peak temperature. The objectives are:

(1) Determine the degree to which the conversion of the carbon in BLS to tar and gas during pyrolysis can be increased due to acoustically increased rates of particle heatup and convective mass transfer of tar through the gas-film boundary layer.

(2) Determine whether acoustically induced backmixing and turbulence in the gas or particle levitating forces can increase the conversion of carbon in BLS particles and tar aerosol and vapor to gases by increasing the BLS particle and tar aerosol and vapor residence times in the reactor.

(3) Understand how heat and mass transfer processes, chemical reaction kinetics, and residence times of BLS particles and tar aerosols and vapors in the reaction chamber affect the conversion of carbon in BLS to char, tar, and gases. Understand the effect of acoustics on these variables. 


\section{[4] EXPERIMENTAL}

\section{[4.1] EXPERIMENTAL REACTOR}

An entrained flow reactor (EFR) was developed to investigate the inflight pyrolysis of BLS particles in a high-intensity resonant axial acoustic field as shown schematically in Fig. 9 and pictorially in Fig. 10. The reactor consists of the following sections: (1) reactor tube and support frame, (2) acoustic compression driver and air purge, (3) horizontal trombone tube, (4) $\mathrm{N}_{2}$ gas preheater and $45^{\circ}$ elbow, (5) particle feeder and $90^{\circ}$ elbow, (6) vertical heated pyrolysis tube, (7) acoustic decoupler/char collector, (8) gas analyzer and product gas analysis system, (9) particle and gas flow visualization system, and (10) data acquisition system. Particles were pyrolyzed inflight in a steady gas flow with or without superimposed, acoustically-induced gas oscillations. Particles were first entrained in a carrier gas, termed primary gas, and then injected into the pyrolysis tube along the centerline of the downward flowing preheated gas, termed secondary gas. Particle residence time was varied by externally heating different sections of the pyrolysis tube and by varying preheated gas velocity. Residue char particles eventually fell out of the pyrolysis tube and formed a pile on the bottom of the acoustic decoupler. Condensed tar and fume settled out on a filter located at the exit of the decoupler. Char, tar, and fume were removed from the decoupler after completion of each experiment. Pyrolysis product gas passing through the filter was continuously analyzed for $\mathrm{CO}$ and $\mathrm{CO}_{2}$.

An EFR design was chosen for the following reasons: (1) the tube and acoustic driver configuration is ideal for exciting several pressure loops of a resonant standing longitudinal sound wave at high sound pressure levels near $160 \mathrm{~dB}$ and frequencies between $300-1000 \mathrm{~Hz}$ for gas temperatures between $400-700^{\circ} \mathrm{C}$, (2) particle heating rates up to several thousand ${ }^{\circ} \mathrm{C} / \mathrm{s}$ can 
be obtained, (3) the rates of particle heatup and product mass transfer are determined by the process variables and not affected by a supporting wire grid in an EFR or a thermocouple or crucible in a RFR and (4) the effect of acoustic oscillations on the gas residence time can be quantified using the conversion of tar to $\mathrm{CO}$ and $\mathrm{CO}_{2}$ at different secondary gas space-times and acoustic amplitude and frequency.

The main disadvantage of the EFR is imprecise determination of particle residence time, due to dispersion of particles from the pyrolysis tube centerline flow. Particle residence times can vary significantly, depending on the degree of particle entrainment in the acousticallyinduced gas oscillations and the radial dispersion distance from the centerline of the vertical reaction tube. Particle residence times in the acoustic reactor are estimated using a numerical model, presented in Appendix 10, that accounts for several acoustic effects.

\section{[4.1.1] Reactor Tube and Support Frame}

The flanged tube sections of the reactor, when bolted together, form a L-shaped tube that is closed at the acoustic driver section and open at the acoustic decoupler section. The reactor tubes were constructed from $52.3 \mathrm{~mm}$ I.D., (2" IPS, sch-40) 304 stainless steel pipe. The tube flange joints were sealed with $3.1 \mathrm{~mm}$ thick graphite gaskets. The tube was fastened to the frame at key points that allowed for thermal expansion without stressing the flange seals when the reactor was heated. In addition, the reactor frame supports the particle feeder, three $\mathrm{N}_{2}$ gas cylinders, cooling water system, product gas exhaust vacuum ejector and ducting, a heater control panel, an acoustic pressure transducer amplifier, and sound generation electronics. 


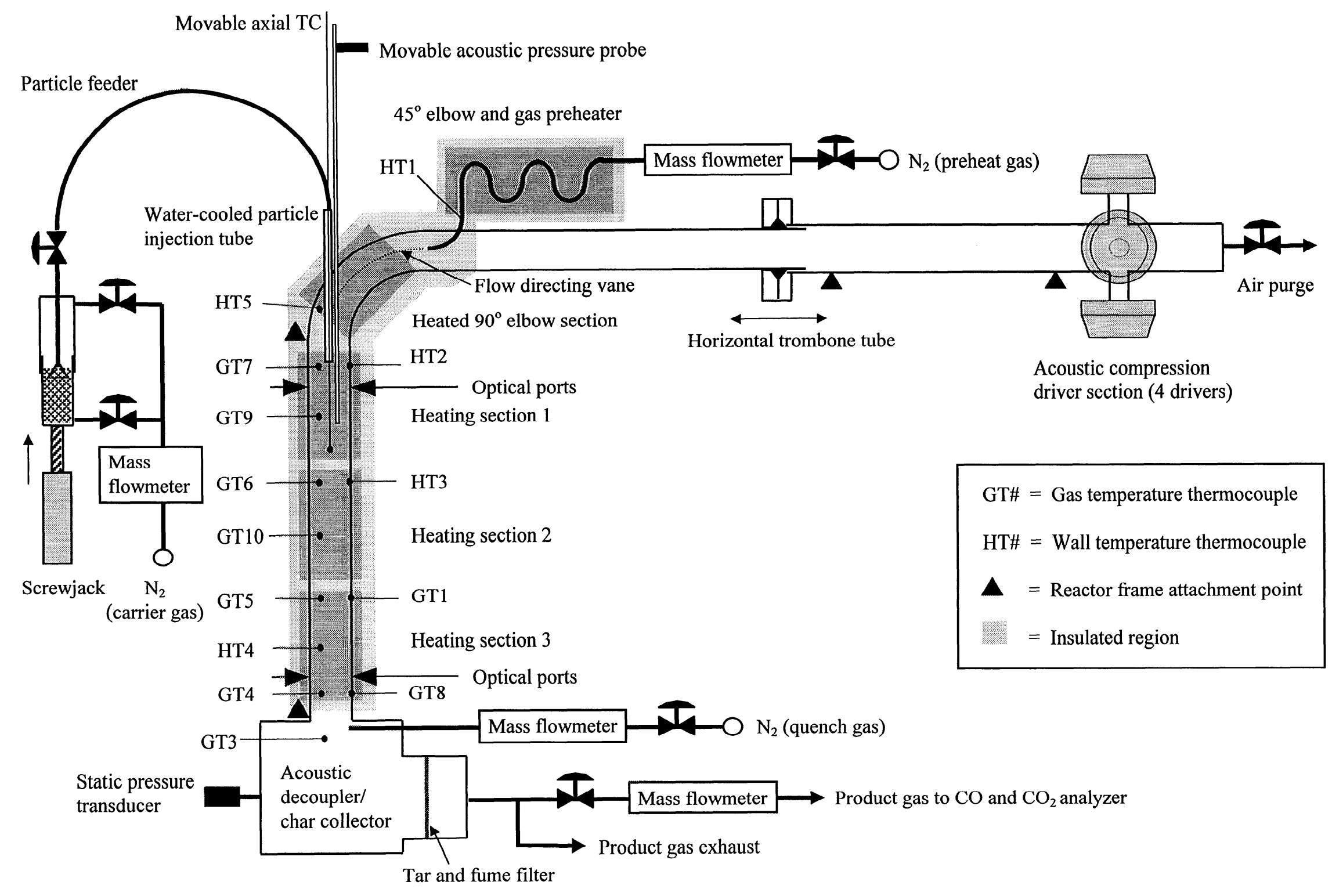

Figure 9. A schematic diagram of the experimental facility. 

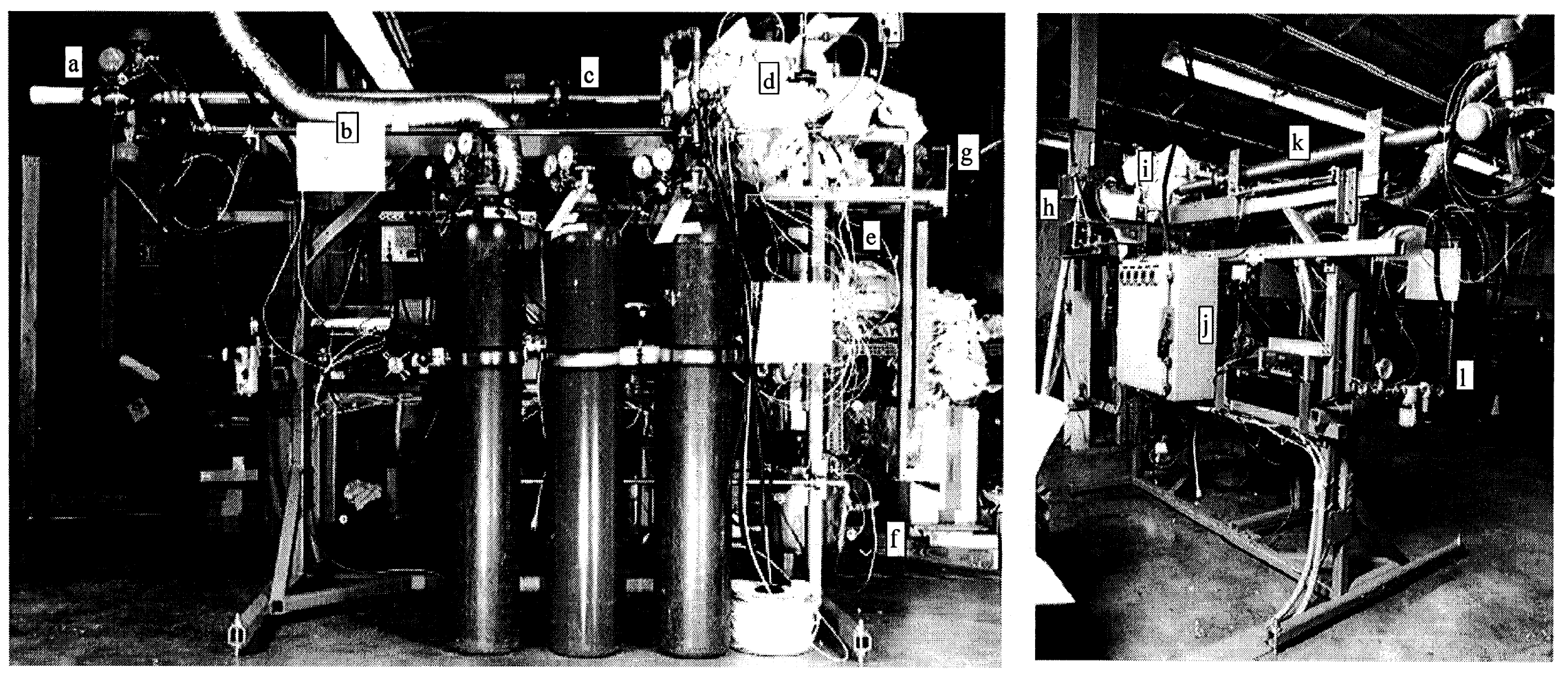

Figure 10. Photographs of the experimental facility showing the gas cylinder side and the instrumentation side. (a) acoustic compression drivers, (b) product gas exhaust, (c) trombone tube, (d) particle injection $90^{\circ}$ elbow, (e) pyrolysis section, (f) acoustic decoupler and $\mathrm{N}_{2}$ gas quench, (g) diode laser for particle residence measurements, (h) particle feeder, (i) $\mathrm{N}_{2}$ gas preheater and $45^{\circ}$ elbow, (j) heater and sound generation instrumentation, (k) trombone tube, and (l) air regulation for vacuum ejector. 


\section{[4.1.2] Acoustic Compression Driver and Air Purge}

The acoustic compression driver section was used to input sound energy into the tube, exciting a resonant standing wave of desired frequency $(310$ and $950-1000 \mathrm{~Hz})$ and amplitude (146-160 dB). Four compression drivers (University Sound $75 \mathrm{~W}$ ) were mounted radially on the tube $0.3 \mathrm{~m}$ away from the capped end. An air purge valve was attached to the capped end and was opened only during pre-experimental pressurization of the reactor with $\mathrm{N}_{2}$. Acoustic compression drivers were driven by a sinusoidal signal, produced by a wave generator (B\&K) and amplified by a $300 \mathrm{~W}$ amplifier (University Sound).

\section{[4.1.3] Horizontal Trombone Tube}

The horizontal trombone tube section was used to adjust reactor length up to $1 \mathrm{~m}$ so that the natural frequency of the tube, more specifically, the frequency of input sound that will excite a resonant standing wave in a tube of a given length, could be tuned to that of the acoustic drivers. The section was constructed from a $60 \mathrm{~mm}$ O.D., $1.07 \mathrm{~m}$ long, (2" IPS, sch-40) pipe that was inserted into a $73 \mathrm{~mm}$ O.D., $1.07 \mathrm{~m}$ long, (2.5" IPS, sch-40) pipe. The gap between inner and outer pipes was sealed with a rubber gasket. The outer pipe was supported on a subframe that could be slid on the top horizontal leg of the reactor frame. The subframe could be moved during an experiment by turning a turnbuckle bolted between the sub-frame and the reactor frame. 


\section{[4.1.4] Secondary Gas Preheater and $45^{\circ}$ Elbow Section}

The $\mathrm{N}_{2}$ gas preheater was constructed by wrapping a $2 \mathrm{~m}$ long, $12.7 \mathrm{~mm}$ O.D., 304 stainless steel tubing into a coil placed between two clam-type, tubular, ceramic heating elements (Mellen). Each half tubular heating section is $9.5 \mathrm{~cm} \mathrm{I.D.} \mathrm{and} 30.4 \mathrm{~cm}$ long and rated at $1080 \mathrm{~W}$. A mass flowmeter (TBE/Hastings Instruments HFM-201) was used to measure the $\mathrm{N}_{2}$ gas flowrate $(5-20 \mathrm{slpm})$ fed to the preheater. The flow reading was displayed on a power supply unit (Model 40). The precision of the flow reading is $\pm 0.2 \%$ of full scale ( $100 \mathrm{slpm})$. The gas temperature at preheater exit was measured by a type- $\mathrm{K}$, exposed junction, $1.59 \mathrm{~mm}$ sheath diameter thermocouple (Omega). Error limits on the thermocouple temperature measurement are $\pm 2.2^{\circ} \mathrm{C}$ or $\pm 0.75 \%$ of the reading, whichever is greater (OMEGA Engineering, 1992). The set point temperature of the preheated gas was maintained by a proportional-integral-derivative (PID) process controller (Athena XT16) that time-proportioned power to the preheater. The preheater was insulated with a $5 \mathrm{~cm}$ thick layer of ceramic wool. Preheated gas was fed into the $45^{\circ}$ long radius elbow on the reactor tube.

\section{[4.1.5] Particle Feeder and $90^{\circ}$ Elbow Section}

A syringe-type laboratory feeder, based on a design by Phong-Anant and Wibberly (1986), was used to steadily feed $0.25-0.6 \mathrm{~g} / \mathrm{min}$ of particles into the pyrolysis tube. Fig. 11 shows a photograph and schematic diagram of the particle feeder. The transparent plastic feed vial is $12.7 \mathrm{~mm}$ in diameter and $150 \mathrm{~mm}$ long. The vial can hold up to $15 \mathrm{~g}$ of particles. The transparent vial containing dried particles (106-125 $\mu \mathrm{m}$ sieve fraction) was screwed upward toward the stationary, inverted cone during operation. In the apex of the inverted cone, particles were entrained in a primary gas flowrate of $0.32 \mathrm{slpm} \mathrm{N}_{2}$ and then transported to the reactor via a 
$2.56 \mathrm{~mm}$ I.D., 304 stainless steel tube. A small flowrate of $0.04-0.05 \mathrm{slpm} \mathrm{N}_{2}$ was introduced into the bottom of the feed vial to promote uniform entrainment, and to prevent clumping of the particles. Primary gas flowrate was measured by a mass flowmeter (TBE/Hastings Instruments HFM-200H) with a full scale of 1 slpm. The particle feed rate was set by adjusting the speed of the screwjack drive motor.
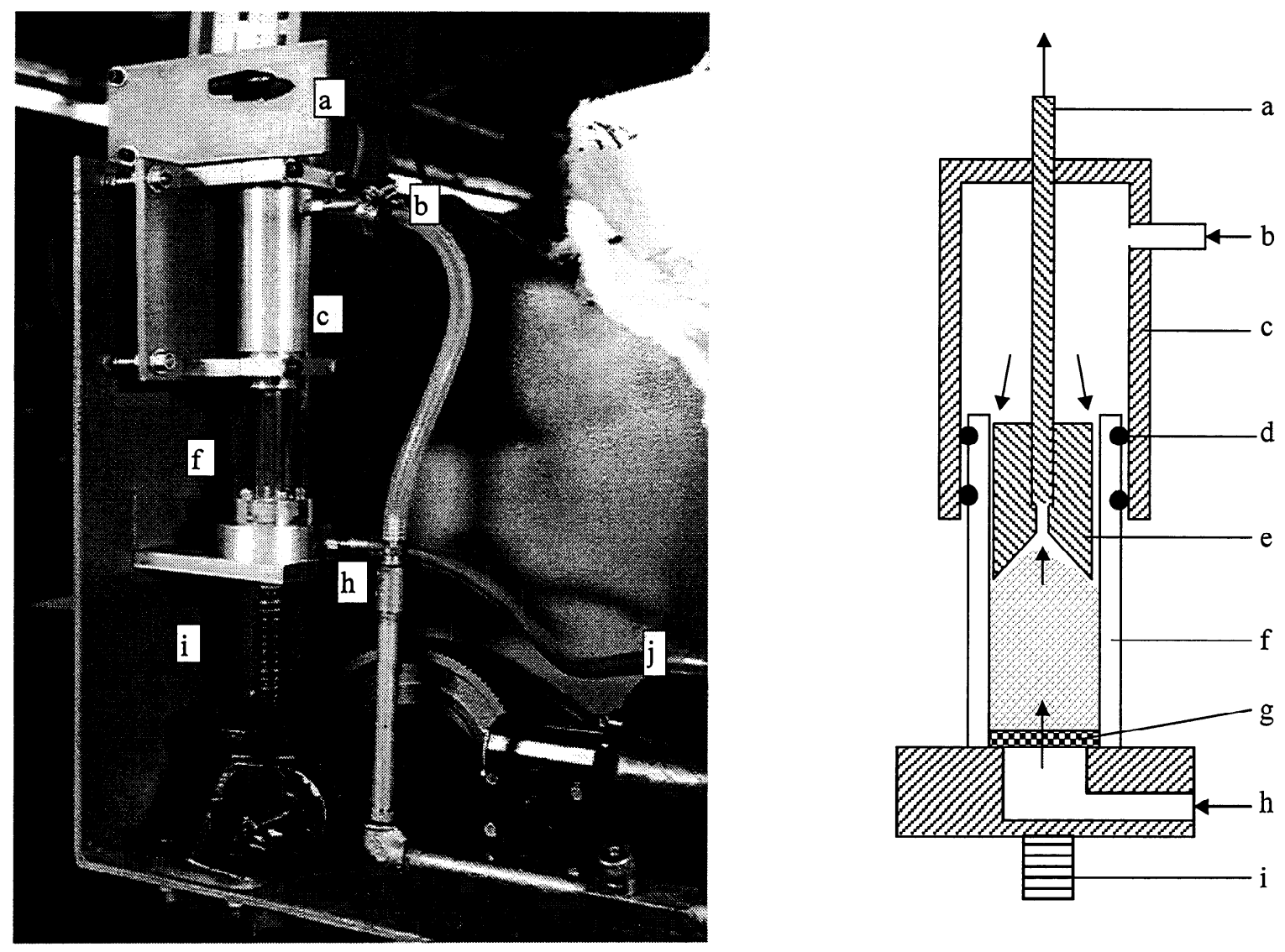

Figure 11. A photograph and schematic diagram of the particle feeder. (a) off-take tube and ball valve, (b) top carrier gas, (c) top tube, (d) o-ring seal, (e) inverted cone, (f) feed vial, (g) sintered distributor plate, (h) bottom carrier gas, (i) screwjack, and $(\mathrm{j})$ electric screwjack drive motor.

Particles in off-take tube were next injected into the $4.52 \mathrm{~mm}$ I.D. tube fitted to the $90^{\circ}$ long radius elbow, which joined the $45^{\circ}$ elbow to the vertical pyrolysis tube. Fig. 13 shows a 
schematic of the $90^{\circ}$ elbow section. The $4.928 \mathrm{~mm}$ I.D. tube is the innermost tube of a three concentric tube water-jacket, whose outermost tube diameter is $12.7 \mathrm{~mm}$. The water-cooled particle injection tube extends $4.76 \mathrm{~cm}$ into the $1.09 \mathrm{~m}$ long vertical, straight section of the pyrolysis tube. Particle injection velocity was $0.677 \mathrm{~m} / \mathrm{s}$, as estimated in Appendix 10, for a primary gas flowrate of $0.32 \mathrm{slpm} \mathrm{N}_{2}$ at a temperature of $77^{\circ} \mathrm{C}$. Particle velocity attained the preheated gas velocity after the particles were injected into the pyrolysis section.
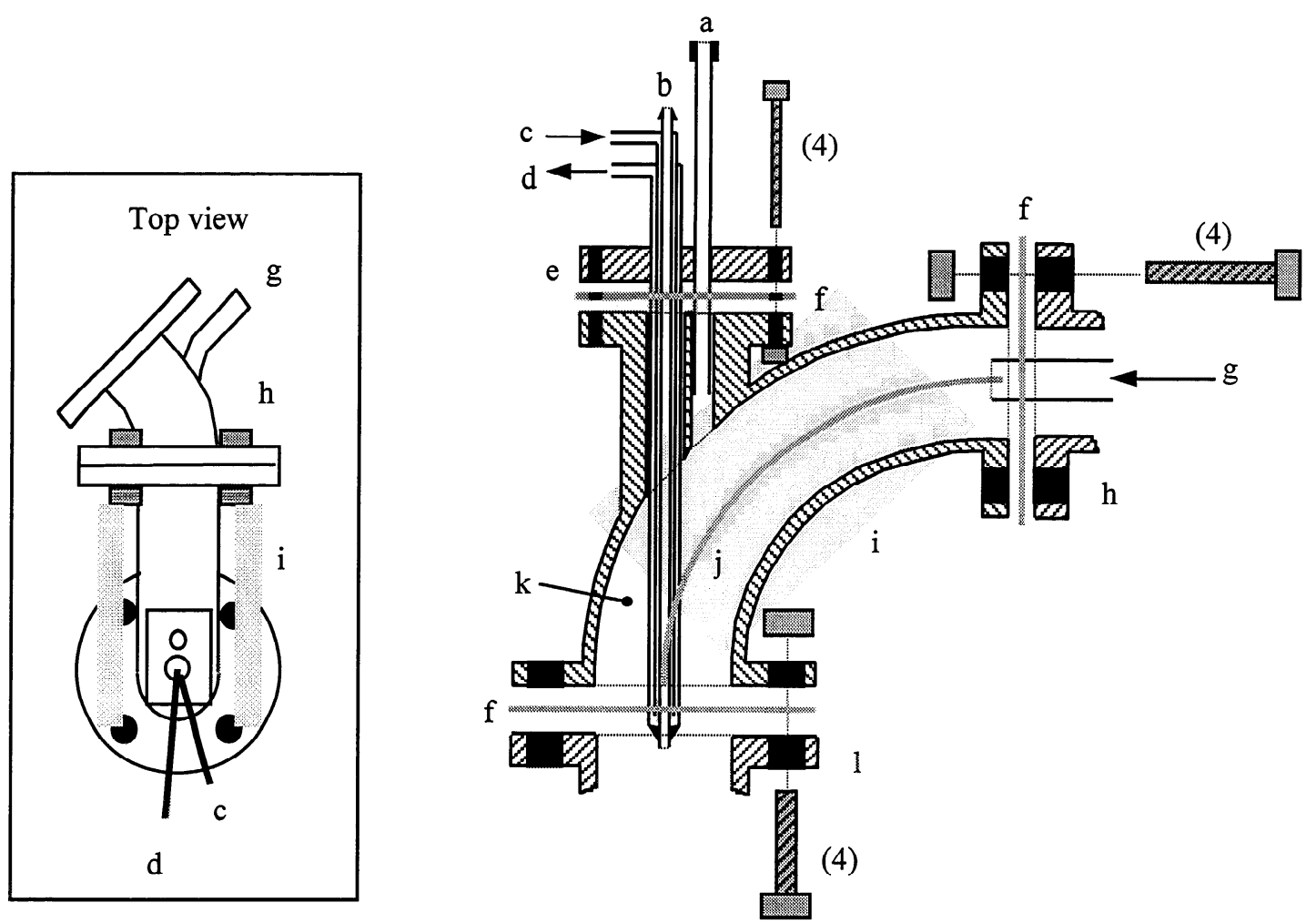

Figure 12. A schematic diagram of the $90^{\circ}$ elbow section. (a) acoustic pressure probe port, (b) inner particle injector tube, (c) cooling water inlet, (d) cooling water outlet, (e) particle injector assembly, (f) graphite gaskets, (g) preheated $\mathrm{N}_{2}$ inlet, (g) $45^{\circ}$ elbow section, (i) plate heaters, (j) flow vane, (k) thermocouple, and (l) pyrolysis tube section.

A vane was placed midway between the inner and outer radii of the elbow to guide the preheated $\mathrm{N}_{2}$ stream into the pyrolysis section. Swirling and channeling of the flow, which 
caused the particles to disperse radially from the centerline and stick to the walls during operation without an acoustic field, was then eliminated.

A type-K, exposed junction, 1.59 or $3.18 \mathrm{~mm}$ sheath diameter thermocouple (Omega) was inserted into the injection tube to measure gas temperature within the injection tube and along the pyrolysis tube centerline. Gas temperature inside the injection tube at the exit was set between $70-90^{\circ} \mathrm{C}$, by adjusting the cooling water flowrate.

Two plate-type ceramic heating elements (Mellen) placed around the $90^{\circ}$ elbow were used to maintain the temperature of elbow inside wall at the set point gas temperature of the pyrolysis section. Each plate heater is $10.5 \mathrm{~cm}$ wide and $18 \mathrm{~cm}$ long and rated at $700 \mathrm{~W}$. Power to the plate heaters was regulated by a PID process controller (Athena XT16). The $90^{\circ}$ elbow section was insulated with a 5-10 cm thick layer of ceramic wool (Zircar).

A movable, water-cooled pressure probe shown in Fig. 13, which could be inserted into a sealable fitting on the $90^{\circ}$ elbow, was used to determine the axial acoustic pressure distribution along the vertical pyrolysis section. The $1.52 \mathrm{~m}$ long, $9.53 \mathrm{~mm}$ O.D. diameter water-cooled probe, constructed of three concentric stainless steel tubes, was based on a similar design by Matta (1993). Matta found that water cooling can maintain the gas within the innermost tube at a low constant temperature, effectively eliminating the influence of high ambient temperature on measured pressure amplitudes. A semi-infinite tube, approximately $20 \mathrm{~m}$ long and capped at the unattached end, was connected to the probe to minimize the backward reflection of the acoustic wave. To account for a frequency-dependent pressure amplitude in the innermost tube, a piezoelectric-type pressure transducer (Kistler $211 \mathrm{~B} 5$ ) on the end of the probe was calibrated against an identical pressure transducer, positioned at the tip of the probe. The probe tip and the 
reference pressure transducer were held in a piston-like block inside a tube attached to the acoustic driver section. An acoustic wave of known frequency and amplitude was generated using the acoustic drivers. The probe was calibrated several times; variability between calibrations was less than $5 \%$. The signals from the probe and reference pressure transducer signals were input to an amplifier (Kistler 5010) and then measured with a two-channel digital oscilloscope (Tektronix TDS 320).

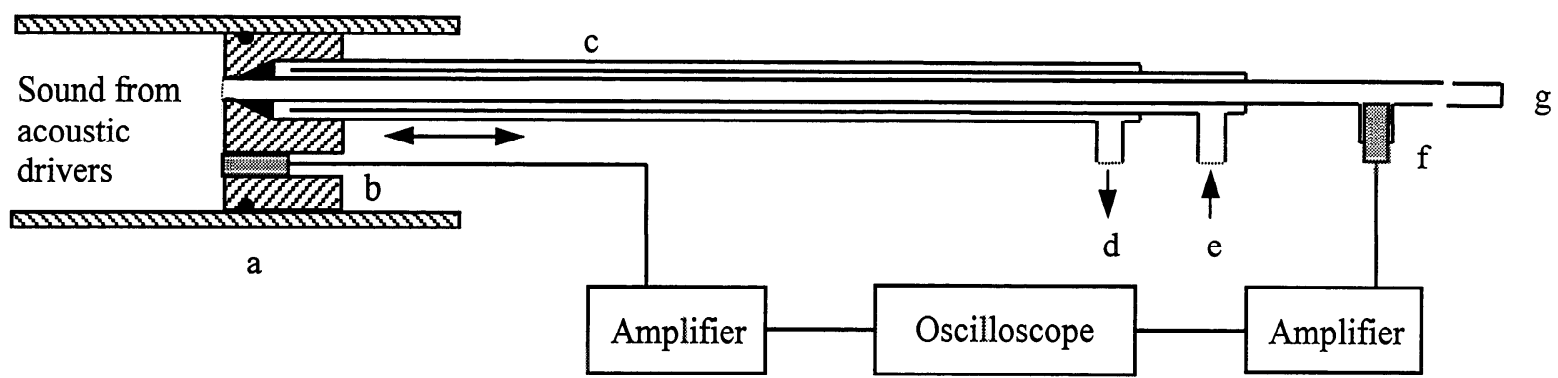

Figure 13. A schematic diagram of the acoustic pressure probe and calibration system. (a) piston with o-ring seal, (b) reference pressure transducer, (c) pressure probe, (d) water outlet, (e) water inlet, (f) probe pressure transducer, and (g) semi-infinite tube.

\section{[4.1.6] Vertical Heated Pyrolysis Tube}

Three heating sections, comprised of two half-cylinder ceramic heating elements surrounding the pyrolysis tube, were used to set the heated length at $0.18,0.48$, or $0.81 \mathrm{~m}$. A photograph of the pyrolysis section without insulation is shown in Fig. 14. The gas temperatures near the centerline $(1.4 \mathrm{~cm}$ from the tube wall) and at the tube wall were measured by type- $\mathrm{K}$, shielded junction, $1.59 \mathrm{~mm}$ sheath diameter thermocouples (Omega). The first set of two thermocouples, inserted through the tube wall opposite one another, are located $5.7 \mathrm{~cm}$ down from the entrance of the tube. Six other sets of thermocouples are spaced 16-17 cm apart, down the length of the tube. PID process controllers (Athena XT16) regulated power to the heating 
elements to maintain inside wall temperature to within $+20^{\circ} \mathrm{C}$ of the centerline gas temperature for each heated section. Variation in the centerline temperature along pyrolysis tube did not exceed $\pm 10^{\circ} \mathrm{C}$ of the mean temperature. For each experiment, process controller setpoints for steady-state operation were determined by preliminary trials without particle injection.

The heated length of the pyrolysis tube was insulated with a $5 \mathrm{~cm}$ thick layer of ceramic wool. The unheated length of the pyrolysis tube was not insulated.

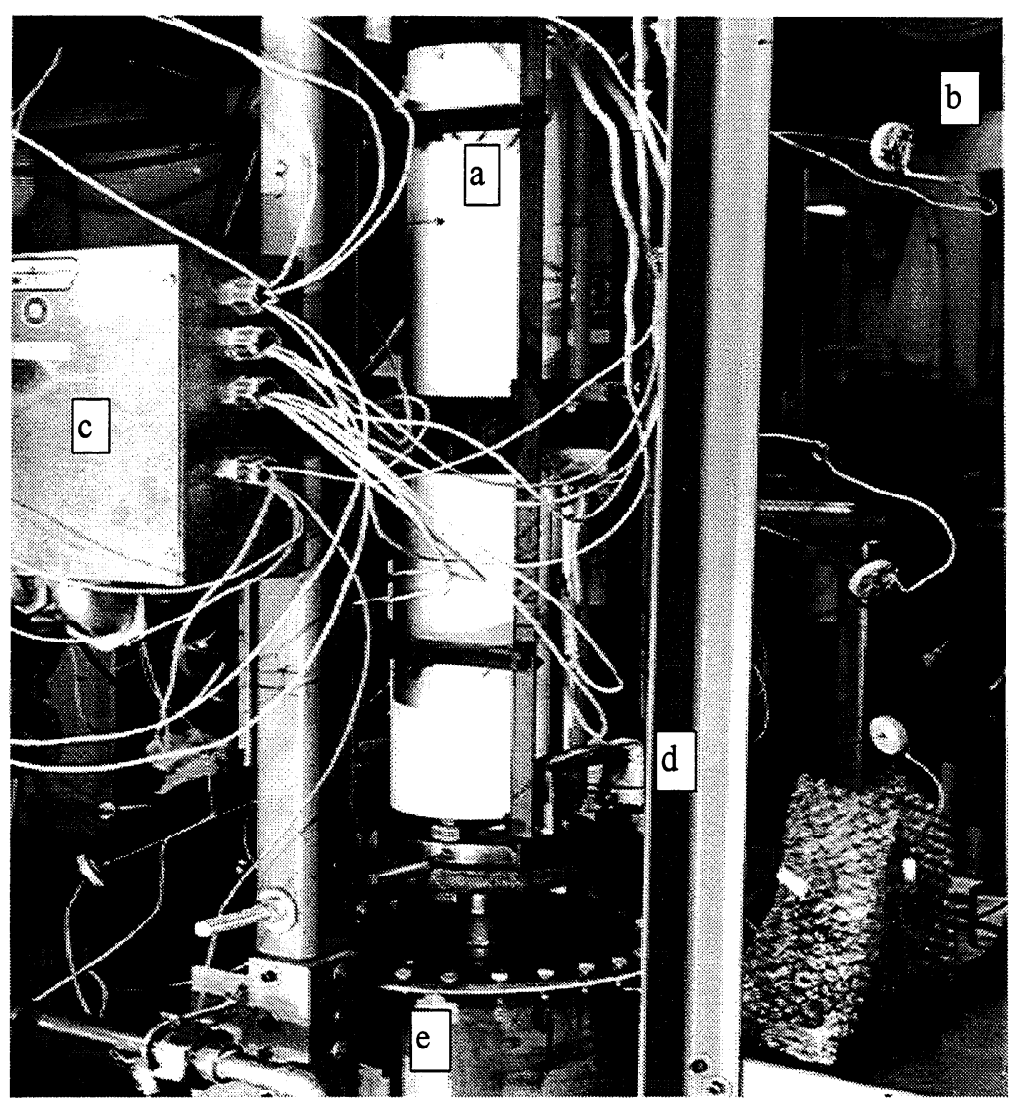

Figure 14. A photograph of pyrolysis section. (a) ceramic heater, (b) thermocouple, (c) heater power supply junction box, (d) optical port, and (e) acoustic decoupler.

Pyrolysis gases were cooled naturally without the addition of quench gas for the 0.18 and $0.48 \mathrm{~m}$ heated sections. The peak gas temperature was decreased by at least $150^{\circ} \mathrm{C}$ within $0.15 \mathrm{~m}$ after the gas left the 0.18 or $0.48 \mathrm{~m}$ heated sections. This was sufficient to quickly stop the 
pyrolysis reactions at a gas cooling rate of $1000^{\circ} \mathrm{C} / \mathrm{s}$. Pyrolysis gases were cooled more rapidly when the $0.81 \mathrm{~m}$ heated section was used, because the acoustic decoupler facilitates quenching with cool $\mathrm{N}_{2}$ gas, and has a large area for natural cooling.

The residence time of a pulse of BLS particles in the pyrolysis tube was qualitatively measured by injecting a pulse of particles through the reactor and then measuring the time delay between interceptions in the laser beams when the front of the particle stream passed, as shown in Fig. 15. The measurement is qualitative because particles can be radially dispersed from the centerline of the secondary flow, which means they can experience different gas velocities.

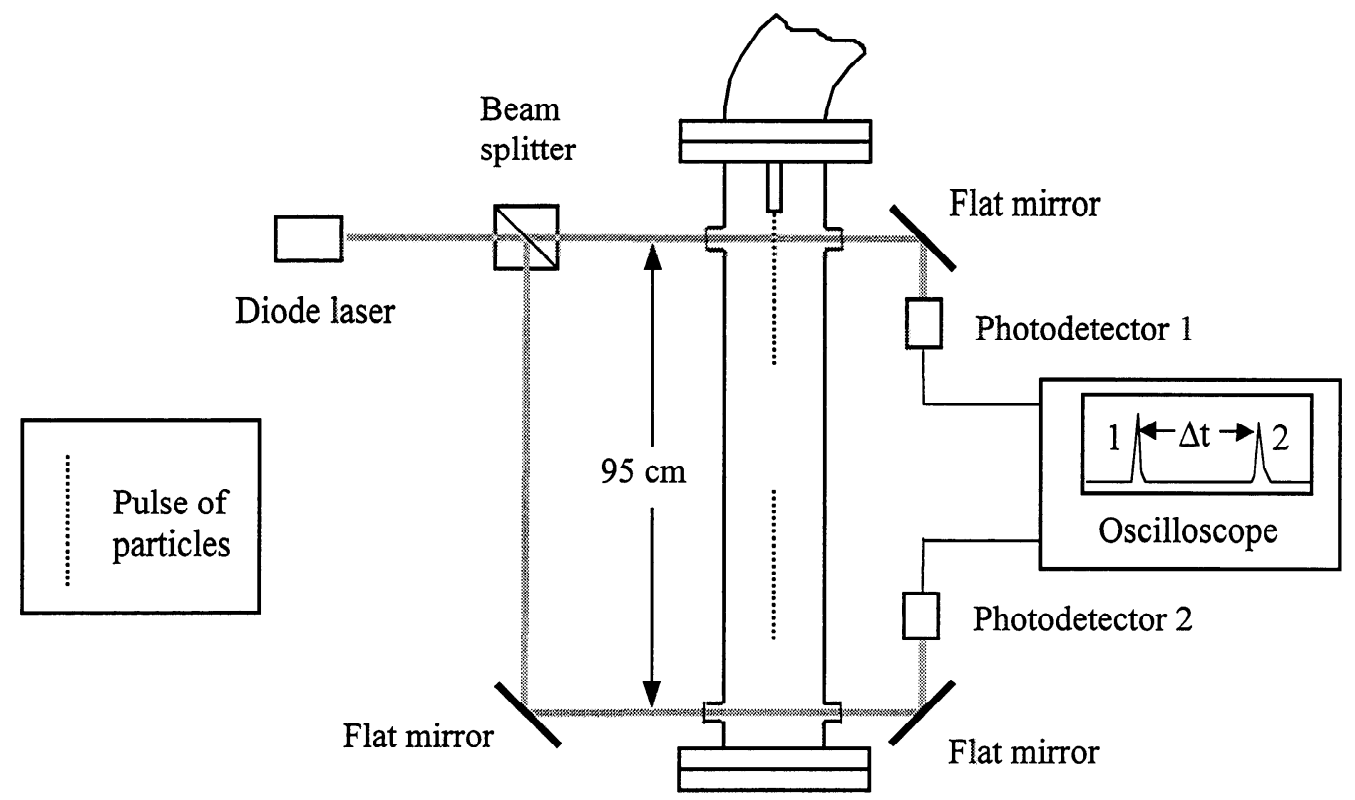

Figure 15. A schematic diagram of the diode laser system for measuring the residence time of a pulse of particles in the pyrolysis tube.

Two $9.5 \mathrm{~mm}$ diameter quartz glass optical ports were located opposite one another on the tube wall 1.3 and $95 \mathrm{~cm}$ after the particle injector exit. A laser beam generated by a diode laser (Thorlabs S1011) was passed through the optical ports in the path of the particle stream. Interceptions in the beam were detected by two high-speed photodetectors (Thorlabs DET100). 
The time difference between the interruptions was measured with an oscilloscope (Tektronix TDS 320). The graphite seals on the quartz glass windows often leaked when the reactor was hot, so the windows were replaced with metal caps during experiments in which pyrolytic conversion data were taken.

\section{[4.1.7] Acoustic Decoupler/Char Collector}

The acoustic decoupler/char collector section served as an open-end condition for reflection of the acoustic wave, and as a char particle and tar/fume collector. The decoupler was connected to the bottom of the vertical pyrolysis section by a bolted-flanged lid. A threedimensional schematic diagram of the acoustic decoupler/char collector is shown in Fig. 16. The char collection section was constructed from a $27 \mathrm{~cm}$ long, $21.8 \mathrm{~cm}$ O.D. (8" IPS schedule 5) pipe with a welded-plate bottom. $\mathrm{N}_{2}$ quench gas was introduced into the decoupler through a tube attached to the lateral face of the $21.8 \mathrm{~cm}$ O.D. decoupler pipe, $2 \mathrm{~cm}$ down from the flanged lid. Quench gas flowrates between $0-20$ slpm $\mathrm{N}_{2}$ were measured by a mass flow meter (TBE/Hastings Instruments HFM-201) with a full scale of 100 slpm. A type-K, shielded junction, $1.59 \mathrm{~mm}$ sheath diameter thermocouple (Omega) was used to measure the gas temperature near the quench gas injection point. Static operating $\mathrm{N}_{2}$ pressure, 0.014 bar above atmospheric, in the reactor was measured by an electronic pressure transducer (SETRA 280E) connected to the expansion chamber by a $30 \mathrm{~cm}$ long, $6.4 \mathrm{~mm}$ O.D. 304 stainless steel tube.

A $5 \mathrm{~cm}$ long, $16.8 \mathrm{~cm}$ O.D. (6" IPS schedule 5) pipe was attached to the lateral face of the $21 \mathrm{~cm}$ O.D. decoupler pipe to hold the tar and fume filter. Condensed tar and fume were removed from the pyrolysis gas stream by a $13 \mathrm{~cm}$ diameter glass-fiber filter (Whatman GF/A) with a $99 \%$ collection efficiency for particles $>0.3 \mu \mathrm{m}$ in diameter. The filter was held between a 
teflon ring bolted to a teflon gasket. The assembled teflon gasket was held between bolted flanges on the $16.8 \mathrm{~cm}$ O.D. pipe and its end cap section. Pyrolysis gas exited the reactor through a $2.13 \mathrm{~cm}$ O.D. (0.5" IPS schedule 40) pipe welded to the $16.8 \mathrm{~cm}$ O.D. end cap section.

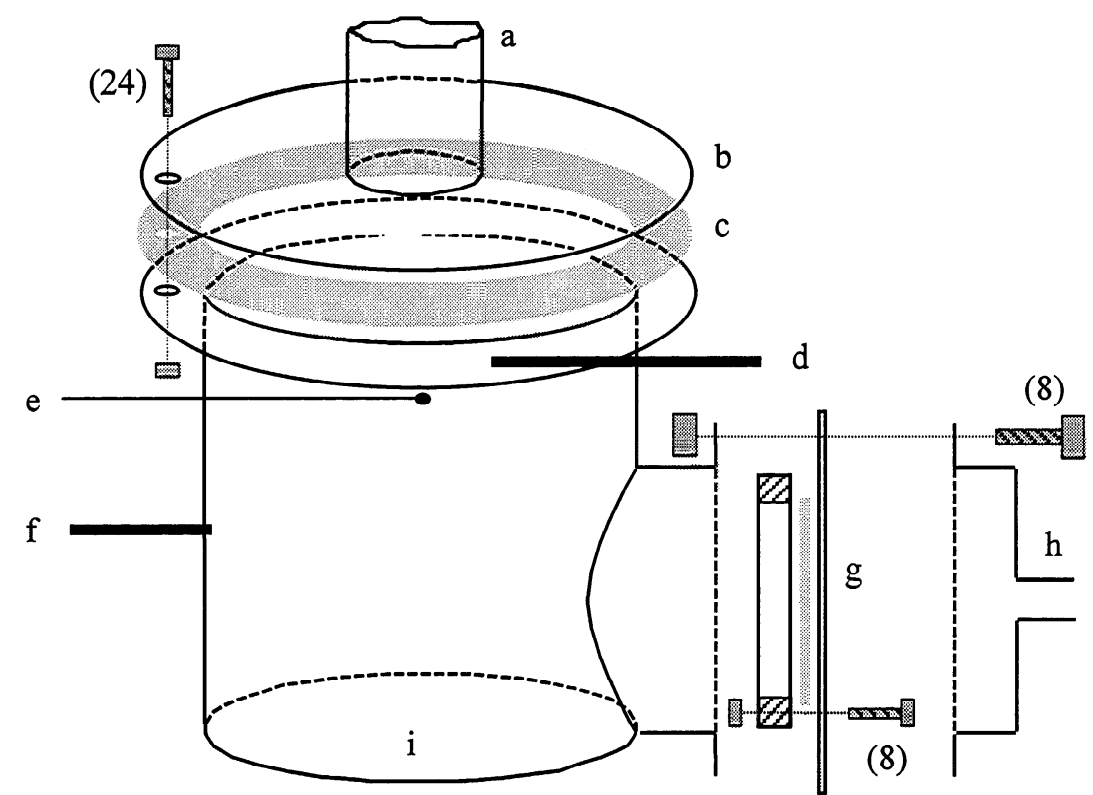

Figure 16. A schematic diagram of the acoustic decoupler/char collector. (a) pyroylsis tube, (b) expansion chamber lid, (c) flange gasket, (d) $\mathrm{N}_{2}$ quench, (e) thermocouple, (f) tube to static pressure transducer, (g) teflon flange seal and tar and fume filter, (h) product gas exhaust tube, and (i) char collection zone.

\section{[4.1.8] Pyrolysis Gas Analysis System}

A schematic of the pyrolysis gas analysis system is shown in Fig. 17. Pyrolysis gases were removed from the decoupler by pulling a vacuum using a custom-made pneumatic ejector, as described in Appendix 12. To maintain a nearly constant pressure in the reactor during an experiment, the compressed air to the ejector was adjusted to offset the pressure drop through the filter, which increases as tar builds up. Approximately $1.5 \mathrm{slpm}$ of the product gas stream leaving the acoustic decoupler was diverted to an in-line particulate filter and then to the gas 
analyzer. The sample gas flowrate was measured by a mass flowmeter (Teledyne Hastings NALtype) with a full scale of 10 slpm.

\section{Calibration gases}

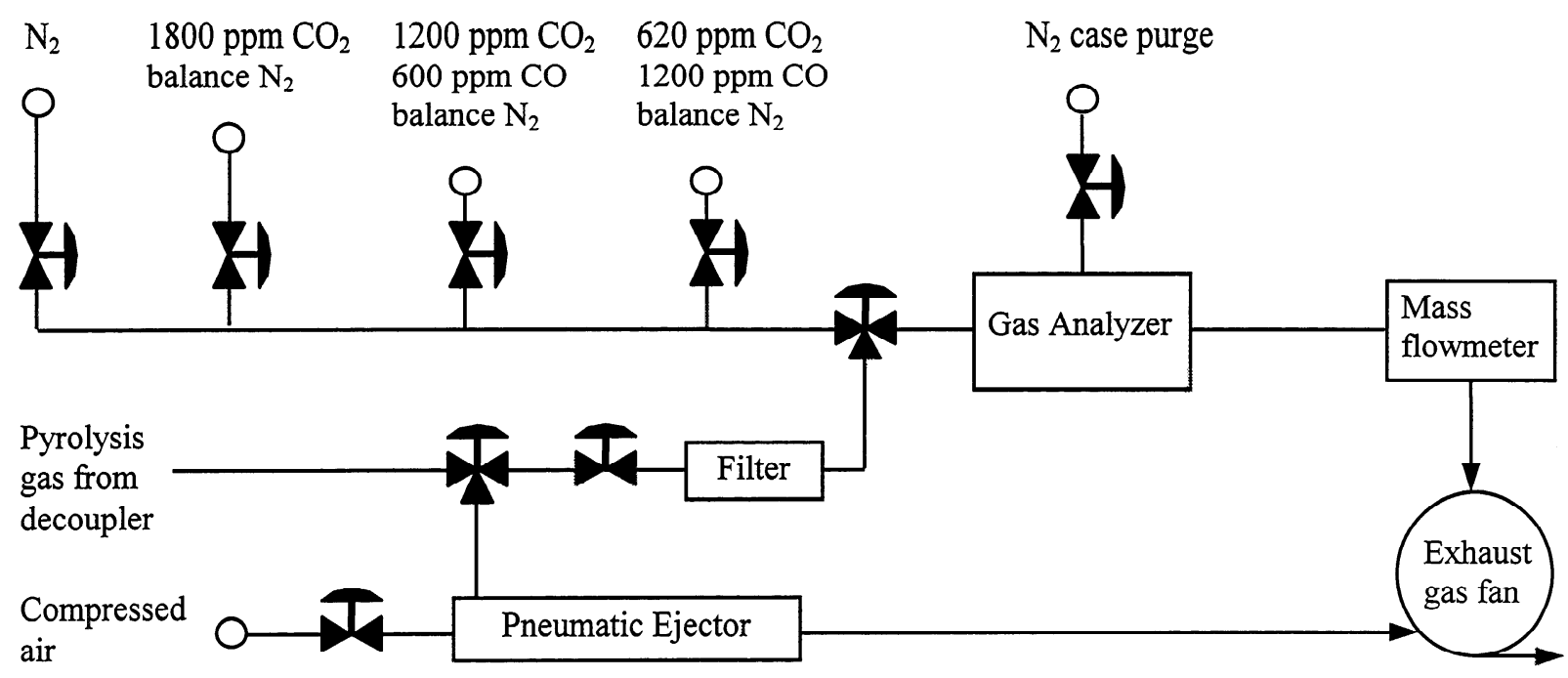

Figure 17. A schematic diagram of the pyrolysis gas analysis system.

A nondispersive, infrared-type, dual gas analyzer (Infrared Industries 702) was used to continuously monitor the concentration of $\mathrm{CO}$ and $\mathrm{CO}_{2}$ in the pyrolysis gas. The precision of the analyzer is $\pm 1 \%$ of full scale. The speed of response is $90 \%$ of full scale in $5 \mathrm{~s}$. Appendix 5 describes the calculation of the $\mathrm{CO}$ and $\mathrm{CO}_{2}$ yields. Commercial grade $\mathrm{N}_{2}$ (Air Products, Inc.) with $99.995 \%$ purity was fed to the reactor, used to calibrate the gas analyzer ( 0 ppm CO and $\mathrm{CO}_{2}$ ), and introduced into the case holding gas analyzer instrumentation. The inside of the gas analyzer case was purged with a flowrate of $10 \mathrm{slpm}$ of $\mathrm{N}_{2}$ to prevent inaccurate measurement of $\mathrm{CO}_{2}$, because of its relatively high concentration in the atmosphere $(\sim 330 \mathrm{ppm})$, with respect to the 0-2000 ppm range of the instrument. Three cylinders of gases with known concentration (Air Products ) were used for gas analyzer calibration: 1800 ppm $\mathrm{CO}_{2}$ in $\mathrm{N}_{2}, 1200 \mathrm{ppm} \mathrm{CO}$ and 619 ppm $\mathrm{CO}_{2}$ in $\mathrm{N}_{2}$, and 1200 ppm $\mathrm{CO}_{2}$ and 610 ppm $\mathrm{CO}$ in $\mathrm{N}_{2}$. 


\section{[4.1.9] Gas and Particle Flow Imaging System}

The pyrolysis tube was exchanged with a $60 \mathrm{~cm}$ long, $52 \mathrm{~mm}$ I.D. pyrex glass section to facilitate visualization of gas and particle flows. A schematic of the gas and particle flow imaging system is shown in Fig. 18. Flow imaging was conducted only for cold flow. The preheater was not operated. The velocity of inflight individual particles, immediately after their injection into the secondary flow, was measured by high speed video. A low speed, high resolution video camera was used to obtain more detailed images of inflight black liquor particles and smoke-particle laden gas flow in the pyrolysis tube which could not be obtained with the high-speed video camera. The particles were illuminated by a $6 \mathrm{~mm}$ thick laser sheet generated using a $4.5 \mathrm{~W}$ argon laser (Spectra-Physics). The cameras were positioned to image the illuminated particles in a backscatter mode at an approximate $60^{\circ}$ angle relative to the laser sheet.

The flight of individual particles from the injector exit to $23 \mathrm{~cm}$ down the pyrex tube were imaged by a high speed digital camera (Kodak EktraPro EM 1012 Motion Analyzer) at a 3000 frames/s in the split-frame mode. A time stamp on each frame allowed measurement of particle velocity as further described in the Gas and Particle Flow Analysis section. The analyzer system is comprised of an intensified imager, an intensified image controller, a processor, and a

video monitor. Images from the intensified imager were stored in the processor and played back to a 4-head video cassette recorder (Sharp) at a rate of 10,30 , or 120 images/s.

A VHS-format video camera (Panasonic CCTV) with higher resolution was used to image the flight of black liquor particles and smoke-particle laden gas flow patterns at 30 frames/s. Tobacco smoke was added to the gas, but not added into carrier gas. Mixing of the 
primary gas jet with the secondary air flow was easily imaged. The video was edited to obtain still snapshots, storable as a PCX format computer graphics file.

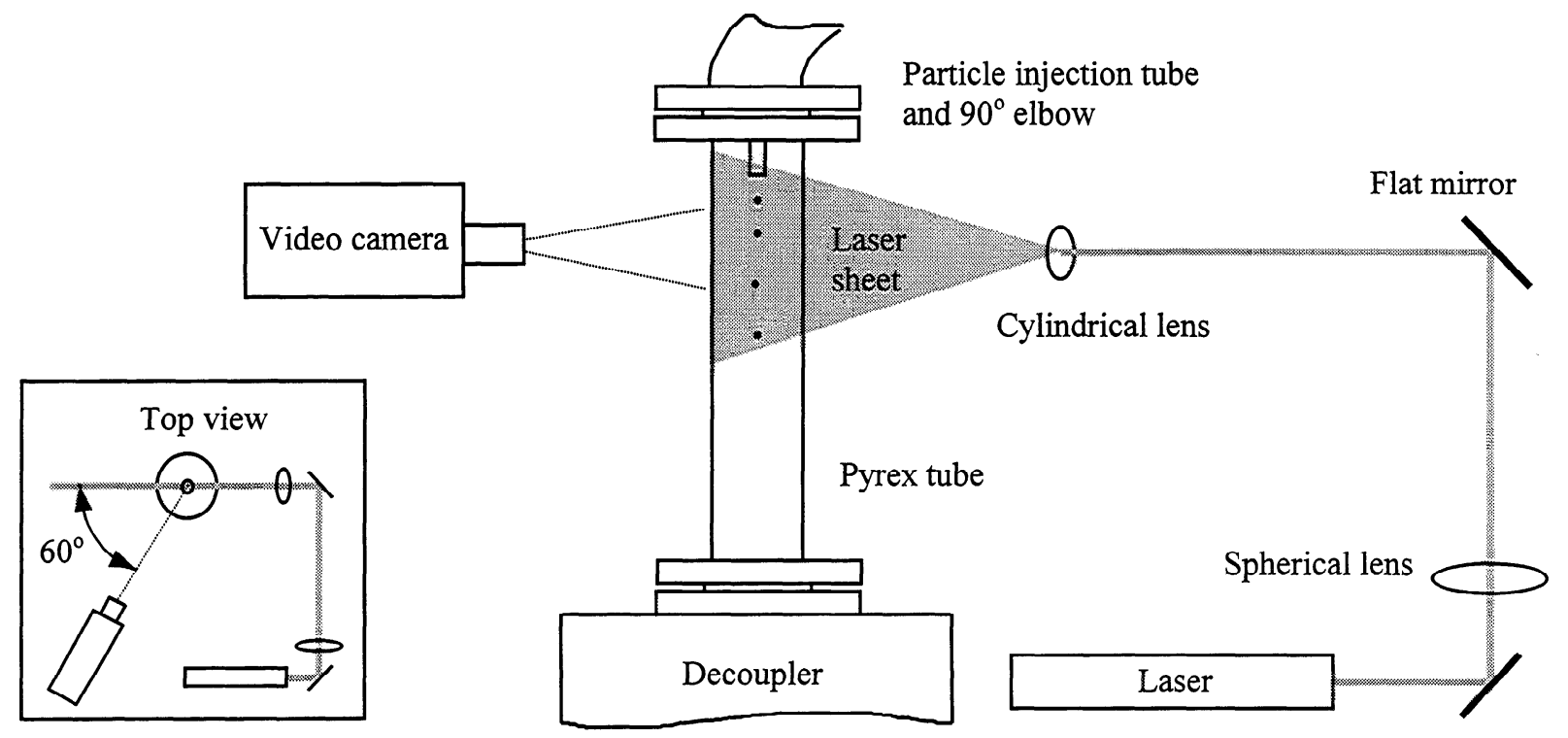

Figure 18. A schematic diagram of the gas and particle flow imaging system.

\section{[4.1.10] Data Acquisition System}

All thermocouple temperatures, gas flowrates, and static pressure measurements were monitored and recorded during the experiments on a 486 microcomputer (GIM DX-4 $100 \mathrm{MHz}$ ). Thermocouple signals were input to a 16 channel multiplexor/signal conditioning board (Computer Boards, Inc., CIO-EXP16) and acquired by an 8 input channel analog to digital (A/D) converter (Computer Boards, Inc., CIO-DAS08). The other 0-5 V signals from static pressure transducers, process controllers (pyrolysis tube wall temperature retransmit), mass flowmeters, and the gas analyzer were acquired in the same way by the computer. The $0-100 \mathrm{mV}$ gas analyzer signal was amplified to a $0-5 \mathrm{~V}$ signal before input to the data acquisition boards. Realtime measurements were displayed on a graphical display/interface, and stored on a hard-drive 
using a program written in Basic (Microsoft Quick BASIC), and the control software for the A/D converter (Computer Boards, Inc., Universal Library). The data were imported to a spreadsheet (Microsoft Excel) for calculation of total $\mathrm{CO}$ and $\mathrm{CO}_{2}$ produced during an experiment.

\section{[4.2] DESIGN OF PYROLYSIS EXPERIMENTS}

Experiments were designed to investigate the pyrolysis of inflight BLS particles in a highintensity acoustic field. Table 14 lists the experimental variables and the fixed parameters. Preliminary testing of the reactor led to development of the experimental plan listed in Table 15, in which pyrolytic product yield data were collected. Experimental difficulties of char sticking to the reactor walls at high sound pressure levels $>154 \mathrm{~dB}$ and time constraints prevented a complete factorial-experimental design to be undertaken. Pyrolytic product yield data were obtained with and without acoustics for different gas temperatures, pyrolysis tube heated lengths, and secondary gas space-times. Progress of secondary cracking reactions of tar was measured by varying the residence time of tar in the hot gas phase. Because tar is entrained in the secondary gas stream flowing through the pyrolysis tube, tar residence time can be varied using different pyrolysis tube heated lengths and flowrates of secondary gas, which can be expressed in terms of the gas space-time.

Char and fume morphology and tar chemical composition data were obtained to indicate physical and chemical effects of increased heat and mass transfer rates induced by acoustics. The locations in the pyrolysis tube at which tarry liquid and tar and $\mathrm{Na}_{2} \mathrm{CO}_{3}$ fume evolution occurred during experiments conducted with or without an acoustics were used to follow the progress of particle pyrolysis reactions. 
Three different particle flow configurations through the reactor were used to determine the effect of particle residence time in the pyrolysis tube, as described in Table 16. Steel-woolplug experiments were done to obtain primary $\mathrm{CO}$ and $\mathrm{CO}_{2}$ yields at long particle residence time. The steel-wool-plug retains the particles while allowing gases to flow through. The steel-woolplug thickness was approximately $1-2 \mathrm{~cm}$. Steel-wool-plug experiments were also conducted to obtain yields of secondary $\mathrm{CO}$ and $\mathrm{CO}_{2}$ produced by secondary cracking of tar at different tar residence times. Tar was released from the particles into the secondary gas flow at the steelwool-plug.

Mean residence time of particles in the $0.18 \mathrm{~m}$ pyrolysis tube length was quantitatively measured using the high-speed video particle imaging system, and particle residence time in the $0.81 \mathrm{~m}$ pyrolysis tube length was qualitatively measured using the diode laser system, as listed in Appendix 9. An empirical correlation was developed to predict the onset of particle levitation, and a numerical model of gas flow and particle motion was used to estimate the mean particle residence times in the pyrolysis tube under high temperature conditions used in pyrolysis experiments, as described in Appendix 10. 
Table 14. A list of experimental variables.

\begin{tabular}{|c|c|c|}
\hline Variable & Type & Description \\
\hline Char yield & Dependent & Expressed as wt $\%$ of BLS \\
\hline Char total carbon yield & Dependent & Expressed as wt $\%$ of BLS and percent of carbon in BLS \\
\hline Char carbonate carbon yield & Dependent & Expressed as wt $\%$ of BLS and percent of carbon in BLS \\
\hline Char organic carbon yield & Dependent & Expressed as wt\% of BLS and percent of carbon in BLS \\
\hline CO yield & Dependent & Expressed as wt $\%$ of BLS and percent of carbon in BLS \\
\hline $\mathrm{CO}_{2}$ yield & Dependent & Expressed as wt\% of BLS and percent of carbon in BLS \\
\hline Char morphology & Dependent & Swelling and structural changes \\
\hline Tar chemical composition & Dependent & Fourier transform infrared analysis of tar captured on glass-fiber filter \\
\hline $\begin{array}{l}\text { Fume morphology and } \\
\text { evolution }\end{array}$ & Dependent & Size of fume and time when released from the particle \\
\hline Acoustic amplitude & Independent & No acoustics to $160 \mathrm{~dB}$ \\
\hline Acoustic frequency & Independent & 310 to $950-1010 \mathrm{~Hz}$ \\
\hline $\begin{array}{l}\text { Preheated gas temperature in } \\
\text { pyrolysis tube }\end{array}$ & Independent & 400,550 , and $700^{\circ} \mathrm{C}$ \\
\hline $\begin{array}{l}\text { Heated length of pyrolysis } \\
\text { section at peak temperature }\end{array}$ & Independent & $\begin{array}{l}0.18,0.48 \text {, and } 0.81 \mathrm{~m} \text {; provides a pseudo residence time expressed in terms of an } \\
\text { arbitrary distance through which the particles fall }\end{array}$ \\
\hline $\begin{array}{l}\text { Preheated gas flowrate through } \\
\text { pyrolysis tube }\end{array}$ & Independent & $\begin{array}{l}5,10 \text {, and } 20 \text { slpm; corresponds to actual gas space-times between } 0.31-6.41 \mathrm{~s} \\
\text { which are also functions of gas temperature and pyrolysis tube heated length; the } \\
\text { actual gas space-time is the actual volume of } \mathrm{N}_{2} \text { gas fed to the reactor divided by } \\
\text { the volume of the heat pyrolysis tube }\end{array}$ \\
\hline Pyrolysis gas & $\begin{array}{l}\text { Fixed } \\
\text { parameter }\end{array}$ & $\mathrm{N}_{2}$ \\
\hline Soda-AQ black liquor & $\begin{array}{l}\text { Fixed } \\
\text { parameter }\end{array}$ & Dry $106-125 \mu \mathrm{m}$ diameter particles \\
\hline $\begin{array}{l}\text { Steady-state feedrate of } \\
\text { particles and gases to reactor }\end{array}$ & $\begin{array}{l}\text { Fixed } \\
\text { parameter }\end{array}$ & 1.2-5 g particles fed during an experiment; typical feeding time about $6 \mathrm{~min}$ \\
\hline $\begin{array}{l}\text { Pyrolysis tube interior wall } \\
\text { temperatures }\end{array}$ & $\begin{array}{l}\text { Fixed } \\
\text { parameter }\end{array}$ & Not to exceed the preheated gas temperature by more than $20^{\circ} \mathrm{C}$ \\
\hline
\end{tabular}



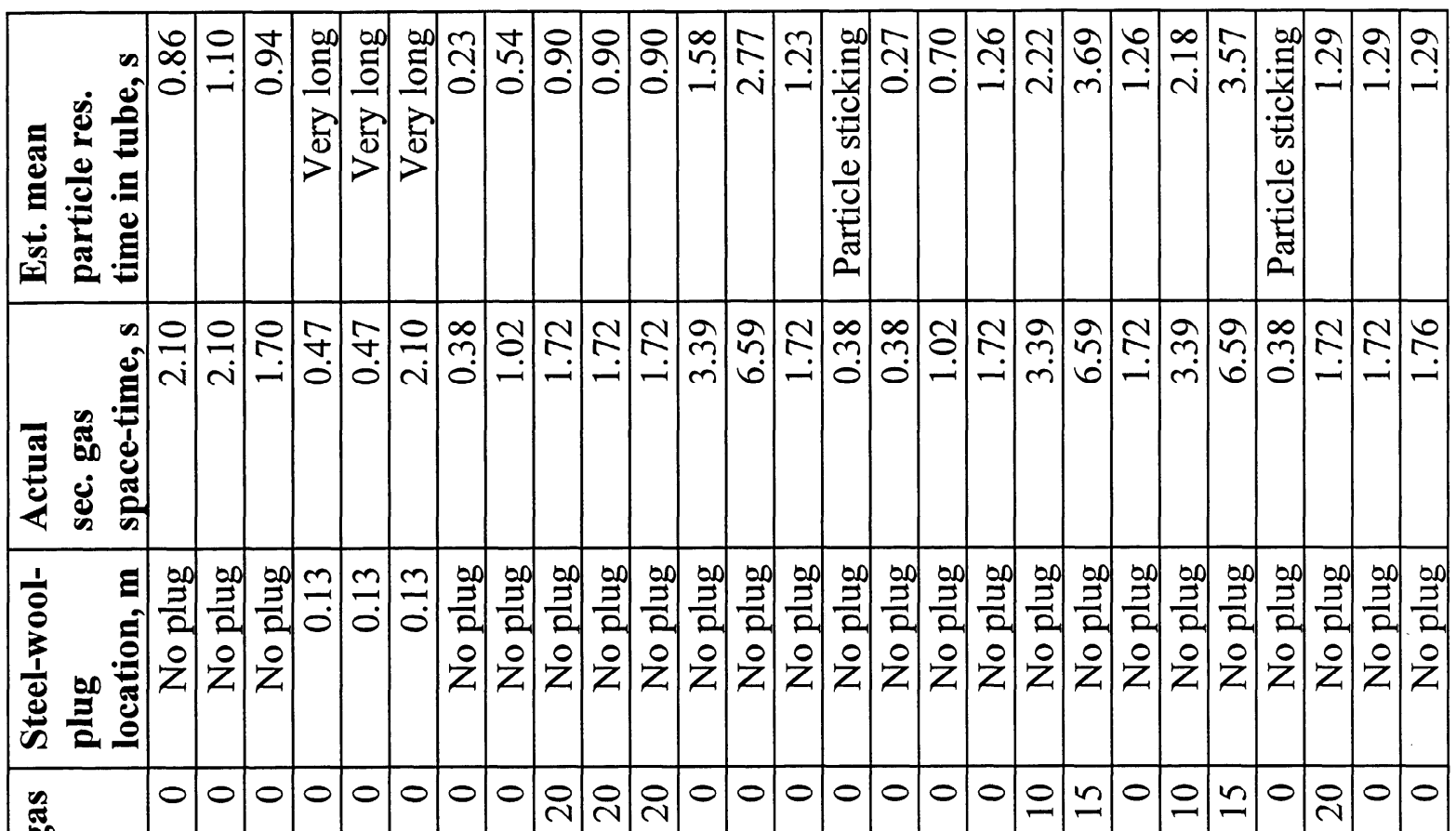

0
0
0
0
0
0
0
0
0
0
0
0
0
0
0
0
0
0
0
0
0
0
0
0
0
0
0
0
0
0
0
4
0
0
01
0

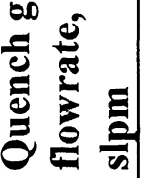

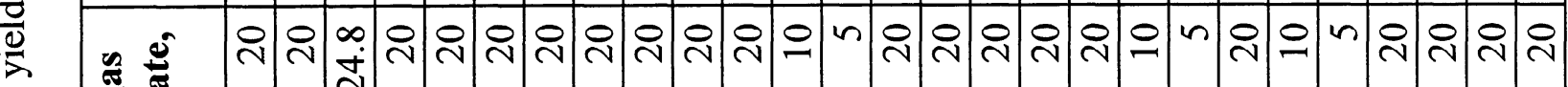

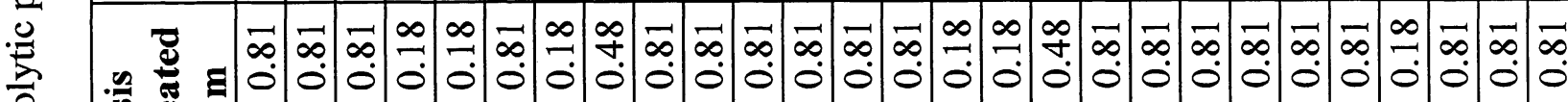

$\overrightarrow{7}$ 를 일 일

. 는

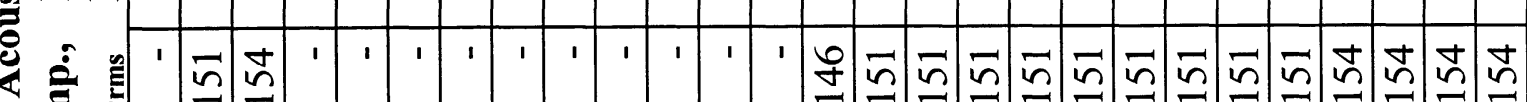

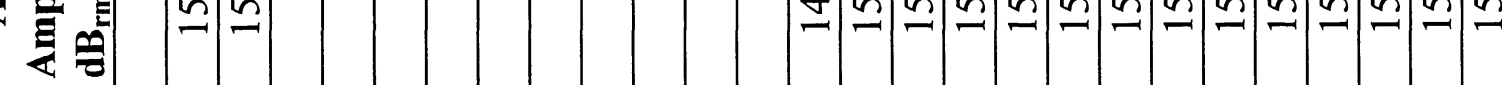

$\frac{1}{2}$

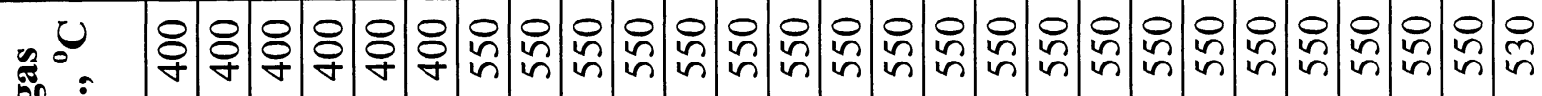
( อ

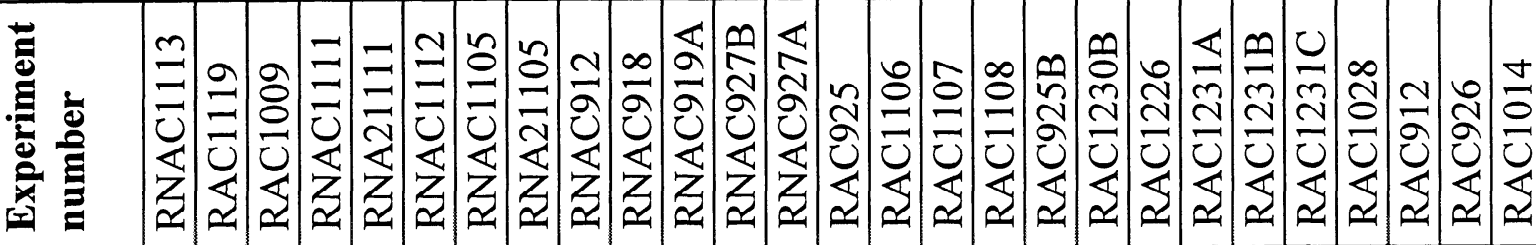


Table 15 (Continued). List of experiments to collect BLS pyrolytic product yield data.

\begin{tabular}{|c|c|c|c|c|c|c|c|c|c|}
\hline $\begin{array}{l}\text { Experiment } \\
\text { Number }\end{array}$ & $\begin{array}{l}\text { Sec. gas } \\
\text { temp., }{ }^{\circ} \mathrm{C}\end{array}$ & $\begin{array}{r}\text { Aco } \\
\text { Amp., } \\
\text { dB } \\
\end{array}$ & $\begin{array}{l}\text { ustic } \\
\text { Freq.9 } \\
\mathrm{Hz}\end{array}$ & $\begin{array}{l}\text { Pyrolysis } \\
\text { tube heated } \\
\text { length, } \mathbf{m} \\
\end{array}$ & $\begin{array}{l}\text { Sec. gas } \\
\text { flowrate, } \\
\text { slpm } \\
\end{array}$ & $\begin{array}{l}\text { Quench gas } \\
\text { flowrate, } \\
\text { Slpm } \\
\end{array}$ & $\begin{array}{l}\text { Steel-wool- } \\
\text { plug } \\
\text { location, m }\end{array}$ & $\begin{array}{l}\text { Actual } \\
\text { sec. gas } \\
\text { space-time, } \mathrm{s} \\
\end{array}$ & $\begin{array}{l}\text { Est. mean } \\
\text { particle res. } \\
\text { time in tube, } \mathbf{s}\end{array}$ \\
\hline RAC930 & 550 & 154 & 990 & 0.81 & 10 & 0 & No plug & 3.39 & 2.27 \\
\hline RAC1227A & 550 & 154 & 960 & 0.81 & 5 & 15 & No plug & 6.59 & 3.88 \\
\hline RAC1207 & 550 & 159 & 970 & 0.81 & 20 & 0 & No plug & 1.72 & At least 1.37 \\
\hline RAC1227B & 550 & 160 & 970 & 0.81 & 10 & 10 & No plug & 3.39 & At least 3.91 \\
\hline RAC1230 & 550 & 158 & 970 & 0.81 & 10 & 10 & No plug & 3.39 & At least 3.91 \\
\hline RAC1224 & 550 & 158 & 970 & 0.81 & 5 & 15 & No plug & 6.59 & Very long \\
\hline RNAC1017 & 550 & - & - & 0.18 & 20 & 0 & 0.13 & 0.38 & Very long \\
\hline RNAC1022 & 550 & - & - & 0.18 & 10 & 0 & 0.13 & 0.75 & Very long \\
\hline RNAC1023 & 550 & - & - & 0.81 & 20 & 0 & 0.13 & 1.72 & Very long \\
\hline RNAC1019 & 550 & - & - & 0.81 & 10 & 0 & 0.13 & 3.39 & Very long \\
\hline RNAC1024 & 550 & - & - & 0.81 & 10 & 0 & 0.13 & 3.39 & Very long \\
\hline RNAC1226 & 550 & - & - & 0.81 & 5 & 15 & 0.13 & 6.59 & Very long \\
\hline RNAC923 & 550 & - & - & 0.81 & 20 & 0 & 0.75 & 1.72 & Very long \\
\hline RAC1206 & 550 & 151 & 960 & 0.81 & 10 & 0 & 0.75 & 3.39 & Very long \\
\hline RNAC1123 & 700 & - & - & 0.18 & 20 & 0 & No plug & 0.32 & 0.21 \\
\hline RNAC1127 & 700 & - & - & 0.48 & 20 & 0 & No plug & 0.86 & 0.49 \\
\hline RNAC1122 & 700 & - & - & 0.81 & 20 & 10 & No plug & 1.46 & 0.82 \\
\hline RAC1126A & 700 & 151 & 960 & 0.18 & 20 & 0 & No plug & 0.32 & 0.25 \\
\hline RAC1127 & 700 & 151 & 990 & 0.48 & 20 & 0 & No plug & 0.86 & 0.64 \\
\hline RAC1130 & 700 & 151 & 990 & 0.48 & 20 & 0 & No plug & 0.86 & 0.64 \\
\hline RAC1126B & 700 & 151 & 950 & 0.81 & 20 & 10 & No plug & 1.46 & 1.15 \\
\hline RAC1130B & 700 & 151 & 950 & 0.81 & 20 & 0 & No plug & 1.46 & 1.15 \\
\hline RAC1130C & 700 & 160 & 950 & 0.81 & 20 & 0 & No plug & 1.46 & Very long \\
\hline RAC1205 & 700 & 160 & 950 & 0.81 & 10 & 10 & No plug & 2.87 & Very long \\
\hline RNAC1124 & 700 & - & - & 0.18 & 20 & 0 & 0.13 & 0.32 & Very long \\
\hline RNAC1125 & 700 & - & - & 0.81 & 20 & 10 & 0.13 & 1.46 & Very long \\
\hline RNAC1204 & 700 & - & - & 0.81 & 20 & 0 & 0.75 & 1.46 & Very long \\
\hline
\end{tabular}


Table 16. Particle flow configurations through the reactor with a steel-wool plug.

\begin{tabular}{|l|l|}
\hline Configuration & Description \\
\hline $\begin{array}{l}\text { Steel-wool porous plug located } 0.13 \mathrm{~m} \text { from the particle injector; } \\
\text { pyrolysis tube not heated } 0.05 \mathrm{~m} \text { downstream of the plug. }\end{array}$ & $\begin{array}{l}\text { Provides an infinite particle residence after the particle has been } \\
\text { heated while falling through } 16 \% \text { of the pyrolysis tube. }\end{array}$ \\
\hline $\begin{array}{l}\text { Steel-wool porous plug located } 0.13 \mathrm{~m} \text { from the particle injector; } \\
\text { pyrolysis tube heated over its entire } 0.81 \mathrm{~m} \text { length. }\end{array}$ & $\begin{array}{l}\text { Provides an infinite particle residence after the particle has been } \\
\text { heated while falling through } 16 \% \text { of the pyrolysis tube and an } \\
\text { extended gas residence time for conversion of tar to gases. }\end{array}$ \\
\hline $\begin{array}{l}\text { Steel-wool porous plug located } 0.75 \mathrm{~m} \text { from the particle injector; } \\
\text { pyrolysis tube heated over its entire } 0.81 \mathrm{~m} \text { length. }\end{array}$ & $\begin{array}{l}\text { Provides an infinite particle residence after the particle has been } \\
\text { heated while falling through 93\% of the heated pyrolysis tube. } \\
\text { Can be used to determine how much more gas can be generated } \\
\text { from the particle beyond that produced in the inflight heating } \\
\text { period. }\end{array}$ \\
\hline
\end{tabular}




\section{[4.3] REACTOR OPERATING PROCEDURE}

(1) Prepare black liquor particles as described in Appendix 3.

(2) Load particle feeder vial with BLS particles. Before preheating the reactor, the particle feeder was loaded with particles, reassembled, and reconfigured for feeding. The particle feeder vial was held inside the oven and filled with $2.5 \mathrm{~g}$ of BLS particles in 15-20 $\mathrm{s}$. The vial was then sealed with a rubber stopper on the particle off-take end and capped with a rubber plug on the bottom carrier gas inlet. The sealed feed vial was weighed to $\pm 0.005 \mathrm{~g}$.

(3) Install particle feeder vial onto reactor. The off-take tube valve on the particle feeder was closed prior to installation of the feeder vial. The rubber stopper and plug were quickly removed from the feeder vial, and then the vial was immediately inserted into the upper section of the particle feeder. About 30 min before feeding, the off-take tube valve was opened, and then $\mathrm{N}_{2}(0.5 \mathrm{slpm})$ was fed through the particle feeding system to purge the vial and gas lines of air. According to preliminary experiments, particles did not escape during air purging as long as the bed of particles was kept at least $1 \mathrm{~cm}$ below the off-take cone. The weight of the full particle feeder measured before and after air purging was the same. A piece of white sticky tape was placed near the open off-take tube valve as another check for escaping particles. No particles were found on the tape.

(4) Wash, dry, and reassemble reactor. The particle feed line and injector, pyrolysis tube, and acoustic decoupler were washed with water and then dried with compressed air and a heat gun several hours prior to preheating the reactor. To dry the pyrolysis tube, compressed air was introduced into the gas preheater and the heating sections were turned on. The reactor 
components, which included a new glass-fiber filter, were reassembled after drying, and the reactor was tested for gas leakage $\left(<0.2\right.$ slpm considered acceptable) at a $\mathrm{N}_{2}$ pressure of 0.0174 bar above atmospheric pressure.

(5) Preheat reactor. The assembled reactor was heated up to the setpoint temperature in increments of $100^{\circ} \mathrm{C}$ by ramping each of the five heating sections to the same intermediate temperature. The temperature was not raised again until all of the sections attained the intermediate temperature. The heat up procedure took 2-4 hours, depending on the peak temperature.

(6) Turn on instrumentation and allow to warm up. About 45-60 min into the reactor preheating period, the gas analyzer and other electronic instrumentation were turned on and allowed to warm up. Flowrates of $\mathrm{N}_{2}$ zero gas and analyzer case purge gas were adjusted to 1.5 and 10 slpm, respectively. The analyzer needed to operate for about 1.5 hours before it gave stable readings with the calibration gases.

(7) Calibrate gas analyzer. About 40 min prior to particle feeding, the analyzer was calibrated using the three certified gases containing $\mathrm{CO}$ and $\mathrm{CO}_{2}$ in $\mathrm{N}_{2}$. Just prior to particle feeding, the calibration was rechecked with the $1200 \mathrm{ppm} \mathrm{CO}$ and $619 \mathrm{ppm} \mathrm{CO}_{2}$ in certified $\mathrm{N}_{2}$. The gas sampling valve was switched to allow pyrolysis gas to flow through the analyzer. An inline needle valve was adjusted to give a flowrate of 1.3-1.6 slpm.

(8) Purge reactor tube of oxygen. When the reactor was preheated within $50^{\circ} \mathrm{C}$ of the peak temperature, $\mathrm{N}_{2}$ was introduced into the hot gas preheater. $20-30$ slpm of $\mathrm{N}_{2}$ was passed through the reactor at 0.0174 bar above atmospheric pressure for at least 30 minutes prior to 
particle feeding. The $\mathrm{CO}_{2}$ level declined from approximately $350 \mathrm{ppm}$ in the air to zero within 3-5 min. Oxygen in the air was assumed to be purged from the reactor at the same rate as $\mathrm{CO}_{2}$.

(9) Adjust $\mathrm{N}_{2}$ flowrates and turn on acoustic field. About 15 minutes into the air purging period, all of the $\mathrm{N}_{2}$ gas flowrates were adjusted to their respective setpoints, and the ejector vacuum was adjusted to achieve the specified reactor pressure. The acoustic wave was turned on, and the amplitude and frequency were set to their approximate values, as indicated by their dial settings on the amplifier and wave generator. The frequency was adjusted to achieve resonance by listening for the highest intensity of the sound emitted from the reactor tubes.

(10) Measure centerline gas temperatures in pyrolysis tube. Once the $\mathrm{N}_{2}$ flowrates had been adjusted to achieve their specified values at the desired reactor pressure, the centerline gas temperatures in the first heating section were measured and then compared with the pyrolysis tube wall thermocouples. Minor adjustments to the heating section setpoint temperatures were made if necessary and the centerline temperatures were rechecked and recorded.

(11) Verify resonance of acoustic field in the reactor tube. To verify whether or not resonance had been achieved in the pyrolysis tube, the sound pressure probe was inserted into the pyrolysis tube at a known distance of 20-30 cm downstream of the particle injection point. The result was quickly recorded by the oscilloscope, and then the probe was withdrawn into its insertion tube on the $90^{\circ}$ elbow section. The probe was only kept in the pyrolysis tube for less than $15-20 \mathrm{~s}$ to minimize cooling of the preheated gas temperature. Once the 
location of maximum sound pressure level was determined, the frequency and the amplitude of the sound were readjusted to achieve resonance by either extending or retracting the trombone tube, or by adjusting the dial settings on the amplifier and wave generator. The above procedures were repeated until resonance was achieved in the pyrolysis section.

(12) Measure the sound pressure profile in the pyrolysis tube. After resonance was achieved, the sound pressure levels were recorded for various distances into the pyrolysis tube. The sound pressure probe was withdrawn from the pyrolysis tube into the insertion tube so that its tip was flush with the $90^{\circ}$ elbow, inside wall. The sound pressure level was recorded, and the frequency was adjusted up to $\pm 5 \mathrm{~Hz}$ during the particle feeding period, if necessary to maintain resonance. Occasional sticking of char particles to the pyrolysis tube wall during runs at high sound pressure levels $(>154 \mathrm{~dB})$ sometimes caused resonance frequency to shift slightly. Profiles of the measured acoustic pressure and calculated acoustic velocity in the pyrolysis tube are shown in Appendix 8.

(13) Set data acquisition program to record data and start particle feeding. The data acquisition program was switched from monitor to record mode immediately before feeding particles. The particle feed vial was raised to bring the bed of particles near the off-take tube. The screwjack motor speed dial position was set to feed the specified mass flowrate. During experiments, the ejector pressure was adjusted occasionally to maintain a steady reactor pressure, and the needle valve on the pyrolysis gas sampling line was adjusted to maintain the specified flowrate of pyrolysis gas through the gas analyzer. Tar accumulation on the glass fiber filter increased its pressure drop, requiring adjustment of the down stream valve 
settings to ensure a steady, unchanging flowrate of preheated gas to the reactor. Particles were fed to the reactor for at least $190 \mathrm{~s}$, typically about $300 \mathrm{~s}$.

(14) Stop particle feeding and configure reactor for shut down. At the end of the feeding period, the bed of particles was lowered from the off-take cone by reversing the screwjack motor direction. The off-take tube valve was closed, and the carrier gas flow was stopped. The particle feeder vial was removed, immediately sealed with the rubber plug and stopper, and later weighed to determine the mass of particles fed. All of the heating sections were shut off immediately. $\mathrm{N}_{2}$ flowrate was not decreased until $\mathrm{CO}_{2}$ concentration declined to nearly zero, which took approximately 1-4 $\mathrm{min} . \mathrm{N}_{2}$ flowrate was reduced to 5 slpm while the acoustic decoupler was cooling down.

(15) Recheck gas analyzer calibration. The gas sampling valve was switched to allow zero gas to flow through the instrument, and then gas analyzer calibration was rechecked using the certified gas mixtures. Analyzer span or zero baseline never drifted more than $20 \mathrm{ppm}$ for both of the gas analyzer channels. Data acquisition was stopped after rechecking the gas analyzer calibration.

(16) Disassemble decoupler and remove char. When the gas temperature in the acoustic decoupler dropped to approximately $60-70^{\circ} \mathrm{C}, \mathrm{N}_{2}$ flow through the reactor was turned off. The decoupler was disassembled, and char was transferred to $250 \mathrm{~mL}$ glass jars, sealed, weighed, and chemically and physically analyzed as further described in Appendix 4 . The glass-fiber filters were removed, placed in sealed plastic bags, and chemically and physically analyzed as further described in Appendix 6. An experiment with an acoustic field could usually be completed within 4.5-6 hours, excluding cleaning time. 


\section{[5] RESULTS AND DISCUSSION}

At gas temperatures between $400-700^{\circ} \mathrm{C}$, char, tarry liquids and vapors, tar and $\mathrm{Na}_{2} \mathrm{CO}_{3}$ fume, $\mathrm{CO}$, and $\mathrm{CO}_{2}$ were generated at various stages of inflight $\mathrm{BLS}$ particle pyrolysis in the acoustic reactor as shown in Fig. 19. The processes that occurred in the reactor corresponded to those of the general mechanism of biomass pyrolysis as shown in Fig. 2.

Particle swelling

- Release of primary $\mathrm{CO}$ and $\mathrm{CO}_{2}$

- Release of tarry liquids and vapors

- Release of tar fume $\left(700^{\circ} \mathrm{C}, \mathrm{No} \mathrm{Ac}\right)$

- $\mathrm{Na}_{2} \mathrm{CO}_{3}$ fume $\left(700^{\circ} \mathrm{C}, 151 \mathrm{~dB}\right)$

- Secondary cracking of tarry liquids and vapors in hot secondary gas stream to produce secondary $\mathrm{CO}_{2}\left(\geq 550^{\circ} \mathrm{C}\right)$

- Release of tar fume $\left(\geq 550^{\circ} \mathrm{C}, 151 \mathrm{~dB}\right)$

- Release of $\mathrm{Na}_{2} \mathrm{CO}_{3}$ fume $\left(700^{\circ} \mathrm{C}\right.$, No $\left.\mathrm{Ac}\right)$

- Release of tar fume $\left(550^{\circ} \mathrm{C}\right.$, No $\left.\mathrm{Ac}\right)$

- Secondary cracking of particle phase to produce $\mathrm{CO}\left(\geq 550^{\circ} \mathrm{C}, \geq 151 \mathrm{~dB}\right)$

$\begin{aligned} & \text { Tarry liquids or vapor } \\ \because & \text { Tar fume } \\ & \mathrm{Na}_{2} \mathrm{CO}_{3} \text { fume }\end{aligned}$

Particle
tube
c)
dB)

Figure 19. A schematic diagram of pyrolytic processes occurring in the acoustic reactor. 
Fig. 19 shows at all gas temperatures studied, tarry liquids and vapors were released from the pyrolyzing BLS particles within the $0.18 \mathrm{~m}$ heated length, and primary $\mathrm{CO}$ and $\mathrm{CO}_{2}$ were released from the pyrolyzing BLS particles within the $0.18-0.81 \mathrm{~m}$ heated length. At a gas temperature of $550^{\circ} \mathrm{C}$, secondary $\mathrm{CO}$ was released by secondary particle pyrolysis within the 0.48-0.81 m heated length with acoustics. At a gas temperature of $700^{\circ} \mathrm{C}$, secondary $\mathrm{CO}$ was released within the $0.18-0.81 \mathrm{~m}$ heated length by secondary particle pyrolysis and by secondary cracking of tars in the secondary gas. At a gas temperature of $400^{\circ} \mathrm{C}$, secondary $\mathrm{CO}$ and $\mathrm{CO}_{2}$ were not released by secondary cracking of tarry liquids and vapors in the hot secondary gas stream. At a gas temperature of $550^{\circ} \mathrm{C}$, secondary $\mathrm{CO}_{2}$ was released within the $0.18-0.81 \mathrm{~m}$ heated length by secondary cracking of tarry liquids and vapors in the hot secondary gas stream. At a gas temperature of $700^{\circ} \mathrm{C}$, secondary $\mathrm{CO}_{2}$ was released over the entire heated length by secondary cracking of tarry liquids and vapors in the hot secondary gas stream. At a gas temperature of $550^{\circ} \mathrm{C}$, tar fume were released from BLS particles within the $0.18-0.48$ and 0.48 $0.81 \mathrm{~m}$ heated lengths with and without acoustics, respectively. At a gas temperature of $700^{\circ} \mathrm{C}$, tar fume were released from BLS particles within the 0.18 and $0.18-0.48 \mathrm{~m}$ heated lengths with and without acoustics, respectively. At a temperature of $700^{\circ} \mathrm{C}, \mathrm{Na}_{2} \mathrm{CO}_{3}$ fume were released from the particles pyrolyzed within the 0.18 and $0.48-0.81$ m heated lengths with and without acoustics, respectively. At a temperature of $550^{\circ} \mathrm{C}$, detectable amounts of $\mathrm{Na}_{2} \mathrm{CO}_{3}$ fume were not released from the particles except at a very long particle residence time obtained by using a steel-wool-plug with acoustics.

The remainder of this section will present and discuss the results of pyrolysis studies encompassing quantification of char yield and chemical composition, SEM imaging of char particles and material collected on glass-fiber filters, FT-IR identification of material collected 
on glass-fiber filters, and quantification of primary and secondary $\mathrm{CO}$ and $\mathrm{CO}_{2}$ yields, and gas particle flow characterization studies encompassing quantification of mean particle residence times and mixing of the particle carrier gas jet and secondary stream.

\section{[5.1] RESULTS OF PYROLYSIS EXPERIMENTS}

\section{[5.1.1] Analysis of Pyrolysis Products}

Quantification of gas and char yields and the percent of the carbon in BLS as total, carbonate, and organic carbon in the char has significant importance in understanding the pyrolysis mechanism of BLS particles.

Char yield and the percent of the carbon in BLS as carbon in the char were used to determine the extent of BLS particle pyrolysis reactions. Char yields are expressed as the weight percent (wt\%) of BLS fed to the reactor. The $95 \%$ confidence level of the char yield, which was based on three triplicate experiments, spanned \pm 2.75 weight percentage points about the mean, as calculated in Appendix 4. For selected chars, total carbon and carbonate carbon in the char were measured by Huffman Laboratories. Organic carbon was calculated from the difference of total carbon and carbonate carbon. Total carbon in all the chars were measured in triplicates or quadruplicates, except for two chars in which the analysis was only duplicated. The $95 \%$ confidence level of the percent of the carbon in BLS as total and organic carbon in the char are calculated in Appendix 4. Only single measurement of carbonate carbon in the char was made. The $95 \%$ confidence level of the percent of the carbon in BLS as carbonate carbon in the char was \pm 0.2 weight percentage points, as reported by Huffman Laboratories. 
Unfortunately, the temperature of the pyrolyzing particles could not be measured using infrared techniques during the heatup period because particle temperatures must be greater than $570^{\circ} \mathrm{C}$. Therefore, SEM imaging of char particles was performed to seek evidence of increased particle heatup rate and greater severity of pyrolysis, e.g., greater swelling, increased surface bubble formation, and particle breakup, with the application of an acoustic field. SEM imaging of material captured on the glass-fiber filters was performed to determine the physical nature of condensable vapor material released from pyrolyzing particles. FT-IR spectroscopy of material captured on the glass-fiber filter were conducted to study changes in chemical functional groups. Sample analysis techniques are described in Appendix 6.

$\mathrm{CO}$ and $\mathrm{CO}_{2}$ yields were obtained through integration of the time-dependent concentrations of $\mathrm{CO}$ and $\mathrm{CO}_{2}$ measured using infrared instrumentation. $95 \%$ confidence level of the $\mathrm{CO}$ and $\mathrm{CO}_{2}$ yields are calculated in Appendix 5.

\section{[5.1.2] Char Analysis}

\section{[5.1.2.1] Char Yields from Inflight Particle Pyrolysis Experiments}

Char yields obtained from non-sticking, inflight particles with and without an acoustic field of $146-154 \mathrm{~dB}$ and $310-1000 \mathrm{~Hz}$ at a gas temperature of $550^{\circ} \mathrm{C}$ are shown in Fig. 20. Char yields obtained from non-sticking, inflight particles with and without an acoustic field of $151 \mathrm{~dB}$ and $950-990 \mathrm{~Hz}$ at gas temperatures of 400 and $700^{\circ} \mathrm{C}$ are shown in Fig. 21. These experiments are termed non-sticking because none or very few BLS particles stuck to the pyrolysis tube wall during the run. Many particles stuck to the pyrolysis tube wall in experiments conducted at sound pressure levels $\geq 158 \mathrm{~dB}$. Mean residence times of non-sticking, inflight particles in the 
pyrolysis tube were calculated using the model presented in Appendix 10. Char yields are listed in Table A4.4 in Appendix 4 and detailed experimental conditions are listed in Table 16.

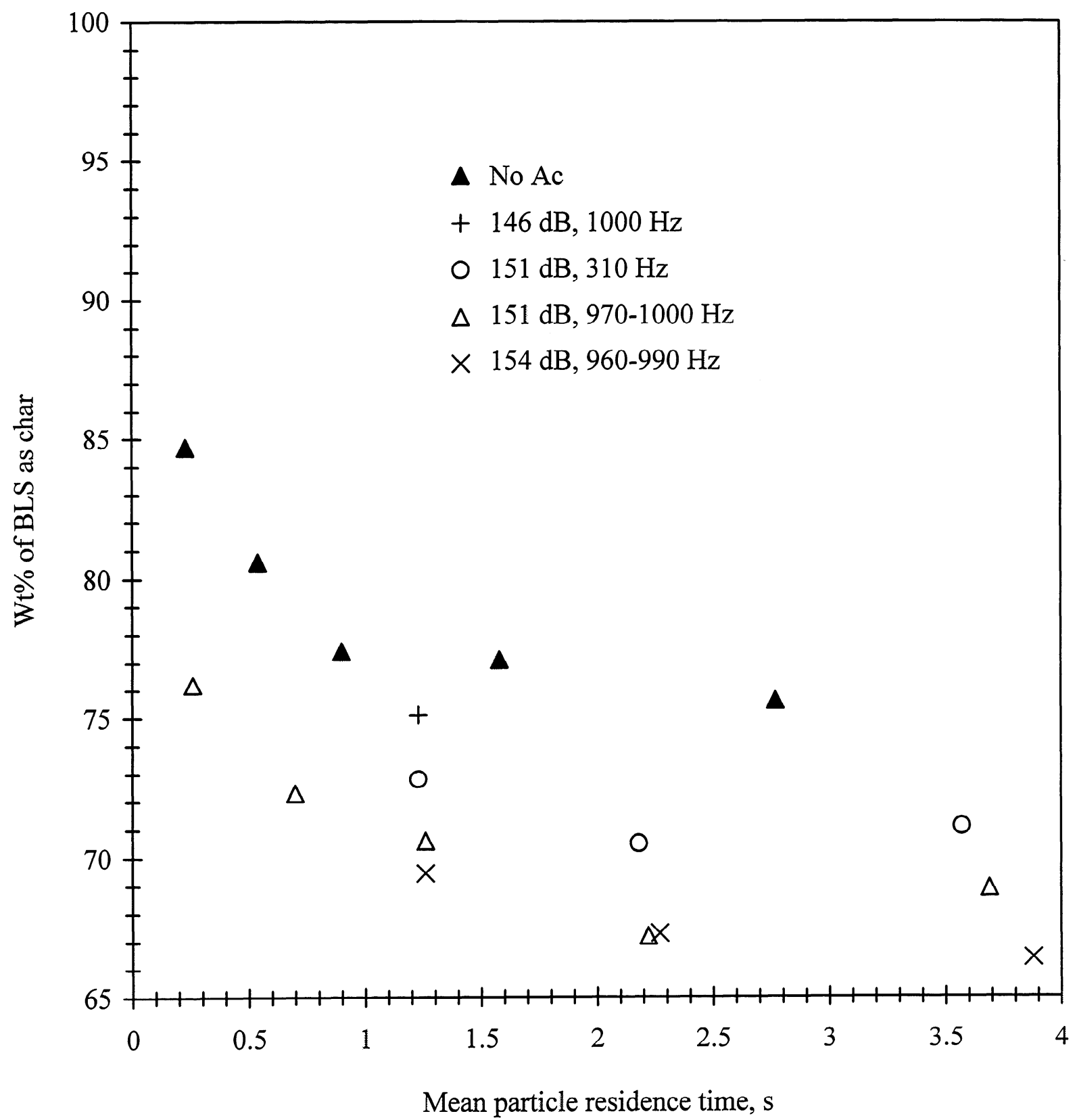

Figure 20. Char yields obtained from non-sticking, inflight particle pyrolysis experiments with and without an acoustic field of $146-154 \mathrm{~dB}$ and $310-1000 \mathrm{~Hz}$ at a gas temperature of $550^{\circ} \mathrm{C}$. Pyrolysis tube and secondary gas flow configurations were: $0.18,0.48$, and $0.81 \mathrm{~m}$ heated length and $20 \mathrm{slpm}$ preheated $\mathrm{N}_{2}$, and $0.81 \mathrm{~m}$ heated length and 5 and 10 slpm preheated $\mathrm{N}_{2}$. 
Fig. 20 indicates:

- An acoustic field reduced char yields by approximately $10 \%$. Char yields obtained with an acoustic field of $151 \mathrm{~dB}$ and $970-1000 \mathrm{~Hz}$ (RAC1107, RAC1108, RAC925B, RAC1230B, and $\mathrm{RAC} 1226)$ were about 6-7 weight percentage points lower than those obtained without acoustics (RNAC1105, RNA21105, RNAC912, RNAC918, RNAC919, RNAC927B, and RNAC927) over the range of particle residence times studied.

- The sound pressure level must be greater than $146 \mathrm{~dB}$ to cause a significant reduction in char yield, as indicated by the char yields obtained with an acoustic field of $146 \mathrm{~dB}$ and $1000 \mathrm{~Hz}$ (RAC925) and without an acoustic field (RNAC912, RNAC918, RNAC919, or RNAC925B).

- At a sound pressure level of $151 \mathrm{~dB}$, reducing the frequency from 970 to $310 \mathrm{~Hz}$ (RAC1231A, RAC1231B, and RAC1231C) caused char yields to increase by about 2 weight percentage points.

- Increasing the sound pressure level from 151 to $154 \mathrm{~dB}$ (RAC912, RAC926, RAC930, and RAC1227A) did not significantly reduce char yields. Some particle sticking occurred in experiment RAC1028, so it was not plotted in Fig. 20. 


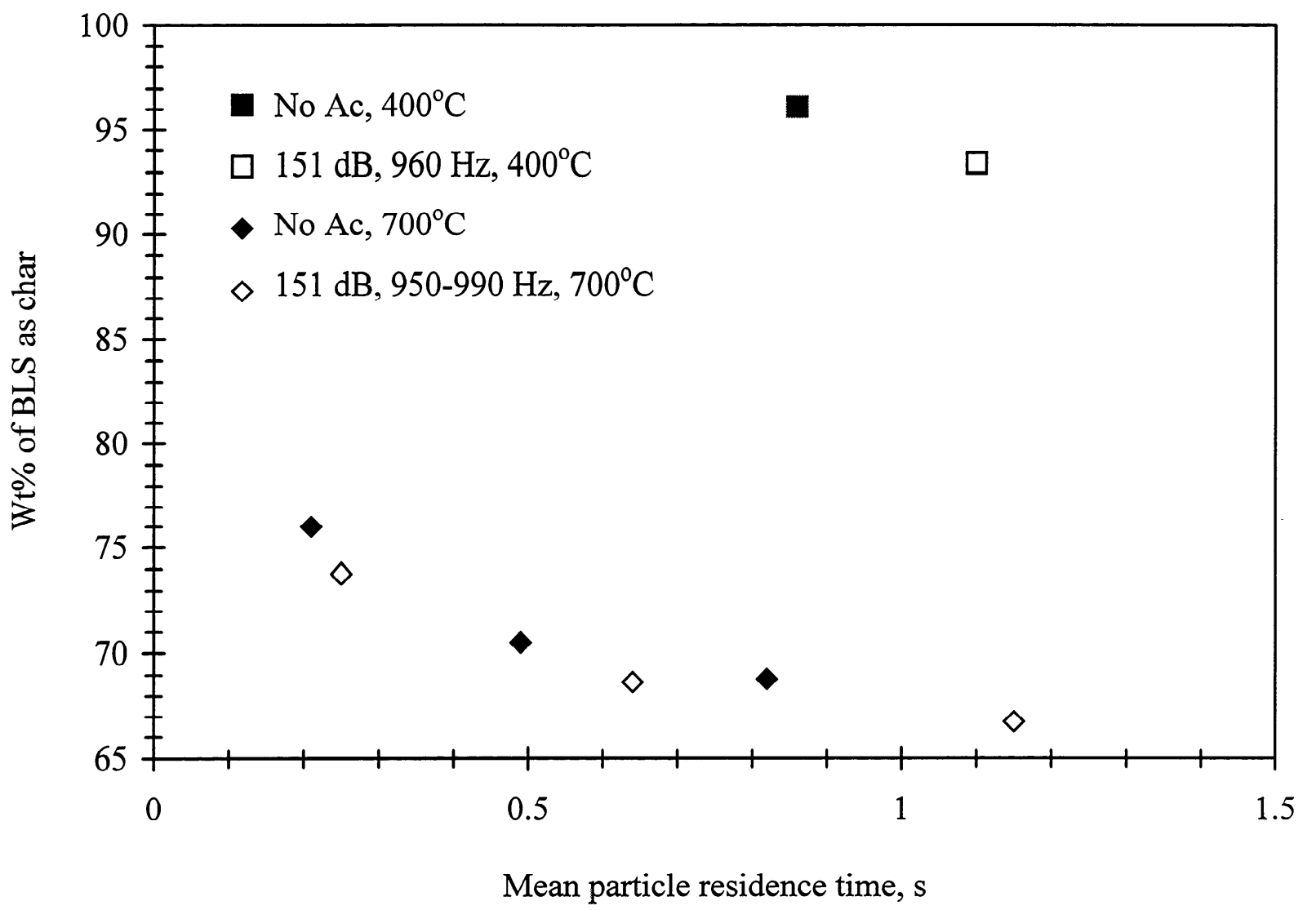

Figure 21. Char yields obtained from non-sticking, inflight particle pyrolysis experiments with and without an acoustic field of $151 \mathrm{~dB}$ and $950-990 \mathrm{~Hz}$ at gas temperatures of 400 and $700^{\circ} \mathrm{C}$. Pyrolysis tube and secondary gas flow configurations were: $0.18,0.48$, and $0.81 \mathrm{~m}$ heated length and 20 slpm preheated $\mathrm{N}_{2}$.

Fig. 21 indicates that at gas temperatures of 400 and $700^{\circ} \mathrm{C}$ acoustics does not significantly reduce char yields. At a gas temperature of $400^{\circ} \mathrm{C}$, the difference between char yields obtained at similar residence times with an acoustic field of $151 \mathrm{~dB}$ and $960 \mathrm{~Hz}$ (RAC1119) and without acoustics (RNAC1113) was not significant. At a gas temperature of $700^{\circ} \mathrm{C}$, char yields were approximately the same between experiments with an acoustic field of $151 \mathrm{~dB}$ and $950-990 \mathrm{~Hz}$ (RAC1126A, RAC1127 and RAC1130, and RAC1126B and RAC1130B) and without acoustics (RNAC1123, RNAC1127, and RNAC1122) at similar particle residence times. 
At gas temperatures of 550 and $700^{\circ} \mathrm{C}$, char yields obtained with an acoustic field of 158-160 dB and frequency of 950-970 Hz (RAC1207, RAC1227B, RAC1230, RAC1224, RAC1130C and RAC1205) were about the same as those obtained with steel wool plugs (RNAC1022, RNAC1023, RNAC1024, RNAC1226) as listed in Table A4.4. The char yields were about 10-18 weight percentage points lower than that obtained from the longest, nonsticking, inflight particle pyrolysis experiment without acoustics (RNAC925). Some of the char yields may be inaccurate due to low char collection efficiency caused by particle sticking to the tube wall or steel-wool-fibers as noted in Table A4.4. Unfortunately, it was beyond the means of this dissertation to construct a vertical pyrolysis tube that was long enough to obtain inflight particle residence times of several tens of seconds as experienced by BLS particles pyrolyzed in steel-wool-plug experiments.

\section{[5.1.2.2] Char Chemical Composition}

Chars that were obtained from non-sticking, inflight particle pyrolysis experiments with (RAC1107, RAC1108, RAC925B, and RAC1226) and without (RNAC1105, RNA21105, RNAC918, and RNAC927A) an acoustic field of $151 \mathrm{~dB}$ and $950-1000 \mathrm{~Hz}$ at a gas temperature of $550^{\circ} \mathrm{C}$ were analyzed for total carbon, carbonate carbon, and organic carbon; the results are shown in Figs. 22-24. Chars that were obtained from non-sticking, inflight particle pyrolysis experiments with (RAC1126A, RAC1127, and RAC1122) and without (RNAC1123, RNAC1127, and RNAC1122) an acoustic field of $151 \mathrm{~dB}$ and $950-990 \mathrm{~Hz}$ at a gas temperature of $700^{\circ} \mathrm{C}$ were analyzed for total carbon, carbonate carbon, and organic carbon; the results are shown in Figs. 25-27. In addition, the wt $\%$ of BLS, or percent of the carbon in BLS as total, carbonate, and, organic carbon are listed in Table A4.4 in Appendix 4. 


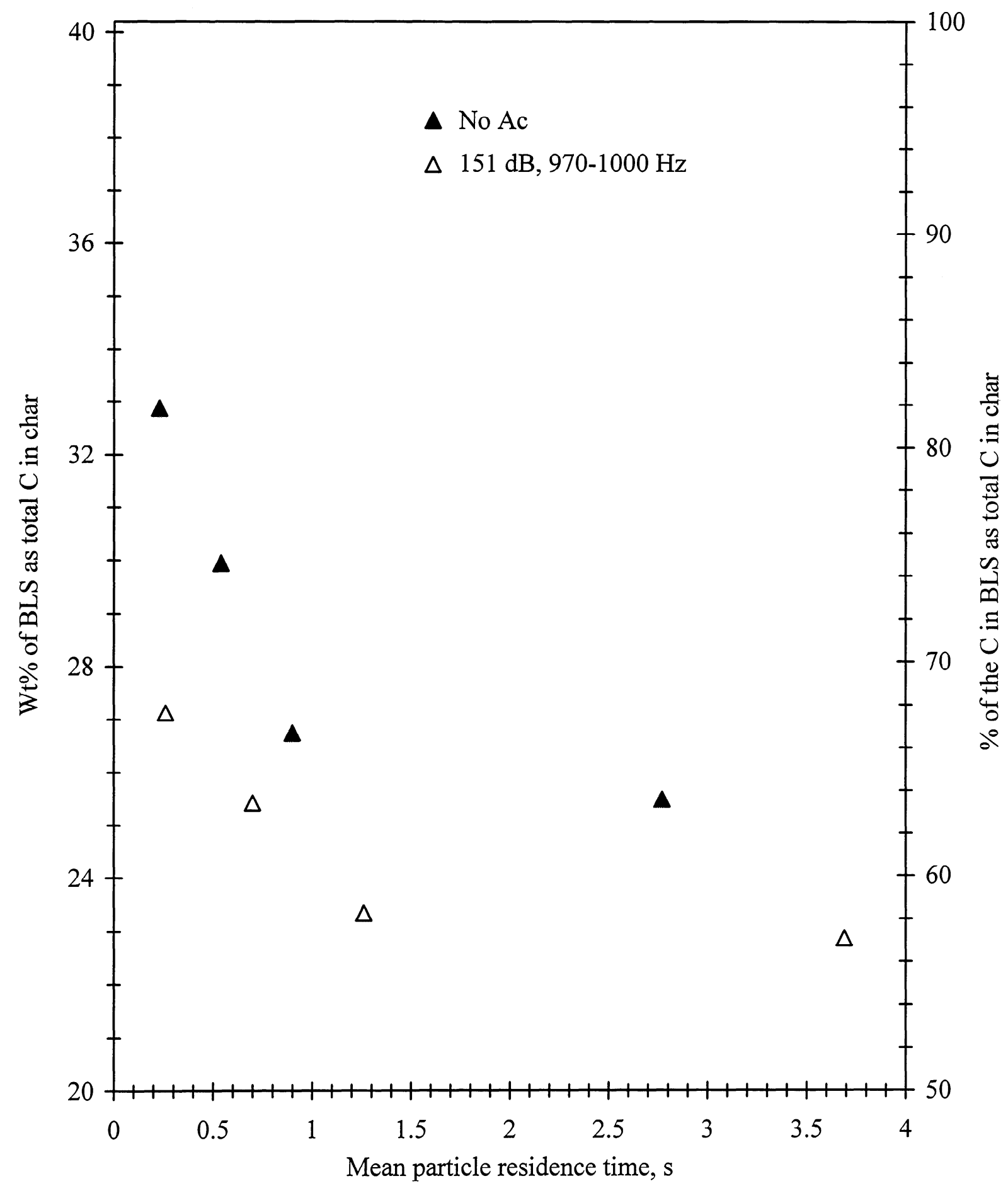

Figure 22. Wt\% of BLS, or percent of the carbon in BLS, as total carbon in char obtained from non-sticking, inflight particle pyrolysis experiments with and without an acoustic field of $151 \mathrm{~dB}$ and $970-1000 \mathrm{~Hz}$ at a gas temperature of $550^{\circ} \mathrm{C}$. Pyrolysis tube and secondary gas flow configurations were: $0.18,0.48$, and $0.81 \mathrm{~m}$ heated lengths and $20 \mathrm{slpm}$ preheated $\mathrm{N}_{2}$, and $0.81 \mathrm{~m}$ heated length and 5 slpm preheated $\mathrm{N}_{2}$. 


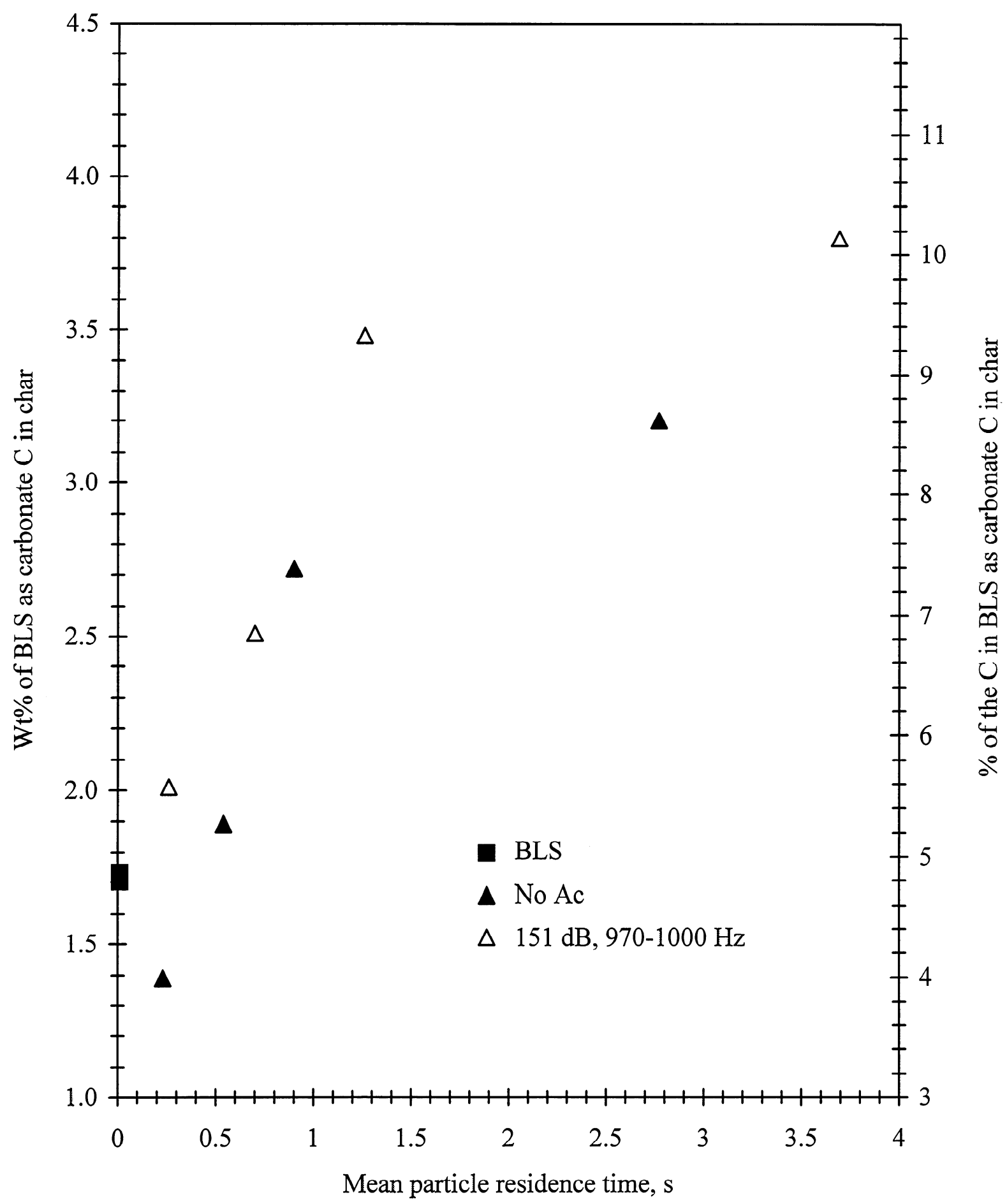

Figure 23. $\mathrm{Wt} \%$ of $\mathrm{BLS}$, or percent of the carbon in BLS, as carbonate carbon in char obtained from non-sticking, inflight particle pyrolysis experiments with and without an acoustic field of $151 \mathrm{~dB}$ and $970-1000 \mathrm{~Hz}$ at a gas temperature of $550^{\circ} \mathrm{C}$. Pyrolysis tube and secondary gas flow configurations were: $0.18,0.48$, and $0.81 \mathrm{~m}$ heated lengths and $20 \mathrm{slpm}$ preheated $\mathrm{N}_{2}$, and $0.81 \mathrm{~m}$ heated length and 5 slpm preheated $\mathrm{N}_{2}$. 


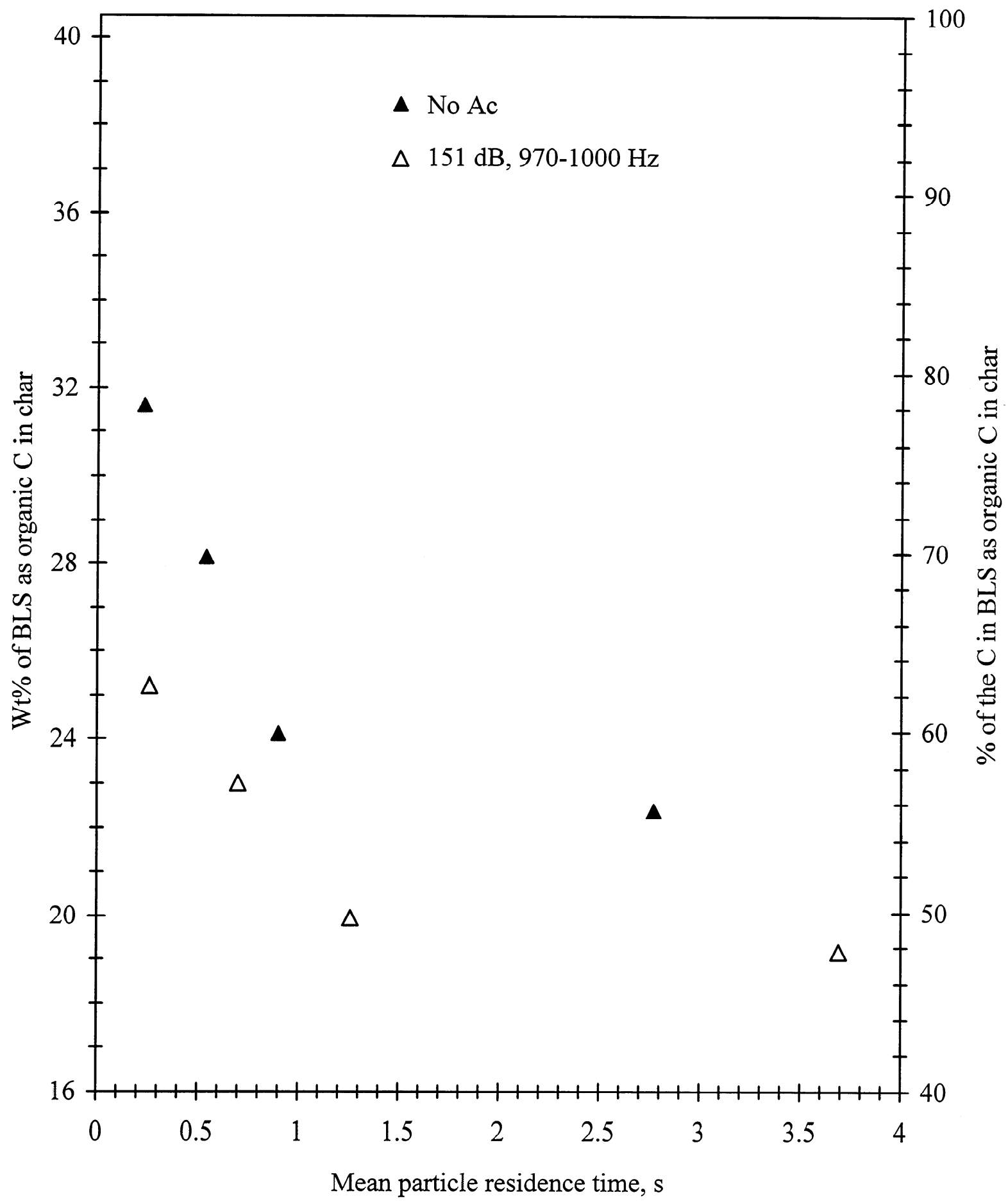

Figure 24. $\mathrm{Wt} \%$ of BLS, or percent of the carbon in BLS, as organic carbon in char obtained from non-sticking, inflight particle pyrolysis experiments with and without an acoustic field of $151 \mathrm{~dB}$ and $970-1000 \mathrm{~Hz}$ at a gas temperature of $550^{\circ} \mathrm{C}$. Pyrolysis tube and secondary gas flow configurations were: $0.18,0.48$, and $0.81 \mathrm{~m}$ heated lengths and $20 \mathrm{slpm}$ preheated $\mathrm{N}_{2}$, and $0.81 \mathrm{~m}$ heated length and 5 slpm preheated $\mathrm{N}_{2}$. 
Figs. 22-24 indicate:

- An acoustic field reduced the wt\% of BLS, or percent of the carbon in BLS, as total and organic carbon by approximately 19 and 24\%, respectively, (RAC1107 with acoustics versus RNAC1105 without acoustics) for the shortest, $0.18 \mathrm{~m}$ pyrolysis tube heated length, or mean particle residence time between $0.23-0.26 \mathrm{~s}$. After a long particle residence time the acoustically induced reduction in the $w t \%$ of BLS, or percent of the carbon in BLS, as total and organic carbon was approximately 11 and $16 \%$, respectively.

- The wt $\%$ of BLS, or percent of the carbon in BLS, as carbonate carbon in the chars obtained with acoustics were correspondingly higher than those obtained without acoustics field at the shortest, $0.23-0.26 \mathrm{~s}$, and all longer, $>0.9 \mathrm{~s}$, particle residence times. When particle residence times were between 0.8-0.9 s, the yields are about the same with and without acoustics. 


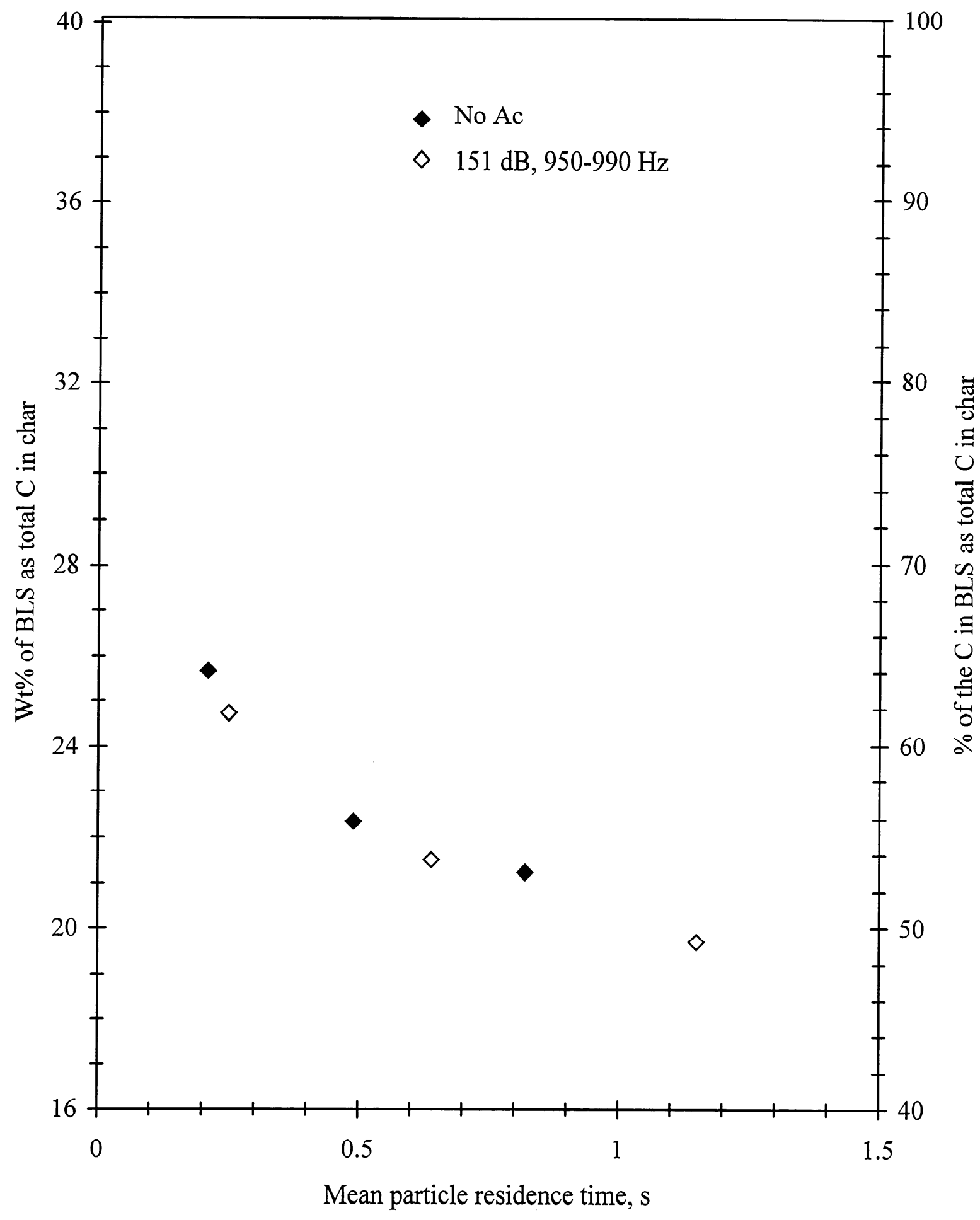

Figure 25. $\mathrm{Wt} \%$ of BLS, or percent of the carbon in BLS, as total carbon in char obtained from non-sticking, inflight particle pyrolysis experiments with and without an acoustic field of $151 \mathrm{~dB}$ and $950-990 \mathrm{~Hz}$ at a gas temperature of $700^{\circ} \mathrm{C}$. Pyrolysis tube and secondary gas flow configurations were: $0.18,0.48$, and $0.81 \mathrm{~m}$ heated lengths and $20 \mathrm{slpm}$ preheated $\mathrm{N}_{2}$. 


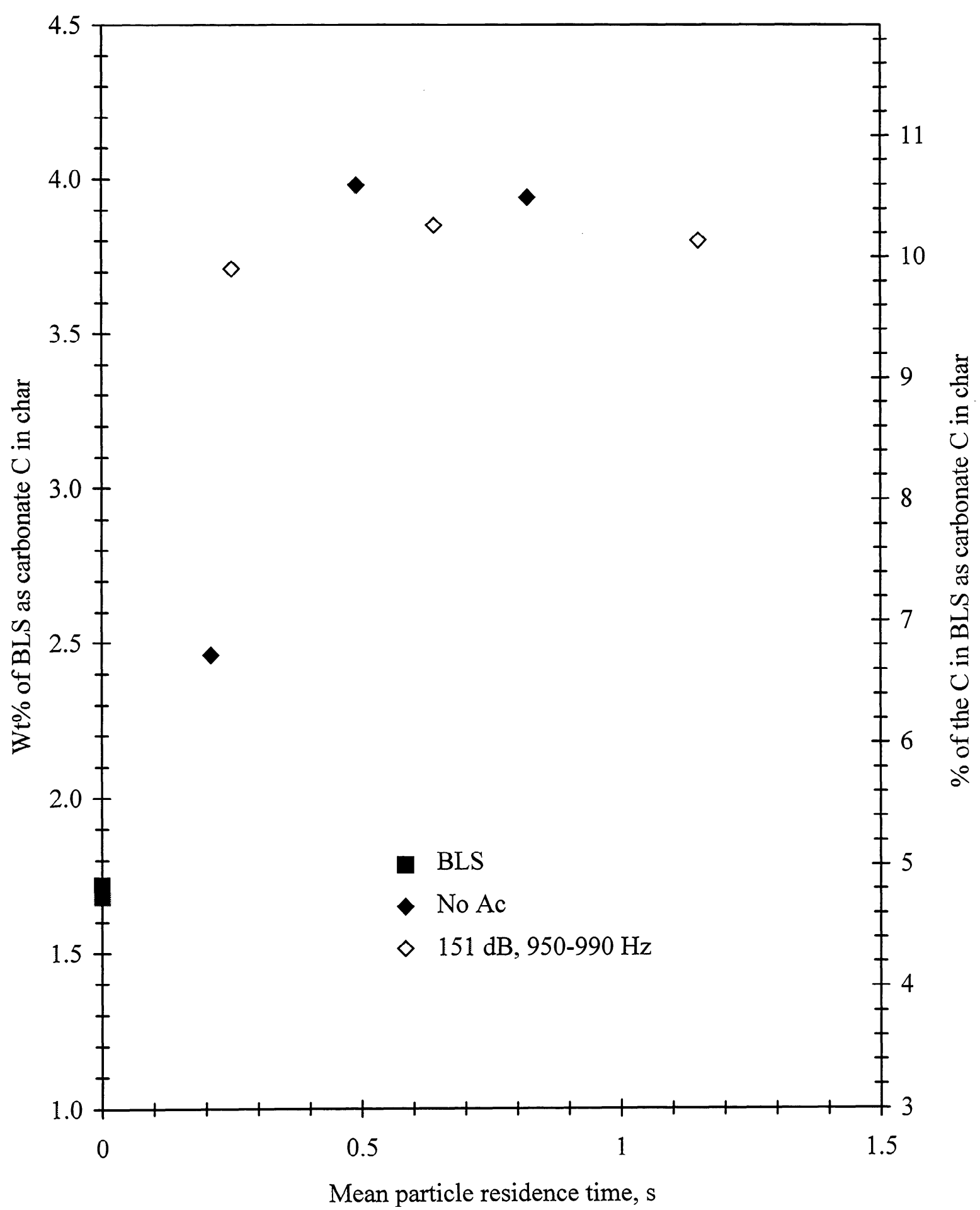

Figure 26. $\mathrm{Wt} \%$ of BLS, or percent of the carbon in BLS, as carbonate carbon in char obtained from non-sticking, inflight particle pyrolysis experiments with and without an acoustic field of $151 \mathrm{~dB}$ and $950-990 \mathrm{~Hz}$ at a gas temperature of $700^{\circ} \mathrm{C}$. Pyrolysis tube and secondary gas flow configurations were: $0.18,0.48$, and $0.81 \mathrm{~m}$ heated lengths and $20 \mathrm{slpm}$ preheated $\mathrm{N}_{2}$. 


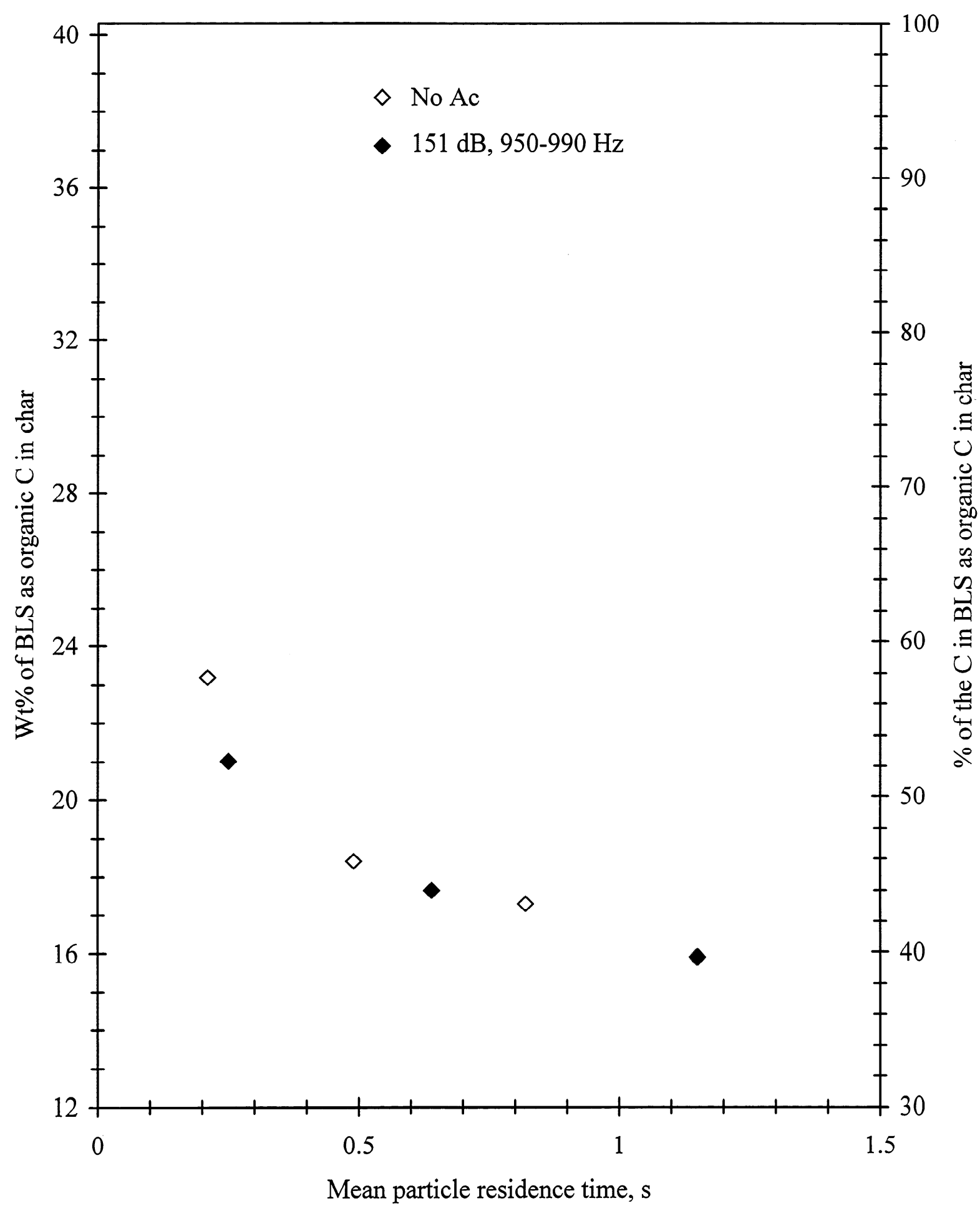

Figure 27. $\mathrm{W} t \%$ of BLS, or percent of the carbon in BLS, as organic carbon in char obtained from non-sticking, inflight particle pyrolysis experiments with and without an acoustic field of $151 \mathrm{~dB}$ and $950-990 \mathrm{~Hz}$ at a gas temperature of $700^{\circ} \mathrm{C}$. Pyrolysis tube and secondary gas flow configurations were: $0.18,0.48$, and $0.81 \mathrm{~m}$ heated lengths and 20 slpm preheated $\mathrm{N}_{2}$. 
Figs. $25-27$ indicate that at a gas temperature of $700^{\circ} \mathrm{C}$, the wt $\%$ of BLS, or percent of the carbon in BLS, as total, carbonate, and organic carbon in the chars were about the same with and without acoustics.

\section{[5.1.2.3] Kinetics of Carbon Conversion to Char and Volatiles}

As reported in the Literature Review, increased substrate heatup rate can increase the yields of tar, liquids, and gases over char by allowing alternative, higher temperature cracking reactions with higher activation energies to proceed before significant polymerization results (Darivakis et al., 1994). A kinetic model (Kobayashi et al., 1976) was used to test whether it was kinetically feasible to obtain the measured percent of the carbon in BLS as carbon in the char due to increased the rates of particle cracking reactions relative to the rates of particle polymerization reactions under acoustically increased rate of particle heatup to temperatures of 550 and $700^{\circ} \mathrm{C}$. The model assumes pyrolysis proceeds by two parallel, first-order, irreversible reactions. One reaction proceeds at low temperatures and produces more carbon char residue and less tar carbon. The other reaction proceeds only at higher temperatures and produces less carbon residue and more tar carbon. Formulation of the model is presented in detail in Appendix 10. The temperature history of the particles was estimated using the particle heatup model in Appendix 9. For modeled cases at a gas temperature of $550^{\circ} \mathrm{C}$ without acoustics and at a gas temperature of $700^{\circ} \mathrm{C}$ with and without acoustics, pyrolyzing BLS particles were assumed to experience the reactor centerline gas temperatures measured by a thermocouple. For the modeled case at a gas temperature of $550^{\circ} \mathrm{C}$ with acoustics, the injected BLS particle was assumed to immediately experience a gas temperature of $550^{\circ} \mathrm{C}$. This was done to account for the best possible case of acoustically enhanced mixing of the cold particle carrier gas jet with 
the hot secondary gas stream. The particle carrier gas and the secondary gas streams were better mixed with acoustics, as will be discussed in the Gas and Particle Flow Analysis section.

Fig. 28 shows that the model reasonably predicts the measured percent of the carbon in BLS as total carbon in the char, except at a gas temperature of $550^{\circ} \mathrm{C}$ with acoustics.

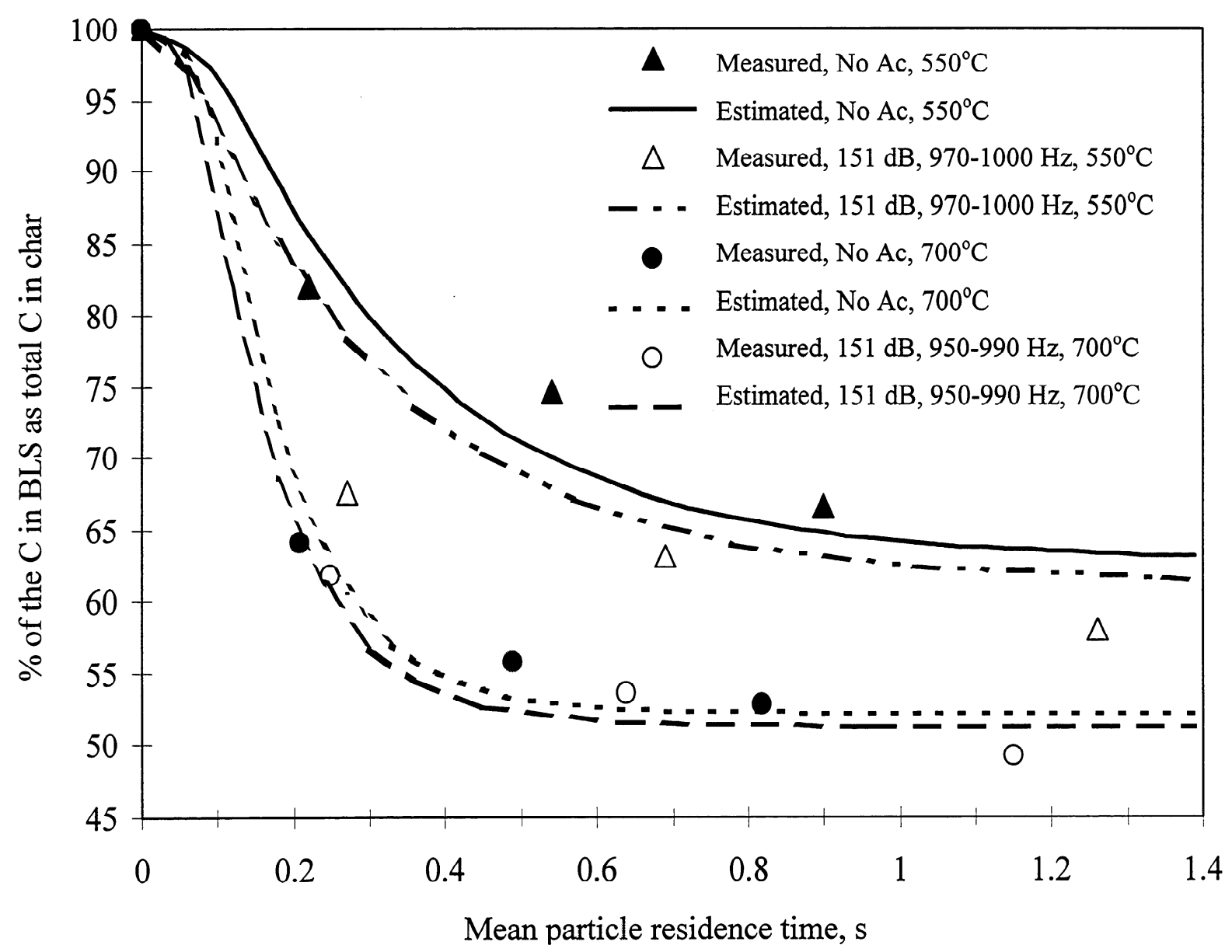

Figure 28. A comparison of the percent of the carbon in BLS as total carbon in the char estimated with a two parallel, first-order, irreversible reaction kinetics model and measured with and without an acoustic field of $151 \mathrm{~dB}$ and $950-1000 \mathrm{~Hz}$ under conditions of $0.21-1.26 \mathrm{~s}$ particle residence time and secondary gas temperatures of 550 and $700^{\circ} \mathrm{C}$.

The model indicates that increased particle heatup to a peak gas temperature of $550^{\circ} \mathrm{C}$ with acoustics cannot significantly increase the rates of high temperature reactions that preferentially 
form tar and gases. The difference of the percent of the carbon in BLS as total carbon in the char between experiments at a gas temperature of $550^{\circ} \mathrm{C}$ with and without acoustics cannot be attributed to increased rates of particle cracking reactions relative to the rates of particle polymerization reactions. Therefore acoustics must be affecting the mass transport of reactive tar products away from the particle, which will be discussed further in the Product Gas Analysis section.

\section{[5.1.2.4] Conclusions}

Analysis of the char yield and chemical composition data indicates:

- At a gas temperature of $550^{\circ} \mathrm{C}$, the acoustic effect on BLS pyrolysis is most prominent during the particle heatup period in the $0.18 \mathrm{~m}$ pyrolysis tube heated length.

- At a gas temperature of $500^{\circ} \mathrm{C}$ but not at $700^{\circ} \mathrm{C}$, an acoustic field of $\geq 151 \mathrm{~dB}$ can reduce both the yields of char and char carbon and increase the char carbonate yield compared to without acoustics.

\section{[5.1.3] SEM Analysis of Char Particles}

\section{[5.1.3.1] Morphology of Char Particles Obtained at a Gas Temperature of $400^{\circ} \mathrm{C}$}

- Char particles made with acoustics (RAC1119) are much more swollen and irregularly shaped and vary more in diameter, as shown in Fig. 29, compared to those obtained without acoustics (RNAC1113) as shown in Fig. 30. 
- Diameters of char particles were ranged between 100-300 and 100-200 $\mu \mathrm{m}$ with and without acoustics, respectively. The average diameter was approximately $150 \mu \mathrm{m}$.
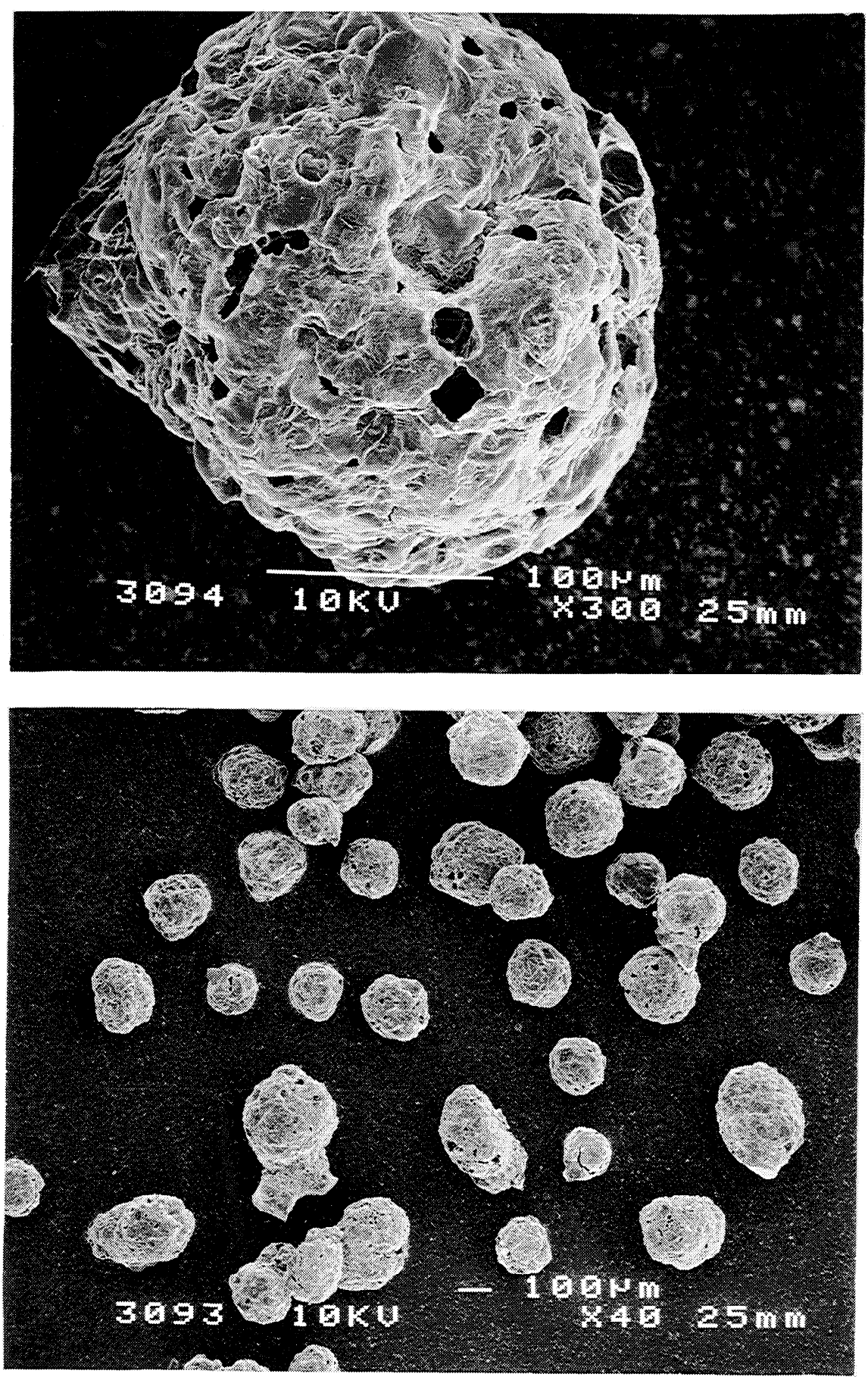

Figure 29. SEM images of char particles obtained with an acoustic tield of 121 as and $960 \mathrm{~Hz}$ (RAC1119) under reactor conditions of $400^{\circ} \mathrm{C}, 0.81 \mathrm{~m}$ pyrolysis tube heated length, $1.10 \mathrm{~s}$ particle residence time, and $2.10 \mathrm{~s}$ secondary gas space-time. 

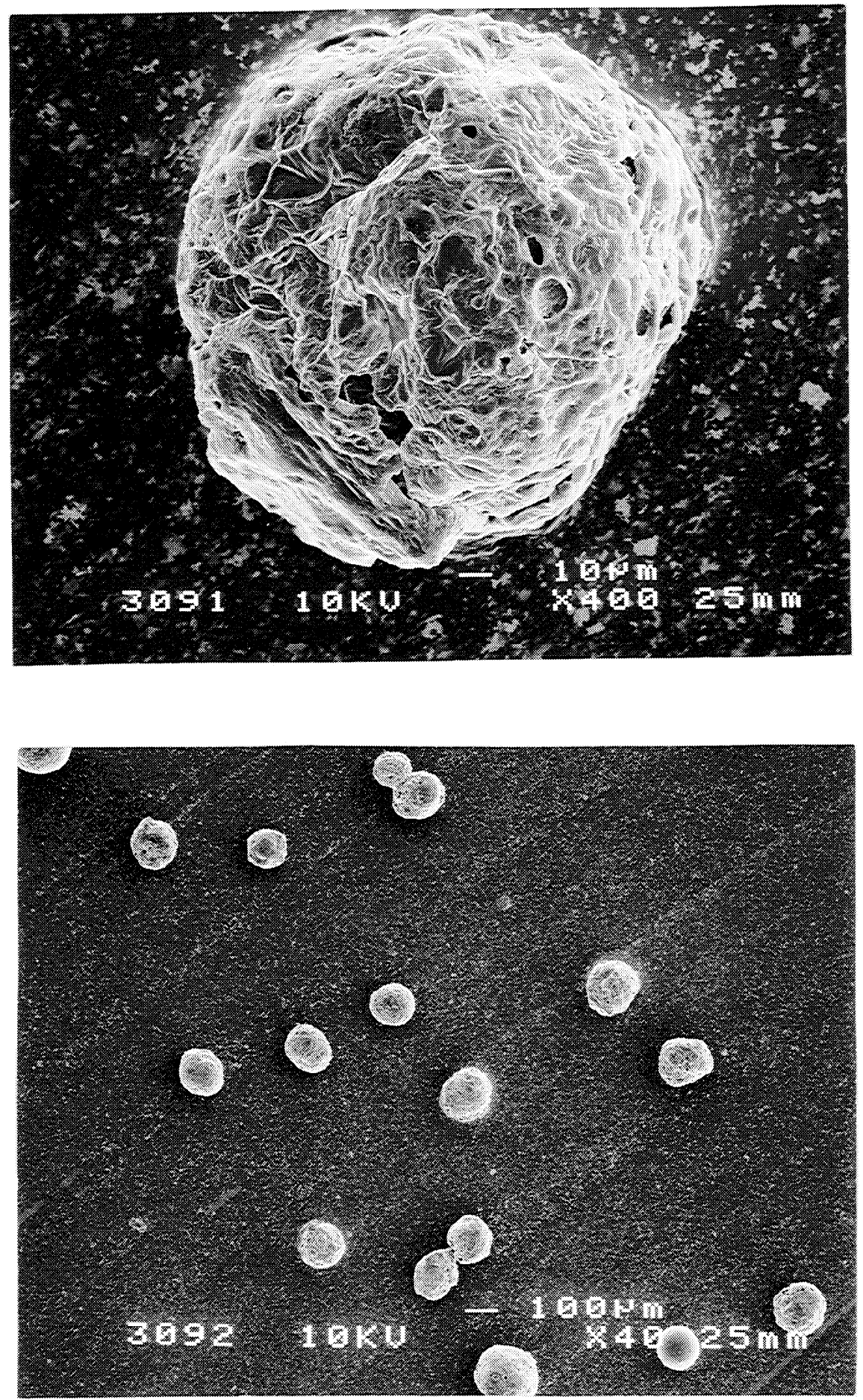

Figure 30. SEM images of char particles obtained without acoustics (RNAC1113) under conditions of $400^{\circ} \mathrm{C}, 0.81 \mathrm{~m}$ pyrolysis tube heated length, $0.86 \mathrm{~s}$ particle residence time, and $2.10 \mathrm{~s}$ secondary gas space-time. 


\section{[5.1.3.2] Morphology of Char Particles Obtained at a Gas Temperature of $550^{\circ} \mathrm{C}$}

- With an acoustic field of $151 \mathrm{~dB}$ and $1000 \mathrm{~Hz}$ (RAC1107) and $0.18 \mathrm{~m}$ pyrolysis tube heated length, char particles are slightly more swollen and contain many more cellular bubbles that are larger in diameter and tend to protrude from the particle surface as shown in Fig. 31 compared to those obtained without acoustics (RNAC1105) as shown in Fig. 32.

- Particle swelling was mostly completed within a particle residence time between 0.54-0.90 s. BLS particles did not continue to swell nor did bubbles continue to form when the pyrolysis tube heated length was extended past $0.48 \mathrm{~m}$ as shown by comparing Fig. 33 (RAC1108) with Fig. 34 (RAC925B) and Fig. 35 (RNA21105) with Fig. 36 (RNAC918). Lack of large surface bubbles in chars without acoustics indicates that particle pyrolysis was not as severe, although the mean particle residence time in experiment RNAC918 was longer than that in similar experiments RAC1107 and RAC1108 with acoustics. Large cellular surface bubbles are present in char particles obtained with an acoustic field of $158 \mathrm{~dB}$ and $970 \mathrm{~Hz}(\mathrm{RAC1207})$ as shown in Fig. 37 that are similar to those observed on char particles from experiments RAC1108 and RAC925B.

- The maximum swollen diameter of char particles typically obtained with and without acoustics was about $300 \mu \mathrm{m}$. Some char particles from RAC1207 were more swollen, such as that shown in Fig. 38.

- By comparing Fig. 38 to Figs. 32, 35, and 36; Fig. 39 to Figs. 31, 33, and 34; and Fig. 40 to Fig. 37, it appears that char particles have shrunk when experiments were conducted both without (RNAC927) and with an acoustic field of 151 and $158 \mathrm{~dB}$ (RAC1226 and RAC1224) 
using a $0.81 \mathrm{~m}$ pyrolysis tube heated length, which indicates again that pyrolysis was completed in the residence times studied.

- The surfaces of char particles that experienced long particle residence times (RAC1226 and RAC1224) were found to have a coating of redeposited tar and submicron diameter fume particles, as shown in Figs. 41 and 42. However, little material is deposited on the surface of char particles that experienced shorter residence times than estimated for RAC1108 as shown in Fig. 43. The redeposition of tar and fume on char particles obtained at sound pressure levels $\geq 158 \mathrm{~dB}$ is probably the cause of the higher percent of total carbon in the char in experiment RAC1207, as listed in Fig A4.3 in Appendix 4.

- Thin-film, blade-like fibrils were found to extend outwards from the exterior surface of all chars obtained from steel-wool-plug experiments as shown in Fig. 44 (RNAC1019). Fibrils are caused by the deposition of hydrocarbon vapor onto the char surface. Thin-film fibrils are produced under conditions of low gas-phase concentration of hydrocarbon vapor (Cullis and Palmer, 1965). Comparison of Fig. 41 showing a steel-wool-fiber located near the reactor wall out of the path of the tar product flow with Fig. 42 showing a steel-wool-fiber located downstream of the deposited char in the path of the tar product flow indicates that carbon fibrils grow on the char surface by redeposition from the hot secondary gas. Objects were magnified 10,000 times their original size in Figs. 45 and 46.

- The interior of the char structure (RNAC1019) is coated with condensed tar material as shown in Fig. 47, which indicates entrapment of tar during pyrolysis. A razor blade was used to cut the char to facilitate SEM imaging and elemental analysis of the interior surfaces. Sodium, potassium, and chloride were found in both the spherical particles and the char 
surface using the SEM elemental detection system. Elements having molecular weights lower than chlorine were not distinguishable from the background signal noise.

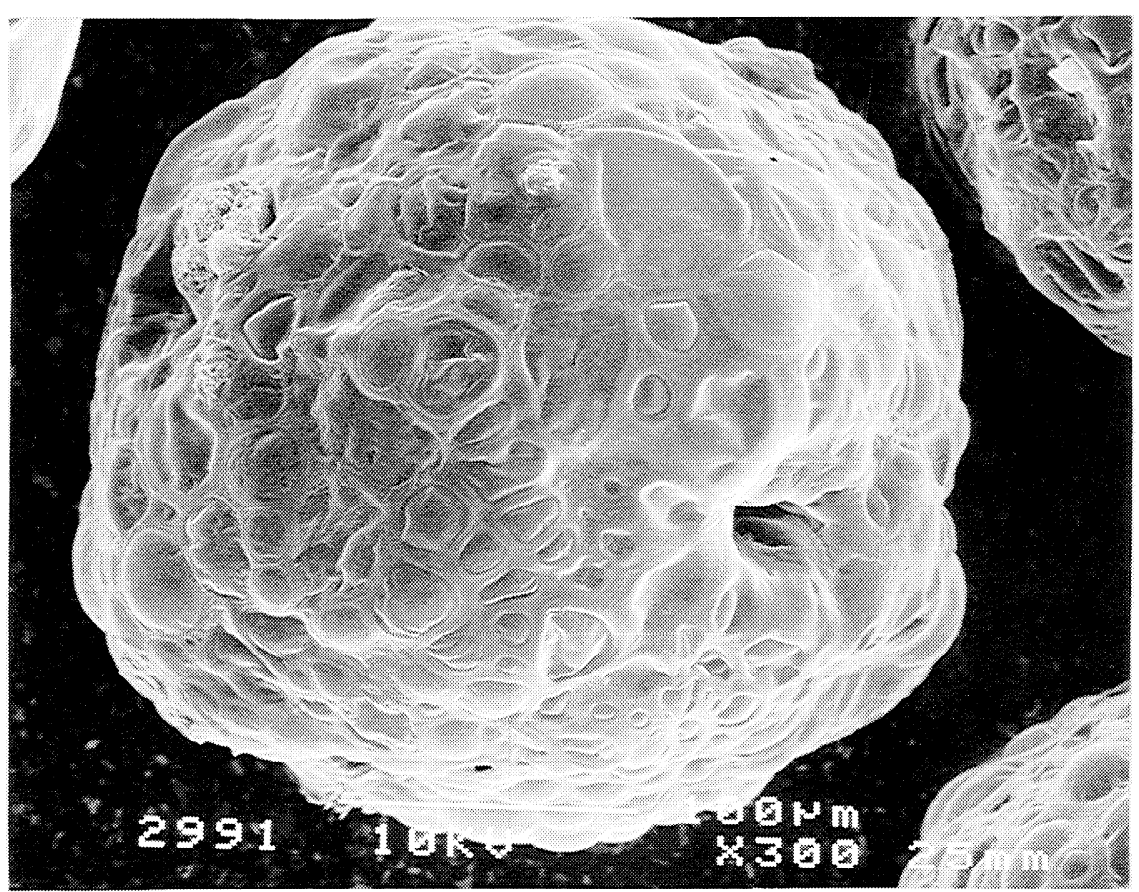

Figure 31. A SEM image of a single char particle obtained with an acoustic field of $151 \mathrm{~dB}$ and $1000 \mathrm{~Hz}$ (RAC1107) under reactor conditions of $550^{\circ} \mathrm{C}, 0.18 \mathrm{~m}$ pyrolysis tube heated length, $0.27 \mathrm{~s}$ particle residence time, and $0.38 \mathrm{~s}$ secondary gas space-time. 


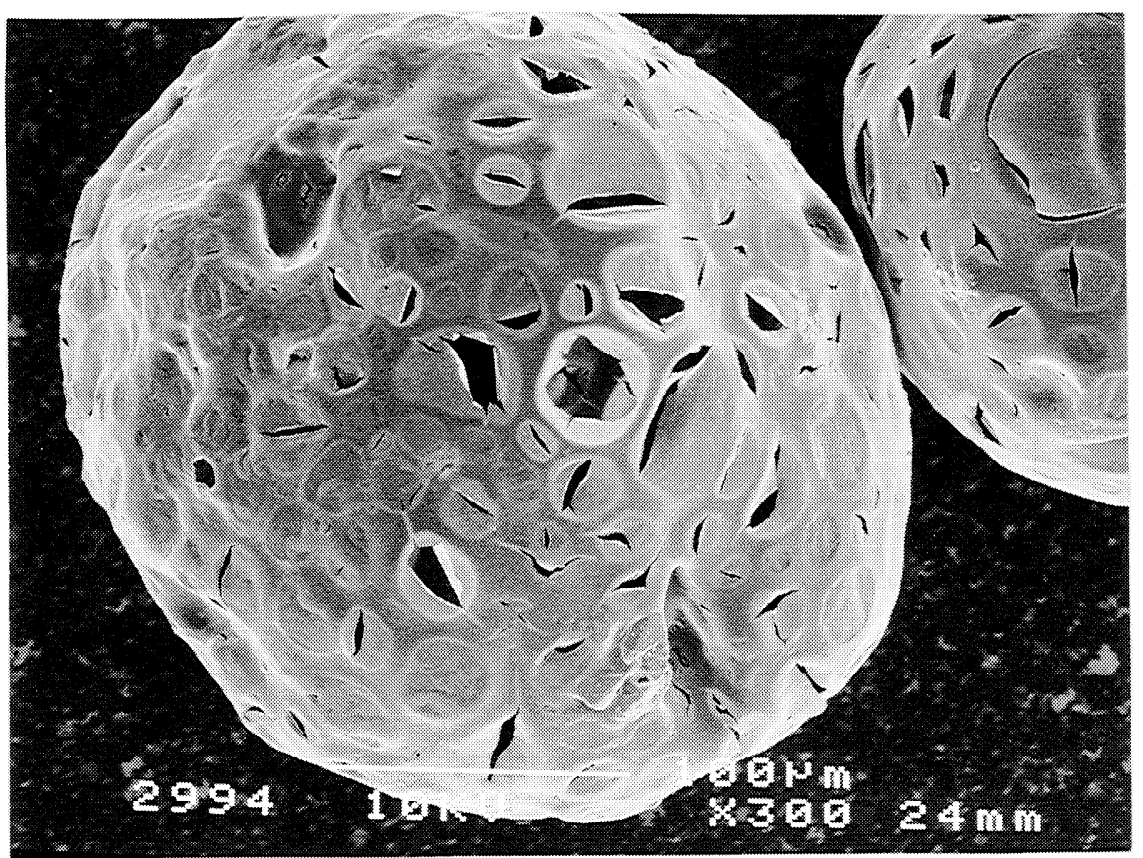

Figure 32. A SEM image of a single char particle obtained without acoustics (RNAC1105) under reactor conditions of $550^{\circ} \mathrm{C}, 0.18 \mathrm{~m}$ pyrolysis tube heated length, $0.23 \mathrm{~s}$ particle residence time, and $0.38 \mathrm{~s}$ secondary gas space-time.

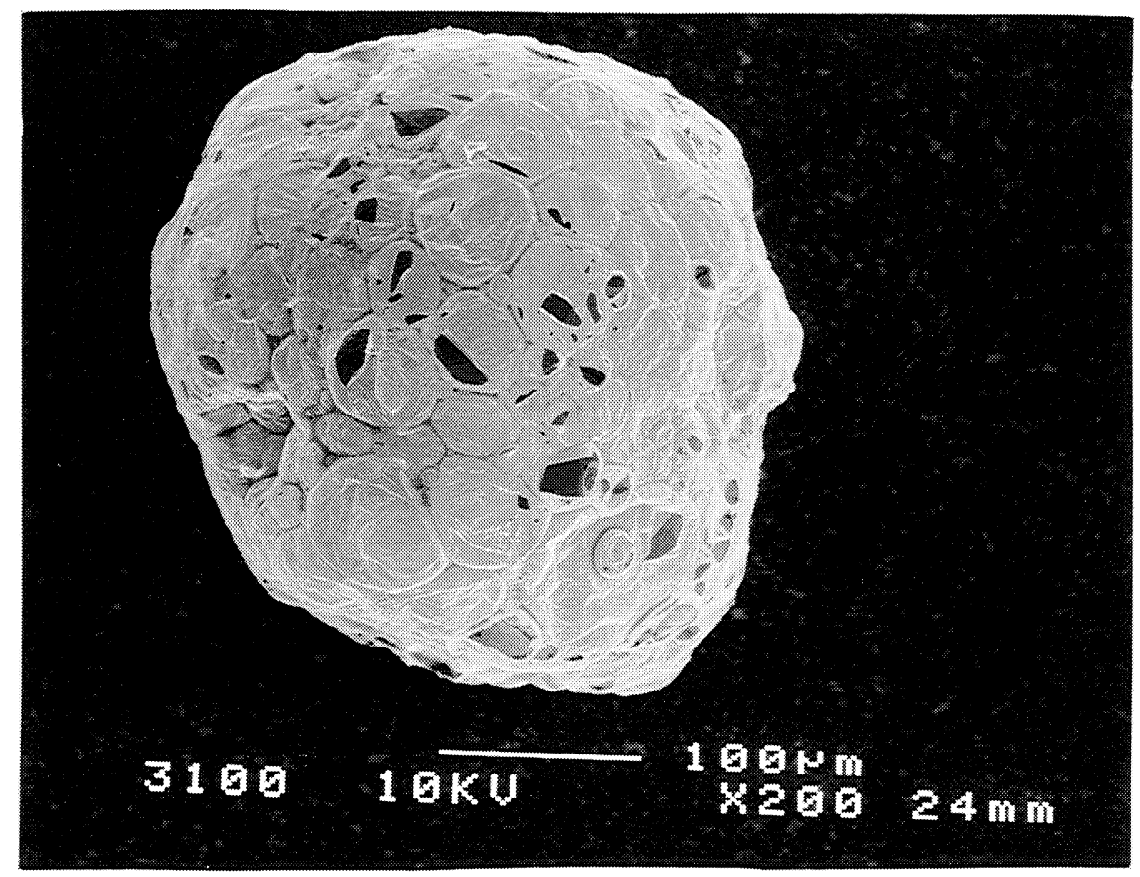

Figure 33. A SEM image of a single char particle obtained with an acoustic field of $151 \mathrm{~dB}$ and $970 \mathrm{~Hz}(\mathrm{RAC1} 108)$ under reactor conditions of $550^{\circ} \mathrm{C}, 0.48 \mathrm{~m}$ pyrolysis tube heated length, $0.70 \mathrm{~s}$ particle residence time, and $1.02 \mathrm{~s}$ secondary gas space-time. 


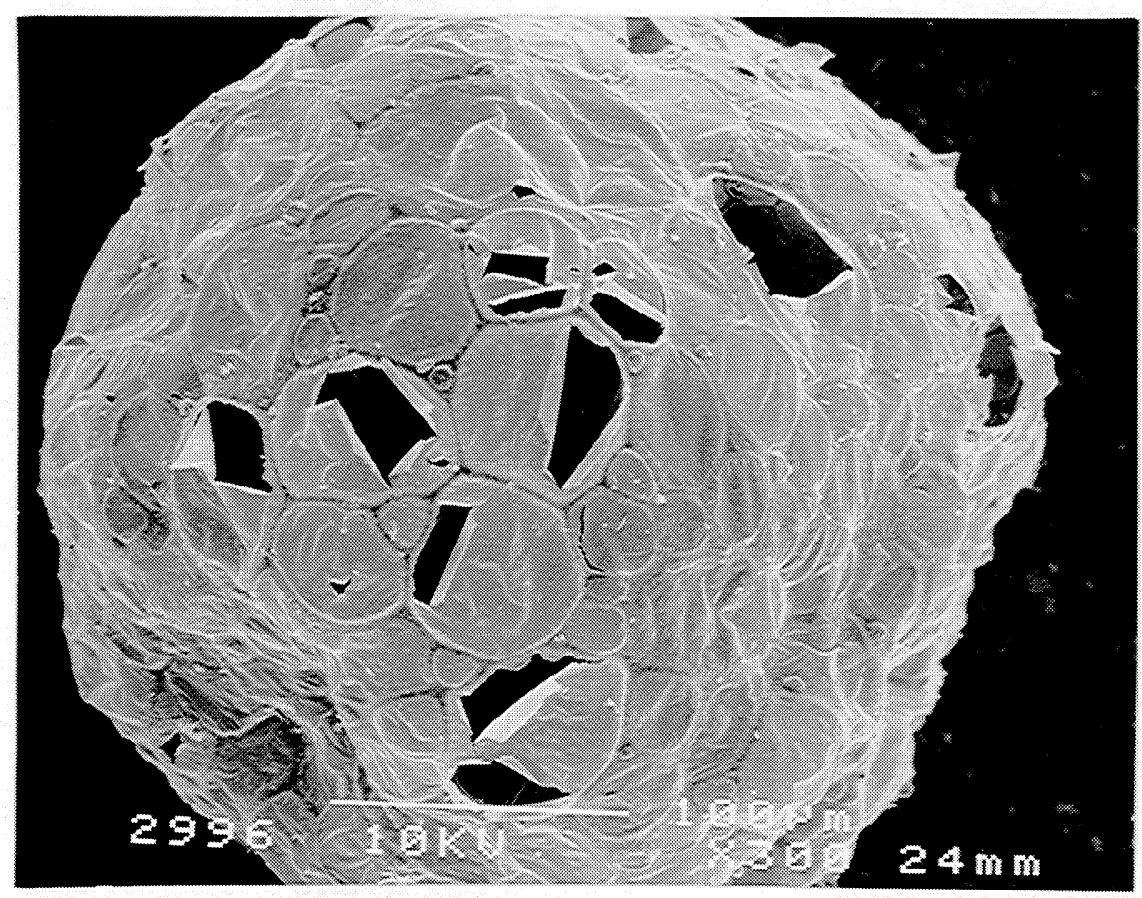

Figure 34. A SEM image of a single char particle obtained with an acoustic field of $151 \mathrm{~dB}$ and $990 \mathrm{~Hz}$ (RAC925B) under reactor conditions of $550^{\circ} \mathrm{C}, 0.81 \mathrm{~m}$ pyrolysis tube heated length, $1.26 \mathrm{~s}$ particle residence time, and $1.72 \mathrm{~s}$ secondary gas space-time.

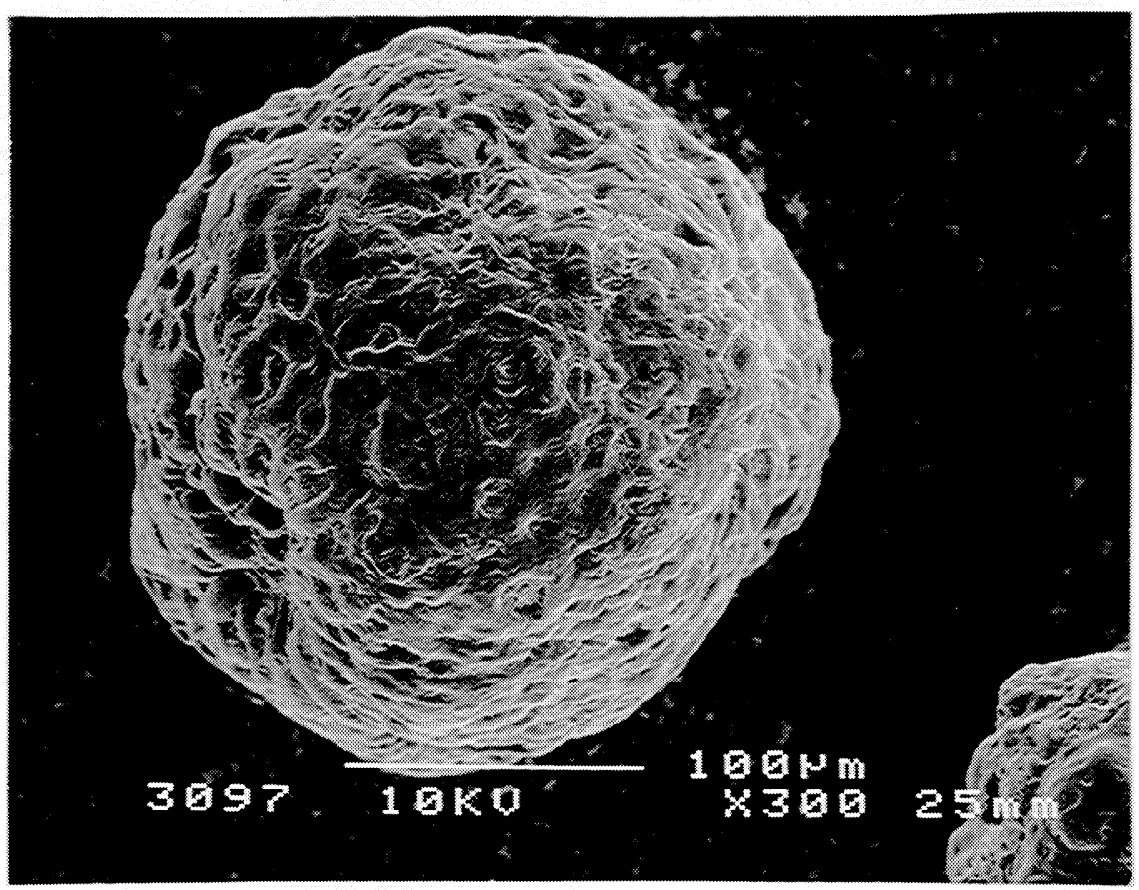

Figure 35. A SEM image of a single char particle obtained without acoustics (RNA21105) under reactor conditions of $550^{\circ} \mathrm{C}, 0.48 \mathrm{~m}$ pyrolysis tube heated length, $0.54 \mathrm{~s}$ particle residence time, and $1.02 \mathrm{~s} \mathrm{secondary} \mathrm{gas} \mathrm{space-time.}$ 


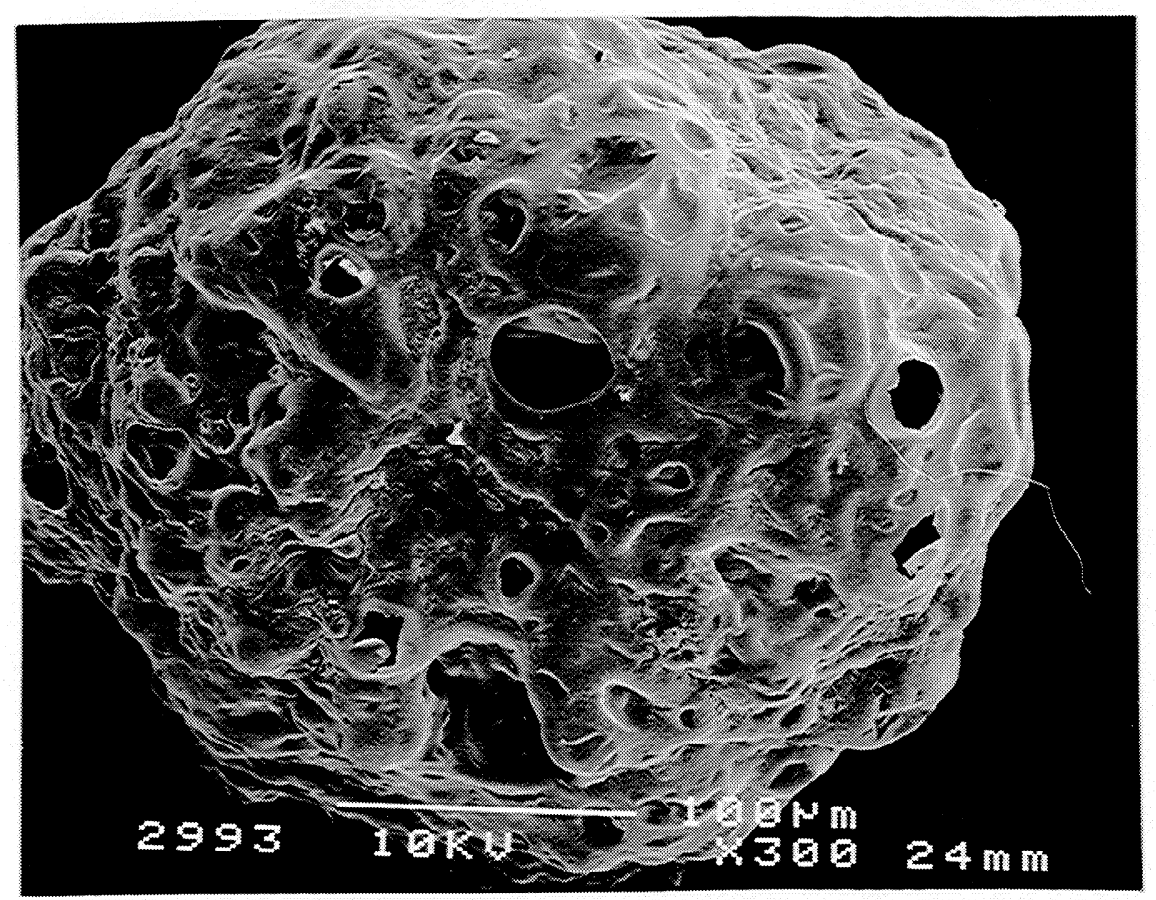

Figure 36. A SEM image of a single char particle obtained without acoustics (RNAC918) under reactor conditions of $550^{\circ} \mathrm{C}, 0.81 \mathrm{~m}$ pyrolysis tube heated length, $0.90 \mathrm{~s}$ particle residence time, and $1.72 \mathrm{~s} \mathrm{secondary} \mathrm{gas} \mathrm{space-time.}$

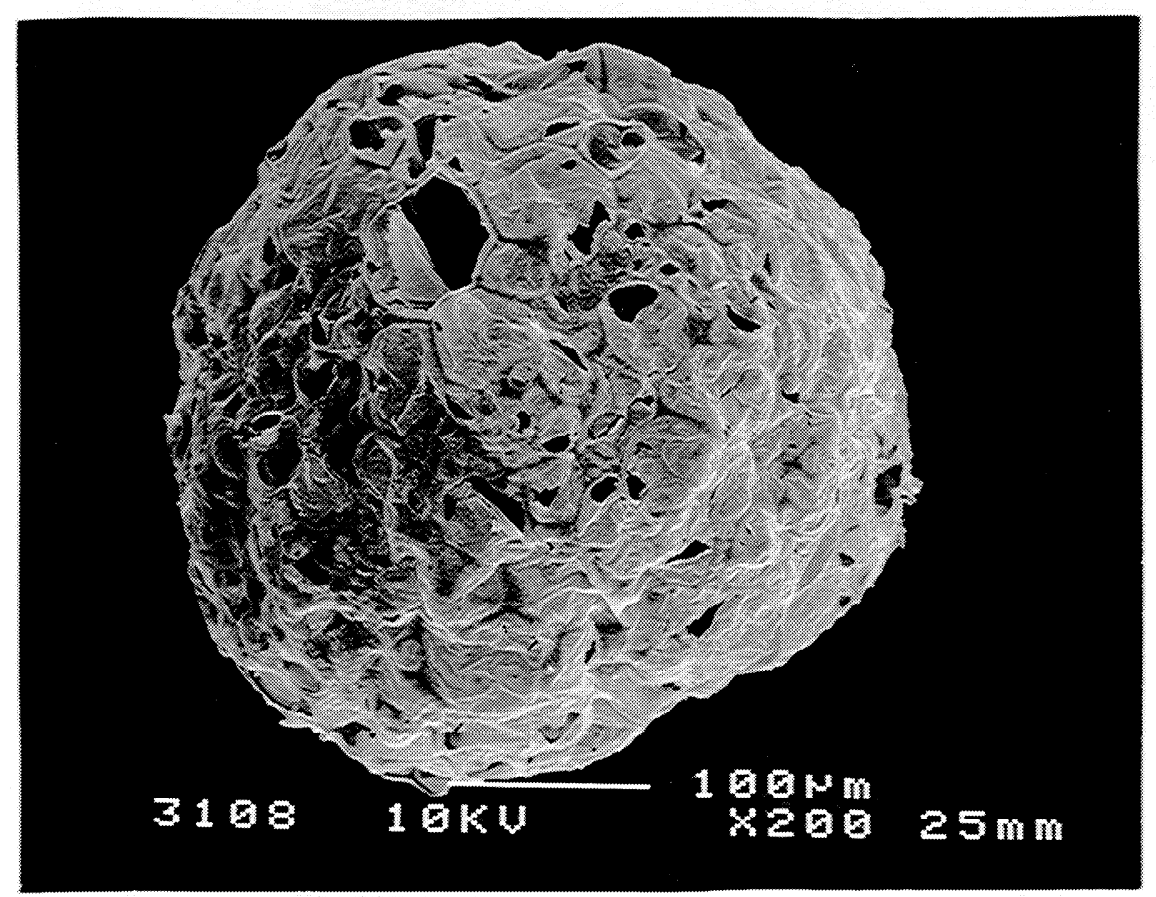

Figure 37. A SEM image of a single char particle obtained with an acoustic field of $158 \mathrm{~dB}$ and $970 \mathrm{~Hz}$ (RAC1207) under reactor conditions of $550^{\circ} \mathrm{C}, 0.81 \mathrm{~m}$ pyrolysis tube heated length, at least $1.37 \mathrm{~s}$ particle residence time (some particles stuck to pyrolysis tube wall), and $1.72 \mathrm{~s}$ secondary gas space-time. 


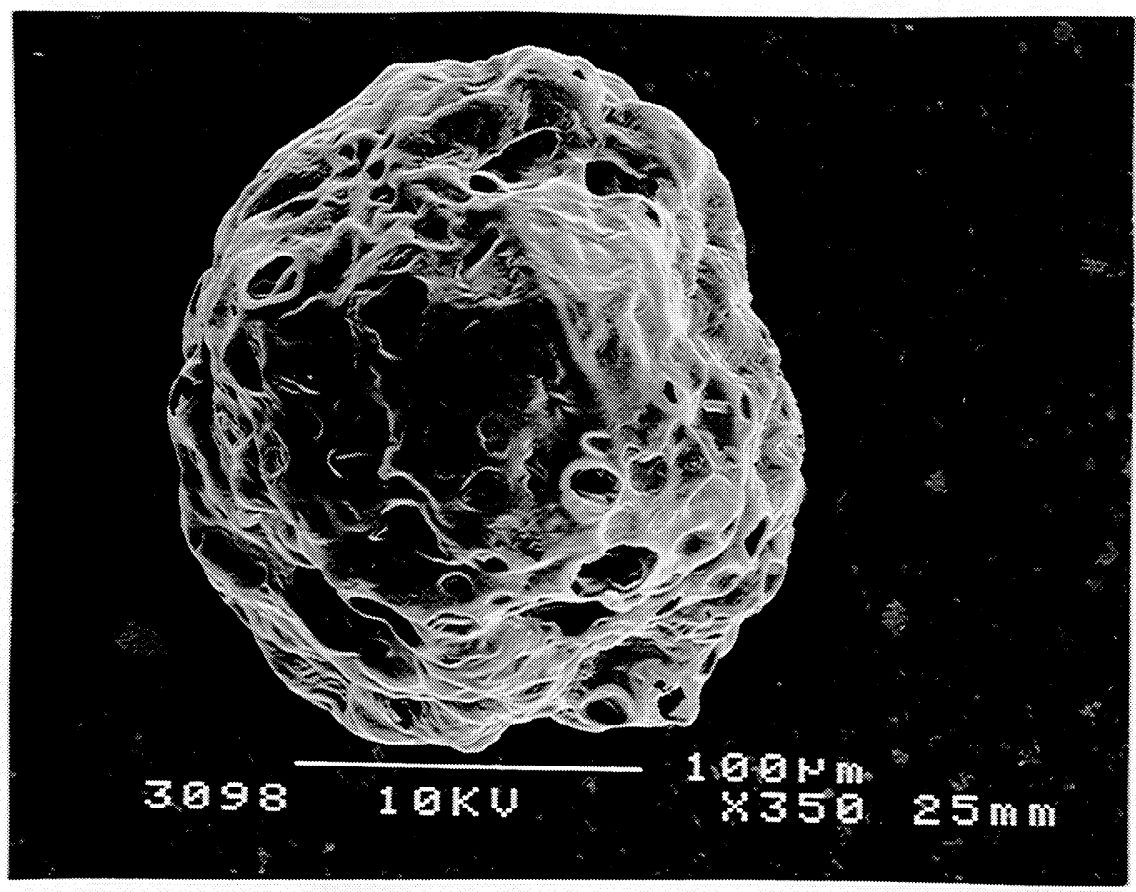

Figure 38. A SEM image of a single char particle obtained without acoustics (RNAC927) under reactor conditions of $550^{\circ} \mathrm{C}, 0.81 \mathrm{~m}$ pyrolysis tube heated length, $2.77 \mathrm{~s}$ particle residence time, and $6.59 \mathrm{~s}$ secondary gas space-time.

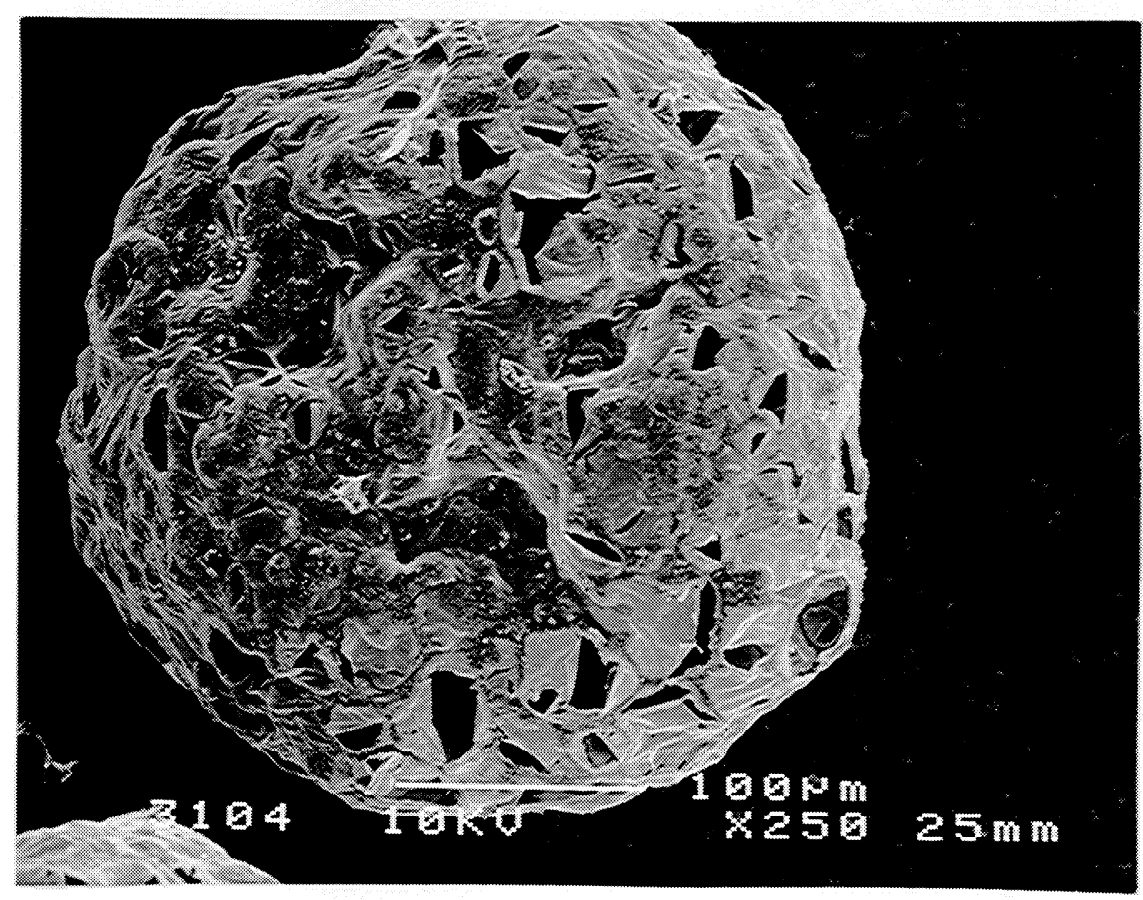

Figure 39. A SEM image of a single char particle obtained with an acoustic field of $151 \mathrm{~dB}$ and $980 \mathrm{~Hz}(\mathrm{RACl} 226)$ under reactor conditions of $550^{\circ} \mathrm{C}, 0.81 \mathrm{~m}$ pyrolysis tube heated length, $3.69 \mathrm{~s}$ particle residence time, and $6.59 \mathrm{~s}$ secondary gas space-time. 


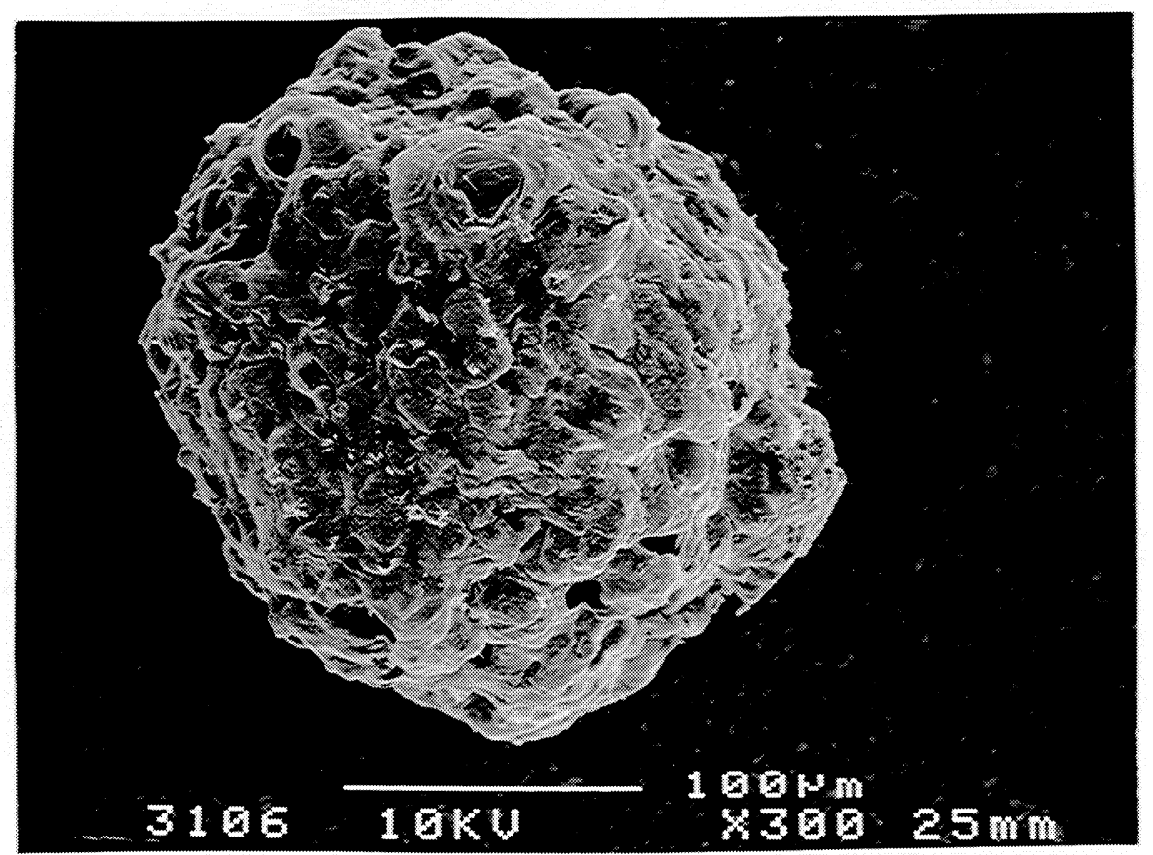

Figure 40. A SEM image of a single char particle obtained with an acoustic field of $158 \mathrm{~dB}$ and $970 \mathrm{~Hz}$ (RAC1224) under reactor conditions of $550^{\circ} \mathrm{C}, 0.81 \mathrm{~m}$ pyrolysis tube heated length, very long particle residence time due to particle levitation and sticking to pyrolysis tube wall, and $6.59 \mathrm{~s}$ secondary gas space-time.

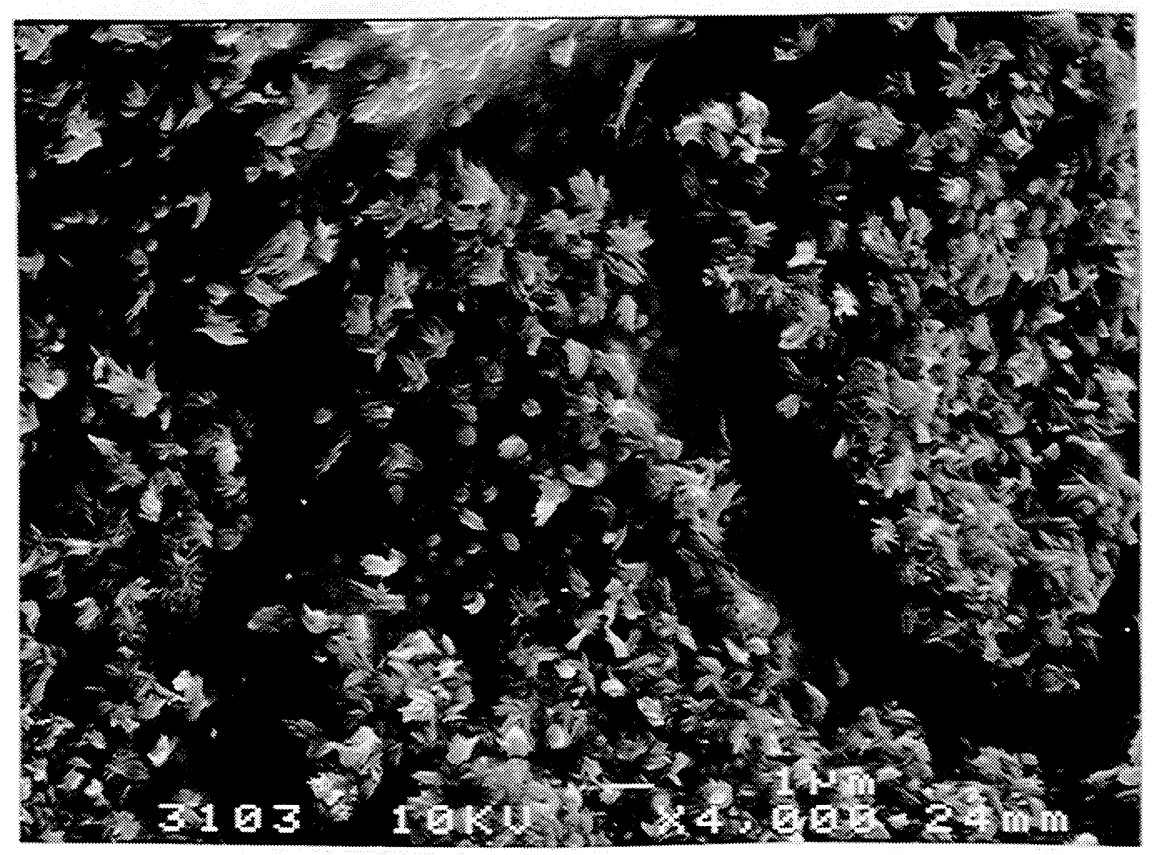

Figure 41. A SEM image of the surface of a char particle obtained with an acoustic field of $151 \mathrm{~dB}$ and $980 \mathrm{~Hz}(\mathrm{RACl} 226)$ under reactor conditions of $550^{\circ} \mathrm{C}, 0.81 \mathrm{~m}$ pyrolysis tube heated length, $3.69 \mathrm{~s}$ particle residence time, and $6.59 \mathrm{~s}$ secondary gas space-time. 


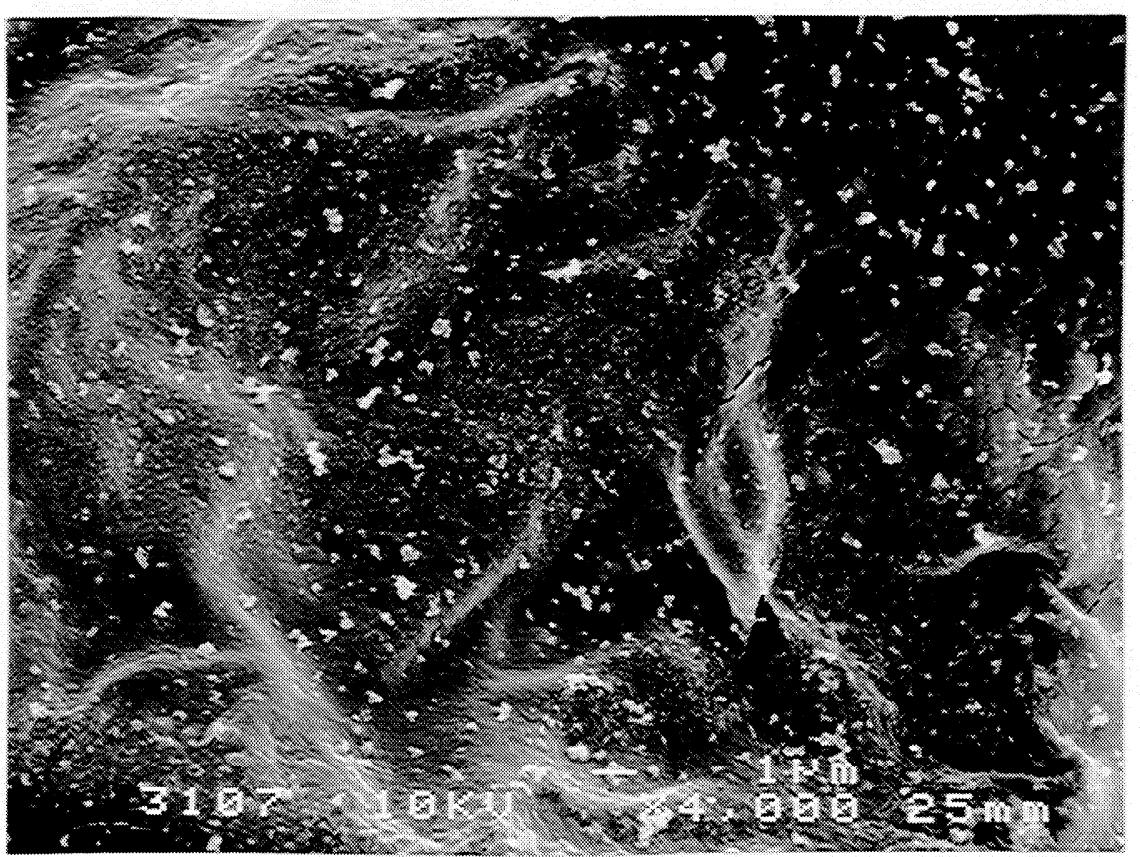

Figure 42. A SEM image of the surface of a char particle obtained with an acoustic field of $158 \mathrm{~dB}$ and $970 \mathrm{~Hz}$ (RAC1224) under reactor conditions of $550^{\circ} \mathrm{C}, 0.81 \mathrm{~m}$ pyrolysis tube heated length, very long particle residence time due to particle levitation and sticking to pyrolysis tube wall, and $6.59 \mathrm{~s}$ secondary gas space-time.

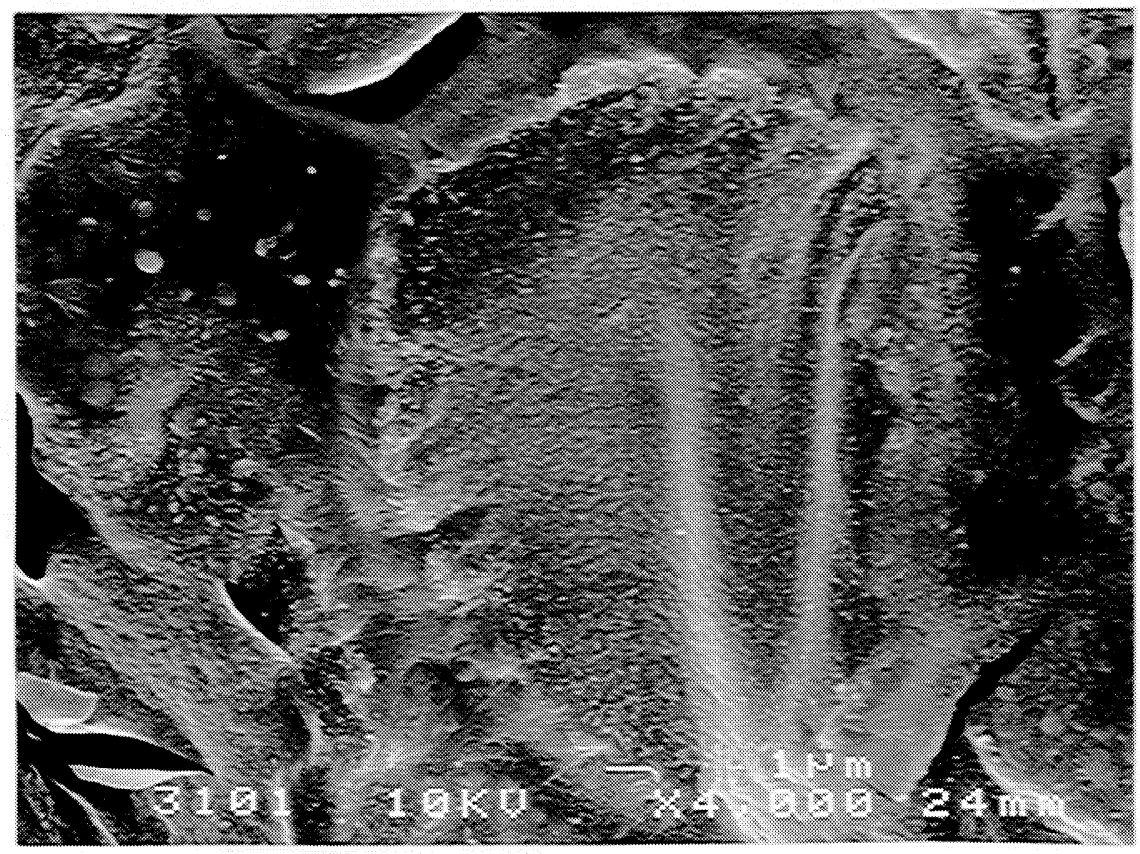

Figure 43. A SEM image of the surface of a char particle obtained with an acoustic field of $151 \mathrm{~dB}$ and $970 \mathrm{~Hz}(\mathrm{RAC1108})$ under reactor conditions of $550^{\circ} \mathrm{C}, 0.48 \mathrm{~m}$ pyrolysis tube heated length, $0.70 \mathrm{~s}$ average particle residence time, and $1.02 \mathrm{~s}$ secondary gas space-time. 


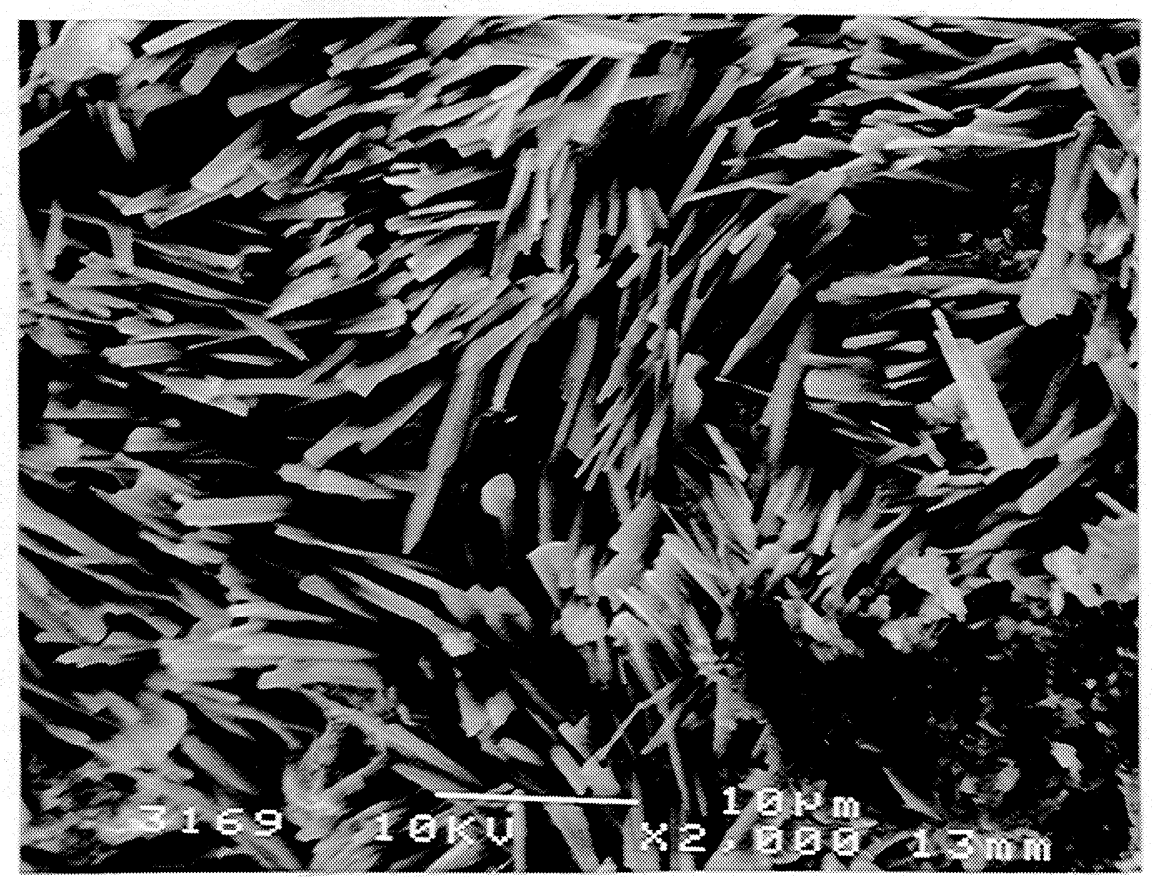

Figure 44. A SEM picture of the exterior surface of the char structure obtained with a steelwool-plug (RNAC1019) located at $0.13 \mathrm{~m}$ downstream from the particle injection point under reactor conditions of $550^{\circ} \mathrm{C}, 0.81 \mathrm{~m}$ pyrolysis tube heated length, and 3.39 s secondary gas space-time.

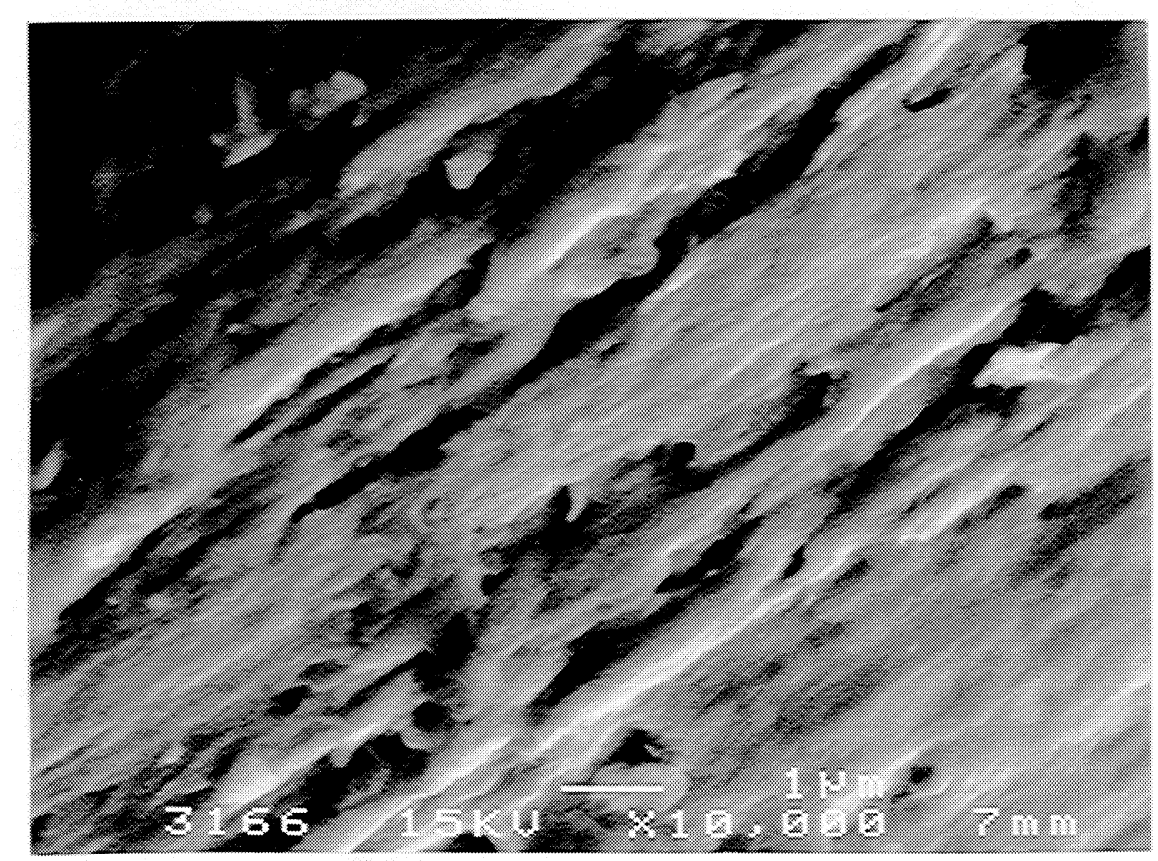

Figure 45. A SEM picture of the exterior surface of a steel-wool-fiber (RNAC1019) located near the pyrolysis tube wall away from the tar product flow obtained with the steel-wool-plug located at $0.13 \mathrm{~m}$ downstream from the particle injection point under reactor conditions of $550^{\circ} \mathrm{C}, 0.81 \mathrm{~m}$ pyrolysis tube heated length, and $3.39 \mathrm{~s}$ secondary gas space-time. 


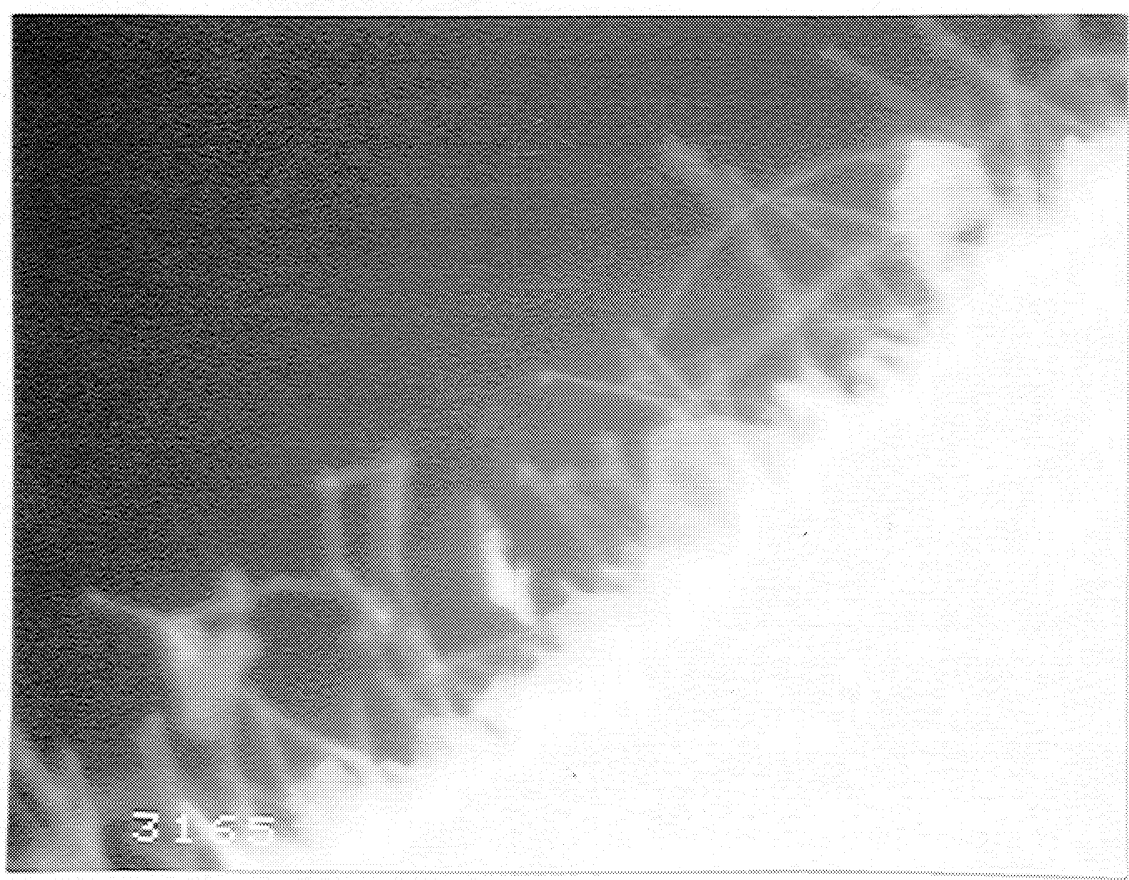

Figure 46. A SEM picture of the exterior surface of a steel-wool-fiber (RNAC1019) located near the pyrolysis tube wall away from the tar product flow obtained with the steel-wool-plug located at $0.13 \mathrm{~m}$ downstream from the particle injection point under reactor conditions of $550^{\circ} \mathrm{C}, 0.81 \mathrm{~m}$ pyrolysis tube heated length, and $3.39 \mathrm{~s}$ secondary gas space-time.

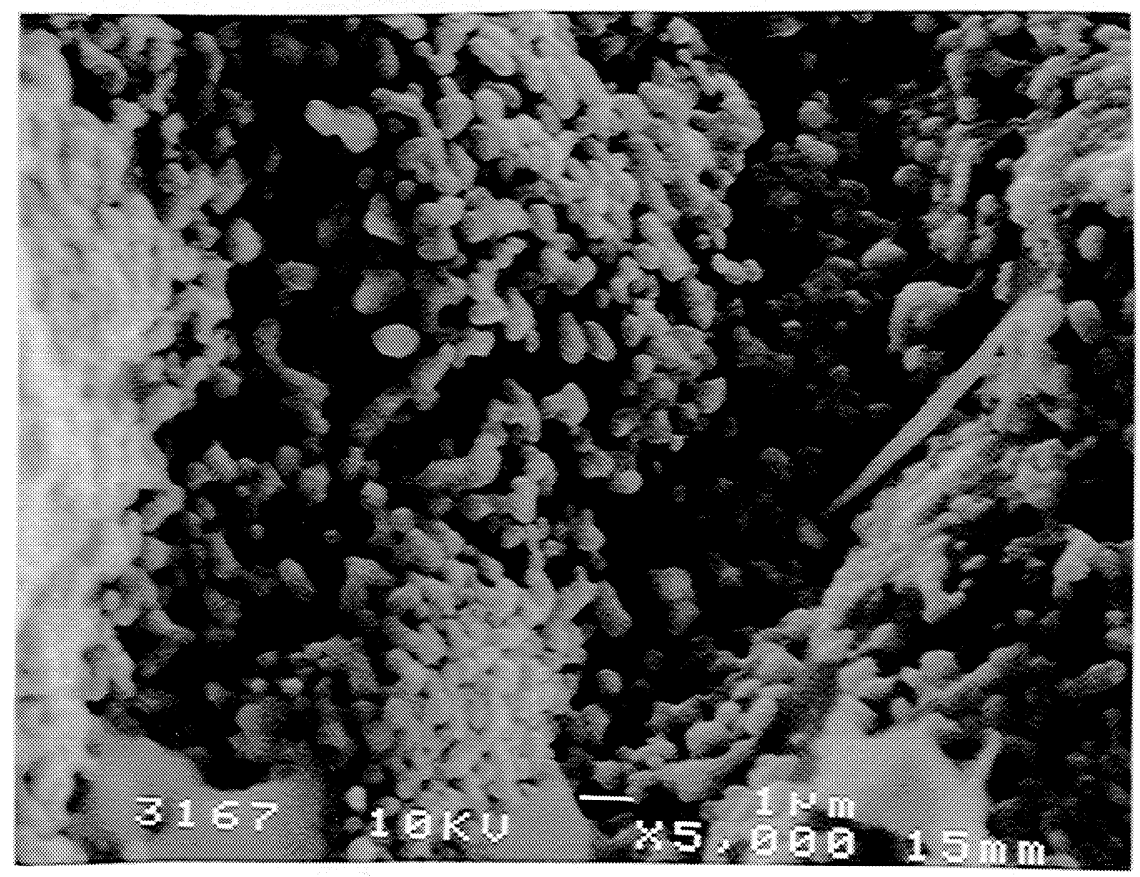

Figure 47. A SEM picture of the interior surface of the char structure obtained with a steelwool-plug (RNAC1019) located at $0.13 \mathrm{~m}$ downstream from the particle injection point under reactor conditions of $550^{\circ} \mathrm{C}, 0.81 \mathrm{~m}$ pyrolysis tube heated length, and $3.39 \mathrm{~s}$ secondary gas space-time. 


\section{[5.1.3.3] Morphology of Char Particles Obtained at a Gas Temperature of $700^{\circ} \mathrm{C}$}

- With an acoustic field of $151 \mathrm{~dB}$ and $960 \mathrm{~Hz}$ (RAC1126A) char particles are much more swollen compared to those without acoustics (RNAC1123), as shown in Figs. 48 and 49, respectively.

- With acoustics, particle swelling was completed within a particle residence time of $0.25 \mathrm{~s}$, or $0.18 \mathrm{~m}$ pyrolysis tube heated length, which is indicated by comparing the extents of swelling and surface bubbling of char particles obtained from RAC1126A as shown in Fig. 46 with those obtained using the $0.48 \mathrm{~m}$ (RAC1130) and $0.81 \mathrm{~m}$ (RAC1126B) pyrolysis tube heated lengths, as shown in Figs. 50 and 51, respectively.

- Figs. 49 and 52 (RNAC1127) indicate that char particle swelling continues into the $0.48 \mathrm{~m}$ pyrolysis tube heated length without the presence of an acoustic field. The SEM results cannot conclude that particles swelling continues into the $0.81 \mathrm{~m}$ pyrolysis tube heated length without acoustics (RNAC1122), as shown by a larger diameter char particle in Fig. 53, because of variability in the char particle diameters.

- Maximum particle diameter was typically about $600 \mu \mathrm{m}$ for experiments with and without acoustics. 


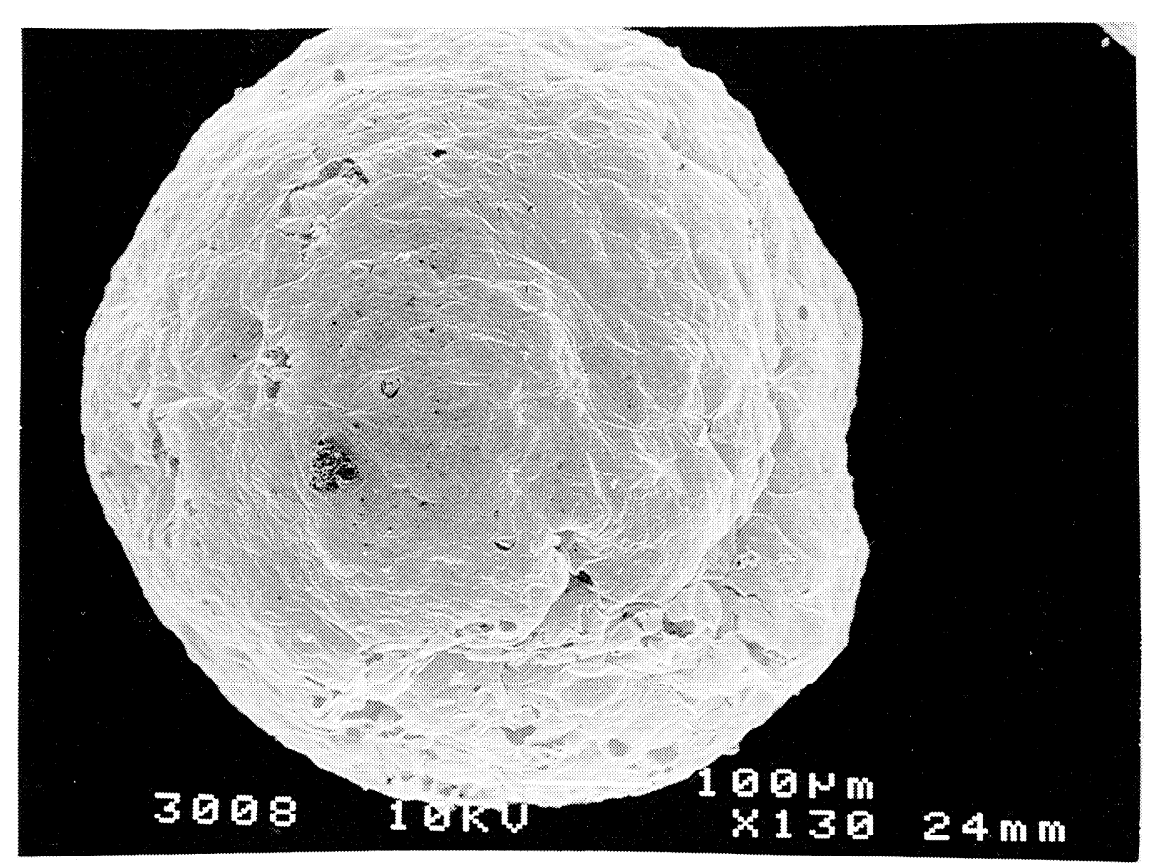

Figure 48. A SEM image of a single char particle obtained with an acoustic field of $151 \mathrm{~dB}$ and $960 \mathrm{~Hz}(\mathrm{RAC1} 126 \mathrm{~A})$ under reactor conditions of $700^{\circ} \mathrm{C}, 0.18 \mathrm{~m}$ pyrolysis tube heated length, $0.25 \mathrm{~s}$ particle residence time, and $0.32 \mathrm{~s}$ secondary gas space-time.

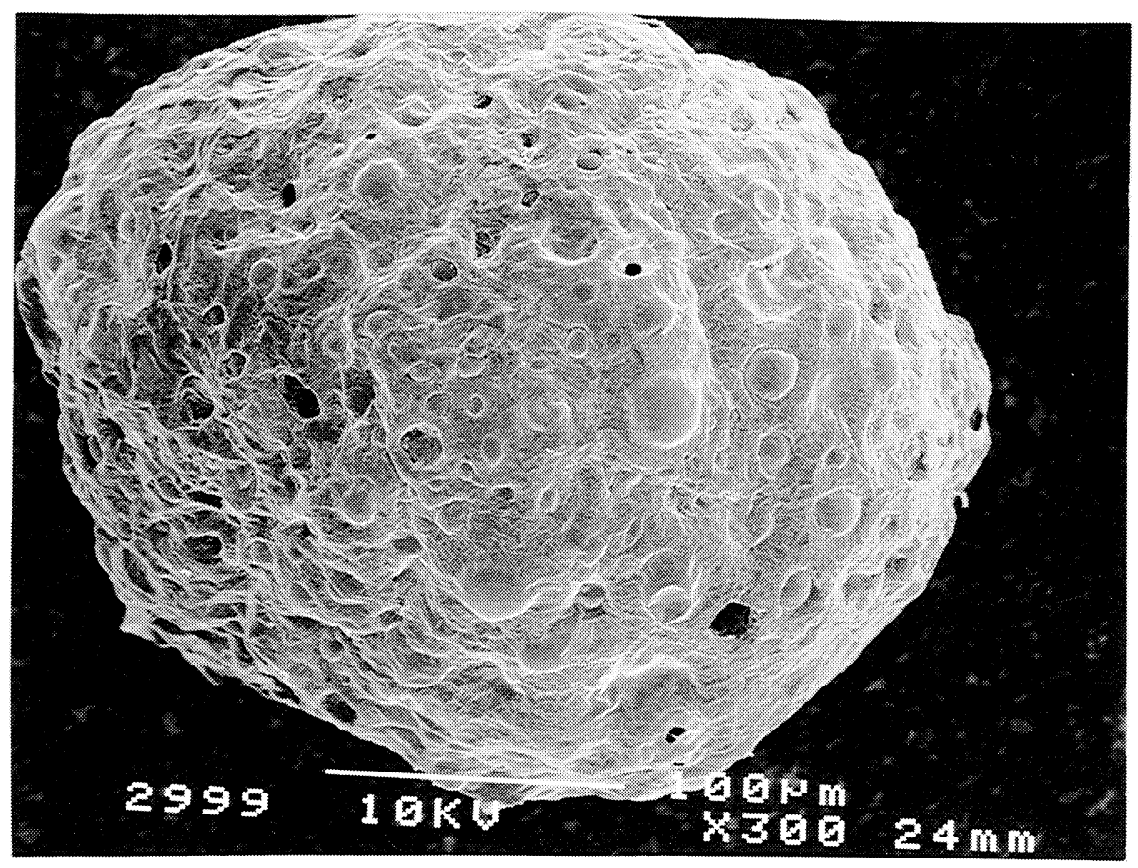

Figure 49. A SEM image of a single char particle obtained without acoustics (RNAC1123) under reactor conditions of $700^{\circ} \mathrm{C}, 0.18 \mathrm{~m}$ pyrolysis tube heated length, $0.21 \mathrm{~s}$ particle residence time, and $0.32 \mathrm{~s}$ secondary gas space-time. 


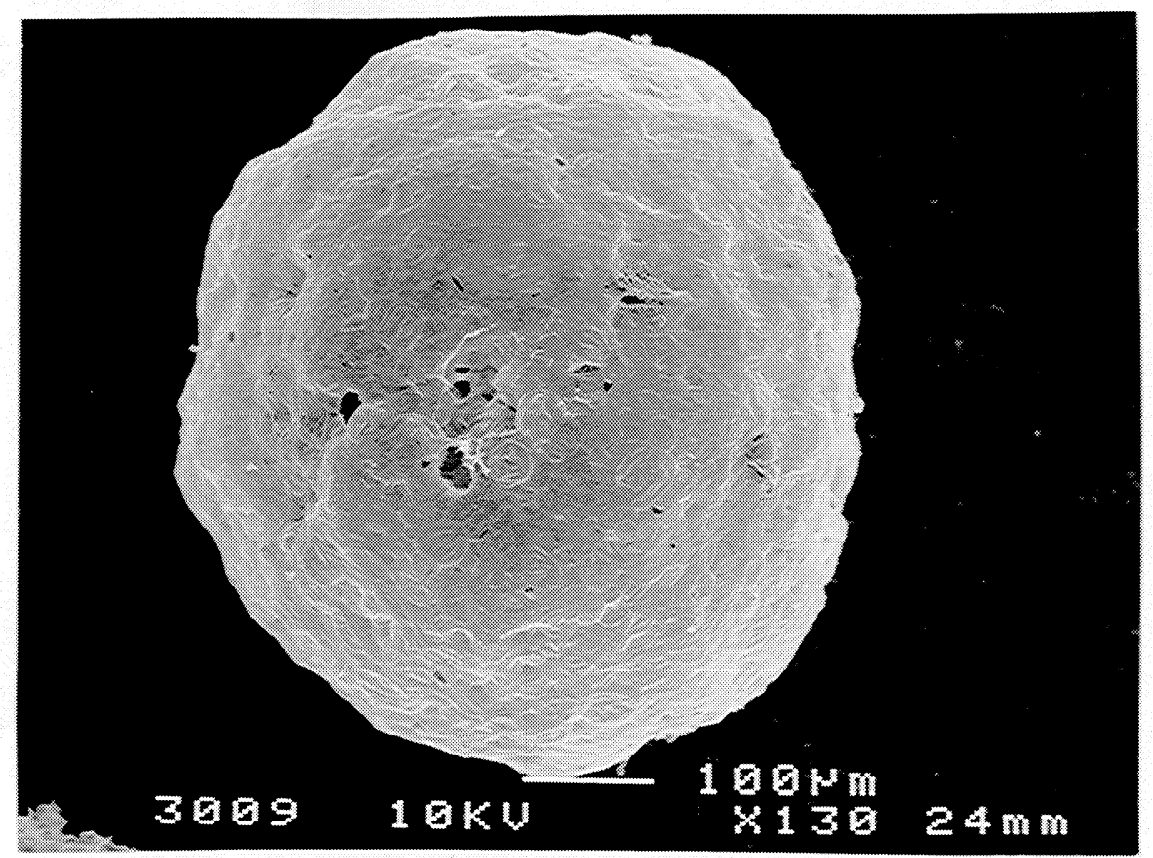

Figure 50. A SEM image of a single char particle obtained with an acoustic field of $151 \mathrm{~dB}$ and $990 \mathrm{~Hz}$ (RAC1130) under reactor conditions of $700^{\circ} \mathrm{C}, 0.48 \mathrm{~m}$ pyrolysis tube heated length, $0.64 \mathrm{~s}$ particle residence time, and $0.86 \mathrm{~s}$ secondary gas space-time.

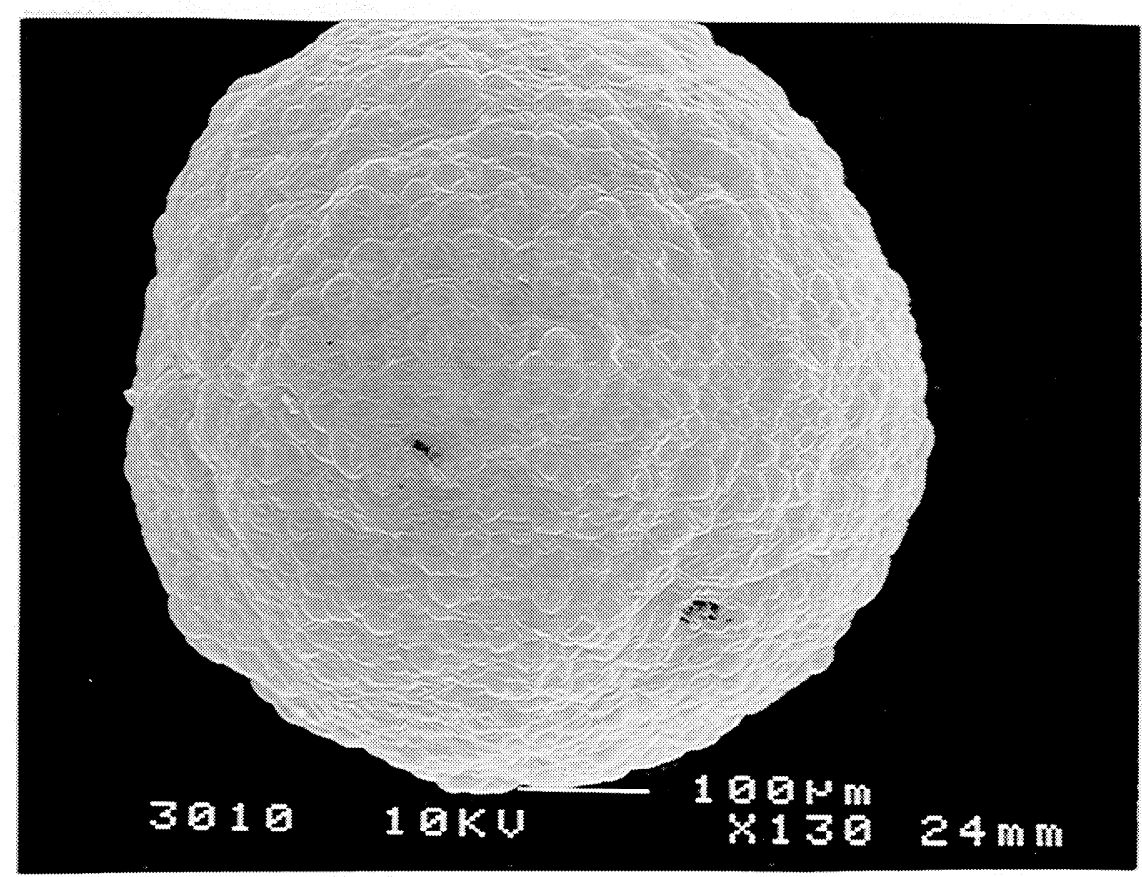

Figure 51. A SEM image of a single char particle obtained with an acoustic field of $151 \mathrm{~dB}$ and $950 \mathrm{~Hz}(\mathrm{RAC1} 126 \mathrm{~B})$ under reactor conditions of $700^{\circ} \mathrm{C}, 0.81 \mathrm{~m}$ pyrolysis tube heated length, $1.15 \mathrm{~s}$ particle residence time, and $1.46 \mathrm{~s}$ secondary gas space-time. 


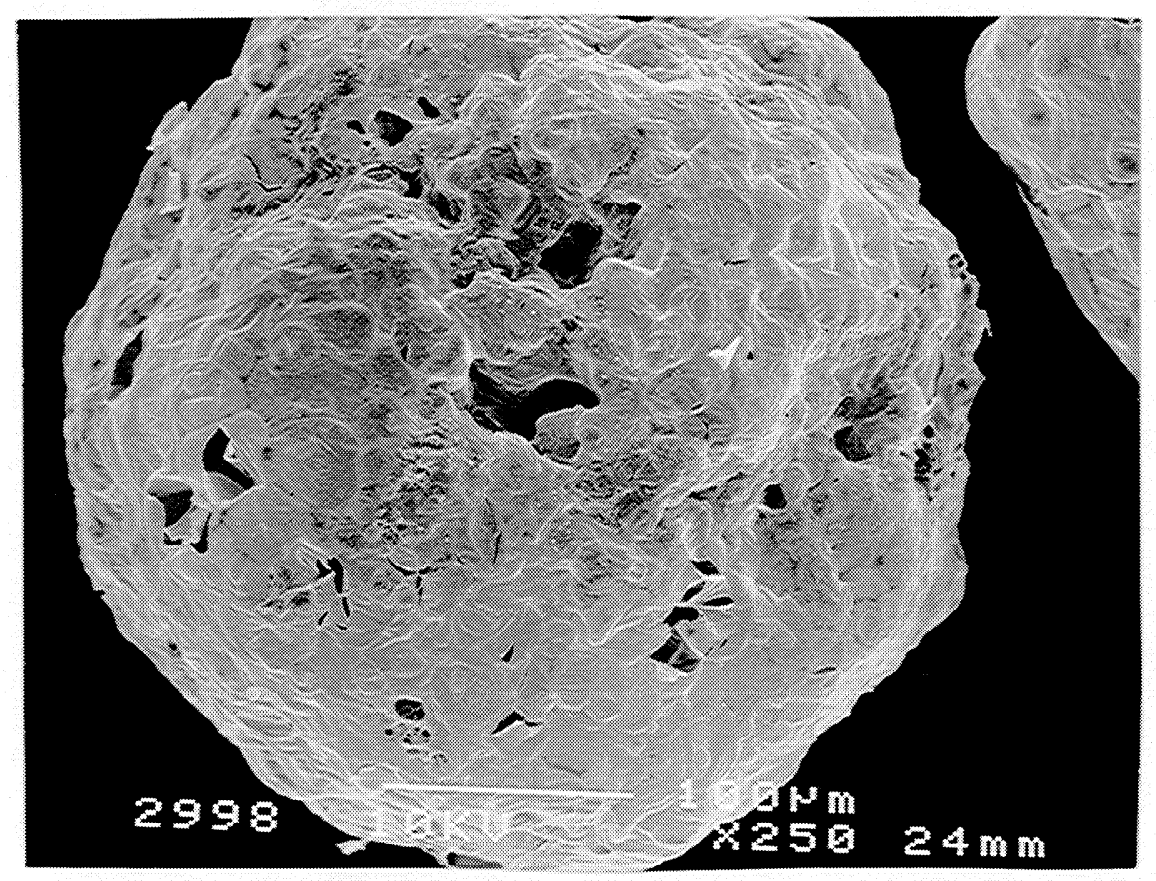

Figure 52. A SEM image of a single char particle obtained without acoustics (RNAC1127) under reactor conditions of $700^{\circ} \mathrm{C}, 0.48 \mathrm{~m}$ pyrolysis tube heated length, $0.49 \mathrm{~s}$ particle residence time, and $0.86 \mathrm{~s}$ secondary gas space-time.

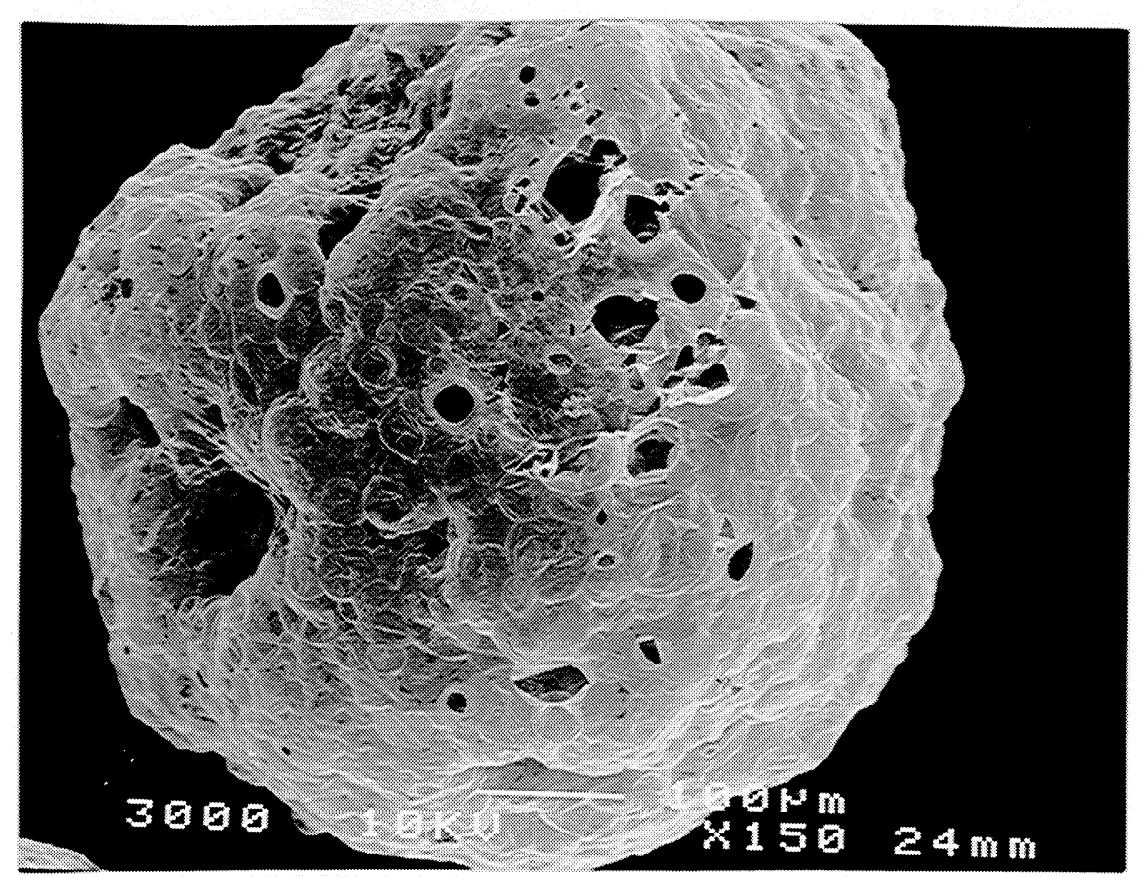

Figure 53. A SEM image of a single char particle obtained without acoustics (RNAC1122) under reactor conditions of $700^{\circ} \mathrm{C}, 0.81 \mathrm{~m}$ pyrolysis tube heated length, $0.82 \mathrm{~s}$ particle residence time, and $1.46 \mathrm{~s}$ secondary gas space-time. 


\section{[5.1.3.4] Conclusions}

Analysis of SEM images of char particles indicates:

- Average swelling rates of BLS particles were increased when pyrolyses were conducted with an acoustic field of $151 \mathrm{~dB}$ for gas temperatures between $400-700^{\circ} \mathrm{C}$. Maximum swollen diameters were increased from 300 to $600 \mu \mathrm{m}$ by increasing the peak gas temperature from 550 to $700^{\circ} \mathrm{C}$, respectively.

- The presence of numerous large bubbles that comprise the surface of chars obtained with acoustics at gas temperatures of 550 and $700^{\circ} \mathrm{C}$ or without acoustics at a gas temperature of $700^{\circ} \mathrm{C}$ indicates that pyrolysis was more severe compared to without acoustics at a gas temperature of $550^{\circ} \mathrm{C}$. This effect is suggested to be due to increased rate of particles heatup as a result of acoustics or use of higher peak temperature.

- Continuation of swelling into the $0.18-0.48 \mathrm{~m}$ pyrolysis tube heated length, or at particle residence times $>0.21-0.26 \mathrm{~s}$, indicates that pyrolysis reactions of particles or primary tar that produce a solid char or gases were not completed. For a gas temperature of $550^{\circ} \mathrm{C}$, the durations of swelling were about the same when using the $0.48 \mathrm{~m}$ pyrolysis tube heated length with acoustics and using the $0.81 \mathrm{~m}$ pyrolysis tube heated length without acoustics. When secondary gas space-times were increased to $3.39 \mathrm{~s}$ or longer in $550^{\circ} \mathrm{C}$ experiments, it was observed that particles had shrunk, which is an indication that primary pyrolysis reactions were completed. 
- It is inconclusive whether acoustics increased the rate of particle swelling at a gas temperature of $700^{\circ} \mathrm{C}$. A slightly shorter particle residence time in the $0.18 \mathrm{~m}$ heated length of the pyrolysis tube heated length without acoustics (RNAC1123) may not have allowed primary particle pyrolysis reactions to be completed, which would prevent attainment of the maximum particle diameter (RAC1126A).

- Tar released from particles can be redeposited on inflight char particles or on the exterior surfaces of char or steel-wool-fibers obtained from steel-wool-plug experiments. Tar released into gas bubbles within the char obtained from steel-wool-plug experiments can be redeposited on the interior surfaces of the char. Tar is more likely to be redeposited on inflight char particles when a particle has a long residence time in the pyrolysis tube.

\section{[5.1.4] SEM Analysis of Material Deposited of Glass-fiber Filters}

\section{[5.1.4.1] Morphology of Material Obtained at a Gas Temperature of $400^{\circ} \mathrm{C}$}

- A tarry liquid coating was deposited on the glass-fiber filter for all six experiments (RNAC113, RNAC1111, RNA21111, RNAC1112, RAC1119, and RAC1009) conducted at a gas temperature of $400^{\circ} \mathrm{C}$. No differences were observed among the tarry liquid coated filters. The color of the tarry liquid coated filters is tan to yellow. Fig. 54 shows a typical tarry liquid coated filter (from RNAC1113). Objects were magnified 5000 times their original size in all SEM images. 
- The ellipsoidal shape of the tar coated around the filter fiber, resulting from liquid surface tension forces, indicates the tar had been in a liquid state when it contacted the filters.

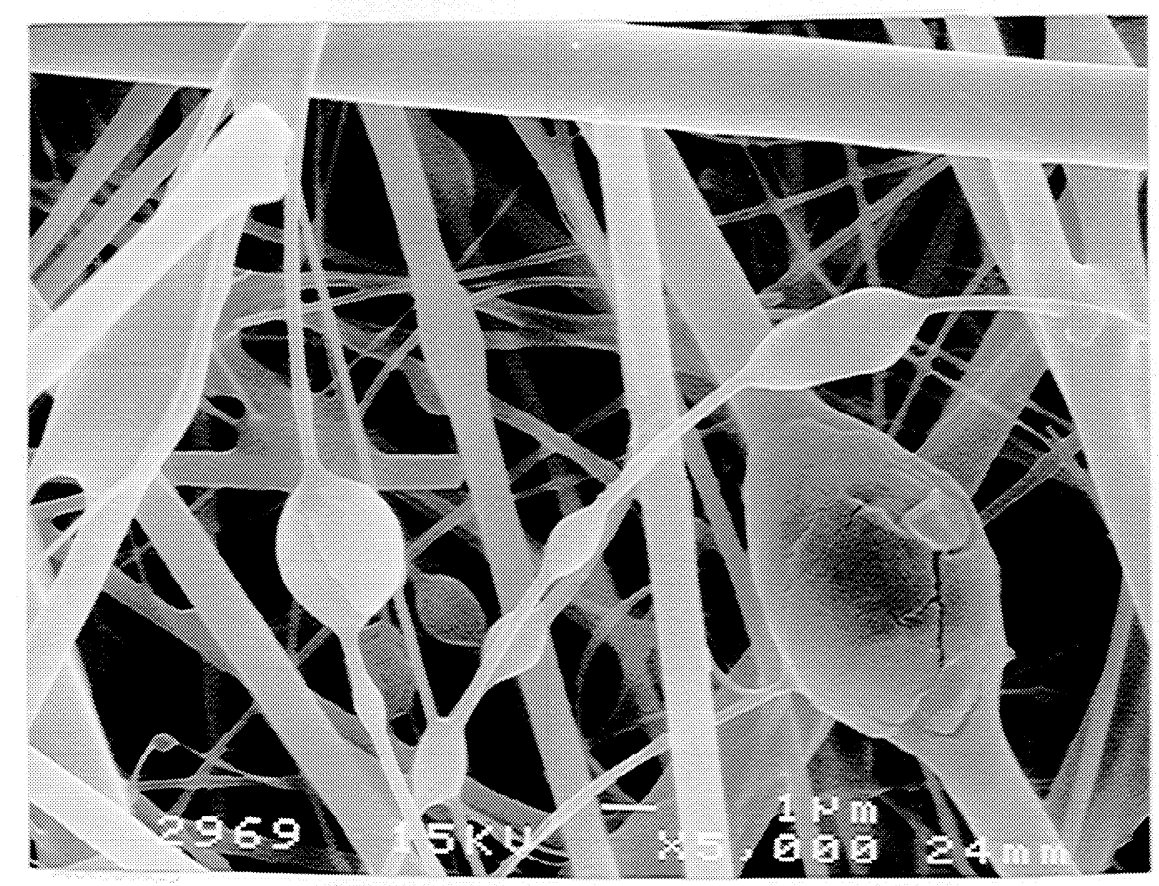

Figure 54. A SEM image of tarry liquid coated glass-fiber filter obtained without acoustics (RNAC1113) under reactor conditions of $400^{\circ} \mathrm{C}, 0.81 \mathrm{~m}$ pyrolysis tube heated length, $0.86 \mathrm{~s}$ particle residence time, and $2.10 \mathrm{~s}$ secondary gas space-time.

\section{[5.1.4.2] Morphology of Material Obtained at a Gas Temperature of $550^{\circ} \mathrm{C}$}

- Only tarry liquid was found on glass-fiber filters obtained from experiments (RNAC1105 and RNA21105) without an acoustics at a gas temperature of $550^{\circ} \mathrm{C}$ using the 0.18 and $0.48 \mathrm{~m}$ pyrolysis tube heated lengths as shown in Fig. 55. Tarry liquid was also found on the glassfiber filter obtained with an acoustic field of $151 \mathrm{~dB}$ and $1000 \mathrm{~Hz}$ at a gas temperature of $550^{\circ} \mathrm{C}$ using the $0.18 \mathrm{~m}$ pyrolysis tube heated length (RAC1107) as shown in Fig. 56. The color of the tarry liquid coated filters is $\tan$ to light brown. 
- Tar fume, e.g., pebble-like objects, were found on filters obtained without an acoustic field under conditions of $0.81 \mathrm{~m}$ pyrolysis tube heated length and secondary gas space-times of $1.72 \mathrm{~s}$ (RNAC918) and longer as shown in Fig. 57. Tar fume were also found on filters obtained with an acoustic field of $151 \mathrm{~dB}$ and $970-990 \mathrm{~Hz}$ under conditions of 0.48 or $0.81 \mathrm{~m}$ pyrolysis tube heated length and secondary gas space-times of $1.02,1.72$, and $6.59 \mathrm{~s}$ (RAC1108, RAC925B, and RAC1226, respectively), as shown in Figs. 58-60. The color of the tar fume coated filters is dark brown.

- Growth of blade- or thorn-like carbon fibrils that are similar to the more developed fibrils shown in Fig. 44 can also be seen on tar fume from experiment RAC1226, as shown in Fig. 60, which indicates that fume was probably levitated for a long time.

- For an acoustic field of $158 \mathrm{~dB}$ (RAC1224), tarry liquid was redeposited on fume particles when the secondary gas space-time was extended to $6.39 \mathrm{~s}$ as indicated in Fig. 61 by larger and less jagged clumps of fume particles that are bonded together by a liquid material compared to the more defined individual particles shown in Fig. 60 .

- BLS particles were pulsed fed for $10 \mathrm{~s}$ on and $10 \mathrm{~s}$ off in an experiment conducted at $158 \mathrm{~dB}$ (RAC1230) to reduce particle sticking to the pyrolysis tube wall, to reduce tar acousticallyinduced fume agglomeration (Zebel, 1966), and to reduce tarry liquid deposition onto char particles. Tar fume deposited on the glass-fiber filter were found to be much smaller and less agglomerated as shown in Fig. 62 compared to those from acoustics experiment with continuous particle feeding as shown in Figs. 58-61 because the tar concentration in the reactor was not as high as that obtained during continuous particle feeding experiments. 
- Only tarry liquid coating was observed on glass-fiber filters obtained from steel-wool-plug experiments, as shown in Fig 63. This is consistent with Fig. 47 that showed tar fume trapped inside the pyrolyzing char structure deposited on the steel-wool-plug.

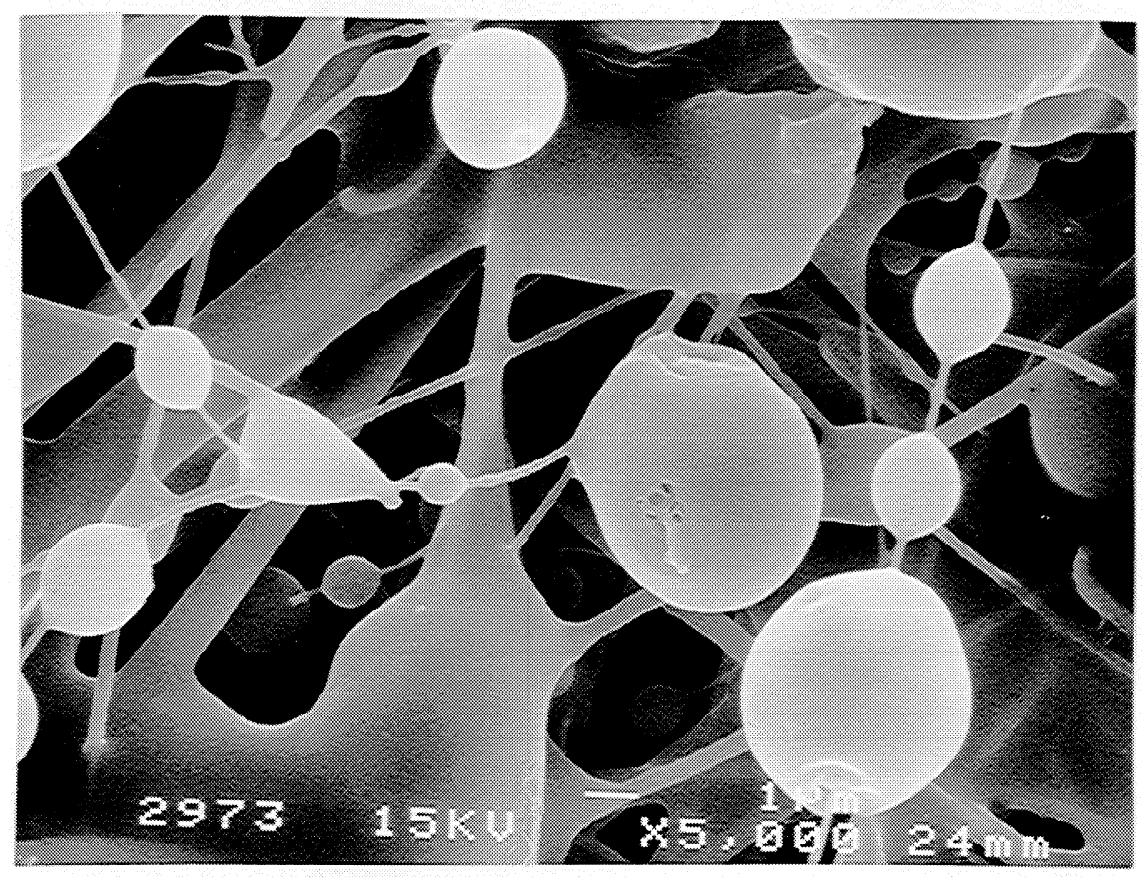

Figure 55. A SEM image of tarry liquid coated glass-fiber filter obtained without acoustics (RNAC1105) under reactor conditions of $550^{\circ} \mathrm{C}, 0.18 \mathrm{~m}$ pyrolysis tube heated length, $0.23 \mathrm{~s}$ particle residence time, and 0.32 or $1.02 \mathrm{~s}$ secondary gas space-time. 


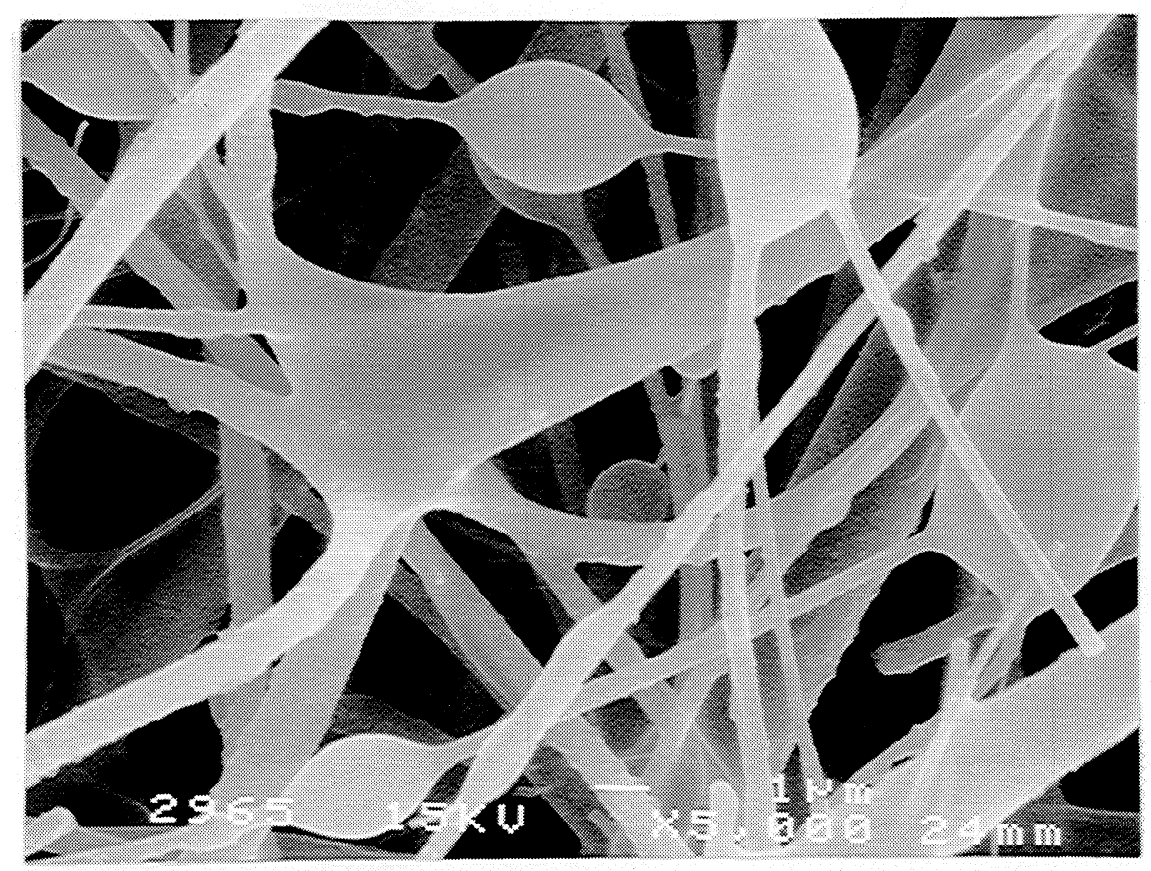

Figure 56. A SEM image of tarry liquid coated glass-fiber filter obtained with an acoustic field of $151 \mathrm{~dB}$ and $1000 \mathrm{~Hz}$ (RAC1107) under reactor conditions of $550^{\circ} \mathrm{C}$, $0.18 \mathrm{~m}$ pyrolysis tube heated length, $0.27 \mathrm{~s}$ particle residence time, and $0.32 \mathrm{~s}$ secondary gas space-time.

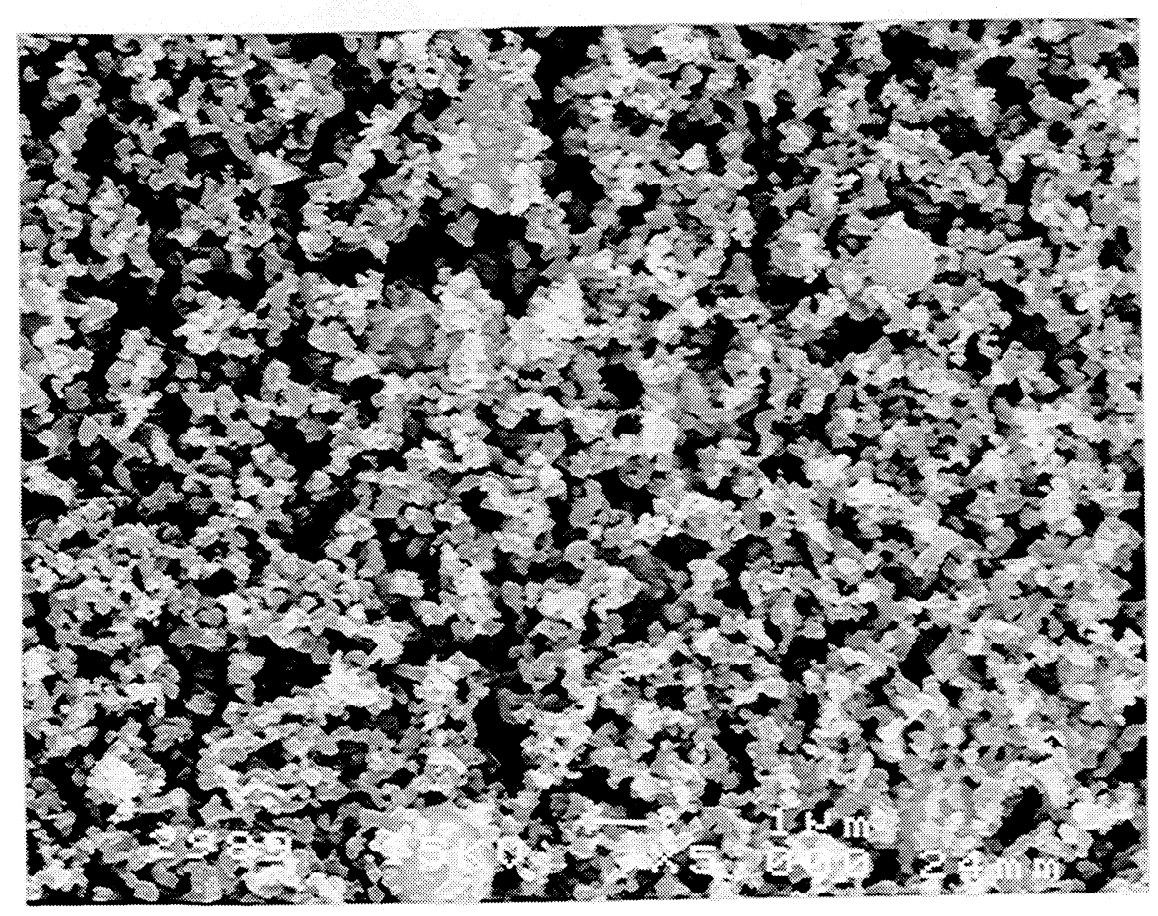

Figure 57. A SEM image of tar fume coated glass-fiber filter obtained without acoustics (RNAC918) under reactor conditions of $550^{\circ} \mathrm{C}, 0.81 \mathrm{~m}$ pyrolysis tube heated length, $0.90 \mathrm{~s}$ particle residence time, and $1.72 \mathrm{~s}$ secondary gas space-time. 


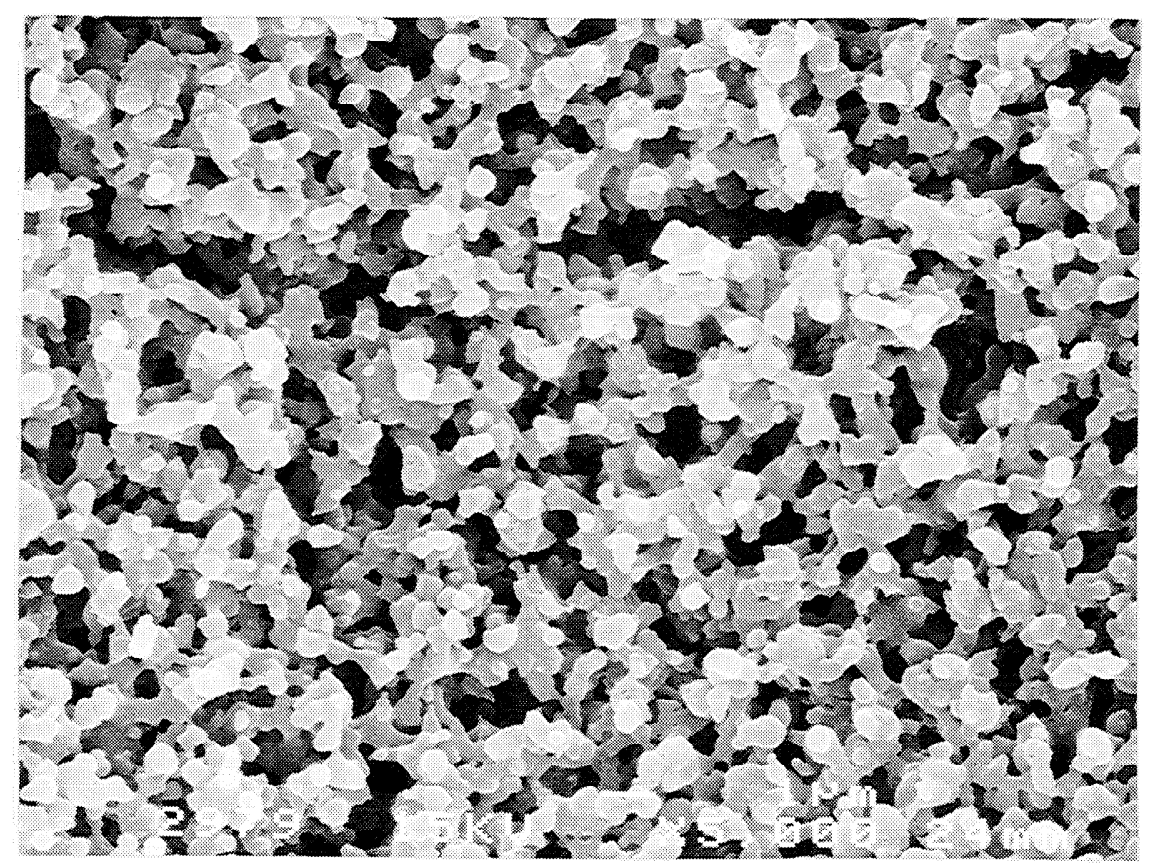

Figure 58. A SEM image of tar fume coated glass-fiber filter obtained with an acoustic field of $151 \mathrm{~dB}$ and $970 \mathrm{~Hz}(\mathrm{RAC1} 108)$ under reactor conditions of $550^{\circ} \mathrm{C}, 0.48 \mathrm{~m}$ pyrolysis tube heated length, $0.70 \mathrm{~s}$ particle residence time, and $1.02 \mathrm{~s}$ secondary gas space-time.

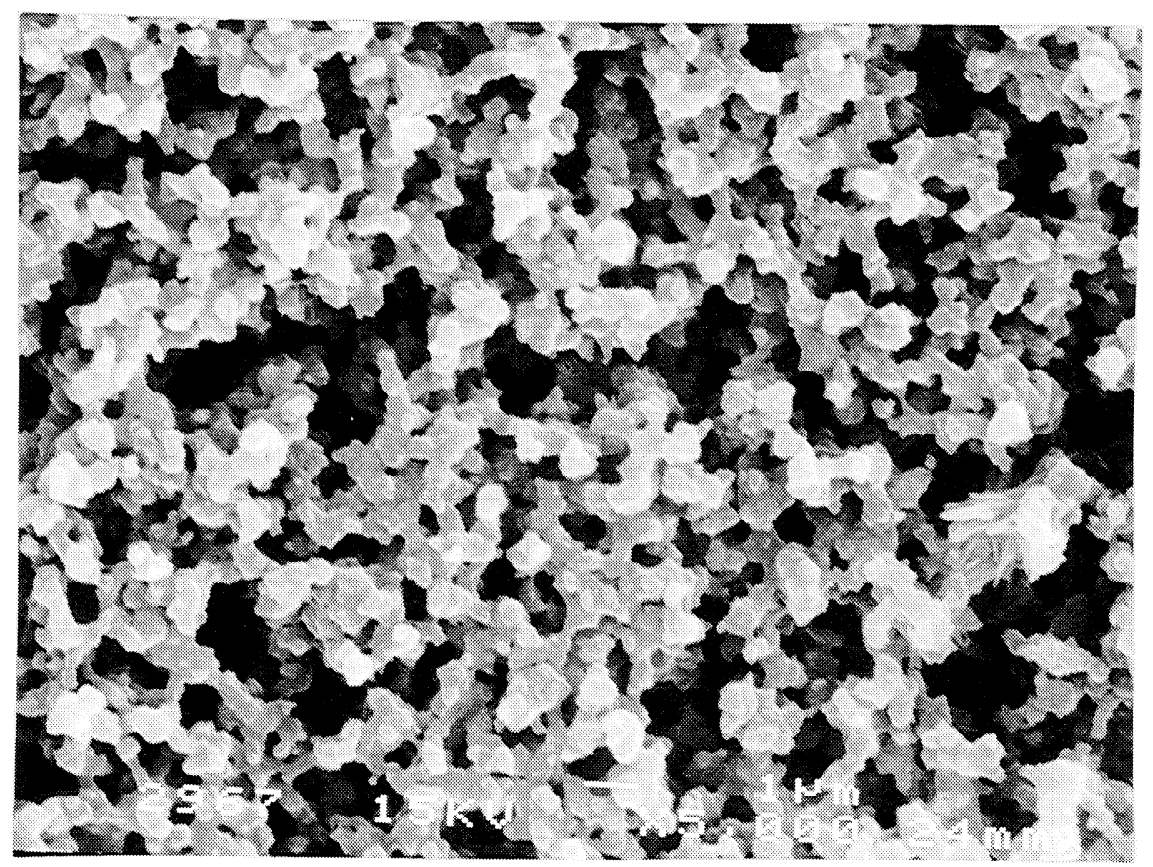

Figure 59. A SEM image of tar fume coated glass-fiber filter obtained with an acoustic field of $151 \mathrm{~dB}$ and $990 \mathrm{~Hz}(\mathrm{RAC} 925 \mathrm{~B})$ under reactor conditions of $550^{\circ} \mathrm{C}, 0.81 \mathrm{~m}$ pyrolysis tube heated length, $1.26 \mathrm{~s}$ particle residence time, and $1.72 \mathrm{~s}$ secondary gas space-time. 


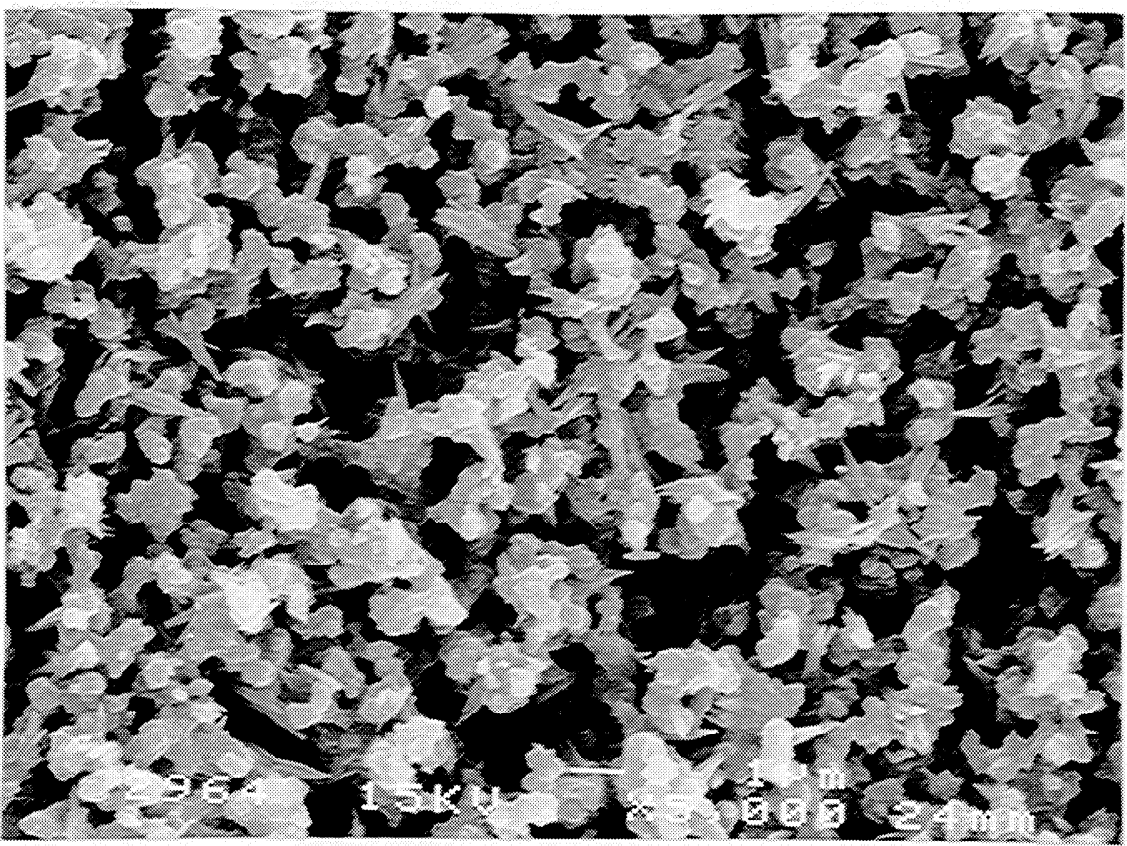

Figure 60. A SEM image of tar fume and carbon fibril coated glass-fiber filter obtained with an acoustic field of $151 \mathrm{~dB}$ and $980 \mathrm{~Hz}$ (RAC1226) under reactor conditions of $550^{\circ} \mathrm{C}, 0.81 \mathrm{~m}$ pyrolysis tube heated length, $3.69 \mathrm{~s}$ particle residence time, and $6.59 \mathrm{~s}$ secondary gas space-time. Carbon fibrils resemble elongated, blade-like objects compared to tar fume pebble-like objects.

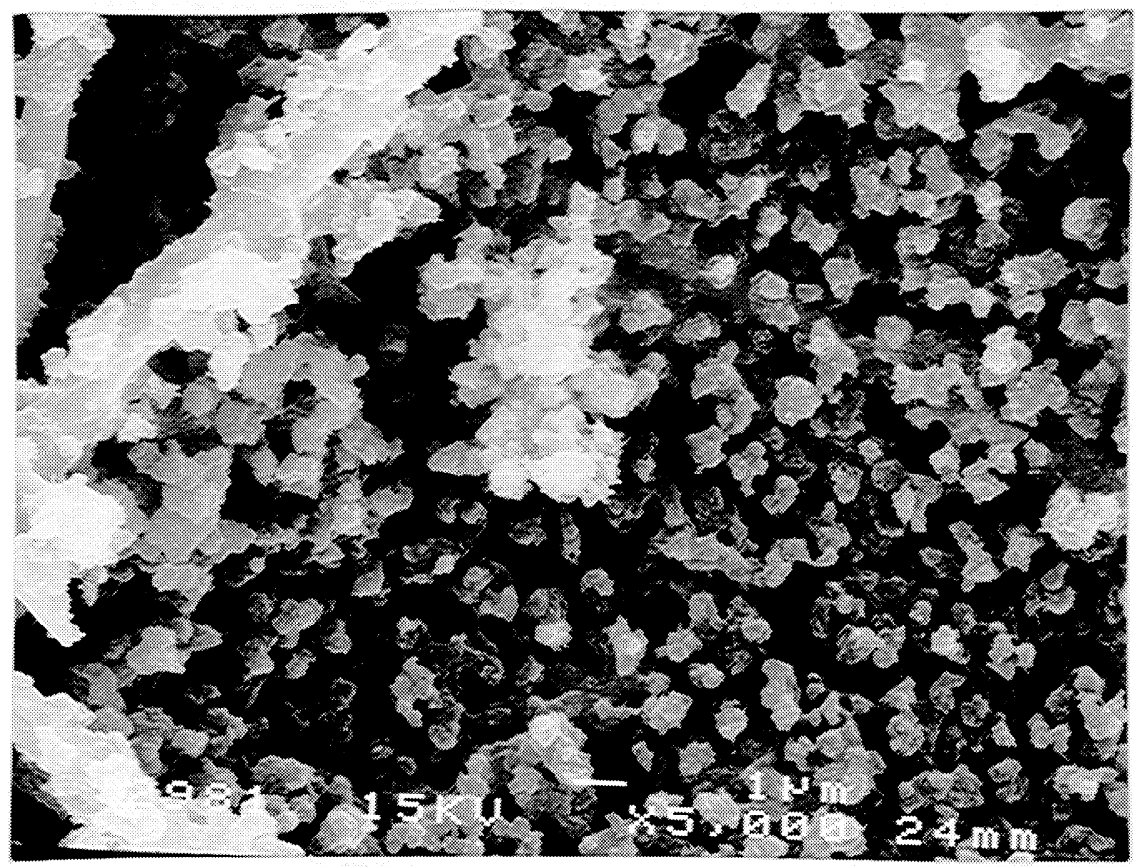

Figure 61. A SEM image of tarry liquid covered tar fume clumps that coated the glass-fiber filter obtained with an acoustic field of $158 \mathrm{~dB}$ and $970 \mathrm{~Hz}$ (RAC1224) under reactor conditions of $550^{\circ} \mathrm{C}, 0.81 \mathrm{~m}$ pyrolysis tube heated length, very long particle residence time due to particle levitation and sticking to pyrolysis tube wall, and 6.59 s secondary gas space-time. 


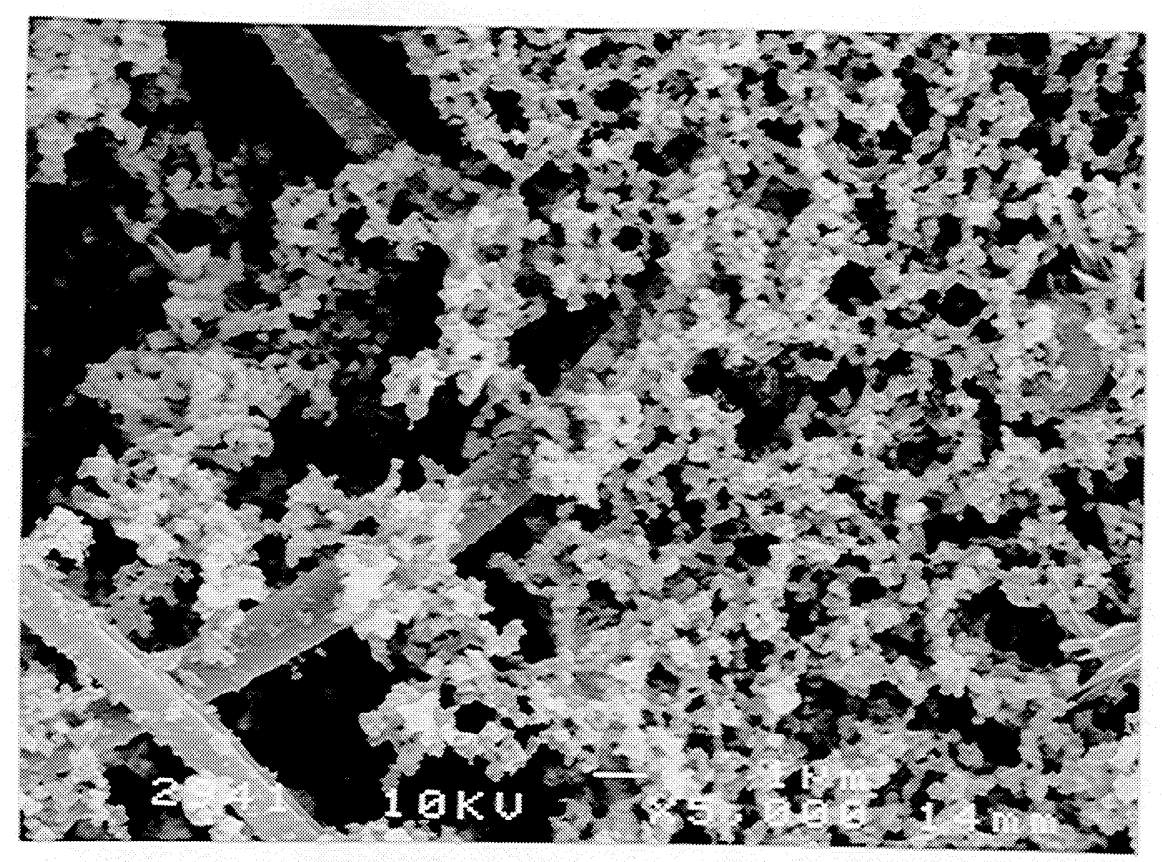

Figure 62. A SEM image of tar fume coated glass-fiber filter obtained with an acoustic field of $158 \mathrm{~dB}$ and $970 \mathrm{~Hz}$ (RAC1230) under reactor conditions of $550^{\circ} \mathrm{C}, 0.81 \mathrm{~m}$ pyrolysis tube heated length, $3.91 \mathrm{~s}$ particle residence time, $3.39 \mathrm{~s}$ secondary gas space-time, and $10 \mathrm{~s}$ on and $10 \mathrm{~s}$ off pulsed feeding of BLS particles.

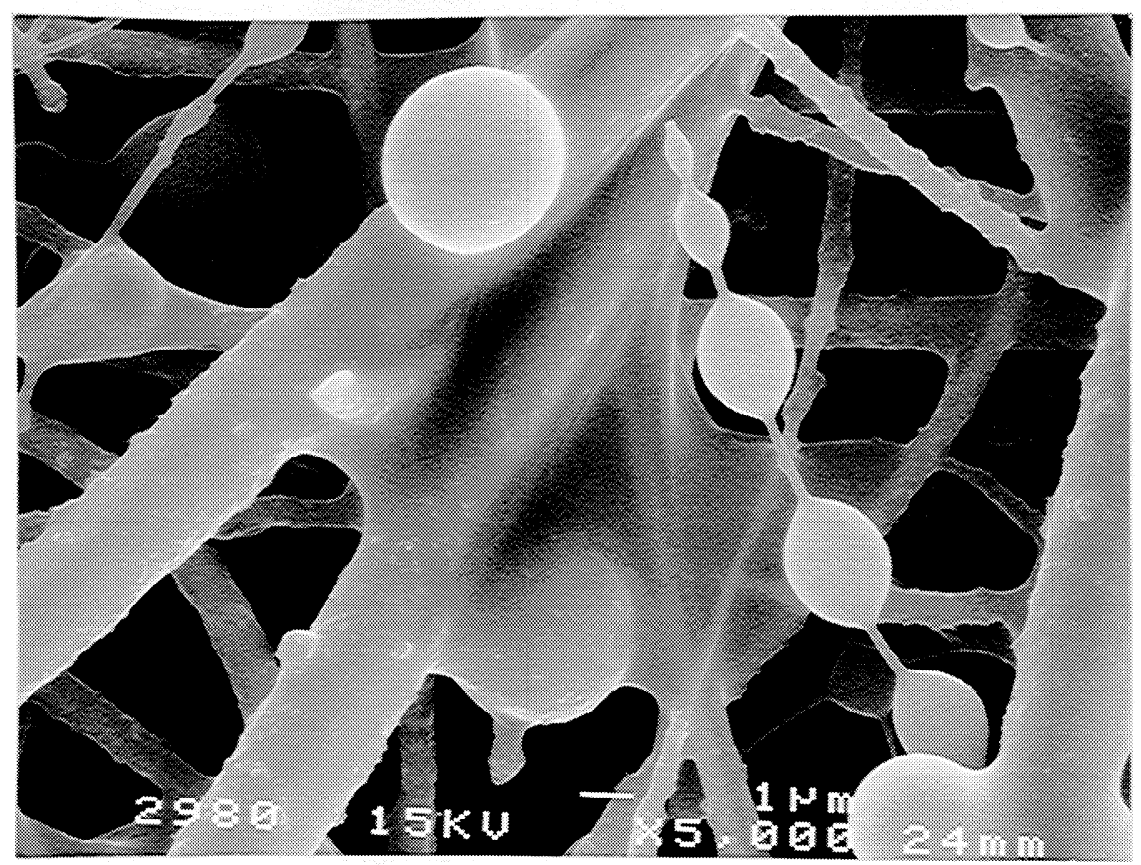

Figure 63. A SEM image of typical tarry liquid coated glass-fiber filter obtained with a steel-wool-plug located $0.13 \mathrm{~m}$ downstream from the particle injection tube exit (RNAC1019) under reactor conditions of $550^{\circ} \mathrm{C}, 0.81 \mathrm{~m}$ pyrolysis tube heated length, and $3.39 \mathrm{~s}$ secondary gas space-time. 


\section{[5.1.4.3] Morphology of Material Obtained at a Gas Temperature of $700^{\circ} \mathrm{C}$}

- Mostly tarry liquids but very little tar fume were observed on the glass-fiber filter obtained without acoustics using the 0.18 pyrolysis tube heated length (RNAC1123) as shown in Fig. 64. Both tarry liquids and fume were observed on the glass-fiber filters obtained without acoustics using 0.48 and $0.81 \mathrm{~m}$ pyrolysis tube heated lengths and 0.86 and $1.46 \mathrm{~s}$ secondary gas space-times (RNAC1127 and RNAC1123) as shown in Figs. 65 and 66, respectively.

- Both tarry liquids and fume were observed on the glass-fiber filters obtained with an acoustic field of $151 \mathrm{~dB}$ and $950-990 \mathrm{~Hz}$ using $0.18,0.48$, and $0.81 \mathrm{~m}$ pyrolysis tube lengths and 0.32 , 0.86 , and $1.46 \mathrm{~s}$ secondary gas space-times (RAC1126A, RAC1127, and RAC1130B) as shown in Figs. 65-69, respectively. It can be seen that small fume particles were agglomerated into larger clumps with acoustics and that tarry liquids coating the fume in RAC1126A as shown in Fig 67 quickly disappeared by secondary cracking in RAC1127 as shown in Fig. 68. 


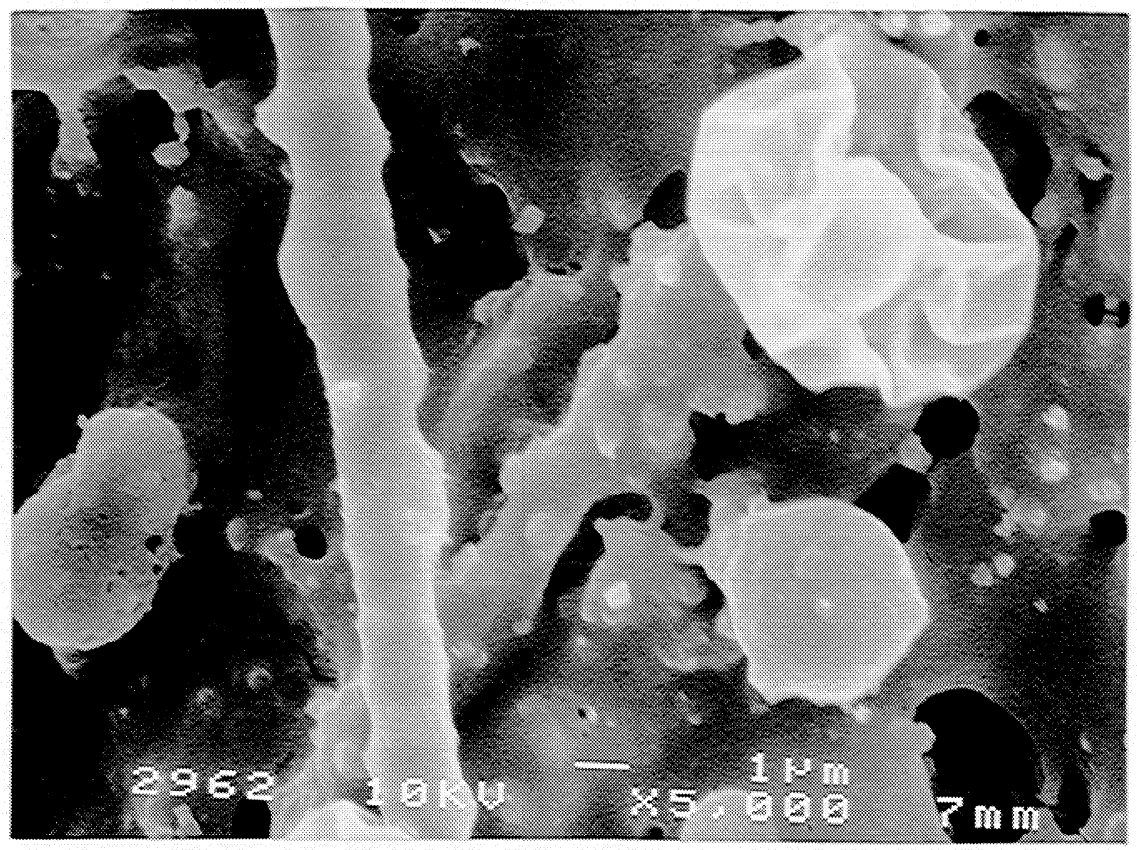

Figure 64. A SEM image of tar coated glass-fiber filter obtained without acoustics (RNAC1123) under reactor conditions of $700^{\circ} \mathrm{C}, 0.18 \mathrm{~m}$ pyrolysis tube heated length, $0.21 \mathrm{~s}$ particle residence time, and $0.32 \mathrm{~s}$ secondary gas space-time.

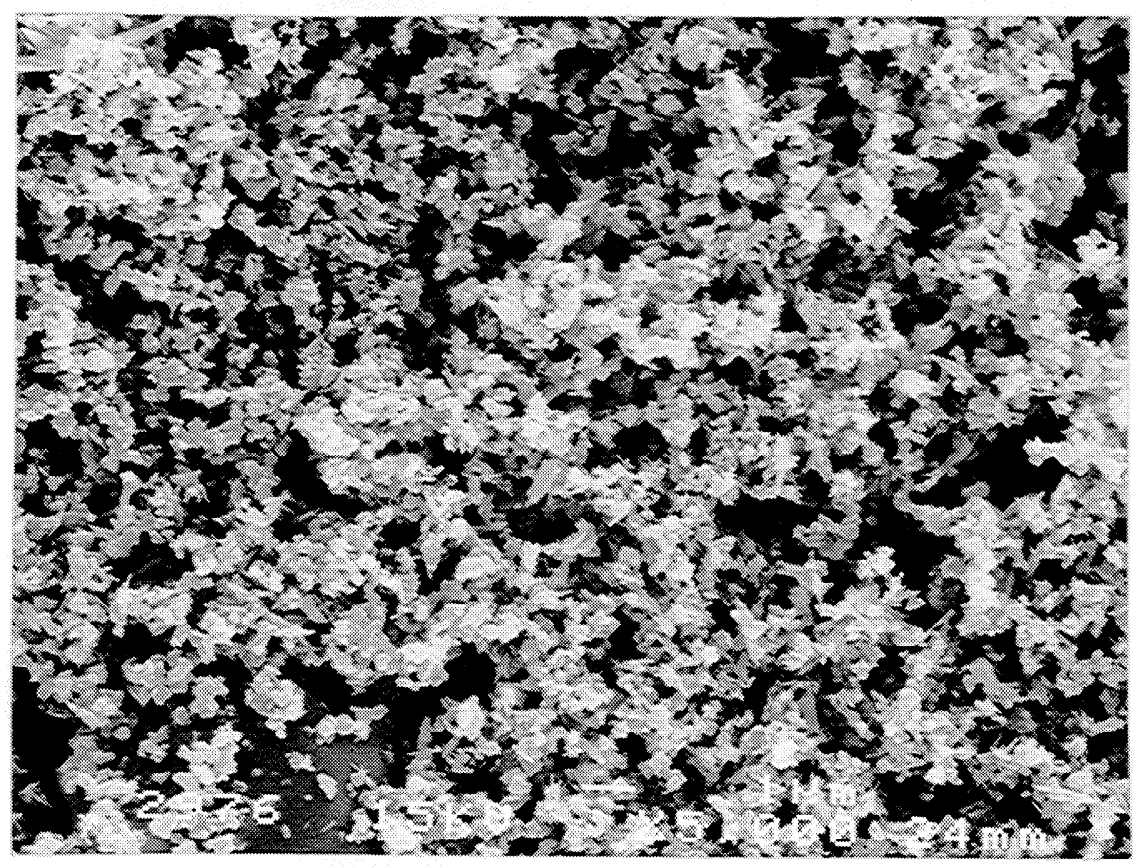

Figure 65. A SEM image of fume coated glass-fiber filter obtained without acoustics (RNAC1127) under reactor conditions of $700^{\circ} \mathrm{C}, 0.48 \mathrm{~m}$ pyrolysis tube heated length, $0.49 \mathrm{~s}$ particle residence time, and $0.86 \mathrm{~s}$ secondary gas space-time. 


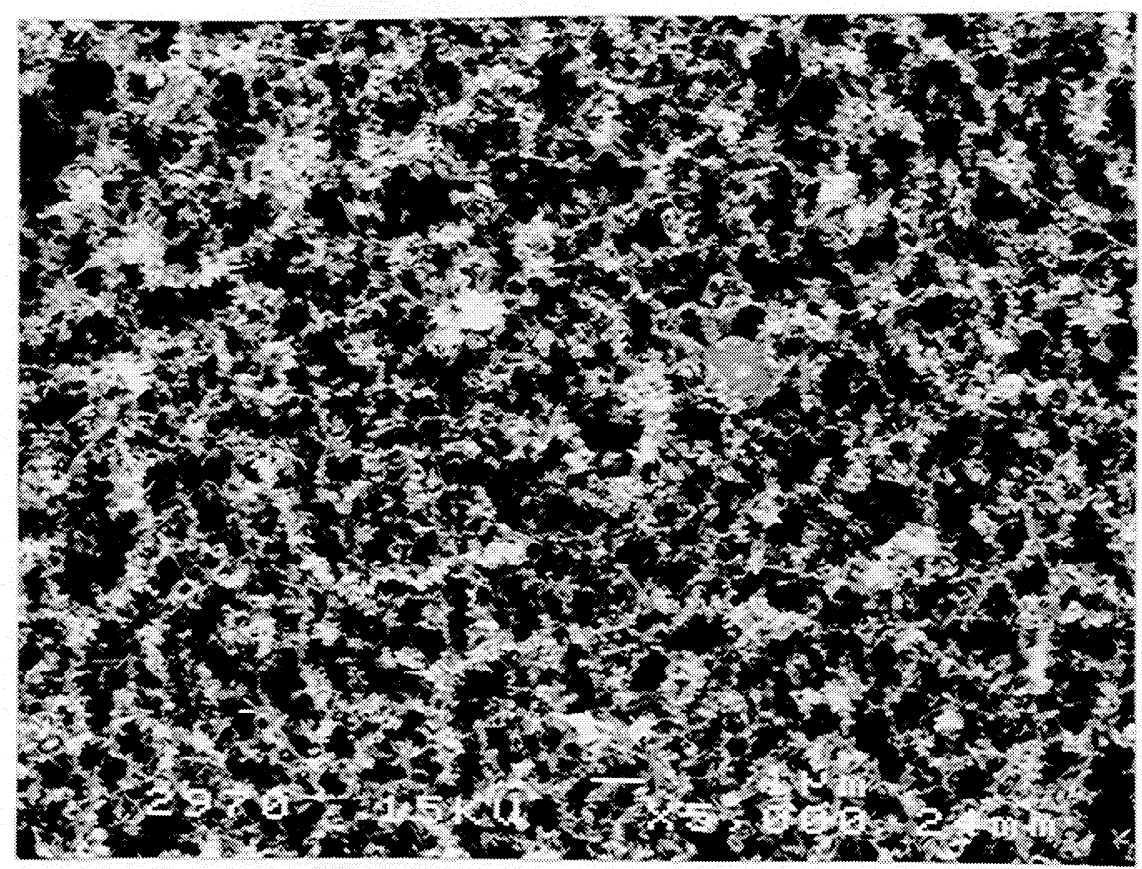

Figure 66. A SEM image of fume coated glass-fiber filter obtained without acoustics (RNAC1122) under reactor conditions of $700^{\circ} \mathrm{C}, 0.81 \mathrm{~m}$ pyrolysis tube heated length, $0.81 \mathrm{~s}$ particle residence time, and $1.46 \mathrm{~s}$ secondary gas space-time.

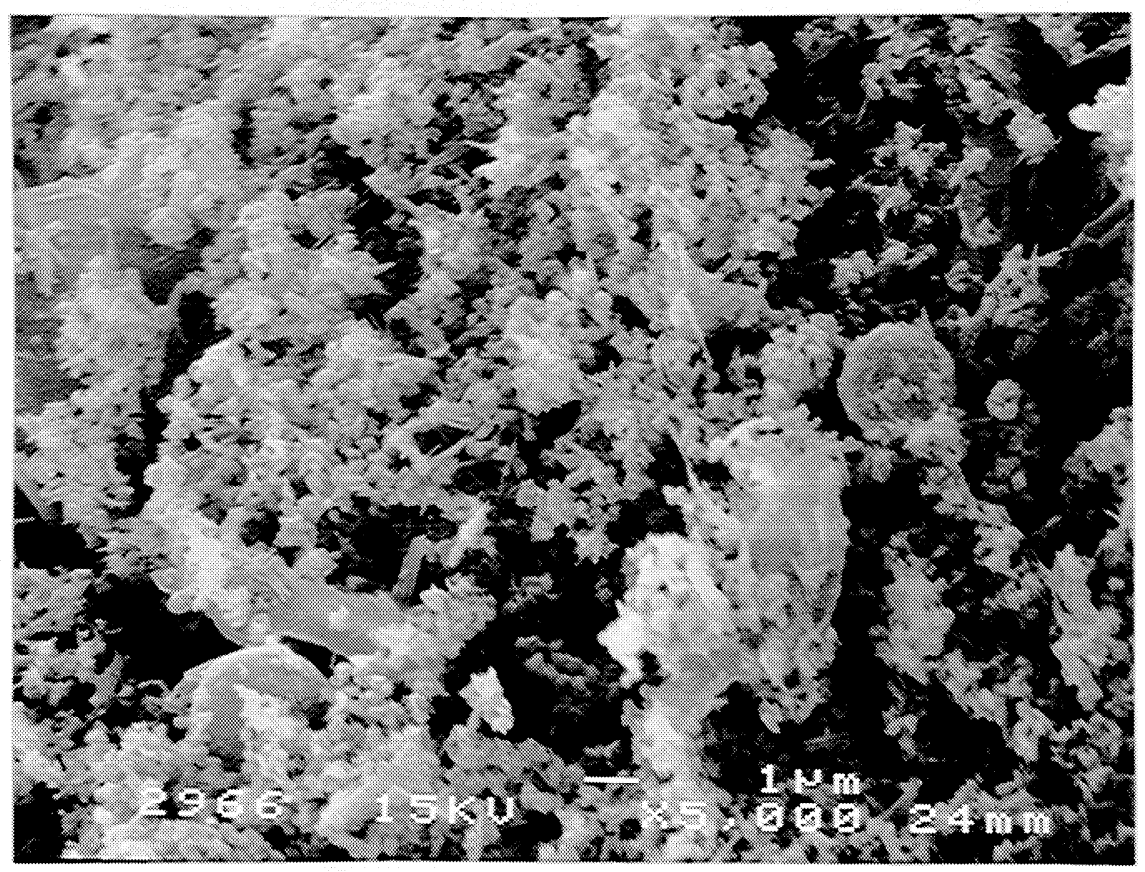

Figure 67. A SEM image of fume coated glass-fiber filter obtained with an acoustic field of $151 \mathrm{~dB}$ and $960 \mathrm{~Hz}(\mathrm{RAC1} 126 \mathrm{~A})$ under reactor conditions of $700^{\circ} \mathrm{C}, 0.18 \mathrm{~m}$ pyrolysis tube heated length, $0.25 \mathrm{~s}$ particle residence time, and $0.32 \mathrm{~s}$ secondary gas space-time. 


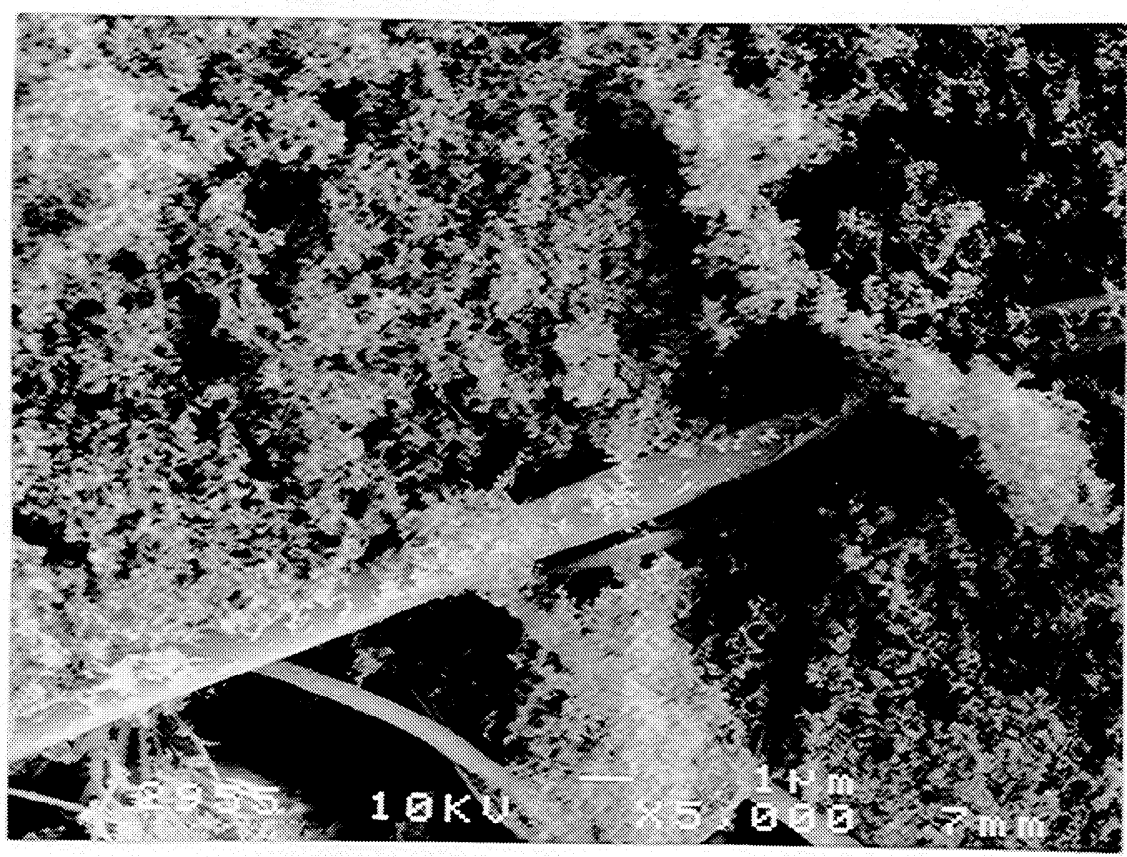

Figure 68. A SEM image of fume coated glass-fiber filter obtained with an acoustic field of $151 \mathrm{~dB}$ and $990 \mathrm{~Hz}(\mathrm{RAC1127})$ under reactor conditions of $700^{\circ} \mathrm{C}, 0.48 \mathrm{~m}$ pyrolysis tube heated length, $0.64 \mathrm{~s}$ particle residence time, and $0.86 \mathrm{~s}$ secondary gas space-time.

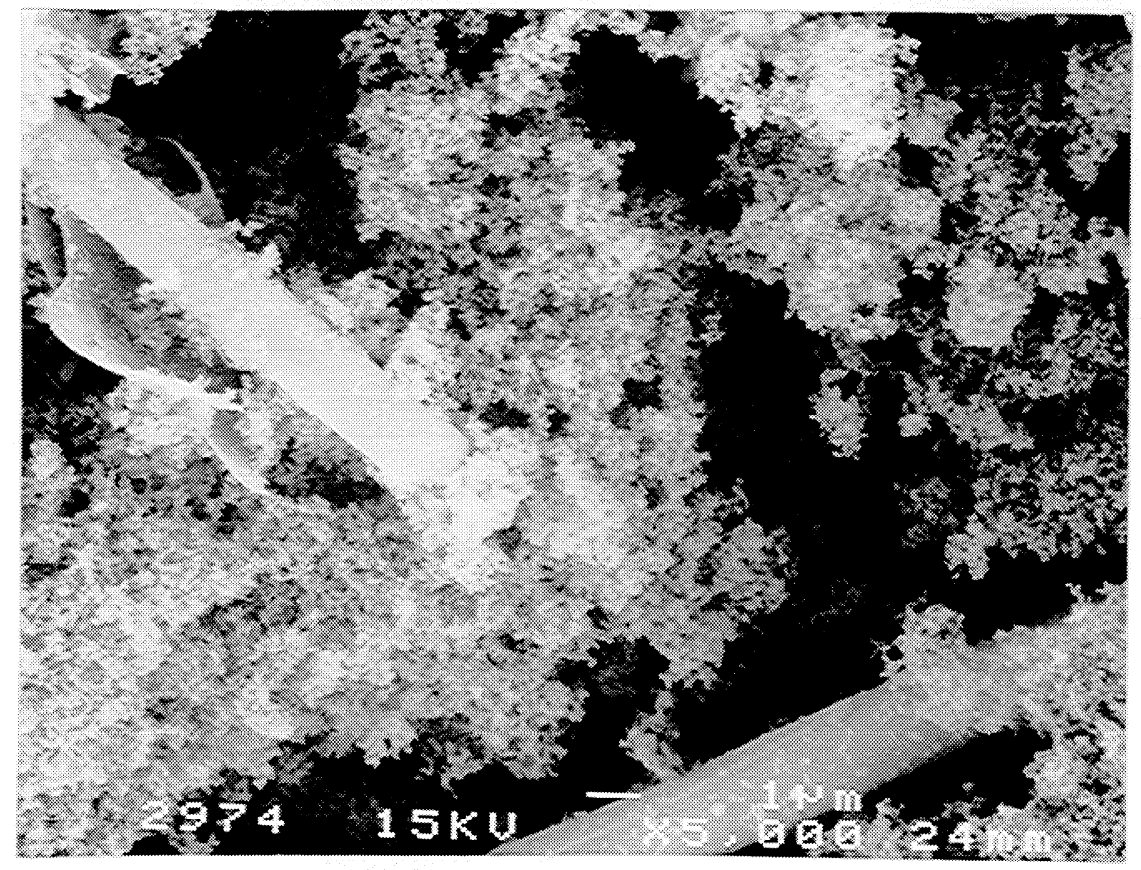

Figure 69. A SEM image of fume coated glass-fiber filter obtained with an acoustic field of $151 \mathrm{~dB}$ and $950 \mathrm{~Hz}(\mathrm{RAC1} 130 \mathrm{~B})$ under reactor conditions of $700^{\circ} \mathrm{C}, 0.81 \mathrm{~m}$ pyrolysis tube heated length, $1.15 \mathrm{~s}$ particle residence time, and $1.46 \mathrm{~s}$ secondary gas space-time. 


\section{[5.1.4.4] Conclusions}

Analysis of SEM images of material deposited on the glass-fiber filters indicates:

- The rate of tar liquid and tar fume release increases when the gas temperature is increased. Tarry liquid is a condensable volatile substance. Tar fume are submicron solid particles that are released from the particles. At a gas temperature of $550^{\circ} \mathrm{C}$, tarry liquid was released from pyrolyzing particles during the particle heatup period and then tar fume was released. At a gas temperature of $700^{\circ} \mathrm{C}$, tarry liquid and tar fume were concurrently released from the particles during the particle heatup period. Tar fume were not released at a gas temperature of $400^{\circ} \mathrm{C}$.

- Acoustically-induced levitation of tar fume can increase its residence time in the heated pyrolysis section and cause the tar fume to agglomerate into clumps of larger particles. Volatile, tarry liquids can recondense on the acoustically levitated tar fume and spend a longer time in the heated pyrolysis section compared to tarry liquid and tar fume that are entrained in the steady flow without acoustics, which can promote additional tar cracking and polymerization.

- The combined mass of tarry liquids and fume was typically $<0.01 \mathrm{~g}$ or $<0.5-1 \mathrm{wt} \%$ of BLS for experiments conducted using a $0.81 \mathrm{~m}$ pyrolysis tube heated length and even less material was deposited on the glass-fiber filters using shorter pyrolysis tube heated lengths. Therefore, most of the material that underwent pyrolytic cracking to produce secondary $\mathrm{CO}_{2}$ was tar vapor that passed through the glass-fiber filter at a temperature of $35-65^{\circ} \mathrm{C}$. About $83 \%$ of the $\sim 24 \mathrm{wt} \%$ of BLS as tar and gases obtained from inflight particle pyrolysis 
without acoustics was released prior to tar fume release at a gas temperature of $550^{\circ} \mathrm{C}$. About $75 \%$ of the approximately $32 \mathrm{wt} \%$ of BLS as tar and gases obtained from inflight particle pyrolysis with an acoustic field of $151 \mathrm{~dB}$ and $970-1000 \mathrm{~Hz}$ was released prior to fume release.

- It was found at a gas temperature of $700^{\circ} \mathrm{C}$, that tarry liquids were transported away from the particle through fume transport.

\section{[5.1.5] FT-IR Analysis of Tarry Liquid and Fume Coated Glass-fiber Filters}

FT-IR analyses were conducted of tarry liquid and fume coated glass-fiber filters. The present FT-IR analysis can only measure substances that condensed out on the filter at a temperature of $35-65^{\circ} \mathrm{C}$. Filters had to be removed from the reactor to perform an analysis with the FT-IR system, as described in Appendix 6. A FT-IR spectrum of a clean glass-fiber filter is shown in Fig. 70. The absorbances of organic and inorganic compounds were measured over wavenumbers of $400-4000 \mathrm{~cm}^{-1}$. The FT-IR spectra in the figures were cut off above $2000 \mathrm{~cm}^{-1}$ because the peaks of interest to this study are all within $2000 \mathrm{~cm}^{-1}$ and the peaks observed $2000 \mathrm{~cm}^{-1}$ are associated with the glass-fiber filter. Table 17 list the wave numbers of peaks corresponding to the compounds observed in the FT-IR spectra of the material deposited on the glass-fiber filters. Compounds in Table 17 can be traced back to constituents of BLS listed in Table 2. 


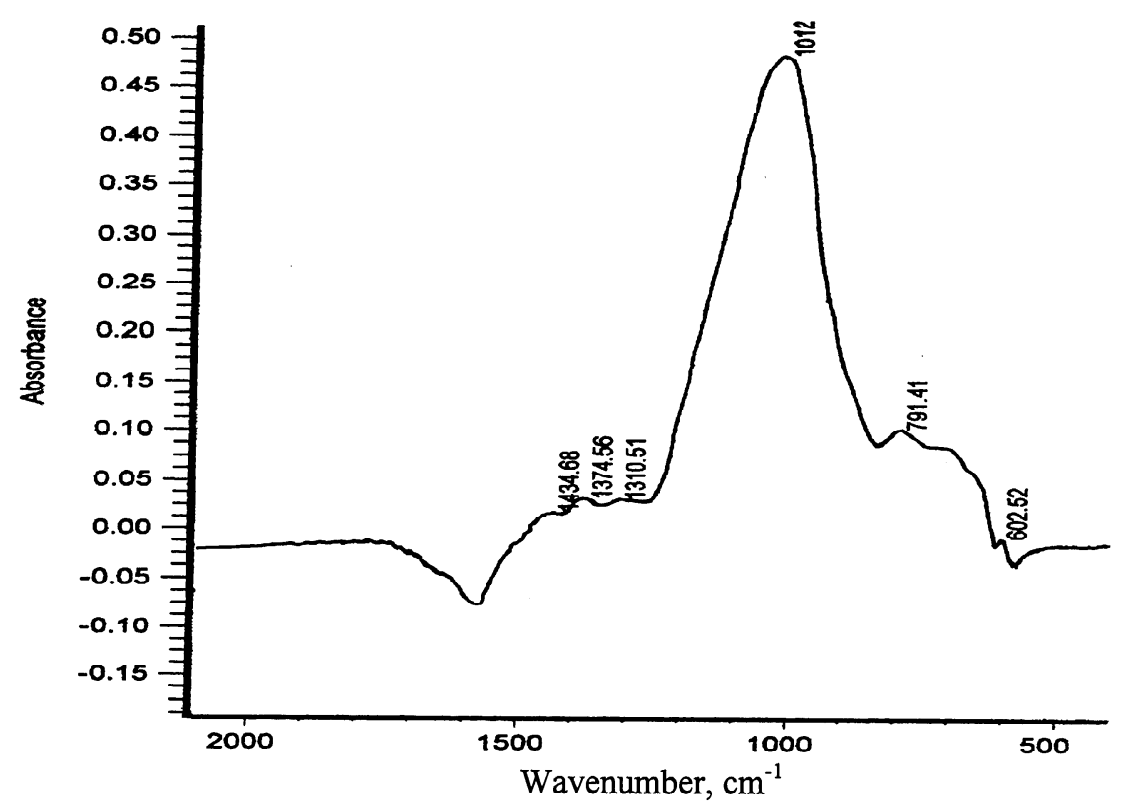

Figure 70. A FT-IR spectrum of a clean glass-fiber filter.

Table 17. A list of chemical species and their corresponding peaks on FT-IR spectra of tar and fume coated glass-fiber filters (Pouchert, 1985; Solomons, 1988).

\begin{tabular}{|l|l|}
\hline Chemical species & Peaks on FT-IR spectra, wavenumber, cm $^{-1}$ \\
\hline $\begin{array}{l}\text { Acetic acid, sodium } \\
\text { salt }\end{array}$ & $\begin{array}{l}\text { Single peaks: 651 (weak), 720 (weak), 925 (weak), 1011 (weak), 1080 } \\
\text { (weak), 1340 (sharp, strong), 1576 (strong), and 1700 (very weak) }\end{array}$ \\
\hline $\begin{array}{l}\text { Benzoic acid, } \\
\text { sodium salt }\end{array}$ & $\begin{array}{l}\text { Single peaks: 681 (sharp, medium), 708 (medium), 846 (sharp, } \\
\text { medium), 1068 (weak), 1308 (very weak), 1415 (combined, strong), } \\
1552 \text { (sharp, strong), and 1623 (sharp, medium) }\end{array}$ \\
\hline Aliphatic ether & Single peak: 1060-1170 (strong) \\
\hline $\begin{array}{l}\text { Formic acid, sodium } \\
\text { salt }\end{array}$ & $\begin{array}{l}\text { Single peaks: 774 (sharp, medium), 1385 (sharp, strong), } \\
1499 \text { (medium), 1605 (broad, strong), and 1689 (weak) }\end{array}$ \\
\hline $\begin{array}{l}\text { Monosubstituted and } \\
\text { highly substituted } \\
\text { aromatic compounds }\end{array}$ & $\begin{array}{l}\text { One or two peaks: 680-840 (strong), two to four peaks: 960-1220 } \\
\text { (weak), single peak: 1470-1530 (medium), and two peaks: 1550-1650 } \\
\text { (combined, medium) }\end{array}$ \\
\hline Sodium carbonate & $\begin{array}{l}\text { Single peaks: 701 (weak), 880 (sharp, strong), 1440 (broad, strong), and } \\
1775 \text { (weak) }\end{array}$ \\
\hline
\end{tabular}




\section{[5.1.5.1] Chemical Composition of Material Obtained at a Gas Temperature of $400^{\circ} \mathrm{C}$}

- Tarry liquids obtained without (RNAC1113) and with acoustics (RAC1119) are nearly identical as indicated by similar FT-IR spectra in Figs. 71 and 72, respectively. Most of the peaks are not well distinguishable from the background spectrum of Fig. 70 because not enough tar was present on the filter to be detected with the FT-IR. The location of the peaks in the spectra match well with peaks of species shown in Table 17. $\mathrm{Na}_{2} \mathrm{CO}_{3}$ was not observed because it was not released from the particle.

- FT-IR spectra of tarry liquid collected on the glass-fiber filters from experiments with steelwool-plugs (RNAC1111, RNA2111 and RNAC1112) are identical to RNAC.

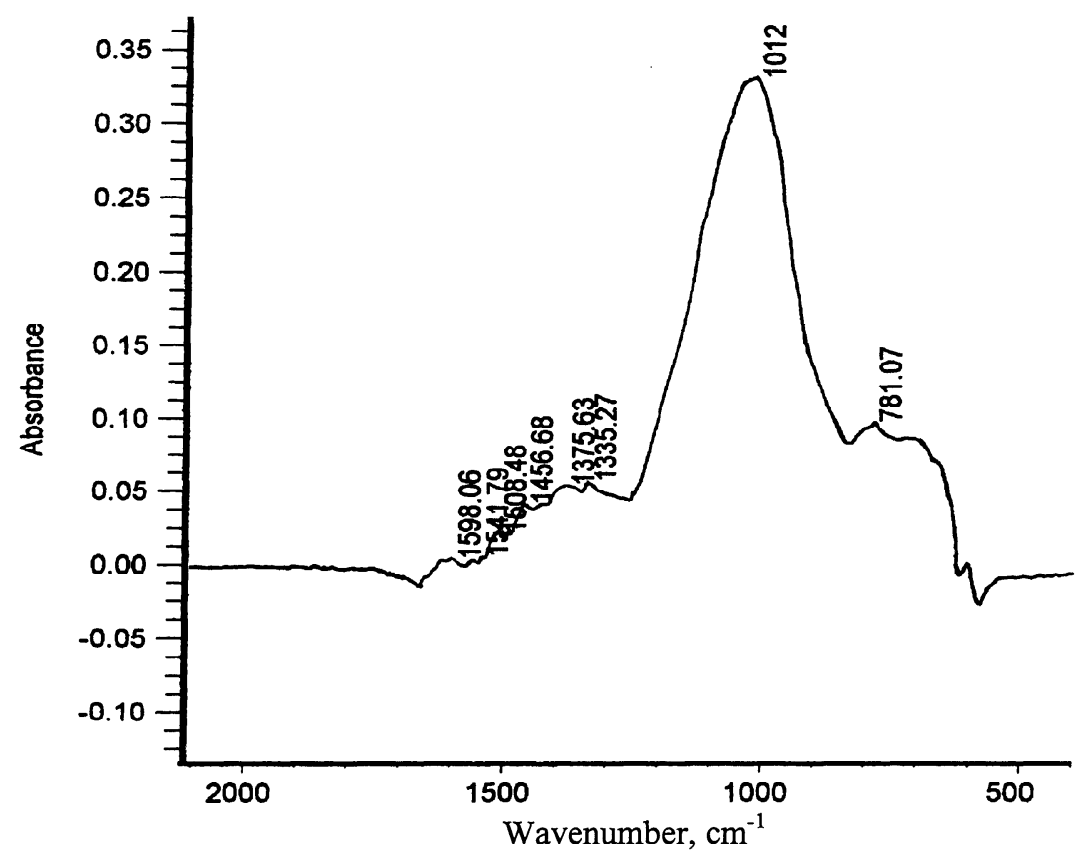

Figure 71. A FT-IR spectrum of tarry liquid coated glass-fiber filter obtained without acoustics (RNAC1113) under reactor conditions of $400^{\circ} \mathrm{C}, 0.81 \mathrm{~m}$ pyrolysis tube heated length, $0.86 \mathrm{~s}$ particle residence time, and $2.10 \mathrm{~s}$ secondary gas space-time. 


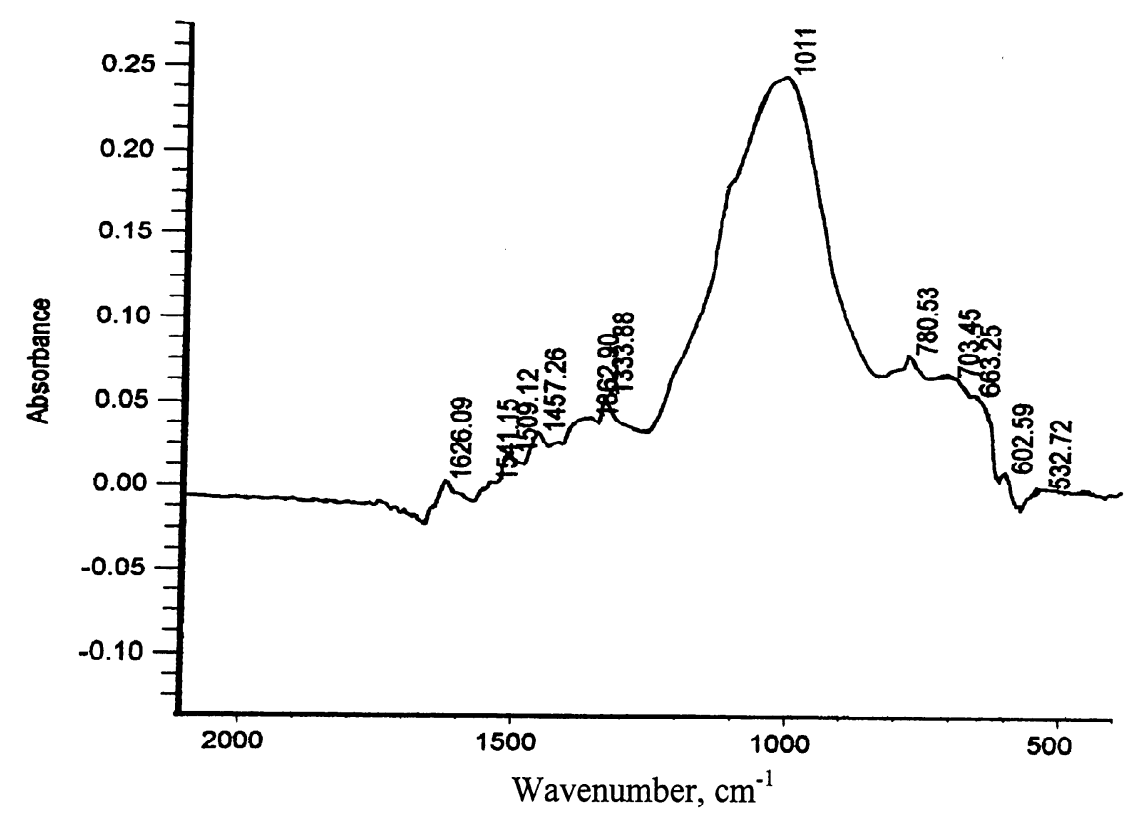

Figure 72. A FT-IR spectrum of tarry liquid coated glass-fiber filter obtained with an acoustic field of $151 \mathrm{~dB}$ and $960 \mathrm{~Hz}$ (RAC1119) under reactor conditions of $400^{\circ} \mathrm{C}, 0.81 \mathrm{~m}$ pyrolysis tube heated length, $1.10 \mathrm{~s}$ particle residence time, and $2.10 \mathrm{~s}$ secondary gas space-time.

\section{[5.1.5.2] Chemical Composition of Material Obtained at a Gas Temperature of $550^{\circ} \mathrm{C}$}

- Low amounts of material were present on the glass-fiber filters obtained without acoustics and $0.18 \mathrm{~m}$ (RNAC1105) and $0.48 \mathrm{~m}$ (RNA21105) pyrolysis tube heated lengths and with an acoustic field of $151 \mathrm{~dB}$ and $1000 \mathrm{~Hz}$ (RAC1107) and $0.18 \mathrm{~m}$ pyrolysis tube heated length. Tarry liquids obtained from these experiments contain aliphatic ethers $\left(1110 \mathrm{~cm}^{-1}\right)$, aromatic compounds (703 and $\left.1457 \mathrm{~cm}^{-1}\right)$, and sodium salts of acetic acid $\left(661\right.$ and $\left.1333 \mathrm{~cm}^{-1}\right)$ and formic acid $\left(778-791,1380,1606\right.$, and $\left.1685 \mathrm{~cm}^{-1}\right)$ as shown in the respective FT-IR spectra in Figs. 73-75. 
- More tar fume was present on the glass-fiber filters obtained without acoustics using the $0.81 \mathrm{~m}$ pyrolysis tube heated length and $1.72 \mathrm{~s}$ (RNAC918) and $2.77 \mathrm{~s}$ (RNAC927) secondary gas space-times and with an acoustic field of $151 \mathrm{~dB}$ and $970-990 \mathrm{~Hz}$ using the $0.48 \mathrm{~m}$ (RAC1108) and $0.81 \mathrm{~m}$ (RAC925B) pyrolysis tube heated lengths. Tar fume obtained from these experiments contained the same compounds that comprise tarry liquids with the addition of sodium salt of benzoic acid (1411 and $1552 \mathrm{~cm}^{-1}$ which is overlapped by the broad irregular shaped peak at $1570 \mathrm{~cm}^{-}$) as shown in the FT-IR spectra in Figs. 76-79. These compounds were always observed because their boiling points are higher than the operating temperature of the glass-fiber filter $\left(35-65^{\circ} \mathrm{C}\right)$.

- Peaks at 880 and $1428 \mathrm{~cm}^{-1}$ corresponding to $\mathrm{Na}_{2} \mathrm{CO}_{3}$ were observed in the FT-IR spectrum of the fume coated, glass-fiber filter obtained from an experiment conducted with an acoustic field of $158 \mathrm{~dB}$ and $970 \mathrm{~Hz}$ under conditions of $0.81 \mathrm{~m}$ pyrolysis tube heated length and $1.72 \mathrm{~s}$ secondary gas space-time (RAC1207) as shown the FT-IR spectra in Fig. 80.

- $\mathrm{Na}_{2} \mathrm{CO}_{3}$ fume was not observed in the FT-IR spectrum of a typical tarry liquid coated glassfiber filter obtained using steel-wool-plugs (RNAC1019) as shown in Fig. 81, because the amount of deposited material was too to be detectable by the FT-IR. This validates the argument drawn from SEM analysis that fume material was trapped inside the char structure which was built up on the steel-wool-plug as particles accumulated.

- Peaks at 880 and $1443 \mathrm{~cm}^{-1}$ corresponding to $\mathrm{Na}_{2} \mathrm{CO}_{3}$ were observed in the FT-IR spectrum of the fume coated glass-fiber filter obtained at a very long inflight particle residence time using a both a steel-wool-plug and an acoustic field of $151 \mathrm{~dB}$ and $960 \mathrm{~Hz}$ (RAC1206) as shown in Fig. 82. The steel-wool-plug was placed $0.75 \mathrm{~m}$ downstream from the particle 
injection point to obtain a longer inflight particle residence time. Individual char particles had pyrolyzed enough while inflight to solidify before they contacted the steel-wool-plug. Acoustic oscillations kept the particles sufficiently agitated to prevent them from sticking together and blocking gas flow through the tube.

- Organic acid-sodium salt peaks at high wavenumbers between 1550-1600 are more prevalent in RAC1207 compared to RAC1206, as shown in the FT-IR spectra in Fig. 80 and 82, respectively. This may be caused by increased release of tar into the secondary gas or increased particle heatup rate and more severe pyrolysis at very high sound pressure level (158 dB for RAC1207), or increased deposition of organic acid-sodium salts on the particles or steel-wool fibers (RAC1206). It should be pointed out that the amount of BLS fed into the reactor was 4.71 and $2.77 \mathrm{~g}$ for experiments RAC1206 and RAC1207, respectively.

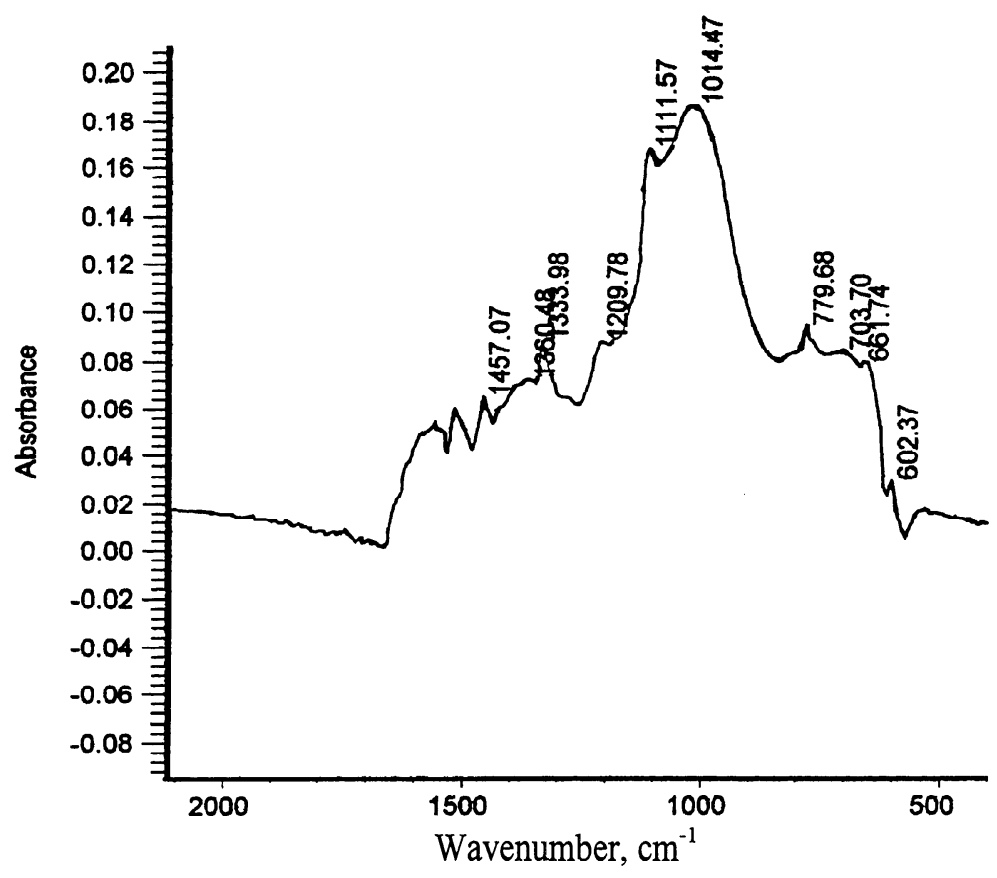

Figure 73. A FT-IR spectrum of tarry liquid coated glass-fiber filter obtained without acoustics (RNAC1105) under reactor conditions of $550^{\circ} \mathrm{C}, 0.18 \mathrm{~m}$ pyrolysis tube heated length, $0.23 \mathrm{~s}$ particle residence time, and $0.38 \mathrm{~s}$ secondary gas space-time. 


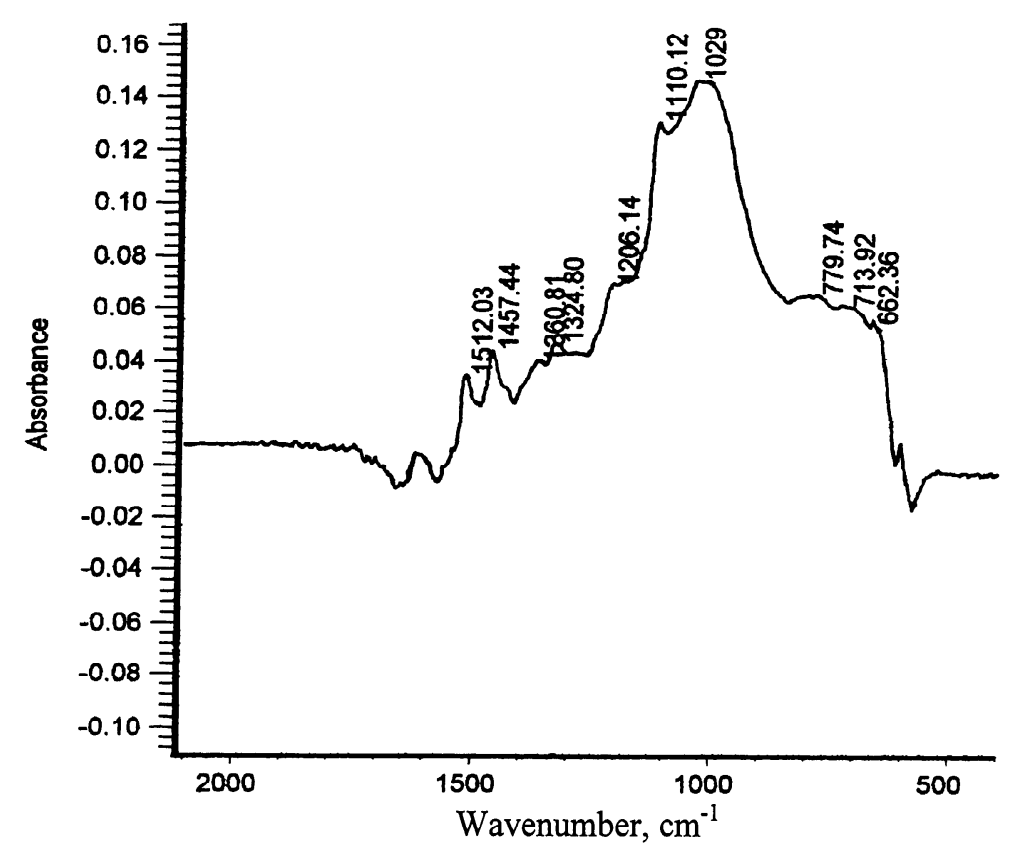

Figure 74. A FT-IR spectrum of tarry liquid coated glass-fiber filter obtained without acoustics field (RNA21105) under reactor conditions of $550^{\circ} \mathrm{C}, 0.48 \mathrm{~m}$ pyrolysis tube heated length, $0.54 \mathrm{~s}$ particle residence time, and $1.02 \mathrm{~s}$ secondary gas space-time.

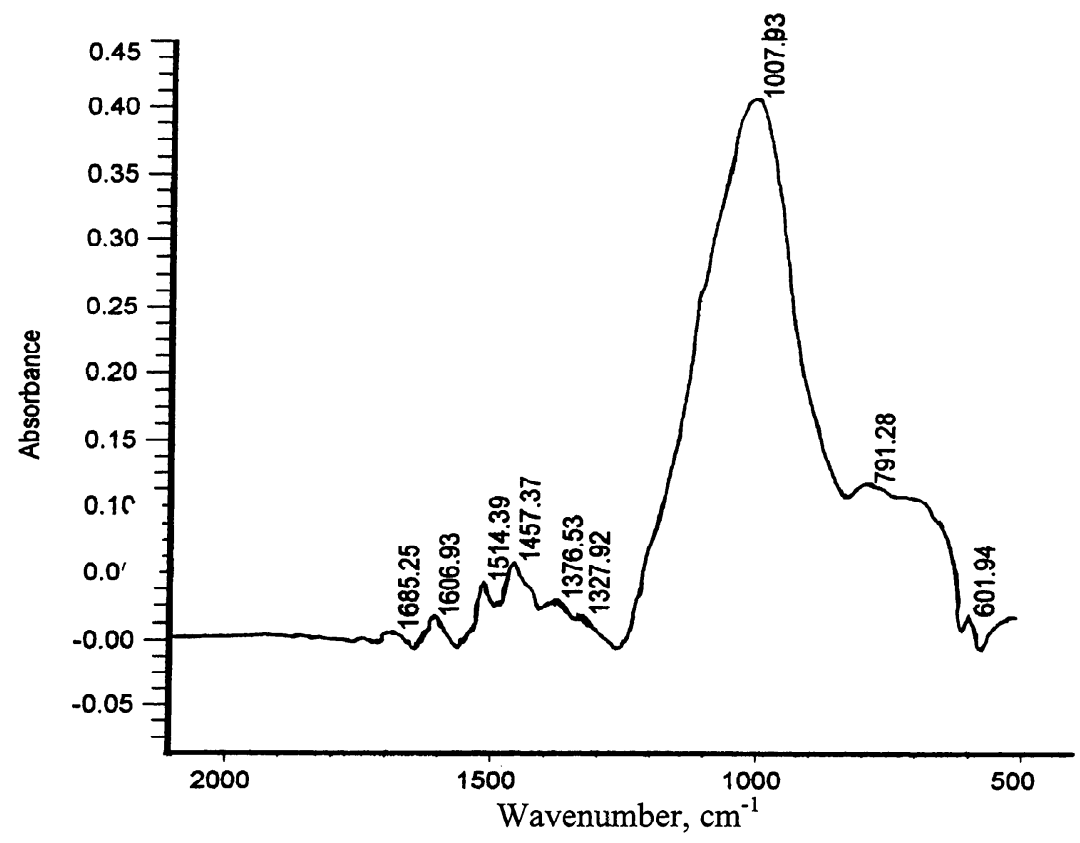

Figure 75. A FT-IR spectrum of tarry liquid coated glass-fiber filter obtained with an acoustic field of $151 \mathrm{~dB}$ and $1000 \mathrm{~Hz}$ (RAC1107) under reactor conditions of $550^{\circ} \mathrm{C}, 0.18 \mathrm{~m}$ pyrolysis tube heated length, $0.27 \mathrm{~s}$ particle residence time, and 0.38 s secondary gas space-time. 


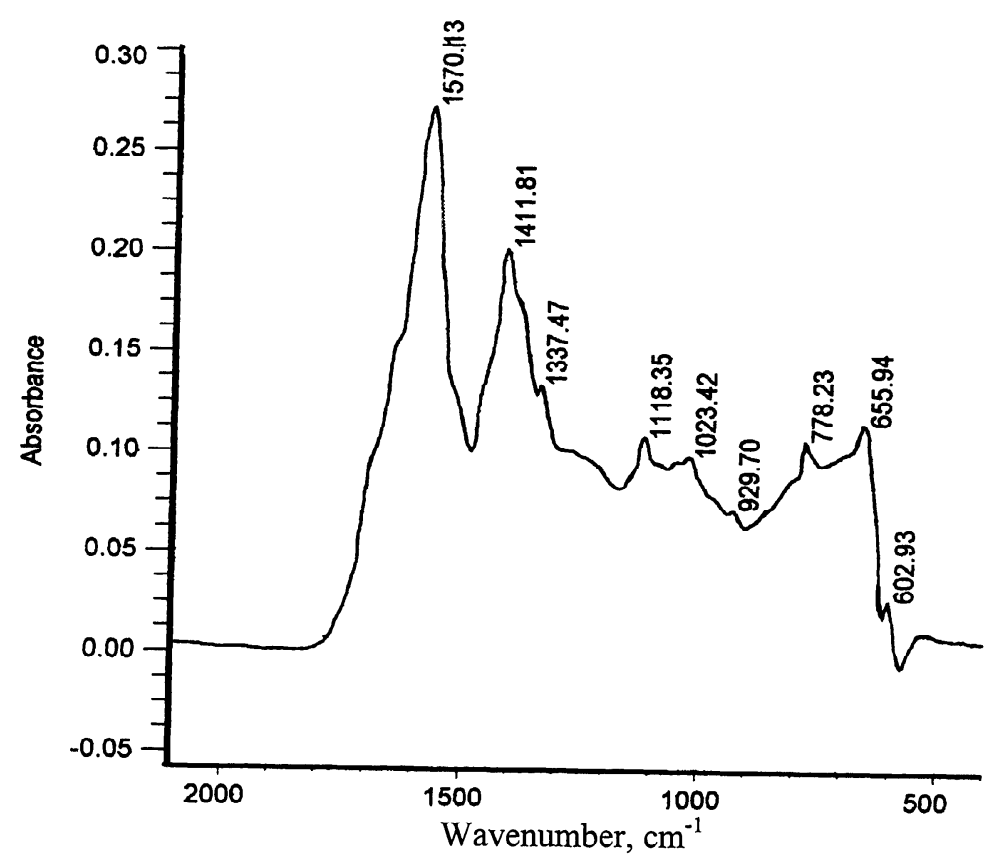

Figure 76. A FT-IR spectrum of tar fume coated glass fiber-filter obtained without an acoustic field (RNAC918) under reactor conditions of $550^{\circ} \mathrm{C}, 0.81 \mathrm{~m}$ pyrolysis tube heated length, $0.90 \mathrm{~s}$ particle residence time, and $1.72 \mathrm{~s}$ secondary gas space-time.

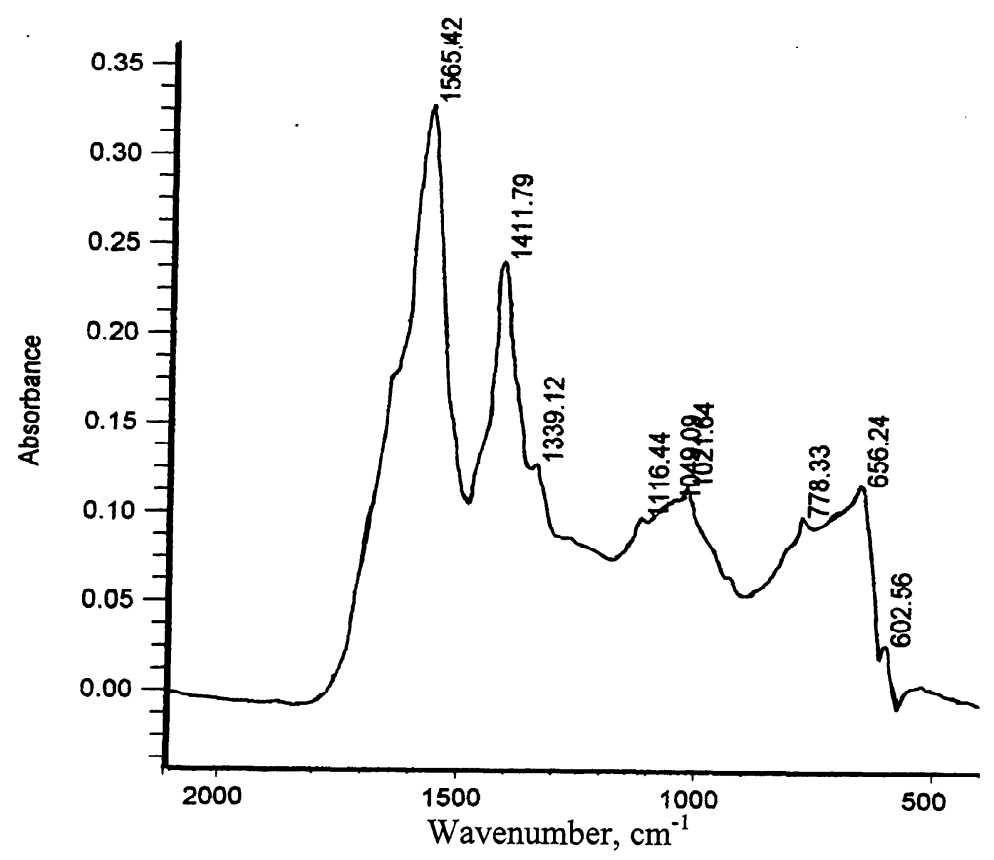

Figure 77. A FT-IR spectrum of tar fume coated glass fiber-filter obtained without acoustics (RNAC927) under reactor conditions of $550^{\circ} \mathrm{C}, 0.81 \mathrm{~m}$ pyrolysis tube heated length, $2.77 \mathrm{~s}$ particle residence time, and $6.59 \mathrm{~s}$ secondary gas space-time. 


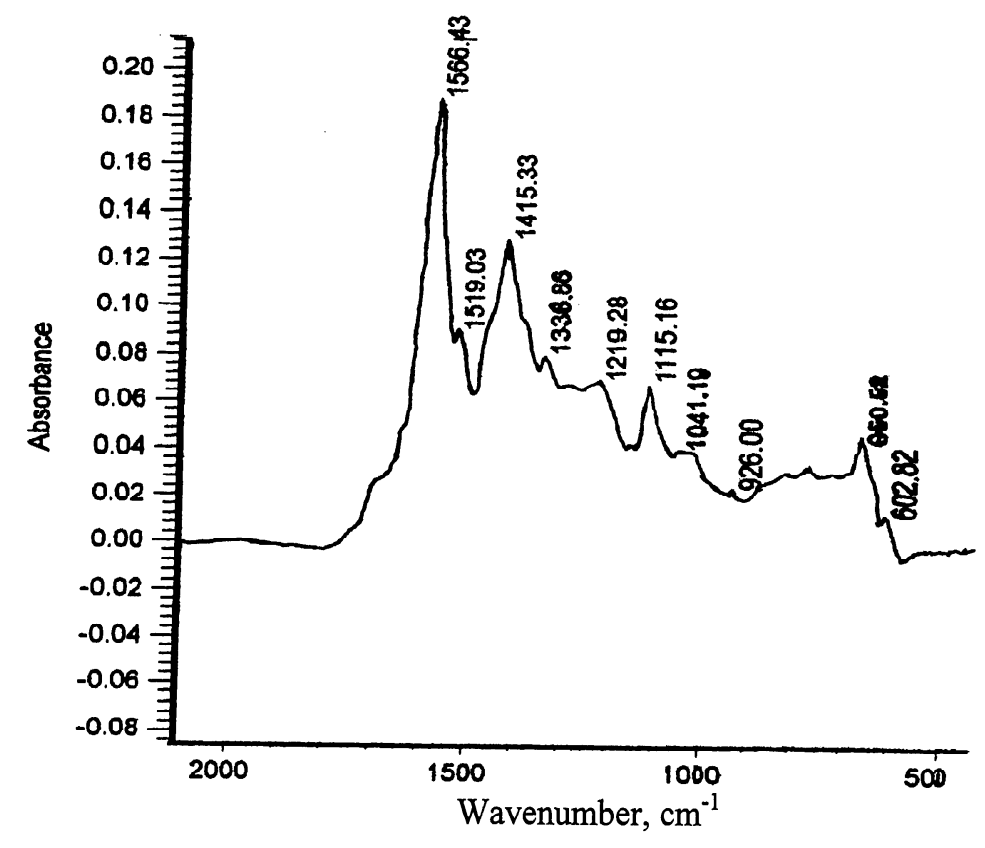

Figure 78. A FT-IR spectrum of tar fume coated glass-fiber filter obtained with an acoustic field of $151 \mathrm{~dB}$ and $970 \mathrm{~Hz}(\mathrm{RAC} 1108)$ under reactor conditions of $550^{\circ} \mathrm{C}, 0.18 \mathrm{~m}$ pyrolysis tube heated length, 0.70 particle residence time, and $1.02 \mathrm{~s}$ secondary gas space-time.

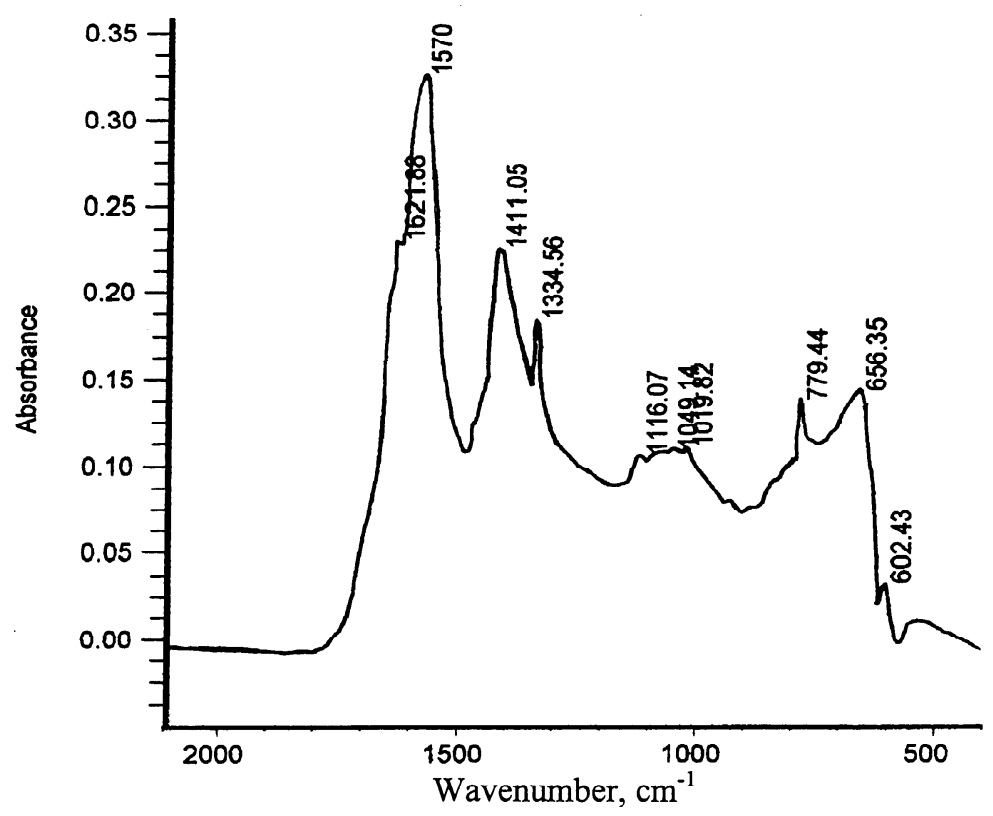

Figure 79. A FT-IR spectrum of tar fume coated glass-fiber filter obtained with an acoustic field of $151 \mathrm{~dB}$ and $990 \mathrm{~Hz}(\mathrm{RAC} 925 \mathrm{~B})$ under reactor conditions of $550^{\circ} \mathrm{C}$, $0.81 \mathrm{~m}$ pyrolysis tube heated length, $1.26 \mathrm{~s}$ particle residence time, and $1.72 \mathrm{~s}$ secondary gas space-time. 


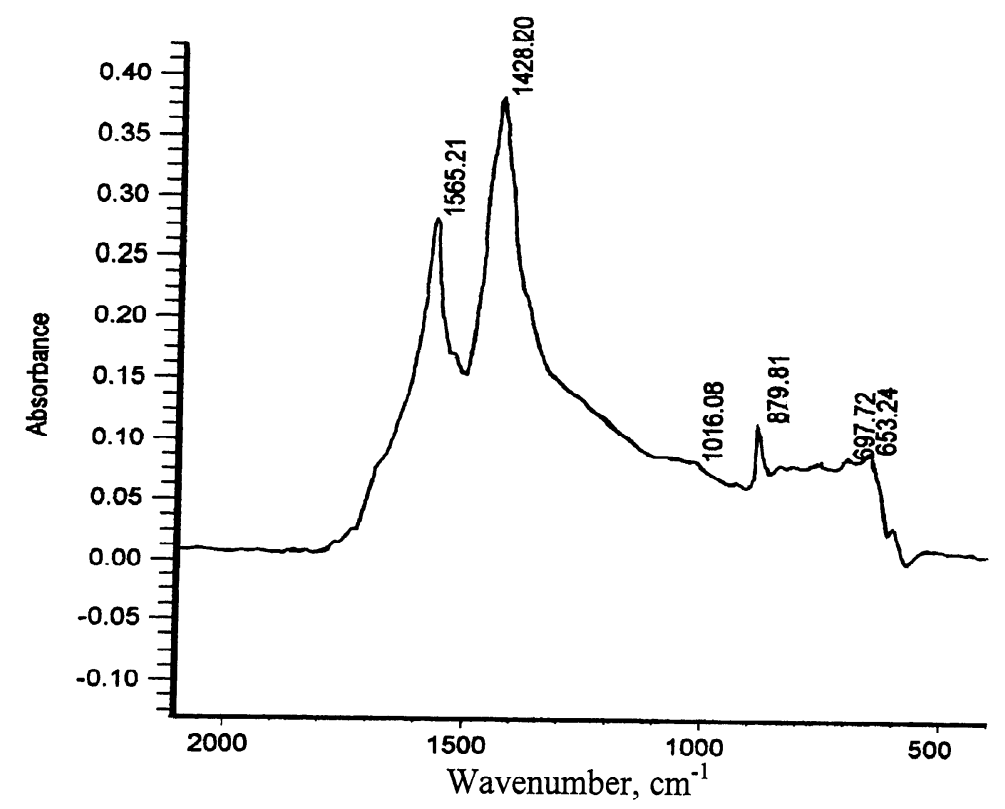

Figure 80. A FT-IR spectrum of tar fume coated glass-fiber filter obtained with an acoustic field of $158 \mathrm{~dB}$ and $970 \mathrm{~Hz}$ (RAC1207) under reactor conditions of $550^{\circ} \mathrm{C}, 0.81 \mathrm{~m}$ pyrolysis tube heated length, at $1.37 \mathrm{~s}$ particle residence time, and $1.72 \mathrm{~s}$ secondary gas space-time.

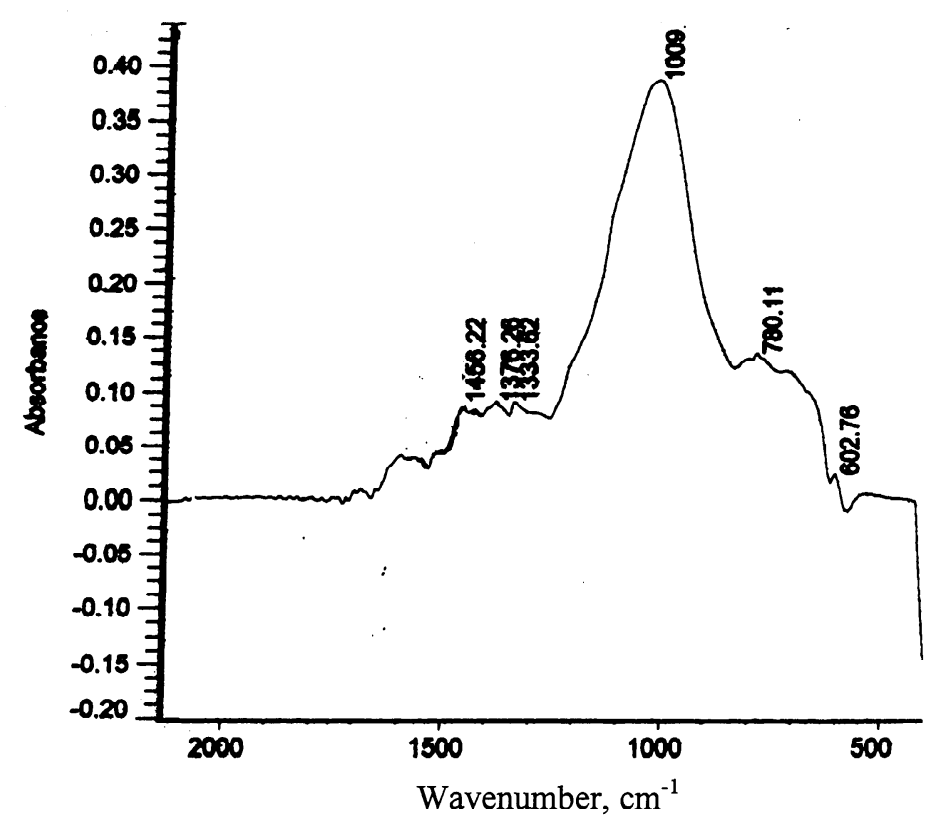

Figure 81. A FT-IR spectrum of typical tar coated glass-fiber filter obtained with a steel-wool-plug located $0.13 \mathrm{~m}$ downstream from the particle injection point (RNAC1019) under reactor conditions of $550^{\circ} \mathrm{C}, 0.81 \mathrm{~m}$ pyrolysis tube heated length, and $3.39 \mathrm{~s}$ secondary gas space-time. 


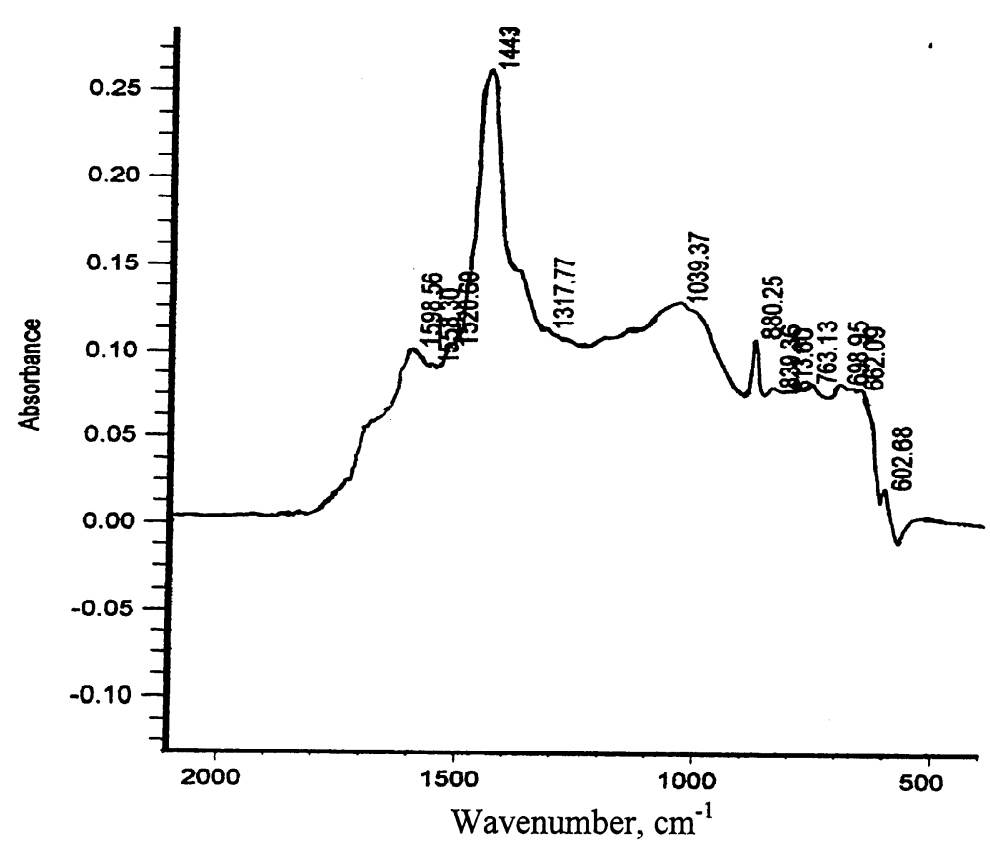

Figure 82. A FT-IR spectrum of tar coated glass fiber-filter obtained with an acoustic field of $151 \mathrm{~dB}$ and $960 \mathrm{~Hz}$ (RAC1206) and a steel-wool-plug located at $0.75 \mathrm{~m}$ under reactor conditions of $550^{\circ} \mathrm{C}, 0.81 \mathrm{~m}$ pyrolysis tube heated length, and $1.72 \mathrm{~s}$ secondary gas space-time.

\section{[5.1.5.3] Chemical Composition of Material Obtained at a Gas Temperature of $700^{\circ} \mathrm{C}$}

- Aliphatic ethers $\left(1111 \mathrm{~cm}^{-1}\right)$ were only present in tarry liquids and fume obtained under conditions of 0.18 pyrolysis tube heated length and $0.32 \mathrm{~s}$ secondary gas space-time as shown in the FT-IR spectra in Fig 83. Sodium salts of acetic acid, benzoic acid, and formic acid were contained in the tar fume obtained without (RNAC1123, RNAC1127, and RNAC1122) and with (RAC1126A, RAC1127, and RAC1126B) an acoustic field of $151 \mathrm{~dB}$ and 950-990 $\mathrm{Hz}$ under conditions of $0.18,0.48$, and $0.81 \mathrm{~m}$ pyrolysis tube heated lengths and secondary gas space-times of 0.32-1.46 $\mathrm{s}$ as shown in the FT-IR spectra in Figs. 83-88.

- $\mathrm{Na}_{2} \mathrm{CO}_{3}$ fume were not observed in the spectra of filters obtained from RNAC1123 and RNAC1127, as shown in Figs. 83 and 84, but peaks at 880 and $1430-1440 \mathrm{~cm}^{-1}$ 
corresponding to $\mathrm{Na}_{2} \mathrm{CO}_{3}$ appeared in the FT-IR spectra of material coated obtained from all other experiments. Only $\mathrm{Na}_{2} \mathrm{CO}_{3}$ fume were present on the filters obtained with an acoustic field of $160 \mathrm{~dB}$ and $950 \mathrm{~Hz}$ under conditions of $0.81 \mathrm{~m}$ pyrolysis tube heated length and $1.46 \mathrm{~s} \mathrm{secondary}$ gas space-time (RAC1126B) as shown in the FT-IR spectra in Fig. 89. This indicates that with a long residence time in the heated pyrolysis tube, tar fume species can be broken down to low molecular weight species that are no longer present on the glass-fiber filter. The boiling points of the low molecular weight species are too low to allow them to condense onto the glass-fiber filter.

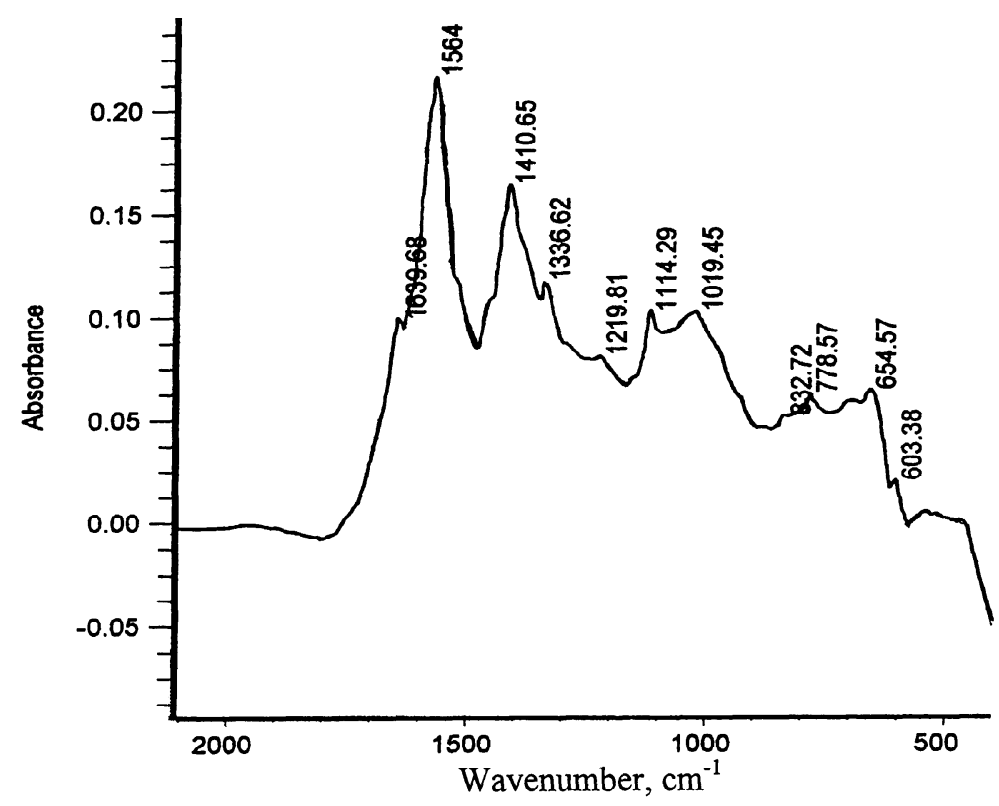

Figure 83. A FT-IR spectrum of tarry liquid coated glass-fiber filter obtained without acoustics (RNAC1123) under reactor conditions of $700^{\circ} \mathrm{C}, 0.18 \mathrm{~m}$ pyrolysis tube heated length, $0.21 \mathrm{~s}$ particle residence time, and $0.32 \mathrm{~s}$ secondary gas space-time. 


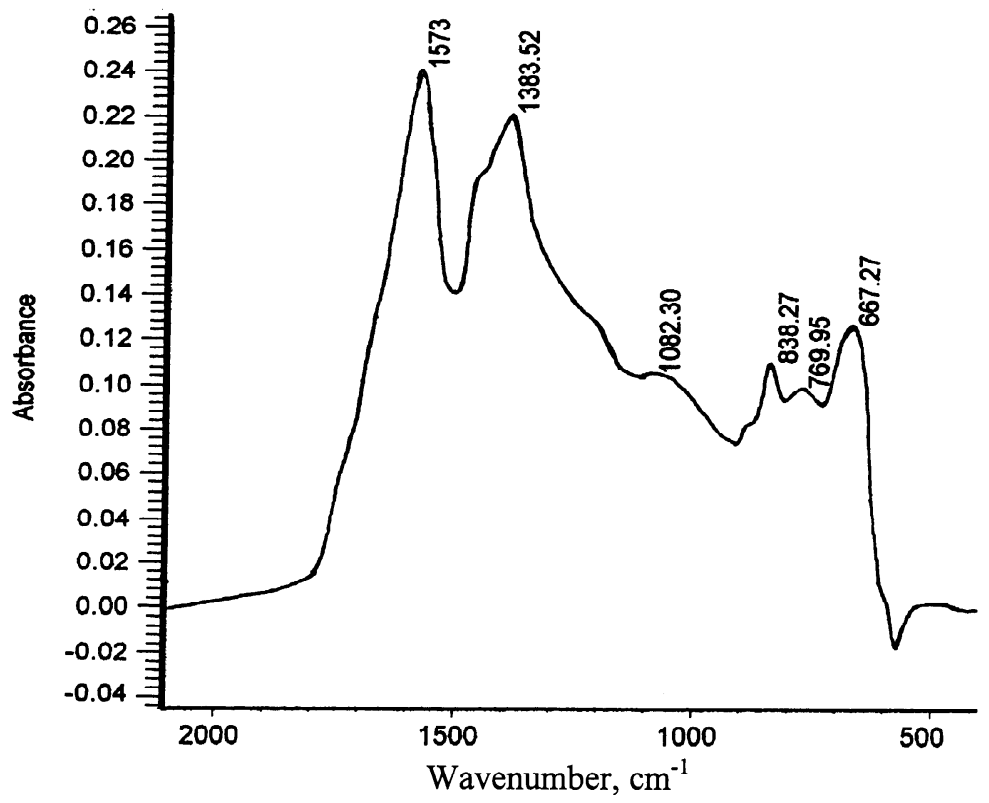

Figure 84. A FT-IR spectrum of tar fume coated glass-fiber filter obtained without acoustics (RNAC1127) under reactor conditions of $700^{\circ} \mathrm{C}, 0.48 \mathrm{~m}$ pyrolysis tube heated length, $0.49 \mathrm{~s}$ particle residence time, and $0.86 \mathrm{~s}$ secondary gas space-time.

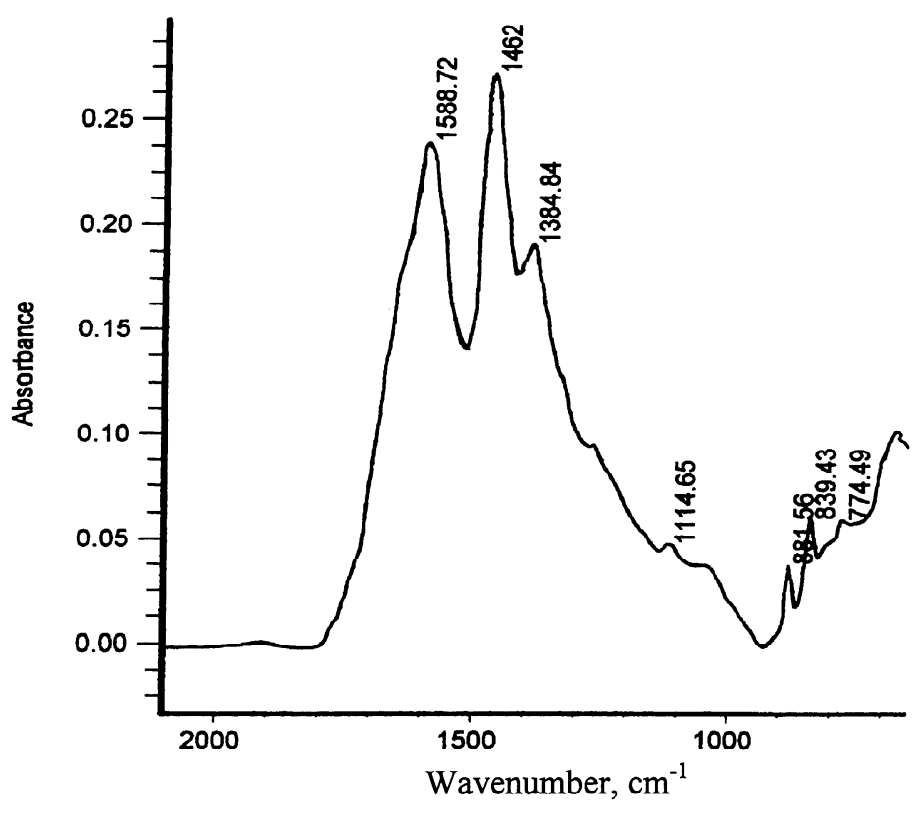

Figure 85. A FT-IR spectrum of tar and $\mathrm{Na}_{2} \mathrm{CO}_{3}$ fume coated glass-fiber filter obtained without acoustics (RNAC1122) under reactor conditions of $700^{\circ} \mathrm{C}, 0.81 \mathrm{~m}$ pyrolysis tube heated length, $0.82 \mathrm{~s}$ particle residence time, and $1.46 \mathrm{~s}$ secondary gas space-time. 


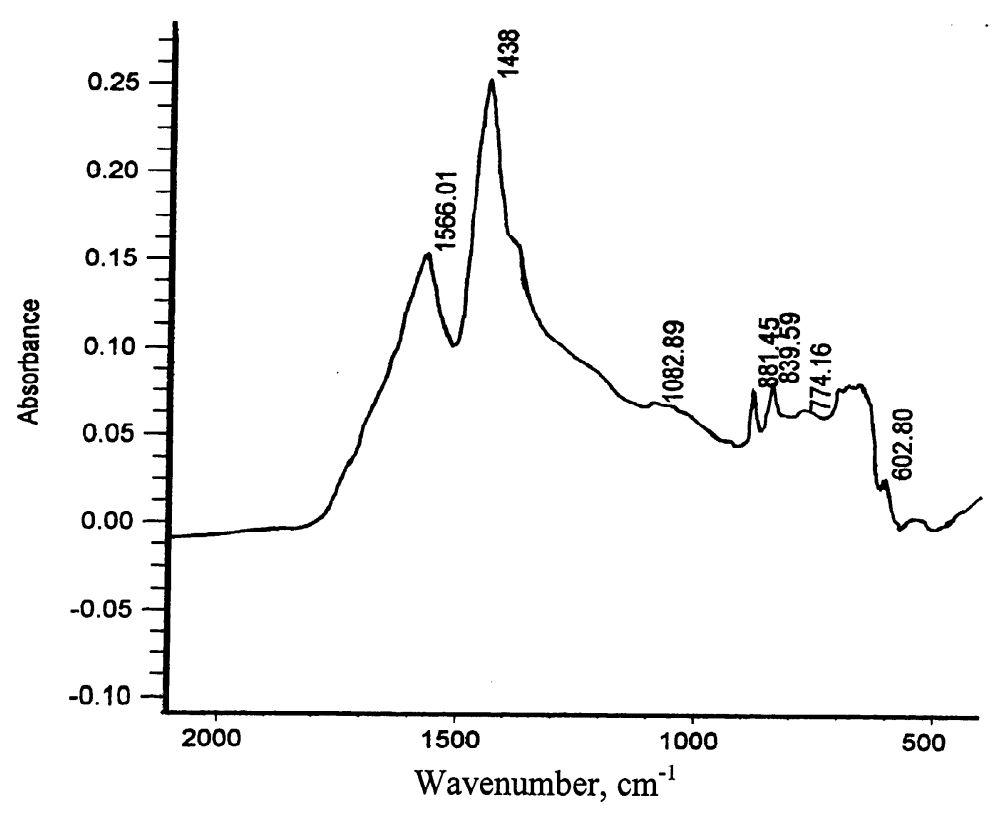

Figure 86. A FT-IR spectrum of $\operatorname{tar}$ and $\mathrm{Na}_{2} \mathrm{CO}_{3}$ fume coated glass-fiber filter obtained with an acoustic field of $151 \mathrm{~dB}$ and $960 \mathrm{~Hz}$ (RAC1126A) under reactor conditions of $700^{\circ} \mathrm{C}, 0.18 \mathrm{~m}$ pyrolysis tube heated length, $0.25 \mathrm{~s}$ particle residence time, and $0.32 \mathrm{~s}$ secondary gas space-time.

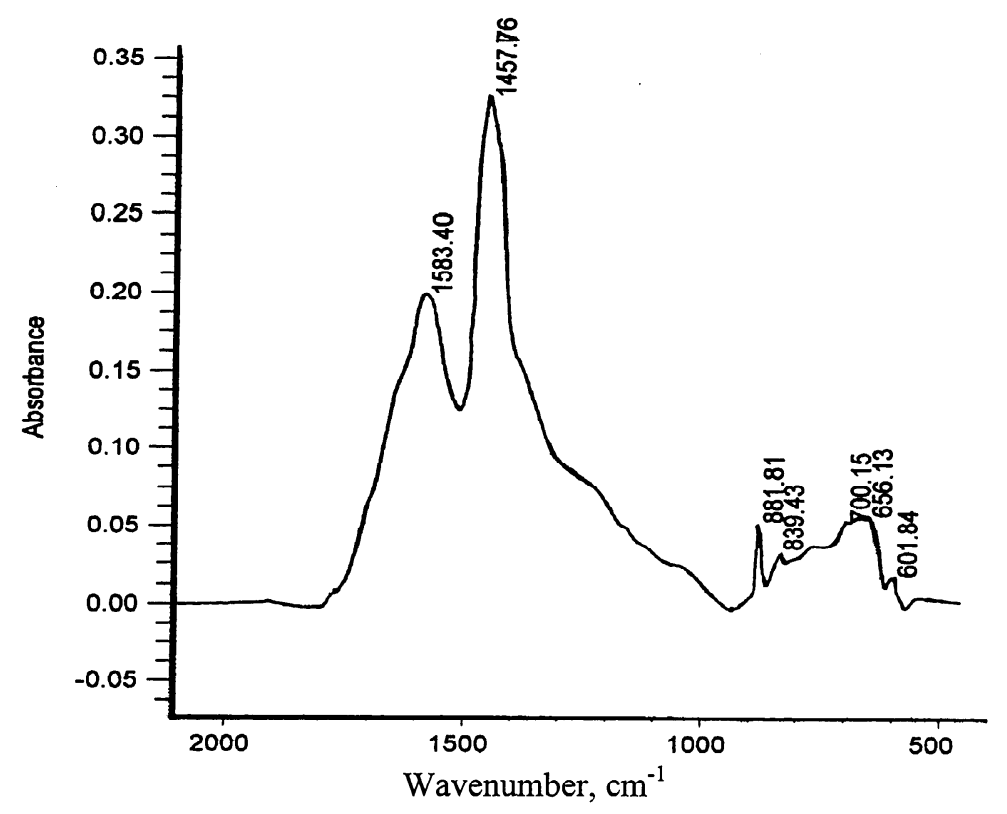

Figure 87. A FT-IR spectrum of tar and $\mathrm{Na}_{2} \mathrm{CO}_{3}$ fume coated glass-fiber filter obtained with an acoustic field of $151 \mathrm{~dB}$ and $990 \mathrm{~Hz}(\mathrm{RAC1127})$ under reactor conditions of $700^{\circ} \mathrm{C}, 0.48 \mathrm{~m}$ pyrolysis tube heated length, $0.64 \mathrm{~s}$ particle residence time, and $0.86 \mathrm{~s}$ secondary gas space-time. 


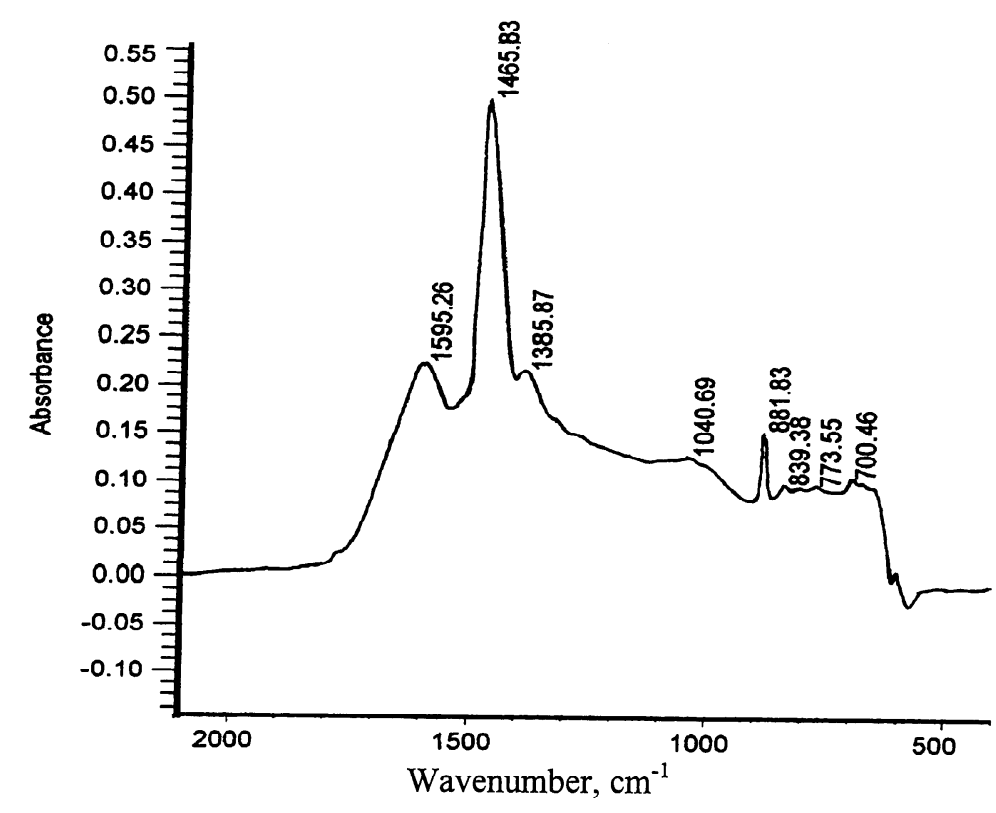

Figure 88. A FT-IR spectrum of tar and $\mathrm{Na}_{2} \mathrm{CO}_{3}$ fume coated glass-fiber filter obtained with an acoustic field of $151 \mathrm{~dB}$ and $950 \mathrm{~Hz}$ (RAC1126B) under reactor conditions of $700^{\circ} \mathrm{C}, 0.81 \mathrm{~m}$ pyrolysis tube heated length, $1.15 \mathrm{~s}$ particle residence time, and $1.46 \mathrm{~s}$ secondary gas space-time.

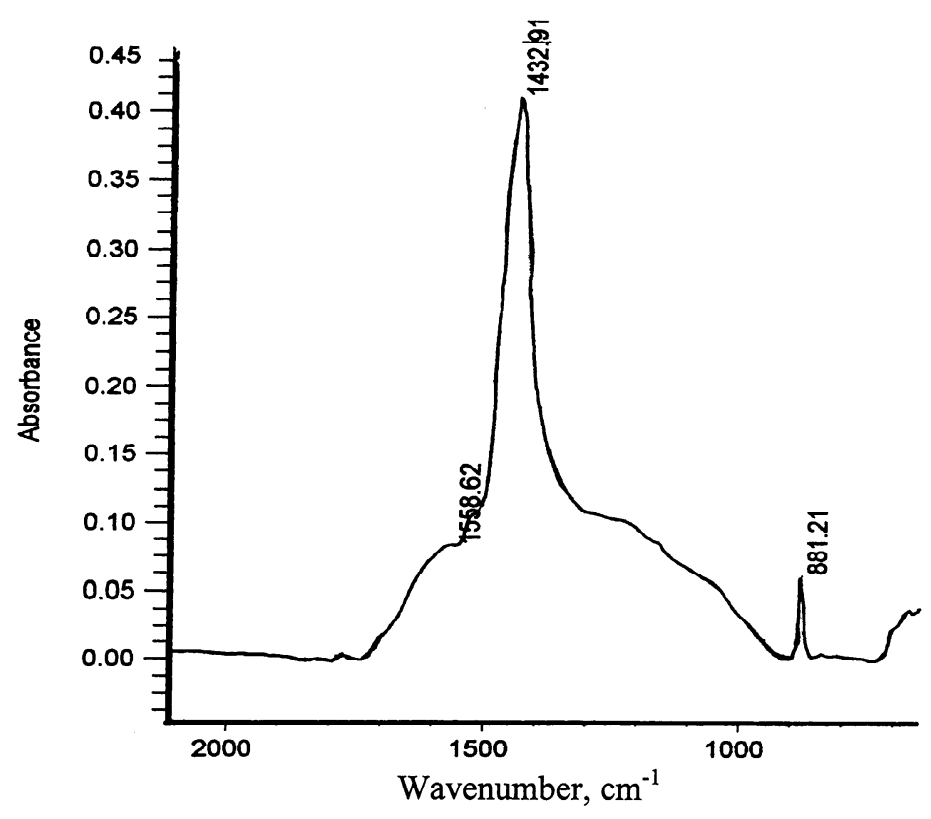

Figure 89. A FT-IR spectrum of $\mathrm{Na}_{2} \mathrm{CO}_{3}$ fume coated glass-fiber filter obtained with an acoustic field of $160 \mathrm{~dB}$ and $950 \mathrm{~Hz}$ (RAC1130C) under reactor conditions of $700^{\circ} \mathrm{C}, 0.81 \mathrm{~m}$ pyrolysis tube heated length, at least $1.37 \mathrm{~s}$ particle residence time, and $1.46 \mathrm{~s}$ secondary gas space-time. 


\section{[5.1.5.4] Conclusions}

Analysis of FT-IR spectra of the tarry liquid and fume coated glass-fiber filters indicates:

- Four types of material can be released during the progression of pyrolysis in the following order: volatiles whose boiling points are below $65^{\circ} \mathrm{C}$, e.g., maximum temperature of the glass-fiber filters during pyrolysis experiments, tarry liquids, tar fume, and $\mathrm{Na}_{2} \mathrm{CO}_{3}$ fume. Release of material is dependent on the particle temperature and the reaction time. It was found that tarry liquids and tar fume contain aliphatic ethers and sodium salts of acetic acid, benzoic acid, and formic acid.

- Tar fume and $\mathrm{Na}_{2} \mathrm{CO}_{3}$ fume were not detected on the glass-fiber filters obtained from steelwool-plug experiments. This suggests that most of the tar and $\mathrm{Na}_{2} \mathrm{CO}_{3}$ fume were entrapped in the char structure, which is in agreement with SEM images that show deposits of fume inside the char and absence of fume on the glass-fiber filters.

- Tar fume can undergo cracking to lower molecular weight volatiles and gases at longer secondary gas space-times at a gas temperature of $700^{\circ} \mathrm{C}$. The extent of tar fume cracking was increased when experiments were conducted with an acoustic field of $151 \mathrm{~dB}$ or higher. 


\section{[5.1.6] Product Gas Analysis}

\section{[5.1.6.1] $\mathrm{CO}$ and $\mathrm{CO}_{2}$ Yields Obtained From Non-sticking, Inflight Particle Pyrolysis} Experiments

$\mathrm{CO}$ and $\mathrm{CO}_{2}$ yields obtained with and without acoustics under conditions of $0.18,0.48$, and $0.81 \mathrm{~m}$ pyrolysis tube heated lengths, $0.23-3.88 \mathrm{~s}$ mean particle residence times, $0.38-6.59 \mathrm{~s}$ secondary gas space-times, and a gas temperature $550^{\circ} \mathrm{C}$ are shown in Figs. 90 and $91 . \mathrm{CO}$ and $\mathrm{CO}_{2}$ yields obtained with and without acoustics under conditions of $0.18,0.48$, and $0.81 \mathrm{~m}$ pyrolysis tube heated lengths, $0.21-1.15 \mathrm{~s}$ mean particle residence times, $0.32-1.46 \mathrm{~s}$ secondary gas space-times, and gas temperatures of 400 and $700^{\circ} \mathrm{C}$ are shown in Figs. 92 and 93 . In addition, $\mathrm{CO}$ and $\mathrm{CO}_{2}$ yields are listed in Tables A5.1 and A5.2 in Appendix 5. 


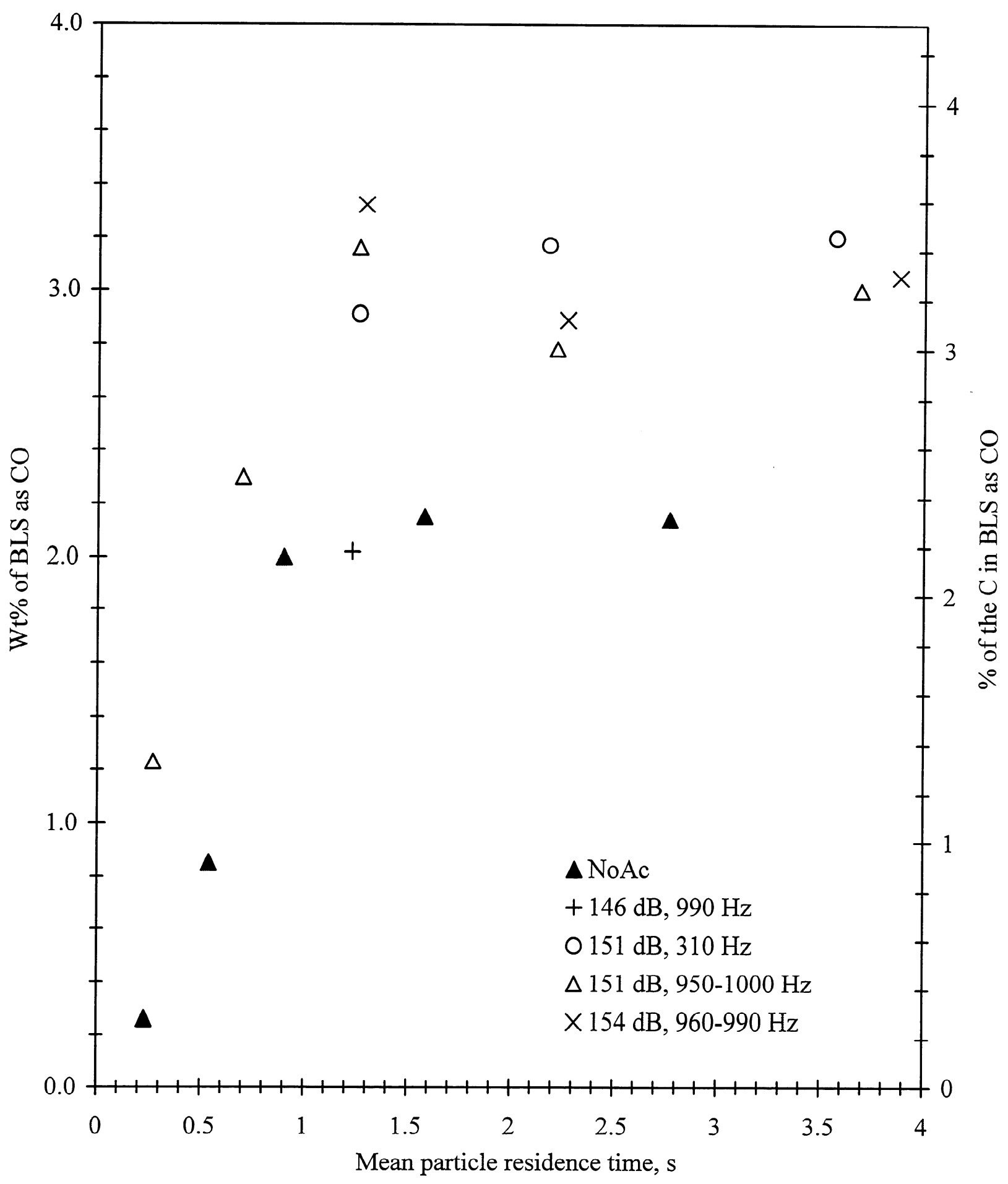

Figure 90. CO yields obtained from the non-sticking, inflight particle pyrolysis experiments with and without an acoustic field of $146-154 \mathrm{~dB}$ and $310-1000 \mathrm{~Hz}$ at a gas temperature of $550^{\circ} \mathrm{C}$. Pyrolysis tube and secondary gas flow configurations were: $0.18,0.48$, and $0.81 \mathrm{~m}$ heated lengths and 20 slpm preheated $\mathrm{N}_{2}$, and $0.81 \mathrm{~m}$ heated length and 5,10, and 20 slpm preheated $\mathrm{N}_{2}$. 


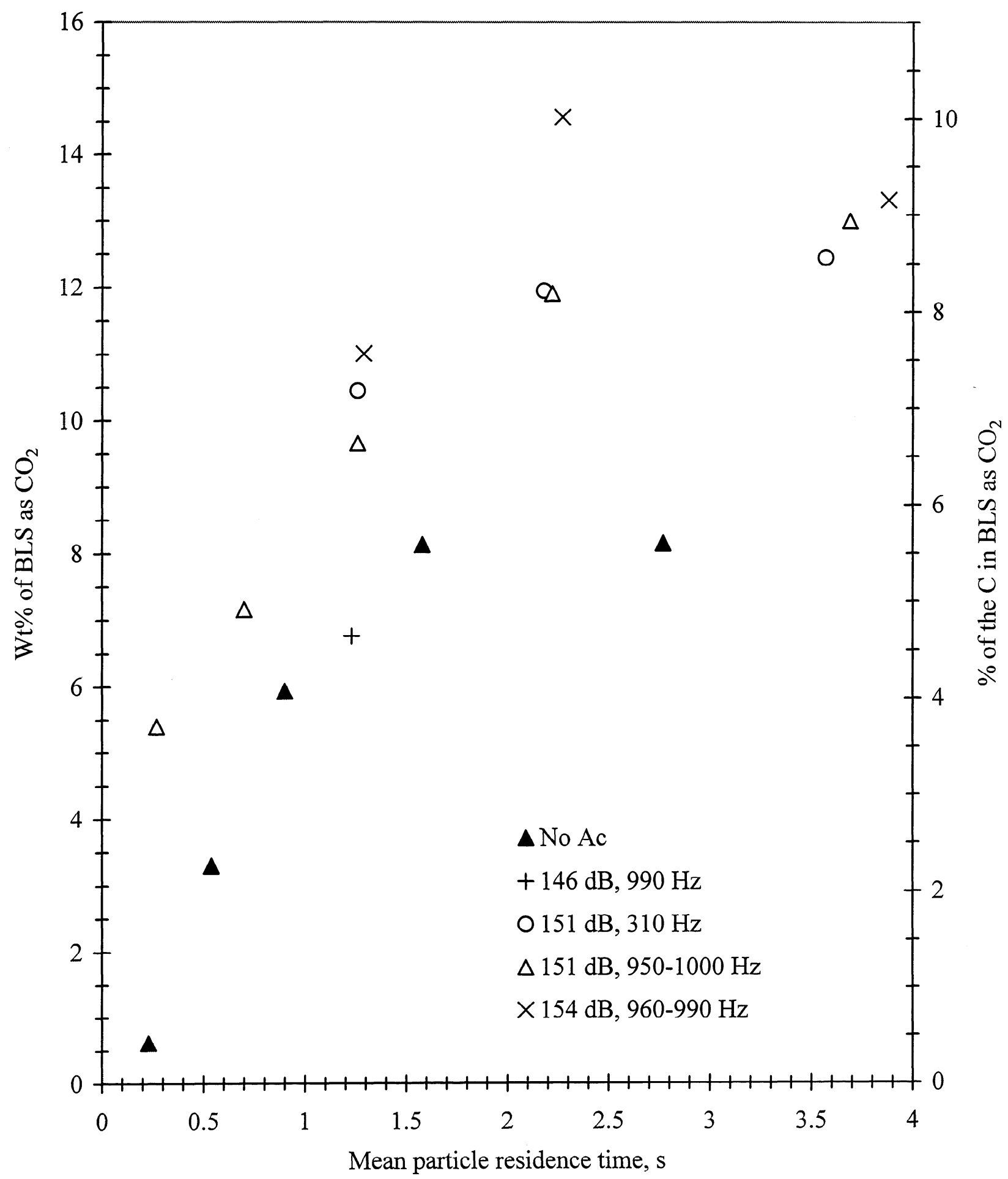

Figure 91. $\mathrm{CO}_{2}$ yields obtained from the non-sticking, inflight particle pyrolysis experiments with and without an acoustic field of $146-154 \mathrm{~dB}$ and $310-1000 \mathrm{~Hz}$ at a gas temperature of $550^{\circ} \mathrm{C}$. Pyrolysis tube and secondary gas flow configurations were: $0.18,0.48$, and $0.81 \mathrm{~m}$ heated lengths and $20 \mathrm{slpm}$ preheated $\mathrm{N}_{2}$, and $0.81 \mathrm{~m}$ heated length and 5,10 , and 20 slpm preheated $\mathrm{N}_{2}$. 
Figs. 90 and 91 indicate:

- CO yields obtained without acoustics (RNAC1105, RNA21105, RNAC912, RNAC918, RNAC919A, RNAC927B, and RNAC927) were always correspondingly lower than those obtained with an acoustic field (RAC925 at146 dB and $1000 \mathrm{~Hz}$; RAC1107, RAC1108, RAC925B, RAC1230B, RAC1230, and RAC1226 at $151 \mathrm{~dB}$ and 950-1000 Hz; RAC1231A, RAC1231B, and RAC1231C at $151 \mathrm{~dB}$ and $310 \mathrm{~Hz}$; and RAC1028, RAC912, RAC926, RAC930, RAC1014, and RAC1227A at $154 \mathrm{~dB}$ and 950-1010 Hz).

- $\mathrm{CO}_{2}$ yields with an acoustic field of $151 \mathrm{~dB}$ were at least 1.5 weight percentage points higher than those obtained without acoustics for the same particle residence times. The $\mathrm{CO}_{2}$ yield obtained using the $0.18 \mathrm{~m}$ pyrolysis tube heated length without acoustics (RNAC1105) was about 5 weight percentage points lower than that obtained with an acoustic field of $151 \mathrm{~dB}$ and $1000 \mathrm{~Hz}$ (RAC1107). Greater production rates and yields of $\mathrm{CO}$ and $\mathrm{CO}_{2}$ obtained in the $0.18 \mathrm{~m}$ and other pyrolysis tube heated lengths using an acoustic field of $151 \mathrm{~dB}$ indicate that pyrolysis was more severe during the particle heatup period.

- $\mathrm{CO}$ and $\mathrm{CO}_{2}$ yields obtained in the $0.18 \mathrm{~m}$ pyrolysis tube heated length using a sound pressure level of $154 \mathrm{~dB}$ (RAC1028) were higher than those obtained using a sound pressure level of $151 \mathrm{~dB}$ (RAC1107). However, the results shown in Figs. 84 and 85 cannot verify whether $\mathrm{CO}$ and $\mathrm{CO}_{2}$ yields were higher due increased particle heatup rate at a sound pressure level of 154 versus $151 \mathrm{~dB}$ because particles often stuck to the pyrolysis tube wall when sound pressure levels were higher than $151 \mathrm{~dB}$. The measured time-dependent $\mathrm{CO}$ and $\mathrm{CO}_{2}$ concentration profiles in the pyrolysis gas, as shown in Fig. A5.26, indicate that increased $\mathrm{CO}$ yield was due to particle sticking because the peak $\mathrm{CO}$ concentration was not 
attained for run times $\leq 160 \mathrm{~s}$, after which particle sticking occurred under constant feedrate of BLS particles to the reactor. $\mathrm{CO}_{2}$ yield probably was not affected by particle sticking because the maximum primary $\mathrm{CO}_{2}$ yield was attained under conditions of rapid particle heatup and short residence times in the $0.18 \mathrm{~m}$ pyrolysis tube heated length.

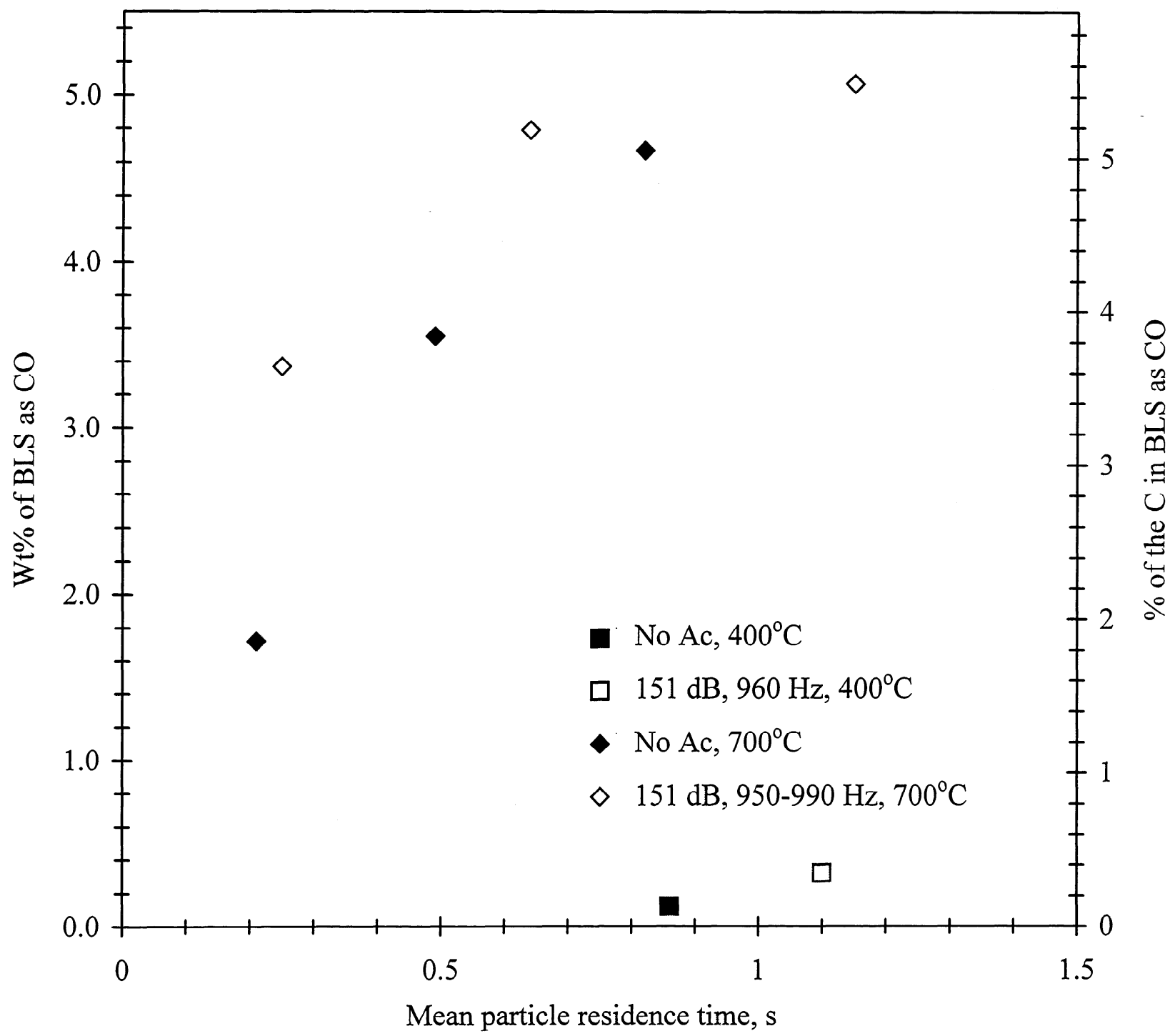

Figure 92. CO yields obtained from the non-sticking, inflight particle pyrolysis experiments with and without an acoustic field of $151 \mathrm{~dB}$ and $950-990 \mathrm{~Hz}$ at gas temperatures of 400 and $700^{\circ} \mathrm{C}$. Pyrolysis tube and secondary gas flow configurations were: $0.18,0.48$, and $0.81 \mathrm{~m}$ heated lengths and $20 \mathrm{slpm}$ preheated $\mathrm{N}_{2}$, and $0.81 \mathrm{~m}$ heated length and 5, 10, and 20 slpm preheated $\mathrm{N}_{2}$. 


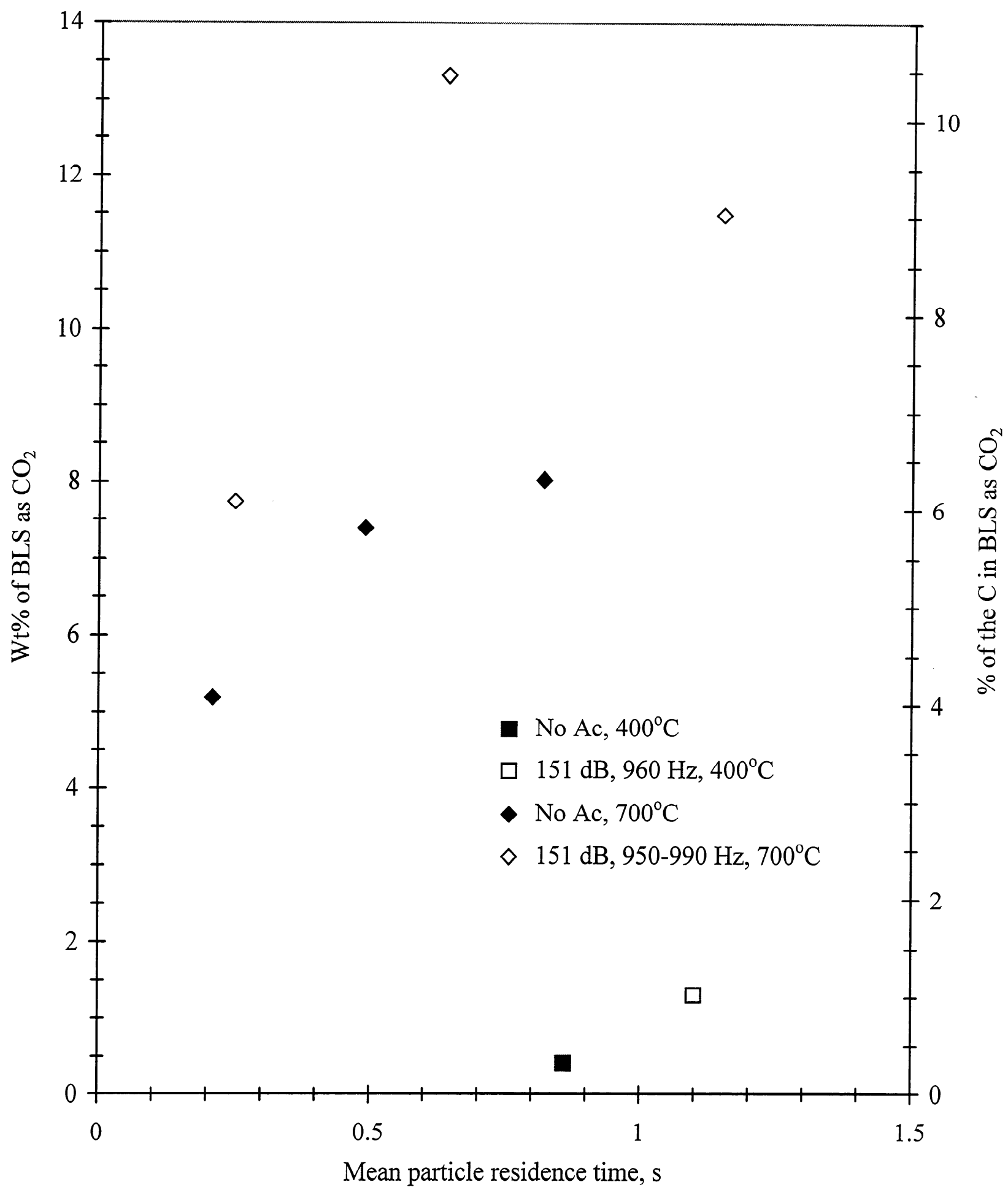

Figure 93. $\mathrm{CO}_{2}$ yields obtained from the non-sticking, inflight particle pyrolysis experiments with and without an acoustic field of $151 \mathrm{~dB}$ and $950-990 \mathrm{~Hz}$ at gas temperatures of 400 and $700^{\circ} \mathrm{C}$. Pyrolysis tube and secondary gas flow configurations were: $0.18,0.48$, and $0.81 \mathrm{~m}$ heated lengths and 20 slpm preheated $\mathrm{N}_{2}$, and $0.81 \mathrm{~m}$ heated length and 5,10, and 20 slpm preheated $\mathrm{N}_{2}$. 
Figs. 92 and 93 indicate:

- At a gas temperature of $400^{\circ} \mathrm{C}, \mathrm{CO}$ and $\mathrm{CO}_{2}$ yields obtained with an acoustic field of $151 \mathrm{~dB}$ and $960 \mathrm{~Hz}$ using the $0.81 \mathrm{~m}$ pyrolysis tube heated length (RAC1119) were much higher than those obtained without an acoustic field (RNAC1113). Measurements were not performed at shorter residence times, because gas concentrations were too low to measure using the gas analyzer.

- At a temperature of $400^{\circ} \mathrm{C}$, measurements conducted with an acoustic field of $154 \mathrm{~dB}$ and $970 \mathrm{~Hz}$ using the $0.81 \mathrm{~m}$ pyrolysis tube heated length and a secondary gas flowrate of 24.9 slpm (RAC1009) show that the CO yield increased to $1.24 \mathrm{wt} \%$ of BLS, or $1.35 \%$ of the carbon in $\mathrm{BLS}$ as $\mathrm{CO}$, and the $\mathrm{CO}_{2}$ yield increased to $3.92 \mathrm{wt} \%$ of $\mathrm{BLS}$, or $2.70 \%$ of the carbon in $\mathrm{BLS}$ as $\mathrm{CO}_{2}$. However, it was found that most of the char had stuck to the pyrolysis tube wall.

- At a gas temperature of $700^{\circ} \mathrm{C}, \mathrm{CO}$ yields obtained without acoustics (RNAC1123, RNAC1127, RNAC1122) were slightly lower compared to those obtained with an acoustic field of $151 \mathrm{~dB}$ and 950-990 Hz (RAC1126A, RAC1127, RAC1130, RAC1126B, and RAC1130B).

- At a gas temperature of $700^{\circ} \mathrm{C}, \mathrm{CO}_{2}$ yields obtained with an acoustic field of $\geq 151 \mathrm{~dB}$ were always higher than those obtained without acoustics for the same particle residence times. $\mathrm{CO}_{2}$ yield reached a maximum with acoustics at a particle residence time of $0.64 \mathrm{~s}$ (RAC1127 and RAC1130) and then decreased slightly. This behavior was repeated in replica experiments. 


\section{[5.1.6.2] $\mathrm{CO}$ and $\mathrm{CO}_{2}$ Yields Obtained From Inflight Particle Pyrolysis Experiments at $\geq 158 \mathrm{~dB}$}

- At a gas temperature of $550^{\circ} \mathrm{C}, \mathrm{CO}$ and $\mathrm{CO}_{2}$ yields obtained with a sound pressure level of $158 \mathrm{~dB}$ (RAC1207, RAC1227B, RAC1224) were similar to those obtained at $154 \mathrm{~dB}$ as shown in Tables A5.1 and A5.2. Particle sticking at a $158 \mathrm{~dB}$ or higher caused a reduction in the secondary production of $\mathrm{CO}_{2}$ and as shown in the time-dependent $\mathrm{CO}$ and $\mathrm{CO}_{2}$ concentration profiles in Figs. A5.31-A5.34. The effect of particle sticking will be discussed in the next section. $\mathrm{CO}_{2}$ yield was higher in experiment RAC1230 because pulsed feeding of particles reduced particle sticking to the pyrolysis tube wall.

- At a gas temperature of $700^{\circ} \mathrm{C}, \mathrm{CO}$ and $\mathrm{CO}_{2}$ yields obtained with an acoustic field of $160 \mathrm{~dB}$ and $950 \mathrm{~Hz}$ (RAC1130C and RAC1205) were substantially higher than those obtained with and without an acoustic field of $151 \mathrm{~dB}$ as shown in Tables A5.1 and A5.2. Yields were higher because particles stuck to the pyrolysis tube wall.

\section{[5.1.6.3] Effects of Secondary Gas Space-time and Particle Residence Time on Primary and Secondary $\mathrm{CO}$ and $\mathrm{CO}_{2}$ Yields Obtained at a Gas Temperature of $400^{\circ} \mathrm{C}$}

Measurements of $\mathrm{CO}$ and $\mathrm{CO}_{2}$ yields were made with a steel-wool-plug located at $0.13 \mathrm{~m}$. It was found that both CO yield of $2.24 \mathrm{wt} \%$ of BLS, or $2.12 \%$ of the carbon in BLS as $\mathrm{CO}$, and the $\mathrm{CO}_{2}$ yield of $4.11 \mathrm{wt} \%$ of $\mathrm{BLS}$, or $2.83 \%$ of the carbon in BLS as $\mathrm{CO}$, were statistically the same for all three experiments conducted: two replicas (RNAC1111 and RNA2111) with a $0.18 \mathrm{~m}$ pyrolysis tube heated length and a secondary gas space-time of $0.47 \mathrm{~s}$ and one (RNAC1112) with a $0.81 \mathrm{~m}$ pyrolysis tube heated length and a secondary gas space-time of $2.1 \mathrm{~s}$. These results indicate that increasing the secondary gas-space time from 0.47 to $2.1 \mathrm{~s}$ 
did not promote secondary cracking of tar in the hot gas phase to $\mathrm{CO}$ and $\mathrm{CO}_{2}$. The observed $\mathrm{CO}$ and $\mathrm{CO}_{2}$ must have been produced by primary pyrolysis of BLS particles. Lower $\mathrm{CO}$ yield and similar $\mathrm{CO}_{2}$ yield obtained from $\mathrm{RACl} 1009$ when compared to that obtained with steel-woolplugs (RNAC1111, RNA2111, and RNAC1112) suggests that $\mathrm{CO}_{2}$ was produced at a faster rate than that of $\mathrm{CO}$ during primary pyrolysis. As a result, increased particle heatup should influence $\mathrm{CO}_{2}$ production more than it would $\mathrm{CO}$ production.

\section{[5.1.6.4] Effects of Secondary Gas Space-time and Particle Residence Time on Primary and Secondary $\mathrm{CO}$ and $\mathrm{CO}_{2}$ Yields Obtained at a Gas Temperature of $550^{\circ} \mathrm{C}$}

Measurements of $\mathrm{CO}$ and $\mathrm{CO}_{2}$ yields were made with the steel-wool-plug located at $0.13 \mathrm{~m}$ downstream from the particle injection point (RNAC1017, RNAC1022, RNAC1023, RNAC1019, RNAC1024, and RNAC1226), except in experiments RNAC923 and RNAC1206 in which the steel-wool-plug was located $0.75 \mathrm{~m}$ downstream from the particle injection point. Except for experiment RAC1206, all steel-wool-plug experiments were performed without acoustics. To accurately measure primary $\mathrm{CO}$ and $\mathrm{CO}_{2}$ yields produced from particle pyrolysis, the product gas was cooled immediately downstream from the steel-wool-plug to prevent secondary pyrolysis of volatiles in the gas phase. Secondary $\mathrm{CO}$ and $\mathrm{CO}_{2}$ yields were measured by extending heating of the pyrolysis tube to $0.62 \mathrm{~m}$ downstream from the steel-wool-plug in conjunction with increasing the secondary gas space-time to promote secondary volatile cracking reactions. 


\section{[5.1.6.4.1] Primary $\mathrm{CO}$ and $\mathrm{CO}_{2}$ Yields}

Fig. 94 shows $\mathrm{CO}$ and $\mathrm{CO}_{2}$ yields obtained from experiments with a steel-wool-plug placed at $0.13 \mathrm{~m}$ and the secondary gas space-time varied from $0.38-6.59 \mathrm{~s}$ and with and without an acoustic field of 151 and $158 \mathrm{~dB}$ and $970-1000 \mathrm{~Hz}$ versus secondary gas space-time. CO yields obtained using a steel-wool-plug were statistically constant over the secondary gas spacetime range studied, which indicates that tar released from particles did not crack in the hot gas phase to form $\mathrm{CO}$ and all of the $\mathrm{CO}$ must have been produced by particle pyrolysis. Mean maximum $\mathrm{CO}$ yield, calculated by averaging the $\mathrm{CO}$ yields obtained from all steel-wool- plug experiments, was $3.08 \mathrm{wt} \%$ of BLS, or $3.34 \%$ of the carbon in BLS as CO. Maximum primary $\mathrm{CO}_{2}$ yield was $6.54 \mathrm{wt} \%$ of $\mathrm{BLS}$, or $4.50 \%$ of carbon in BLS, which obtained using a steel-woolplug and a $0.38 \mathrm{~s}$ secondary gas space-time (RNAC1017).

To determine whether the amount of $\mathrm{CO}_{2}$ produced without acoustics during inflight pyrolysis (RNAC912, RNAC918, and RNAC919A) was solely a primary product of particle pyrolysis, the steel-wool-plug was placed $0.75 \mathrm{~m}$ downstream from the particle injection point (RNAC923). Inflight particles underwent pyrolysis in the same manner as without a steel-woolplug until they deposited on the plug. Once particles contacted the plug, additional residence time became available to allow pyrolysis reaction to be completed. The inflight pyrolyzing BLS particles did not solidify before they contacted the steel-wool-plug, indicating that particle pyrolysis reactions were not fully completed while inflight. When the steel-wool-plug was remove from the pyrolysis tube, once liquid particles were found to be coalesced into clumps of small char structures. $\mathrm{CO}_{2}$ yield of $6.89 \mathrm{wt} \%$ of $\mathrm{BLS}$, or $4.75 \%$ of the carbon in $\mathrm{BLS}$ as $\mathrm{CO}_{2}$, was slightly higher than the maximum primary $\mathrm{CO}_{2}$ yield given by RNAC1017 


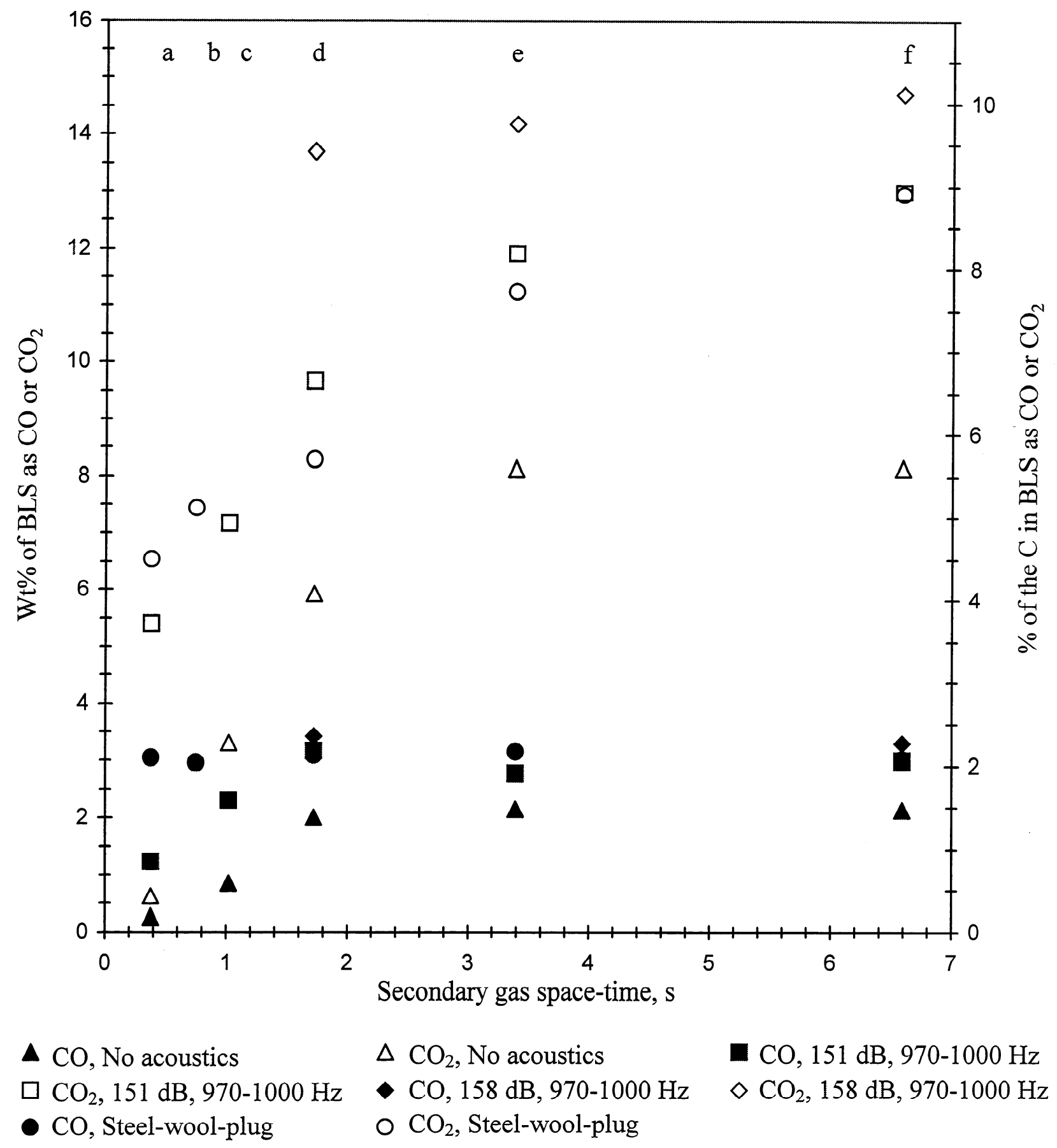

Figure 94. $\mathrm{CO}$ and $\mathrm{CO}_{2}$ yields obtained from inflight, particle pyrolysis experiments and steel-wool-plug experiments conducted at a gas temperature of $550^{\circ} \mathrm{C}$ with steel-wool-plug located $0.13 \mathrm{~m}$ downstream from the particle injection point. Pyrolysis tube and secondary gas flow configurations were: (a) $0.18 \mathrm{~m}$ heated length and 20 slpm secondary gas; (b) $0.18 \mathrm{~m}$ heated length and $10 \mathrm{slpm}$ preheated $\mathrm{N}_{2}$; (c) $0.48 \mathrm{~m}$ heated length and 20 slpm preheated $\mathrm{N}_{2}$; (d) $0.81 \mathrm{~m}$ heated length and $20 \mathrm{slpm}$ preheated $\mathrm{N}_{2}$; (e) $0.81 \mathrm{~m}$ heated length and $10 \mathrm{slpm}$ preheated $\mathrm{N}_{2}$; and (f) $0.81 \mathrm{~m}$ heated length and $5 \mathrm{slpm}$ preheated $\mathrm{N}_{2}$. 


\section{[5.1.6.4.2] Secondary $\mathrm{CO}$ and $\mathrm{CO}_{2}$ Yields}

The additional particle residence time in experiment RNAC923 also caused the $\mathrm{CO}$ yield to increase to from about $2 \mathrm{wt} \%$ of BLS without acoustics (RNAC912, RNAC918, RNAC919A) to $2.93 \mathrm{wt} \%$ of BLS, or $3.37 \%$ of the carbon in BLS. This same mean maximum CO yield was achieved using an acoustic field of $151 \mathrm{~dB}$ when the particle residence time were $\geq 1.19 \mathrm{~s}$. The fact that $\mathrm{CO}$ yield was only $2.15 \mathrm{wt} \%$ of BLS for experiment RNAC927A conducted without acoustics and a $2.77 \mathrm{~s}$ particle residence time supports the argument that the additional CO may be produced by secondary pyrolysis reactions of the particle. These secondary reactions do not begin until approximately $27-29 \mathrm{wt} \%$ of BLS as volatiles are first released from the pyrolyzing particle. An experiment (RAC1206) that was similar to RNAC923 was conducted with a steelwool-plug located $0.13 \mathrm{~m}$ downstream from the particle injection point using an acoustic field of $151 \mathrm{~dB}$ and $960 \mathrm{~Hz}$ and a $3.39 \mathrm{~s}$ secondary gas space-time. It was found that $\mathrm{CO}$ yield was similar and $\mathrm{CO}_{2}$ yield was about 1.7 weight percentage points higher than that obtained from the corresponding acoustic experiment $(\mathrm{RAC1230 \textrm {B }})$ that did not use a steel-wool-plug. $\mathrm{CO}_{2}$ yield obtained from RAC1206 was higher than that obtained from RAC1230B because tar fume particles had more residence time in the heated pyrolysis tube due to tar deposition on the steelwool-fibers and acoustically-induced levitation.

The entire $0.81 \mathrm{~m}$ pyrolysis tube heated length of the reactor had to be used to achieve the mean maximum CO yield using an acoustic field of $151 \mathrm{~dB}$ and $310-970 \mathrm{~Hz}$ and a $1.72 \mathrm{~s}$ secondary gas space-time (RAC1231A and RAC925B). Without acoustics, only about 60-70\% of the mean maximum $\mathrm{CO}$ yield was attained using the entire $0.81 \mathrm{~m}$ pyrolysis tube heated length of the reactor for all secondary gas space-times (RNAC912, RNAC918, RNAC919A, 
RNAC927B, and RNAC927). $\mathrm{CO}_{2}$ was produced by primary pyrolysis of BLS particles and by cracking of tar in the hot gas phase. About $25 \%$ of the $8.15 \mathrm{wt} \%$ of $\mathrm{BLS}$ as $\mathrm{CO}_{2}$ obtained without a acoustics for secondary gas space-times of 3.39 and $6.59 \mathrm{~s}$ (RNAC927B and RNAC927) must have been produced by secondary cracking. Much of the $\mathrm{CO}_{2}$ produced from steel-wool-plug or acoustic experiments using secondary gas space-times $\geq 0.75 \mathrm{~s}$ originated from secondary cracking of tar in the hot gas phase.

It can be concluded that an acoustic field cannot significantly increase the secondary $\mathrm{CO}$ yield beyond the mean maximum $\mathrm{CO}$ yield obtained from steel-wool-plug experiments, in which the particle residence times are very long. Prior to making comparisons of maximum secondary $\mathrm{CO}_{2}$ yields among experiments conducted with and without acoustics or a steel-wool-plug, the time-dependent $\mathrm{CO}_{2}$ production behavior during the experimental run will be discussed.

\section{[5.1.6.4.3] Effect of Tar Polymerization on Secondary $\mathrm{CO}_{2}$ Yield}

Profiles of measured $\mathrm{CO}_{2}$ concentrations were found to be characteristically different among experiments conducted with and without acoustics and with a steel-wool-plug. The molar ratio of $\mathrm{CO}$ to $\mathrm{CO}_{2}$, as shown in Figs. A5.8-A5.14 remained nearly constant during the run for all experiments performed without acoustics. $\mathrm{CO}$ and $\mathrm{CO}_{2}$ concentrations increased to their steadystate levels shortly after particle injection was started and then gradually decreased to zero when particle injection was stopped to end the run.

$\mathrm{CO}$ and $\mathrm{CO}_{2}$ increased to their steady-state levels shortly after injection and remained constant throughout the run for acoustics or steel-wool-plug experiments (RAC1107 and RNAC1017) with a pyrolysis tube heated length of $0.18 \mathrm{~m}$, as shown in Figs A5.17 and A5.35. 
However, $\mathrm{CO}_{2}$ concentration reached a maximum value and then gradually decreased during the run in other acoustic and steel-wool-plug experiments using longer, 0.48 and $0.81 \mathrm{~m}$ pyrolysis tube heated lengths and longer secondary gas space-times, as shown in Figs A5.18-A5.25, A5.27-A5.28, and A5.30-A5.34. CO concentration reached the steady-state value that corresponded to the set point feedrate of BLS particles with the exception of experiments RAC1106, RAC1028, and RAC1014, in which particles stuck to the pyrolysis tube wall as shown in Figs. A5.16, A5.26, and A5.29. In experiments where the $\mathrm{CO}_{2}$ concentration decreased with time, the molar ratio of $\mathrm{CO}$ to $\mathrm{CO}_{2}$ was approximately constant for the first $100 \mathrm{~s}$ into the run and then began to increase when the $\mathrm{CO}_{2}$ concentration started to decrease.

It is postulated that a fraction of the tar molecules contacted char surfaces long enough to polymerize into the char matrix which caused $\mathrm{CO}_{2}$ concentration to decrease during experiments conducted with an acoustic field or steel-wool-plug using longer, 0.48 and $0.81 \mathrm{~m}$ pyrolysis tube heated lengths. This is supported by SEM Analysis of tar deposition and entrapment in the char structure, as shown in Figs. 40 and 43. Polymerization of the tar molecule into the char prevented further secondary cracking reactions that otherwise could release $\mathrm{CO}_{2}$ functional groups, as shown in Fig. 2. More specifically, the tar molecule must have been polymerized into the char by a $\mathrm{C}-\mathrm{O}$ bond of the $\mathrm{CO}_{2}$ functional group in order to prevent further secondary cracking of polymerized tar by pathways that produce $\mathrm{CO}_{2}$. Tar molecules that had eventually polymerized into the char, first may have escaped from the particles and then recontacted the char, or they may have contacted the char while still in the pyrolyzing particle.

For experiments using a steel-wool-plug, BLS particles accumulated and pyrolyzed on the steel-wool-plug during the run and eventually formed a cylindrical char mound whose internal 
pore network and surface area increased during the run as shown in Fig. 95. BLS particles that were injected at the initiation of the run eventually melted and coalesced into a solid char. BLS particles that were injected at a later stage of the run likely pyrolyzed inside the liquid upper portion of the growing char structure. The depth of the molten portion could not be measured. Char structures obtained at a gas temperature of $400^{\circ} \mathrm{C}$ were low in height and very spread out, indicating that pyrolyzing BLS particles were partially liquid for a relatively long time before polymerization reactions produced enough char to build a solid mound. The sructure of char mounds obtained at gas temperatures of 550 and $700^{\circ} \mathrm{C}$ were taller, indicating that polymerization reactions that form char were quite rapid. Feedrates of BLS particles were similar for most of the experiments, as shown in Figs. A5.35-A5.42.

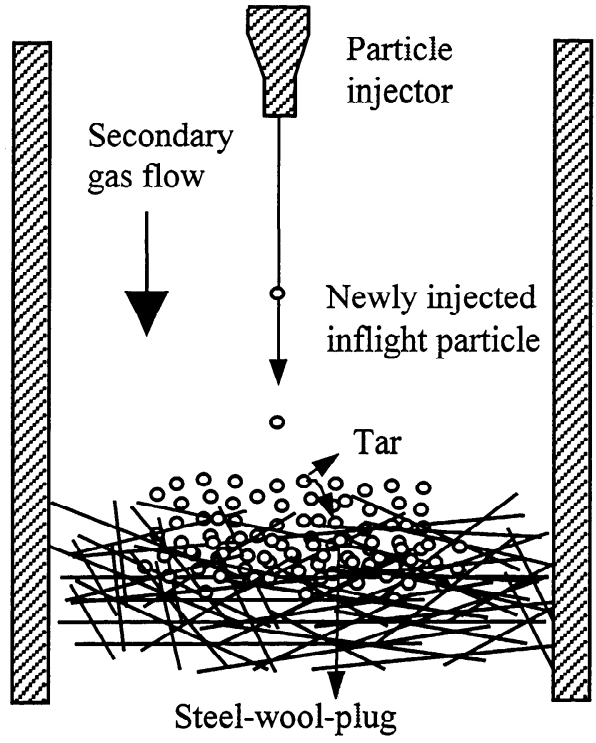

Deposition of BLS particle at an early stage during a steel-wool-plug experiment

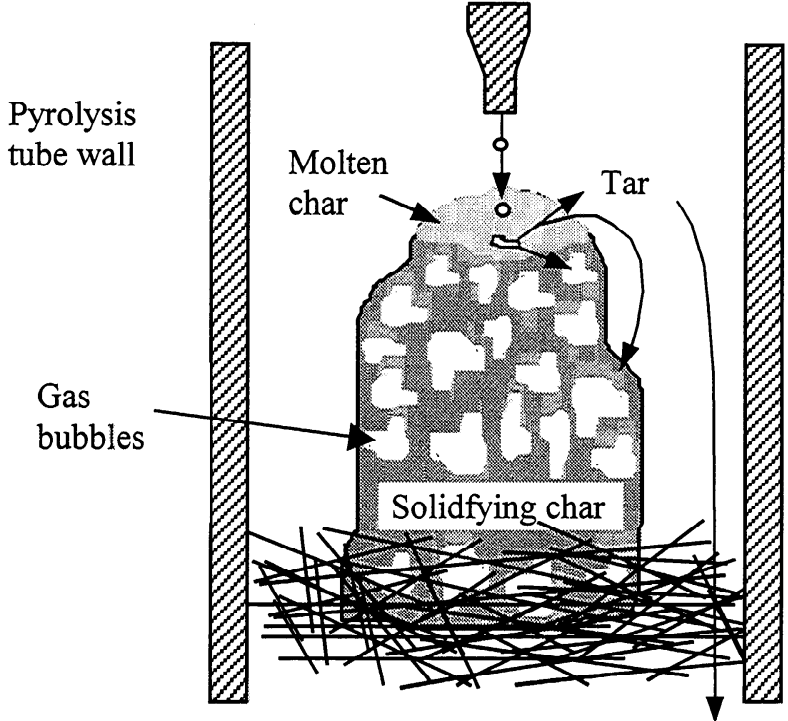

Deposition and accumulation of BLS particles at a later stage during a steel-wool-plug experiment

Figure 95. An illustration of deposition and accumulation of BLS particles at different times during a typical steel-wool-plug experiment. 
A tar molecule that was released inside the liquid, pyrolyzing portion of the coalesced char structure had a longer transit time to reach the exterior surface than a tar molecule that escaped from within an inflight, 106-125 $\mu \mathrm{m}$ diameter BLS particle or from a BLS particle that was initially deposited on the steel wool plug. As a result, tar generated at a later stage in steelwool-plug experiments had more opportunity to polymerize into the char matrix than did tar that was produced inside of inflight BLS particles. Because more external char surface area was available later in the run, tar that escaped from the char structure into the hot gas phase later in the run would have even more opportunity to recontact the char and polymerize into the char structure. In addition, tar molecules would also experience longer transit times within large clumps of char stuck that stuck to the pyrolysis tube wall in experiments with an acoustic field of $158 \mathrm{~dB}$.

It is postulated that the reduction of $\mathrm{CO}_{2}$ yield due to tar polymerization into the char can be estimated by mulitplying the $\mathrm{CO}$ concentration measured throughout the run by the molar ratio of $\mathrm{CO}_{2}$ to $\mathrm{CO}$ obtained in the first 50-100 s of the run, in which the molar ratio of $\mathrm{CO}_{2}$ to CO was always constant as described in Appendix 5. This empirical estimation method can be seen to correctly estimate the time-dependent concentration of $\mathrm{CO}_{2}$ based on the measured $\mathrm{CO}$ concentration for all experiments without acoustics in which particle or tar concentrations did not change in the pyrolysis tube as the run progressed, as shown in Figs. A5.3, A5.6, A5.7, A5.9-A5.15, A5.17, A5.35, A5.43-A5.46, A5.49, and A5.50.

As shown in Fig. 96, higher estimated mean $\mathrm{CO}_{2}$ yields obtained from steel-wool-plug experiments compared to those obtained with an acoustic field of $151 \mathrm{~dB}$ and $970-1000 \mathrm{~Hz}$ indicate that tar was released farther downstream in the heated pyrolysis tube in these acoustics 
experiments. It is not likely that faster particle heatup in an acoustic field of $159 \mathrm{~dB}$ and $970 \mathrm{~Hz}$ increased the tar yield compared to that obtained with a steel-wool-plug because the estimated mean $\mathrm{CO}_{2}$ yields were similar at the longest, $6.59 \mathrm{~s}$ secondary gas space-time. Higher estimated mean $\mathrm{CO}_{2}$ yields obtained at a sound pressure level of $159 \mathrm{~dB}$ compared to those obtained with a steel-wool-plug correspondingly shorter secondary gas space-times suggest that the residence time of tar fume was longer. Higher estimated $\mathrm{CO}_{2}$ yields obtained with an acoustic field of $151 \mathrm{~dB}$ and $310 \mathrm{~Hz}$ compared to that obtained at $151 \mathrm{~dB}$ and $970-1000 \mathrm{~Hz}$ indicate that tar residence time in the hot gas phase was affected by the gas flowfield. 


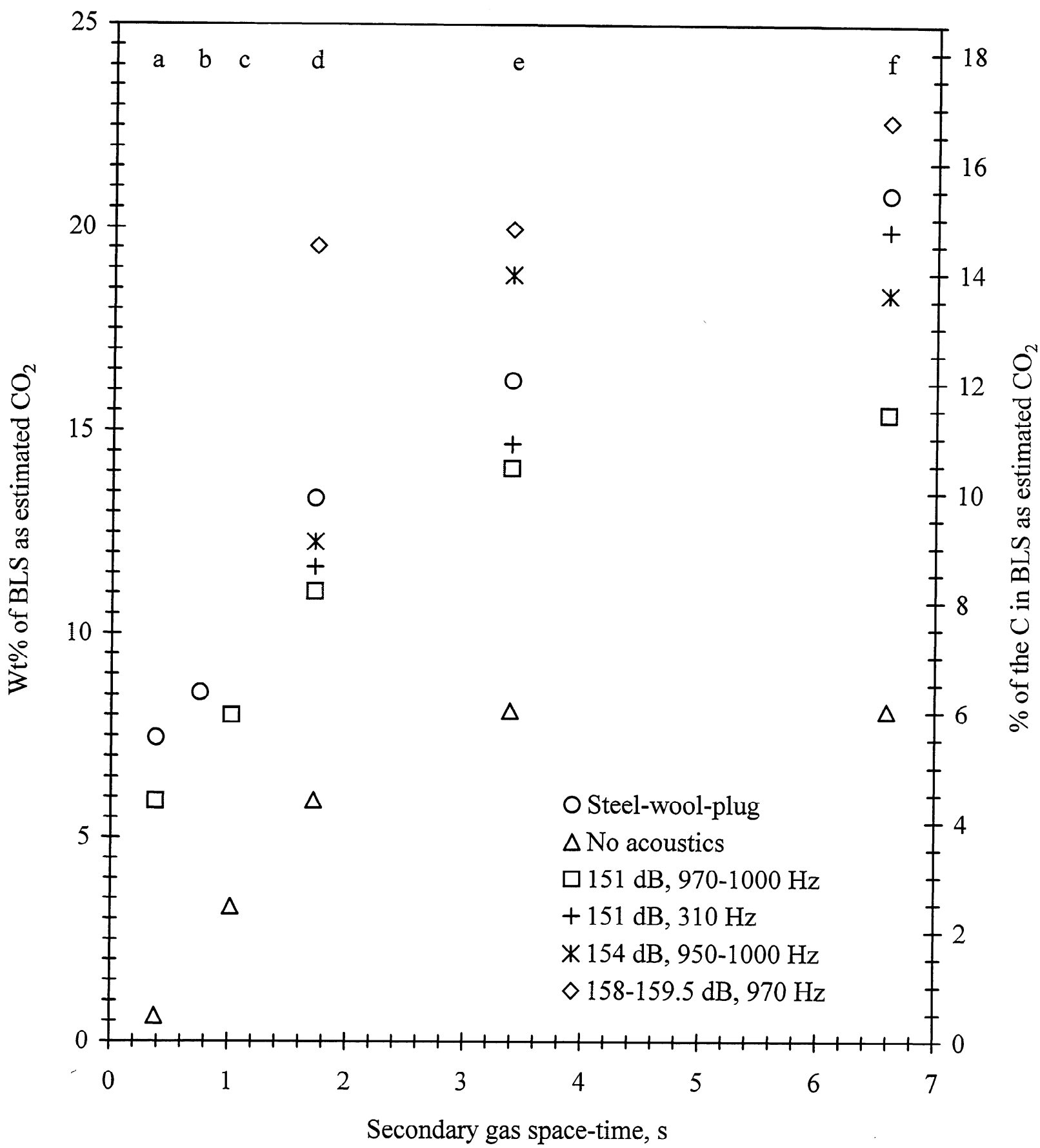

Figure 96. Estimated mean $\mathrm{CO}_{2}$ yields obtained from inflight particle experiments and steelwool-plug experiments conducted at a gas temperature of $550^{\circ} \mathrm{C}$ with steel-woolplug located $0.13 \mathrm{~m}$ downstream from the particle injection point. Pyrolysis tube and secondary gas flow configurations were: (a) $0.18 \mathrm{~m}$ heated length and 20 slpm secondary gas; (b) $0.18 \mathrm{~m}$ heated length and 10 slpm preheated $\mathrm{N}_{2}$;

(c) $0.48 \mathrm{~m}$ heated length and $20 \mathrm{slpm}$ preheated $\mathrm{N}_{2}$; (d) 0.81 m heated length and 20 slpm preheated $\mathrm{N}_{2}$; (e) $0.81 \mathrm{~m}$ heated length and 10 slpm preheated $\mathrm{N}_{2}$; and (f) $0.81 \mathrm{~m}$ heated length and $5 \mathrm{slpm}$ preheated $\mathrm{N}_{2}$. 


\section{[5.1.6.4] Effect of Gasification on $\mathrm{CO}$ and $\mathrm{CO}_{2}$ Yields Obtained at Gas Temperatures of 550 and $700^{\circ} \mathrm{C}$}

It is highly unlikely that gasification of the char carbon by $\mathrm{CO}_{2}$ in the pyrolysis product gas occurred during experiments conducted at a gas temperature of $550^{\circ} \mathrm{C}$, because the gasification reaction rate is very slow. Residence times in excess of $100 \mathrm{~min}$ are necessary to obtain $99 \%$ conversion of the carbon at a gas temperature of $600^{\circ} \mathrm{C}$ and $4 \mathrm{bar} \mathrm{CO}_{2}$ (Backman et al., 1992). Furthermore, the $\mathrm{CO}$ concentration did not increase nor did $\mathrm{CO}_{2}$ concentration decrease during the run as required by the gasification reaction stoichiometry,

$$
\mathrm{C}(\mathrm{s})+\mathrm{CO}_{2} \longrightarrow 2 \mathrm{CO} \text {. }
$$

According to Backman et al. (1992), the gasification rate of char carbon by $\mathrm{CO}_{2}$ is over ten times faster at a temperature of $700^{\circ} \mathrm{C}$ and pressure of 4 bar $\mathrm{CO}_{2}$ than at $600^{\circ} \mathrm{C}$.

At a gas temperature of $700^{\circ} \mathrm{C}$, gasification of the char carbon by $\mathrm{CO}_{2}$ (see Eq. 26) or decomposition of $\mathrm{Na}_{2} \mathrm{CO}_{3}$ (see Eq. 4) could have caused the continuous increase in $\mathrm{CO}$ concentration and decrease in $\mathrm{CO}_{2}$ concentration after about $200 \mathrm{~s}$ into the run in experiments with an acoustic field (RAC1205) or steel-wool-plugs (RNAC1124 and RNAC1204) as shown in Figs. A5.52, A5.53, and A5.55. During the first $100 \mathrm{~s}$ into the run, CO concentration did not increase beyond the steady-state level given by the feedrate of BLS particles to the reactor. The $\mathrm{CO}$ concentration also remained constant during another run with a steel-wool-plug that lasted under $200 \mathrm{~s}$ (RNAC1125), as shown in Fig. A5.54. For RNAC1125 and RNAC1124, the molar ratios of $\mathrm{CO}$ to $\mathrm{CO}_{2}$ were 0.3191 and 0.4255 , respectively, during the first $100 \mathrm{~s}$ of the run. The lower molar ratio of $\mathrm{CO}$ to $\mathrm{CO}_{2}$ for $\mathrm{RNAC1} 125$ suggests that some $\mathrm{CO}_{2}$ was produced by cracking of tar in the hot gas phase. It is suggested that gasification of char by $\mathrm{CO}_{2}$ or 
decomposition of $\mathrm{Na}_{2} \mathrm{CO}_{3}$ to produce $\mathrm{CO}$ only occurs at residence times $>200 \mathrm{~s}$ at a gas temperature of $700^{\circ} \mathrm{C}$ but not at $550^{\circ} \mathrm{C}$.

\section{[5.1.6.5] Conclusions}

Analysis of $\mathrm{CO}$ and $\mathrm{CO}_{2}$ yields indicates:

- At a gas temperature of $400^{\circ} \mathrm{C}$, maximum primary $\mathrm{CO}$ and $\mathrm{CO}_{2}$ yields were approximately 2.24 and $4.12 \mathrm{wt} \%$ of BLS, or 2.42 and $2.82 \%$ of the carbon in $\mathrm{BLS}$ as $\mathrm{CO}$ and $\mathrm{CO}_{2}$, respectively. These maximum yields were determined using a steel-wool-plug at the shortest, $0.47 \mathrm{~s} \mathrm{secondary} \mathrm{gas} \mathrm{space-time.} \mathrm{It} \mathrm{was} \mathrm{found} \mathrm{that} \mathrm{tarry} \mathrm{liquids} \mathrm{released} \mathrm{from} \mathrm{particles} \mathrm{into}$ the hot gas phase did not crack to produce $\mathrm{CO}$ or $\mathrm{CO}_{2}$ with an acoustic field of $154 \mathrm{~dB}$ and $1000 \mathrm{~Hz}$ or with a steel-wool-plug when the secondary gas space-time was extended to $2.10 \mathrm{~s}$.

- At a gas temperature of $550^{\circ} \mathrm{C}$, the maximum primary $\mathrm{CO}$ yield without acoustics was approximately $2.15 \mathrm{wt} \%$ of $\mathrm{BLS}$, or $2.33 \%$ of the carbon in $\mathrm{BLS}$ as $\mathrm{CO}$, at particle residence times between $0.88-2.76 \mathrm{~s}$. With an acoustic field of $\geq 151 \mathrm{~dB}$ or with a steel-wool-plug, maximum CO yield was increased to approximately $3.1 \mathrm{wt} \%$ of $\mathrm{BLS}$, or $3.36 \%$ of the carbon in BLS. With acoustics or a steel-wool-plug, a particle residence time $\geq 1.26 \mathrm{~s}$ was necessary to produce the additional $0.95 \mathrm{wt} \%$ of BLS as CO over that produced without acoustics (3.1 wt $\%-2.15 \mathrm{wt} \%=0.95 \mathrm{wt} \%$ of BLS). This additional amount of CO produced with acoustics or a steel-wool-plug was due to secondary pyrolysis reactions of the particles that proceeded below a critical char yield of about $71-73 \mathrm{wt} \%$ of BLS. 
- At a gas temperature of $550^{\circ} \mathrm{C}$, maximum primary $\mathrm{CO}_{2}$ yield was between $6-6.5 \mathrm{wt} \%$ of $\mathrm{BLS}$, or $4.1-4.5 \%$ of the carbon in BLS as $\mathrm{CO}_{2}$, which was determined using a steel-wool-plug and the shortest $0.38 \mathrm{~s}$ secondary gas space-time (RNAC923). Without acoustics, secondary gas space-times of $\geq 1.72 \mathrm{~s}$ were required to achieve the primary $\mathrm{CO}_{2}$ yield obtained with an acoustic field of $151 \mathrm{~dB}$ or a steel-wool plug.

- At a gas temperature of $700^{\circ} \mathrm{C}$, gasification of the char by $\mathrm{CO}_{2}$ in the product gas complicated the determination of primary and secondary $\mathrm{CO}$ and $\mathrm{CO}_{2}$ yields.

- A fraction of the $\mathrm{CO}_{2}$ functional groups of primary tar molecules can be released by secondary cracking at temperatures of 550 and $700^{\circ} \mathrm{C}$. These $\mathrm{CO}_{2}$ functional groups were not released when the primary tar molecules polymerized into the char. As a result, secondary $\mathrm{CO}_{2}$ yields can be reduced under conditions that promote entrapment of primary tar within the pyrolyzing particle or redeposition of tar onto the char surface. Entrapment of tar within the char or redeposition of tar onto the particle surface is indicated by a continuous decrease in the $\mathrm{CO}_{2}$ concentration during several experimental runs conducted with a steel-wool-plug or acoustics. At a gas temperature of $550^{\circ} \mathrm{C}$ and secondary space-time of $6.59 \mathrm{~s}$, empirically corrected mean $\mathrm{CO}_{2}$ yields were about the same for experiments with an acoustic field of $158 \mathrm{~dB}$ and $970 \mathrm{~Hz}$ and with a steel-wool-plug. Empirically corrected mean $\mathrm{CO}_{2}$ yields obtained with a steel-wool-plug were always higher than those with an acoustic field of $151 \mathrm{~dB}$ and $310-1000 \mathrm{~Hz}$.

- Within the gas temperature range of this study, it was found that increased particle heatup rate due to an acoustic field of $\geq 151 \mathrm{~dB}$ can increase the rates of primary $\mathrm{CO}$ and $\mathrm{CO}_{2}$ 
production. Decrease char yields obtained in the shortest $0.18 \mathrm{~m}$ pyrolysis tube heated length indicate that more tar can be released into the gas phase when particles heatup rate is increased. When the particle is rapidly heated to temperatures at which tar is released, a large fraction of primary gas production coincides with tarry liquid release. Increasing the particle heatup rate can increase the rate of primary gas production, which increases the internal particle gas pressure that acts as the driving force for internal transport of tar to the particle surface. Increasing the particle heatup rate can increase the particle swelling rate (Miller, 1986), which can affect the internal morphology and transport time of tar to the particle surface. At a gas temperature of $550^{\circ} \mathrm{C}$ without acoustics, the particle heatup rates were too low to enhance internal tar transport to the particle surface. Hence, more tar remained in the pyrolyzing particle to eventually polymerize into the char matrix, resulting in higher char yield and lower secondary pyrolytic $\mathrm{CO}_{2}$ yield. At a gas temperature of $700^{\circ} \mathrm{C}$, constant char yields with or without acoustics indicate that there is a critical particle heatup rate above which primary gas and tar production coincide, which can sufficiently enhance internal mass transport of reactive tars, and/or that secondary cracking of reactive tars to form $\mathrm{CO}_{2}$ is much more kinetically favored than is polymerization into char at a gas temperature of $700^{\circ} \mathrm{C}$ than at $550^{\circ} \mathrm{C}$.

- At gas temperatures of 550 and $700^{\circ} \mathrm{C}$, secondary $\mathrm{CO}_{2}$ yields obtained at similar particle residence time with an acoustic field of $\geq 146 \mathrm{~dB}$ always exceeded those without acoustics. At a gas temperature of $550^{\circ} \mathrm{C}$, lower char yields with acoustics compared to that without acoustics indicate that more tar feedstock was available for secondary cracking. At a gas temperature of $550^{\circ} \mathrm{C}$, higher secondary $\mathrm{CO}_{2}$ yields obtained with an acoustic field of $158 \mathrm{~dB}$ and secondary gas space-times of 1.72 and $3.39 \mathrm{~s}$ compared to that obtained with a steel- 
wool-plug at the same secondary gas space-times suggests that tar residence time in the pyrolysis tube was increased by acoustics.

\section{[5.2] GAS AND PARTICLE FLOW ANALYSIS}

Smoke-laden gas and particle flows were analyzed using the diode laser system and highand low-speed video systems to determine whether particles spent longer time in the pyrolysis tube when an acoustic field was applied.

\section{[5.2.1] Estimation of Particle Residence Time Using the Diode Laser System}

The diode laser system was used to qualitatively measure the residence time of a pulse of particles in a $0.95 \mathrm{~m}$ section of the pyrolysis tube. Measurements were performed using a secondary gas flowrate of $56 \mathrm{slpm}$ cold air at a temperature of $20^{\circ} \mathrm{C}$. The average flow velocity was equal to that corresponding to a secondary flowrate of $20 \mathrm{slpm} \mathrm{N}_{2}$ preheated to a temperature of $550^{\circ} \mathrm{C}$. It was found that the mean residence time of the pulse of BLS particles was $1.12 \mathrm{~s}$ and ranged between 1.03-1.20 s without acoustics and was between 1.11-1.89 $\mathrm{s}$ with an acoustic field of 146-154 dB and $970 \mathrm{~Hz}$. Particle residence times increased with the increase of sound pressure level. Residence times of individual particle pulses are listed in Table A9.1. in Appendix 9.

The diode laser measurement is qualitative because of particle dispersion. Only the residence times of those particles that cross the laser beam path were measured. Particle dispersion also increases the length of the scattered light signal, making measurements difficult. It was found that the scattered light signals on the oscilloscope were about $2 \mathrm{~s}$ longer than the estimate $2-3 \mathrm{~s}$ time span of the pulse when the an acoustic field of approximately $154 \mathrm{~dB}$ was 
applied. Small groups of peaks occurred intermittently along the oscilloscope time axis, indicating that the particle pulse was significantly dispersed by gas oscillations.

\section{[5.2.2] High- and Low-Speed Video Imaging of Gas and Particle Flows in Simulated Pyrolysis Tube}

Images of gas and particle flows through the $0.5 \mathrm{~m}$ long pyrex glass simulated pyrolysis tube section were obtained for secondary gas flowrates of 14,28 , and 56 slpm cold air at a temperature of $20^{\circ} \mathrm{C}$ using low-speed and high-speed video cameras. The average flow velocities of $0.116,0.232$, and $0.464 \mathrm{~m} / \mathrm{s}$ were equal to those under corresponding flowrates of 5,10 , and $20 \mathrm{slpm} \mathrm{N}_{2}$ preheated to $550^{\circ} \mathrm{C}$. Char particles produced from $400^{\circ} \mathrm{C}$ pyrolysis experiments RNAC1113 and RAC1119 were used in the imaging studies. These $125-300 \mu \mathrm{m}$ diameters char particles were comparable to those produced in the $0.18 \mathrm{~m}$ pyrolysis tube heated length during $550^{\circ} \mathrm{C}$ pyrolysis experiments. The average diameter of the char particles used in the cold flow imaging study was 150-200 $\mu \mathrm{m}$ as determined from SEM analyses. The densities of these char particles should be comparable to those obtained during the heatup period to $550^{\circ} \mathrm{C}$, as discussed in Appendix 9. Fully swollen char particles obtained using at a gas temperature of $550^{\circ} \mathrm{C}$ were not used, because their terminal velocities would be much lower than those of BLS particles undergoing swelling. Within the $0.185 \mathrm{~m}$ pyrex tube length imaged, the flight behavior of these char particles produced at a gas temperature of $400^{\circ} \mathrm{C}$ should be comparable to that of BLS particles which undergo swelling while being heated to a temperature of $550^{\circ} \mathrm{C}$ in the $0.18 \mathrm{~m}$ pyrolysis tube heated section.

Mean char particle residence times in the simulated pyrex tube section were obtained from high-speed video images. Figs. 97 and 98 show still images of particles at secondary gas flowrates of 14 and 56 slpm cold air with and without an acoustic field of 151-159.5 dB and 
$970 \mathrm{~Hz}$. Particle residence times in various sections of the pyrolysis tube $0.045-0.085$, 0.05-0.175, and $0.145-0.185 \mathrm{~m}$ downstream from the particle injection point were measured to estimate the particle injection velocity, mean particle residence time in the $0.18 \mathrm{~m}$ tube section, and the final particle velocity at the end of the $0.18 \mathrm{~m}$ tube section, respectively. The injection and final velocities of the particle were used to estimate the particle drag coefficient and the degree of carrier gas jet penetration into the secondary gas flow. Individual particles were tracked across the video monitor screen while playing the high-speed video at 10 or 30 frames/s. Particles to be tracked were chosen randomly within the $0.5-1 \mathrm{~s}$ time span of recorded video. Each particle was tracked only once. Distances on the video monitor screen were scaled to actual distances by relating the pyrex glass tube diameter on the video monitor to its actual diameter. The time for the particle to travel through a section was calculated using the time stamped on each image. The mean particle residence time in each section of the pyrex tube was calculated by averaging the residence times of 30 individual particles. For a secondary gas flowrate of $14 \mathrm{slpm}$ of cold air, mean particle residence times in the $0.18 \mathrm{~m}$ tube section were 0.33 and $0.29 \mathrm{~s}$ with and without acoustics, respectively. For a secondary gas flowrate of 56 slpm cold air, mean particle residence times in the $0.18 \mathrm{~m}$ tube section were 0.20 and $0.16 \mathrm{~s}$ with and without acoustics, respectively. Tables A9.2-A9.4 show the calculated velocities of individual particles in the three sections of the simulated pyrolysis tube for the studied flow cases.

Fig. 97 shows that the dispersion of particles was increased from the centerline of the secondary gas flow with acoustics at high sound pressure level. When the sound pressure level was $151 \mathrm{~dB}$ as compared to without an acoustic field. Dispersion increased with the decrease of secondary air flowrate in the presence of an acoustic field as shown in Fig 98. 
(a)

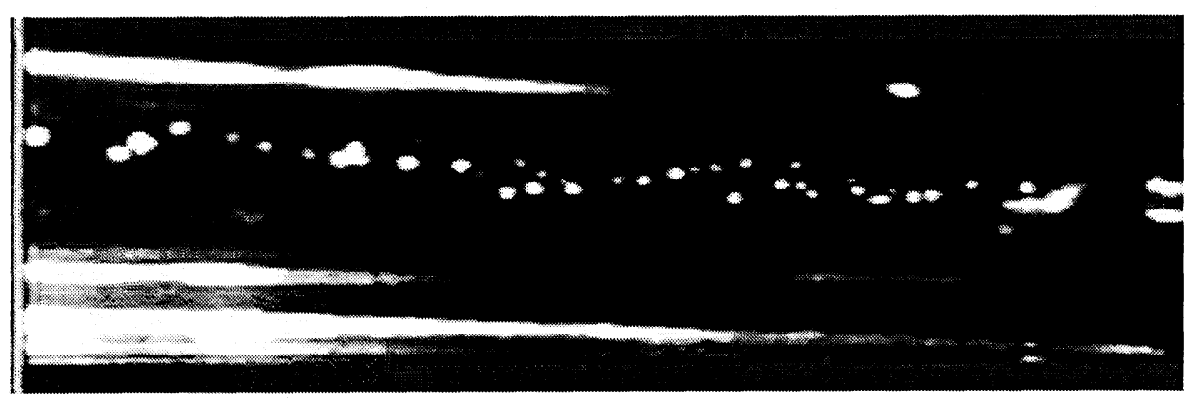

(b)

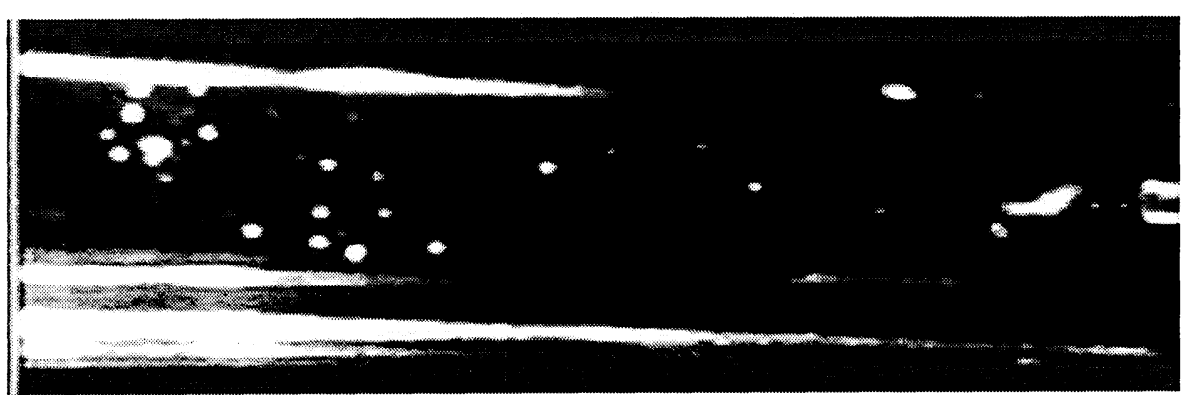

(c)

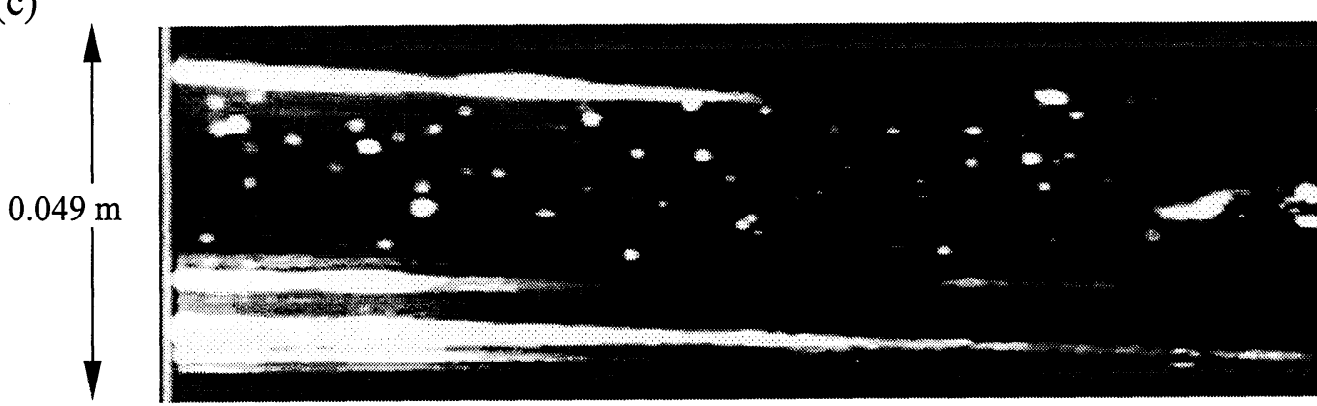

Particle injection tube exit $0.185 \mathrm{~m}$

Figure 97. High-speed video images of inflight char particles in the first $0.185 \mathrm{~m}$ section of simulated pyrolysis tube following the particle injection tube exit using secondary gas flowrate of $56 \mathrm{slpm}$ cold air at a temperature of $20^{\circ} \mathrm{C}$ (a) without acoustics, (b) with an acoustic field of $151 \mathrm{~dB}$ and $970 \mathrm{~Hz}$, and (c) with an acoustic field of $158 \mathrm{~dB}$ and $970 \mathrm{~Hz}$. 
(a)

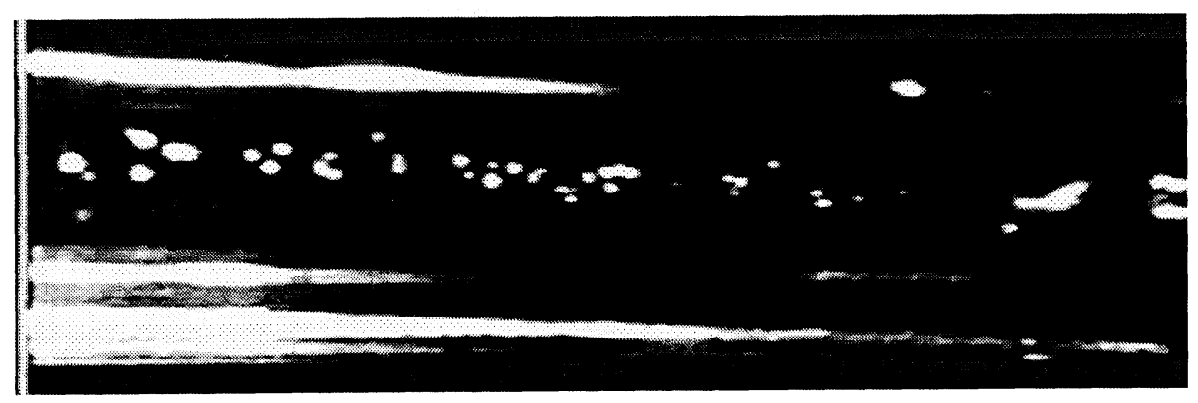

(b)

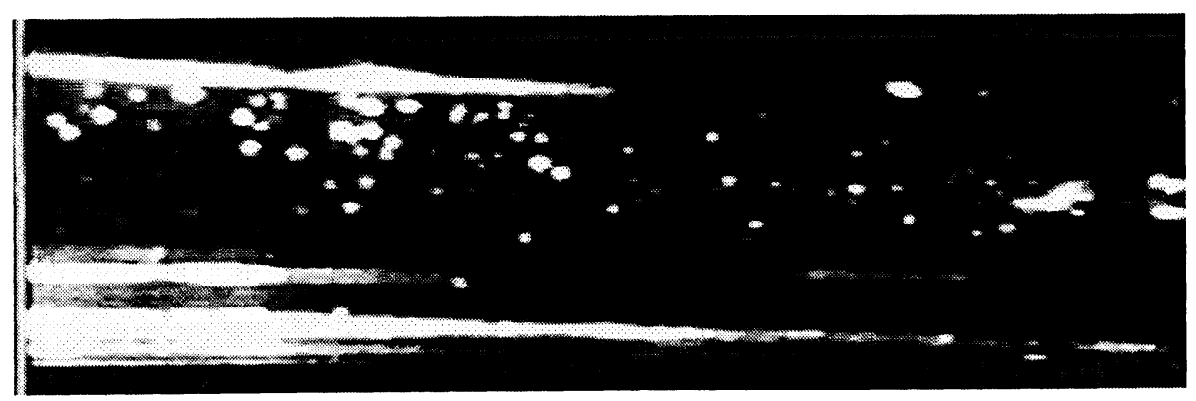

(c)

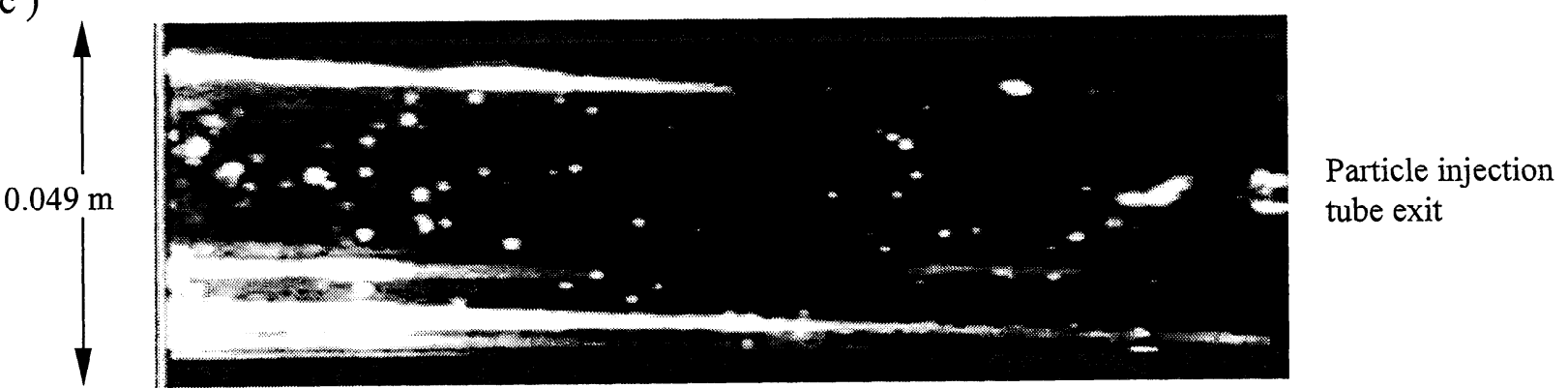

Figure 98. High-speed video images of inflight char particles in $0.185 \mathrm{~m}$ section of simulated pyrolysis tube following the particle injection tube exit using secondary gas flowrate of $14 \mathrm{slpm}$ cold air at a temperature of $20^{\circ} \mathrm{C}$ (a) without acoustics, (b) with an acoustic field of $151 \mathrm{~dB}$ and $970 \mathrm{~Hz}$, and (c) with an acoustic field of $158 \mathrm{~dB}$ and $970 \mathrm{~Hz}$. 
The $\mathrm{N}_{2}$ particle carrier gas jet was better mixed with the smoke-laden, secondary air flow when using an acoustic field of $151 \mathrm{~dB}$ and $970 \mathrm{~Hz}$ as shown in Fig. 99. At secondary air flowrates of 14 and 56 slpm the flow was laminar, and a few traveling, rolling vortices were observed in the video taken with an acoustic field of $151 \mathrm{~dB}$ and $970 \mathrm{~Hz}$. At a sound pressure level of $158 \mathrm{~dB}$, the secondary air flow became turbulent and was very well mixed.

(a)

$$
\text { Particle injection }
$$
tube exit

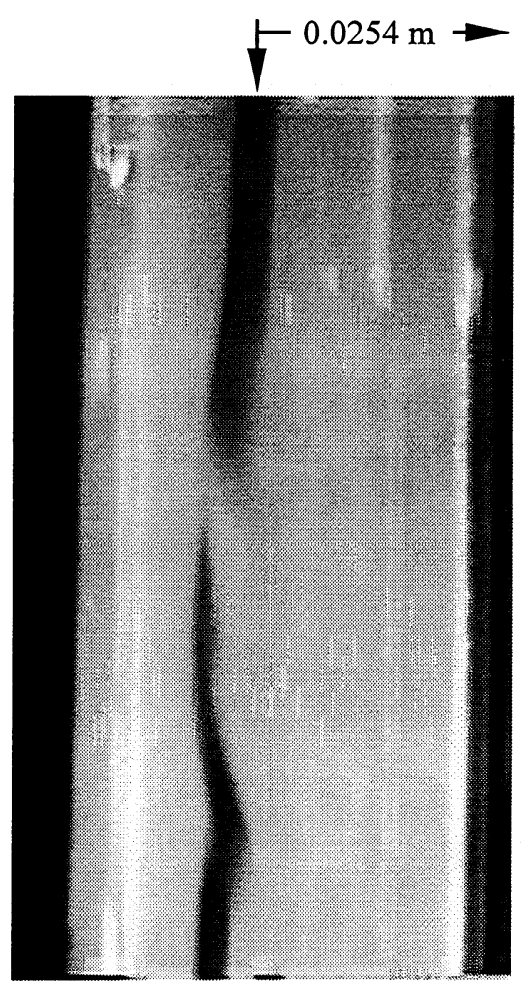

(b)

Particle injection tube exit

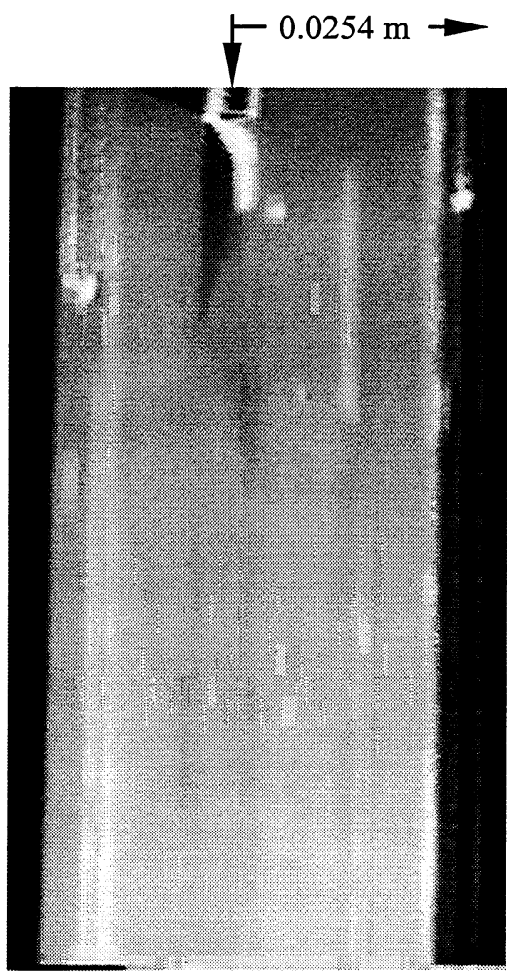

(c) Particle injection tube exit

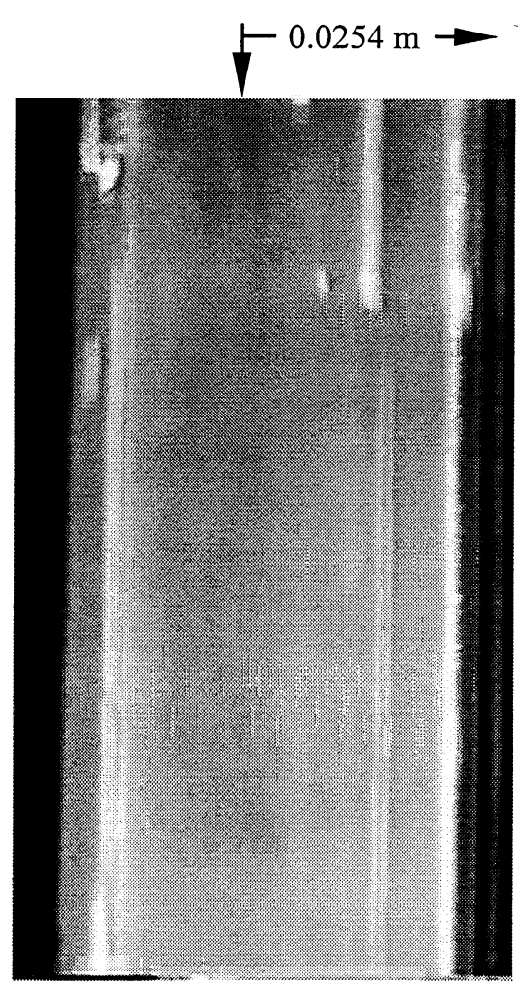

Figure 99. Low-speed video images of $\mathrm{N}_{2}$ particle carrier gas jet in $0.09 \mathrm{~m}$ long section of pyrex glass tube following the particle injection point: (a) without acoustics using a secondary gas flowrate of 14 slpm cold air, (b) without acoustics using a secondary gas flowrate of $56 \mathrm{slpm}$ cold air, and (c) with an acoustic field of $151 \mathrm{~dB}$ and $970 \mathrm{~Hz}$ using secondary gas flowrates of 14 or 56 slpm cold air. 
The low-speed video imaging shows that char particles were dispersed from the centerline to a distance equal to about $0.5-0.7$ times the pyrolysis tube radius as shown in Fig. 101a. After the hot or cold flow experiments conducted without acoustics, char particles were found in a pile in the decoupler bottom that was only between $2-4 \mathrm{~cm}$ across, which indicates that particles were not completely dispersed to the pyrolysis tube wall. However, in experiments conducted with an acoustic field of $151 \mathrm{~dB}$, char particles were found spread out over much of the decoupler bottom. This could be due to dispersion, but is most likely due to acoustically-induced gas pulsations that enhance mixing and dispersion of particles at the entrance to the decoupler.

With an acoustic field of $159 \mathrm{~dB}$ and $970 \mathrm{~Hz}$ and a secondary air flowrate of $14 \mathrm{slpm}$, char particles were levitated at 0-0.4, 0.19-0.22, and 0.36-0.39 $\mathrm{m}$ downstream from the particle injection tube exit, as shown in Figs 100 and 101b. With an acoustic field of $161 \mathrm{~dB}$ and $340 \mathrm{~Hz}$, char particles were levitated at 0.01-0.05 and 0.42-0.48 m downstream of the particle injection point, as shown in Fig. 101c. Char particles were levitated between the acoustic pressure anti-node and $\lambda / 8$ downstream from the pressure anti-node at both 970 and $310 \mathrm{~Hz}$, as shown respectively in Figs. A9.2 and A9.4 in Appendix 9. This phenomena of particle levitation due to acoustic radiation pressure agrees with that reported by Doinikov (1996). The sharply defined cross-sectional plane of particle levitation in the tube is characteristic of radiation pressureinduced levitation (King, 1934). Comparison of Fig. 101b with Fig. 101d shows that particles were not levitated at $159 \mathrm{~dB}$ when the secondary air flowrate was increased to $56 \mathrm{slpm}$. Particles were not levitated at sound pressures of $151 \mathrm{~dB}$ for any secondary air flowrate, as shown in Fig 101a. 


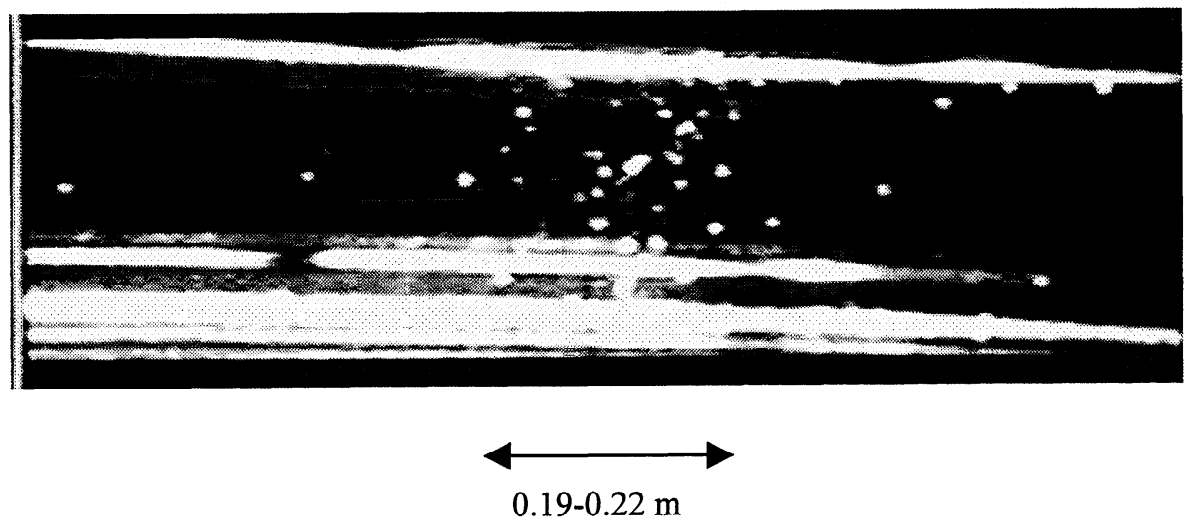

Figure 100. A high-speed video image of particles in the pyrex glass tube levitated at 0.19-0.22 $\mathrm{m}$ downstream of particle injection tube exit obtained with an acoustic field of $159 \mathrm{~dB}$ and $970 \mathrm{~Hz}$ for a 14 slpm flowrate of cold air. 
(a)

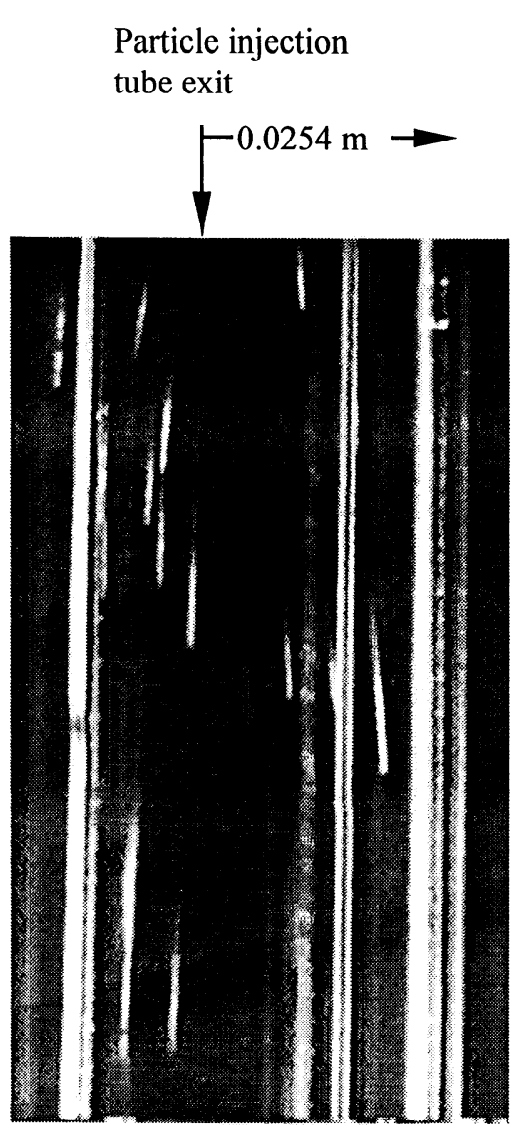

(b)

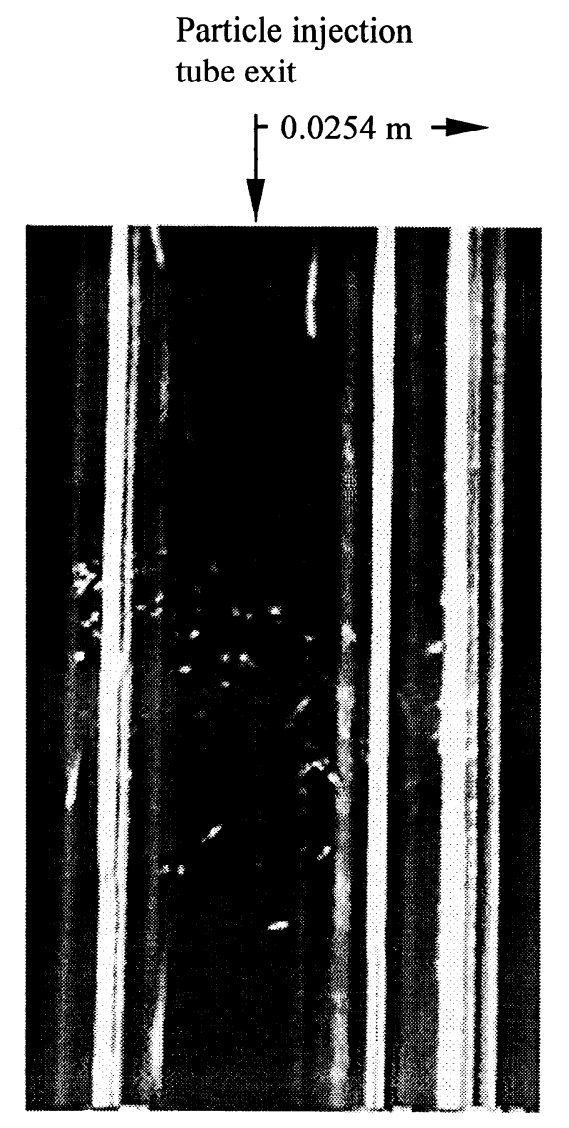

(c)

Particle injection tube exit

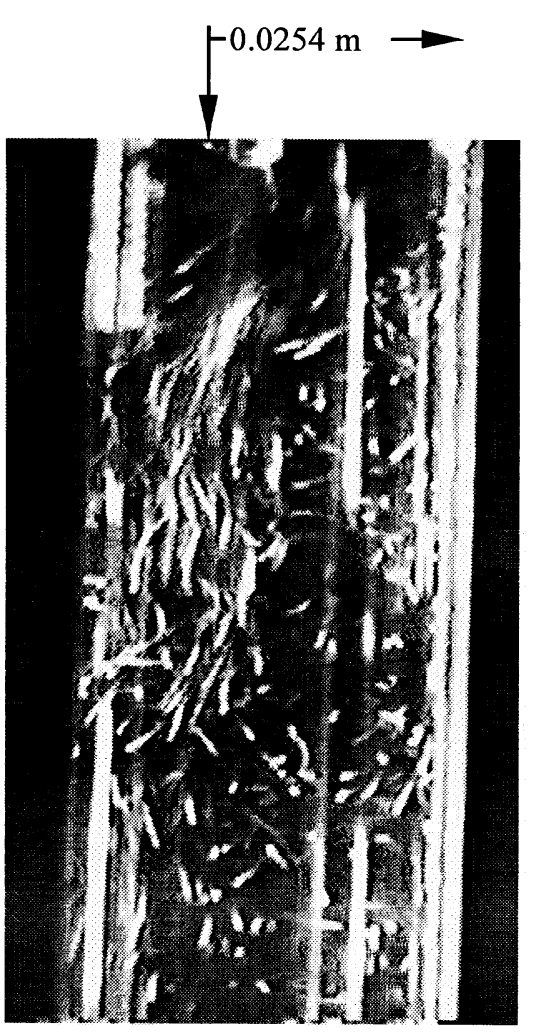

(d)

Particle injection tube exit

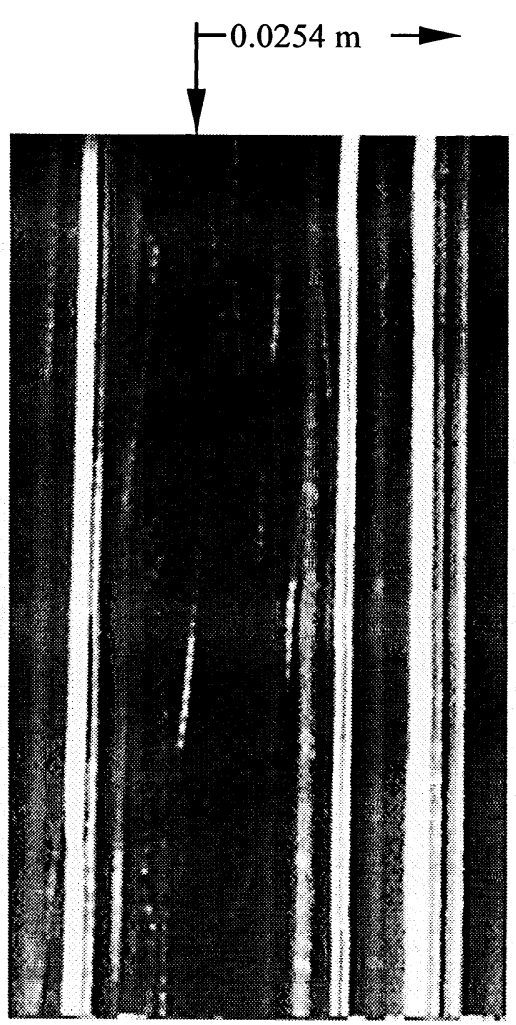

Figure 101. Low-speed video images of particles in the pyrex glass tube (a) obtained between 0.15-0.27 $\mathrm{m}$ downstream from particle injection point with or without an acoustic field of $151 \mathrm{~dB}$ and $970 \mathrm{~Hz}$ and secondary air flowrates of 14 or $56 \mathrm{slpm}$, (b) showing levitation between 0.19-0.22 m downstream from particle injection point with an acoustic field of $159 \mathrm{~dB}$ and $970 \mathrm{~Hz}$ and secondary air flowrate of $14 \mathrm{slpm}$, (c) showing levitation between 0.01-0.08 m downstream from the particle injection point with an acoustic field of $161 \mathrm{~dB}$ and $340 \mathrm{~Hz}$ and a flowrate of $14 \mathrm{slpm}$, and (d) obtained between 0.15-0.27 $\mathrm{m}$ downstream from the particle injection point with an acoustic field of $159 \mathrm{~dB}$ and 


\section{[5.2.3] Conclusions}

Analysis of the results of high- and low-speed video imaging of gas and char particle flows in the simulated pyrolysis tube indicate:

- Mean residence times of $125-300 \mu \mathrm{m}$ diameter particles in the first $0.18 \mathrm{~m}$ of the simulated pyrolysis tube section were nearly the same with and without an acoustic field of $151 \mathrm{~dB}$ and $970 \mathrm{~Hz}$, which suggests that enhancement of pyrolysis with acoustics is due to increased rate of particle heatup.

- The $\mathrm{N}_{2}$ particle carrier gas jet was better mixed with the secondary smoke-laden gas flow in the presence of an acoustic field. Better mixing of the cold carrier gas jet and the secondary flow increased particle heatup rate.

- Radial dispersion of char particles from the centerline of the secondary gas flow was increased when an acoustic field of $151 \mathrm{~dB}$ or higher was applied. Fast particle dispersion from the cold core of the particle carrier gas jet into the surrounding hot secondary gas stream increased the particle heatup rate.

- Char particle levitation at a sound pressure level of $158 \mathrm{~dB}$ was observed, which suggests that tar fume particles can also be levitated in an acoustic field. Acoustically levitated tar fume would spend longer residence times in the pyrolysis tube, resulting in the higher observed secondary $\mathrm{CO}_{2}$ yields due to increased secondary cracking in of tar in the hot gas phase. 


\section{[6] CONCLUSIONS/CONTRIBUTIONS}

- Increased heatup of inflight particles in the shortest, $0.18 \mathrm{~m}$ pyrolysis tube heated length using an acoustic field of $151 \mathrm{~dB}$ or higher and gas temperature of $550^{\circ} \mathrm{C}$ can decrease char yield and increase primary $\mathrm{CO}$ and $\mathrm{CO}_{2}$ yields. Increased particle heatup is indicated by larger quantity and size of surface bubbles and larger diameters of char particles as shown in SEM images, gas and particle flow imaging experiments, and a numerical particle heatup model. Lower char yields and higher secondary $\mathrm{CO}_{2}$ yields obtained at gas temperatures of 550 and $700^{\circ} \mathrm{C}$ for all mean particle residence times using an acoustic field of $\geq 151 \mathrm{~dB}$ indicate that more tar can be released into the hot gas phase when particles are heated faster.

- Increased tar production under rapid particle heatup conditions is not due to increased rates of particle cracking reactions relative to the rates of particle polymerization reaction, but is due to increased rates of primary $\mathrm{CO}$ and $\mathrm{CO}_{2}$ production. Increased internal gas pressure due to increased rates of $\mathrm{CO}$ and $\mathrm{CO}_{2}$ production drives out more tar from within the particles. A fraction of the tar molecules was found to release $\mathrm{CO}_{2}$ functional groups by secondary cracking in the hot gas phase. Secondary $\mathrm{CO}_{2}$ yields increased with an increase in the secondary gas space-time. $\mathrm{CO}$ is not released by secondary cracking of tar in the hot gas phase at 400 and $550^{\circ} \mathrm{C}$. Secondary $\mathrm{CO}$ was released by secondary pyrolysis reactions of the particle, which proceeded below a critical char yield of 71-73 wt $\%$ of BLS.

- Tarry liquids, tar fume, and $\mathrm{Na}_{2} \mathrm{CO}_{3}$ fume were released at different stages of particle inflight pyrolysis. Tarry liquids were released in the $0.18 \mathrm{~m}$ heated section at all gas 
temperatures studied, however the release of tar and $\mathrm{Na}_{2} \mathrm{CO}_{3}$ fume depended on particle residence time and gas temperature. Tar fume was not released into the secondary gas stream in steel-wool-plug experiments because of long tar transit distance between the interior and surface of the char mound.

- A fraction of the $\mathrm{CO}_{2}$ functional groups of primary tar molecules can be released by secondary cracking at temperatures of 550 and $700^{\circ} \mathrm{C}$. These $\mathrm{CO}_{2}$ functional groups were not released when the primary tar molecules polymerized into the char. As a result, secondary $\mathrm{CO}_{2}$ yields can be reduced under conditions that promote entrapment of primary tar within the pyrolyzing particle or redeposition of tar onto the char surface. Entrapment of tar within the char or redeposition of tar onto the particle surface is indicated by a continuous decrease in the $\mathrm{CO}_{2}$ concentration during several experimental runs conducted with a steel-wool-plug or acoustics.

- Acoustically-induced levitation of tar fume can increase its residence time in the heated pyrolysis tube which promotes secondary cracking of tarry liquids that contact the fume. or increases tar polymerization if tar molecules contact char particles. Acoustically-induced levitation of BLS particles can increase its residence time in the heated pyrolysis tube which promotes tar redeposition on the particles and tar polymerization into the char. Particle residence times in the 0.48 and $0.81 \mathrm{~m}$ pyrolysis tube heated lengths were found to be increased by applying an acoustic field of $146 \mathrm{~dB}$ or higher due to increased dispersion of particles from the reactor centerline compared to that without acoustics. 
- Transport of tar from the char surface through the gas-film boundary layer was found not to be limited within the ranges of acoustic pressure amplitudes and gas temperatures studied. It was found that differences of char yields obtained with and without acoustics at similar particle residence times in the pyrolysis tube were much smaller at a gas temperature of $700^{\circ} \mathrm{C}$ than at $550^{\circ} \mathrm{C}$. This behavior is different from that for a process limited by gas-film mass transport. If tar transport through the gasfilm were limited, larger differences of char yields obtained with and without an acoustic field of $151 \mathrm{~dB}$ and $950-1000 \mathrm{~Hz}$ at similar particle residence times should have been observed at a gas temperature of $700^{\circ} \mathrm{C}$, because the tar production rate during particle heatup without acoustics was higher at $700^{\circ} \mathrm{C}$ compared to that at $550^{\circ} \mathrm{C}$.

- With respect to development of industrial black liquor gasifiers, until char gasification rates can be significantly enhanced at a lower temperature of $550^{\circ} \mathrm{C}$ compared to those at $\geq 700^{\circ} \mathrm{C}$, through use of catalysts or other means, there is no advantage to applying a high-intensity acoustic field during pyrolysis at gas temperatures $\leq 700^{\circ} \mathrm{C}$ which results in a substantial char residue. 


\section{[7] LITERATURE CITED}

Adams, T.N.; Frederick, W.J. (1988) Kraft Recovery Boiler Physical and Chemical Processes, p. 99, American Paper Institute, New York.

Alen, R.; Sjorstrom, E. (1980) Isolation of hydroxy acids from pine kraft black liquor: part II. purification by distillation, Paperi Puu, 62(8), 469-471.

Alen, R.; Arpiainen, V.T.; van Heiningen, A.R.P. (1992) Effect of liquor type and pyrolysis rate on the steam gasification reactivities of black liquors, Proceedings TAPPI/CPPA 1992

International Chemical Recovery Conference, Seattle, WA, 641-649.

Alen, R.; Arpiainen, V.; McKeough, P.; Venelampi, E. (1994) Rapid pyrolysis of kraft black liquor, part 1. release of carbon, Paperi Ja Puu 76(10), 650-656.

Alen, R.; Rytkonen, S.; McKeough, P. (1995) Thermogravimetric behavior of black liquors and their organic constituents, Journal of Analytical and Applied Pyrolysis 31, 1-13.

Allen, G.G.; Mattile, T. (1971) Lignin, Sarkanen, K.V.; Ludwig, C.H., eds., Chp. 14, WileyInterscience, New York.

Al Taweel, A.M.; Landau, J. (1976) Mass transfer between solid spheres and oscillating fluids-a critical review, The Canadian Journal of Chemical Engineering 54, 532-539.

Anthony, D.B.; Hottel, H.C.; Howard, J.B.; Meisner, H.P. (1975) Rapid devolatization of pulverized coal, Fifteenth Symposium (International) on Combustion, The Combustion Institute, Pittsburgh, PA, 1303-1317.

Arpaci, V.S.; Gemmen, R.S.; Keller, J.O. (1990) Pulse combustion: numerical analysis of droplet mass transfer enhancement, American Society of Mechanical Engineers, AES 16, 81-90.

Arpaci, V.S.; Gemmen, R.S.; Keller, J.O. (1991) Heat/mass transfer from a cylinder in the strongly oscillating flow of a pulse combustor tailpipe, Proceedings of the International Symposium on Pulsating Combustion, Vol. 1, Sandia National Laboratories/Gas Research Institute, Monterey, CA, August 5-8.

Arpiainen, V.; McKeough, P.; Pyykkonen, M. (1995) Rapid pyrolysis of kraft black liquor, part 2. release of sodium, Paperi Ja Puu 77(1-2), 39-44.

Arpiainen, V.; Jokiniemi, J.; Kauppinen, E.; Kurkela, M.; McKeough, P.J.; Mikkanen, P., The release of carbon, sodium, and sulphur during the rapid pyrolysis of black liquor, Proceedings TAPPI/CPPA 1995 International Chemical Recovery Conference, Toronto, Canada, A217-A225. 
Avni, E.; Davoudzadeh, F.; Coughlin, R.W. (1985) Flash pyrolysis of lignin, Fundamentals of Thermochemical Biomass Conversion, Milne, T.A.; Mudge, L.K.; Overend, R.P, ed., p. 329-343, Elsevier Applied Science Publishers Ltd., London.

Backman, R.; Frederick, W.J.; Hupa, M. (1992) Pressurized gasification of spent pulping liquors: thermodynamic and kinetic constraints, Proceedings TAPPI/CPPA 1992 International Chemical Recovery Conference, Seattle, WA, 617-625.

Backman, R.; Forssen, M.; Hupa, M.; Ranio, J.; Sorvari, V.; Whitty, K. (1995) Liquor-liquor differences in combustion and gasification processes: pyrolysis behavior and char reactivity, Proceedings TAPPI/CPPA 1995 International Chemical Recovery Conference, Toronto, Canada, A245-A253.

Backman, R.; Hupa, M.; Keskinen, J.; Kymalainen, M.; Janka, K.; Moisio, M. (1996)

Measurement of time-dependent fume release during black liquor pyrolysis, Journal of Pulp and Paper Science 22(1), J17-J23.

Bartle, K.D.; Kandiyoti, R.; Katheklakis, I.E.; Shi-Lin, L. (1990) Effect of freeboard residence time on the molecular mass distributions of fluidized bed pyrolysis tars, Fuel 69, 172-176.

Bartolome, L.G.; Hoff, J.E.; Purdy, K.R. (1969) Effect of resonant acoustic vibrations on drying rates of potato cylinders, Food and Technology 23(3), 47-50.

Basset, A.B., (1888) On the motion of a sphere in a viscous liquid, Philosophical Transactions of the Royal Society, A179, 43-69.

Bate, A.E.; Stephens, R.W.B. (1950) Wave Motion and Sound, pp. 420-421, Edward Arnold and Company, London.

Baxter, L.L.; Smith, P.J.; Smoot, L.D. (1985) Comparison of model predictions and experimental data for coal-water mixture combustion, Spring Meeting of the Western States Section/The Combustion Institute, San Antonio, TX, April.

Belles, F.E.; Kentfield, J.A.C.; Putnam, A.A. (1986) Pulse combustion, Progress in Energy and Combustion Science 12, 43-79.

Bennet, C.O.; Myers, J.E. (1974) Momentum, Heat, and Mass Transfer, pp. 477-544, McGraw Hill, Inc., New York.

Bergholm, A. (1963) Recovery of chemicals from sodium-based waste liquors, Svensk Papperstidning 66(4), 125-132.

Bergougnou, M.A.; Graham, R.G. (1984) Fast pyrolysis of biomass, Journal of Analytical and Applied Pyrolysis 6, 95-135. 
Bhattacharya, P.K.; Kunzu, D.; Parthiban, V. (1986) Pyrolysis of black liquor solids, Industrial Engineering Process Development 25, 420-426.

Bird, R.B.; Lightfoot, E.N.; Stewart, W.E. (1960) Transport Phenomena, John Wiley and Sons, Inc., New York.

Blackwell, B.; King, T. (1985) Chemical Reactions in Kraft Recovery Boilers, Sandwell and Company, Ltd., Vancouver, Canada.

Bjorkman, A. (1968) Pyrolysis of spent pulping liquors, Proceedings IUPAC/EUCEPA Symposium on Recovery of Pulping Chemicals, Helsinki, Finland, 235-267.

Blasczyk, J. (1991) Acoustically disturbed fuel droplet combustion, Fuel 70, 1023-1025.

Bolker, H.I.; Fleming, B.I.; Kubes, G.J.; MacLeod, J.M. (1982) Thermal analysis of spent black liquor: activation energies, Journal of Wood Chemistry and Technology 2(3), 279-295.

Borisov, Y.Y.; Gynkina, N.M. (1962) On acoustic drying in a standing sound wave, Soviet Physics-Acoustics 8(1), 95-96.

Boroson M.L.; Howard, J.B; Longwell, J.P.; Peters W.A. (1989a) Product yields and kinetics from the vapor phase cracking of wood pyrolysis tars, AIChe Journal 35(1), 120-128.

Boroson M.L.; Howard, J.B; Longwell, J.P.; Peters W.A. (1989b) Heterogeneous cracking of wood pyrolysis tars over fresh wood char surfaces, Energy and Fuels 3(6), 135-140.

Brink, D.L.; Feuerstein, D.L.; Thomas, J.F. (1967) Malodorous products from the combustion of kraft black liquor: I., Tappi Journal 50, 258-284.

Brink, D.L.; Jones, K.H.; Thomas, J.F. (1970) Malodorous products from the combustion of kraft black liquor, III., Tappi Journal 53, 837-843.

Brink, D.L.; Thomas, J.F. (1975) Pyrolysis-gasification-combustion, feasibility in pulping recovery systems-the first stage reactor, Proceedings of the TAPPI 1975 Alkaline Pulping Conference, Williamsburg, VA, October 27-29, 205-213.

Cameron, J.H.; Grace, T.M. (1985) Kinetic study of sulfate reduction with kraft black liquor char, Industrial and Engineering Chemistry Fundamentals 24(4), 443.

Canale, R.P.; Chapra, S.C. (1988) Numerical Methods for Engineers, 2nd Ed., McGraw Hill, Inc.

Cao, Z.; Gong, M.; Li, Z.; Liu, S.; Ma, Y.; Wang, C. (1992) Development of an acoustic levitation reactor, Powder Technology 69, 125-131. 
Carangal, A.C.; Frederick, W.J.; Iisa, K.; Pianpucktr, R.; Sricharoenchaikul, V.; Wag, K.J. (1995) Char residue yields and chemical species distributions from rapid pyrolysis of black liquor, Paper 253g, AIChE Annual Meeting, Miami Beach, FL, November 12-17.

Carvalho, Jr., J.A.; Daniel, B.T.; Miller, N., Zinn, B.T. (1987) Combustion characteristics of pulverized coal under pulsating and non-pulsating conditions, Fuel 66, 4-8.

Celik, I.; Wang, Y. (1991) Pulsating gas-solid flow inside a bench-scale reactor, Combustion and Flame 84, 225-237.

Cerfontain, M.B.; Kapteijn, F.; Meijer, R.; Moulijn, J.A. (1987) Alkali-catalyzed carbon gasification in $\mathrm{CO} / \mathrm{CO}_{2}$ mixtures: an extended model for the oxygen exchange and gasification reaction, Journal of Catalysts 107, 173-180.

Cheng, R.M.; Kaye, J. (1960) Acoustic streaming near a heated cylinder, Journal of the Acoustical Society of America 32(5), 579-584.

Cheng, P.; Fand, R.M. (1963) The influence of sound on heat transfer from a cylinder in crossflow, International Journal of Heat and Mass Transfer 6, 571-596.

Clancy, P.; Flogel, K.; Grossbach, R.; Lierke, E.G. (1983) Acoustic positioning for space processing of materials science samples in mirror furnaces, 1983 Ultrasonics Symposium, IEEE, New York, 1129-1139.

Clift, R.; Grace, J.R.; Weber, M.E. (1978) Bubbles, Drops, and Particles, pp.285-320, Academic Press, Inc., New York.

Colby, M.Y. (1938) Sound Waves and Acoustics, Henry Holt and Company, New York.

Cullis, C.F.; Palmer, H.B. (1965) Chemistry and Physics of Carbon, Vol. I., Walker, P.L., ed., Chp. 5, Marcel Dekker, Inc., New York.

Darivakis, G.S.; Howard, J.B.; Peters, W.A. (1994) A rationale for heating rate and coal type effects on liquids yields and substrate morphology changes during rapid pyrolysis, Energy and Fuels 8,1024-1032.

Deglise, X.; Magne, P. (1987) Biomass, Hall, D.O.; Overend, R.P., ed., Chp. 10, John Wiley and Sons, Inc., New York.

Diebold, J.; Scahill, J. (1985) Fundamentals of Thermochemical Biomass Conversion, Milne, T.A.; Mudge, L.K.; Overend, R.P, ed., p. 539-535, Elsevier Applied Science Publishers Ltd., London.

Doinikov, A.A. (1996) Theory of acoustic radiation pressure for actual fluids, Physical Review E 54(6), 6297-6303. 
Dutta, S.; Wen, C.Y. (1979) Coal Conversion Technology, Lee, E.S., Wen, C.Y., ed., Chp. 2, Addison-Wesley Publishing Co., London.

Elder, T.J; Soltes, E.J. (1981) Organic Chemicals from Biomass, Goldstein, I.S., ed., Chp. 5, CRC Press, Inc., Boca Raton, FL.

Fand, R.M.; Kaye, J. (1960) Acoustic streaming near a heated cylinder, The Journal of the Acoustical Society of America 32(5), 579-584.

Fletcher, T.H. (1989) Time-resolved particle temperature and mass loss measurements of a bituminous coal during devolatization, Combustion and Flame 78, 223-236.

Forssen, M.; Frederick, W.J.; Hupa, M.; Hyoty P. (1992) Sulfur and sodium volatization during black liquor pyrolysis, Proceedings TAPPI/CPPA 1992 International Chemical Recovery Conference, Seattle, WA, 599-608.

Frederick, W.J.; Hupa, M. (1993) Combustion Properties of Kraft Black Liquors, April Report for United States Department of Energy, DE-FG02-90CE 40936.

Frederick, W.J.; Hupa, M.; Uusikartano, T. (1994) Volatiles yield and char carbon yields during black liquor pyrolysis, Bioresource Technology 48, 59-64.

Frederick, W.J.; Grace, T.M.; Sricharoenchaikul, V. (1995a) Thermal conversion of tar to light gases during black liquor pyrolysis, Proceedings TAPPI/CPPA 1995 International Chemical Recovery Conference, Toronto, Canada, A209-A216.

Frederick, W.J.; Reis, V.V.O; Vakkilainen, E.K.; Wag, K.J. (1995b) Potassium and chloride enrichment during black liquor combustion, laboratory and mill measurements and a mechanistic model, Proceedings TAPPI/CPPA 1995 International Chemical Recovery Conference, Toronto, Canada, B63-B75.

Friehaut, J.D.; Seery, D.J.; Zabielski, M.F. (1982) A parametric investigation of tar release in coal devolatization, Nineteenth Symposium (International) on Combustion, The Combustion Institute, Pittsburgh, PA 1159-1167.

Freihaut, J.D.; Proscia, W.M.; Seery, D.J. (1989) Chemical characteristics of tars produced in a novel low-severity entrained flow reactor, Energy and Fuels 3, 692-703.

Gairns, S.A.; Kubes, G.J.; van Heiningen, A.R.P. (1994) New insights into TRS gas formation during pyrolysis of black liquor, Paper 104d, AIChE Spring National Meeting, Atlanta, GA, April 17-21.

Gauvin, W.H.; Sayegh, N.N. (1979) Numerical analysis of variable property heat transfer to a single sphere in high temperature surrroundings, AIChE Journal 25(3) 522-534. 
Gavalas, G.R.; Iatridis, B. (1979) Pyrolysis of a precipitated kraft lignin, Industrial Engineering Chemistry Product Research and Development 18(2), 127-130.

Gibbins-Matham, J.; Kandiyoti, R. (1988) Coal pyrolysis yields from fast and slow heating in a wire-mesh apparatus with a gas sweep, Energy and Fuels 2, 505-511.

Grace, T.M. (1992) Chemical Recovery in the Alkaline Pulping Processes, 3rd Ed., Green, R.P., Hough, G., ed., Chp. 5., TAPPI Press, Atlanta, GA.

Griffen, T.P.; Howard, J.B.; Peters, W.A. (1993) An experimental and modeling study of heating rate and particle size effects in bituminous coal pyrolysis, Energy and Fuels 7, 297-305.

Gupta, A.; Rajan, S. (1991) Equivalence ratio and frequency effects on the combustion characteristics of micronized clean coal in pulse combustors, Proceedings of the International Symposium on Pulsating Combustion, Vol. 1, Sandia National Laboratories/Gas Research Institute, Monterey, CA, August 5-8.

Ha, M.Y.; Koopmann, G.; Reethof, G.; Scaroni, A.W.; Yavuzkurt, S. (1989) Effect of acoustic field on the combustion of coal particles in a flat flame burner, Fossil Fuels Symposium, 12th Annual Energy-sources Technology Conference and Exhibition, American Society of Mechanical Engineers, Houston, TX, Jan. 22-25, 53-58.

Ha, M.Y.; Koopmann, G.; Scaroni, A.W.; Yavuzkurt, S. (1991a) A model of the enhancement of coal combustion using high-intensity acoustic fields, Transactions of the American Society of Mechanical Engineers 113, 277-285.

Ha, M.Y.; Yavuzkurt, S. (1991b) A model of the enhancement of combustion of coal-water slurry using high-intensity acoustic fields, Transactions of the American Society of Mechanical Engineers 113, 268-276.

Ha, M.Y.; Yavuzkurt, S. (1993a) A theoretical investigation of acoustic enhancement of heat and mass transfer-I. pure oscillating flow, International Journal of Heat and Mass Transfer 36(8), 2183-2192.

Ha, M.Y.; Yavuzkurt, S. (1993b) A theoretical investigation of acoustic enhancement of heat and mass transfer-II. oscillating flow with a steady velocity component, International Journal of Heat and Mass Transfer 36(8), 2193-2202.

Hajaligol, M.R.; Howard, J.B.; Longwell, J.P.; Peters W.A. (1982) Product compositions and kinetics for rapid pyrolysis of cellulose, Industrial Engineering Chemistry Process Design and Development 21, 457-465.

Hemond, C.J. (1983) Engineering Acoustics and Noise Control, pp. 3-28, Prentice-Hall, Inc., Englewood Cliffs, NJ. 
Hodgins, J.W.; Hoffman, T.W.; Pei, D.C. (1957) The effect of sonic energy on mass transfer in solid-gas contacting operations, The Canadian Journal of Chemical Engineering 35, 18-24.

Howard, J.B; Longwell, J.P.; Nunn, T.R.; Peters W.A. (1985a) Product compositions and kinetics in the rapid pyrolysis of sweet wood gum hardwood, Industrial Engineering Chemistry Process Design and Development 24, 836-844.

Howard, J.B; Longwell, J.P.; Nunn, T.R.; Peters W.A. (1985b) Product compositions and kinetics in the rapid pyrolysis of milled wood lignin, Industrial Engineering Chemistry Process Design and Development 24, 844-852.

Howard, J.B.; Peters, W.A.; Serio, M.A. (1987) Kinetics of vapor-phase reactions of prompt coal pyrolysis tars, Industrial Engineering Chemistry Research 26, 1831-1838.

Howard, J.B.; Oh, M.S.; Peters, W.A. (1987) An experimental and modeling study of softening coal pyrolysis. AIChE Journal 35(5), 775-792.

Hupa, M.; Solin, P.; Hyoty, P. (1987) Combustion behavior of black liquor droplets, Journal of Pulp and Paper Science 13(2), J67-J72.

Hurd, C.D. (1929) The Pyrolysis of Carbon Compounds, p. 424, The Chemical Catalog Company, Inc., New York.

Kapteijn, F.; Meijer, R.; Moulijn, J.A.; van der Linden, B. (1991) The interaction of $\mathrm{H}_{2} \mathrm{O}, \mathrm{CO}_{2}$, $\mathrm{H}_{2}$, and $\mathrm{CO}$ with the alkali-carbonate/carbon system: a thermogravimetric study, Fuel 70, 205214.

Khan, M.R. (1989) A literature survey and an experimental study of coal devolatization at mild and severe conditions: influences of heating rate, temperature, and reactor type on products yield and composition, Fuel 68, 1522-1531.

King, L.V. (1934) On the acoustic radiation pressure on spheres, Proceedings of the Royal Society of London A147, 212-240.

Kobayashi, H.; Howard, J.B; Sarofim, A.F. (1976) Coal Devolatization at High Temperatures, Sixteenth Symposium (International) on Combustion, The Combustion Institute, Pittsburgh, PA, 411.

Kubes, G.J. (1984) The effect of wood species on kraft recovery furnace operation-an investigation using differential thermal analysis, Journal of Pulp and Paper Science 1(5), J63-J68.

Levenspiel, O. (1972) Chemical Reaction Engineering, p. 5, John Wiley and Sons, Inc., New York. 
Li., J.; van Heiningen, A.R.P. (1990) Sodium emission during pyrolysis and gasification of black liquor char, Tappi Journal 73(12), 213-219

Lighthill, M.J. (1978) Acoustic streaming, Journal of Sound and Vibration 61, 391-418.

Lilly, W.D.; Suuberg, E.M.; Unger, P.E. (1985) Experimental study on mass transfer from pyrolyzing coal particles, Fuel 64, 956-954.

Lyman, F.A.; Sabnis, J.S. (1982) Effect of oscillating flow on combustion rate of coal particles, Combustion and Flame 47, 157-172.

Mackay, D.M.; Roberts, P.V. (1982) The dependence of char and carbon yield on lignocellulosic precursor composition, Carbon 20(2), 99-105.

Marshall, W.; Ranz, W. (1952) Evaporation from drops, part 1., Chemical Engineering Progress 48(3), 143-146.

Matta, L.M. (1994) Investigation of Flow Turning Loss in Unstable Solid Propellant Rocket Motors, Ph.D. Thesis, Georgia Institute of Technology, Atlanta, GA.

Miller, P.T. (1986) Swelling of Kraft Black Liquor, an Understanding of the Associated Phenomena During Pyrolysis, Ph.D. Thesis, Institute of Paper Chemistry, Appleton, WI.

Myers, R.H.; Walpole, R.E. (1985) Probability and Statistics for Engineers and Scientists., MacMillan Publishing Co., New York.

Niksa, S.; Russel, W.B.; Saville, D.A. (1982) Time-resolved weight loss kinetics for the rapid devolatization of a bituminous coal, Nineteenth Symposium (International) on Combustion, The Combustion Institute, Pittsburgh, PA, 1151-1157.

Pai, S. (1954) Fluid Dynamics of Jets, pp. 71-95, D. Van Nostrand Company, Inc., New York.

Phong-Anant, D.; Wibberly, L.J. (1986) A simple laboratory feeder for fine particles, Combustion Science and Technology 49, 93-97.

Pouchert, C.J. (1985) The Aldrich Library of FT-IR Spectra, Edition 1, Volume 1, Aldrich Chemical Co., Milwaukee, WI.

Purdy, K.R. (1963) Viscous Flow Under the Influence of a Resonant Acoustic Field, Ph.D. Thesis, Georgia Institute of Technology, Atlanta, GA.

Rawson, S.A., (1988) An Experimental Investigation of the Influence of High Intensity Acoustics on Heat and Mass Transfer Rates from Spheres as Related to Coal-Water Slurry Fuel Combustion Enhancement, M.S. thesis, The Pennsylvania State University, University Park, PA. 
Rudinger, G. (1980) Fundamentals of gas-particle flow, Handbook of Powder Technology, Vol. 2, Allen T.; Williams, J.C., ed., Chp. 10, Elsevier Scientific Publishing Co., New York. Schoneborn, P.R. (1975) The interaction between a single particle and an oscillating fluid, International Journal of Multiphase Flow 2, 307-317.

Serio, M.A.; Solomon, P.R.; Suuberg, E.M. (1992) Coal pyrolysis experiments, kinetic rates and mechanisms, Progress in Energy Combustion Science 18, 133-220.

Severyanin, V.S. (1969) The combustion of solid fuel in a pulsating flow, Teploenergetika 16(1), 6-8.

Shafizadeh, F. (1982) Introduction to pyrolysis of biomass, Journal of Analytical and Applied Pyrolysis 3, 283-305.

Shafizadeh, F. (1985) Fundamentals of Thermochemical Biomass Conversion, Milne, T.A.; Mudge, L.K.; Overend, R.P, ed., pp. 183-217, Elsevier Applied Science Publishers Ltd., London.

Smoot. L.D.; Fletcher, T.H.; Smith, K.L. (1993) Coal Science and Technology, Vol.20, p.196, Elsevier, Amsterdam.

Snow, D.K.; Fricke, A.L.; Beckwith, W.F. (1982) Thermogravimetric-gas chromatographic analysis of black Liquor, CPPA 68th Annual Meeting, Montreal, Canada, 68B, 67-69.

Solomons, T.W.G. (1988) Organic Chemistry, p. 206, John Wiley and Sons, Inc., New York.

Stigsson, L.L.; Hesseborn, B. (1995) Gasification of black liquor, Proceedings TAPPI/CPPA 1995 International Chemical Recovery Conference, Toronto, Canada, B277-B295.

Street, R.L.; Vennard, J.K. (1982) Elementary Fluid Mechanics, pp. 189-197, John Wiley and Sons, Inc., New York.

Sujith, R.I. (1994) Behavior of Droplet in an Axial Acoustic Field, Ph.D. Thesis, Georgia Institute of Technology, Atlanta, GA.

Verrill, C.L. (1992) Inorganic Aerosol Formation During Black Liquor Drop Combustion, Ph.D. Thesis, Institute of Paper Science and Technology, Atlanta, GA.

Vertzberger, M. (1994) Personal communication, Aerospace Engineering Department, Georgia Institute of Technology, Atlanta, GA.

Wenzl, H.F.J. (1970) The Chemical Technology of Wood, p. 254, Academic Press, Inc., New York.

Westervelt, P.J. (1955) The theory of steady forces caused by sound waves, Journal of the Acoustical Society of America 23(4), 312-315. 
Westervelt, P.J. (1993) Experimental investigation of Oseen-type forces, Advances in Nonlinear Acoustics, Hobeck, H., ed., Thirteenth International symposium on Nonlinear Acoustics, pp. 627-631, Bergen, Norway, June 28, World Scientific, New Jersey.

Zebel, G. (1966) Aerospace Science, Davies, C.N., ed., pp. 52-55, Academic Press, Inc., New York.

\section{[8] ACKNOWLEDGEMENTS}

I have much appreciation and respect for those individuals who provided direction and helped along the way:

Advisor: Dr. Junyong Zhu

Advisory Committee: Dr. Jeff Empie, Dr. Tom Grace, and Dr. Jim Frederick at IPST and Dr. Jeff Jagoda at GA Tech

Advisor at start of thesis: Dr. Bob Horton

GA Tech Aerospace Engineering: Bob Daniel, Dr. Larry Matta, and Dr. Ben Zinn

IPST Technicians, Engineers, and Office Staff Members

I am thankful for the considerable financial and logistical support provided by:

Institute of Paper Science and Technology and its Member Companies

Georgia Institute of Technology 


\section{[A1] APPENDIX I. LIST OF MAJOR EXPERIMENTAL EQUIPMENT}

\section{COMPONENT}

Reactor frame and tube sections

Heating elements: gas preheater and pyrolysis section

Heating elements $90^{\circ}$ elbow section

Heater controller

Heater relays, heat sink, and fuses

Thermocouples and wire

Ceramic insulation

Particle feeder

Particle feeder motor

Static pressure transducer

\section{DESCRIPTION}

VENDOR
Frame: carbon steel, $2 \mathrm{~m}$ wide by $3 \mathrm{~m}$ high by $3.5 \mathrm{~m}$ long space required; Main reactor tubes: 52.3 mm I.D., (2" IPS, schedule 40) 304 stainless steel pipe; Acoustic decoupler, acoustic pressure probe and pneumatic ejector: 304 stainless steel

Ceramic clam shell tubular type: $9.5 \mathrm{~cm}$ I.D., $30.4 \mathrm{~cm}$ long, $1180 \mathrm{~W} /$ half, model no. 11-324 $120 \mathrm{VAC}$ per half

Ceramic plate type: $10.5 \mathrm{~cm}$ wide, $18 \mathrm{~cm}$ long, $1.3 \mathrm{~cm}$ thick, $700 \mathrm{~W}$, model no. $12 \mathrm{~F}-994$

Electronic PID process controller: autotuning, $120 \mathrm{VAC}, 0-5 \mathrm{VDC}$ process variable retransmit, model no. XT16

Solid state relay: 10 and $25 \mathrm{~A}$, model no. SSR240AC(10 or 25); heat sink: model no. FHS-1; fuses: model no. $\mathrm{KAX}(10$ or 25 )

Type K: shielded ungrounded and exposed junction, $1.59 \mathrm{~mm}$ and $3.18 \mathrm{~mm}$ sheath diameter, stainless steel sheath, cat. no. TB-CAIN(1/16" or $1 / 8$ ")(E or G)-(length); extension grade wire: 20 AWG., cat. no. EXPP-K-20

Alumina/ceramic fiber composite: $1.3 \mathrm{~cm}$ thick

Syringe-type with bed fluidization: feedrate up to $4 \mathrm{~g} / \mathrm{min}, 15 \mathrm{~g}$ capacity

Minarik 0-55 rpm electric motor with series 500 controller: $120 \mathrm{VAC}$, dial-type speed control

Electronic type: $0-2.41$ bar, model no. $280 \mathrm{E}$
Custom fabricated at IPST

Mellen Co.

Penacook, NH

Mellen Co.

Penacook, NH

Athena Controls, Inc., Plymouth

Meeting, PA

OMEGA

Engineering, Inc. Stamford, CT

OMEGA

Engineering, Inc. Stamford, CT

Zircar Products, Inc. Florida, NY

Custom fabricated at IPST

Available at IPST

SETRA, Inc. Acton, MA 
Nitrogen mass

flowmeter

Tar/fume filter

Gas analyzer system

Video imaging system

Sine wave generator

Acoustic driver amplifier

Acoustic compression driver

Acoustic pressure transducer and amplifier

Oscilloscope

Laser diode kit and photodetector
0-100 slpm : model no. HFM-201;

0-1 slpm: model no. HFM-200H:

power supply: model no. 40

Glass fiber type: item no. GF/A, $13 \mathrm{~cm}$ diameter

Infrared Industries carbon monoxide and carbon dioxide analyzer: nondispersive infrared, 0-2000 ppm, model no. 702; Teledyne Hasting mass flowmeter: NAL type, 0-10 slpm nitrogen; gas metering equipment: regulators, valves, and tubing

Panasonic CCTV video camera: CCD type, 30 frames/s, model no. WV-1414; Kodak Ektapro EM Motion Analyzer, 239 by 192 pixel full frame resolution at 1000 frames/s, model no. 1012; Spectra-Physics argon ion laser: $5 \mathrm{~W}$, model no. 165; Spectra-Physics laser exciter: model 265; Sharp 4-head video cassette recorder; optics: cylindrical lens, flat lens, and mounts; pyrex glass tube: $52 \mathrm{~mm} \mathrm{I.D.,} 60 \mathrm{~cm}$ long

B\&K, analog, model no. 3050

Single channel: $300 \mathrm{~W}, 8 \Omega$, model no. A300/1

Heavy-duty driver unit: $75 \mathrm{~W}, 250-4000 \mathrm{~Hz}$, model no. ID-75

Piezoelectric type: 0-6.895 bar, model no. 211 B5; Dual mode amplifier: model 5010

Two-channel, digital, model no. TDS-320

Fixed output laser diode: $4.2 \mathrm{~mW}, 670 \mathrm{~nm}$ wavelength, item no. S1011; high-speed photodetector: 20 ns rise time, model no. DET100, 350-1100 nm wavelength
TBE/Hastings

Instruments, Inc.

Hampton, VA

Whatman

Maidstone, England

Available at IPST

Georgia Institute of

Technology, Atlanta, GA
Available at IPST

University Sound, a Mark IV Co. Buchanan, MI

University Sound, a Mark IV Co. Buchanan, MI

Kistler Instrument Co., Amherst, NY

Tektronix, Inc. Beaverton, OR

Thorlabs, Inc. Newton, NJ 
Data acquisition computer

Data acquisition boards
Microcomputer: $486 \mathrm{DX}-4,100 \mathrm{MHz}$;

DIGIview monitor: 14" diagonal

CIO-DAS08: A/D board $8(-5$ to $+5 \mathrm{~V})$ input channels; CIO-EXP16: 16 input channel multiplexor to a single output channel, thermocouple signal conditioning; CIO MINI37 screw terminal board
GIM Computer

Atlanta, GA

Computer Boards.

Inc., Mansfield, MA 
[A2] APPENDIX 2. DATA ACQUISITION COMPUTER PROGRAM

' Program written by Steve Koepke for Institute of Paper Science and Technology on 8-5-96.

' This program is used to read temperature, pressure, and gas flow data from the acoustic reactor.

' The data are stored on a hard drive during program execution. Real time data are displayed to

' an interactive graphic interface on the computer monitor. The location and label of the data on

' the graphic interface corresponds to the location of the data measurement on the reactor.

' This program is written in Microsoft Quick BASIC. This program is run in the Microsoft

' Quick BASIC editor by setting the directory to C:IQB45 and then starting the program,

' including the Universal library, by typing: $\mathrm{QB} / \mathrm{L} \mathrm{CBQB}$. This program is stored

' aslQB45LREACTORZ.BAS, and it is to be used with the Computer Boards, Inc. CIO-

' DAS08 A/D (eight channel) conversion board and two CIO-EXP16 (16 channel input to a

' single output channel) multiplexor and thermocouple signal conditioning boards which are

' installed on the GIM 486, $100 \mathrm{Mhz}$, DX-4 microcomputer and reactor frame. The CIO-DAS08

' support software includes a setup/calibration/test program, InstaCal, and the Universal Library

' Programmers Interface for use with Microsoft Quick BASIC.

'\$INCLUDE: 'CB.BI' ' Mandatory INCLUDE file to access default parameter values

CONST BoardNum $=0$ 'Board number

CONST Range $\%=0$

CONST Scale $\%=0$

CONST Options $\%=0$

- Initiate error handling activating error handling will trap errors like bad channel numbers and

' non-configured conditions.

' Parameters:

- PRINTALL :all warnings and errors encountered will be printed

- STOPALL :if any error is encountered, the program will stop

UDStat $\%=$ cbErrHandling\%(PRINTALL, STOPALL $)$

' Setup screen graphic interface background color to black.

SCREEN 12

CLS

' Set graphics colors

$\begin{array}{ll}\text { Brush1 }=8 & \text { 'Dark grey } \\ \text { Brush2 }=7 & \text { ' Light grey } \\ \text { Brush3 }=10 & \text { 'Green } \\ \text { Brush4 }=14 & \text { 'Yellow } \\ \text { Brush5 }=12 & \text { 'Bright red } \\ \text { Brush6 }=11 & \text { 'Bright blue } \\ \text { Brush7 }=15 & \text { 'Bright white } \\ \text { Brush8 }=13 & \text { 'Magenta }\end{array}$


' Setup data acquisition mode - data acquisition to the screen only or also with storage to the file

" "c:lreactor.txt".

COLOR Brush2

LOCATE 2, 1

PRINT "Setup up data acquisition configuration."

PRINT

PRINT

INPUT "Save data to a disk file? Enter (Y or N): ", SaveData\$

INPUT "Enter the data sampling interval (seconds): ", TimeInterval!

PRINT

CLS

IF SaveData $\$=$ "y" THEN

OPEN “c:Ireactor.txt" FOR OUTPUT AS \#1

LOCATE 27, 1

PRINT "Press [Spacebar] to stop data acquisition and storage."

ELSE

LOCATE 27, 1

PRINT "Press [Spacebar] to stop data acquisition."

END IF

' Set location of data measurement label on graphic interface screen.

$$
\mathrm{Pi}=4 \text { * ATN(1) 'Pi }
$$

LINE $(233,150)-(237,100)$, Brush3, BF ' Preheated gas, F1

LINE $(179,160)-(183,51)$, Brush3, BF ' Particle feeder, F2

LINE (175, 360)-(117, 356), Brush3, BF ' Quench gas, F3

LINE (190, 278)-(221, 280), Brush4, BF ' Gas thermocouple 1

LINE $(138,330)-(170,332)$, Brush4, BF ' Gas thermocouple 4

LINE $(138,278)-(170,280)$, Brush4, BF ' Gas thermocouple 5

LINE $(138,230)-(170,232)$, Brush4, BF ' Gas thermocouple 6

LINE $(138,179)-(170,181)$, Brush4, BF ' Gas thermocouple 7

LINE (138, 250)-(170, 252), Brush4, BF ' Gas thermocouple 10

LINE $(138,203)-(170,205)$, Brush4, BF ' Gas thermocouple 9

LINE (138, 305)-(170, 307), Brush5, BF ' Heater thermocouple 4

LINE $(190,326)-(221,328)$, Brush4, BF ' Gas thermocouple 8

LINE $(190,230)-(221,232)$, Brush5, BF ' Heater thermocouple 3

LINE $(190,179)-(221,181)$, Brush5, BF ' Heater thermocouple 2

LINE $(138,149)-(175,160)$, Brush5 ' Heater thermocouple 5

LINE $(138,150)-(175,161)$, Brush5

LINE $(138,151)-(175,162)$, Brush5

LINE (208, 358)-(221, 360), Brush6, BF 'Static pressure 1

'Draw reactor on graphic screen.

'Draw solid shapes.

CIRCLE (220, 180), 30, Brush1, Pi / 2, Pi ' Upper elbow 
CIRCLE (220, 180), 50, Brush1, Pi / 2, Pi

LINE (190, 180)-(190, 400), Brush1

- Vertical tube

LINE (170, 180)-(170, 400), Brush1

LINE (170, 400)-(190, 400), Brush1

LINE $(220,150)-(520,150)$, Brush1

LINE $(220,130)-(520,130)$, Brush1

LINE $(520,130)-(520,150)$, Brush1

PAINT $(180,250)$, Brush1

LINE (497, 130)-(507, 112), Brush1, BF

LINE (497, 130)-(507, 112), Brush2, B

LINE $(489,112)-(515,99)$, Brush1, BF

LINE $(489,112)-(515,99)$, Brush2, B

LINE $(489,168)-(515,181)$, Brush1, BF

LINE $(489,168)-(515,181)$, Brush2, B

LINE $(497,150)-(507,168)$, Brushl, BF

LINE $(497,150)-(507,168)$, Brush2, B

LINE (152, 350)-(208, 405), Brush1, BF

LINE (152, 350)-(208, 405), Brush2, B

LINE (208, 384)-(230, 398), Brush1, BF

' Upper trombone

- Paint reactor

' Upper acoustic driver

LINE $(208,384)-(230,398)$, Brush2, B

' Outline reactor.

CIRCLE (220, 180), 30, Brush2, Pi / 2, Pi

CIRCLE (220, 180), 50, Brush2, Pi / 2, Pi

LINE (190, 180)-(190, 350), Brush2

LINE (170, 180)-(170, 350), Brush2

LINE (170, 350)-(190, 350), Brush2

LINE $(220,150)-(520,150)$, Brush2

LINE $(220,130)-(520,130)$, Brush2

LINE (520, 130)-(520, 150), Brush2

FOR $\mathrm{r}=1$ TO 13

CIRCLE (502, 140), r, Brush1

NEXT $r$

CIRCLE $(502,140), 13$, Brush2

' Lower acoustic driver

' Outline reactor

' Outline reactor

'Decoupler

'Decoupler offtake tube

‘ Upper elbow

' Vertical tube

' Upper trombone

- Side acoustic driver

' Collect data from CIO-DAS08 and CIO-EXP16 boards.

StartTime! = TIMER 'TIMER is the computer internal clock time, updated about 10 times/s.

DO

IF TIMER $>=$ Nextsampletime! THEN

Time! $=$ TIMER

Nextsampletime! = Time! + TimeInterval!

Elaspedtime! $=$ Time! - StartTime!

Chan $\%=3$ 'Collect static pressure 1. Here Chan $\%=$ CIO-DAS08

' input channel \# only. See comment for Chan $\%=36$.

UDStat $\%=$ cbAIn $\%$ (BoardNum, Chan $\%$, Range $\%$, DataValue\%) 'Universal Lib. function

DataStatPressure $1 \%=$ DataValue\% 


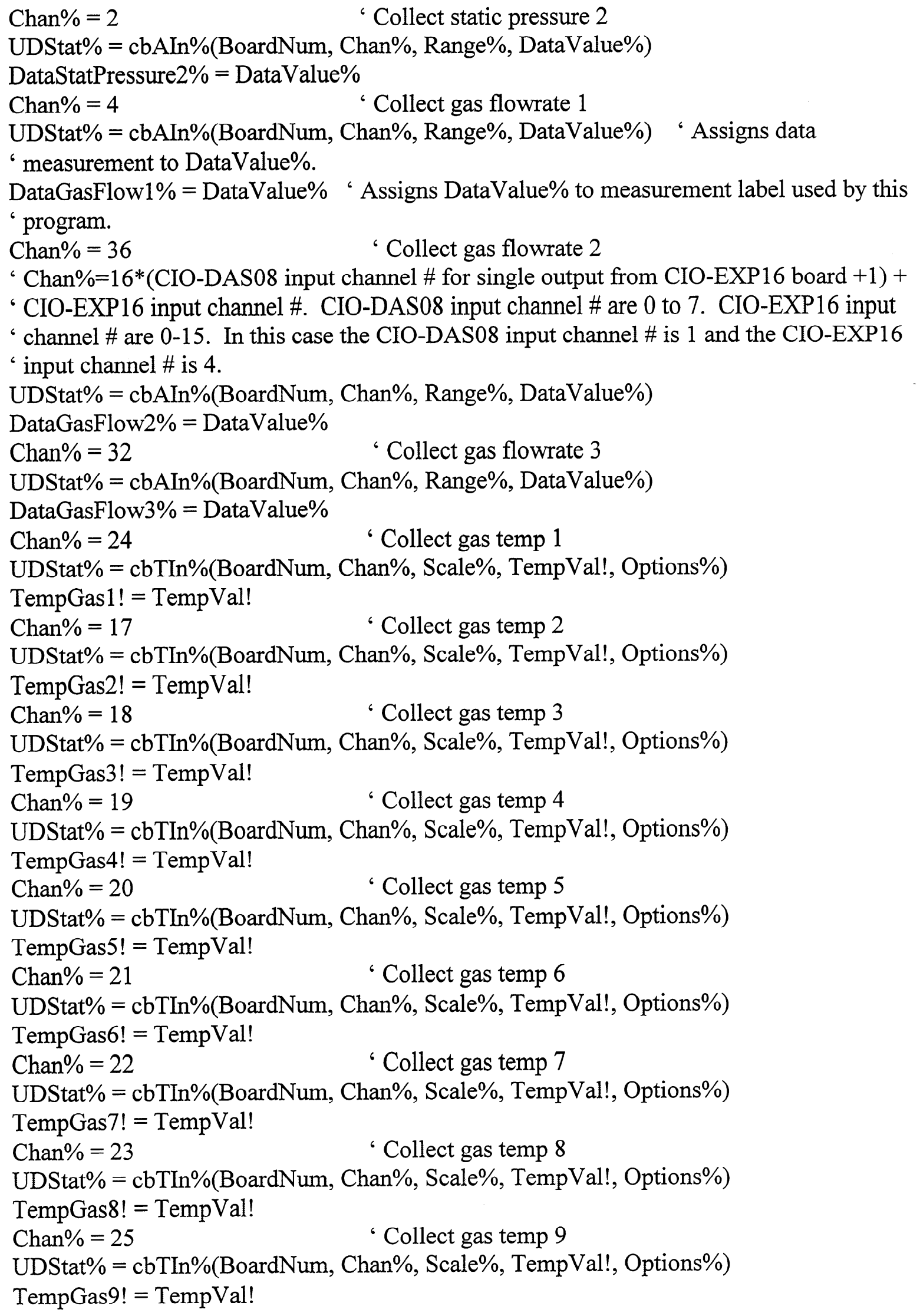




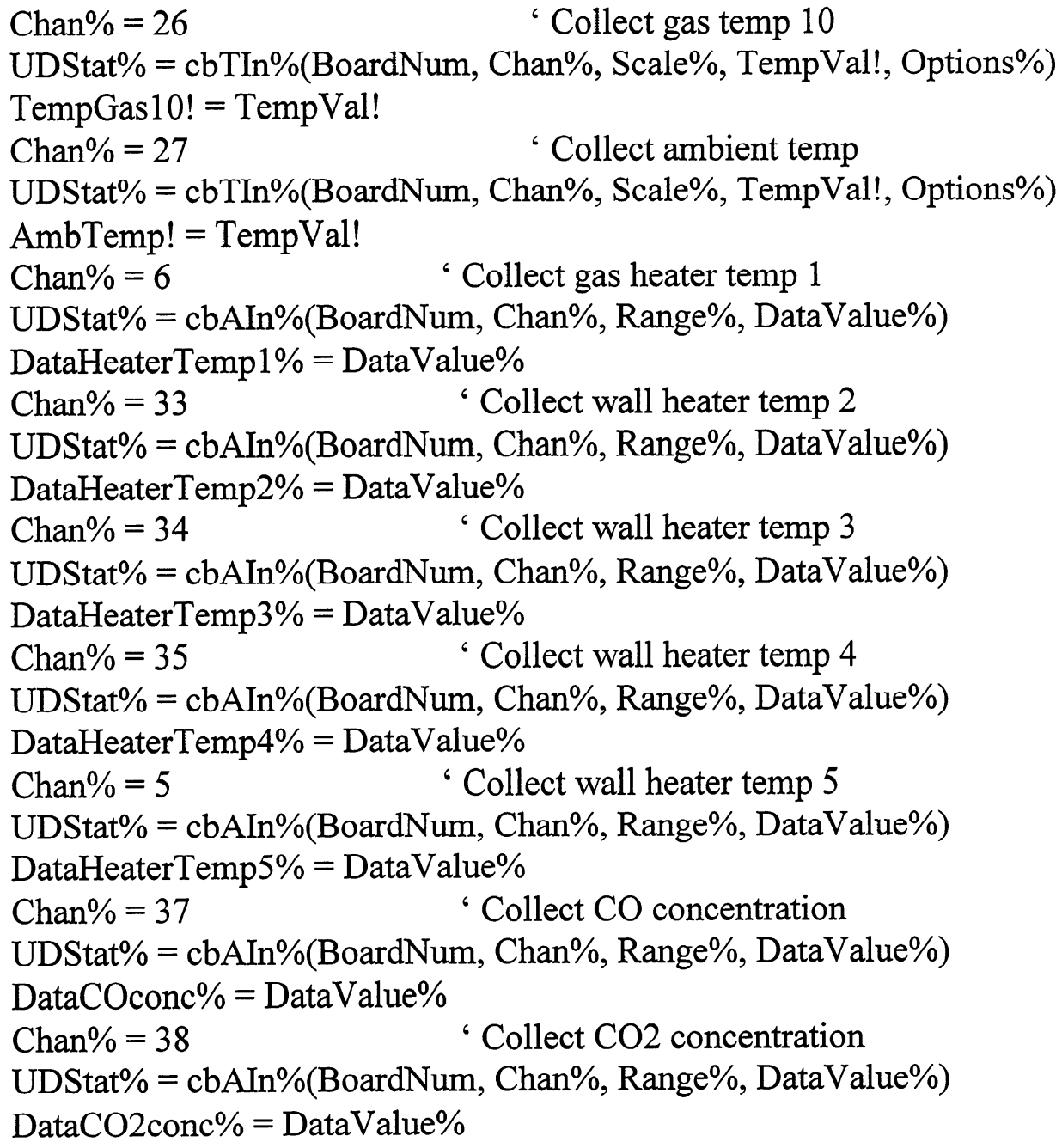

' Convert A/D board counts to physical measurements based on 0-5 VDC output from ' measurement devices.

StatPressure $1 !=49.7 / 5 *(10 *$ DataStatPressure $1 \% / 4096-5.03)$

StatPressure $2 !=49.7 / 5 *(10 *$ DataStatPressure $2 \% / 4096-5.03)$

GasFlow1! $=100 *$ (DataGasFlow1\% / 2048 - 1)

GasFlow2! $=1 *($ DataGasFlow2\% / $2048-1)$

GasFlow3! $=100 *($ DataGasFlow3\% / $2048-1)$

HeaterTemp $1 !=1318 *$ (DataHeaterTemp $1 \% / 2048-1)-18$

HeaterTemp2! $=1318 *$ (DataHeaterTemp2\% / 2048 - 1) -18

HeaterTemp3! = $1318 *$ (DataHeaterTemp3\% / 2048 - 1) -18

HeaterTemp4! $=1318 *$ (DataHeaterTemp4\% / 2048 - 1) -18

HeaterTemp $5 !=1318 *($ DataHeaterTemp5\%/ 2048 - 1) -18

COconc! $=2000 *($ DataCOconc\% $/ 2048-1)$

CO2conc! $=2000 *($ DataCO2conc $\% / 2048-1)$

' Store formatted measurement on hard drive.

IF SaveData\$ = "y" THEN 
PRINT \#1, USING “\#\#\#\#\#\#.\#\# “; Elaspedtime!;

PRINT \#1, USING “\#\#.\#\# “; StatPressure1!; StatPressure2!;

PRINT \#1, USING “\#\#\#.\# "; GasFlow1!;

PRINT \#1, USING “\#.\#\#\# “; GasFlow2!;

PRINT \#1, USING “\#\#\#.\# “; GasFlow3!;

PRINT \#1, USING “\#\#\#\# “; TempGas1!; TempGas2!; TempGas3!; TempGas4!;

PRINT \#1, USING “\#\#\#\# “; TempGas5!; TempGas6!; TempGas7!; TempGas8!;

PRINT \#1, USING “\#\#\# “; TempGas9!; TempGas10!;

PRINT \#1, USING “\#\#\#\# “; AmbTemp!;

PRINT \#1, USING “\#\#\#\# “; HeaterTemp1!; HeaterTemp2!; HeaterTemp3!;

PRINT \#1, USING “\#\#\#\#“; HeaterTemp4!; HeaterTemp5!;

PRINT \#1, USING “\#\#\#\# “; COconc!; CO2conc!

END IF

' Print physical measurements on the graphic screen interface

LOCATE 23, 43 'Screen grid: 0,0 at top left corner of screen.

COLOR Brush6

PRINT USING "P1=\#\#.\#\# “; StatPressure1!; : PRINT "PSIA"

LOCATE 25,45

PRINT USING "P2=\#\#.\#\# “; StatPressure2!; : PRINT "PSIA"

LOCATE 5, 26

COLOR Brush3

PRINT USING "F1=\#\#.\# "; GasFlow1!; : PRINT "SLPM"

LOCATE 3, 16

PRINT USING "F2=\#.\#\#\# "; GasFlow2!; : PRINT "SLPM"

LOCATE 23, 2

PRINT USING "F3=\#\#\#.\# “; GasFlow3!; : PRINT "SLPM"

COLOR Brush8

LOCATE 25, 2

PRINT USING “ATC=\#\# “; AmbTemp!; : PRINT CHR\$(248); "C"

LOCATE 18,30

COLOR Brush4

PRINT USING "GT1=\#\#\# “; TempGas1!; : PRINT CHR\$(248); "C"

LOCATE 23, 30

PRINT USING "GT2=\#\#\# “; TempGas2!; : PRINT CHR\$(248); "C"

LOCATE 25, 32

PRINT USING "GT3=\#\#\# "; TempGas3!; : PRINT CHR\$(248); "C"

LOCATE 21,7

PRINT USING “GT4=\#\#\# “; TempGas4!; : PRINT CHR\$(248); "C"

LOCATE 16,6

PRINT USING "GT10=\#\#\# "; TempGas10!; : PRINT CHR\$(248); "C"

LOCATE 18,7

PRINT USING "GT5=\#\#\# “; TempGas5!; : PRINT CHR\$(248); "C"

LOCATE 15,7

PRINT USING "GT6=\#\#\# “; TempGas6!; : PRINT CHR\$(248); "C" 
LOCATE 13,7

PRINT USING "GT9=\#\#\# “; TempGas9!; : PRINT CHR\$(248); "C"

LOCATE 12,7

PRINT USING “GT7=\#\#\# “; TempGas7!; : PRINT CHR\$(248); "C"

LOCATE 21, 30

PRINT USING "GT8=\#\# "; TempGas8!; : PRINT CHR\$(248); "C"

LOCATE 6, 26

COLOR Brush 5

PRINT USING “HT1=\#\#\#\# “; HeaterTemp1!; : PRINT CHR\$(248); "C “

LOCATE 12,30

PRINT USING "HT2=\#\#\# “; HeaterTemp2!; : PRINT CHR\$(248); “C “

LOCATE 15,30

PRINT USING "HT3=\#\#\# “; HeaterTemp3!; : PRINT CHR\$(248); “C “ “

LOCATE 20,6

PRINT USING "HT4=\#\#\# “; HeaterTemp4!; : PRINT CHR\$(248); “C “ “

LOCATE 10,6

PRINT USING “HT5=\#\#\# “; HeaterTemp5!; : PRINT CHR\$(248); "C “

LOCATE 16,50

COLOR Brush7

PRINT USING "CO= \#\#\#\# “; COconc!; : PRINT "ppm”

LOCATE 18,50

PRINT USING "CO2= \#\#\#\# “; CO2conc!; : PRINT "ppm"

LOCATE 1,1

COLOR Brush2

PRINT USING “\#\#\#\#\#.\#\#”; Elaspedtime!;

PRINT " seconds elasped"

END IF

LOOP UNTIL INKEY $\$=$ “ “ " Data acquisition stops and hard file is closed when the space-bar

' $k e y$ is pressed.

COLOR Brush2

IF SaveData $\$=$ "y" THEN

CLOSE \#1

LOCATE 27, 1

PRINT "Run data has been saved and data acquisition has been stopped. "

ELSE

LOCATE 27, 1

PRINT "Data acquisition has been stopped.

66

PRINT

END IF;

END 


\section{[A3] APPENDIX 3. PREPARATION BLACK LIQUOR PARTICLES}

Soda-AQ black liquor at $45 \%$ solids was obtained from Mead Corp., Kingsport, TN. The liquor was stored in a refrigerator. The liquor was mixed using a propeller-type paint mixer for 20 minutes. Five $200 \mathrm{~mL}$ samples were withdrawn, poured into a $35 \mathrm{~cm}$ wide by $40 \mathrm{~cm}$ long 304 stainless steel pan, and dried at $105^{\circ} \mathrm{C}$ in an oven with fresh air recirculation for about 6 days. The liquor was stirred twice each day during the drying process. The dried liquor was transferred to a ceramic jar of a ball mill that was filled with $2.5 \mathrm{~cm}$ diameter ceramic balls. A flowchart of the particle grinding, sieving, and drying procedure is shown in Fig. A3.1. Three batches of particles were made with each batch being mixed with $1 / 2$ of the previous batch.

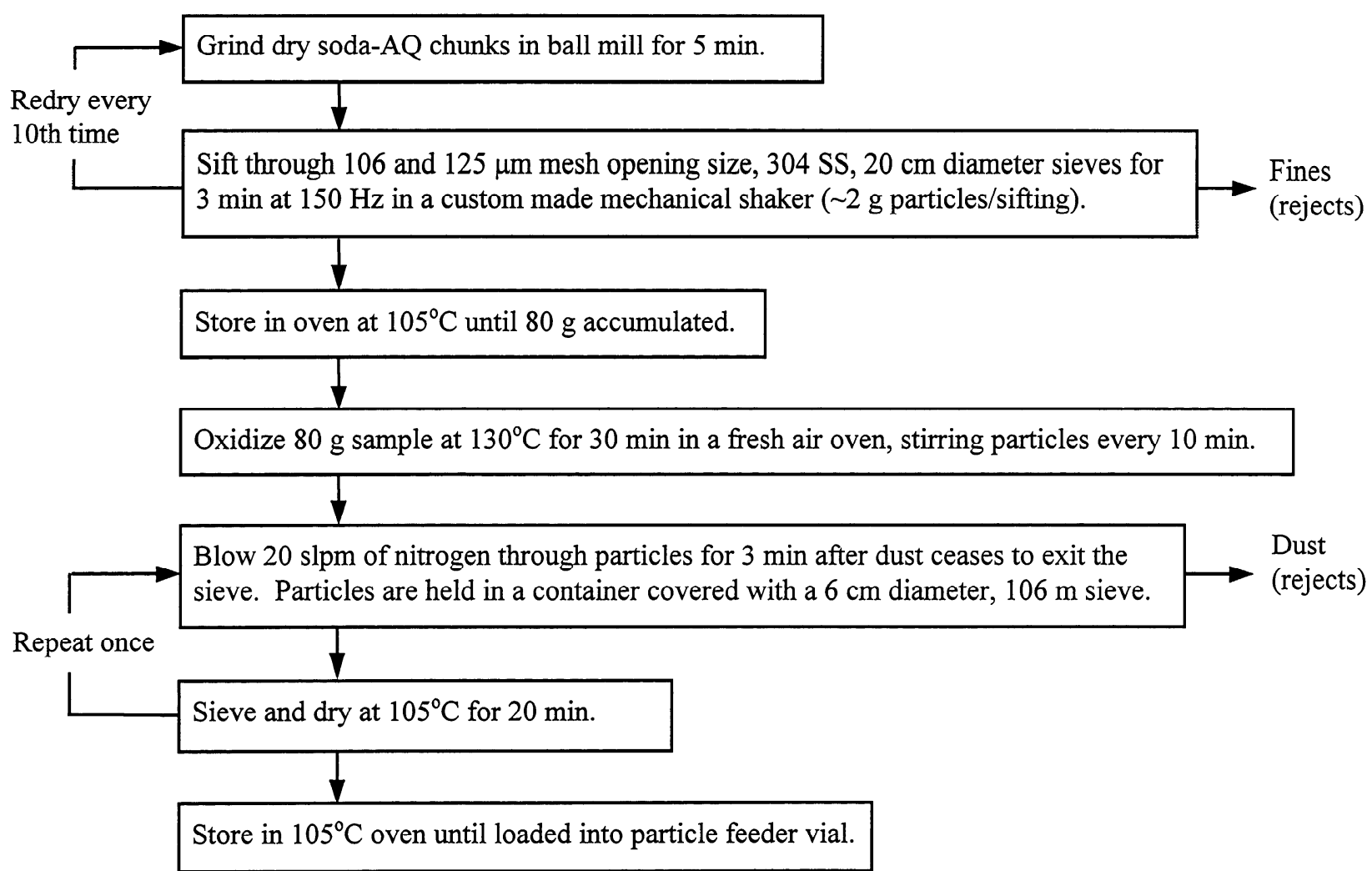

Figure A3.1. A flowchart of BLS particle preparation. 
[A4] APPENDIX 4. CHAR COLLECTION, TAR EXTRACTION, CHEMICAL COMPOSITION, AND UNCERTAINTY ANALYSIS

\section{[A4.1] CHAR COLLECTION}

A spatula was used to transfer the char from the decoupler to a $250 \mathrm{~mL}$ glass jar. The jar was held inside of the decoupler to eliminate spillage loss. The remaining $0.05-0.10 \mathrm{~g}$ of particles that could not be scooped up with the spatula was vacuumed into a stainless steel container. The vacuuming container was constructed from a $38 \mathrm{~mm}$ diameter by an approximately $120 \mathrm{~mm}$ long tube with threaded-caps at both ends. Entrained char was separated from the vacuumed air using a $0.2 \mu \mathrm{m}$ pore diameter membrane filter placed at the end of the tube, whose cap was connected to a vacuum. The vacuuming container was carefully inserted into the jar. Metal foil was wrapped over the gap between the jar and the container, and then the contents were poured into the jar.

Chunks of coalesced char particles, which stuck to the pyrolysis tube wall and thermocouples during runs at high sound pressure levels $(\geq 154 \mathrm{~dB})$ were dislodged with a stainless steel wire brush. Chunks were removed and collected after the pyrolysis tube walls had cooled to temperatures below $200^{\circ} \mathrm{C}$.

The jar containing the char obtained from the decoupler and stuck to the tube walls was weighed on an electronic balance with a precision of $\pm 0.00005 \mathrm{~g}$. The mass of BLS particles fed to the reactor was calculated as the difference in particle feeder vial mass measured before and after particle feeding. A lower accuracy balance of precision $\pm 0.005 \mathrm{~g}$ was used to measure the mass of particles fed to the reactor, because the mass of the particle feeder vial, approximately 
$430 \mathrm{~g}$ when full with particles, exceeded the capacity of the higher accuracy scale. The wt $\%$ of BLS as char $W_{C}$ is given by,

$$
W_{C}=\frac{\text { g char collected in jar }}{\mathrm{g} \mathrm{BLS} \mathrm{fed}} \times 100
$$

\section{[A4.2] TAR EXTRACTION FROM CHAR}

Two char samples (RNAC918 and RAC925B) were refluxed in a soxhlet apparatus to determine whether extractable tar remained in the char particles, using a method developed for coal char (Serio et al., 1992). Char samples were refluxed in $150 \mathrm{~mL}$ of tetrahydrofuran first for 2 hours and then for an additional 16 hours. Approximately $0.18 \mathrm{~g}$ of char was placed into a fritted-bottom glass vial. Next, the sample and vial were dried in a $105^{\circ} \mathrm{C}$ oven for $30 \mathrm{~min}$, cooled in a desiccator for 1 hour, and then weighed to within $\pm 0.00005 \mathrm{~g}$. After the sample was refluxed for 2 hours, the sample and vial were dried under vacuum in a desiccator for 12 hours, dried at a temperature of $105^{\circ} \mathrm{C}$ for $30 \mathrm{~min}$, allowed to cool in a dessicator, and weighed to within $\pm 0.00005 \mathrm{~g}$. The same sample was refluxed for an additional 16 hours, and then the sample and vial were dried and weighed. Table A4.1 shows that very little tar was extracted from either tar. A similar result, $1 \%$ decrease in char mass, was obtained when extraction (RNAC918) was performed with pyridine, another commonly used solvent (Serio et al., 1992). It is concluded that black liquor tar is insoluble in tetrahydrofuran and pyridine due to very high molecular weight fragments, and therefore, cannot be extracted, or tar is not present in an extractable form, because it had polymerized into char during pyrolysis. The latter is thought to be true. 
Table A4.1. Mass of chars, RNAC918 and RAC925B, after soxhlet extraction of tar in tetrahydrofuran for 2 and 18 hours.

\begin{tabular}{|l|r|r|r|r|}
\hline $\begin{array}{l}\text { Experiment } \\
\text { number }\end{array}$ & $\begin{array}{l}\text { Initial mass of } \\
\text { dry char, } \mathbf{g}\end{array}$ & $\begin{array}{l}\text { Mass of dry char } \\
\text { after refluxing for } \\
\mathbf{2 ~ h r , ~} \mathbf{g}\end{array}$ & $\begin{array}{l}\text { Mass of dry char } \\
\text { after refluxing for } \\
\mathbf{1 8 ~ h r , ~} \mathbf{g}\end{array}$ & $\begin{array}{l}\text { Percentage } \\
\text { change in mass }\end{array}$ \\
\hline RNAC918 & 0.1926 & 0.1909 & 0.1905 & -1.09 \\
\hline RAC925B & 0.1794 & 0.1783 & 0.1779 & -0.84 \\
\hline
\end{tabular}

\section{[A4.3] CHAR CHEMICAL COMPOSITION AND UNCERTAINTY ANALYSIS}

Total carbon and carbonate carbon in the char was measured by Huffman Laboratories, Inc., Golden, CO. Total carbon was measured using a total carbon analyzer (LECO). Approximately $50 \mathrm{mg}$ of pulverized char were loaded into a ceramic boat and combusted at $1500^{\circ} \mathrm{C}$ in oxygen carrier gas. The mass of $\mathrm{CO}_{2}$ in the carrier gas was measured by a nondispersive infrared sensor. The wt $\%$ of char as total carbon $H_{T C}$ is given by,

$$
H_{T C}=\left(\frac{\mathrm{g} \mathrm{CO}_{2} \text { produced }}{\mathrm{g} \text { char input to analyzer }}\right)\left(\frac{12.011 \mathrm{~g} \mathrm{C}}{1 \mathrm{~g} \mathrm{CO}_{2}}\right) \times 100
$$

Carbonate carbon was measured using a Coulometrics System 140 analyzer. Approximately 50 $\mathrm{mg}$ of pulverized char was acidified with $0.1 \mathrm{~N}$ perchloric acid. Carbonate carbon in the sample was released as $\mathrm{CO}_{2}$, which was measured by a nondispersive infrared sensor. The wt $\%$ of char as carbonate carbon $\mathrm{HCO}_{\mathrm{CO}}$ is given by,

$$
H_{C O 3}=\left(\frac{\mathrm{g} \mathrm{CO}_{2} \text { released during acidification }}{\mathrm{g} \text { char input to analyzer }}\right)\left(\frac{12.011 \mathrm{~g} \mathrm{C}}{1 \mathrm{~g} \mathrm{CO}_{2}}\right) \times 100 .
$$

The wt $\%$ of char as organic carbon $H o c$ was not measured, but can be expressed as,

$$
H O C=H T C-H_{C O 3}
$$


Huffman stated that with $95 \%$ confidence interval limits, the population mean of total carbon is $\pm 1 \%$ for a $0-50 \mathrm{wt} \%$ range and the population mean of carbonate carbon is \pm 0.2 weight percentage points for a $0-10 \mathrm{wt} \%$ range. The $\mathrm{wt} \%$ of total carbon measured by a single analysis was $1.8 \%$ greater than that of the known sample. Table A4.2 shows the results of a known sample, containing organic and carbonate carbon.

Table A4.2. Comparison of a known sample, containing organic and carbonate carbon, with measured result from Huffman Laboratories, Inc., Golden, CO.

\begin{tabular}{|lr|r|r|}
\hline Sample: & Known, wt\% & Measured, wt\% \\
3,5-Dimethoxy benzyl alcohol & $\mathbf{0 . 3 6 4 1} \mathbf{g}$ & & \\
Sodium carbonate, & $\mathbf{0 . 4 9 7 9 ~ g}$ & & \\
Total mass & $\mathbf{0 . 8 6 2 0 ~ g}$ & & 34.30 \\
\hline Total C & & 27.69 & 27.76 \\
\hline Organic C & 6.54 & 6.54 \\
\hline Carbonate C & & \\
\hline
\end{tabular}

Initially, only a single analysis was conducted for each char. According to Huffman, some of the highly swollen char particles were blown off the sample boat by the oxygen curtain at the entrance to their LECO analyzer. As a result, single analyses of the wt $\%$ of total carbon in the char were falsely low for the highly swollen particles obtained in experiments at $700^{\circ} \mathrm{C}$. The problem was resolved by fitting a special lid over the sample boat. Single analyses performed on chars obtained in experiments at $550^{\circ} \mathrm{C}$ were not low, because the char particles were too dense to be blown off the sample boat. All chars were reanalyzed 2-4 times, courtesy of Huffman Labs. Analyses, using the covered sample boat, of the wt $\%$ of total carbon, carbonate carbon, and organic carbon for various chars are shown in Table A4.3. Single analyses conducted with the uncovered sample boat on chars made at $550^{\circ} \mathrm{C}$ also are shown in Table A4.2 and were included in the data used to calculate the statistics. A $95 \%$ confidence interval of the mean $H_{T C}$ was 
calculated for three or more analyses. For independent measurements with a Gaussian distribution, the confidence interval of the population mean $\mu$ is given by,

$$
\mu=\bar{x} \pm \frac{t s}{\sqrt{n}}
$$

where $\bar{x}$ is the mean of $n$ measurements with sample standard deviation $s$, and $t$ is the Student's t-statistic for $(n-1)$ degrees of freedom. The Student's t-statistics for 2 and 3 degrees of freedom are 4.303 and 3.182, respectively, for a two-tailed test at the $95 \%$ confidence level (Myers and Walpole, 1985).

The analysis and calculation results of total, carbonate, and organic carbon in the chars, expressed as the wt\% of BLS fed or as percent of the carbon in BLS, are shown in Table A4.4. A set of triplicate runs without an acoustic field (RNAC912, RNAC918, and RNAC919) and four sets of duplicate runs with acoustics (RAC1127 and RAC1130; RAC1126B and RAC1130B; RAC912 and RAC926; and RAC1227B and RAC1230) were conducted to obtain the estimated uncertainty in the wt $\%$ of BLS converted to char. Besides variation in the char yield between repeat runs, the estimated uncertainty implicitly includes any variations due to the measurement of the mass of BLS fed and char collected and due to the efficiency of char collection. For the triplicate runs without an acoustic field, the sample mean and standard deviation of the $\mathrm{wt} \%$ of BLS converted to char were 77.27 and 1.106, respectively. For the four sets of duplicated runs with an acoustic field, individual char yields within each set were within $1.1 \mathrm{wt} \%$ of each other. Char yields decreased more slowly below $70 \mathrm{wt} \%$ and at long residence times, which can not be determined precisely. Variation of particle residence times in the tube, due to dispersion of particles away from the centerline, became larger when sound pressure level was 
increased, pyrolysis tube heated lengths were 0.48 and $0.81 \mathrm{~m}$, and preheated $\mathrm{N}_{2}$ space-time was increased. Therefore, additional runs to obtain an estimated uncertainty of the mean char yield at long residence times were not performed. Uncertainty limits of the mean wt $\%$ of BLS converted to char were \pm 2.75 weight percentage points at the $95 \%$ confidence level, as calculated using the standard deviation of the triplicate runs.

The uncertainty of the $w \mathrm{t} \%$ of BLS, or percent of the carbon in BLS, as total, carbonate, and organic carbon in the char was estimated using the procedure presented by Mitchell (1983). Let the result $R$ be expressed as a functional relationship among $n$ independent variables,

$$
R=\mathrm{f}\left(\bar{x}_{1}, \bar{x}_{2}, \ldots, \bar{x}_{n}\right) .
$$

where each independent variable has mean $\bar{x}$ and uncertainty limits $\pm \omega$. If the uncertainty of all independent variables are specified with same confidence level, the magnitude of the uncertainty $\omega R$ in the result can be expressed as,

$$
\omega_{R}=\left[\left(\frac{\partial R}{\partial \bar{x}_{1}} \omega_{1}\right)^{2}+\left(\frac{\partial R}{\partial \bar{x}_{2}} \omega_{2}\right)^{2}+\ldots+\left(\frac{\partial R}{\partial \bar{x}_{N}} \omega_{n}\right)^{2}\right]^{1 / 2}
$$

The wt $\%$ of BLS as total carbon in the char $W_{T C}$ can be expressed as,

$$
W_{T C}=\frac{W_{C} H_{T C}}{100}
$$

and the magnitude of the uncertainty $\omega_{W_{T C}}$ is given by, 


$$
\begin{aligned}
\omega_{W T C} & =\left[\left(\frac{\partial W_{T C}}{\partial W_{C}} \omega_{W C}\right)^{2}+\left(\frac{\partial W_{T C}}{\partial H_{T C}} \omega_{H T C}\right)^{2}\right]^{1 / 2} \\
& =\left[\left(\frac{H_{T C}}{100} \omega_{W C}\right)^{2}+\left(\frac{W_{C}}{100} \omega_{H T C}\right)^{2}\right]^{1 / 2},
\end{aligned}
$$

where $\omega_{W C}= \pm 2.75$ weight percentage points and $\omega_{H T C}$ are the uncertainty limits. The percent of the carbon in BLS as total carbon in the char $M_{T C}$ can be expressed as,

$$
M_{T C}=\frac{W_{C} H_{T C}}{H_{B L S}}
$$

and the magnitude of the uncertainty $\omega_{M \pi c}$ is given by,

$$
\begin{aligned}
\omega_{M T C} & =\left[\left(\frac{\partial M_{T C}}{\partial W_{C}} \omega_{W C}\right)^{2}+\left(\frac{\partial M_{T C}}{\partial H_{T C}} \omega_{H T C}\right)^{2}+\left(\frac{\partial M_{T C}}{\partial H_{B L S}} \omega_{H B L S}\right)^{2}\right]^{1 / 2} \\
& =\left[\left(\frac{H_{T C}}{H_{B L S}} \omega_{W C}\right)^{2}+\left(\frac{W_{C}}{H_{B L S}} \omega_{H T C}\right)^{2}+\left(-\frac{W_{C} H_{T C}}{H_{B L S}{ }^{2}} \omega_{H B L S}\right)\right]^{1 / 2},
\end{aligned}
$$

where $H_{B L S}=39.56$ is the wt $\%$ of BLS as carbon and $\omega_{H B L S}= \pm 3.07$ weight percentage points.

The wt $\%$ of BLS as carbonate carbon in the char $W_{\mathrm{CO}}$ can be expressed as,

$$
W_{\mathrm{CO} 3}=\frac{W_{C} H_{C O 3}}{100}
$$

and the magnitude of the uncertainty $\omega_{W c o s}$ is given by, 


$$
\begin{aligned}
\omega_{W C O 3} & =\left[\left(\frac{\partial W_{C O 3}}{\partial W_{C}} \omega_{W C}\right)^{2}+\left(\frac{\partial W_{C O 3}}{\partial H_{C O 3}} \omega_{H C O 3}\right)^{2}\right]^{1 / 2} \\
& =\left[\left(\frac{H_{C O 3}}{100} \omega_{W C}\right)^{2}+\left(\frac{W_{C}}{100} \omega_{H C O 3}\right)^{2}\right]^{1 / 2},
\end{aligned}
$$

where $\omega \mathrm{Hcos}_{3}= \pm 0.2$ weight percentage points. The percent of the carbon in BLS as carbonate carbon in the char $M c_{c o 3}$ can be expressed as,

$$
M_{C O 3}=\frac{W_{C} H_{C O 3}}{H_{B L S}},
$$

and the magnitude of the uncertainty $\omega_{\text {Mcos }}$ is given by,

$$
\begin{aligned}
\omega_{M C O 3} & =\left[\left(\frac{\partial M_{C O 3}}{\partial W_{C}} \omega_{W C}\right)^{2}+\left(\frac{\partial M_{C O 3}}{\partial H_{C O 3}} \omega_{H C O 3}\right)^{2}+\left(\frac{\partial M_{C O 3}}{\partial H_{B L S}} \omega_{H B L S}\right)^{2}\right]^{1 / 2} \\
& =\left[\left(\frac{H_{C O 3}}{H_{B L S}} \omega_{W C}\right)^{2}+\left(\frac{W_{C}}{H_{B L S}} \omega_{H C O 3}\right)^{2}+\left(-\frac{W_{C H C O 3}}{H_{B L S}{ }^{2}} \omega_{H B L S}\right)\right]^{1 / 2} .
\end{aligned}
$$

The wt $\%$ of BLS as organic carbon in the char Woc is given by,

$$
W_{O C}=W_{T C}-W_{C O 3},
$$

and the magnitude of the uncertainty $\omega_{\text {woc }}$ can be expressed as,

$$
\omega_{W O C}=\left[\left(\frac{\partial W_{O C}}{\partial W_{T C}} \omega_{W T C}\right)^{2}+\left(\frac{\partial W_{O C}}{\partial W_{C O 3}} \omega_{W C O 3}\right)^{2}\right]^{1 / 2}=\left[\left(\omega_{T C C}\right)^{2}+\left(-\omega_{W C O 3}\right)^{2}\right]^{1 / 2} .
$$


The percent of the carbon in BLS as organic carbon in the char Moc is given by,

$$
M_{O C}=M_{T C}-M_{C O 3},
$$

and the magnitude of the uncertainty $\omega_{\text {Moc }}$ can be expressed as,

$$
\omega_{M O C}=\left[\left(\frac{\partial M O C}{\partial M T C} \omega_{M T C}\right)^{2}+\left(\frac{\partial M O C}{\partial M_{C O 3}} \omega_{M C O 3}\right)^{2}\right]^{1 / 2}=\left[\left(\omega_{M T C}\right)^{2}+\left(-\omega_{M C O 3}\right)^{2}\right]^{1 / 2}
$$


Table A4.3. Char analysis results (measured with covered sample boat unless indicated otherwise) from Huffman Laboratories, Inc., Golden, CO.

\begin{tabular}{|c|c|c|c|c|c|}
\hline \multirow{2}{*}{$\begin{array}{l}\text { Experiment } \\
\text { number }\end{array}$} & \multicolumn{3}{|c|}{ Total C, wt\% of char } & \multirow[t]{2}{*}{ Carbonate $\mathrm{C}, \mathrm{wt} \%$} & \multirow{2}{*}{$\begin{array}{l}\text { Organic C, wt\% } \\
\text { (by difference) }\end{array}$} \\
\hline & Measurement & Sample mean ${ }^{\mathrm{a}}$ & $\begin{array}{l}\text { Std. Dev. of } \\
\text { Measurement }\end{array}$ & & \\
\hline BLS & $38.18^{\mathrm{b}}, 38.39,39.32,39.37^{\mathrm{c}}, 42.36$ & $39.56 \pm 3.07$ & 1.93 & 1.70 & 37.86 \\
\hline RNAC1105 & $37.56,38.3,39.20^{b}$ & $38.35 \pm 2.04$ & 0.821 & 1.64 & 36.71 \\
\hline RNA21105 & $35.92,36.54,37.48$ & $36.65 \pm 1.95$ & 0.785 & 2.34 & 34.31 \\
\hline RNAC918 & $31.94,33.90,34.61^{b}, 35.68$ & $33.84 \pm 2.51$ & 1.58 & 3.52 & 30.51 \\
\hline RNAC927A & $32.16,32.79,34.58^{b}$ & $33.18 \pm 2.48$ & 1.255 & 4.23 & 28.95 \\
\hline RAC1107 & $34.62,34.96^{\mathrm{b}}, 35.67$ & $34.96 \pm 1.33$ & 0.536 & 2.64 & 32.44 \\
\hline RAC1108 & $32.22,35.62,35.97$ & $34.60 \pm 5.15$ & 2.071 & 3.47 & 31.13 \\
\hline RAC925B & $31.99^{b}, 32.55,32.94$ & $32.49 \pm 1.19$ & 0.478 & 4.93 & 27.56 \\
\hline $\mathrm{RAC}_{1226^{\mathrm{d}}}$ & $31.30,31.60,32.98,34.57$ & $32.61 \pm 2.38$ & 1.496 & 5.52 & 27.09 \\
\hline RAC1207 & $35.56,36.61,39.19^{b}$ & $37.12 \pm 4.64$ & 1.868 & 5.98 & 30.14 \\
\hline RNAC1123 & $31.48,34.28,34.41$ & $33.39 \pm 4.11$ & 1.655 & 3.24 & 30.15 \\
\hline RNAC1127 & $32.02,32.60$ & 31.31 & 0.410 & 5.65 & 25.97 \\
\hline RNAC1122 & $29.89,32.18,30.58$ & $30.88 \pm 2.92$ & 1.175 & 5.72 & 24.72 \\
\hline RAC1126A & $32.59,32.73,33.97$ & $33.10 \pm 1.89$ & 0.759 & 5.02 & 28.08 \\
\hline $\mathrm{RAC} 1127$ & $30.58,30.79,32.04$ & $31.14 \pm 1.96$ & 0.789 & 5.65 & 25.49 \\
\hline RAC1130B & $29.84,27.76,28.93$ & $28.84 \pm 2.59$ & 1.043 & 5.64 & 23.20 \\
\hline RAC1130C & $32.49,33.76$ & 33.13 & 0.898 & 6.17 & 26.96 \\
\hline
\end{tabular}

a Uncertainty limits at $95 \%$ confidence level.

b Single analysis with uncovered sample boat.

c Not included in the samples that were initially analyzed with the uncovered sample boat.

d Analysis by Galbraith Laboratories, Knoxville, TN. 
Table A4.4. Measured quantities of BLS fed, char collected, and total, carbonate, and organic carbon in the char.

\begin{tabular}{|c|c|c|c|c|c|c|c|c|c|}
\hline \multirow{2}{*}{$\begin{array}{l}\text { Experiment } \\
\text { Number }\end{array}$} & \multirow{2}{*}{$\begin{array}{l}\text { BLS } \\
\text { fed, g }\end{array}$} & \multicolumn{2}{|c|}{ Char collected, } & \multicolumn{2}{|c|}{ Total $\mathrm{C}$ in char as } & \multicolumn{2}{|c|}{ Carbonate $\mathrm{C}$ in char as } & \multicolumn{2}{|c|}{ Organic $C$ in char as } \\
\hline & & $\mathbf{g}$ & $\begin{array}{l}\text { Wt\% of } \\
\text { BLS }\end{array}$ & $\begin{array}{l}\text { Wt\% of } \\
\text { BLS }^{\mathbf{a}}\end{array}$ & $\begin{array}{l}\% \text { of the } \\
C \text { in } B L S^{a} \\
\end{array}$ & $\begin{array}{l}\text { Wt\% of } \\
\text { BLS }^{\text {a }}\end{array}$ & $\begin{array}{l}\% \text { of the } \\
C \text { in } B L S^{a}\end{array}$ & $\begin{array}{l}\text { Wt } \% \text { of } \\
\text { BLS }^{\text {a }}\end{array}$ & $\begin{array}{l}\% \text { of the } \\
C \text { in } B L S^{a}\end{array}$ \\
\hline RNAC1113 & 4.31 & 4.1437 & 96.1 & NA & - & - & - & - & - \\
\hline RAC1119 & 5.69 & 5.3165 & 93.4 & NA & - & - & - & - & - \\
\hline $\mathrm{RAC1009}$ & 4.73 & $\mathrm{~S}$ & - & - & - & - & - & - & - \\
\hline RNAC1111 & 3.70 & $\mathrm{M}$ & - & - & - & - & - & - & - \\
\hline RNA21111 & 2.55 & $\mathrm{M}$ & - & - & - & - & - & - & - \\
\hline RNAC1112 & 4.86 & $\mathrm{M}$ & - & - & - & - & - & - & - \\
\hline RNAC1105 & 5.00 & 4.2337 & 84.7 & $32.48 \pm 2.02$ & $82.1 \pm 8.2$ & $1.39 \pm 0.18$ & $3.51 \pm 0.30$ & $31.09 \pm 2.03$ & $78.6 \pm 8.2$ \\
\hline RNA21105 & 4.70 & 3.7902 & 80.6 & $29.54 \pm 1.16$ & $74.7 \pm 7.5$ & $1.89 \pm 0.17$ & $4.78 \pm 0.40$ & $27.65 \pm 1.17$ & $69.9 \pm 7.5$ \\
\hline RNAC912 & 3.59 & 2.7336 & 76.1 & NA & - & - & - & - & - \\
\hline RNAC918 & 3.89 & 3.0119 & 77.4 & $26.34 \pm 2.12$ & $66.6 \pm 7.5$ & $2.72 \pm 0.18$ & $6.88 \pm 0.59$ & $23.62 \pm 2.13$ & $59.7 \pm 7.5$ \\
\hline RNAC919A & 3.61 & 2.8281 & 78.3 & $\mathrm{NA}$ & - & - & - & - & - \\
\hline RNAC927B & 1.36 & 1.0485 & 77.1 & NA & - & - & - & - & - \\
\hline RNAC927A & 1.25 & 0.9329 & 75.6 & $25.08 \pm 2.09$ & $63.4 \pm 7.2$ & $3.20 \pm 0.19$ & $8.09 \pm 0.69$ & $21.88 \pm 2.10$ & $55.3 \pm 7.2$ \\
\hline RAC925 & 2.29 & 1.7203 & 75.1 & $\mathrm{NA}$ & - & - & & - & - \\
\hline RAC1106 & 3.68 & $\mathrm{~S}$ & - & - & - & - & & - & - \\
\hline $\mathrm{RAC} 1107$ & 3.63 & 2.7655 & 76.2 & $26.73 \pm 1.40$ & $67.6 \pm 6.3$ & $2.01 \pm 0.17$ & $5.08 \pm 0.44$ & $24.72 \pm 1.41$ & $62.5 \pm 6.3$ \\
\hline RAC1108 & 3.20 & 2.3145 & 72.3 & $25.02 \pm 3.84$ & $63.2 \pm 10.9$ & $2.51 \pm 0.17$ & $6.34 \pm 0.55$ & $22.51 \pm 3.84$ & $56.9 \pm 10.9$ \\
\hline RAC925B & 1.89 & 1.3350 & 70.6 & $22.94 \pm 1.23$ & $58.0 \pm 5.5$ & $3.48 \pm 0.20$ & $8.80 \pm 0.76$ & $19.46 \pm 1.25$ & $49.2 \pm 5.6$ \\
\hline RAC1230B & 3.97 & 2.6671 & 67.2 & NA & - & - & - & - & - \\
\hline $\mathrm{RAC} 1226$ & 3.29 & 2.2654 & 68.9 & $22.47 \pm 1.87$ & $56.8 \pm 6.6$ & $3.80 \pm 0.21$ & $9.61 \pm 0.84$ & $18.67 \pm 1.88$ & $48.4 \pm 6.7$ \\
\hline RAC1231A & 3.32 & 2.3956 & 72.8 & NA & - & - & - & - & - \\
\hline RAC1231B & 2.74 & 1.9306 & 70.5 & $\mathrm{NA}$ & - & - & - & - & - \\
\hline RAC1231C & 3.45 & 2.4544 & 71.1 & $\mathrm{NA}$ & - & - & - & - & - \\
\hline RAC1028 & 3.72 & 2.8024 & 75.3 & $\mathrm{NA}$ & - & - & - & - & - \\
\hline
\end{tabular}


Table A4.4 (Continued). Measured quantities of BLS fed, char collected, and total, carbonate, and organic carbon in the char.

\begin{tabular}{|c|c|c|c|c|c|c|c|c|c|}
\hline \multirow{2}{*}{$\begin{array}{l}\text { Experiment } \\
\text { number }\end{array}$} & \multirow{2}{*}{$\begin{array}{l}\text { BLS } \\
\text { fed, } g\end{array}$} & \multicolumn{2}{|c|}{ Char collected, } & \multicolumn{2}{|c|}{ Total $C$ in char as } & \multicolumn{2}{|c|}{ Carbonate $\mathbf{C}$ in char as } & \multicolumn{2}{|c|}{ Organic $\mathrm{C}$ in char as } \\
\hline & & $\mathbf{g}$ & $\begin{array}{l}\text { Wt\% of } \\
\text { BLS }\end{array}$ & $\begin{array}{l}\text { Wt\% of } \\
\text { BLS }^{\mathrm{a}}\end{array}$ & $\begin{array}{l}\text { \% of the } \\
C \text { in BLS }\end{array}$ & $\begin{array}{l}\text { Wt\% of } \\
\text { BLS }^{\mathrm{a}}\end{array}$ & $\begin{array}{l}\text { \% of the } \\
\mathrm{C} \text { in } \mathrm{BLS}^{\mathrm{a}}\end{array}$ & $\begin{array}{l}\text { Wt\% of } \\
\text { BLS }^{\mathbf{a}}\end{array}$ & $\begin{array}{l}\% \text { of the } \\
C \text { in } B L S^{a}\end{array}$ \\
\hline RAC912 & 3.40 & 2.3742 & 69.8 & $\mathrm{NA}$ & - & - & - & - & - \\
\hline RAC926 & 1.19 & 0.8221 & 69.1 & NA & - & - & - & - & - \\
\hline RAC1014 & 4.72 & $\mathrm{~S}$ & - & - & - & - & - & - & - \\
\hline RAC930 & 1.51 & 1.0169 & 67.3 & $\mathrm{NA}$ & - & - & - & - & - \\
\hline RAC1227A & 3.42 & 2.2704 & 66.4 & NA & - & - & - & - & - \\
\hline RAC1207 & 2.77 & 1.8020 & 65.1 & $24.17 \pm 3.19$ & $61.1 \pm 9.4$ & $3.90 \pm 0.21$ & $9.85 \pm 0.87$ & $20.27 \pm 3.20$ & $51.3 \pm 9.4$ \\
\hline RAC1227B & 3.18 & 2.0426 & 64.2 & NA & & - & - & - & - \\
\hline RAC1230 & 1.85 & 1.1631 & 63.7 & $\mathrm{NA}$ & - & - & - & - & - \\
\hline RAC1224 & 2.51 & 1.5782 & 62.9 & $\mathrm{NA}$ & - & - & - & - & - \\
\hline RNAC1017 & 3.97 & $\mathrm{M}$ & - & - & - & - & - & - & - \\
\hline RNAC1022 & 2.35 & 1.5480 & 65.9 & NA & - & - & - & - & - \\
\hline RNAC1023 & 3.50 & 2.0895 & 59.7 & $\mathrm{NA}$ & - & - & - & - & - \\
\hline RNAC1019 & 1.53 & $\mathrm{M}$ & - & - & - & - & - & - & - \\
\hline RNAC1024 & 2.97 & 1.9034 & 64.1 & $\mathrm{NA}$ & - & - & - & - & - \\
\hline RNAC1226 & 3.11 & 1.7805 & 57.3 & $\mathrm{NA}$ & - & - & - & - & - \\
\hline RNAC923 & 3.66 & $\mathrm{M}$ & - & - & - & - & - & - & - \\
\hline RAC1206 & 4.71 & $\mathrm{M}$ & - & - & - & - & - & - & - \\
\hline RNAC1123 & 2.38 & 1.8115 & 76.0 & $25.37 \pm 3.26$ & $64.1 \pm 9.6$ & $2.46 \pm 0.18$ & $6.21 \pm 0.53$ & $22.91 \pm 3.26$ & $57.9 \pm 9.6$ \\
\hline RNAC1127 & 2.47 & 1.7405 & 70.5 & 22.07 & 55.8 & $3.98 \pm 0.21$ & $10.06 \pm 0.88$ & 18.09 & 45.74 \\
\hline RNAC1122 & 2.98 & 2.0509 & 68.8 & $20.94 \pm 2.18$ & $52.9 \pm 6.92$ & $3.94 \pm 0.21$ & $9.96 \pm 0.87$ & $17.0 \pm 2.19$ & $42.9 \pm 6.97$ \\
\hline RAC1126A & 2.71 & 1.9993 & 73.8 & $24.43 \pm 1.67$ & $61.8 \pm 6.4$ & $3.71 \pm 0.20$ & $9.38 \pm 0.81$ & $20.72 \pm 1.68$ & $52.5 \pm 6.5$ \\
\hline RAC1127 & 2.92 & 1.9890 & 68.1 & $21.21 \pm 1.56$ & $53.6 \pm 5.8$ & $3.85 \pm 0.21$ & $9.73 \pm 0.85$ & $17.36 \pm 1.57$ & $43.9 \pm 5.9$ \\
\hline RAC1130 & 2.47 & 1.7092 & 69.2 & NA & - & - & - & - & - \\
\hline RAC1126B & 2.12 & 1.4041 & 66.2 & NA & - & - & - & - & - \\
\hline RAC1130B & 2.81 & 1.8924 & 67.3 & $19.41 \pm 1.92$ & $49.1 \pm 6.2$ & $3.8 \pm 0.21$ & $9.61 \pm 0.84$ & $15.61 \pm 1.93$ & $39.5 \pm 6.3$ \\
\hline
\end{tabular}


Table A4.4 (Continued). Measured quantities of BLS fed, char collected, and total, carbonate, and organic carbon in the char.

\begin{tabular}{|c|c|c|c|c|c|c|c|c|c|}
\hline \multirow{2}{*}{$\begin{array}{l}\text { Experiment } \\
\text { number }\end{array}$} & \multirow{2}{*}{$\begin{array}{l}\text { BLS } \\
\text { fed, } g\end{array}$} & \multicolumn{2}{|c|}{ Char collected, } & \multicolumn{2}{|c|}{ Total $\mathrm{C}$ in char as } & \multicolumn{2}{|c|}{ Carbonate $\mathbf{C}$ in char as } & \multicolumn{2}{|c|}{ Organic $\mathrm{C}$ in char as } \\
\hline & & $\mathbf{g}$ & $\begin{array}{l}\text { Wt\% of } \\
\text { BLS }\end{array}$ & $\begin{array}{l}\text { Wt\% of } \\
\text { BLS }^{\text {a }}\end{array}$ & $\begin{array}{l}\text { \% of the } \\
C \text { in } B L S^{a}\end{array}$ & $\begin{array}{l}\text { Wt\% of } \\
\text { BLS }^{\mathrm{a}}\end{array}$ & $\begin{array}{l}\text { \% of the } \\
C \text { in BLS }\end{array}$ & $\begin{array}{l}\text { Wt } \% \text { of } \\
\text { BLS }^{\mathrm{a}}\end{array}$ & $\begin{array}{l}\text { \% of the } \\
C \text { in } B L S^{a}\end{array}$ \\
\hline RAC1130C & 2.16 & 1.3365 & 61.9 & 20.51 & 51.8 & $3.82 \pm 0.21$ & $9.66 \pm 0.86$ & 16.69 & 42.1 \\
\hline RAC1205 & 2.74 & 1.7402 & 63.5 & $\mathrm{NA}$ & - & - & - & - & - \\
\hline RNAC1124 & 2.00 & $\mathrm{M}$ & - & - & - & - & - & - & - \\
\hline RNAC1125 & 1.24 & $\mathrm{M}$ & - & - & - & - & - & - & - \\
\hline RNAC1204 & 2.30 & $M$ & - & - & - & - & - & - & - \\
\hline
\end{tabular}

a Uncertainty limits at $95 \%$ confidence level.

M A considerable quantity of the char melted into the steel-wool plug.

NA Not analyzed for total C, organic C, and carbonate C.

$\mathrm{S}$ A considerable amount of char stuck to the pyrolysis tube wall. 
[A5] APPENDIX 5. CALCULATION OF CO AND $\mathrm{CO}_{2}$ YIELDS AND UNCERTAINTY ANALYSIS

\section{[A5.1] PARTICLE FEEDER CALIBRATION}

Fig. A5.1 shows the particle feedrate that corresponded to the dial setting of the screw jack motor speed. The measured concentrations (ppm volume) of $\mathrm{CO}$ and $\mathrm{CO}_{2}$ and the estimated concentration of $\mathrm{CO}_{2}$ in the pyrolysis gas versus time are shown in Figs. A5.2-A5.56 (where noted, $\mathrm{D}=\#$ denotes the dial setting of the screw jack motor speed). Table A5.1 shows the $\mathrm{CO}$ yield calculated from the measured $\mathrm{CO}$ concentrations in the pyrolysis gas. Table A5.2 shows the actual and estimated yields of $\mathrm{CO}_{2}$ calculated from the measured and estimated $\mathrm{CO}_{2}$ concentrations in the pyrolysis gas. First, methodology for calculating actual $\mathrm{CO}$ and $\mathrm{CO}_{2}$ yields will be presented, and then methodology for calculating the estimated $\mathrm{CO}_{2}$ yield will be discussed.

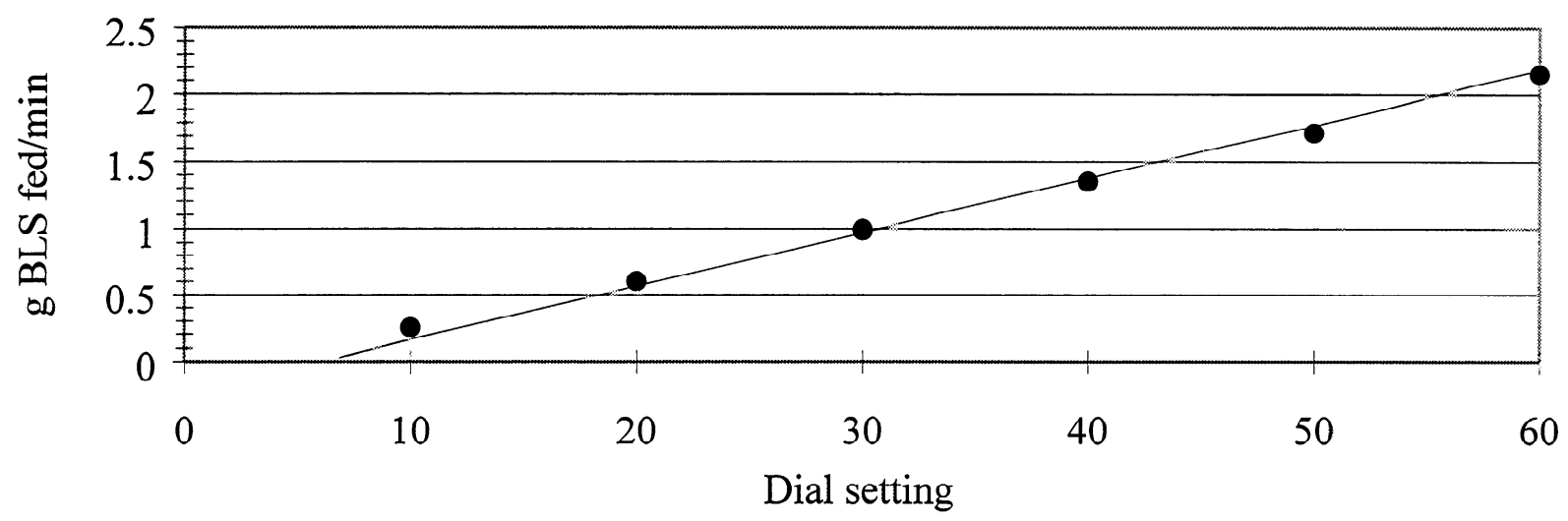

Figure A5.1. Feedrate of BLS particles versus dial setting of screw jack motor speed. Calibration conditions: bulk density of BLS $=855 \mathrm{~kg} / \mathrm{m}^{3}, 13 \mathrm{~g}$ of BLS initially in feeder vial, and $5 \mathrm{~g}$ of BLS fed. 
[A5.2] CALCULATION OF ACTUAL CO AND $\mathrm{CO}_{2}$ YIELDS FROM MEASURED CO AND $\mathrm{CO}_{2}$ CONCENTRATIONS

The ppm of $\mathrm{CO}$ or $\mathrm{CO}_{2}$ in the pyrolysis gas is given by,

$$
\text { ppm } \mathrm{CO} \text { or } \mathrm{CO}_{2}=\frac{\text { volumes } \mathrm{CO} \text { or } \mathrm{CO}_{2}}{10^{6} \text { volumes total gas }} .
$$

The total gas was assumed to be comprised only of $\mathrm{CO}, \mathrm{CO}_{2}$, and $\mathrm{N}_{2}$, because very low relative yields of hydrocarbon gases were reported by Frederick et al. (1995a) for pine kraft black liquor pyrolyzed in an EFR. The wt $\%$ of BLS as $\mathrm{CO} W_{\mathrm{CO}}$ and as $\mathrm{CO}_{2} W_{\mathrm{CO} 2}$ can be expressed as,

$$
W_{C O}=\frac{\sum_{n=1}^{N}\left(V_{C O(n)} \mathrm{LsTP}\right)\left(\frac{1 \mathrm{~mol} \mathrm{CO}}{22.414 \mathrm{LsTP}}\right)\left(\frac{28.01 \mathrm{~g} \mathrm{CO}}{1 \mathrm{~mol} \mathrm{CO}}\right)}{\mathrm{g} \mathrm{BLS} \mathrm{fed}} \times 100
$$

and

$$
W_{\mathrm{CO} 2}=\frac{\sum_{n=1}^{N}\left(V_{\operatorname{CO} 2(n)} \mathrm{LsTP}\right)\left(\frac{1 \mathrm{~mol} \mathrm{CO}_{2}}{22.414 \mathrm{LsTP}_{\mathrm{T}}}\right)\left(\frac{44.01 \mathrm{~g} \mathrm{CO}_{2}}{1 \mathrm{~mol} \mathrm{CO}_{2}}\right)}{\mathrm{g} \mathrm{BLS} \mathrm{fed}},
$$

where $n$ is an integer that indexes both the experimental time $t(n)$ (s) and the sampling time interval defined between $t_{(n)}$ and $t_{(n-1)}, N$ is the total number of sampling intervals, and $V_{C O(n)}$ and $V_{\mathrm{CO} 2(n)}$ are the volumes of $\mathrm{CO}$ and $\mathrm{CO}_{2}$, respectively, calculated for each sampling time interval. Volumes of $\mathrm{CO}$ and $\mathrm{CO}_{2}$ (LsTP) in the pyrolysis gas for each sampling time interval can be calculated as, 


$$
V_{C O(n)}=V_{N 2(n)} \frac{\left[\frac{X_{C O(n)}}{10^{6}-X_{C O(n)}}+\frac{X_{C O(n)} X_{\operatorname{CO} 2(n)}}{\left(10^{12}-10^{6} X_{C O(n)}\right)\left(10^{12}-10^{6} X_{\operatorname{CO} 2(n)}\right)}\right]}{\left[1-\frac{X_{C O(n)} X_{C O 2(n)}}{\left(10^{12}-10^{6} X_{C O(n)}\right)\left(10^{12}-10^{6} X_{\operatorname{CO} 2(n)}\right)}\right]}
$$

and

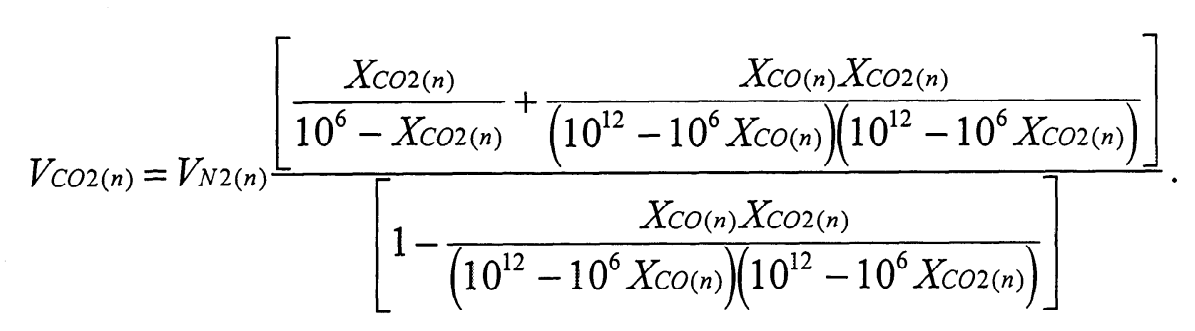

The average $\mathrm{CO}$ concentration $X_{C O(n)}$ within each sampling time interval is given by,

$$
X_{C O(n)}=\frac{\text { measured ppm CO at } t_{(n)}+\text { measured ppm CO at } t_{(n-1)}}{2},
$$

and the average $\mathrm{CO}_{2}$ concentration $X_{C O 2(n)}$ within each sampling time interval is given by,

$$
X_{C O 2(n)}=\frac{\text { measured } \mathrm{ppm} \mathrm{CO}_{2} \text { at } t_{(n)}+\text { measured } \mathrm{ppm} \mathrm{CO}_{2} \text { at } t_{(n-1)}}{2} .
$$

The average volume of $\mathrm{N}_{2}$ fed to the reactor $V_{N 2(n)}$ (LSTP) during each sampling time interval is given by,

$$
\begin{aligned}
V_{N 2(n)}=\left(\frac{\left(V_{N 2 P(n)}+V_{N 2 C(n)}+V_{N 2 Q(n)}\right)}{2}\right. & \\
& \left.+\frac{\left(V_{N 2 P(n-1)}+V_{N 2 C(n-1)}+V_{N 2 Q(n-1)}\right)}{2}-V_{N 2 L}\right)\left(t_{(n)}-t_{(n-1)}\right),
\end{aligned}
$$


where $V_{N 2 P}, V_{N 2 C}$, and $V_{N 2 Q}$ are the flowrates (LsTP / s) of preheated, carrier, and quench $\mathrm{N}_{2}$, respectively, and $V_{N 2 L}$ is the flowrate of $\mathrm{N}_{2}$ leaked $(\leq 0.0033$ LsTP / s) from the reactor at the experimental time index $n$. The percent of the carbon in BLS as $\mathrm{CO} M c o$ and as $\mathrm{CO}_{2} M_{\mathrm{CO} 2}$ can be expressed as,

$$
M_{C O}=\frac{\sum_{n=1}^{N}\left(V_{C O(n)} \text { LSTP }\right)\left(\frac{1 \mathrm{~mol} \mathrm{CO}}{22.414 \text { LstP }}\right)\left(\frac{12.011 \mathrm{~g} \mathrm{C}}{1 \mathrm{~mol} \mathrm{CO}}\right)}{\mathrm{g} \mathrm{BLS} \mathrm{fed}\left(\frac{\mathrm{g} \mathrm{C} \text { fed }}{\mathrm{g} \mathrm{BLS} \mathrm{fed}}\right)} \times 100
$$

and

$$
M_{\mathrm{CO} 2}=\frac{\sum_{n=1}^{N}\left(V_{\text {CO2 }(n)} \mathrm{LSTP}\right)\left(\frac{1 \mathrm{~mol} \mathrm{CO} 2}{22.414 \mathrm{LsTP}}\right)\left(\frac{12.011 \mathrm{~g} \mathrm{C}}{1 \mathrm{~mol} \mathrm{CO}_{2}}\right)}{\mathrm{g} \mathrm{BLS} \mathrm{fed}\left(\frac{\mathrm{g} \mathrm{C} \text { fed }}{\mathrm{g} \mathrm{BLS} \mathrm{fed}}\right)} \times 100
$$

The lower and upper tolerance limits on actual $\mathrm{CO}$ and $\mathrm{CO}_{2}$ yields were calculated using Eqs. A5.2-A5.10 by adding or subtracting the instrument error, reported by the manufacturer at the $95 \%$ confidence level, to or from the measured value for each time interval. To calculate the lower tolerance limit, the measured values were adjusted as follows: 20 ppm was subtracted from the measured $\mathrm{CO}$ and $\mathrm{CO}_{2}$ concentrations, assuming an error of $-1 \%$ of $2000 \mathrm{ppm}$ full scale. $0.0033 \mathrm{LsTP} / \mathrm{s}$ was subtracted from the measured volume of $\mathrm{N}_{2}$ input to the reactor, assuming an error of $-0.2 \%$ of 100 slpm full scale. $0.01 \mathrm{~g}$ was added to the measured mass of BLS fed to the reactor, assuming errors of $+0.005 \mathrm{~g}$ on the mass before feeding and $-0.005 \mathrm{~g}$ on the mass after feeding. To obtain the lower tolerance limit in terms of percent of carbon in BLS 
as estimated $\mathrm{CO}_{2}, 3.07$ weight percentage points were added from the average wt $\%$ of BLS as carbon in the solids (39.56 as shown in Table A4.3).

To calculate the upper tolerance limit, the measured values were adjusted as follows: 20 ppm was added to the measured $\mathrm{CO}$ and $\mathrm{CO}_{2}$ concentrations, assuming an error of $+1 \%$ of 2000 ppm full scale. 0.0033 Lstr / s was added to the measured volume of $\mathrm{N}_{2}$ input to the reactor, assuming an error of $+0.2 \%$ of 100 slpm full scale. $0.01 \mathrm{~g}$ was subtracted from the measured BLS fed to the reactor, assuming errors of $+0.005 \mathrm{~g}$ on the particle feeder vial mass before feeding and $-0.005 \mathrm{~g}$ on the particle feeder vial mass after feeding. To obtain the upper tolerance limit in terms of percent of carbon in BLS as estimated $\mathrm{CO}_{2}, 3.07$ weight percentage points were subtracted from the average wt $\%$ of BLS as carbon in the solids (39.56 as shown in Table A4.3).

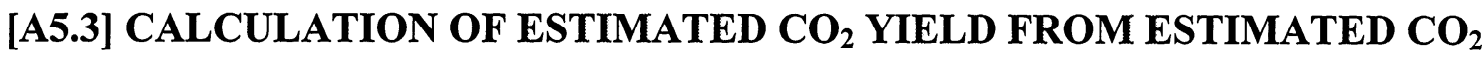 CONCENTRATION}

The higher, or estimated, $\mathrm{CO}_{2}$ yield can be calculated using Eqs. A5.3, A5.5, A5.6, A5.8, and A5.10 provided that $X_{\mathrm{CO}(n)}$ can be reasonably estimated. If it assumed that the initial molar ratio of $\mathrm{CO}$ to $\mathrm{CO}_{2}$ remains constant during the run and that the $\mathrm{CO}$ concentration is proportional to the set point feedrate of BLS particles (the particle feedrate was varied in stepwise fashion during the run in several experiments to maintain the gas concentrations within the measurement range of the gas analyzer), the estimated $X_{\operatorname{CO} 2(n)}$ can be calculated by,

$$
\text { Estimated } X_{\mathrm{CO}(n)}=\frac{X_{C O}(n)}{\varphi}
$$

where $\varphi$ is the average molar ratio of $\mathrm{CO}$ to $\mathrm{CO}_{2}$ given by, 


$$
\varphi=\frac{\sum_{n=N S}^{N e} \frac{X_{C O}(n)}{X_{C O 2(n)}}}{N e-N s}
$$

where $n=N s$ and $N e$ are the sample indices that designate the start and end of the data to be averaged. Ns usually corresponded to an experimental time $t(n) \cong 20 \mathrm{~s}$ after initial detection of $\mathrm{CO}$ and $\mathrm{CO}_{2}$, and $\mathrm{Ne}$ usually corresponded to the experimental time $t(n)$, at which the molar ratio of $\mathrm{CO}$ to $\mathrm{CO}_{2}$ began to increase due to decreasing $\mathrm{CO}_{2}$ concentration. Measured $\mathrm{CO}$ and $\mathrm{CO}_{2}$ concentrations made prior to $t_{(n)} \cong 20 \mathrm{~s}$ were not used to calculate $\varphi$, because instrument error was a significant fraction of the measured value at very low gas concentrations. Profiles of the estimated $\mathrm{CO}_{2}$ concentrations, as shown in Figs. A5.2-A5.56, were calculated using $\varphi$. The lower and upper bounds on the estimated $\mathrm{CO}_{2}$ yields, as shown in Table A5.2, were calculated by estimating $X_{\operatorname{CO} 2(n)}$ at \pm 1 standard deviation of $\varphi$ as given by,

\pm 1 std. dev. of $\varphi= \pm\left[\frac{(N e-N s) \sum_{n=N s}^{N e}\left(\frac{X_{C O}(n)}{X_{C O 2(n)}}\right)^{2}-\left(\sum_{n=N s}^{N e} \frac{X_{C O}(n)}{X_{C O 2(n)}}\right)^{2}}{(N e-N s)(N e-N s-1)}\right]^{1 / 2}$ 
Table A5.1. CO yields calculated from measured $\mathrm{CO}$ concentration in the pyrolysis gas.

\begin{tabular}{|c|c|c|c|c|c|c|}
\hline & \multicolumn{3}{|c|}{ Wt $\%$ of BLS } & \multicolumn{3}{|c|}{$\%$ of the $\mathrm{C}$ in $\mathrm{BLS}$} \\
\hline & L.B. & Meas. & U.B. & L.B. & Meas. & U.B. \\
\hline RNAC1113 & 0.08 & 0.12 & 0.17 & 0.08 & 0.13 & 0.20 \\
\hline RAC1119 & 0.28 & 0.32 & 0.36 & 0.28 & 0.35 & 0.42 \\
\hline RAC1009 & 1.15 & 1.24 & 1.34 & 1.16 & 1.35 & 1.57 \\
\hline RNAC1111 & 2.07 & 2.22 & 2.37 & 2.09 & 2.40 & 2.78 \\
\hline RNA21111 & 2.06 & 2.24 & 2.42 & 2.07 & 2.42 & 2.84 \\
\hline RNAC1112 & 2.11 & 2.26 & 2.42 & 2.12 & 2.45 & 2.84 \\
\hline RNAC1105 & 0.22 & 0.26 & 0.30 & 0.22 & 0.28 & 0.36 \\
\hline RNA21105 & 0.78 & 0.85 & 0.92 & 0.78 & 0.92 & 1.08 \\
\hline RNAC912 & 2.02 & 2.17 & 2.32 & 2.04 & 2.35 & 2.72 \\
\hline RNAC918 & 1.70 & 1.83 & 1.96 & 1.71 & 1.98 & 2.30 \\
\hline RNAC919A & 1.85 & 1.99 & 2.14 & 1.86 & 2.16 & 2.51 \\
\hline RNAC927B & 1.89 & 2.15 & 2.42 & 1.91 & 2.33 & 2.84 \\
\hline RNAC927A & 1.86 & 2.14 & 2.43 & 1.88 & 2.32 & 2.86 \\
\hline RAC925 & 1.86 & 2.02 & 2.18 & 1.88 & 2.19 & 2.56 \\
\hline $\mathrm{RAC} 1106$ & 1.70 & 1.82 & 1.95 & 1.71 & 1.97 & 2.28 \\
\hline RAC1107 & 1.13 & 1.23 & 1.33 & 1.14 & 1.33 & 1.56 \\
\hline RAC1108 & 2.14 & 2.30 & 2.47 & 2.16 & 2.49 & 2.90 \\
\hline RAC925B & 2.91 & 3.16 & 3.41 & 2.93 & 3.43 & 4.00 \\
\hline RAC1230B & 2.59 & 2.78 & 2.98 & 2.61 & 3.01 & 3.49 \\
\hline RAC1226 & 2.75 & 3.00 & 3.23 & 2.77 & 3.25 & 3.79 \\
\hline RAC1231A & 2.71 & 2.91 & 3.11 & 2.73 & 3.15 & 3.65 \\
\hline RAC1231B & 2.94 & 3.17 & 3.36 & 2.97 & 3.44 & 3.95 \\
\hline RAC1231C & 2.99 & 3.20 & 3.42 & 3.01 & 3.47 & 4.01 \\
\hline RAC1028 & 2.21 & 2.36 & 2.51 & 2.22 & 2.56 & 2.95 \\
\hline RAC912 & 3.58 & 3.80 & 4.02 & 3.61 & 4.12 & 4.71 \\
\hline RAC926 & 3.03 & 3.32 & 3.62 & 3.05 & 3.60 & 4.24 \\
\hline RAC1014 & 2.67 & 2.90 & 3.12 & 2.69 & 3.14 & 3.66 \\
\hline RAC930 & 2.56 & 2.89 & 3.23 & 2.58 & 3.13 & 3.79 \\
\hline RAC1227A & 2.82 & 3.05 & 3.30 & 2.84 & 3.31 & 3.87 \\
\hline RAC1207 & 3.12 & 3.42 & 3.74 & 3.14 & 3.71 & 4.39 \\
\hline RAC1227B & 2.90 & 3.15 & 3.42 & 2.92 & 3.42 & 4.01 \\
\hline RAC1230 & 3.03 & 3.45 & 3.88 & 3.05 & 3.74 & 4.55 \\
\hline RAC1224 & 2.99 & 3.30 & 3.62 & 3.02 & 3.58 & 4.25 \\
\hline RNAC1017 & 2.87 & 3.04 & 3.22 & 2.89 & 3.30 & 3.77 \\
\hline RNAC1022 & 2.73 & 2.96 & 3.20 & 2.75 & 3.21 & 3.75 \\
\hline RNAC1023 & 2.90 & 3.09 & 3.28 & 2.93 & 3.35 & 3.85 \\
\hline RNAC1019 & 2.90 & 3.21 & 3.53 & 2.93 & 3.48 & 4.14 \\
\hline RNAC1024 & 2.87 & 3.09 & 3.35 & 2.85 & 3.35 & 3. \\
\hline
\end{tabular}


Table A5.1 (continued). CO yields calculated from measured CO concentrations in the pyrolysis gas.

\begin{tabular}{|c|c|c|c|c|c|c|}
\hline & \multicolumn{3}{|c|}{ Wt $\%$ of BLS } & \multicolumn{3}{|c|}{$\%$ of $C$ in $B L S$} \\
\hline & L.B. & Meas. & U.B. & L.B. & Meas. & U.B. \\
\hline RNAC1226 & 2.81 & 3.02 & 3.26 & 2.79 & 3.27 & 3.82 \\
\hline RNAC923 & 2.93 & 3.11 & 3.29 & 2.96 & 3.37 & 3.86 \\
\hline RAC1206 & 3.00 & 3.27 & 3.54 & 3.02 & 3.54 & 4.16 \\
\hline RNAC1123 & 1.56 & 1.72 & 1.88 & 1.57 & 1.86 & 2.20 \\
\hline RNAC1127 & 3.34 & 3.55 & 3.76 & 3.37 & 3.85 & 4.40 \\
\hline RNAC1122 & 4.45 & 4.67 & 4.89 & 4.48 & 5.06 & 5.74 \\
\hline RAC1126A & 3.18 & 3.37 & 3.57 & 3.21 & 3.65 & 4.18 \\
\hline RAC1127 & 4.52 & 4.82 & 5.12 & 4.56 & 5.22 & 6.00 \\
\hline RAC1130 & 4.49 & 4.75 & 5.02 & 4.53 & 5.15 & 5.88 \\
\hline $\mathrm{RAC1126B}$ & 4.82 & 5.11 & 5.40 & 4.85 & 5.54 & 6.34 \\
\hline RAC1130B & 4.78 & 5.03 & 5.30 & 4.81 & 5.45 & 6.21 \\
\hline RAC1130C & 5.57 & 5.93 & 6.31 & 5.61 & 6.43 & 7.40 \\
\hline RAC1205 & 4.79 & 5.14 & 5.54 & 4.76 & 5.57 & 6.50 \\
\hline RNAC1124 & 7.72 & 8.21 & 8.72 & 7.77 & 8.90 & 10.22 \\
\hline RNAC1125 & 4.09 & 4.49 & 4.97 & 4.12 & 4.87 & 5.83 \\
\hline RNAC1204 & 15.86 & 16.66 & 17.5 & 15.98 & 18.06 & 20.48 \\
\hline
\end{tabular}


Table A5.2. $\mathrm{CO}_{2}$ yields calculated from measured $\mathrm{CO}_{2}$ concentrations and estimated $\mathrm{CO}_{2}$ concentrations in the pyrolysis gas.

\begin{tabular}{|c|c|c|c|c|c|c|c|c|c|c|}
\hline & \multicolumn{3}{|c|}{ Wt\% of BLS } & \multicolumn{3}{|c|}{$\%$ of the $C$ in $B L S$} & \multicolumn{2}{|c|}{$\% \mathrm{CO} / \mathrm{CO}_{2}$} & \multicolumn{2}{|c|}{ Estimated $\mathrm{CO}_{2}$, -Std. Dev. to +Std. Dev. } \\
\hline & L.B. & Meas. & U.B. & L.B. & Meas. & U.B. & Mean & Std. Dev. & Wt\% of BLS & $\%$ of the $\mathrm{C}$ in BLS \\
\hline RNAC1113 & 0.34 & 0.41 & 0.49 & 0.22 & 0.28 & 0.37 & 0.4718 & & & \\
\hline RAC1119 & 1.22 & 1.30 & 1.38 & 0.78 & 0.89 & 1.03 & 0.3021 & 0.0553 & $1.3-1.8$ & $1.0-1.3$ \\
\hline RAC1009 & 3.74 & 3.92 & 4.11 & 2.40 & 2.71 & 3.07 & 0.4976 & & & 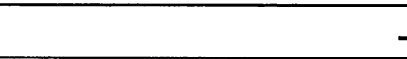 \\
\hline RNAC1111 & 3.90 & 4.15 & 4.40 & 2.50 & 2.86 & 3.29 & 0.6983 & 0.0556 & $4.6-5.4$ & $3.4-4.0$ \\
\hline RNA21111 & 3.71 & 4.00 & 4.30 & 2.38 & 2.76 & 3.21 & 0.7738 & 0.1043 & $4.0-5.2$ & $3.0-3.9$ \\
\hline RNAC1112 & 3.92 & 4.18 & 4.45 & 2.51 & 2.89 & 3.32 & 0.8468 & 0.1050 & $3.6-4.6$ & $2.7-3.4$ \\
\hline RNAC1105 & 0.55 & 0.62 & 0.69 & 0.35 & 0.43 & 0.52 & 0.6577 & & - & - \\
\hline RNA21105 & 3.14 & 3.30 & 3.45 & 2.02 & 2.28 & 2.57 & 0.4007 & 0.0321 & $3.0-3.5$ & $2.2-2.6$ \\
\hline RNAC912 & 5.73 & 6.02 & 6.32 & 3.68 & 4.15 & 4.72 & 0.5570 & 0.0375 & $5.6-6.5$ & $4.2-4.9$ \\
\hline RNAC918 & 5.51 & 5.78 & 6.05 & 3.53 & 3.99 & 4.52 & 0.5029 & 0.0344 & $5.3-6.0$ & $4.0-4.5$ \\
\hline RNAC919A & 5.70 & 5.98 & 6.27 & 3.65 & 4.13 & 4.68 & 0.5317 & 0.0335 & $5.5-6.3$ & $4.1-4.7$ \\
\hline RNAC927B & 7.51 & 8.13 & 8.77 & 4.82 & 5.61 & 6.55 & 0.4160 & 0.0376 & $7.5-8.9$ & $5.6-6.7$ \\
\hline RNAC927A & 7.33 & 8.15 & 9.01 & 4.70 & 5.62 & 6.73 & 0.4140 & 0.360 & $7.5-8.8$ & $5.6-6.6$ \\
\hline RAC925 & 6.43 & 6.76 & 7.10 & 4.12 & 4.66 & 5.30 & 0.4612 & 0.03007 & $6.5-7.4$ & $4.9-5.5$ \\
\hline RAC1106 & 5.12 & 5.37 & 5.62 & 3.29 & 3.70 & 4.20 & & 4 & - & - \\
\hline RAC1107 & 5.16 & 5.40 & 5.63 & 3.31 & 3.73 & 4.20 & 0.3247 & 0.0211 & $5.5-6.3$ & $4.1-4.7$ \\
\hline RAC1108 & 6.83 & 7.16 & 7.50 & 4.38 & 4.94 & 5.60 & 0.4528 & 0.0351 & $7.4-8.6$ & $5.5-6.4$ \\
\hline RAC925B & 9.16 & 9.66 & 10.18 & 5.87 & 6.66 & 7.60 & 0.4435 & 0.0476 & 9.9-12.2 & $7.4-9.1$ \\
\hline RAC1230B & 11.45 & 11.91 & 12.38 & 7.34 & 8.22 & 9.24 & 0.3124 & 0.0237 & $13.0-15.2$ & $9.7-11.4$ \\
\hline RAC1226 & 12.44 & 13.00 & 13.56 & 7.98 & 8.97 & 10.13 & 0.3022 & 0.0217 & $14.4-16.5$ & $10.8-12.3$ \\
\hline RAC1231A & 10.01 & 10.45 & 10.91 & 6.42 & 7.21 & 8.14 & 0.3923 & 0.0209 & $11.0-12.3$ & $8.2-9.2$ \\
\hline RAC1231B & 11.38 & 11.95 & 12.35 & 7.30 & 8.24 & 9.22 & 0.3402 & 0.0192 & $13.9-15.5$ & $10.4-11.6$ \\
\hline RAC1231C & 11.95 & 12.45 & 12.95 & 7.65 & 8.59 & 9.66 & 0.2516 & 0.0208 & $18.3-21.6$ & $13.7-16.2$ \\
\hline $\mathrm{RAC} 1028$ & 6.61 & 6.92 & 7.23 & 4.24 & 4.77 & 5.40 & 0.3857 & 0.0386 & - & - \\
\hline RAC912 & 10.02 & 10.46 & 10.91 & 6.43 & 7.22 & 8.14 & 0.5442 & 0.0356 & $10.2-11.7$ & $7.6-8.7$ \\
\hline RAC926 & 10.40 & 11.01 & 11.64 & 6.67 & 7.60 & 8.69 & 0.4441 & 0.0559 & $10.6-13.5$ & $7.9-10.1$ \\
\hline RAC1014 & 8.98 & 9.44 & 9.90 & 5.76 & 6.51 & 7.39 & 0.3147 & 0.0596 & $11.3-16.4$ & $8.5-12.3$ \\
\hline
\end{tabular}


Table A5.2 (Continued). $\mathrm{CO}_{2}$ yields calculated from measured $\mathrm{CO}_{2}$ concentrations and estimated $\mathrm{CO}_{2}$ concentrations in the pyrolysis gas.

\begin{tabular}{|c|c|c|c|c|c|c|c|c|c|c|}
\hline & \multicolumn{3}{|c|}{ Wt\% of BLS } & \multicolumn{3}{|c|}{$\%$ of the $\mathrm{C}$ in $\mathrm{BLS}$} & \multicolumn{2}{|c|}{$\%$ of $\mathrm{CO} / \mathrm{CO}_{2}$} & \multicolumn{2}{|c|}{ Estimated $\mathrm{CO}_{2},-$ Std. Dev. to +Std. Dev. } \\
\hline & L.B. & Meas. & U.B. & L.B. & Meas. & U.B. & Mean & Std. Dev. & Wt $\%$ of BLS & $\mathrm{C}$ in BLS \\
\hline RAC930 & 13.52 & 14.57 & 15.67 & 8.66 & 10.05 & 11.69 & 0.2516 & 0.0247 & $17.1-20.6$ & $12.8-15.4$ \\
\hline RAC1227A & 12.77 & 13.32 & 13.90 & 8.19 & 9.19 & 10.38 & 0.2721 & 0.0205 & $17.0-19.8$ & $12.7-14.8$ \\
\hline RAC1207 & 13.02 & 13.69 & 14.38 & 8.35 & 9.45 & 10.73 & 0.2755 & 0.0256 & $17.8-21.3$ & $13.3-15.9$ \\
\hline RAC1227B & 13.57 & 14.18 & 14.80 & 8.70 & 9.78 & 11.05 & 0.2437 & 0.0195 & $18.8-22.0$ & $14.1-16.5$ \\
\hline RAC1230 & 16.39 & 17.34 & 18.32 & 10.51 & 11.96 & 13.68 & 0.2774 & 0.0302 & 17.9-22.1 & 13.4-16.5 \\
\hline RAC1224 & 14.02 & 14.72 & 15.45 & 8.98 & 10.15 & 11.52 & 0.2380 & 0.0273 & $20.1-25.2$ & $15.0-18.8$ \\
\hline RNAC1017 & 6.23 & 6.54 & 6.85 & 3.99 & 4.50 & 5.11 & 0.6670 & 0.0517 & $6.9-8.0$ & $5.2-6.0$ \\
\hline RNAC1022 & 6.96 & 7.43 & 7.93 & 4.46 & 5.13 & 5.92 & 0.5470 & 0.0692 & $7.5-9.6$ & $5.6-7.2$ \\
\hline RNAC1023 & 7.91 & 8.28 & 8.66 & 5.07 & 5.71 & 6.46 & 0.3620 & 0.0310 & $12.2-14.5$ & $9.1-10.8$ \\
\hline RNAC1019 & 11.22 & 12.01 & 12.83 & 7.19 & 8.28 & 9.57 & 0.3195 & 0.0477 & $13.9-18.6$ & 10.4-13.9 \\
\hline RNAC1024 & 9.85 & 10.47 & 11.11 & 6.32 & 7.22 & 8.30 & 0.3219 & 0.0228 & $14.2-16.9$ & $10.6-12.6$ \\
\hline RNAC1226 & 12.42 & 12.96 & 13.52 & 7.96 & 8.94 & 10.09 & 0.2381 & 0.0252 & $18.6-23.1$ & 13.9-17.3 \\
\hline RNAC923 & 6.57 & 6.89 & 7.21 & 4.21 & 4.75 & 5.39 & 0.6634 & 0.0575 & $6.8-8.1$ & $5.1-6.1$ \\
\hline RAC1206 & 12.90 & 13.67 & 14.45 & 8.27 & 9.43 & 10.79 & 0.3073 & 0.0300 & $15.7-18.8$ & $11.7-14.1$ \\
\hline RNAC1123 & 4.88 & 5.18 & 5.49 & 3.13 & 3.57 & 4.09 & 0.5462 & 0.0426 & $4.6-5.3$ & $3.4-4.0$ \\
\hline RNAC1127 & 7.03 & 7.39 & 7.76 & 4.51 & 5.10 & 5.79 & 0.7806 & 0.0735 & $6.6-8.0$ & $4.9-6.0$ \\
\hline RNAC1122 & 7.67 & 8.03 & 8.39 & 4.92 & 5.54 & 6.26 & 0.8845 & 0.0433 & $7.7-8.4$ & $5.8-6.3$ \\
\hline RAC1126A & 7.38 & 7.74 & 8.10 & 4.73 & 5.34 & 6.04 & 0.6791 & 0.0286 & $7.8-8.5$ & $5.8-6.4$ \\
\hline RAC1127 & 12.89 & 13.48 & 14.08 & 8.26 & 9.30 & 10.50 & 0.4672 & 0.0361 & $14.9-17.4$ & $11.1-13.0$ \\
\hline RAC1130 & 12.67 & 13.15 & 13.65 & 8.12 & 9.07 & 10.19 & 0.4914 & 0.0200 & 14.1-15.2 & $10.5-11.4$ \\
\hline RAC1126B & 11.00 & 11.51 & 12.04 & 7.05 & 7.94 & 8.99 & 0.6750 & 0.0514 & $10.8-12.6$ & $8.1-9.4$ \\
\hline RAC1130B & 10.99 & 11.47 & 11.97 & 7.04 & 7.91 & 8.93 & 0.6623 & 0.0331 & 11.4-12.5 & $8.5-9.3$ \\
\hline RAC1130C & 17.18 & 17.96 & 18.76 & 11.01 & 12.39 & 14.00 & 0.3958 & 0.0518 & $20.3-26.2$ & $15.2-19.6$ \\
\hline RAC1205 & 20.63 & 21.54 & 22.47 & 13.23 & 14.86 & 16.77 & 0.2110 & 0.0472 & & - \\
\hline RNAC1124 & 17.73 & 18.64 & 19.58 & 11.36 & 12.86 & 14.60 & 0.4255 & 0.0551 & - & - \\
\hline RNAC 1125 & 19.51 & 20.39 & 21.62 & 12.50 & 14.07 & 16.14 & 0.3191 & 0.0430 & & - \\
\hline RNAC1204 & 17.94 & 19.02 & 20.13 & 11.50 & 13.12 & 15.01 & 0.2005 & 0.0300 & - & 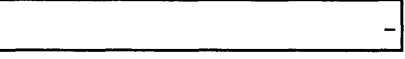 \\
\hline
\end{tabular}




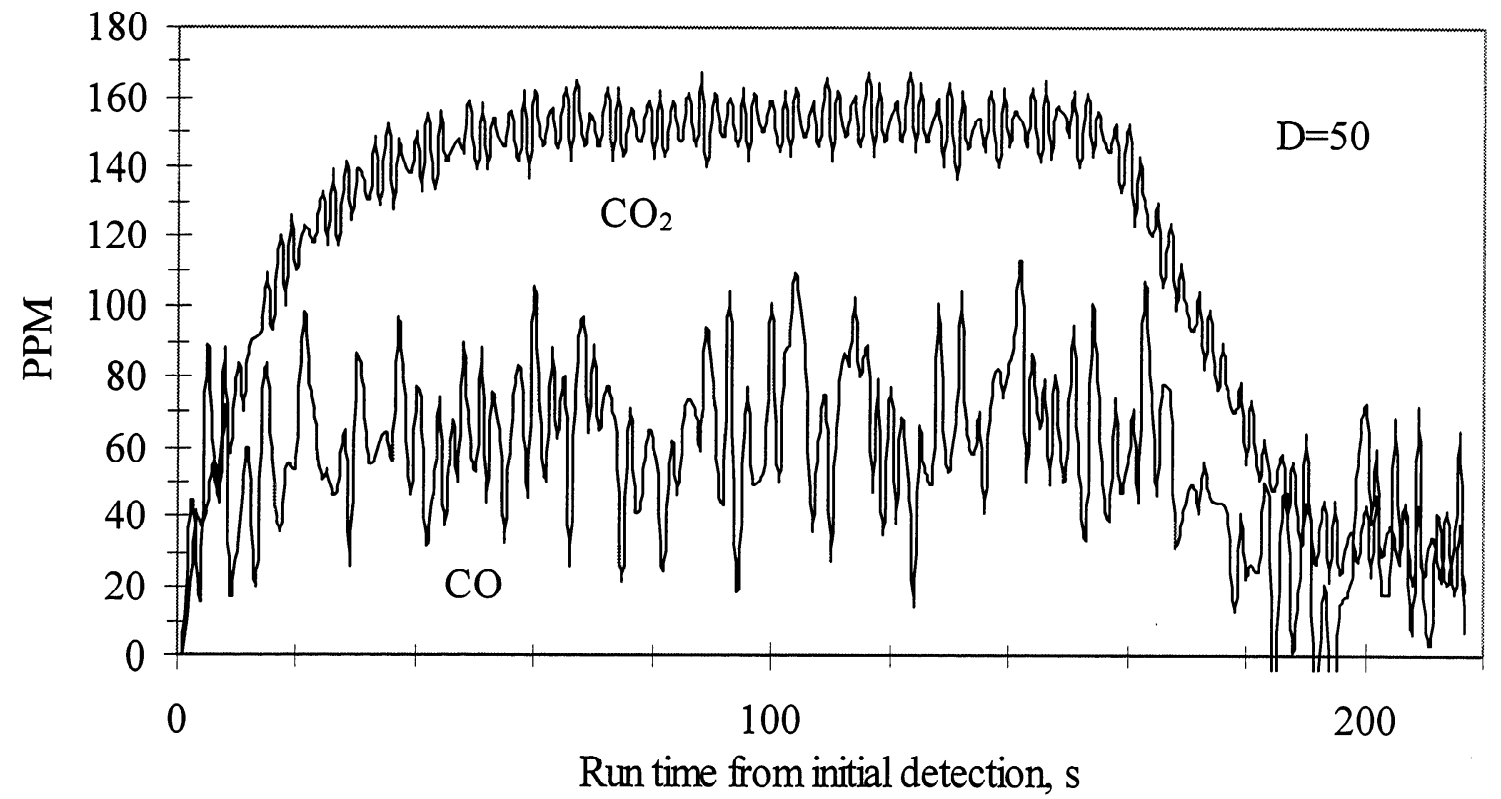

Figure A5.2. Profiles of $\mathrm{CO}$ and $\mathrm{CO}_{2}$ concentrations in the pyrolysis gas obtained without acoustics (RNAC1113) under reactor conditions of $400^{\circ} \mathrm{C}, 0.81 \mathrm{~m}$ pyrolysis tube heated length, $0.85 \mathrm{~s}$ particle residence time, and $2.10 \mathrm{~s}$ secondary gas space-time.

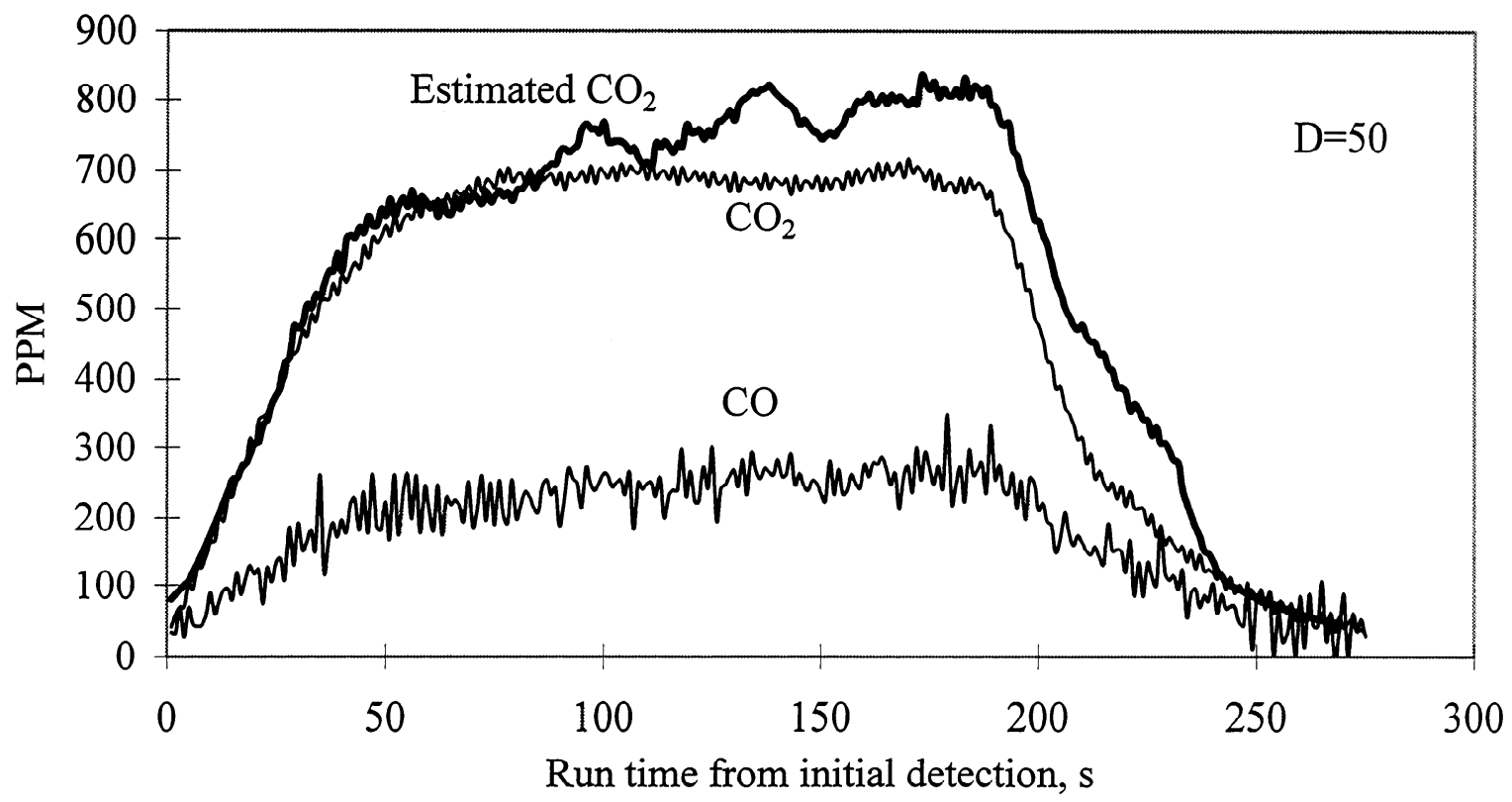

Figure A5.3. Profiles of $\mathrm{CO}$ and $\mathrm{CO}_{2}$ concentrations in the pyrolysis gas obtained in an acoustic field of $151 \mathrm{~dB}$ and $960 \mathrm{~Hz}$ (RAC1119) under reactor conditions of $400^{\circ} \mathrm{C}$, $0.81 \mathrm{~m}$ pyrolysis tube heated length, $1.05 \mathrm{~s}$ particle residence time, and $2.10 \mathrm{~s}$ secondary gas space-time. 


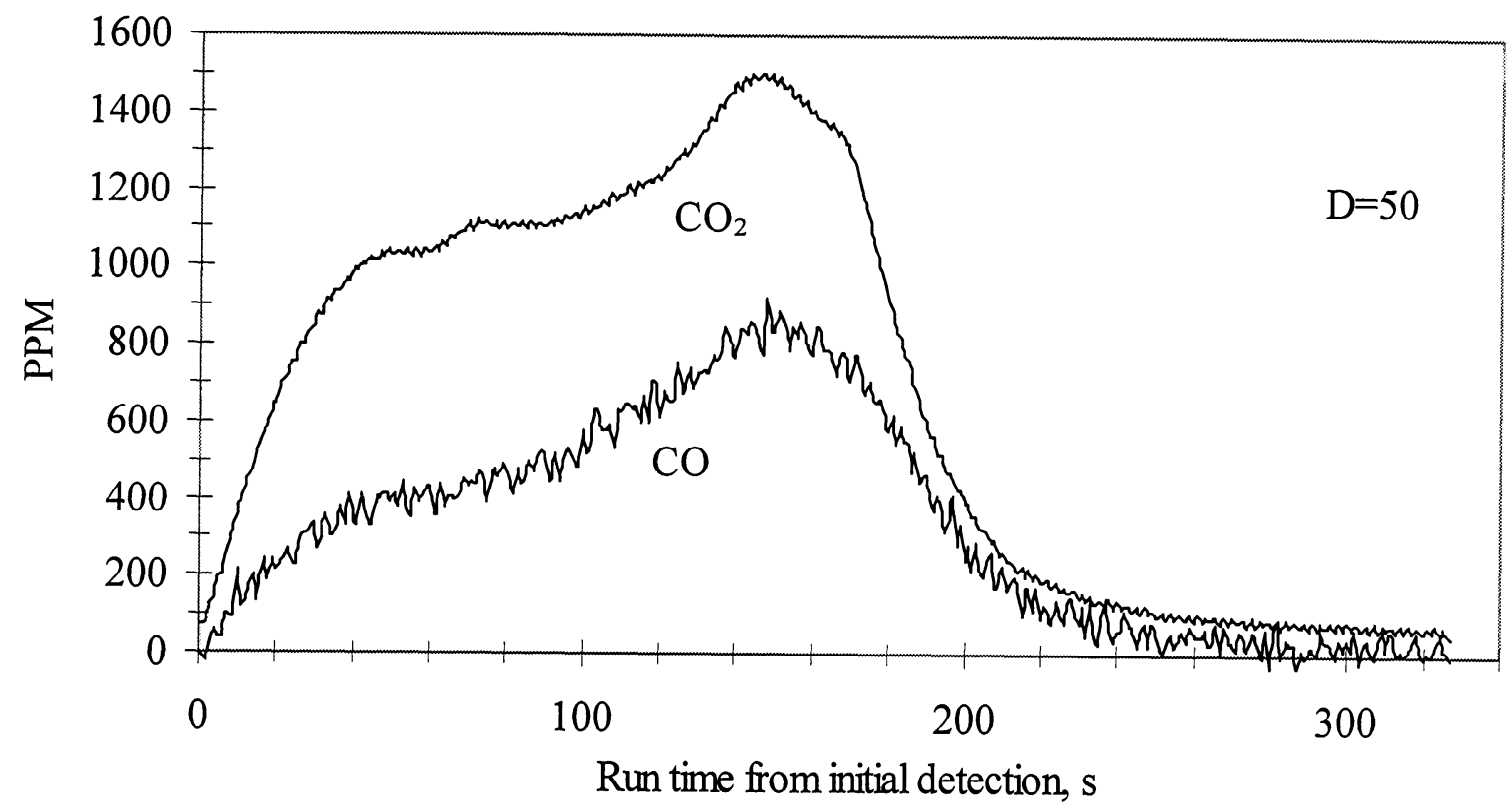

Figure A5.4. Profiles of $\mathrm{CO}$ and $\mathrm{CO}_{2}$ concentrations in the pyrolysis gas obtained in an acoustic field of $154 \mathrm{~dB}$ and $960 \mathrm{~Hz}$ (RAC1009) under reactor conditions of $400^{\circ} \mathrm{C}, 0.81 \mathrm{~m}$ pyrolysis tube heated length, and $1.70 \mathrm{~s}$ secondary gas space-time.

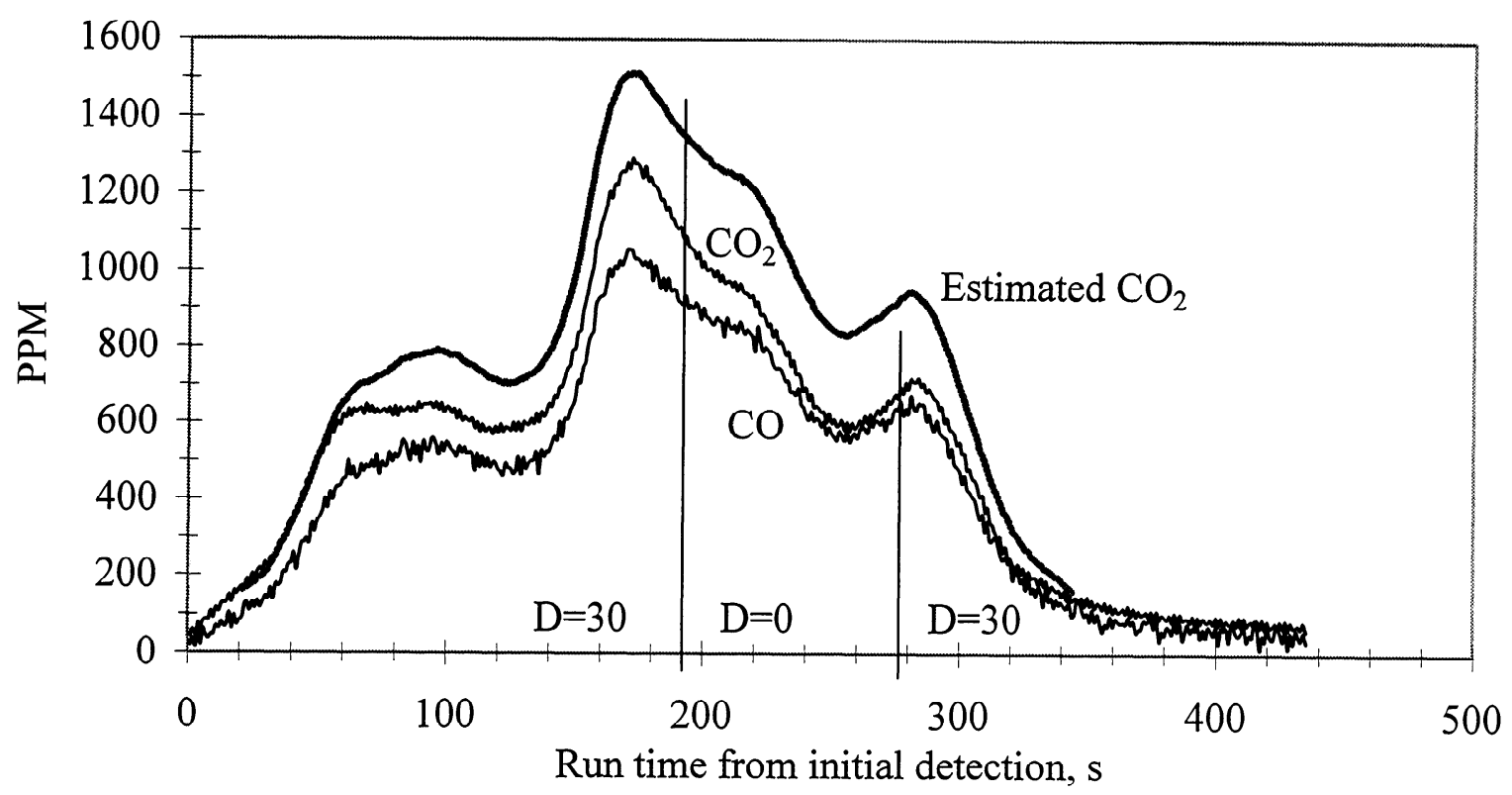

Figure A5.5. Profiles of $\mathrm{CO}$ and $\mathrm{CO}_{2}$ concentrations in the pyrolysis gas obtained with a steelwool-plug located at $0.13 \mathrm{~m}$ (RNAC1111) under reactor conditions of $400^{\circ} \mathrm{C}$, $0.18 \mathrm{~m}$ pyrolysis tube heated length, and $0.47 \mathrm{~s}$ secondary gas space-time. 


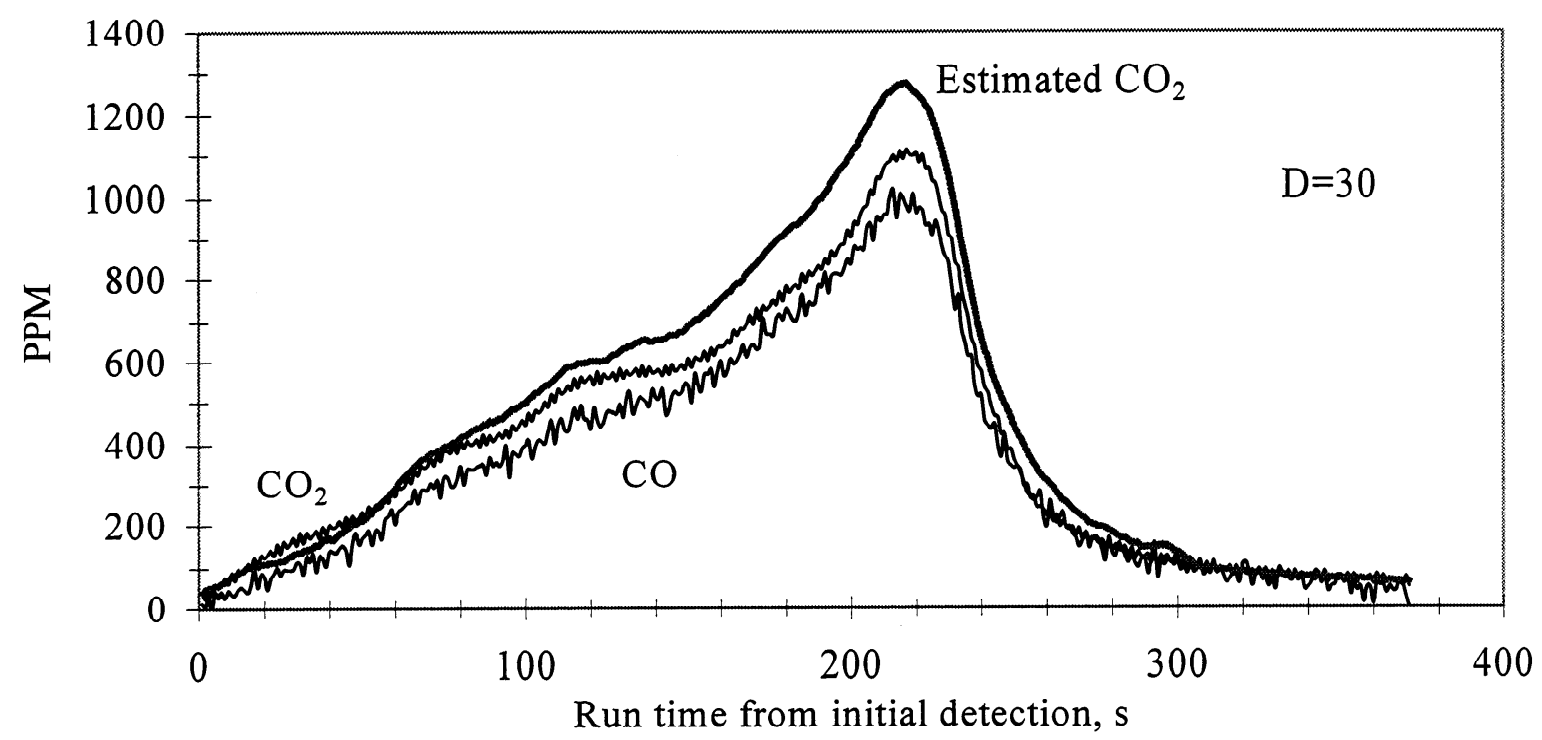

Figure A5.6. Profiles of $\mathrm{CO}$ and $\mathrm{CO}_{2}$ concentrations in the pyrolysis gas obtained with a steelwool-plug located at $0.13 \mathrm{~m}$ (RNAC2111) under reactor conditions of $400^{\circ} \mathrm{C}$, $0.18 \mathrm{~m}$ pyrolysis tube heated length, and $0.47 \mathrm{~s}$ secondary gas space-time.

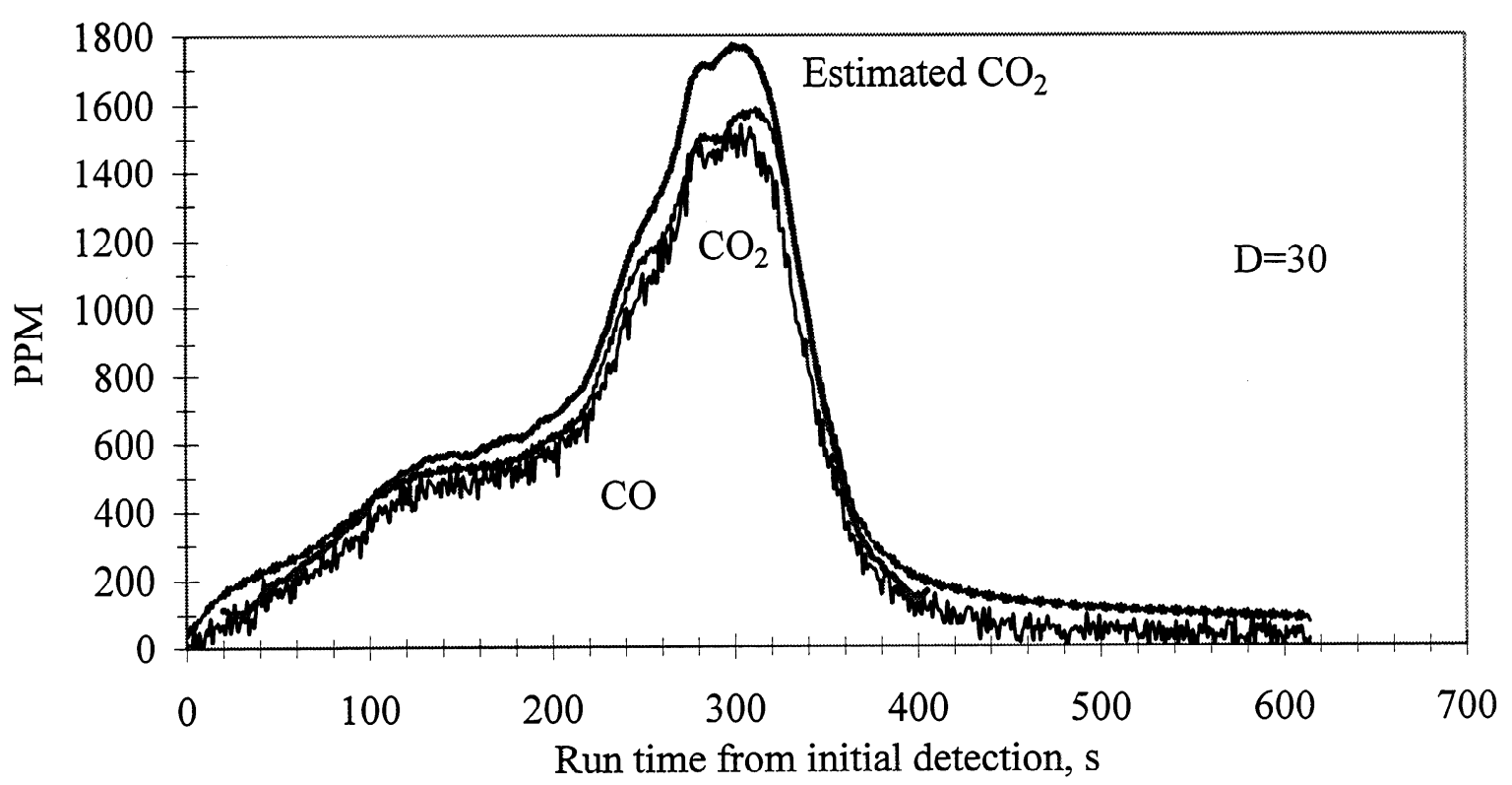

Figure A5.7. Profiles of $\mathrm{CO}$ and $\mathrm{CO}_{2}$ concentrations in the pyrolysis gas obtained with a steelwool-plug located at $0.13 \mathrm{~m}$ (RNAC1112) under reactor conditions of $400^{\circ} \mathrm{C}$, $0.81 \mathrm{~m}$ pyrolysis tube heated length, and $2.10 \mathrm{~s}$ secondary gas space-time. 


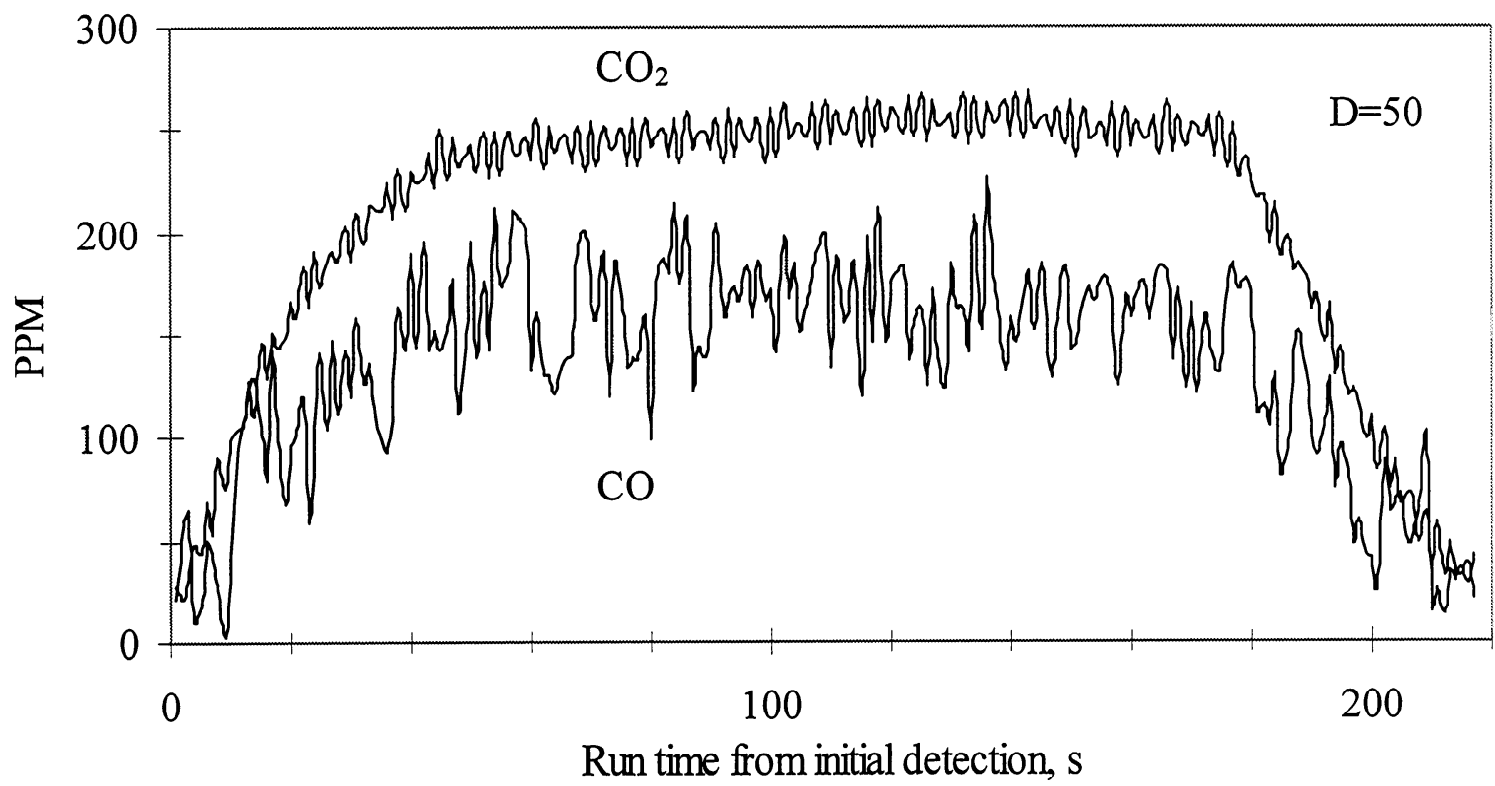

Figure A5.8. Profiles of $\mathrm{CO}$ and $\mathrm{CO}_{2}$ concentrations in the pyrolysis gas obtained without acoustics (RNAC1105) under reactor conditions of $550^{\circ} \mathrm{C}, 0.18 \mathrm{~m}$ pyrolysis tube heated length, $0.23 \mathrm{~s}$ particle residence time, and $0.38 \mathrm{~s}$ secondary gas space-time.

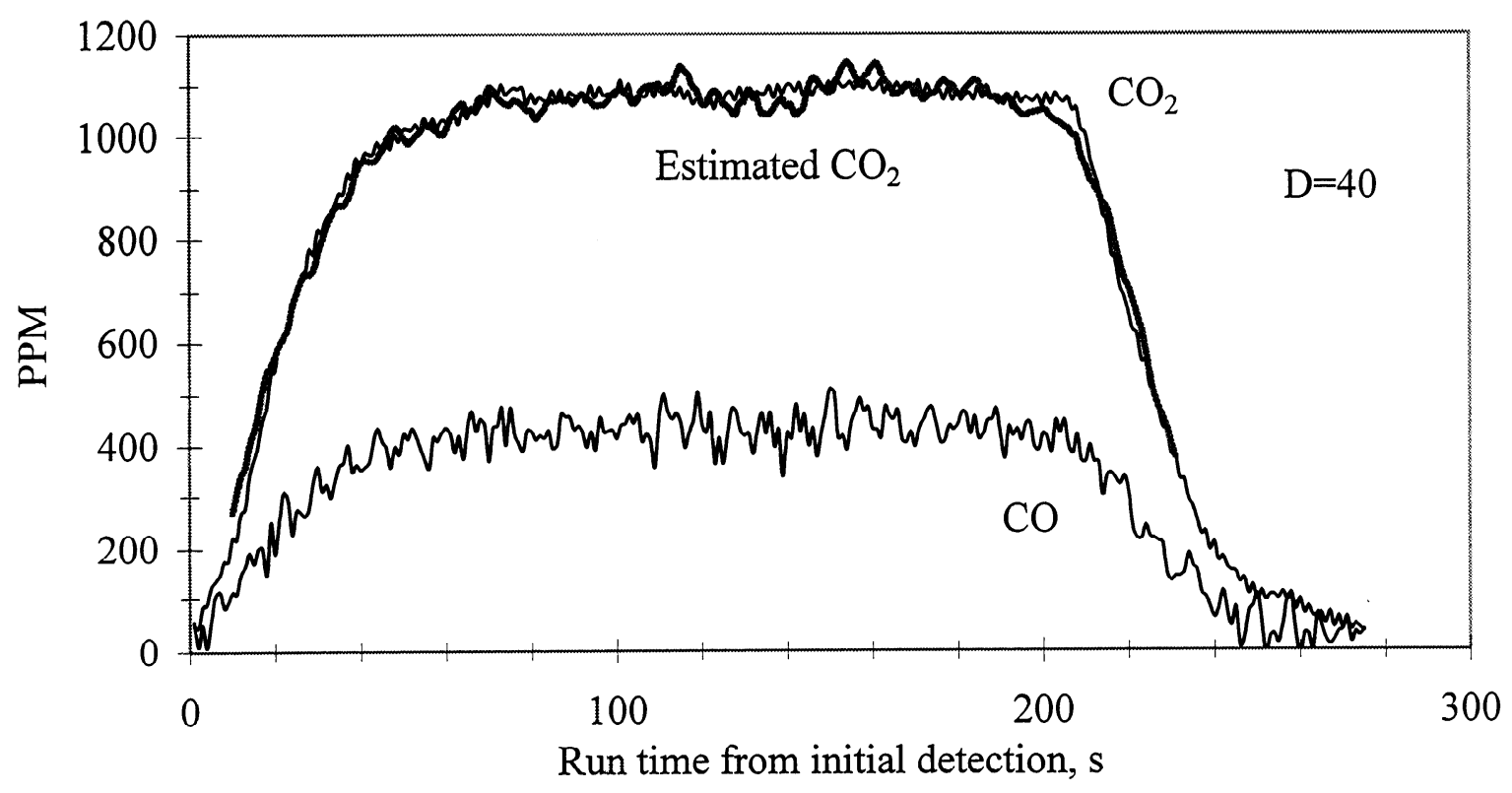

Figure A5.9. Profiles of $\mathrm{CO}$ and $\mathrm{CO}_{2}$ concentrations in the pyrolysis gas obtained without acoustics (RNAC21105) under reactor conditions of $550^{\circ} \mathrm{C}, 0.48 \mathrm{~m}$ pyrolysis tube heated length, $0.54 \mathrm{~s}$ particle residence time, and $1.02 \mathrm{~s}$ secondary gas space-time. 


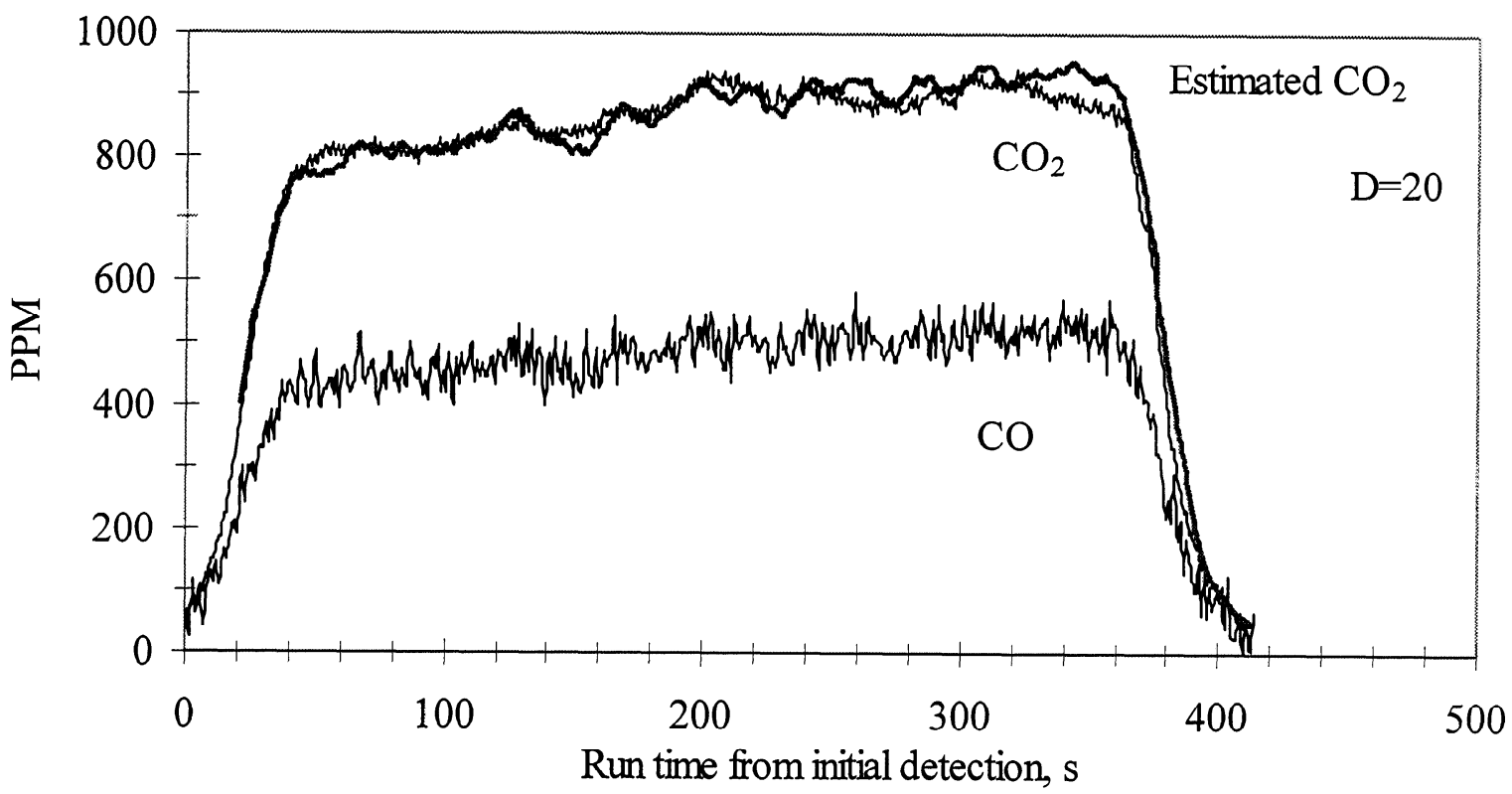

Figure A5.10. Profiles of $\mathrm{CO}$ and $\mathrm{CO}_{2}$ concentrations in the pyrolysis gas obtained without acoustics (RNAC912) under reactor conditions of $550^{\circ} \mathrm{C}, 0.81 \mathrm{~m}$ pyrolysis tube heated length, $20 \mathrm{slpm} \mathrm{N}_{2}$ quench, $0.90 \mathrm{~s}$ particle residence time, and $1.72 \mathrm{~s}$ secondary gas space-time.

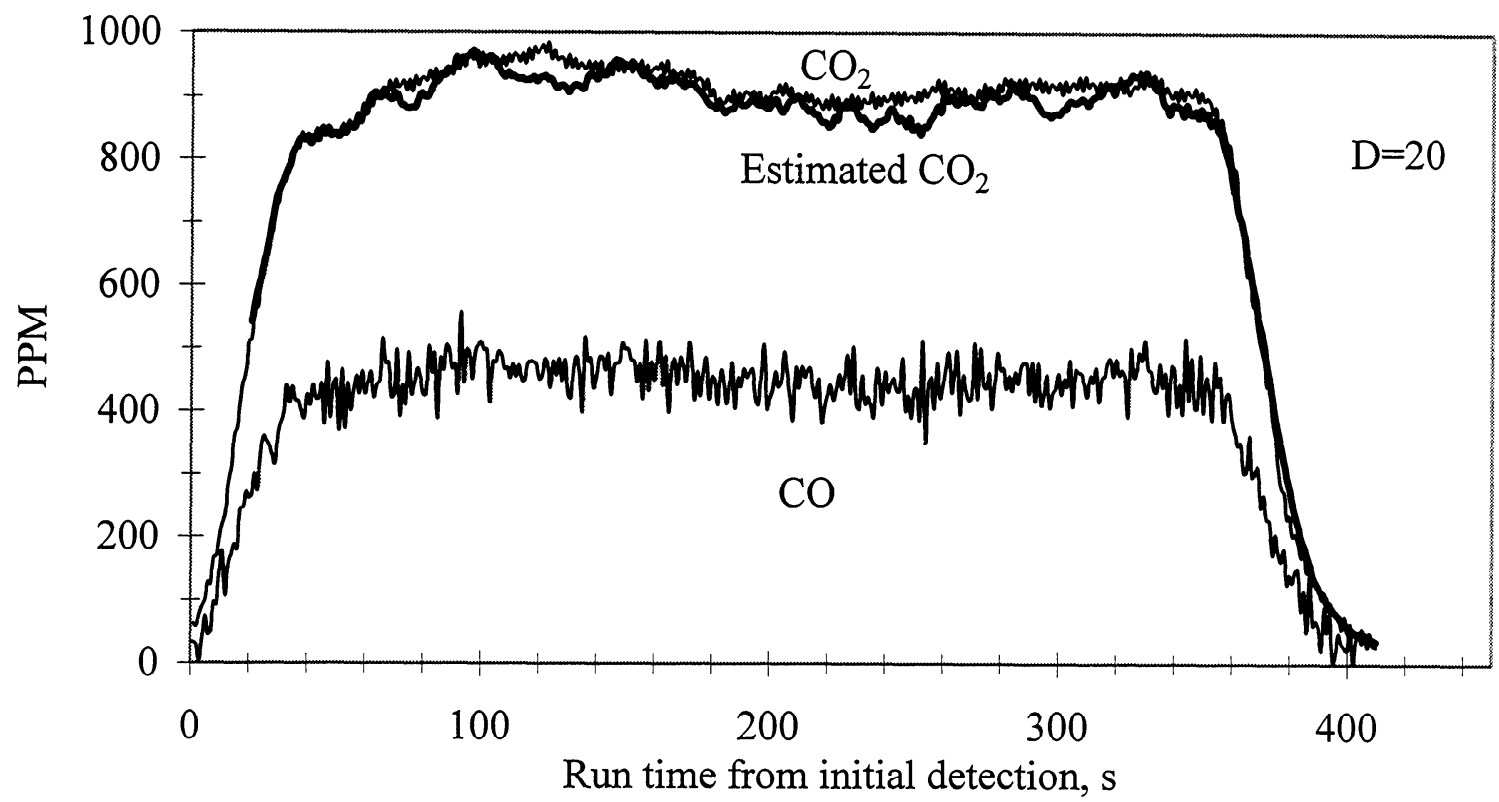

Figure A5.11. Profiles of $\mathrm{CO}$ and $\mathrm{CO}_{2}$ concentrations in the pyrolysis gas obtained without acoustics (RNAC918) under reactor conditions of $550^{\circ} \mathrm{C}, 0.81 \mathrm{~m}$ pyrolysis tube heated length, $20 \mathrm{slpm} \mathrm{N}_{2}$ quench, $0.90 \mathrm{~s}$ particle residence time, and $1.72 \mathrm{~s}$ secondary gas space-time. 


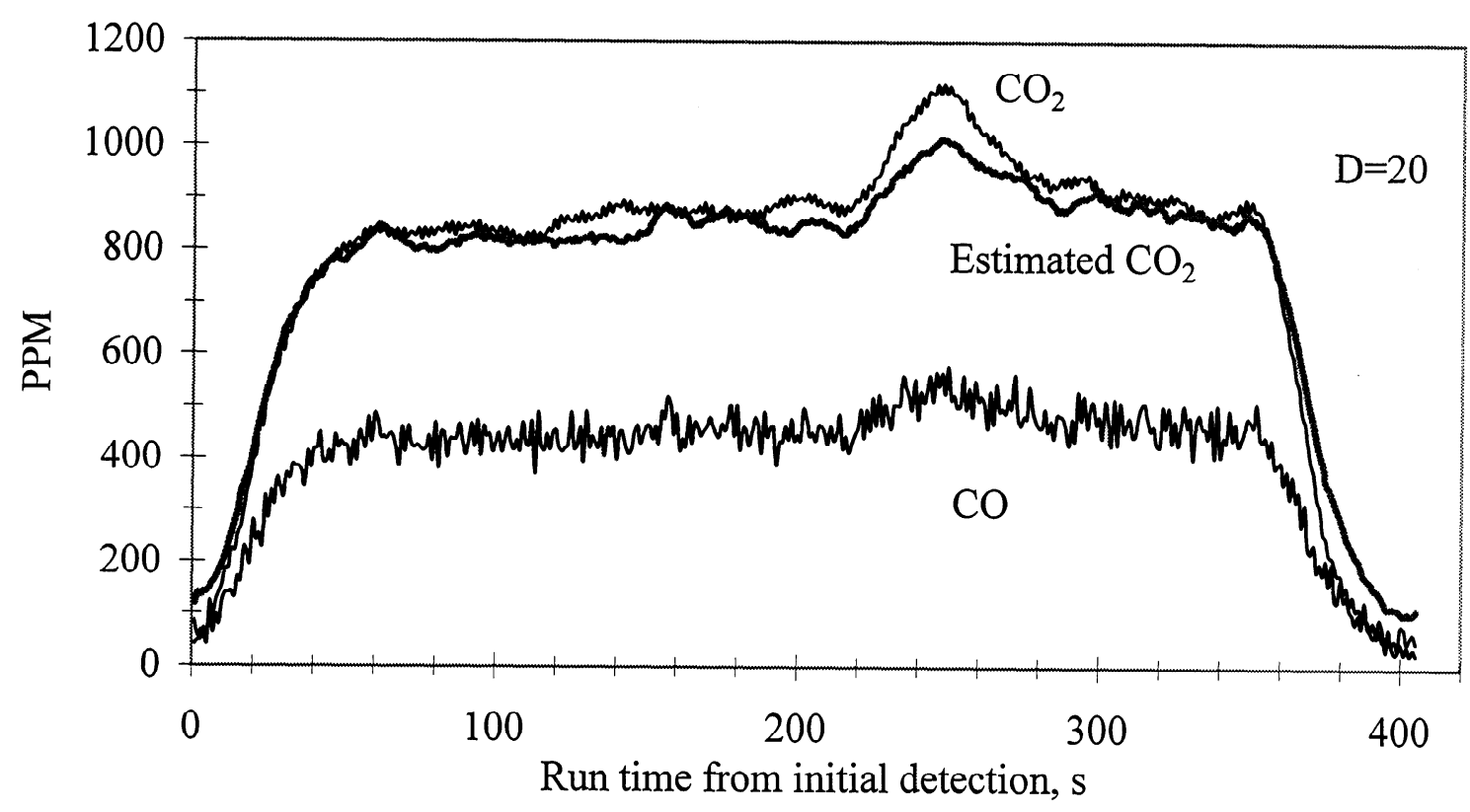

Figure A5.12. Profiles of $\mathrm{CO}$ and $\mathrm{CO}_{2}$ concentrations in the pyrolysis gas obtained without acoustics (RNAC919A) under reactor conditions of $550^{\circ} \mathrm{C}, 0.81 \mathrm{~m}$ pyrolysis tube heated length, 20 slpm $\mathrm{N}_{2}$ quench, $0.90 \mathrm{~s}$ particle residence time, and $1.72 \mathrm{~s}$ secondary gas space-time.

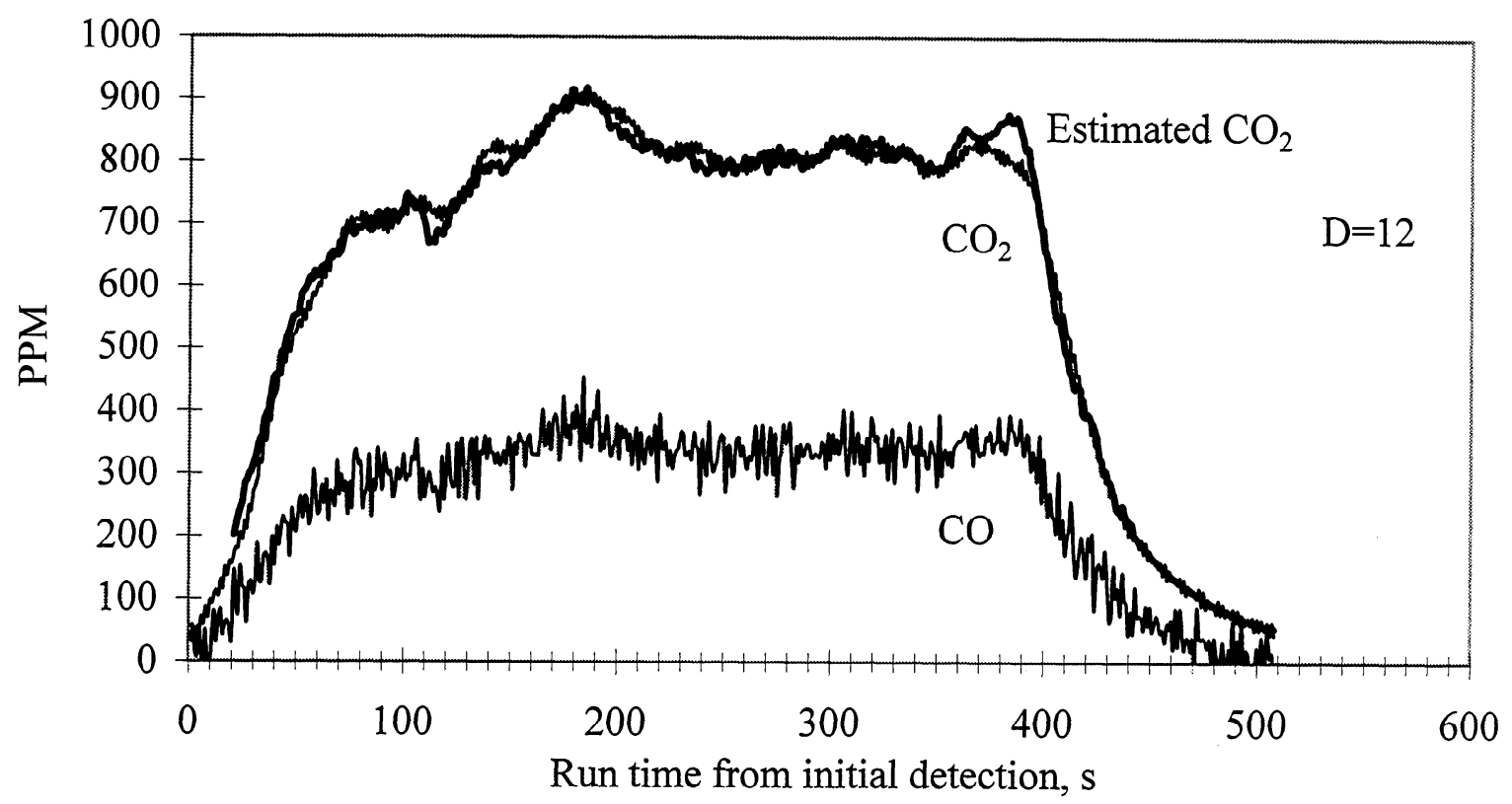

Figure A5.13. Profiles of $\mathrm{CO}$ and $\mathrm{CO}_{2}$ concentrations in the pyrolysis gas obtained without acoustics (RNAC927B) under reactor conditions of $550^{\circ} \mathrm{C}, 0.81 \mathrm{~m}$ pyrolysis tube heated length, $1.58 \mathrm{~s}$ particle residence time, and $3.39 \mathrm{~s}$ secondary gas space-time. 


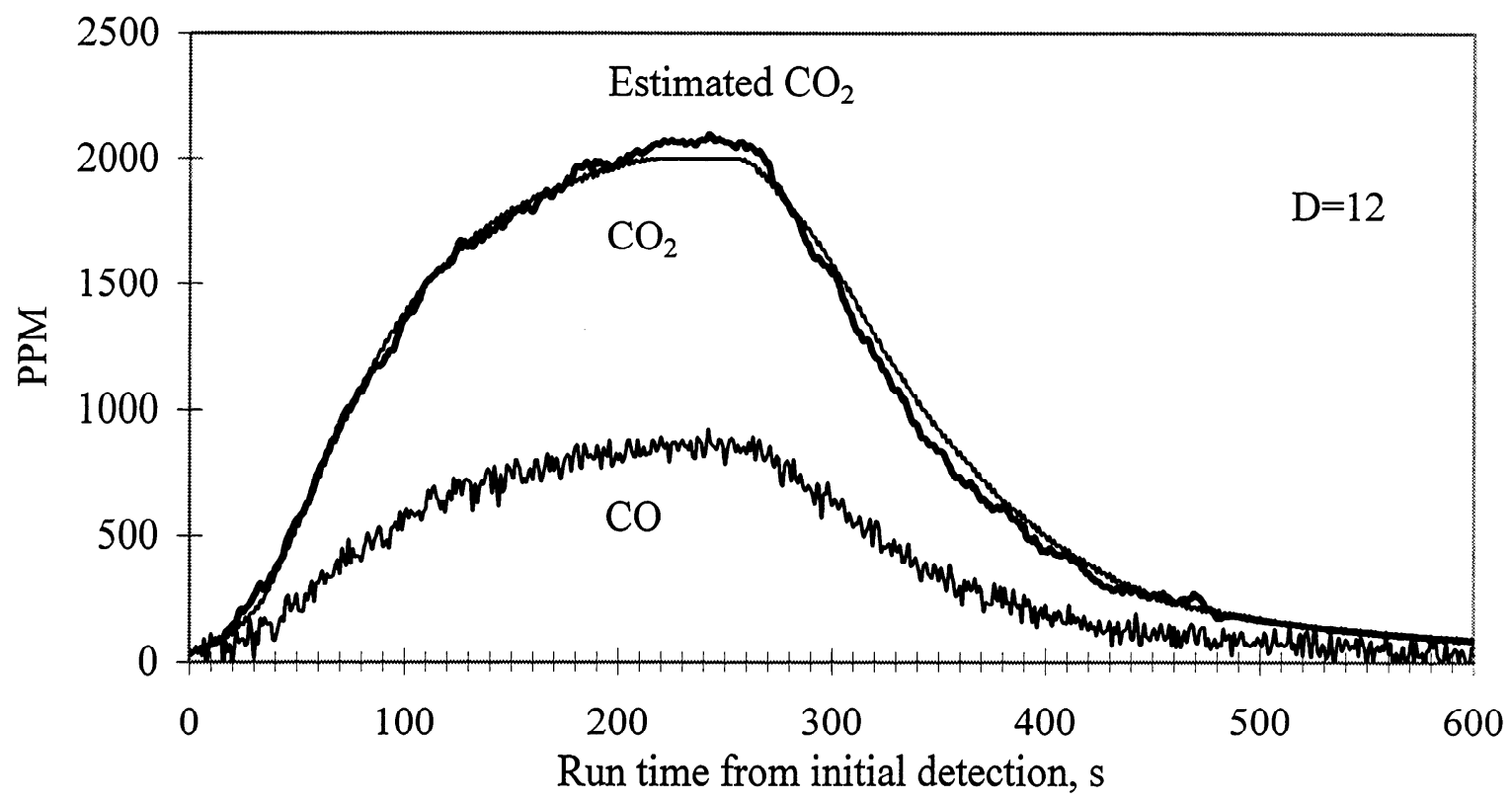

Figure A5.14. Profiles of $\mathrm{CO}$ and $\mathrm{CO}_{2}$ concentrations in the pyrolysis gas obtained without acoustics (RNAC927) under reactor conditions of $550^{\circ} \mathrm{C}, 0.81 \mathrm{~m}$ pyrolysis tube heated length, $2.77 \mathrm{~s}$ particle residence time, and $6.59 \mathrm{~s}$ secondary gas space-time.

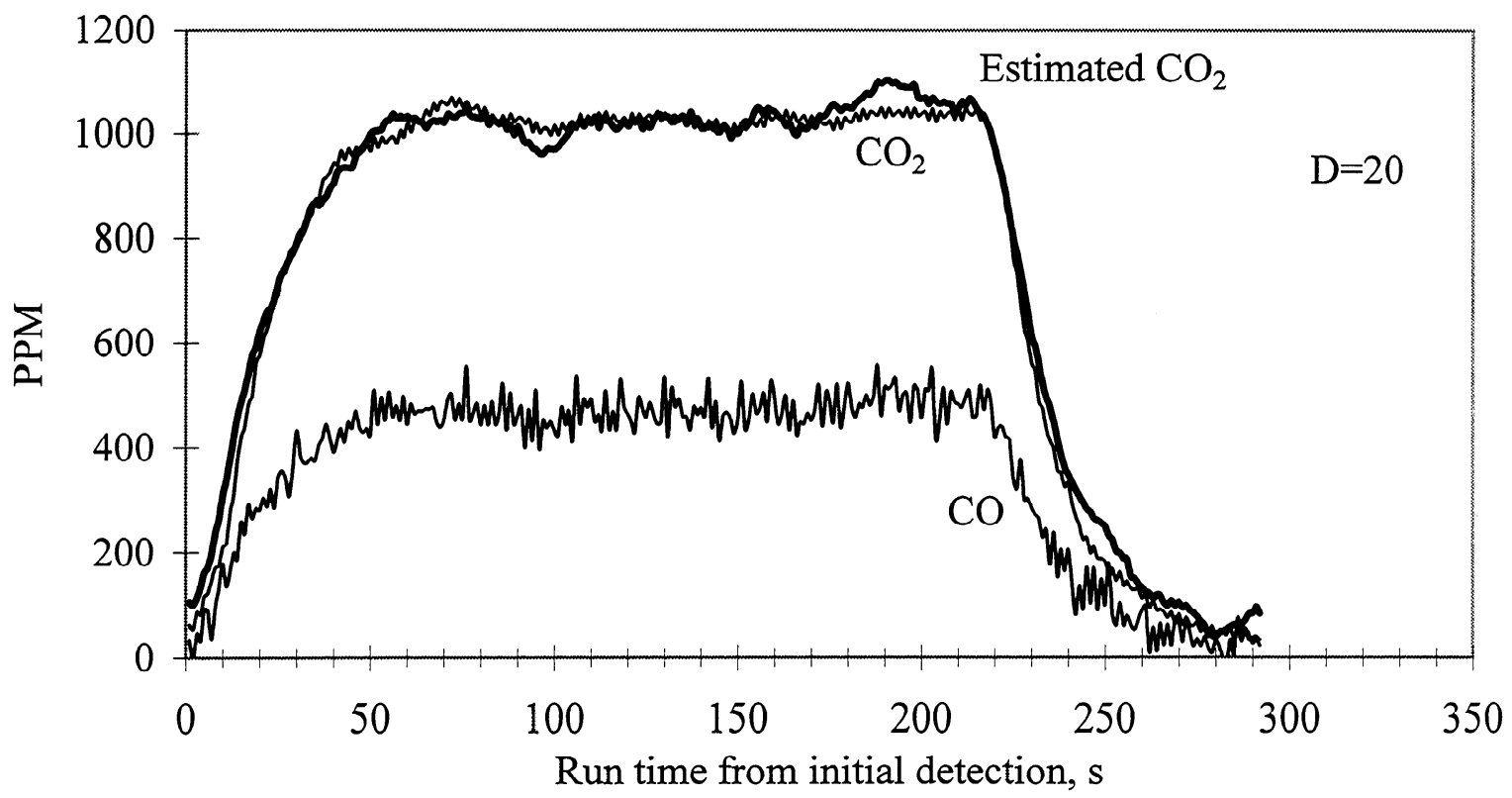

Figure A5.15. Profiles of $\mathrm{CO}$ and $\mathrm{CO}_{2}$ concentrations in the pyrolysis gas obtained with an acoustic field of $146 \mathrm{~dB}$ and $1000 \mathrm{~Hz}$ (RAC925) under reactor conditions of $550^{\circ} \mathrm{C}, 0.81 \mathrm{~m}$ pyrolysis tube heated length, $1.23 \mathrm{~s}$ particle residence time, and $1.72 \mathrm{~s}$ secondary gas space-time. 


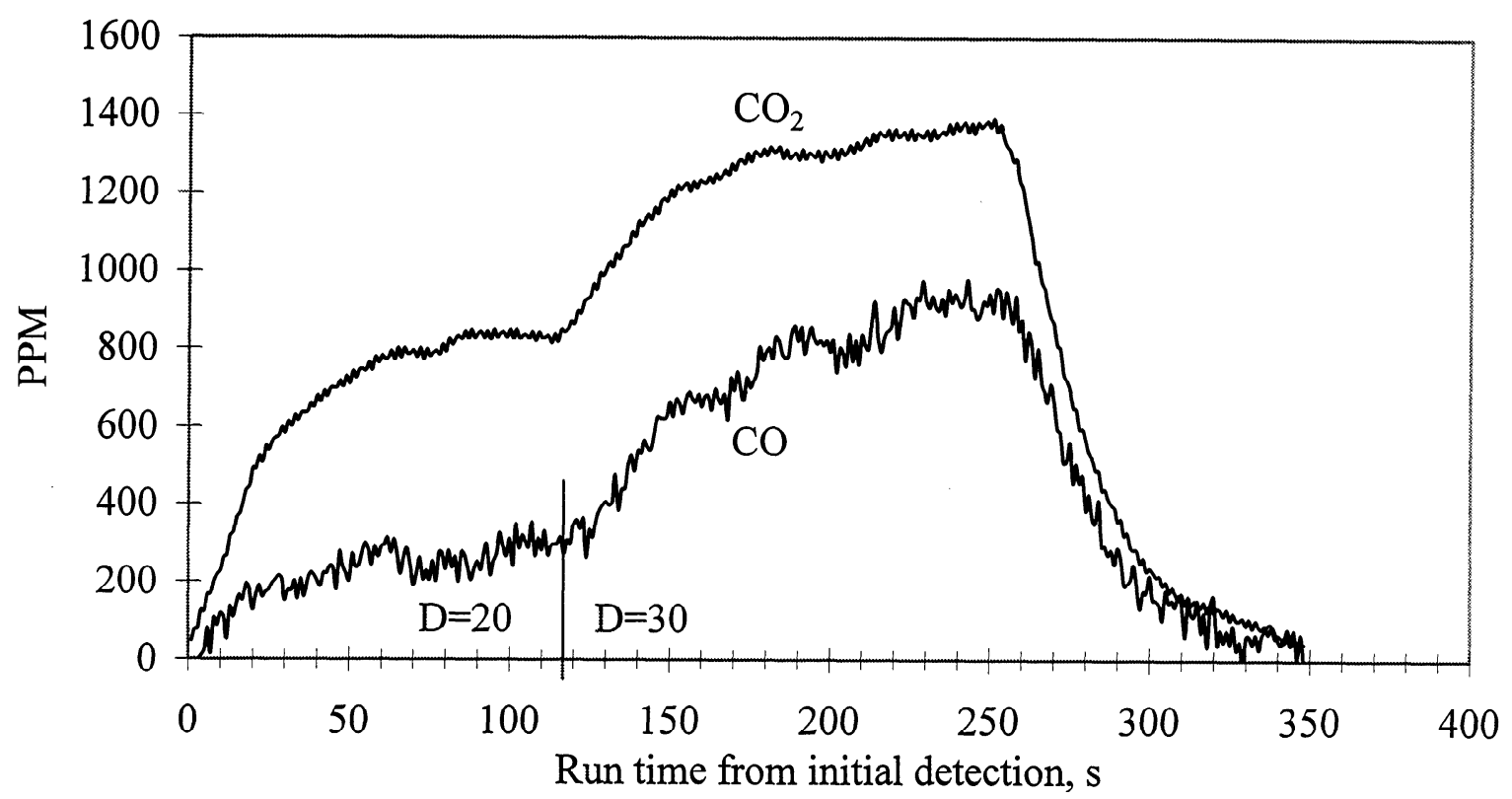

Figure A5.16. Profiles of $\mathrm{CO}$ and $\mathrm{CO}_{2}$ concentrations in the pyrolysis gas obtained with an acoustic field of $151 \mathrm{~dB}$ and $950 \mathrm{~Hz}$ (RAC1106) under reactor conditions of $550^{\circ} \mathrm{C}, 0.18 \mathrm{~m}$ pyrolysis tube heated length, and $0.38 \mathrm{~s}$ secondary gas space-time.

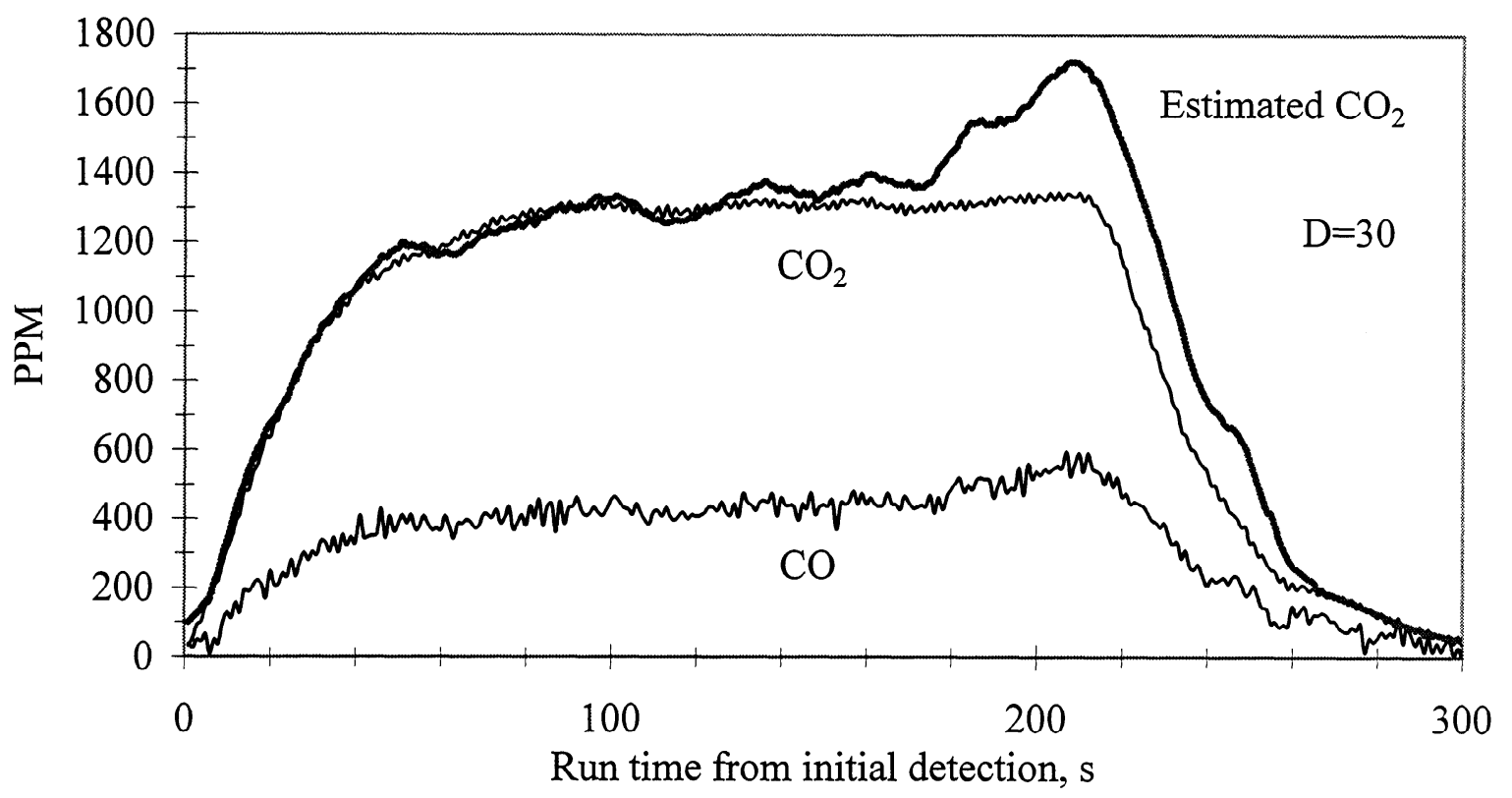

Figure A5.17. Profiles of $\mathrm{CO}$ and $\mathrm{CO}_{2}$ concentrations in the pyrolysis gas obtained with an acoustic field of $151 \mathrm{~dB}$ and $1000 \mathrm{~Hz}$ (RAC1107) under reactor conditions of $550^{\circ} \mathrm{C}, 0.18 \mathrm{~m}$ pyrolysis tube heated length, $0.27 \mathrm{~s}$ particle residence time, and $0.38 \mathrm{~s}$ secondary gas space-time. 


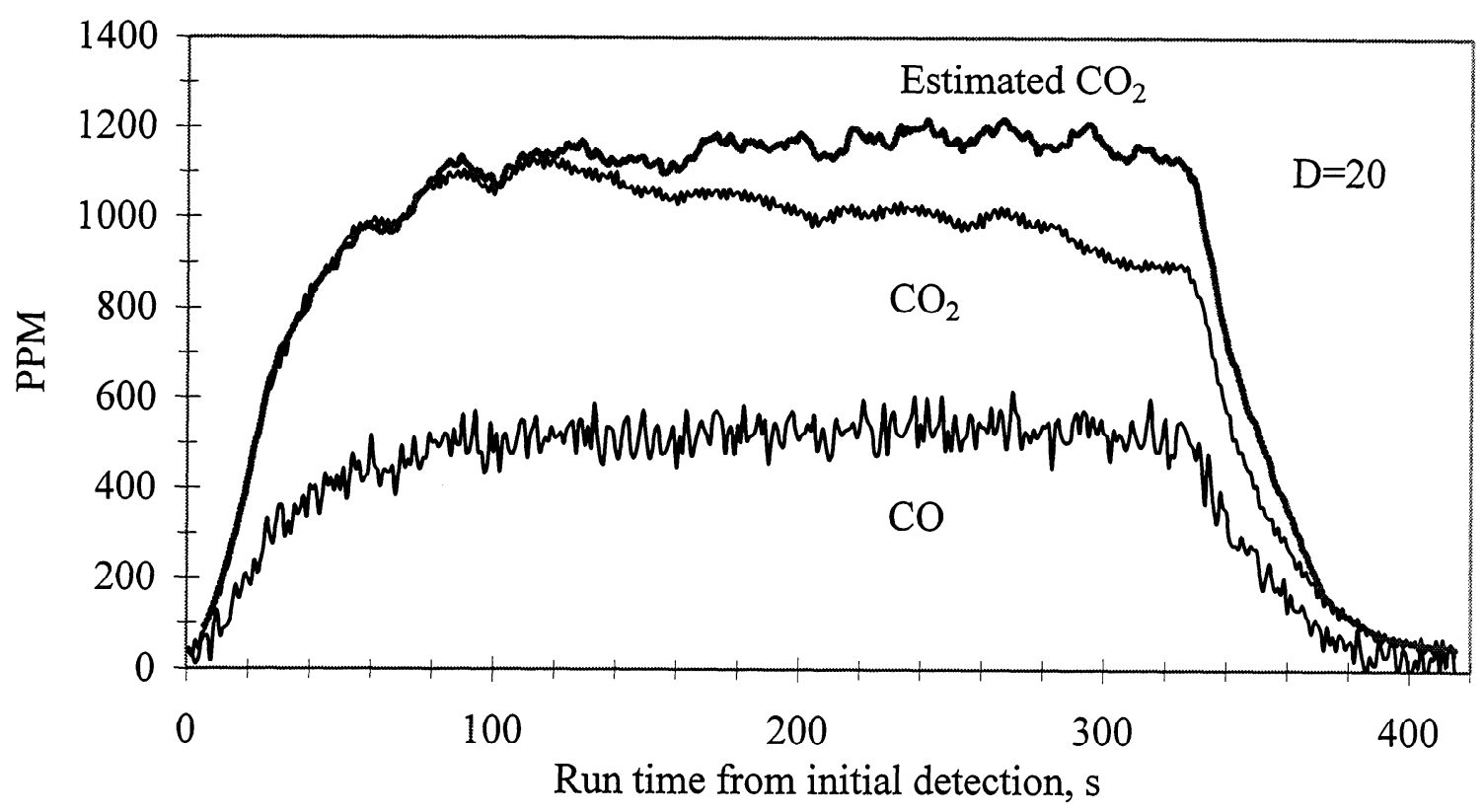

Figure A5.18. Profiles of $\mathrm{CO}$ and $\mathrm{CO}_{2}$ concentrations in the pyrolysis gas obtained with an acoustic field of $151 \mathrm{~dB}$ and $970 \mathrm{~Hz}$ (RAC1108) under reactor conditions of $550^{\circ} \mathrm{C}, 0.48 \mathrm{~m}$ pyrolysis tube heated length, $0.70 \mathrm{~s}$ particle residence time, and $1.02 \mathrm{~s}$ secondary gas space-time.

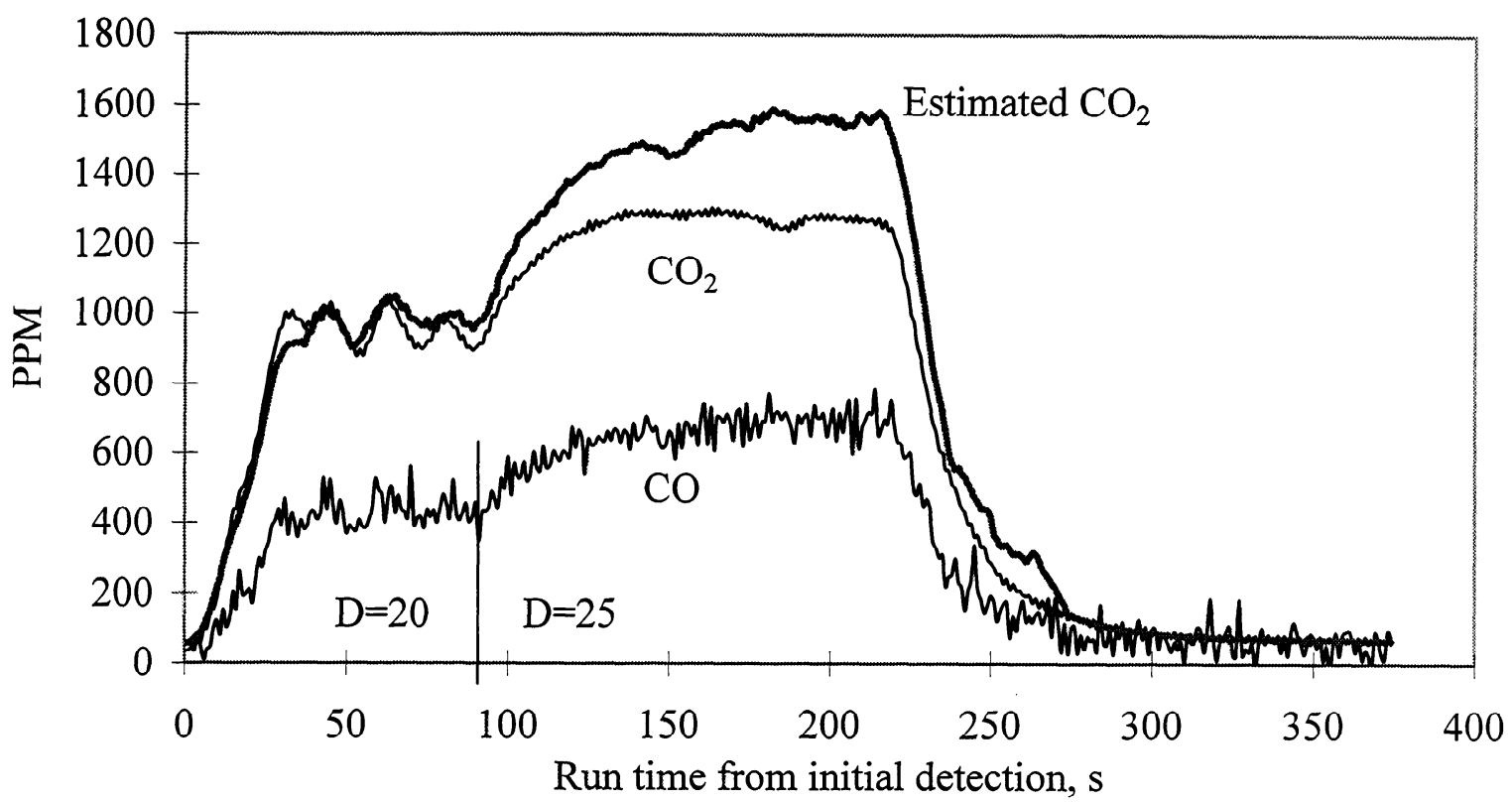

Figure A5.19. Profiles of $\mathrm{CO}$ and $\mathrm{CO}_{2}$ concentrations in the pyrolysis gas obtained with an acoustic field of $151 \mathrm{~dB}$ and $990 \mathrm{~Hz}$ (RAC925B) under reactor conditions of $550^{\circ} \mathrm{C}, 0.81 \mathrm{~m}$ pyrolysis tube heated length, $1.26 \mathrm{~s}$ particle residence time, and $1.72 \mathrm{~s}$ secondary gas space-time. 


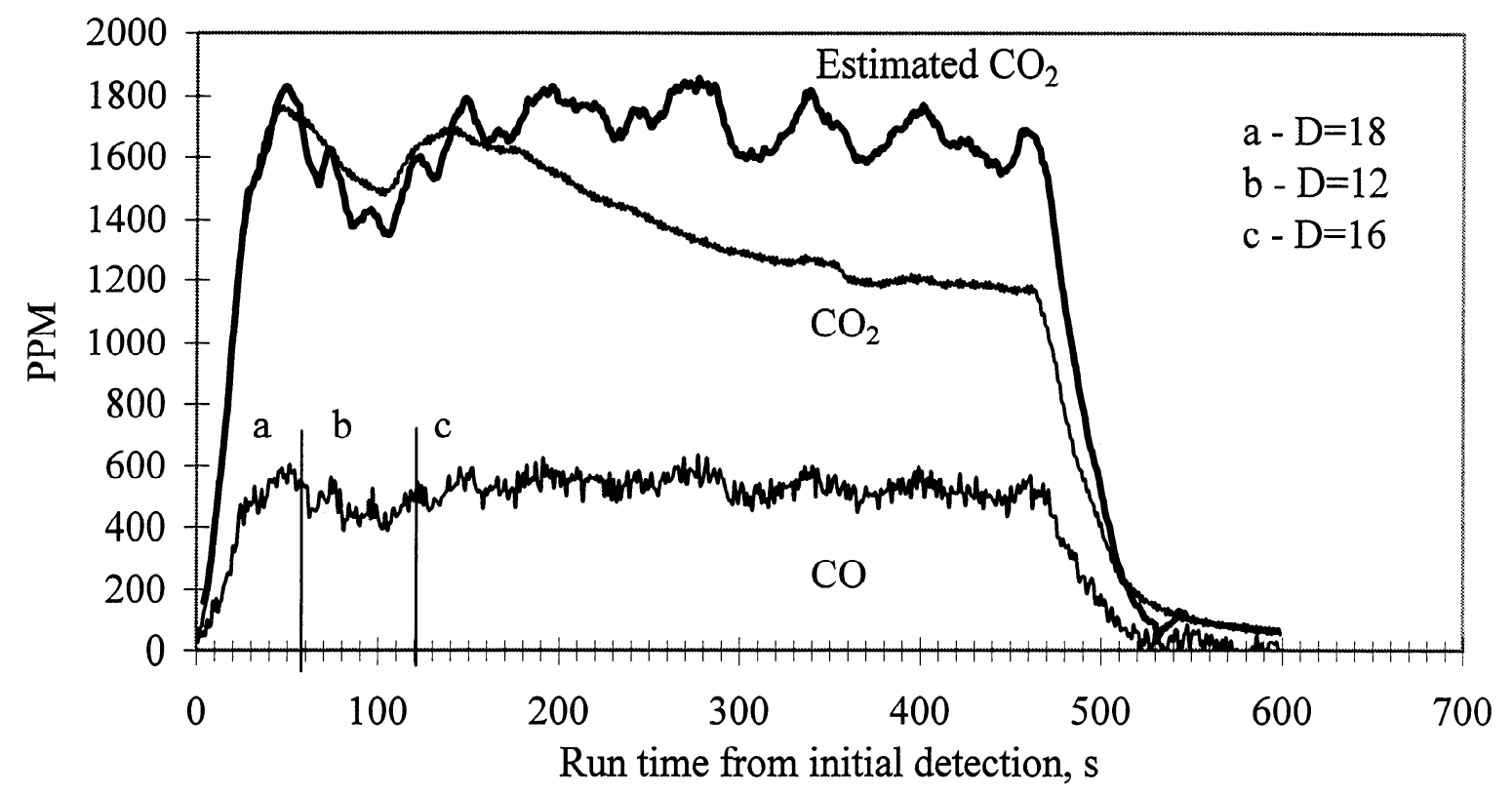

Figure A5.20. Profiles of $\mathrm{CO}$ and $\mathrm{CO}_{2}$ concentrations in the pyrolysis gas obtained with an acoustic field of $151 \mathrm{~dB}$ and $980 \mathrm{~Hz}$ (RAC1230B) under reactor conditions of $550^{\circ} \mathrm{C}, 0.81 \mathrm{~m}$ pyrolysis tube heated length, $10 \mathrm{slpm} \mathrm{N}_{2}$ quench, $2.22 \mathrm{~s}$ particle residence time, and $3.39 \mathrm{~s}$ secondary gas space-time.

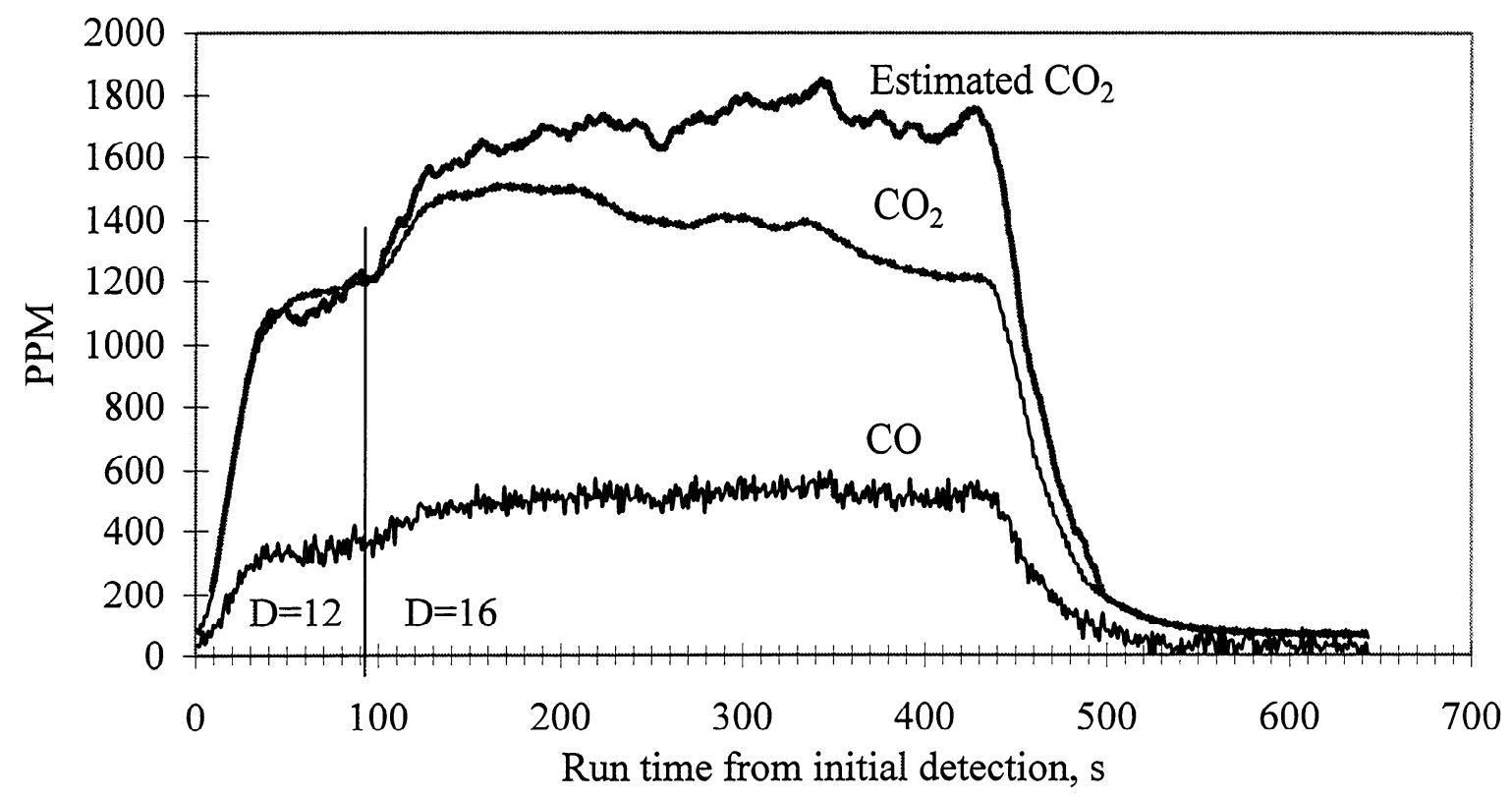

Figure A5.21. Profiles of $\mathrm{CO}$ and $\mathrm{CO}_{2}$ concentrations in the pyrolysis gas obtained with an acoustic field of $151 \mathrm{~dB}$ and $980 \mathrm{~Hz}$ (RAC1226) under reactor conditions of $550^{\circ} \mathrm{C}, 0.81 \mathrm{~m}$ pyrolysis tube heated length, $15 \mathrm{slpm} \mathrm{N}_{2}$ quench, $3.69 \mathrm{~s}$ particle residence time, and $6.59 \mathrm{~s}$ secondary gas space-time. 


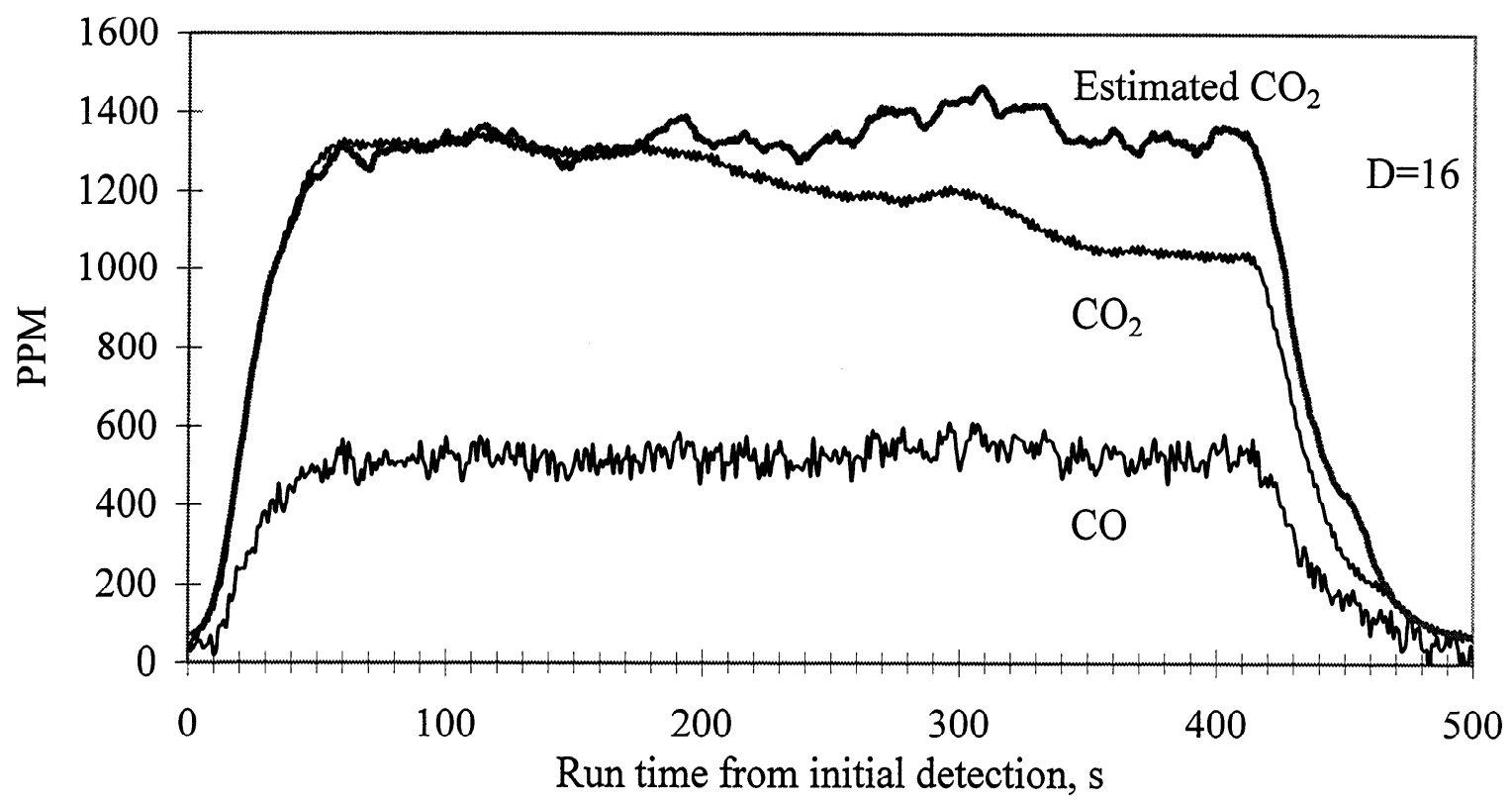

Figure A5.22. Profiles of $\mathrm{CO}$ and $\mathrm{CO}_{2}$ concentrations in the pyrolysis gas obtained with an acoustic field of $151 \mathrm{~dB}$ and $310 \mathrm{~Hz}$ (RAC1231A) under reactor conditions of $550^{\circ} \mathrm{C}, 0.81 \mathrm{~m}$ pyrolysis tube heated length, $1.26 \mathrm{~s}$ particle residence time, and $1.72 \mathrm{~s}$ secondary gas space-time.

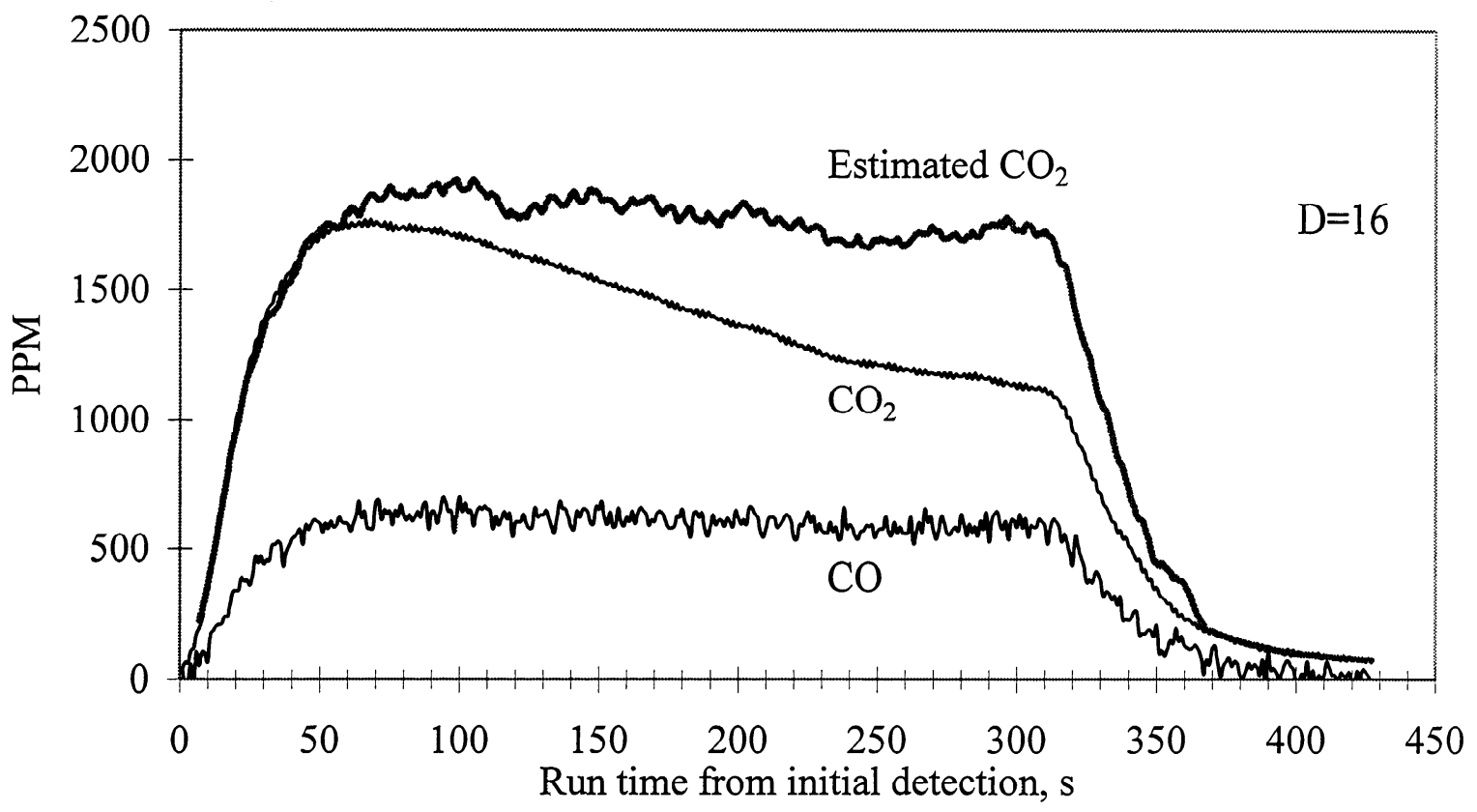

Figure A5.23. Profiles of $\mathrm{CO}$ and $\mathrm{CO}_{2}$ concentrations in the pyrolysis gas obtained with an acoustic field of $151 \mathrm{~dB}$ and $310 \mathrm{~Hz}$ (RAC1231B) under reactor conditions of $550^{\circ} \mathrm{C}, 0.81 \mathrm{~m}$ pyrolysis tube heated length, $10 \mathrm{slpm} \mathrm{N}_{2}$ quench, $2.18 \mathrm{~s}$ particle residence time, and $3.39 \mathrm{~s}$ secondary gas space-time. 


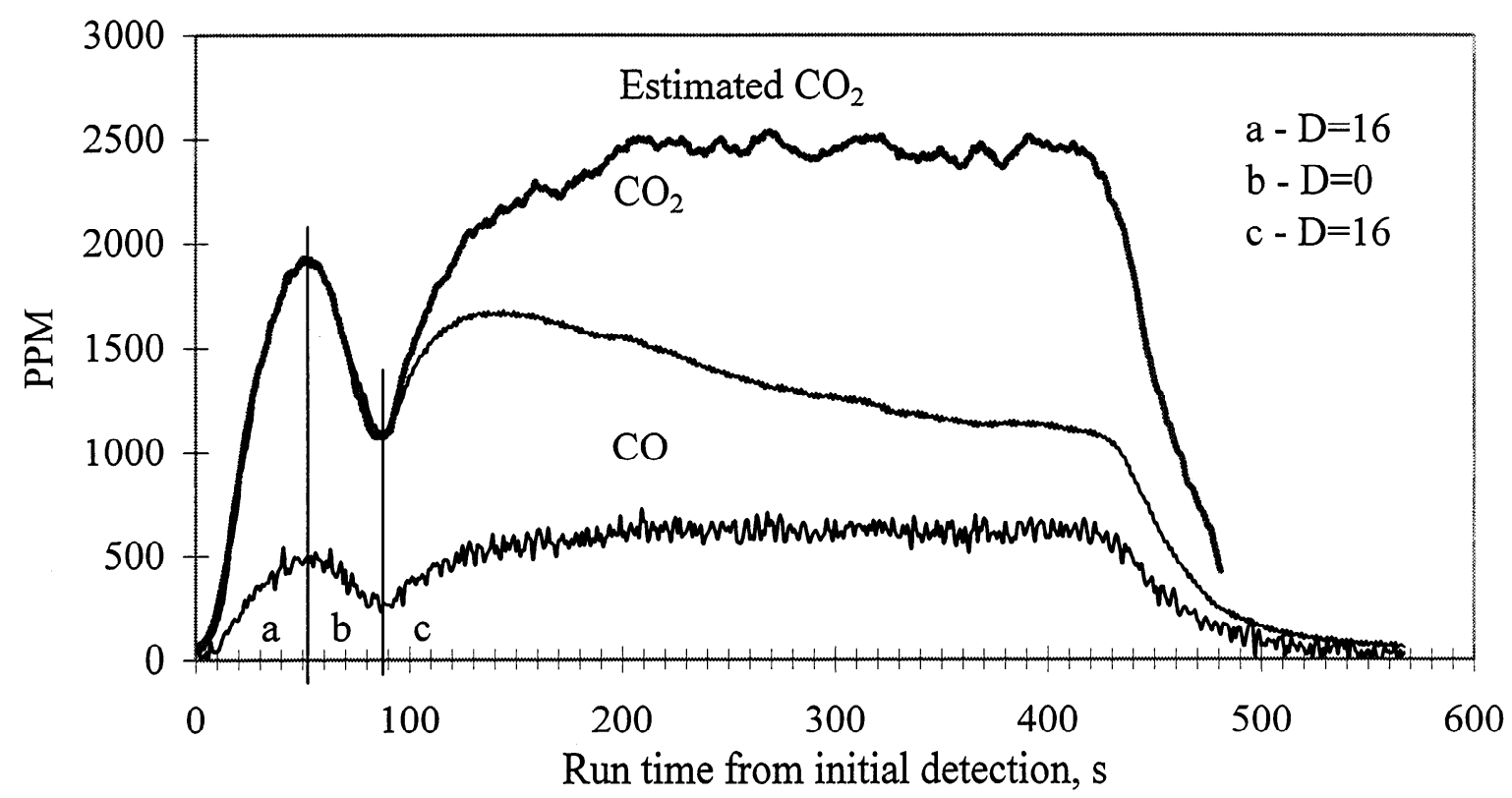

Figure A5.24. Profiles of $\mathrm{CO}$ and $\mathrm{CO}_{2}$ concentrations in the pyrolysis gas obtained with an acoustic field of $151 \mathrm{~dB}$ and $310 \mathrm{~Hz}$ (RAC1231C) under reactor conditions of $550^{\circ} \mathrm{C}, 0.81 \mathrm{~m}$ pyrolysis tube heated length, $15 \mathrm{slpm} \mathrm{N}_{2}$ quench, $3.57 \mathrm{~s}$ particle residence time, and $6.59 \mathrm{~s}$ preheated $\mathrm{N}_{2}$ actual space-time.

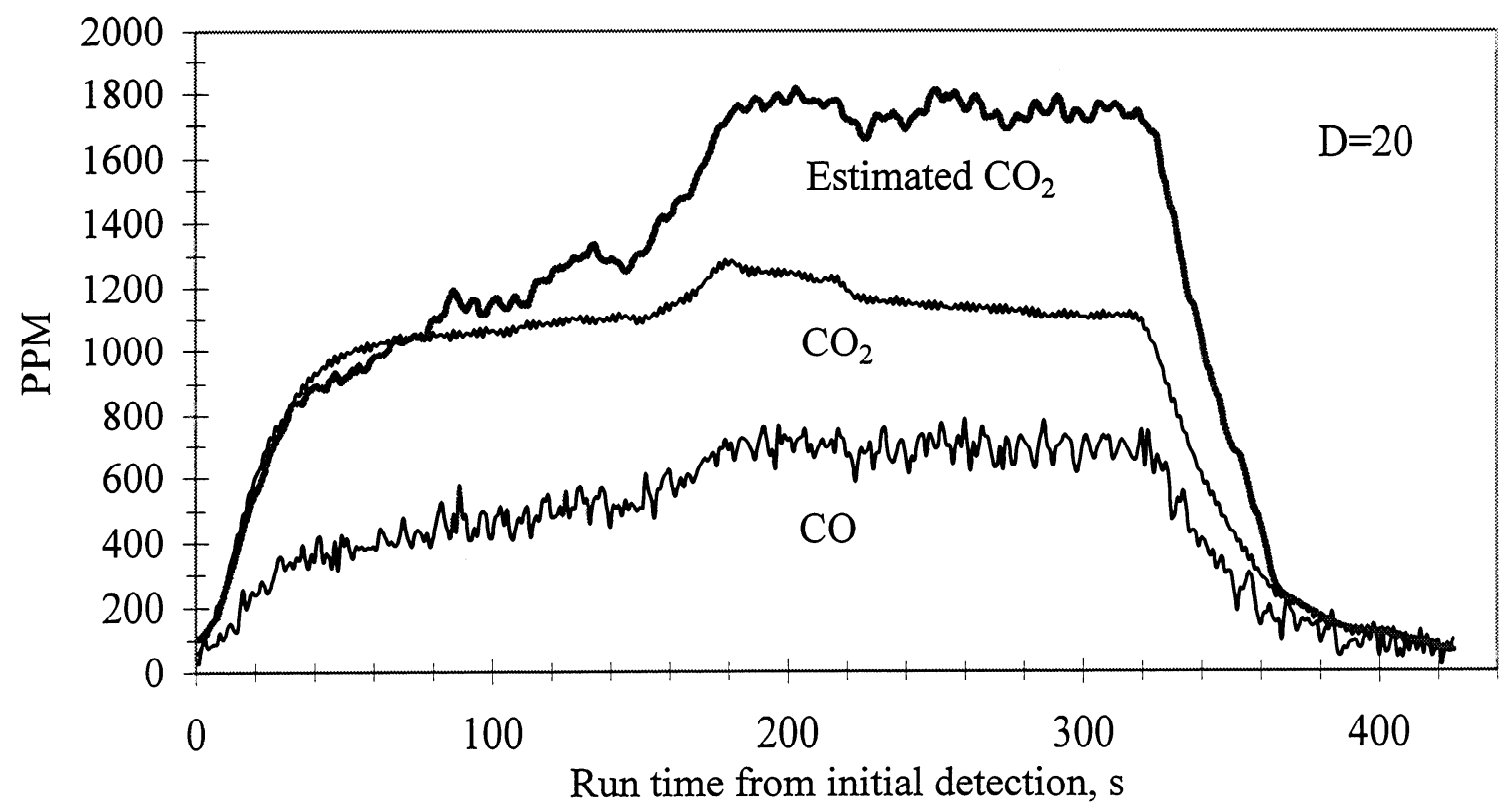

Figure A5.25. Profiles of $\mathrm{CO}$ and $\mathrm{CO}_{2}$ concentrations in the pyrolysis gas obtained with an acoustic field of $154 \mathrm{~dB}$ and $1010 \mathrm{~Hz}$ (RAC1028) under reactor conditions of $550^{\circ} \mathrm{C}, 0.18 \mathrm{~m}$ pyrolysis tube heated length, and $0.38 \mathrm{~s}$ secondary gas space-time. 


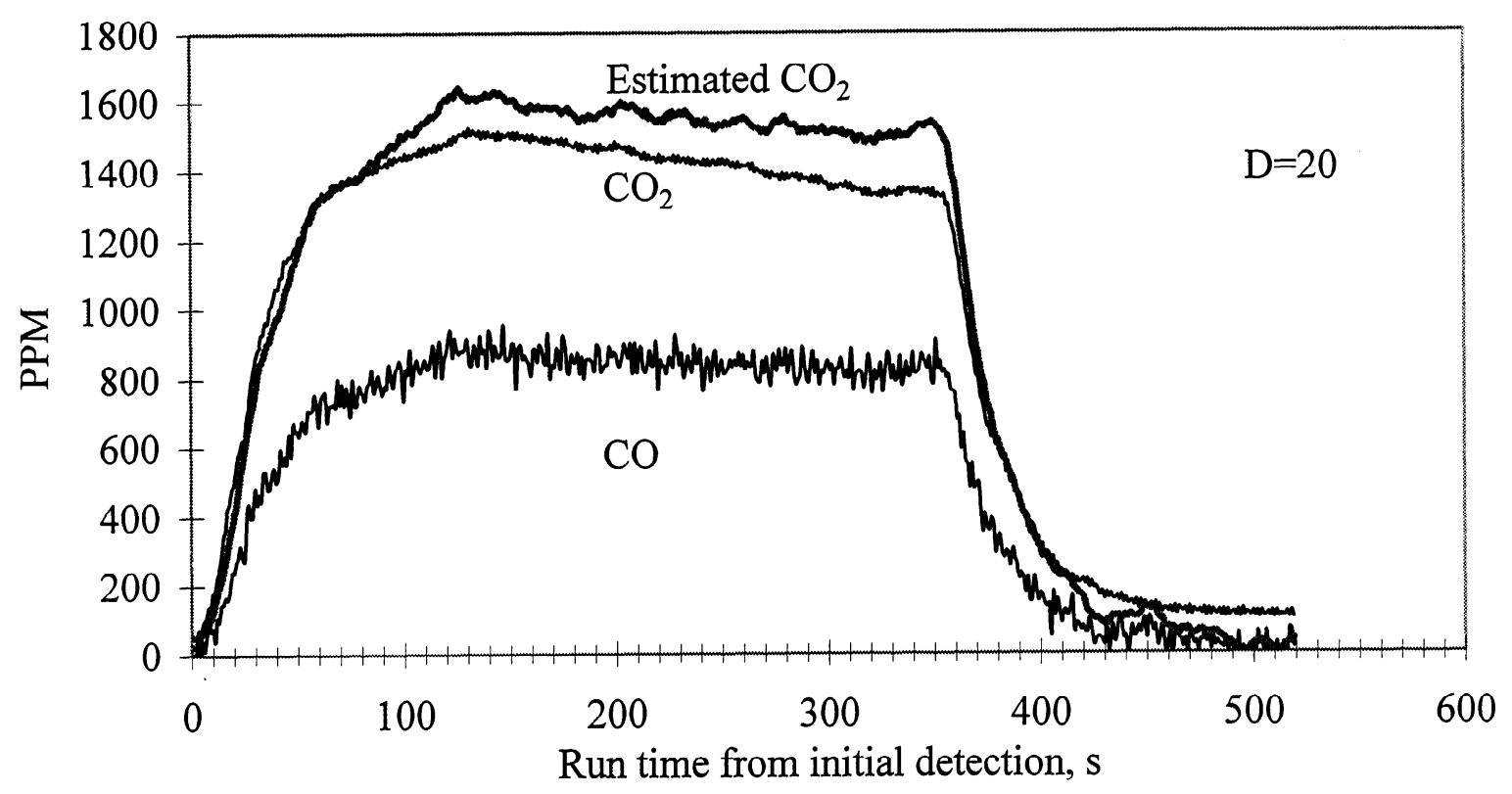

Figure A5.26. Profiles of $\mathrm{CO}$ and $\mathrm{CO}_{2}$ concentrations in the pyrolysis gas obtained with an acoustic field of $154 \mathrm{~dB}$ and $950 \mathrm{~Hz}$ (RAC912) under reactor conditions of $550^{\circ} \mathrm{C}$, $0.81 \mathrm{~m}$ pyrolysis tube heated length, $20 \mathrm{slpm} \mathrm{N}_{2}$ quench, $1.29 \mathrm{~s}$ particle residence time, and $1.72 \mathrm{~s}$ secondary gas space-time.

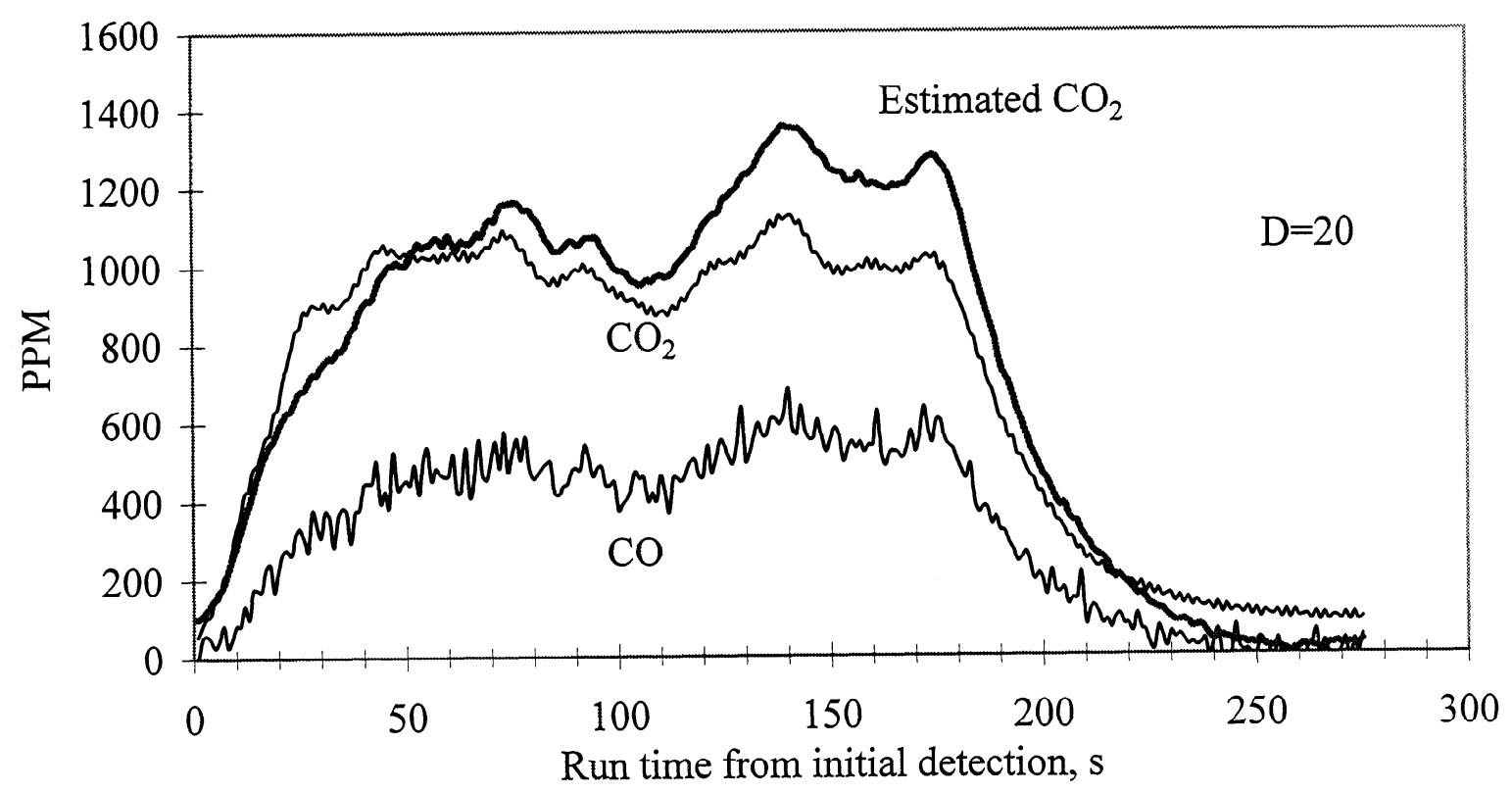

Figure A5.27. Profiles of $\mathrm{CO}$ and $\mathrm{CO}_{2}$ concentrations in the pyrolysis gas obtained with an acoustic field of $154 \mathrm{~dB}$ and $990 \mathrm{~Hz}$ (RAC926) under reactor conditions of $550^{\circ} \mathrm{C}, 0.81 \mathrm{~m}$ pyrolysis tube heated length, $1.29 \mathrm{~s}$ particle residence time, and $1.72 \mathrm{~s}$ secondary gas space-time. 


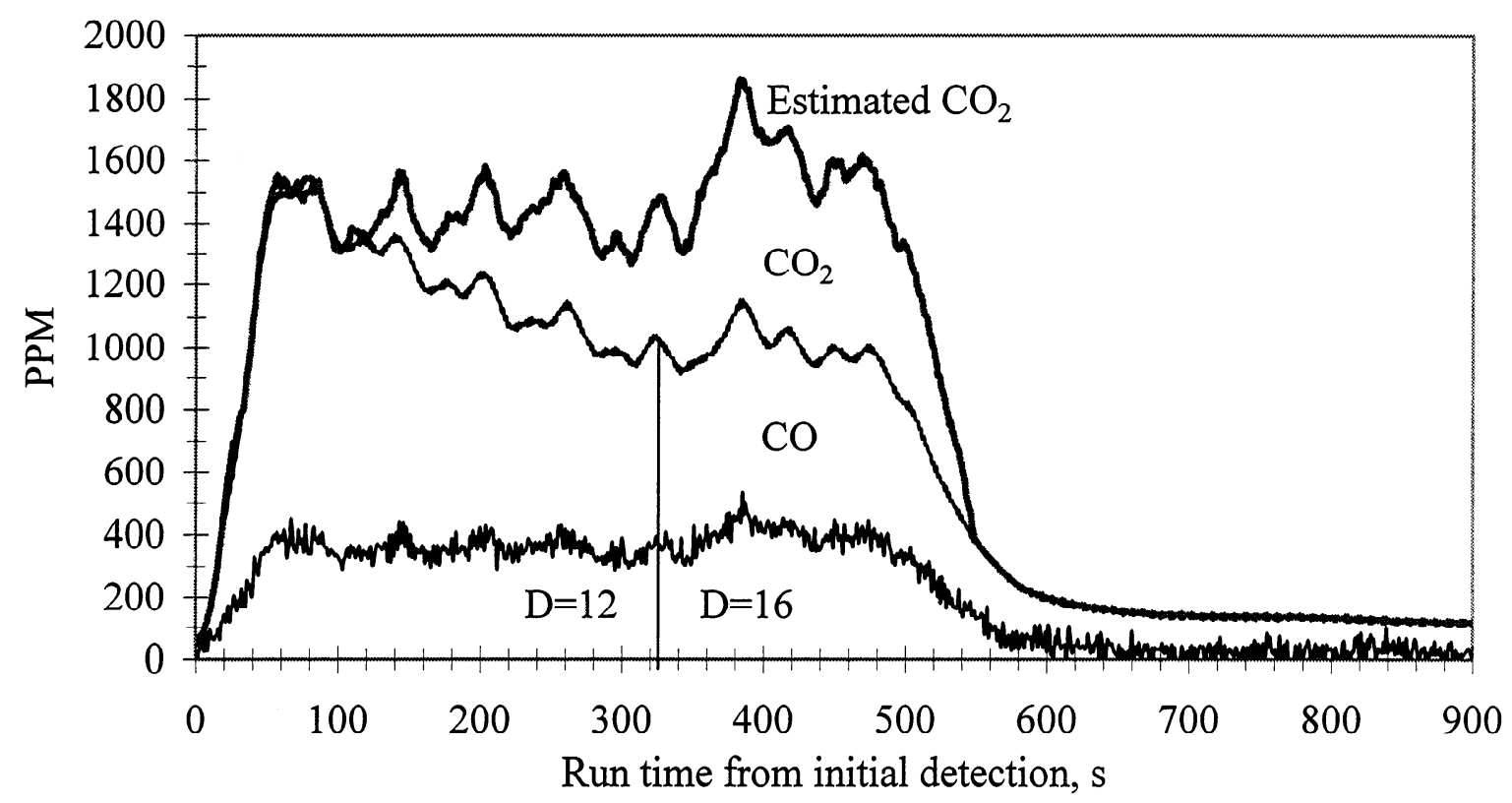

Figure A5.28. Profiles of $\mathrm{CO}$ and $\mathrm{CO}_{2}$ concentrations in the pyrolysis gas obtained with an acoustic field of $154 \mathrm{~dB}$ and $990 \mathrm{~Hz}$ (RAC930) under reactor conditions of $550^{\circ} \mathrm{C}, 0.81 \mathrm{~m}$ pyrolysis tube heated length, $2.27 \mathrm{~s}$ particle residence time, and 3.39 s secondary gas space-time.

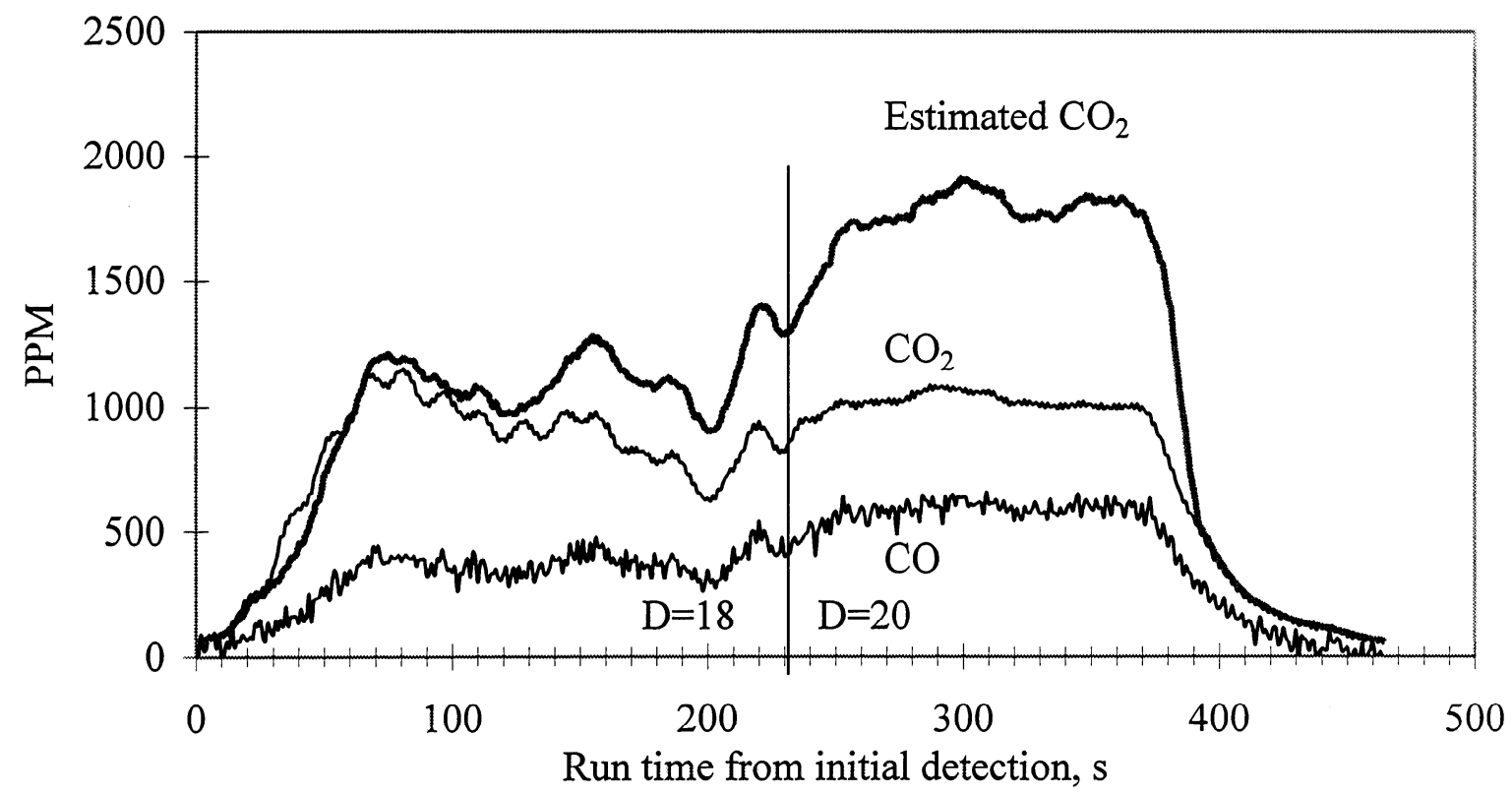

Figure A5.29. Profiles of $\mathrm{CO}$ and $\mathrm{CO}_{2}$ concentrations in the pyrolysis gas obtained with an acoustic field of $154 \mathrm{~dB}$ and $1010 \mathrm{~Hz}$ (RAC1014) under reactor conditions of $530^{\circ} \mathrm{C}, 0.81 \mathrm{~m}$ pyrolysis tube heated length, $1.29 \mathrm{~s}$ particle residence time, and $1.76 \mathrm{~s}$ secondary gas space-time. 


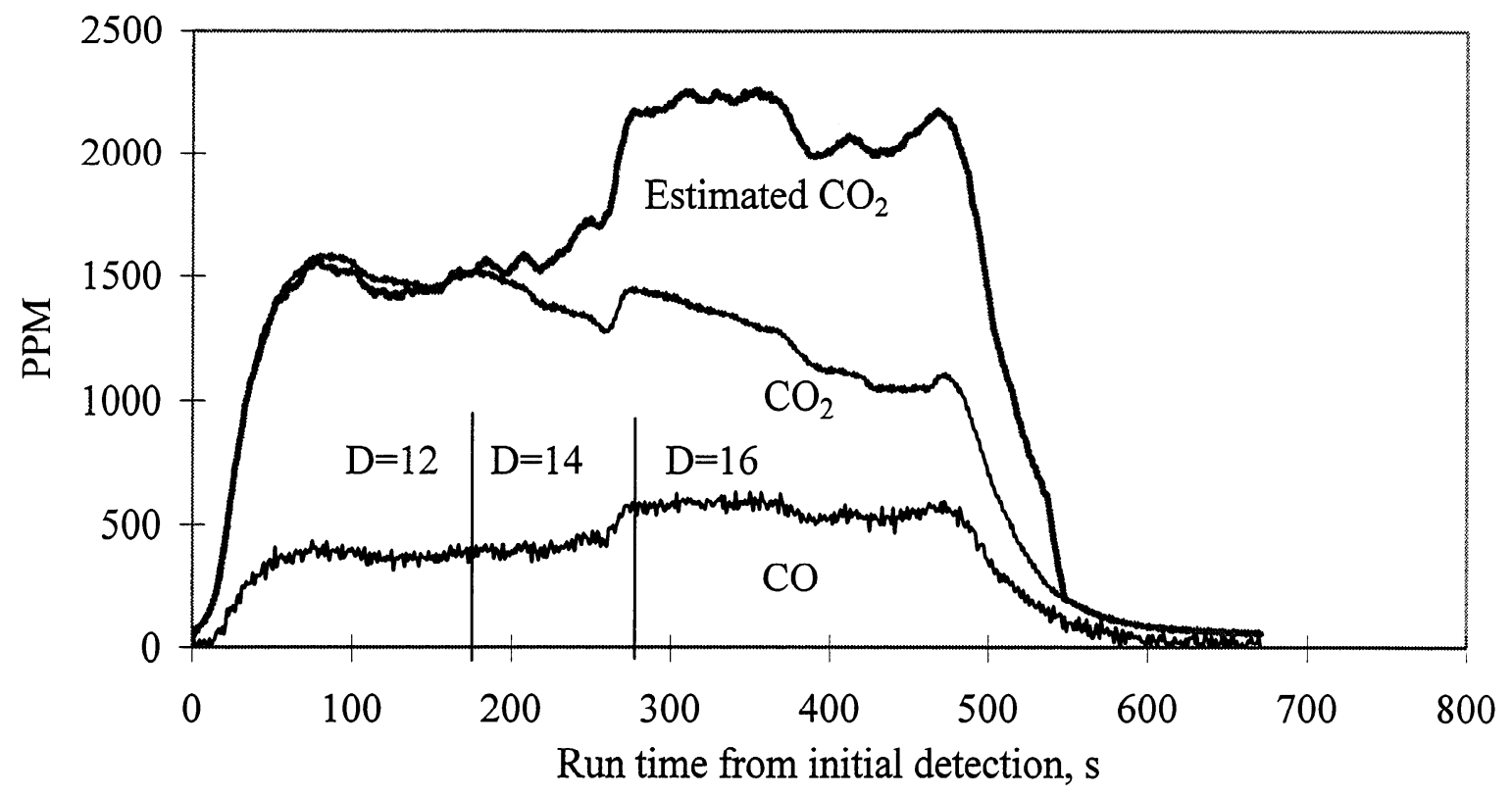

Figure A5.30. Profiles of $\mathrm{CO}$ and $\mathrm{CO}_{2}$ concentrations in the pyrolysis gas obtained with an acoustic field of $154 \mathrm{~dB}$ and $960 \mathrm{~Hz}$ (RAC1227A) under reactor conditions of $550^{\circ} \mathrm{C}, 0.81 \mathrm{~m}$ pyrolysis tube heated length, $15 \mathrm{slpm} \mathrm{N}_{2}$ quench, $3.88 \mathrm{~s}$ particle residence time, and $6.59 \mathrm{~s}$ secondary gas space-time.

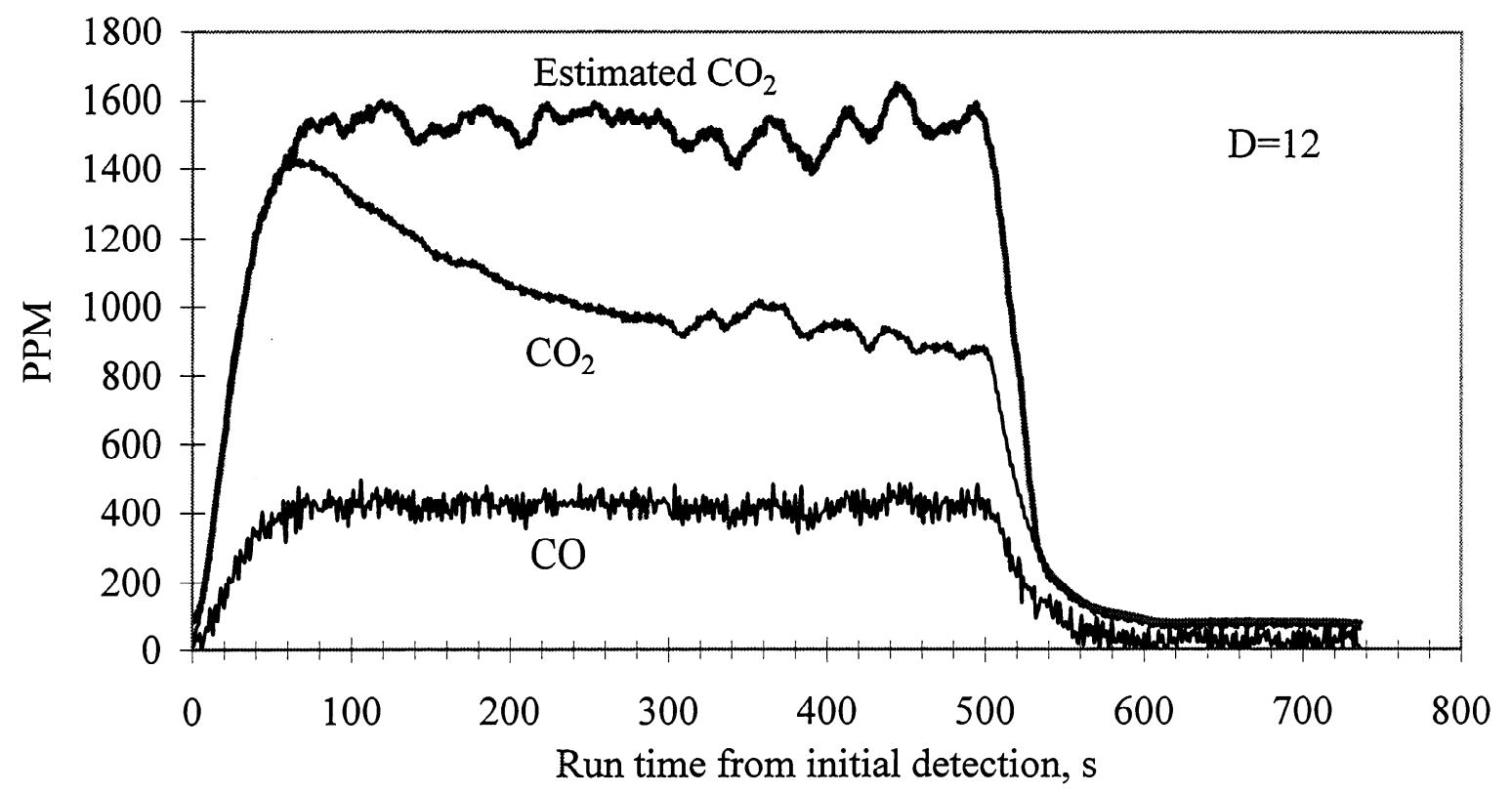

Figure A5.31. Profiles of $\mathrm{CO}$ and $\mathrm{CO}_{2}$ concentrations in the pyrolysis gas obtained with an acoustic field of $158 \mathrm{~dB}$ and $970 \mathrm{~Hz}$ (RAC1207) under reactor conditions of $550^{\circ} \mathrm{C}, 0.81 \mathrm{~m}$ pyrolysis tube heated length, $1.37 \mathrm{~s}$ particle residence time, and $1.72 \mathrm{~s}$ secondary gas space-time. 


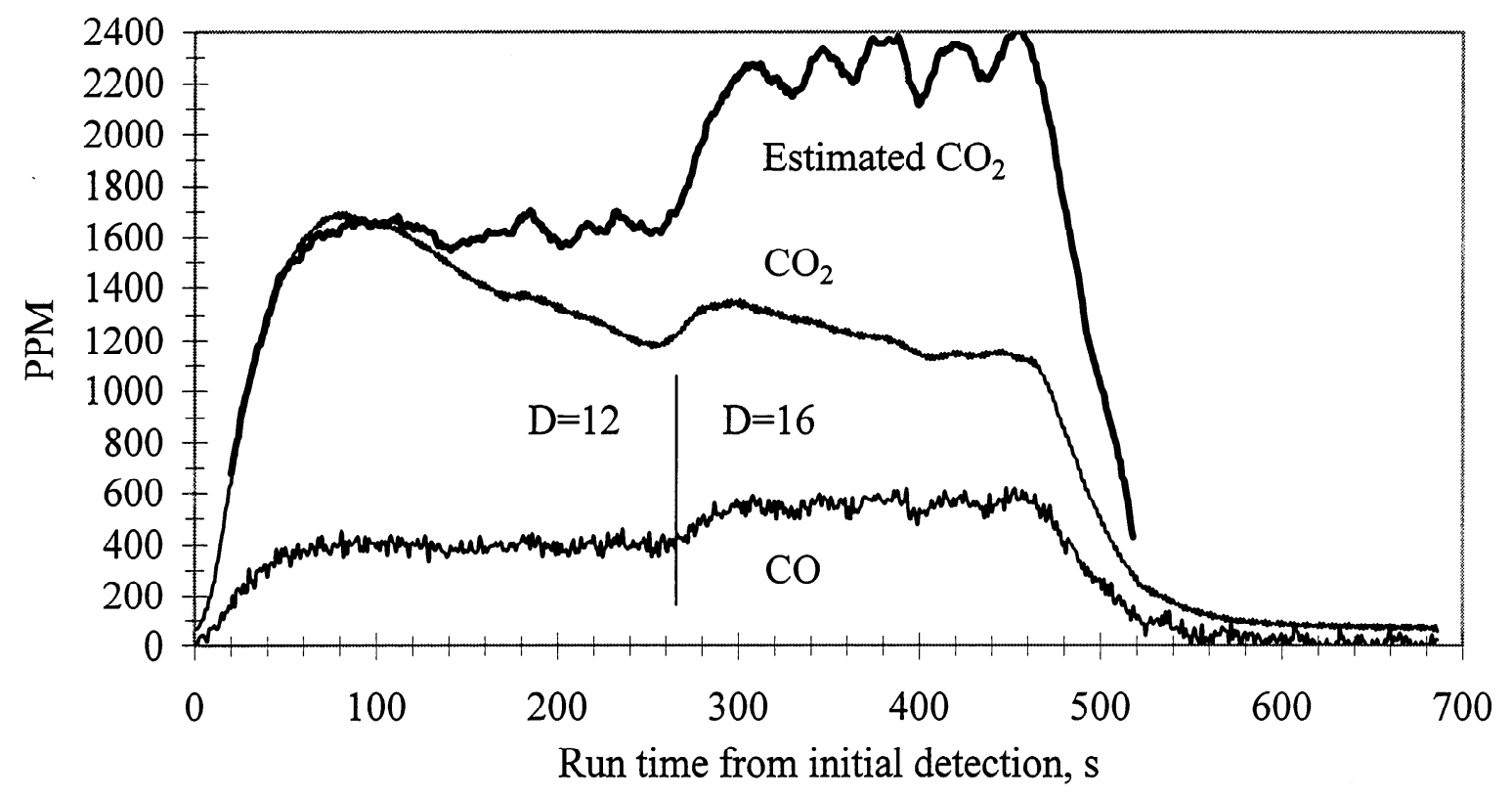

Figure A5.32. Profiles of $\mathrm{CO}$ and $\mathrm{CO}_{2}$ concentrations in the pyrolysis gas obtained with an acoustic field of $159.5 \mathrm{~dB}$ and $970 \mathrm{~Hz}$ (RAC1227B) under reactor conditions of $550^{\circ} \mathrm{C}, 0.81 \mathrm{~m}$ pyrolysis tube heated length, $10 \mathrm{slpm} \mathrm{N}_{2}$ quench, $3.91 \mathrm{~s}$ particle residence time, and $3.39 \mathrm{~s}$ secondary gas space-time.

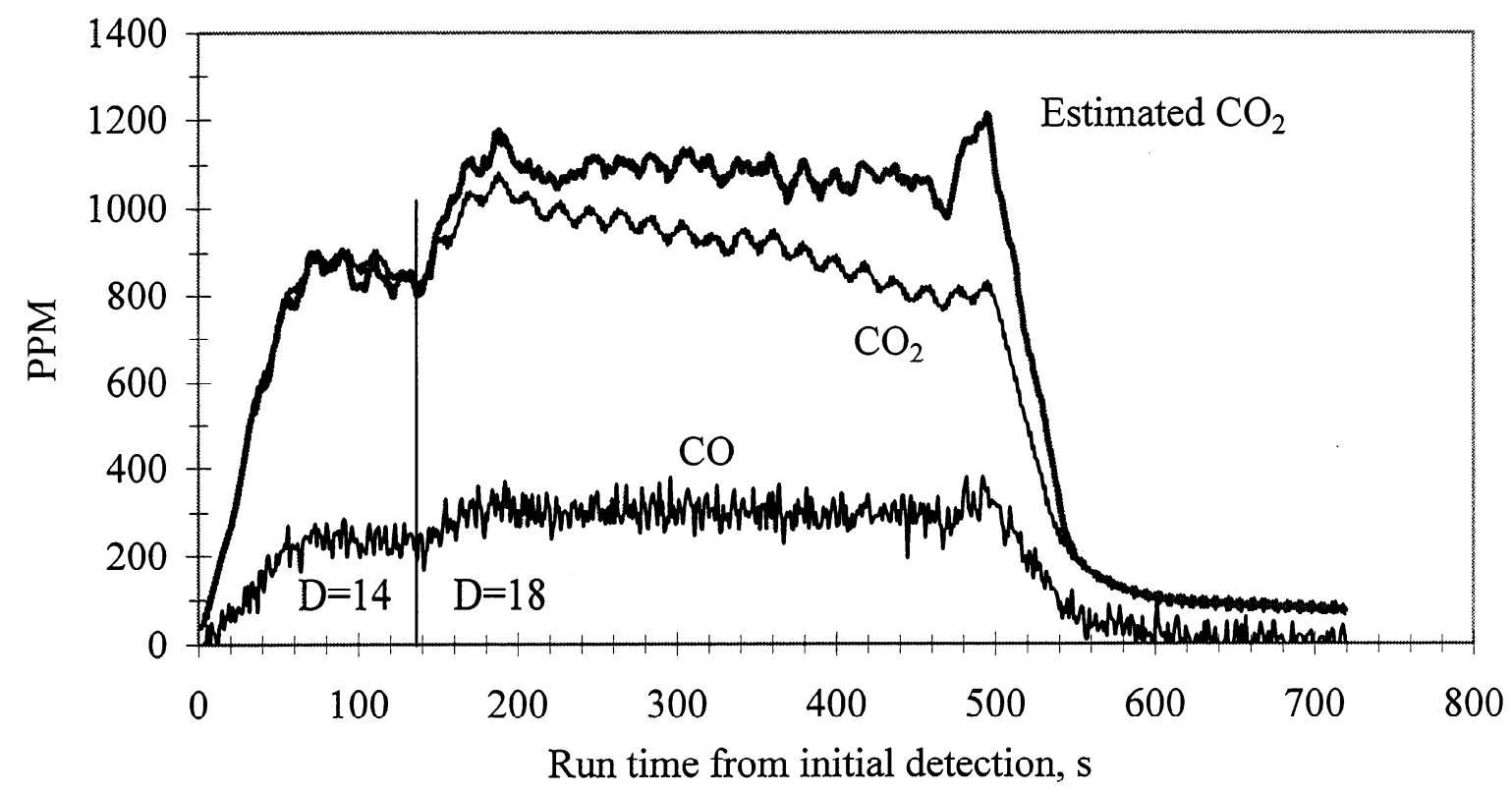

Figure A5.33. Profiles of $\mathrm{CO}$ and $\mathrm{CO}_{2}$ concentrations in the pyrolysis gas obtained with an acoustic field of $159.5 \mathrm{~dB}$ and $970 \mathrm{~Hz}$ (RAC1230) under reactor conditions of $550^{\circ} \mathrm{C}, 0.81 \mathrm{~m}$ pyrolysis tube heated length, $10 \mathrm{slpm} \mathrm{N}_{2}$ quench, 3.91 particle residence time, $3.39 \mathrm{~s}$ secondary gas space-time, and pulsed feeding of BLS particles. 


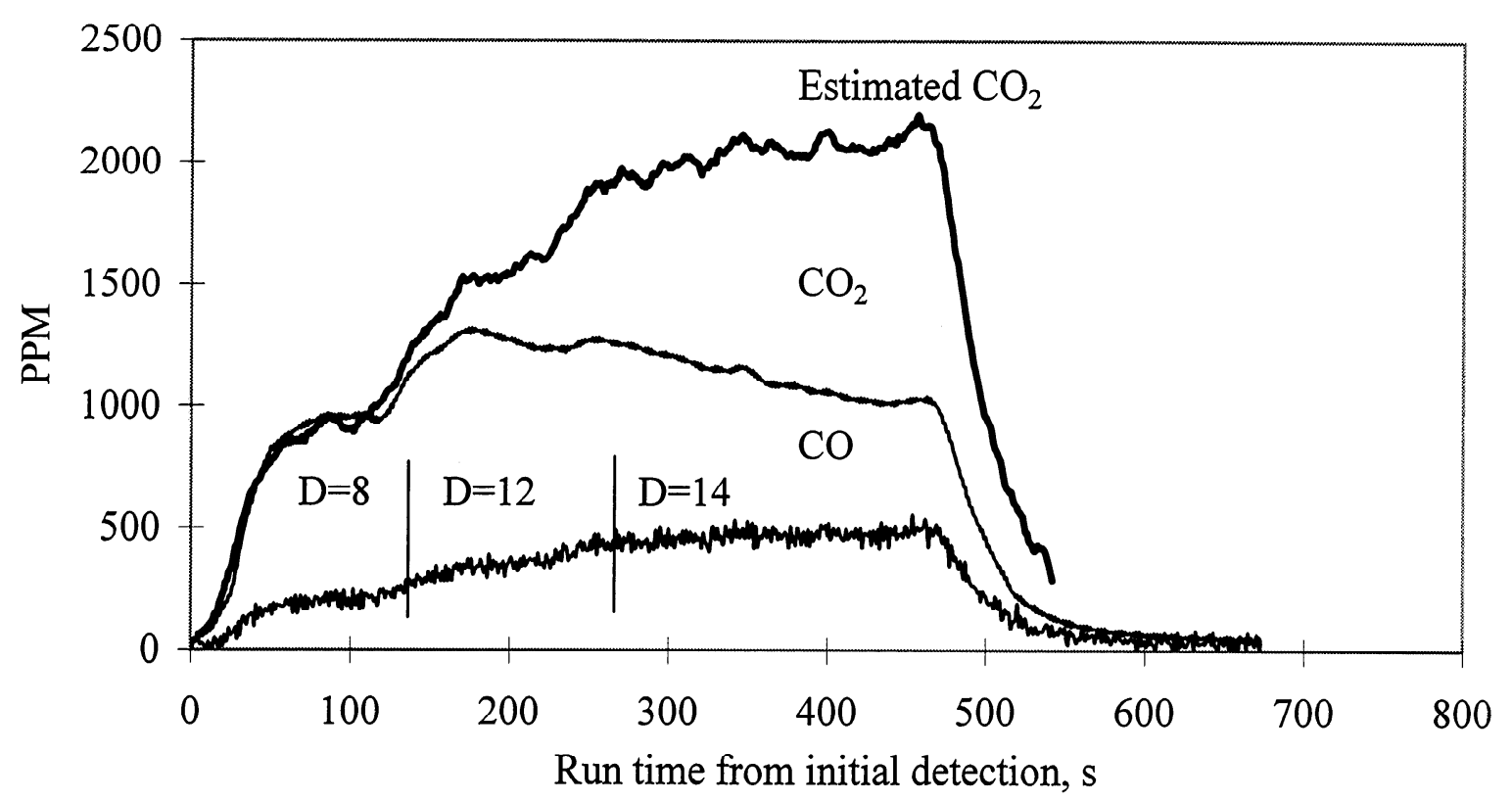

Figure A5.34. Profiles of $\mathrm{CO}$ and $\mathrm{CO}_{2}$ concentrations in the pyrolysis gas obtained with an acoustic field of $158 \mathrm{~dB}$ and $970 \mathrm{~Hz}$ (RAC1224) under reactor conditions of $550^{\circ} \mathrm{C}, 0.81 \mathrm{~m}$ pyrolysis tube heated length, $15 \mathrm{slpm} \mathrm{N}_{2}$ quench, very long particle residence time, and $6.59 \mathrm{~s}$ secondary gas space-time.

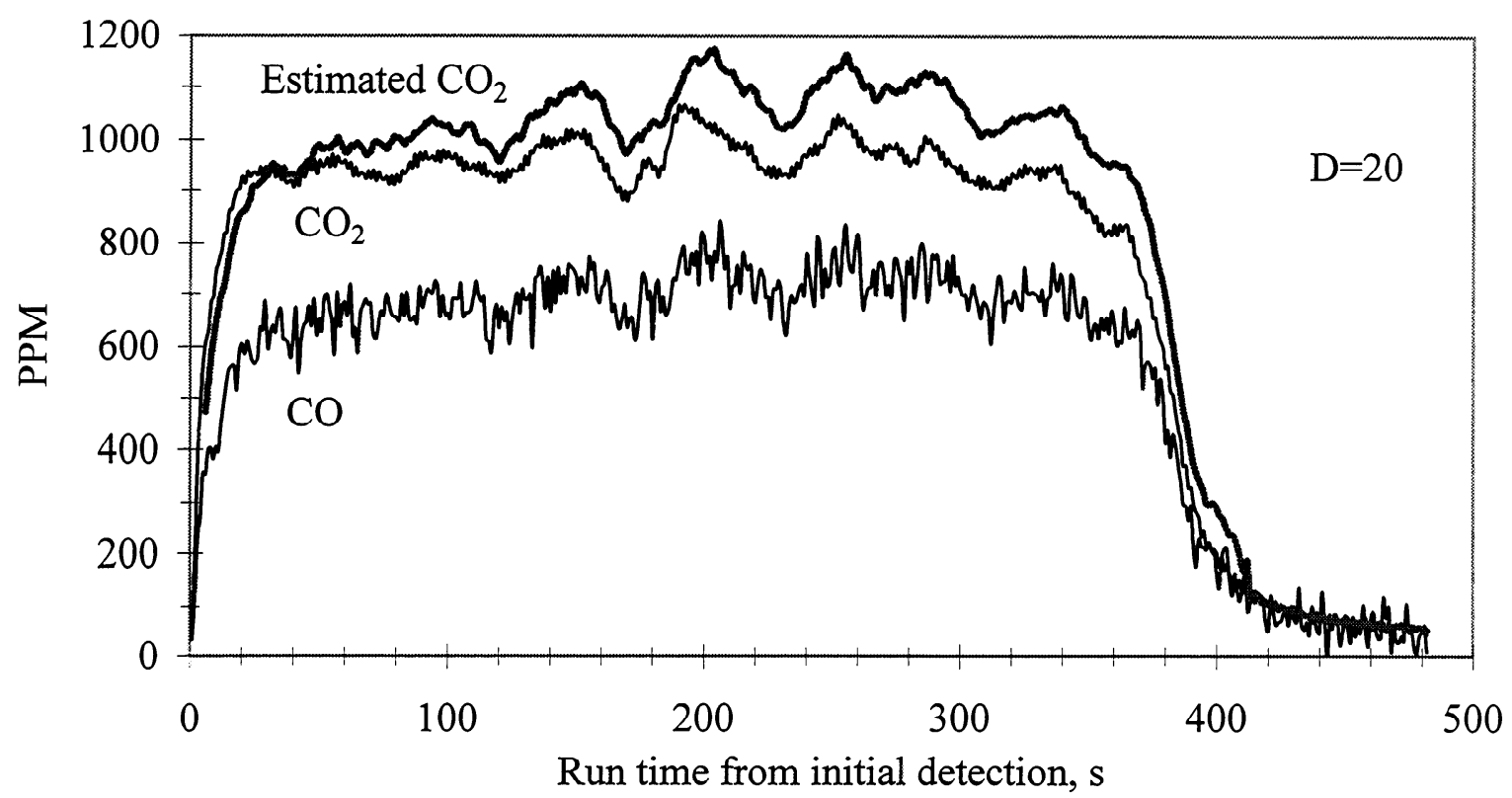

Figure A5.35. Profiles of $\mathrm{CO}$ and $\mathrm{CO}_{2}$ concentrations in the pyrolysis gas obtained with a steelwool-plug located at $0.13 \mathrm{~m}$ (RNAC1017) under reactor conditions of $550^{\circ} \mathrm{C}$, $0.18 \mathrm{~m}$ pyrolysis tube heated length, and $0.38 \mathrm{~s}$ secondary gas space-time. 


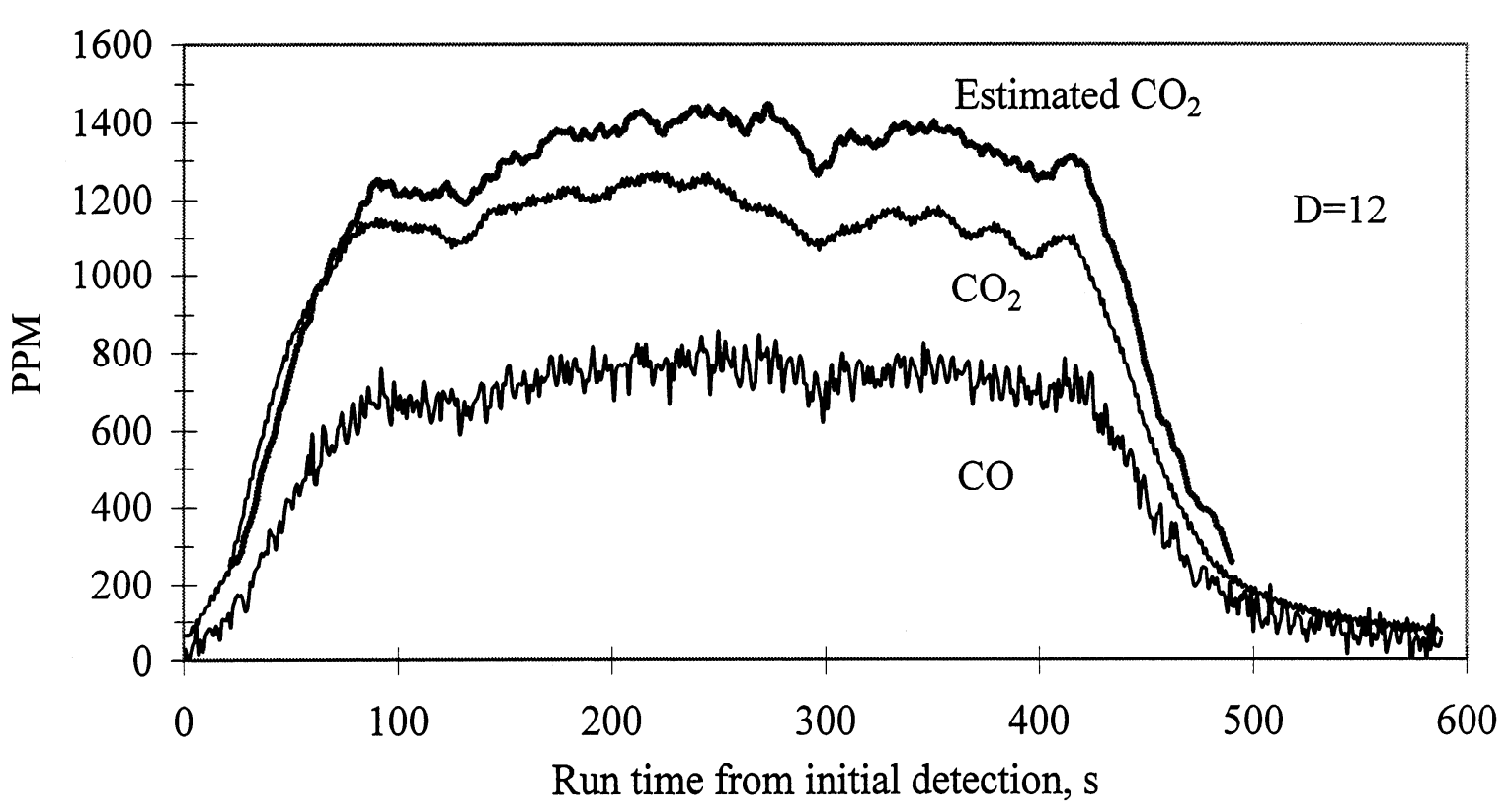

Figure A5.36. Profiles of $\mathrm{CO}$ and $\mathrm{CO}_{2}$ concentrations in the pyrolysis gas obtained with a steelwool-plug located at $0.13 \mathrm{~m}(\mathrm{RNAC1022})$ under reactor conditions of $550^{\circ} \mathrm{C}$, $0.18 \mathrm{~m}$ pyrolysis tube heated length, and $0.75 \mathrm{~s}$ secondary gas space-time.

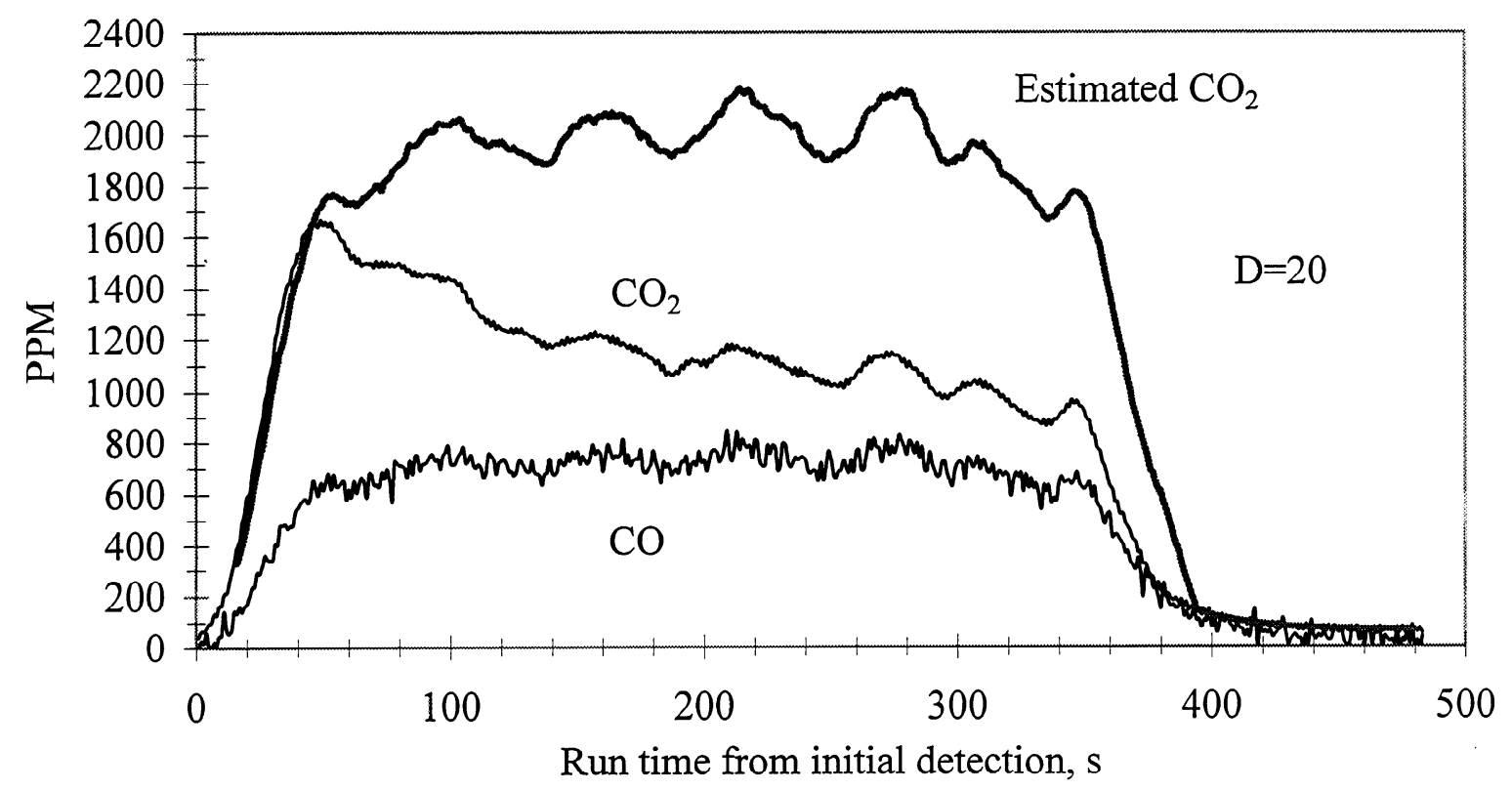

Figure A5.37. Profiles of $\mathrm{CO}$ and $\mathrm{CO}_{2}$ concentrations in the pyrolysis gas obtained with a steelwool-plug located at $0.13 \mathrm{~m}$ (RNAC1023) under reactor conditions of $550^{\circ} \mathrm{C}$, $0.81 \mathrm{~m}$ pyrolysis tube heated length, and $1.72 \mathrm{~s}$ secondary gas space-time. 


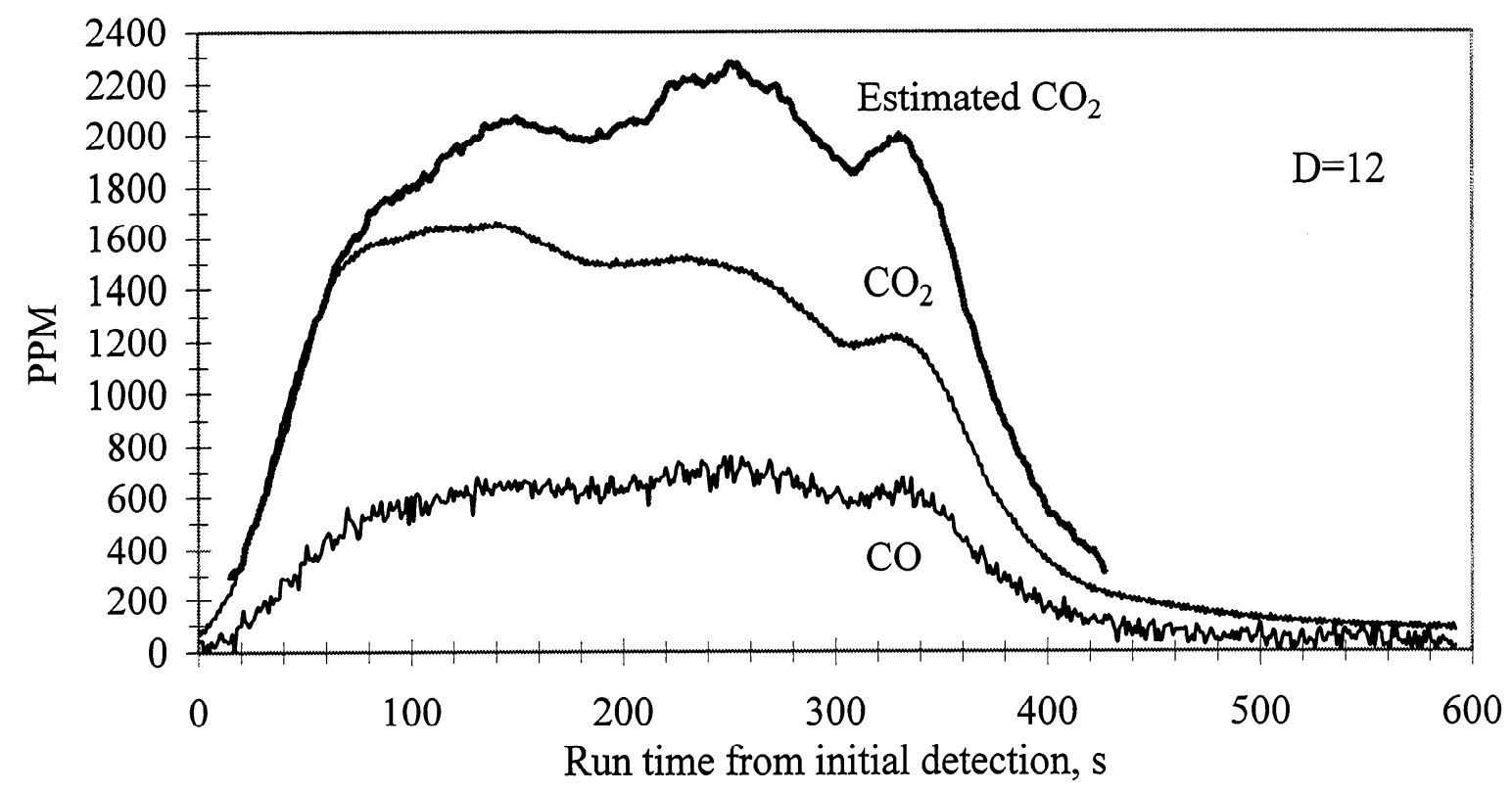

Figure A5.38. Profiles of $\mathrm{CO}$ and $\mathrm{CO}_{2}$ concentrations in the pyrolysis gas obtained with a steelwool-plug located at $0.13 \mathrm{~m}$ (RNAC1019) under reactor conditions of $550^{\circ} \mathrm{C}$, $0.81 \mathrm{~m}$ pyrolysis tube heated length, and $3.39 \mathrm{~s}$ secondary gas space-time.

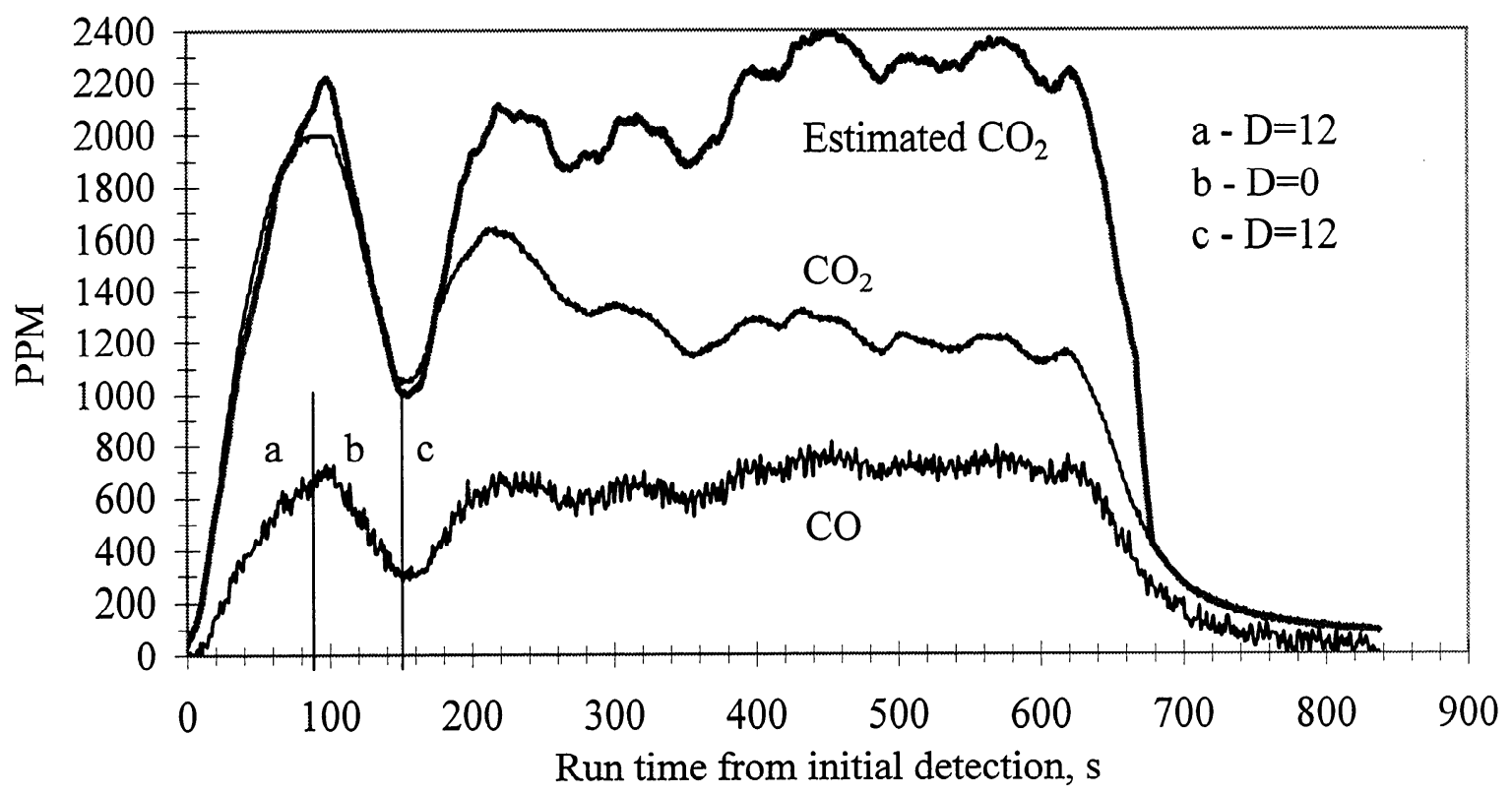

Figure A5.39. Profiles of $\mathrm{CO}$ and $\mathrm{CO}_{2}$ concentrations in the pyrolysis gas obtained with a steelwool-plug located at $0.13 \mathrm{~m}$ (RNAC1024) under reactor conditions of $550^{\circ} \mathrm{C}$, $0.81 \mathrm{~m}$ pyrolysis tube heated length, and $3.39 \mathrm{~s}$ secondary gas space-time. 


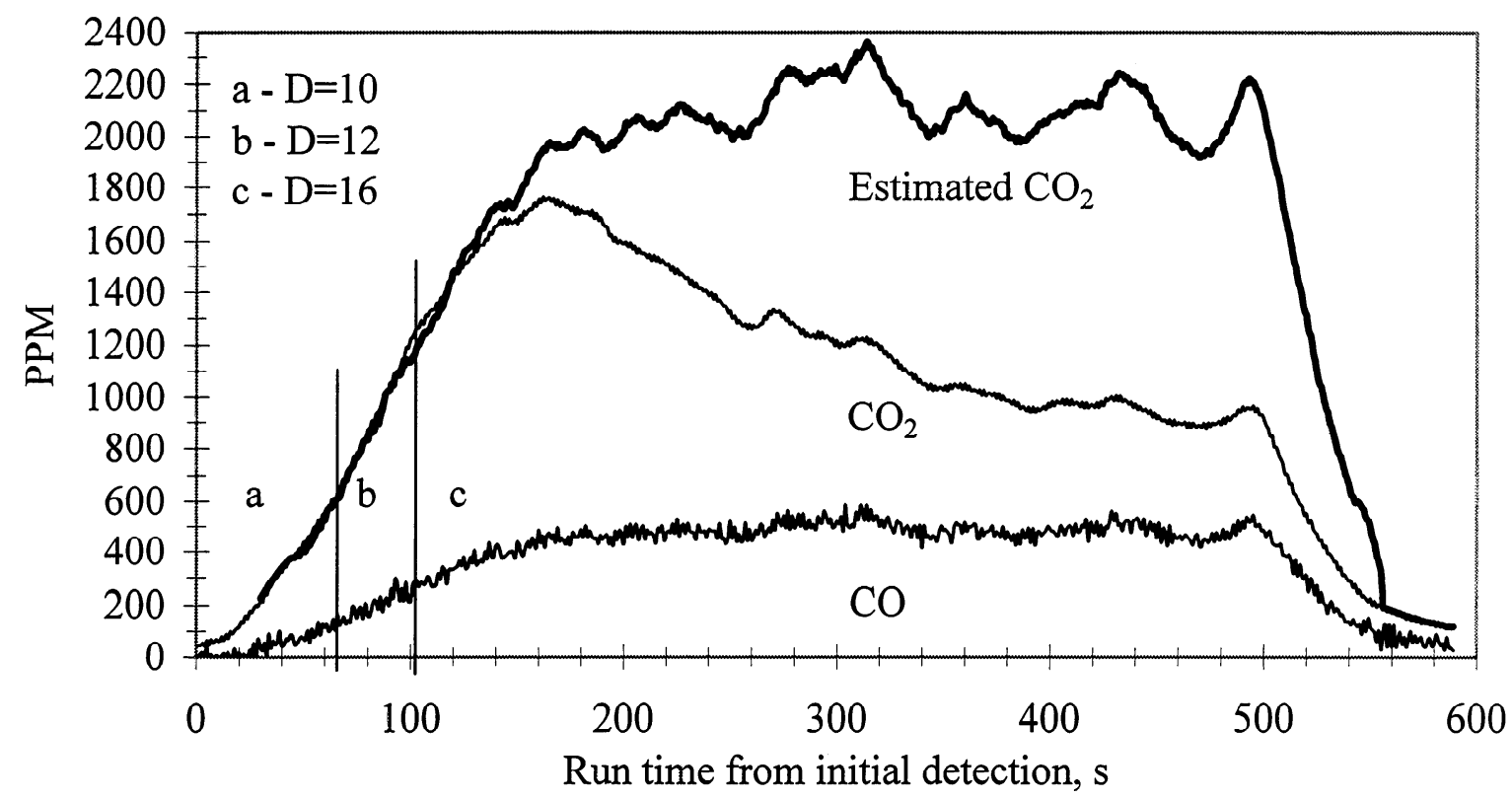

Figure A5.40. Profiles of $\mathrm{CO}$ and $\mathrm{CO}_{2}$ concentrations in the pyrolysis gas obtained with a steelwool-plug located at $0.13 \mathrm{~m}(\mathrm{RNAC1226})$ under reactor conditions of $550^{\circ} \mathrm{C}$, $0.81 \mathrm{~m}$ pyrolysis tube heated length, $15 \mathrm{slpm} \mathrm{N}_{2}$ quench, and $6.59 \mathrm{~s}$ secondary gas space-time.

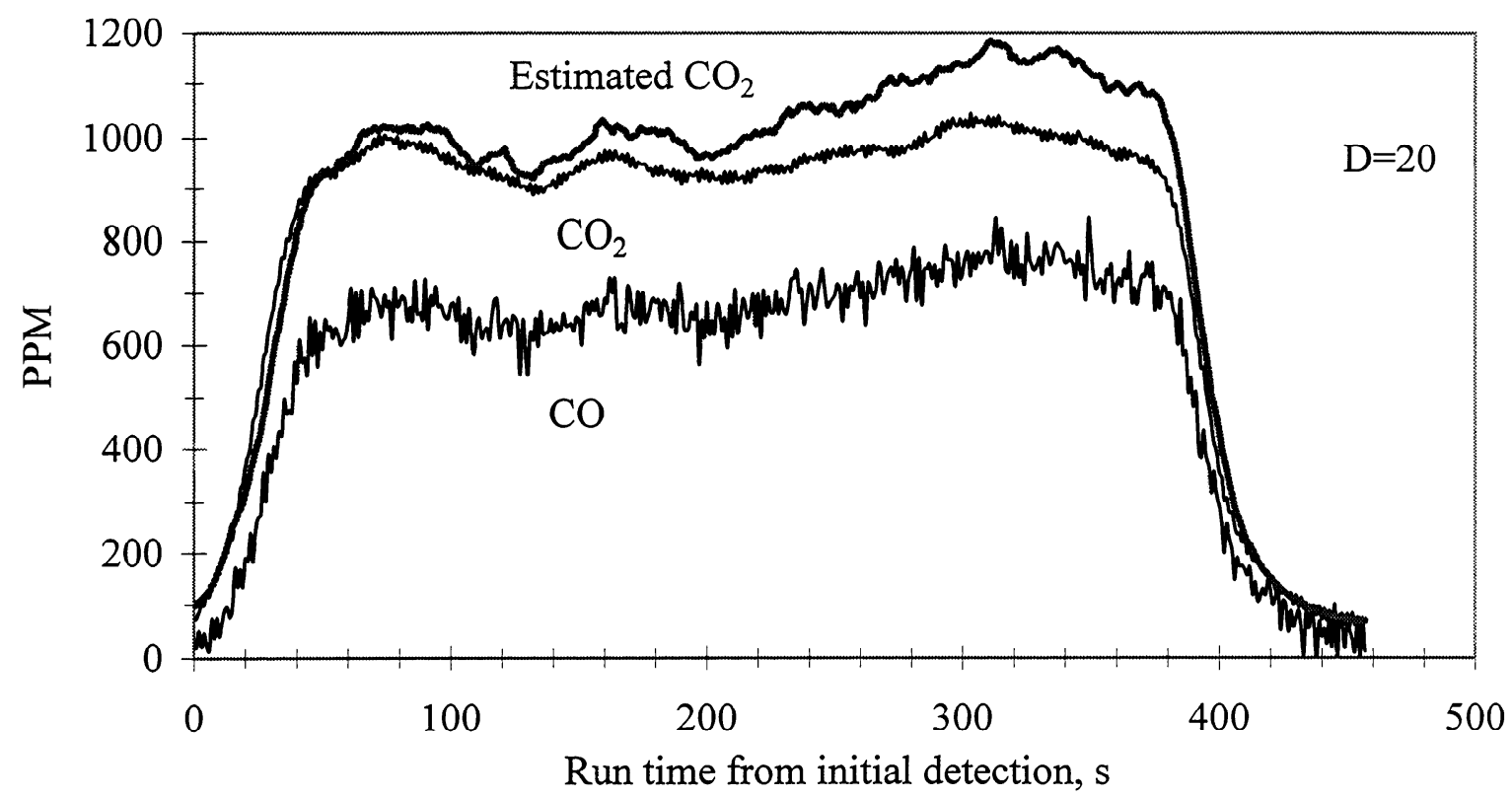

Figure A5.41. Profiles of $\mathrm{CO}$ and $\mathrm{CO}_{2}$ concentrations in the pyrolysis gas obtained with a steelwool-plug located at $0.75 \mathrm{~m}$ (RNAC923) under reactor conditions of $550^{\circ} \mathrm{C}$, $0.81 \mathrm{~m}$ pyrolysis tube heated length, and $1.72 \mathrm{~s}$ secondary gas space-time. 


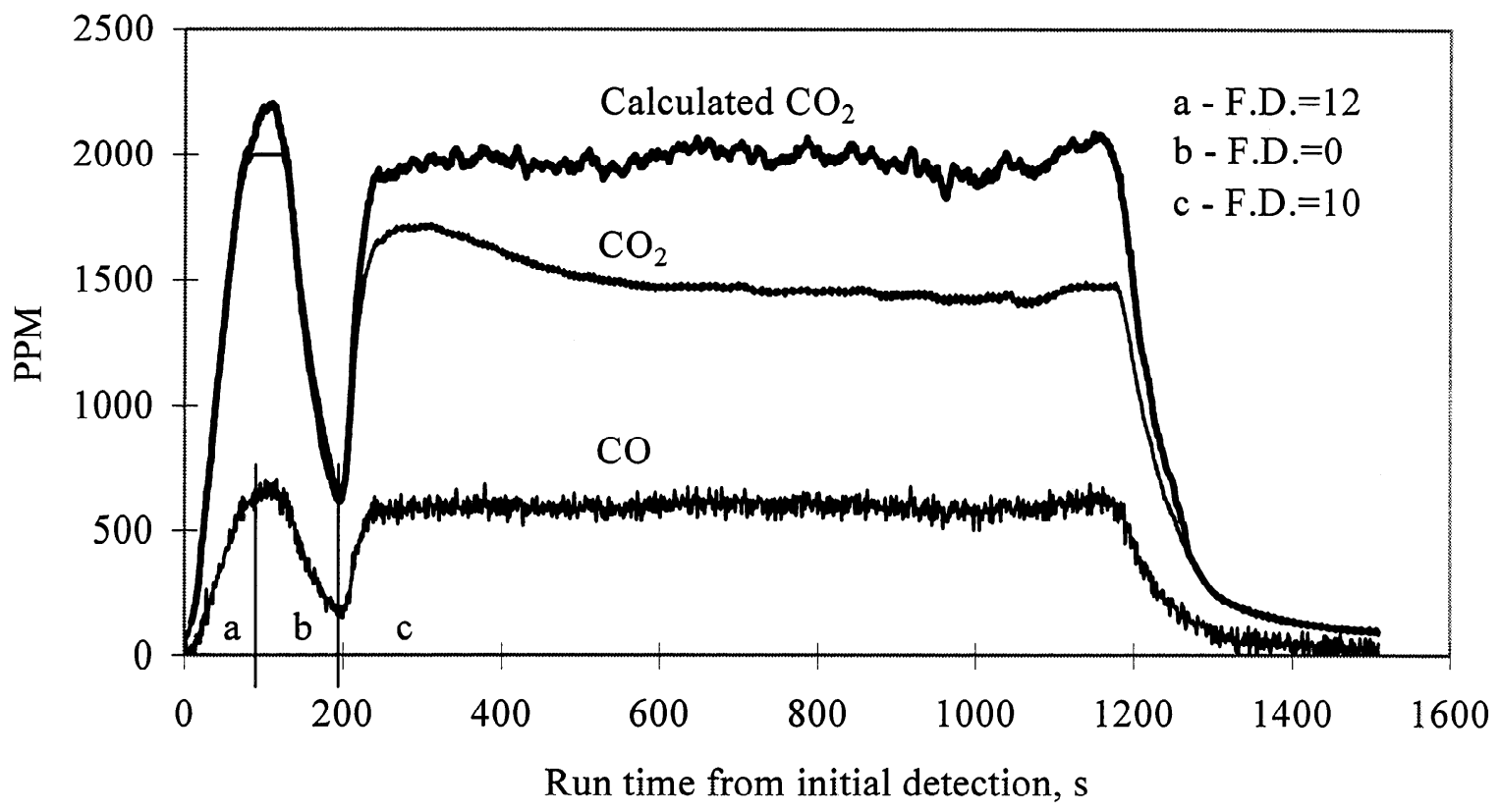

Figure A5.42. Profiles of $\mathrm{CO}$ and $\mathrm{CO}_{2}$ concentrations in the pyrolysis gas obtained with a steelwool-plug located at $0.75 \mathrm{~m}$ and an acoustic field of $151 \mathrm{~dB}$ and $960 \mathrm{~Hz}$ (RAC1206) under reactor conditions of $550^{\circ} \mathrm{C}, 0.81 \mathrm{~m}$ pyrolysis tube heated length, and $3.39 \mathrm{~s}$ secondary gas space-time.

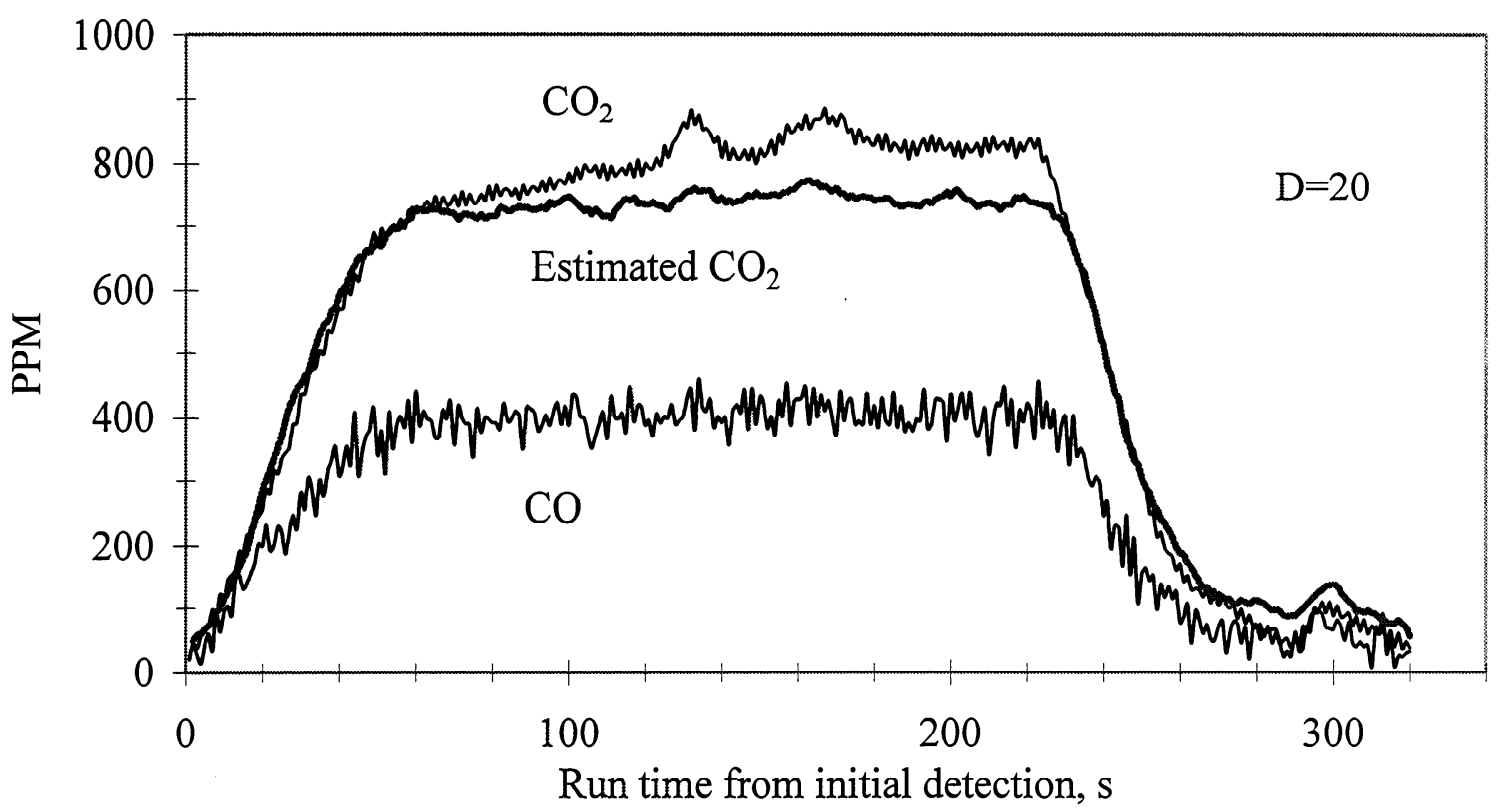

Figure A5.43. Profiles of $\mathrm{CO}$ and $\mathrm{CO}_{2}$ concentrations in the pyrolysis gas obtained without acoustics (RNAC1123) under reactor conditions of $700^{\circ} \mathrm{C}, 0.18 \mathrm{~m}$ pyrolysis tube heated length, $0.21 \mathrm{~s}$ particle residence time, and $0.32 \mathrm{~s}$ secondary gas space-time. 


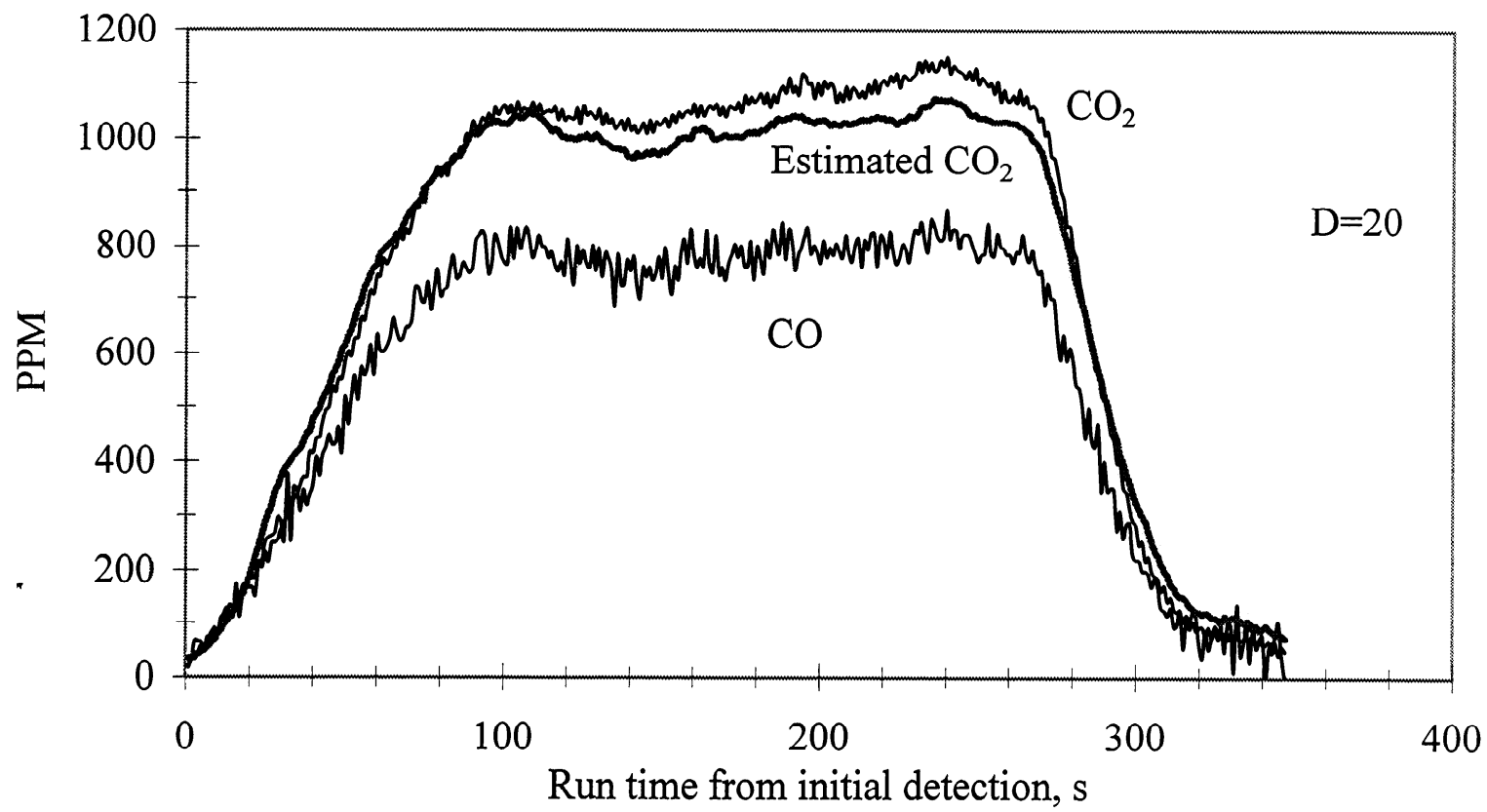

Figure A5.44. Profiles of the measured $\mathrm{CO}$ and $\mathrm{CO}_{2}$ concentrations and the estimated $\mathrm{CO}_{2}$ concentration in the pyrolysis gas obtained without acoustics (RNAC1127) under reactor conditions of $700^{\circ} \mathrm{C}, 0.48 \mathrm{~m}$ pyrolysis tube heated length, $0.49 \mathrm{~s}$ particle residence time, and $0.86 \mathrm{~s}$ secondary gas space-time.

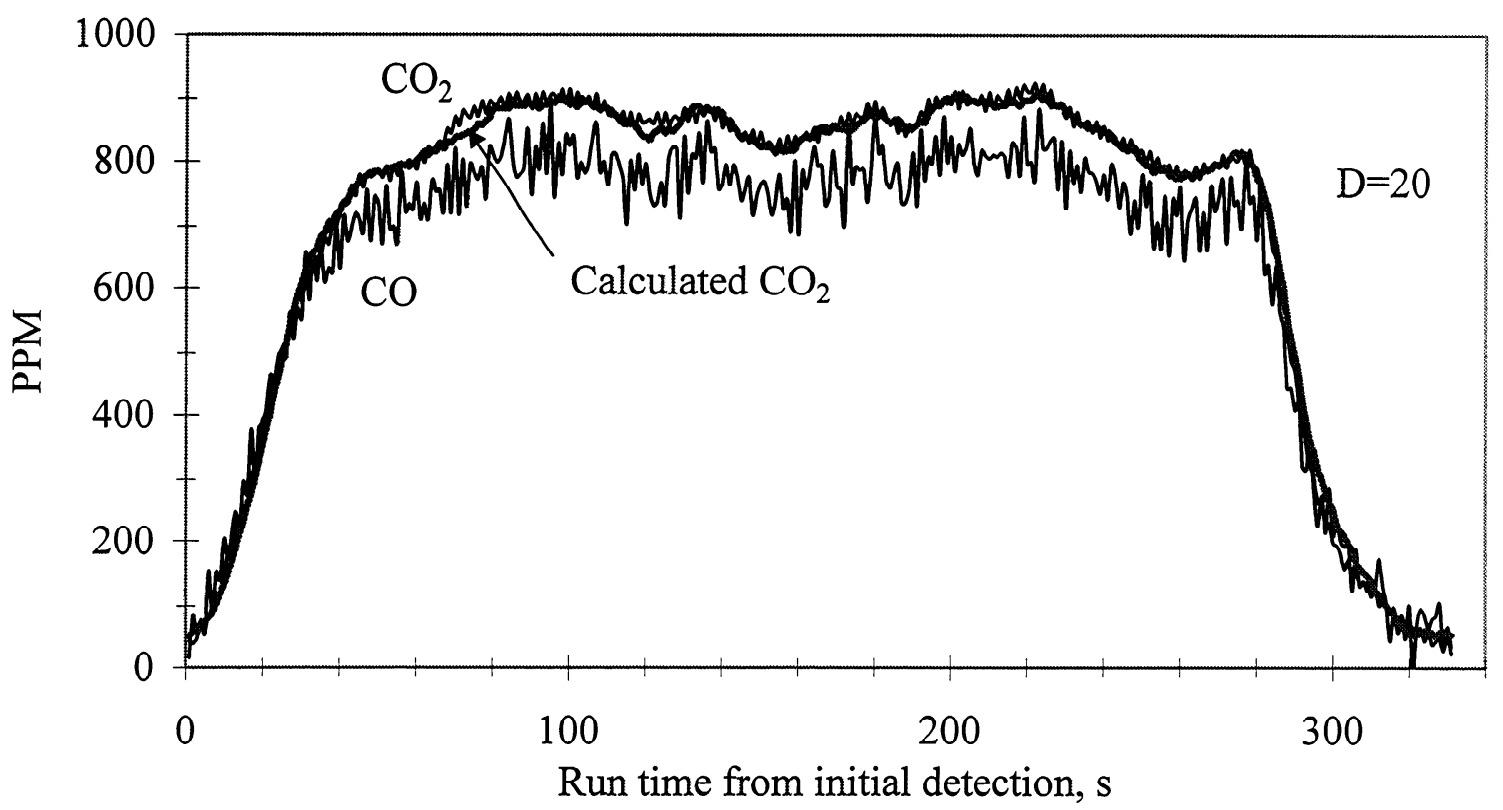

Figure A5.45. Profiles of $\mathrm{CO}$ and $\mathrm{CO}_{2}$ concentrations in the pyrolysis gas obtained without acoustics (RNAC1122) under reactor conditions of $550^{\circ} \mathrm{C}, 0.81 \mathrm{~m}$ pyrolysis tube heated length, $10 \mathrm{slpm} \mathrm{N}_{2}$ quench, $0.82 \mathrm{~s}$ particle residence time, and $1.46 \mathrm{~s}$ secondary gas space-time. 


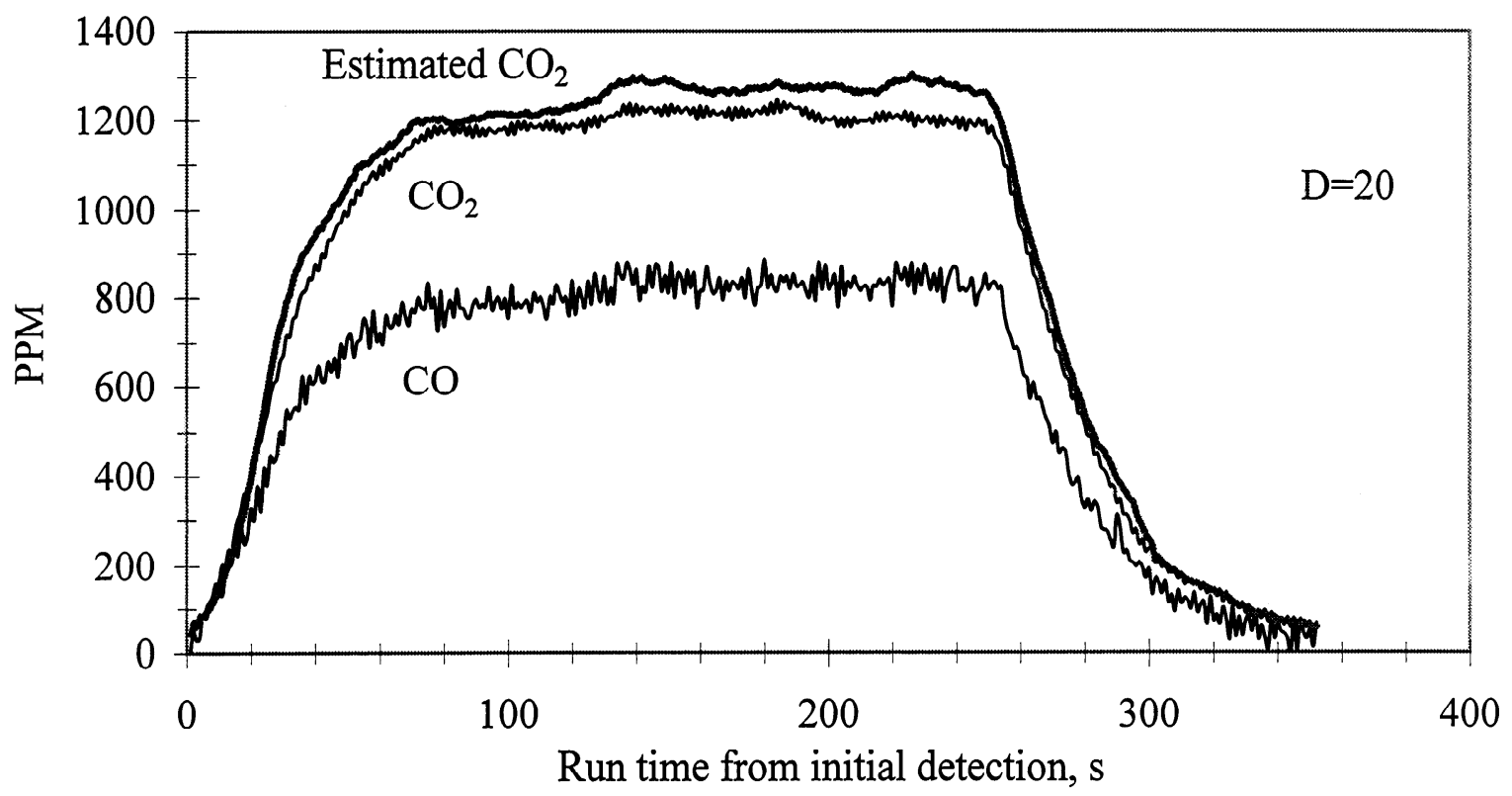

Figure A5.46. Profiles of $\mathrm{CO}$ and $\mathrm{CO}_{2}$ concentrations in the pyrolysis gas obtained in an acoustic field of $151 \mathrm{~dB}$ and $960 \mathrm{~Hz}$ (RAC1126A) under reactor conditions of $700^{\circ} \mathrm{C}, 0.18 \mathrm{~m}$ pyrolysis tube heated length, $0.25 \mathrm{~s}$ particle residence time, and $0.32 \mathrm{~s}$ secondary gas space-time.

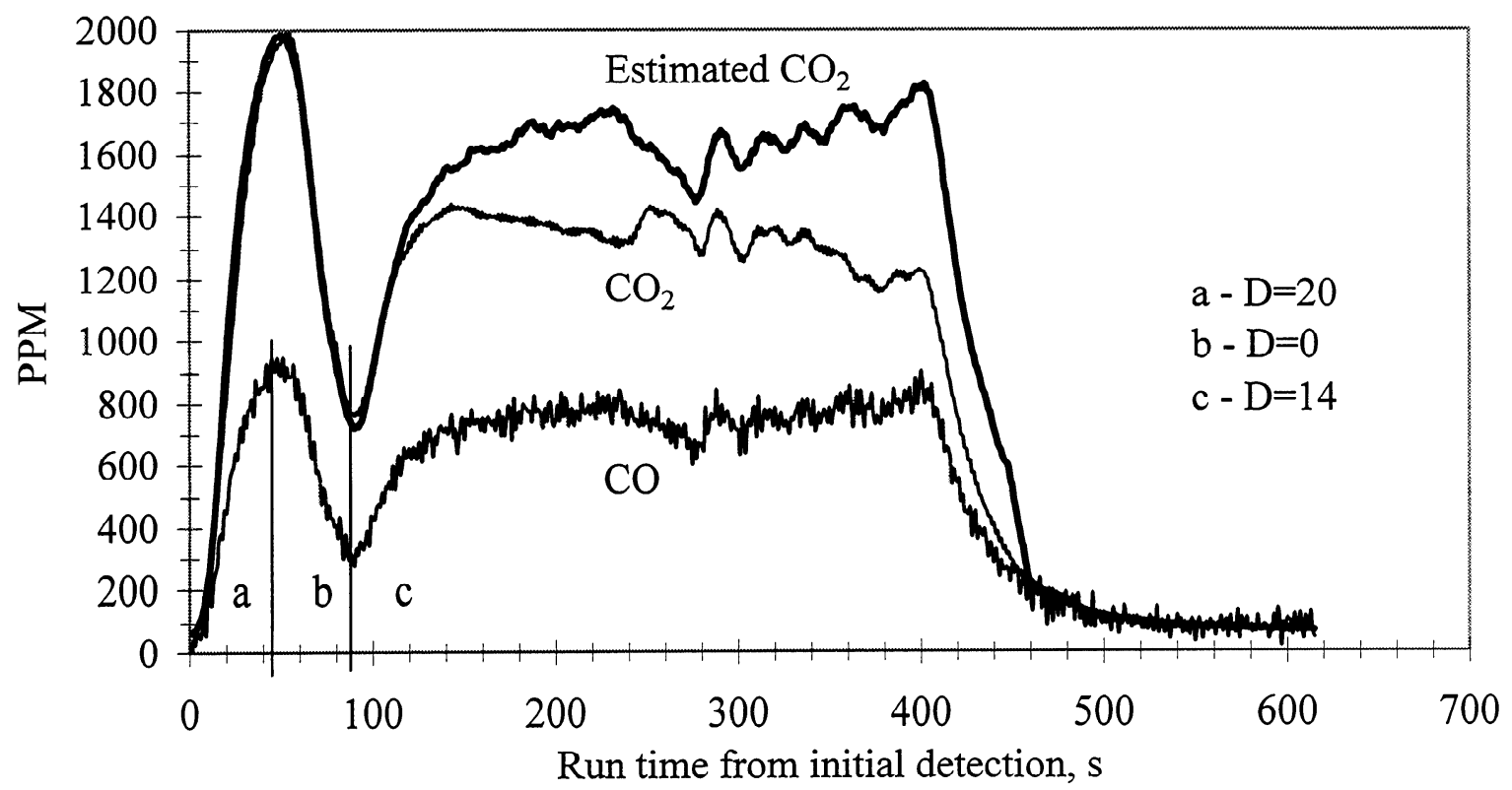

Figure A5.47. Profiles of $\mathrm{CO}$ and $\mathrm{CO}_{2}$ concentrations in the pyrolysis gas obtained in an acoustic field of $151 \mathrm{~dB}$ and $960 \mathrm{~Hz}$ (RAC1127) under reactor conditions of $700^{\circ} \mathrm{C}, 0.48 \mathrm{~m}$ pyrolysis tube heated length, $0.64 \mathrm{~s}$ particle residence time, and $0.86 \mathrm{~s}$ secondary gas space-time. 


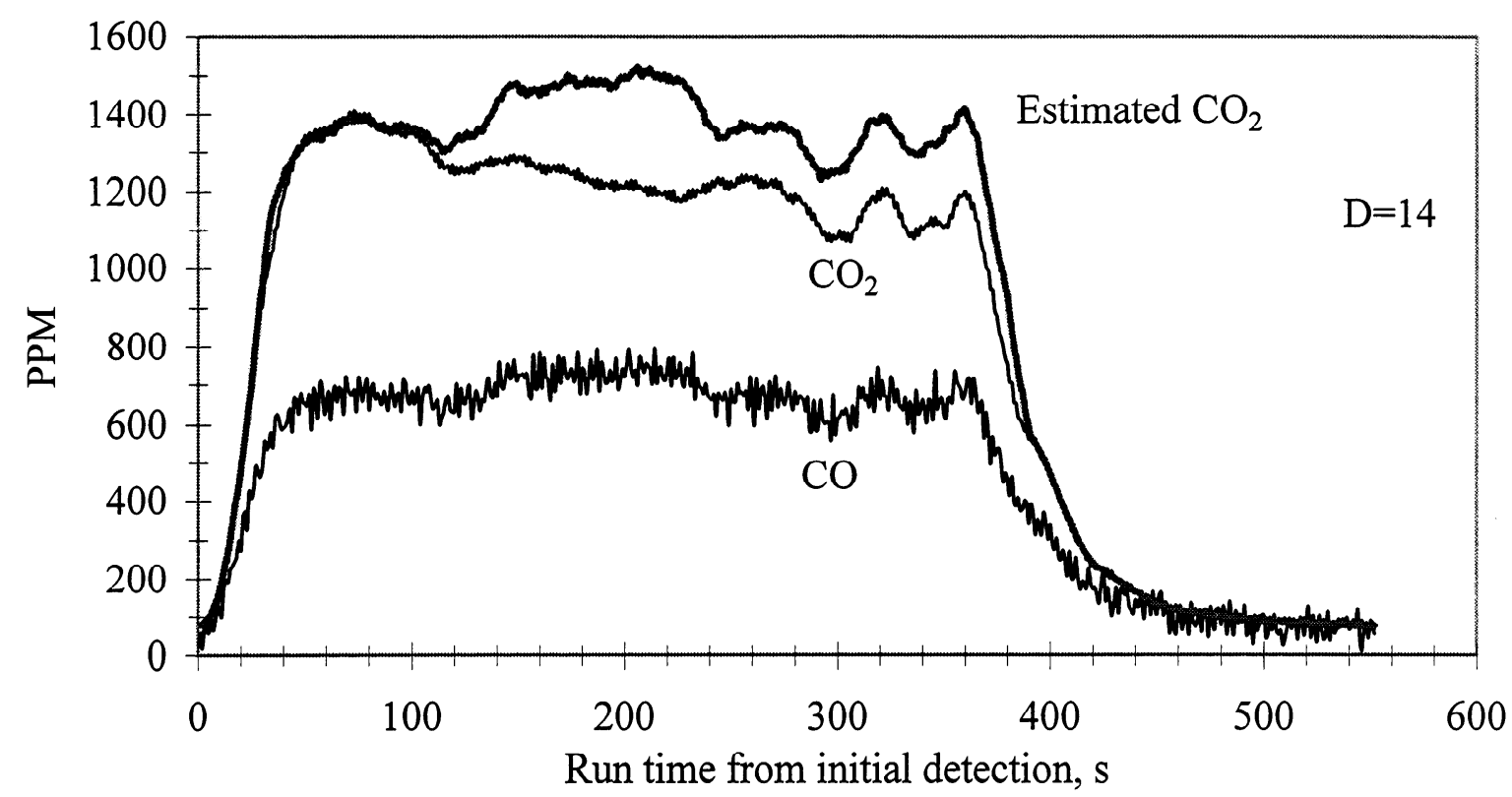

Figure A5.48. Profiles of $\mathrm{CO}$ and $\mathrm{CO}_{2}$ concentrations in the pyrolysis gas obtained in an acoustic field of $151 \mathrm{~dB}$ and $990 \mathrm{~Hz}$ (RAC1130) under reactor conditions of $700^{\circ} \mathrm{C}, 0.48 \mathrm{~m}$ pyrolysis tube heated length, $0.64 \mathrm{~s}$ particle residence time, and $0.86 \mathrm{~s}$ secondary gas space-time.

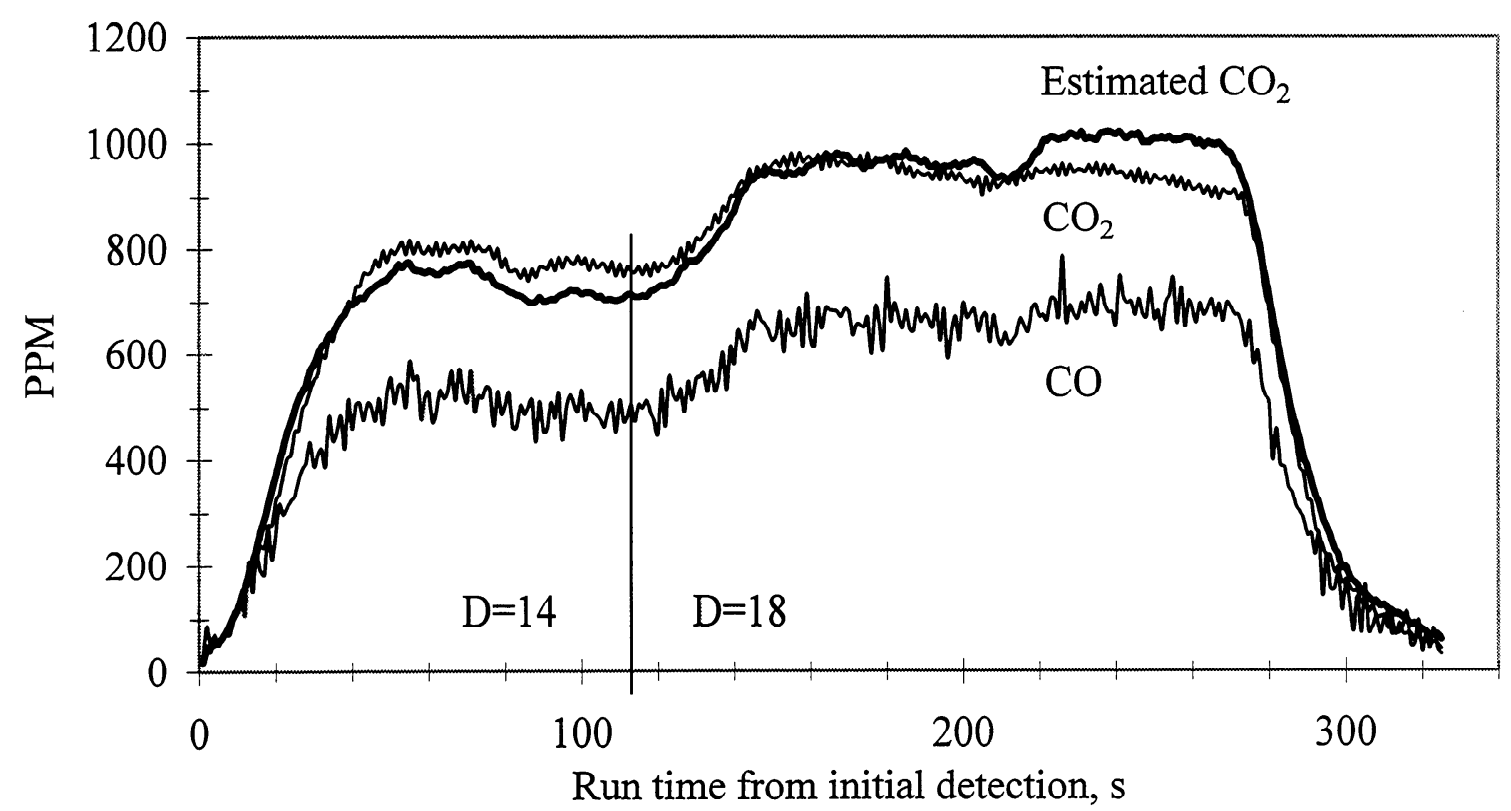

Figure A5.49. Profiles of $\mathrm{CO}$ and $\mathrm{CO}_{2}$ concentrations in the pyrolysis gas obtained in an acoustic field of $151 \mathrm{~dB}$ and $950 \mathrm{~Hz}$ (RAC1126B) under reactor conditions of $700^{\circ} \mathrm{C}, 0.81 \mathrm{~m}$ pyrolysis tube heated length, $10 \mathrm{slpm} \mathrm{N}_{2}$ quench, $1.15 \mathrm{~s}$ particle residence time, and $1.46 \mathrm{~s}$ secondary gas space-time. 


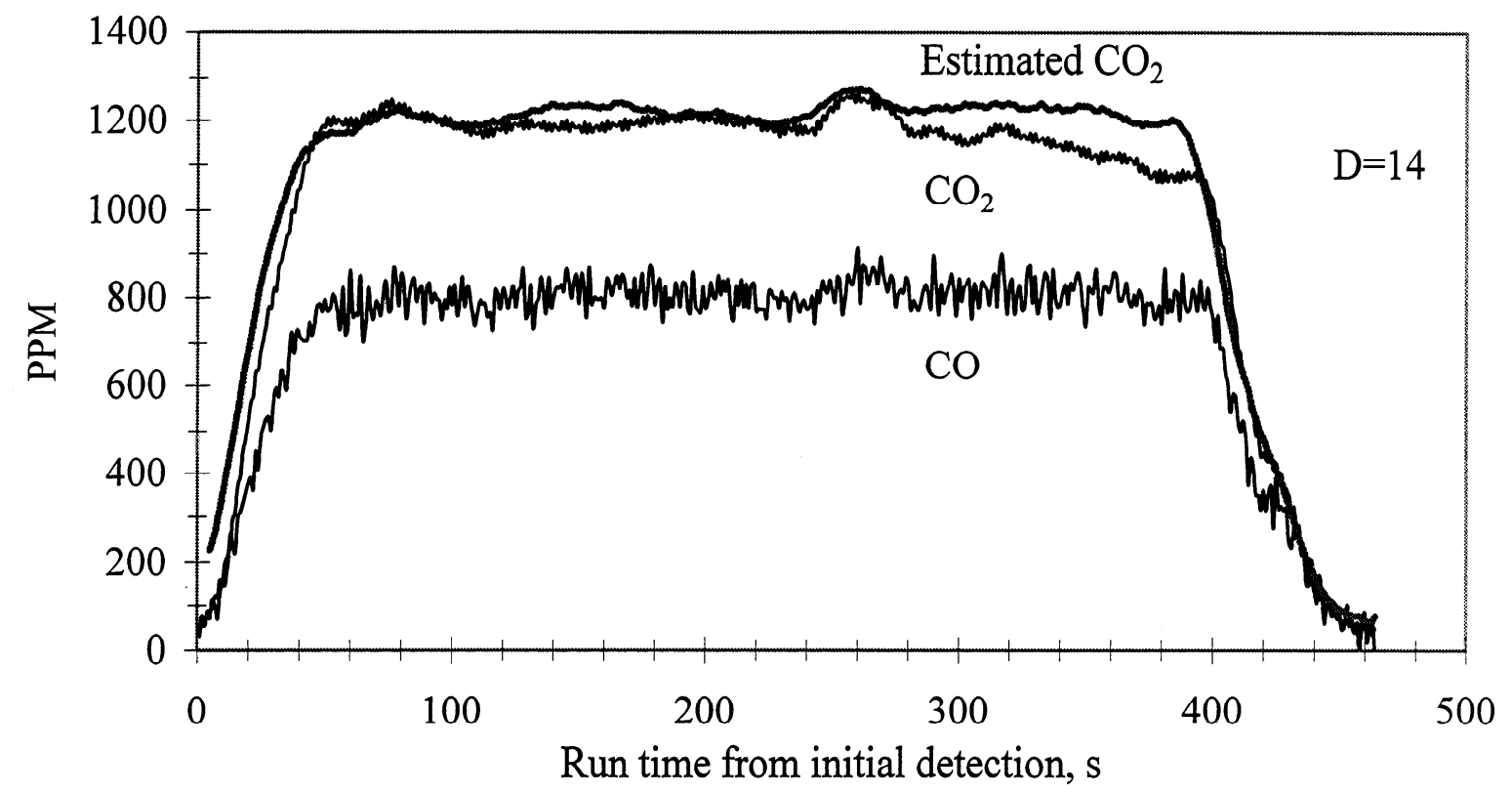

Figure A5.50. Profiles of $\mathrm{CO}$ and $\mathrm{CO}_{2}$ concentrations in the pyrolysis gas obtained in an acoustic field of $151 \mathrm{~dB}$ and $950 \mathrm{~Hz}$ (RAC1130B) under reactor conditions of $700^{\circ} \mathrm{C}, 0.81 \mathrm{~m}$ pyrolysis tube heated length, $1.15 \mathrm{~s}$ particle residence time, and $1.46 \mathrm{~s}$ secondary gas space-time.

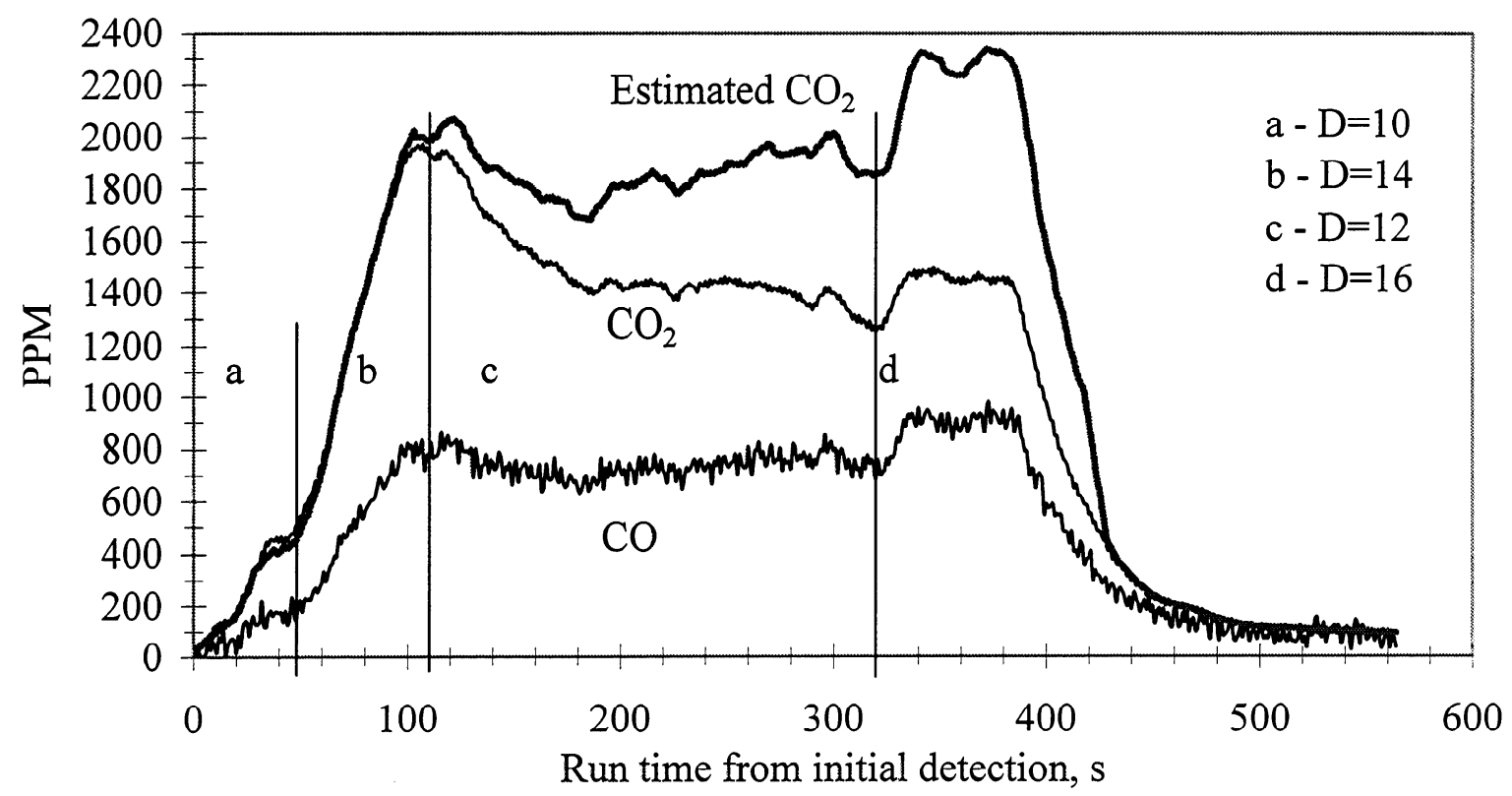

Figure A5.51. Profiles of $\mathrm{CO}$ and $\mathrm{CO}_{2}$ concentrations in the pyrolysis gas obtained in an acoustic field of $160 \mathrm{~dB}$ and $950 \mathrm{~Hz}(\mathrm{RAC1} 130 \mathrm{C})$ under reactor conditions of $700^{\circ} \mathrm{C}, 0.81 \mathrm{~m}$ pyrolysis tube heated length, very long particle residence time, and $1.46 \mathrm{~s}$ secondary gas space-time. 


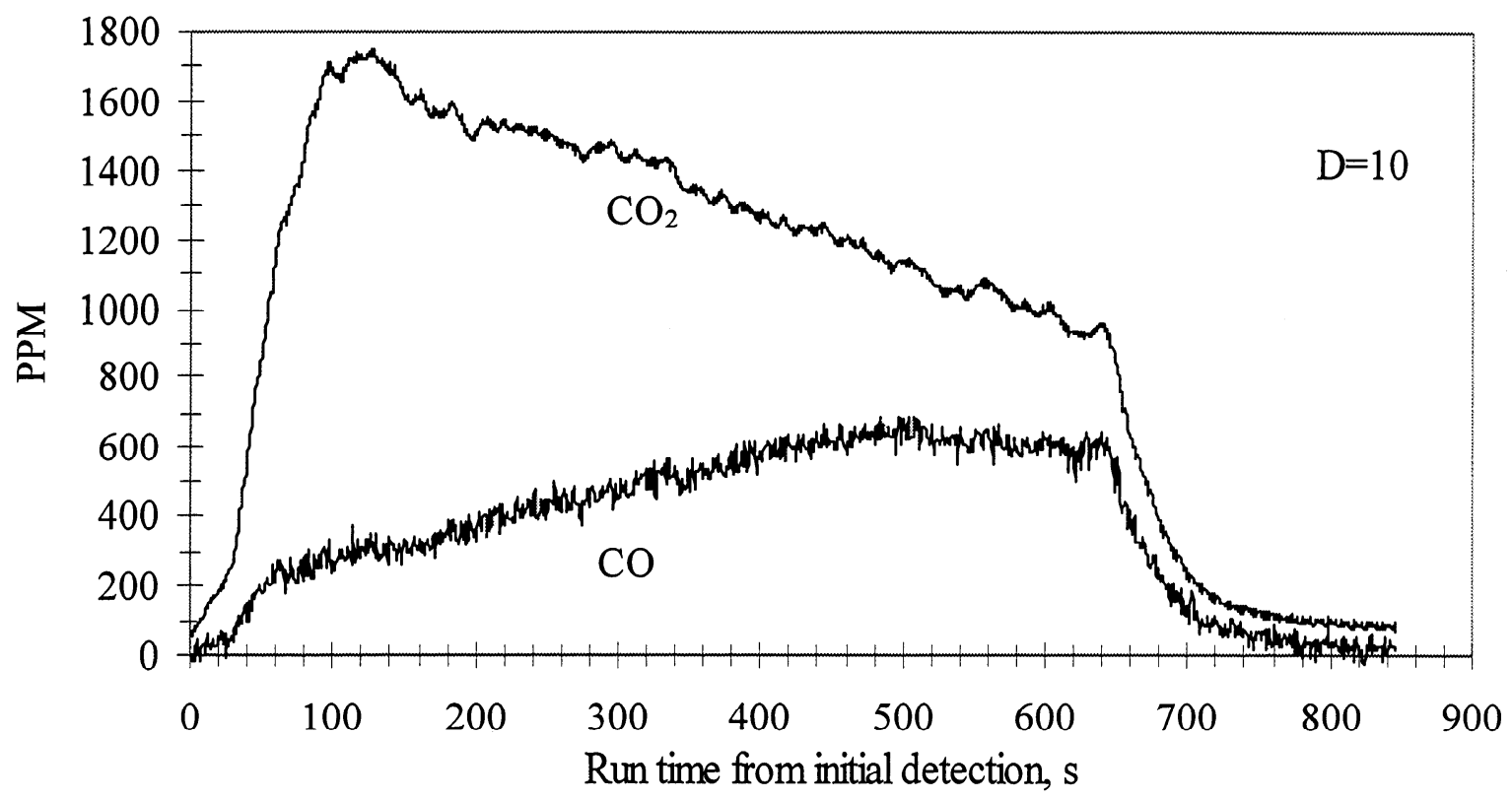

Figure A5.52. Profiles of $\mathrm{CO}$ and $\mathrm{CO}_{2}$ concentrations in the pyrolysis gas obtained in an acoustic field of $160 \mathrm{~dB}$ and $950 \mathrm{~Hz}$ (RAC1205) under reactor conditions of $700^{\circ} \mathrm{C}, 0.81 \mathrm{~m}$ pyrolysis tube heated length, $10 \mathrm{slpm} \mathrm{N}_{2}$ quench, very long particle residence time, and $2.87 \mathrm{~s}$ secondary gas space-time.

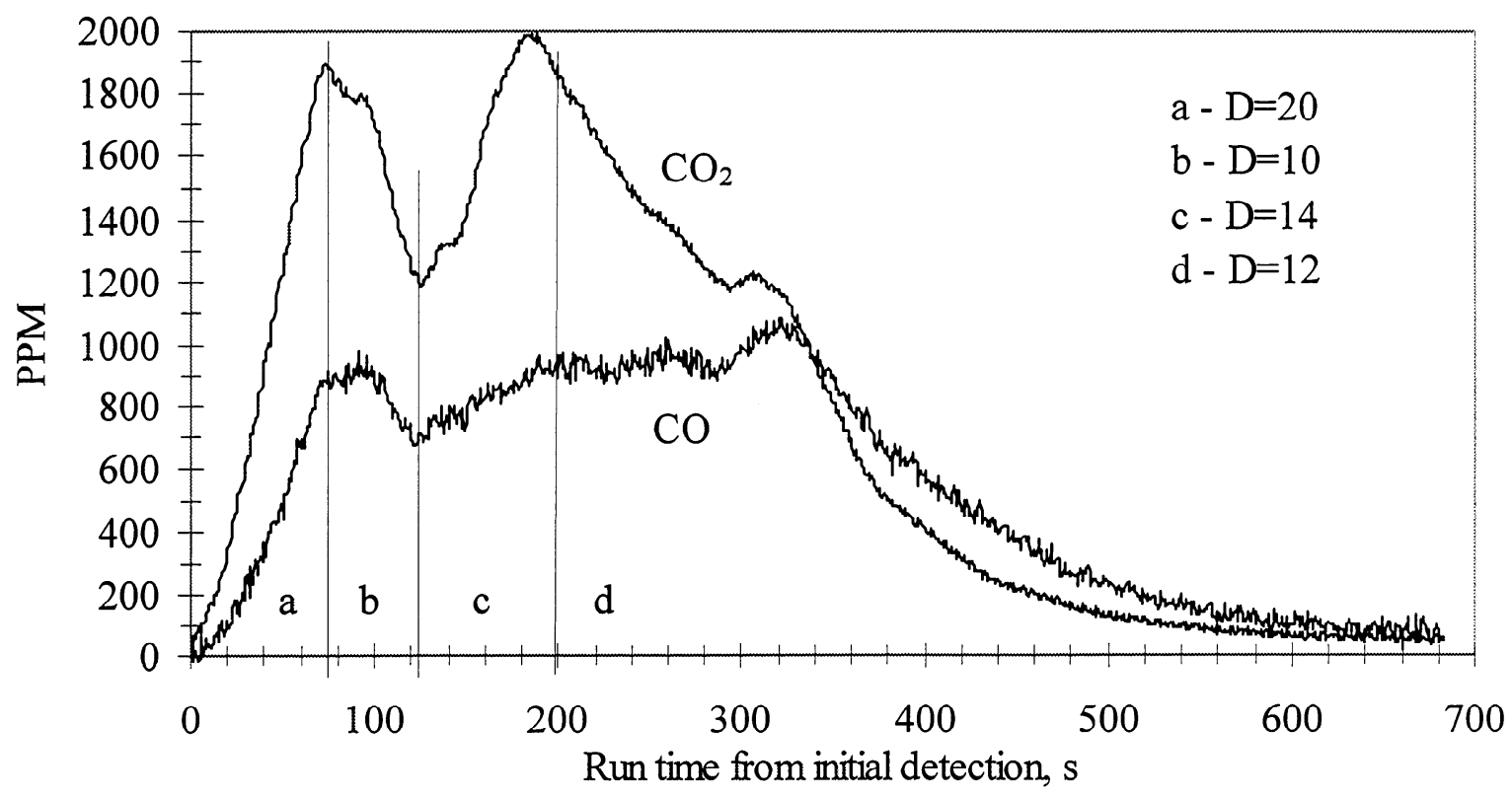

Figure A5.53. Profiles of $\mathrm{CO}$ and $\mathrm{CO}_{2}$ concentrations in the pyrolysis gas obtained with a steelwool-plug located at $0.13 \mathrm{~m}$ (RNAC1124) under reactor conditions of $700^{\circ} \mathrm{C}$, $0.18 \mathrm{~m}$ pyrolysis tube heated length, and $0.32 \mathrm{~s}$ secondary gas space-time. 


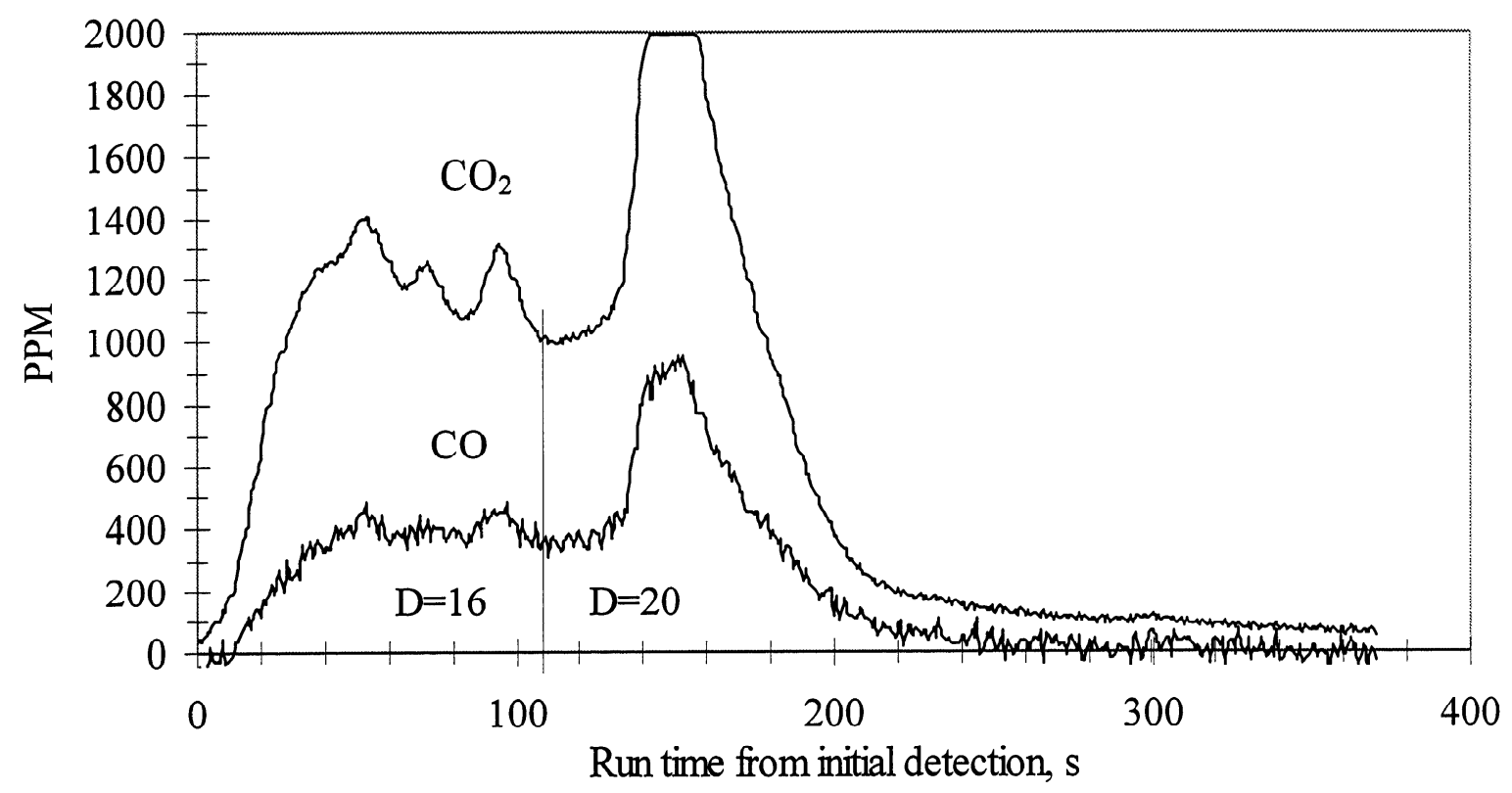

Figure A5.54. Profiles of $\mathrm{CO}$ and $\mathrm{CO}_{2}$ concentrations in the pyrolysis gas obtained with a steelwool-plug located at $0.13 \mathrm{~m}(\mathrm{RNAC} 1125)$ under reactor conditions of $700^{\circ} \mathrm{C}$, $0.81 \mathrm{~m}$ pyrolysis tube heated length, $10 \mathrm{slpm} \mathrm{N}_{2}$ quench, and $1.46 \mathrm{~s}$ secondary gas space-time.

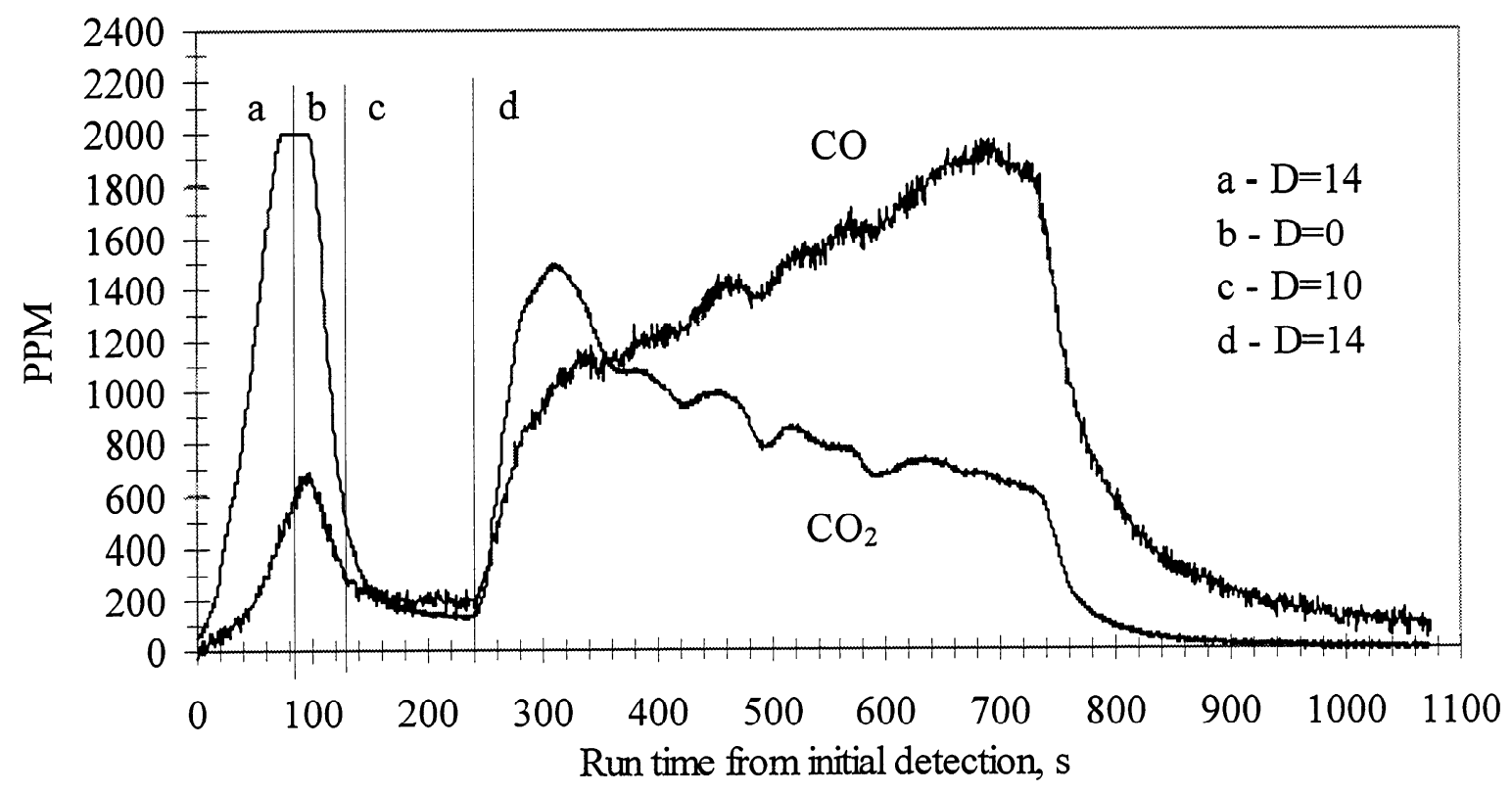

Figure A5.55. Profiles of $\mathrm{CO}$ and $\mathrm{CO}_{2}$ concentrations in the pyrolysis gas obtained with a steelwool-plug located at $0.75 \mathrm{~m}$ (RNAC1204) under reactor conditions of $700^{\circ} \mathrm{C}$, $0.81 \mathrm{~m}$ pyrolysis tube heated length, and $1.46 \mathrm{~s}$ secondary gas space-time. 


\section{[A6] APPENDIX 6. SEM IMAGING AND FT-IR ANALYSIS METHODS OF TARRY LIQUID AND FUME ON GLASS-FIBER FILTERS}

\section{[A6.1 SEM IMAGING}

Magnified images of tar coated glass-fiber filters were obtained with a scanning electron microscope (SEM; JEOL, model JSM-6400). Samples were prepared as follows: First, a $7 \mathrm{~mm}$ by $7 \mathrm{~mm}$ strip of double-sided, sticky-backed graphite tape was pressed onto an aluminum sample holder. Second, an approximately $7 \mathrm{~mm}$ by $7 \mathrm{~mm}$ strip of tar coated filter was placed onto the tape. Third, samples were gold-coated in the IPST plasma coater for $3 \mathrm{~min}$ to prevent charging of the sample by the electron beam, which causes white regions in the image. Fourth, samples were dried under a vacuum at $35^{\circ} \mathrm{C}$ for $4-8$ hours. SEM accelerator voltage was set between $10-15 \mathrm{kV}$.

\section{[A6.2] FT-IR ANALYSIS}

Organic compounds absorb electromagnetic energy in the infrared region of the spectrum (Solomons, 1988). Infrared energy causes atoms and groups of atoms to vibrate faster about the covalent bonds that connect them. Covalent bonds can only vibrate at certain frequencies, usually expressed in terms of wavenumber, and at certain energy levels. Infrared energy is absorbed only when a molecule is excited from one quantized, vibrational energy level to a higher quantized, vibrational energy level. Molecules vibrate by covalent bond stretching or bending. Bonds between atoms with lower masses vibrate at higher frequencies than do bonds between atoms with higher masses. Stiff, triple bonds vibrate at higher frequencies than do single bonds. 
The FT-IR operates by measuring the difference in absorbance between a reference beam and an incident beam that is reflected from the sample, as the frequency of incident radiation is varied. The absorption of energy is indicated as a peak on a frequency spectrum. A nonlinear molecule with $n$ atoms has $3 n-6$ fundamental vibrational modes. Harmonics of fundamental vibrational modes may be observed in spectra, but they are usually of much lower intensity. There can be many peaks in the spectra. Peaks can overlap. Molecules with symmetrical bonds will not absorb infrared energy, because infrared energy can only be absorbed if the dipole moment changes as a vibration occurs. Therefore, every compound has a statistically unique infrared spectrum. With careful interpretation, the FT-IR spectrum of an unknown compound can be used to identify the compound, or at least provide information concerning its functional groups. The spectrum of unknown compound can be compared with cataloged spectra of pure compounds (Pouchert, 1985) for positive identification.

FT-IR spectra of a clean glass-fiber filter and several tar coated glass-fiber filters were obtained by Analytical Services at IPST. The infrared absorbance was measured over a $1 \mathrm{~cm}$ by $8 \mathrm{~cm}$ section of the filters. The large, platen-type, sample holder on the FT-IR (Nicolet MagnaIR 550) was used. 


\section{[A7] APPENDIX 7. THERMOCOUPLE TEMPERATURE MEASUREMENTS AND ERROR ANALYSIS}

Table A7.1 shows the temperatures of the pyrolysis tube wall and nitrogen gas inside the reactor measured by type $\mathrm{K}, 1.59 \mathrm{~mm}$ diameter, $304 \mathrm{SS}$ sheath thermocouples (OMEGA) fitted to the pyrolysis tube. The location of the thermocouples on the pyrolysis tube is shown in Fig. 11 in the Experimental section. Table A7.2 shows the centerline gas temperatures measured with a $1.59 \mathrm{~mm}$ sheath diameter thermocouple inserted through the particle injection tube into the first heating section. The centerline gas temperatures, measured with a $3.18 \mathrm{~mm}$ sheath diameter thermocouple inserted through the particle injection tube, were nearly the same as the near-centerline gas temperatures measured with a pyrolysis tube thermocouple for an experiment performed with and without an acoustic field at $550^{\circ} \mathrm{C}$ as shown in Table A7.3.

Hardware error limits on thermocouple temperature measurements are $\pm 2.2^{\circ} \mathrm{C}$ or $\pm 0.75 \%$ of the reading, whichever is greater (OMEGA Engineering, 1992). Error in measured gas temperature caused by heat conduction through the thermocouple probe to or away from the thermocouple bead junction can be calculated by (Mitchell, 1983),

$$
T_{s}-T_{g}=\frac{T_{w}-T_{g}}{\cosh \left(L \sqrt{\frac{h C_{t c}}{k_{t c} A_{t c}}}\right)},
$$

where $T_{s}$ is the absolute temperature of the thermocouple bead junction, $T_{w}$ is the absolute temperature of thermocouple lead wires at a distance $L$ from the thermocouple junction ( $L$ is the length of the thermocouple wire leads from their junction to $0.64 \mathrm{~cm}$ inside the particle injection tube or to the pyrolysis tube wall), $T_{g}$ is the absolute temperature of the gas, $C_{t c}$ is the 
thermocouple circumference, $k_{t c}$ is the thermocouple thermoconductivity, $A_{t c}$ is the area of the thermocouple wire leads, and $h$ is the convective heat transfer coefficient for a cylindrical rod (DeWitt and Incropera, 1990) as given by,

$$
h=0.911 \frac{k_{g}}{d_{t c}} \operatorname{Re}^{0.385} \operatorname{Pr}^{0.333} .
$$

where $d_{t c}$ is the diameter of the thermocouple probe ( $d_{t c}$ was assumed to be that of the thermocouple bead junction) and $\mathrm{Re}$ is calculated using the velocity of the gas flowing past the thermocouple probe. The velocity of the gas flowing past the axial thermocouple bead junction was assumed to be the same as the centerline preheated $\mathrm{N}_{2}$ velocity. The velocity of the gas flowing past the pyrolysis tube wall thermocouple bead junction was assumed to be the same as the preheated $\mathrm{N}_{2}$ average velocity in the tube, which is one-half the centerline velocity for laminar flow through a tube. The average velocity of the preheated $\mathrm{N}_{2}$ was calculated using Eq. 28 in the Results and Discussion section. The centerline and average velocity of preheated $\mathrm{N}_{2}$ in the pyrolysis tube at temperatures of 550 and $700^{\circ} \mathrm{C}$ are shown in Table A7.4.

Error in the measured gas temperature caused by radiative heat transfer (Mitchell, 1983) from the hotter pyrolysis tube wall to the cooler thermocouple bead junction can be calculated by,

$$
T_{g}-T_{s}=\frac{\varepsilon \sigma}{h}\left(T_{s}{ }^{4}-T_{w}{ }^{4}\right),
$$

where $\varepsilon$ is the emissivity of the thermocouple wire (i.e., nickel oxide), $\sigma$ is the StefanBoltzmann constant, and $h$ is the convection coefficient for a spherical thermocouple bead junction (see Eq. 19 and 21). $\mathrm{N}_{2}$ and $\mathrm{CO}_{2}$ were not included in the energy balance. $\mathrm{N}_{2}$ is 
transparent to incident thermal radiation. $\mathrm{CO}_{2}$ can emit and absorb thermal radiation, but its concentration in the pyrolysis gas is too low to be influential. Chromel and an alumel lead wires, used in the $1.59 \mathrm{~mm}$ sheath diameter thermocouple, are each $0.254 \mathrm{~mm}$ in diameter (OMEGA Engineering, 1992). Because the thermocouple wires are 90-95\% nickel, there thermoconductivity was assumed to be that of pure nickel. The thermocouple bead junction diameter is approximately $0.9 \mathrm{~mm}$. The conduction error was calculated assuming bare thermocouple wires, without the presence of the sheath which has a very low thermoconductivity. Table A7.5 shows the values of the input variables and the maximum thermal conduction and radiation errors of the measured gas and tube wall temperatures. 
Table A7.1. Pyrolysis tube wall and gas temperatures measured with thermocouples (not corrected for conduction and radiation errors).

\begin{tabular}{|c|c|c|c|c|c|c|c|c|c|c|c|c|c|}
\hline $\begin{array}{l}\text { Experiment } \\
\text { number }\end{array}$ & HT2 & HT3 & HT4 & HT5 & GT1 & GT2 & GT4 & GT5 & GT6 & GT7 & GT8 & GT9 & GT10 \\
\hline RNAC1113 & 411 & 379 & 400 & 430 & 387 & - & 198 & 404 & 387 & 409 & 235 & 394 & 417 \\
\hline RAC1119 & 411 & 380 & 400 & 430 & 388 & 150 & 190 & 407 & 390 & 400 & 232 & 399 & 410 \\
\hline RAC1009 & 409 & 390 & 400 & 420 & 402 & 161 & 191 & 409 & 397 & 409 & 263 & 396 & 405 \\
\hline RNAC1111 & 415 & 191 & 161 & 430 & 79 & - & 91 & 185 & 292 & 409 & 48 & 389 & 178 \\
\hline RNA21111 & 416 & 209 & 170 & 430 & 79 & - & 100 & 208 & 307 & 415 & 54 & 387 & 183 \\
\hline RNAC1112 & 410 & 378 & 399 & 430 & 384 & - & 211 & 407 & 396 & 408 & 235 & 397 & 410 \\
\hline RNAC1105 & 565 & 293 & 235 & 560 & 119 & 129 & 150 & 296 & 414 & 555 & 76 & 529 & 244 \\
\hline RNA21105 & 560 & 541 & 332 & 560 & 306 & - & 243 & 401 & 533 & 551 & 122 & 536 & 538 \\
\hline RNAC912 & 566 & 545 & 548 & 579 & 520 & 200 & 269 & 549 & 542 & 555 & 410 & 551 & 548 \\
\hline RNAC918 & 568 & 548 & 548 & 579 & 514 & 200 & 287 & 550 & 544 & 557 & 392 & 551 & 548 \\
\hline RNAC919A & 568 & 547 & 549 & 583 & 527 & 202 & 291 & 550 & 543 & 556 & 384 & 551 & 554 \\
\hline RNAC927B & 560 & 539 & 552 & 576 & 535 & 118 & 274 & 552 & 545 & 550 & 385 & 561 & 548 \\
\hline RNAC927A & 560 & 539 & 550 & 575 & 534 & 73 & 272 & 552 & 545 & 549 & 386 & 551 & 554 \\
\hline RAC925 & 554 & 541 & 549 & 563 & 535 & 237 & 290 & 551 & 544 & 536 & 386 & 545 & 558 \\
\hline RAC1106 & 558 & 307 & - & 557 & 132 & 80 & - & 229 & 515 & 518 & 81 & 519 & 417 \\
\hline $\mathrm{RAC} 1107$ & 554 & 308 & 173 & 551 & 129 & 67 & 111 & 237 & 426 & 527 & 76 & 528 & 235 \\
\hline RAC1108 & 552 & 546 & 374 & 557 & 304 & 132 & 205 & 432 & 530 & 529 & 143 & 535 & 546 \\
\hline RAC925B & 551 & 538 & 547 & 566 & 533 & 204 & 263 & 553 & 546 & 516 & 387 & 556 & 551 \\
\hline RAC1230B & 540 & 539 & 544 & 549 & 545 & 87 & 286 & 552 & 540 & 500 & 361 & 550 & 548 \\
\hline RAC1226 & 542 & 540 & 544 & 550 & 551 & 53 & 299 & 557 & 543 & 501 & 355 & 555 & 563 \\
\hline $\mathrm{RAC} 1231 \mathrm{~A}$ & 552 & 544 & 543 & 549 & 546 & 168 & 409 & 545 & 532 & 528 & 369 & 548 & 548 \\
\hline RAC1231B & 552 & 544 & 542 & 548 & 546 & 78 & 401 & 549 & 540 & 527 & 368 & 548 & 550 \\
\hline RAC $1231 \mathrm{C}$ & 552 & 543 & 542 & 549 & 544 & 31 & 372 & 554 & 544 & 527 & 357 & 546 & 550 \\
\hline RAC1028 & 541 & 304 & 153 & 550 & 132 & 58 & 89 & 554 & 420 & 519 & 83 & 524 & 233 \\
\hline RAC912 & 552 & 543 & 549 & 562 & 526 & 193 & 241 & 554 & 548 & 519 & 383 & 558 & 550 \\
\hline RAC926 & 546 & 541 & 281 & 562 & 527 & 173 & 281 & 550 & 548 & 505 & 387 & 557 & 549 \\
\hline RAC1014 & 494 & 523 & 532 & 500 & 527 & 208 & 202 & 539 & 523 & 469 & 348 & 512 & 541 \\
\hline
\end{tabular}


Table A7.1 (Continued). Pyrolysis tube wall and gas temperatures measured with thermocouples (not corrected for conduction and radiation errors).

\begin{tabular}{|c|c|c|c|c|c|c|c|c|c|c|c|c|c|}
\hline $\begin{array}{l}\text { Experiment } \\
\text { number }\end{array}$ & HT2 & HT3 & HT4 & HT5 & GT1 & GT2 & GT4 & GT5 & GT6 & GT7 & GT8 & GT9 & GT10 \\
\hline RAC930 & 540 & 541 & 548 & 563 & 524 & 105 & 260 & 549 & 546 & 493 & 493 & 543 & 552 \\
\hline RAC1227A & 530 & 539 & 544 & 550 & 543 & 44 & 273 & 553 & 541 & 500 & 341 & 550 & 554 \\
\hline RAC1207 & 543 & 540 & 542 & 540 & 538 & 117 & 411 & 545 & 538 & 509 & 372 & 548 & 548 \\
\hline RAC1227B & 535 & 538 & 544 & 550 & 537 & 72 & 362 & 595 & 541 & 492 & 364 & - & 539 \\
\hline RAC1230 & 535 & 538 & 544 & 527 & 536 & 83 & 301 & 548 & 543 & 494 & 370 & 554 & 548 \\
\hline RAC1224 & 528 & 541 & 544 & 513 & 543 & 50 & 285 & 554 & 545 & 476 & 543 & 555 & 557 \\
\hline RNAC1017 & 574 & 323 & 233 & 557 & 116 & - & 136 & 291 & 403 & 502 & 75 & 511 & 237 \\
\hline RNAC1022 & 553 & 276 & 127 & 555 & 98 & 52 & 69 & 178 & 390 & 544 & 58 & 519 & 217 \\
\hline RNAC1023 & 540 & 517 & 530 & 538 & 524 & 208 & 272 & 538 & 530 & 534 & 337 & 518 & 541 \\
\hline RNAC1019 & 520 & 510 & 530 & 550 & 520 & - & 250 & 536 & 528 & 535 & 327 & 533 & 538 \\
\hline RNAC1024 & 548 & 517 & 533 & 550 & 525 & 120 & 310 & 540 & 533 & 533 & 336 & 531 & 541 \\
\hline RNAC1226 & 555 & 541 & 544 & 551 & 545 & 47 & 285 & 555 & 549 & 544 & 350 & 558 & 556 \\
\hline RNAC923 & 567 & 547 & 549 & 577 & 523 & 246 & 276 & 550 & 542 & 554 & 383 & 549 & 552 \\
\hline RAC1206 & 545 & 542 & 542 & 554 & 540 & 118 & 330 & 551 & 540 & 506 & 361 & 550 & 554 \\
\hline RNAC1123 & 710 & 393 & 186 & 662 & 123 & 145 & 186 & 345 & 512 & 692 & 78 & 675 & 293 \\
\hline RNAC1127 & 705 & 712 & 302 & 670 & 408 & 231 & 302 & 538 & 692 & 684 & 145 & 698 & 693 \\
\hline RNAC1122 & 705 & 700 & 407 & 682 & 669 & 297 & 407 & 702 & 680 & 688 & 519 & 700 & 706 \\
\hline RAC1126A & 717 & 422 & 210 & 654 & 155 & 51 & 116 & 266 & 531 & 692 & 77 & 688 & 299 \\
\hline RAC1127 & 684 & 707 & 451 & 670 & 414 & 43 & 242 & 554 & 697 & 637 & 171 & 702 & 693 \\
\hline RAC1130 & 680 & 704 & 442 & 662 & 403 & 116 & 230 & 541 & 695 & 633 & 161 & 698 & 680 \\
\hline RAC1126B & 710 & 699 & 696 & 668 & 691 & 207 & 512 & 701 & 685 & 658 & 484 & 690 & 708 \\
\hline RAC1130B & 685 & 688 & 692 & 662 & 691 & 225 & 459 & 693 & 677 & 638 & 492 & 687 & 690 \\
\hline RAC1130C & 685 & 692 & 691 & 662 & 691 & 128 & 439 & 695 & 692 & 655 & 492 & 686 & 690 \\
\hline RAC1205 & 688 & 692 & 687 & 604 & 681 & 96 & 492 & 691 & 698 & 642 & 471 & 692 & 695 \\
\hline RNAC1124 & 715 & 423 & 277 & 656 & 130 & 133 & 174 & 344 & 541 & 692 & 77 & 692 & 313 \\
\hline RNAC1125 & 693 & 683 & 401 & 666 & 670 & 202 & 401 & 706 & 693 & 679 & 490 & 708 & 710 \\
\hline RNAC1204 & 702 & 698 & 696 & 658 & 695 & 181 & 514 & 693 & 680 & 684 & 500 & 698 & 701 \\
\hline
\end{tabular}


Table A7.2. Centerline gas temperatures measured with a $1.59 \mathrm{~mm}$ sheath diameter thermocouple inserted through the particle injection tube (not corrected for conduction and radiation errors).

\begin{tabular}{|c|c|c|c|c|c|c|c|c|}
\hline \multirow{2}{*}{$\begin{array}{l}\text { Experiment } \\
\text { number }\end{array}$} & \multicolumn{8}{|c|}{ Thermocouple junction distance from the exit of particle injection tube, $\mathrm{cm}$} \\
\hline & -0.64 & 0.64 & 1.9 & 3.18 & 4.45 & 10.8 & 15.88 & 23.5 \\
\hline RNAC 1113 & 82 & 194 & 293 & 329 & 371 & 393 & 396 & 392 \\
\hline RAC1119 & 74 & 212 & 333 & 370 & 380 & 394 & 395 & 391 \\
\hline RAC1009 & 82 & 220 & 325 & 353 & 375 & 388 & 392 & 389 \\
\hline RNAC1111 & 79 & 180 & 283 & 332 & 375 & 396 & - & - \\
\hline RNA21111 & 70 & 185 & 292 & 334 & 375 & 391 & - & - \\
\hline RNAC1112 & 75 & 184 & 283 & 329 & 368 & 388 & - & - \\
\hline RNAC1105 & 90 & 278 & 432 & 484 & 526 & 544 & 534 & 480 \\
\hline RNA21105 & 90 & 274 & 430 & 479 & 523 & 543 & 548 & 546 \\
\hline RNAC912 & 80 & 268 & 410 & 452 & 507 & 539 & 550 & 550 \\
\hline RNAC918 & 79 & 281 & 425 & 467 & 510 & 542 & 551 & 552 \\
\hline RNAC919A & 81 & 280 & 421 & 468 & 512 & 544 & 551 & 551 \\
\hline RNAC927B & 79 & 240 & 420 & 447 & 493 & 524 & 543 & 551 \\
\hline RNAC927A & 80 & 239 & 416 & 448 & 490 & 525 & 542 & 552 \\
\hline RAC925 & 85 & 272 & 444 & 489 & 522 & 538 & 540 & 538 \\
\hline RAC1106 & 93 & 255 & 453 & 522 & 549 & 548 & 529 & 487 \\
\hline RAC1107 & 79 & 244 & 451 & 511 & 533 & 546 & 533 & 480 \\
\hline RAC1108 & 70 & 268 & 457 & 511 & 528 & 542 & 540 & 531 \\
\hline RAC925B & 78 & 275 & 475 & 508 & 530 & 546 & 552 & 550 \\
\hline RAC1230B & 72 & 270 & 488 & 511 & 533 & 551 & 558 & 552 \\
\hline RAC1226 & 72 & 240 & 455 & 510 & 533 & 548 & 553 & 550 \\
\hline RAC1231A & 66 & 291 & 450 & 490 & 521 & 539 & 545 & 546 \\
\hline RAC1231B & 78 & 295 & 465 & 498 & 525 & 546 & 548 & 544 \\
\hline RAC1231C & 80 & 297 & 471 & 500 & 525 & 545 & 549 & 547 \\
\hline RAC1028 & 84 & 269 & 479 & 508 & 523 & 531 & 518 & 482 \\
\hline RAC912 & 82 & 289 & 449 & 510 & 534 & 552 & 552 & 552 \\
\hline RAC926 & 82 & 293 & 484 & 512 & 532 & 548 & 555 & 549 \\
\hline RAC1014 & 80 & 298 & 422 & 454 & 480 & 500 & 512 & 535 \\
\hline
\end{tabular}


Table A7.2 (Continued). Centerline gas temperatures measured with a $1.59 \mathrm{~mm}$ sheath diameter thermocouple inserted through the particle injection tube (not corrected for conduction and radiation errors).

\begin{tabular}{|c|c|c|c|c|c|c|c|c|}
\hline \multirow{2}{*}{$\begin{array}{l}\text { Experiment } \\
\text { number }\end{array}$} & \multicolumn{8}{|c|}{ Thermocouple junction distance from the exit of particle injection tube, $\mathrm{cm}$} \\
\hline & -0.64 & 0.64 & 1.9 & 3.18 & 4.45 & 10.8 & 15.88 & 23.5 \\
\hline RAC930 & 83 & 276 & 470 & 509 & 539 & 548 & 553 & 548 \\
\hline RAC1227A & 71 & 272 & 458 & 509 & 532 & 550 & 556 & 551 \\
\hline RAC1207 & 68 & 304 & 474 & 510 & 528 & 545 & 549 & 546 \\
\hline RAC1227B & 80 & 370 & 484 & 511 & 530 & 548 & 553 & 545 \\
\hline RAC1230 & 79 & 394 & 485 & 511 & 529 & 549 & 556 & \\
\hline RAC1224 & 79 & 357 & 475 & 496 & 525 & 549 & 554 & 555 \\
\hline RNAC1017 & 88 & 250 & 425 & 488 & 532 & 548 & - & - \\
\hline RNAC1022 & 88 & 236 & 415 & 464 & 506 & 528 & - & - \\
\hline RNAC1023 & 85 & 252 & 411 & 458 & 506 & 527 & - & - \\
\hline RNAC1019 & 85 & 259 & 401 & 461 & 503 & 532 & - & - \\
\hline RNAC1024 & 85 & 259 & 411 & 461 & 506 & 532 & - & - \\
\hline RNAC1226 & 85 & 290 & 436 & 470 & 508 & 540 & - & - \\
\hline RNAC923 & 81 & 250 & 394 & 466 & 510 & 542 & 549 & 549 \\
\hline RAC1206 & 82 & 263 & 407 & 493 & 527 & 544 & 554 & 546 \\
\hline RNAC1123 & 85 & 400 & 586 & 636 & 678 & 698 & 688 & 642 \\
\hline RNAC1127 & 80 & 416 & 584 & 632 & 672 & 704 & 711 & 711 \\
\hline RNAC1122 & 84 & 438 & 580 & 635 & 675 & 708 & 709 & 705 \\
\hline RAC1126A & 82 & 406 & 617 & 644 & 680 & 701 & 698 & 654 \\
\hline RAC1127 & 80 & 465 & 615 & 642 & 668 & 692 & 702 & 707 \\
\hline RAC1130 & 77 & 400 & 606 & 636 & 659 & 690 & 702 & 704 \\
\hline RAC1126B & 84 & 423 & 604 & 656 & 690 & 707 & 703 & 699 \\
\hline RAC1130B & 80 & 408 & 595 & 647 & 676 & 697 & 696 & 693 \\
\hline RAC1130C & 83 & 442 & 624 & 646 & 666 & 686 & 695 & 702 \\
\hline RAC1205 & 85 & 439 & 634 & 657 & 672 & 693 & 701 & 705 \\
\hline RNAC1124 & 80 & 380 & 592 & 640 & 680 & 692 & - & - \\
\hline RNAC1125 & 88 & 399 & 578 & 631 & 665 & 683 & - & - \\
\hline RNAC1204 & 83 & 387 & 570 & 612 & 655 & 686 & 702 & 705 \\
\hline
\end{tabular}


Table A7.3. Centerline gas temperature measured with a $3.18 \mathrm{~mm}$ sheath diameter thermocouple inserted through the particle injection tube and the corresponding near-centerline gas temperature measured with a pyrolysis tube thermocouple (not corrected for conduction and radiation errors).

\begin{tabular}{|l|r|r|r|r|r|}
\hline Experiment number & GT9 (Axial) & GT6 (Axial) & GT10 (Axial) & GT5 (Axial) & GT4 (Axial) \\
\hline RNAC912 & $551(550)$ & $542(541)$ & $548(551)$ & $549(544)$ & $269(505)$ \\
\hline RAC912 & $558(550)$ & $548(543)$ & $550(548)$ & $554(543)$ & $241(478)$ \\
\hline
\end{tabular}

Table A7.4. Centerline and average velocity of preheated $\mathrm{N}_{2}$ in the pyrolysis tube at temperatures of 550 and $700^{\circ} \mathrm{C}$ for laminar flow.

\begin{tabular}{|c|c|c|c|c|}
\hline \multirow{2}{*}{$\begin{array}{l}\text { Preheated } \mathrm{N}_{2} \\
\text { flowrate, slpm }\end{array}$} & \multicolumn{2}{|c|}{ Velocity of preheated $\mathrm{N}_{2}$ at $550^{\circ} \mathrm{C}$} & \multicolumn{2}{|c|}{ Velocity of preheated $\mathrm{N}_{2}$ at $700^{\circ} \mathrm{C}$} \\
\hline & Average, $\mathbf{m} / \mathbf{s}$ & Centerline, $\mathbf{m} / \mathbf{s}$ & Average, $\mathbf{m} / \mathbf{s}$ & Centerline, $\mathrm{m} / \mathrm{s}$ \\
\hline 20 & 0.464 & 0.933 & 0.55 & 1.10 \\
\hline 10 & 0.232 & 0.464 & 0.27 & 0.55 \\
\hline 5 & 0.116 & 0.232 & 0.14 & 0.27 \\
\hline
\end{tabular}


Table A7.5. Thermal conduction and radiation errors of the measured gas and pyrolysis tube wall temperatures.

\begin{tabular}{|c|c|c|c|c|c|c|c|c|c|c|}
\hline Location & $\begin{array}{l}\text { Measured } \\
\text { temp., }{ }^{\circ} \mathrm{C}\end{array}$ & $\begin{array}{l}\text { Max. wall } \\
\text { temp., }{ }^{\circ} \mathrm{C}\end{array}$ & $\begin{array}{l}\mathbf{L}, \\
\mathrm{cm}\end{array}$ & $\begin{array}{c}U_{g}, \\
\mathbf{m} / \mathbf{s}\end{array}$ & $\begin{array}{l}\rho g \\
\mathbf{k g} / \mathbf{m}^{\mathbf{3}}\end{array}$ & $\begin{array}{l}\mu g, \\
\mathrm{~N} \bullet \mathrm{s} / \mathbf{m}^{2}\end{array}$ & $\begin{array}{l}k g \\
\mathrm{~W} / \mathrm{m} \bullet \mathrm{K}\end{array}$ & $\begin{array}{l}k t c, \\
W / m \bullet K\end{array}$ & $\begin{array}{l}\text { Max. conduction } \\
\text { temp. error }^{\mathrm{b}},{ }^{\circ} \mathrm{C}\end{array}$ & $\begin{array}{l}\text { Max. radiation } \\
\text { temp. error }^{b},{ }^{\circ} \mathrm{C}\end{array}$ \\
\hline $\begin{array}{l}\text { Axial TC } \\
0.64 \mathrm{~cm}^{\mathrm{a}} \\
\end{array}$ & 280 & 570 & 1.28 & 1 & 0.6125 & $2.75 \times 10^{-5}$ & 0.0470 & 69.2 & 18.5 & 52 \\
\hline $\begin{array}{l}\text { Axial TC, } \\
1.9 \mathrm{~cm}^{\mathrm{a}}\end{array}$ & 420 & 570 & 2.54 & 1 & 0.4868 & $3.189 \times 10^{-5}$ & 0.0499 & 67.0 & 1.2 & 38 \\
\hline $\begin{array}{l}\text { Axial TC, } \\
3.2 \mathrm{~cm}^{\mathrm{a}}\end{array}$ & 500 & 570 & 3.8 & 1 & 0.4373 & $3.415 \times 10^{-5}$ & 0.0535 & 64.6 & 0 & 19 \\
\hline Tube wall & $540-570$ & 570 & 1.59 & 0.5 & 0.4080 & $3.564 \times 10^{-5}$ & 0.0559 & 68.2 & 1.9 & 10 \\
\hline $\begin{array}{l}\text { Axial TC, } \\
0.64 \mathrm{~cm}^{\mathrm{a}}\end{array}$ & 400 & 720 & 1.28 & 1 & 0.5029 & $3.128 \times 10^{-5}$ & 0.0485 & 66.5 & 27 & 100 \\
\hline $\begin{array}{l}\text { Axial TC, } \\
1.9 \mathrm{~cm}^{\mathrm{a}}\end{array}$ & 580 & 720 & 2.54 & 1 & 0.3963 & $3.630 \times 10^{-5}$ & 0.0574 & 68.6 & 1.8 & 57 \\
\hline $\begin{array}{l}\text { Axial TC, } \\
3.2 \mathrm{~cm}^{\mathrm{a}}\end{array}$ & 640 & 720 & 3.8 & 1 & 0.3694 & $3.785 \times 10^{-5}$ & 0.0635 & 69.7 & 0 & 33 \\
\hline Tube wall & $680-720$ & 720 & 1.59 & 0.5 & 0.3469 & $3.933 \times 10^{-5}$ & 0.0634 & 71.5 & 2.6 & 19 \\
\hline
\end{tabular}

a Distance from the exit of the particle injection tube to the thermocouple junction (gas temperature in the particle injection tube, $0.64 \mathrm{~cm}$ before the exit, was approximately $77^{\circ} \mathrm{C}$ ).

b True gas temperature $=$ gas temperature measured using thermocouple - conduction error - radiation error 


\section{[A8] APPENDIX 8. AMPLITUDES OF MEASURED ACOUSTIC PRESSURE AND CALCULATED ACOUSTIC VELOCITY IN THE HEATED PYROLYSIS TUBE}

Figs. A8.1-A8.30 show profiles of the measured acoustic pressure amplitude and the calculated acoustic velocity amplitude in the pyrolysis tube obtained with an acoustic field of $146-160 \mathrm{~dB}_{\mathrm{rms}}$ and $310-1010 \mathrm{~Hz}$ under reactor conditions of $400-700^{\circ} \mathrm{C}, 0.18-0.81 \mathrm{~m}$ pyrolysis tube heated lengths, and 0.31-6.41 s preheated $\mathrm{N}_{2}$ actual space-time. The probe acoustic pressure transducer was calibrated against a reference pressure transducer. Table A8.1 shows the output voltage of probe acoustic pressure transducer (Kistler model 211B5, serial number C67647) that corresponded to the acoustic pressure measured by the reference transducer (Kistler model 211B5, serial number C46869).

Table A8.1. Output voltage of probe acoustic pressure transducer corresponding to the acoustic pressure measured by reference transducer.

\begin{tabular}{|c|c|c|c|c|c|c|c|c|c|}
\hline \multicolumn{2}{|c|}{$\begin{array}{l}\text { Reference pressure } \\
\text { transducer }\end{array}$} & \multicolumn{8}{|c|}{ Probe acoustic pressure transducer, $m V_{\text {rms }}$} \\
\hline $\mathbf{P a}_{\text {rms }}$ & $\mathbf{d B}_{\mathrm{rms}}$ & $300 \mathrm{~Hz}$ & $310 \mathrm{~Hz}$ & $320 \mathrm{~Hz}$ & $954 \mathrm{~Hz}$ & $968 \mathrm{~Hz}$ & $980 \mathrm{~Hz}$ & $992 \mathrm{~Hz}$ & $1002 \mathrm{~Hz}$ \\
\hline 414 & 146.3 & 53 & 55 & 55 & 35.9 & 35.8 & 39 & 45.5 & 43 \\
\hline 551 & 148.8 & 70 & 72 & 71 & 48 & 49 & 52 & 57 & 58.3 \\
\hline 689 & 150.7 & 88 & 90 & 91 & 59.6 & 64 & 65 & 72 & 72 \\
\hline 827 & 152.3 & 104 & 107 & 108 & 72.1 & 75 & 77.8 & 86 & 86 \\
\hline 965 & 3.7 & 120 & 120 & 125 & 85 & 86 & 90 & 101 & 100 \\
\hline 1103 & \begin{tabular}{|l|}
154.8 \\
\end{tabular} & - & & - & 98.5 & 95 & 105 & 113 & 115 \\
\hline 1241 & 155.9 & - & - & - & 108.6 & 105 & 117 & 128 & 128 \\
\hline 1378 & 6.8 & - & - & - & 120 & 115 & 129 & 140 & 141 \\
\hline 1517 & 157.6 & - & - & - & 133 & 125 & 147 & 153 & 155 \\
\hline 1655 & \begin{tabular}{l|l|}
158.4 \\
\end{tabular} & - & & - & 143 & 138 & 157 & 166 & 168 \\
\hline 1793 & 159.1 & - & - & - & 153 & 150 & 169 & 183 & 181 \\
\hline 1931 & \begin{tabular}{|l|}
159.7 \\
\end{tabular} & - & - & - & 168 & 164 & 182 & 195 & 194 \\
\hline 2068 & 160.3 & & & & 174 & 173 & 196 & 202 & 207 \\
\hline$: \mathbf{P a}_{\text {rms }} \mathbf{v}$ & s. $\mathrm{mV}_{\mathrm{rms}}$ & 0.9994 & 0.9969 & 0.9990 & 0.9985 & 0.9976 & 0.9994 & 0.9986 & 0.9996 \\
\hline
\end{tabular}


The acoustic velocity in the resonant standing wave was assumed to be $90^{\circ}$ out of phase with the acoustic pressure (Colby, 1938). The acoustic velocity amplitude $\hat{u}_{g}$ at different positions on the standing wave can be expressed as,

$$
\hat{u}_{g}=\mid \hat{u}_{s w} \sin \left[\left(z_{m}-z_{p p}\right) \frac{2 \pi}{\left(4 \lambda_{1 / 4}\right)}\right],
$$

where $z_{p p}$ is the distance from the particle injection tube exit to the position of maximum acoustic pressure on the standing wave, $z_{m}$ is the distance from the particle injection tube exit to the position of acoustic pressure measurements on the standing wave, and $\lambda_{1 / 4}$ is the distance between pressure nodes or pressure anti-nodes. $\lambda_{1 / 4}$ was estimated to the nearest $0.2 \mathrm{~cm}$, and $z_{p p}$ was measured to the nearest $1 \mathrm{~cm}$. Eq. A8.1 was derived by expressing Eq. 16 in terms of the acoustic velocity, without respect to cycle time by letting $\sin 2 \pi f t=1$. Using Eq. $10, \hat{u}_{s w}$ can be expressed in terms of the acoustic pressure amplitude of the standing wave as,

$$
\hat{u}_{s w}=\frac{\hat{p}_{s w}}{c \rho_{g}}
$$

where $\hat{p}_{s w}$ is the acoustic pressure amplitude of the standing wave. The velocity of sound can be calculated using Eq. 7. The acoustic pressure amplitude was obtained by multiplying the root mean square acoustic pressure by the $\sqrt{2}$. Table A8.2 lists the values of the variables used to calculate acoustic pressure amplitudes on the standing wave. 
Table A8.2. Values of variables used to calculate acoustic pressure amplitudes of the standing wave.

\begin{tabular}{|r|r|r|r|}
\hline Temperature, ${ }^{\mathbf{}} \mathbf{C}$ & \multicolumn{1}{|c|}{$\gamma$} & \multicolumn{1}{c|}{$\mathbf{~} \mathbf{m} / \mathbf{s}$} & $\rho_{g}, \mathbf{k g} / \mathbf{m}^{\mathbf{3}}$ \\
\hline 20 & 1.400 & 345 & 1.1473 \\
\hline 400 & 1.372 & 523 & 0.5028 \\
\hline 550 & 1.357 & 576 & 0.4103 \\
\hline 700 & 1.343 & 623 & 0.3469 \\
\hline
\end{tabular}

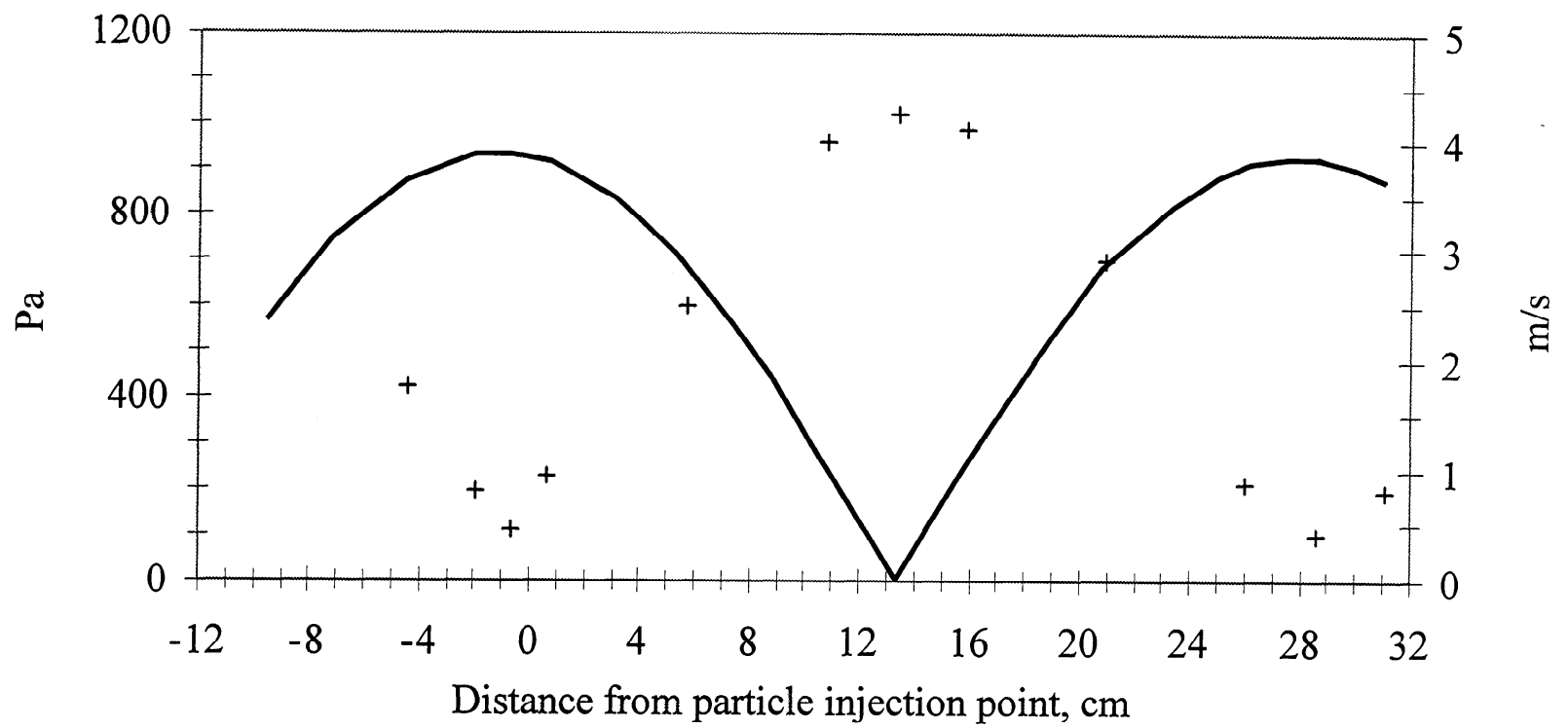

Figure A8.1. Profiles of the measured acoustic pressure amplitude $(+)$ and the calculated acoustic velocity amplitude $(-)$ in the pyrolysis tube obtained with an acoustic field of $151 \mathrm{~dB}$ and $960 \mathrm{~Hz}$ (RAC1119) under reactor conditions of $400^{\circ} \mathrm{C}, 0.81 \mathrm{~m}$ pyrolysis tube heated length, $0.86 \mathrm{~s}$ particle residence time, and $2.10 \mathrm{~s}$ secondary gas space-time. 


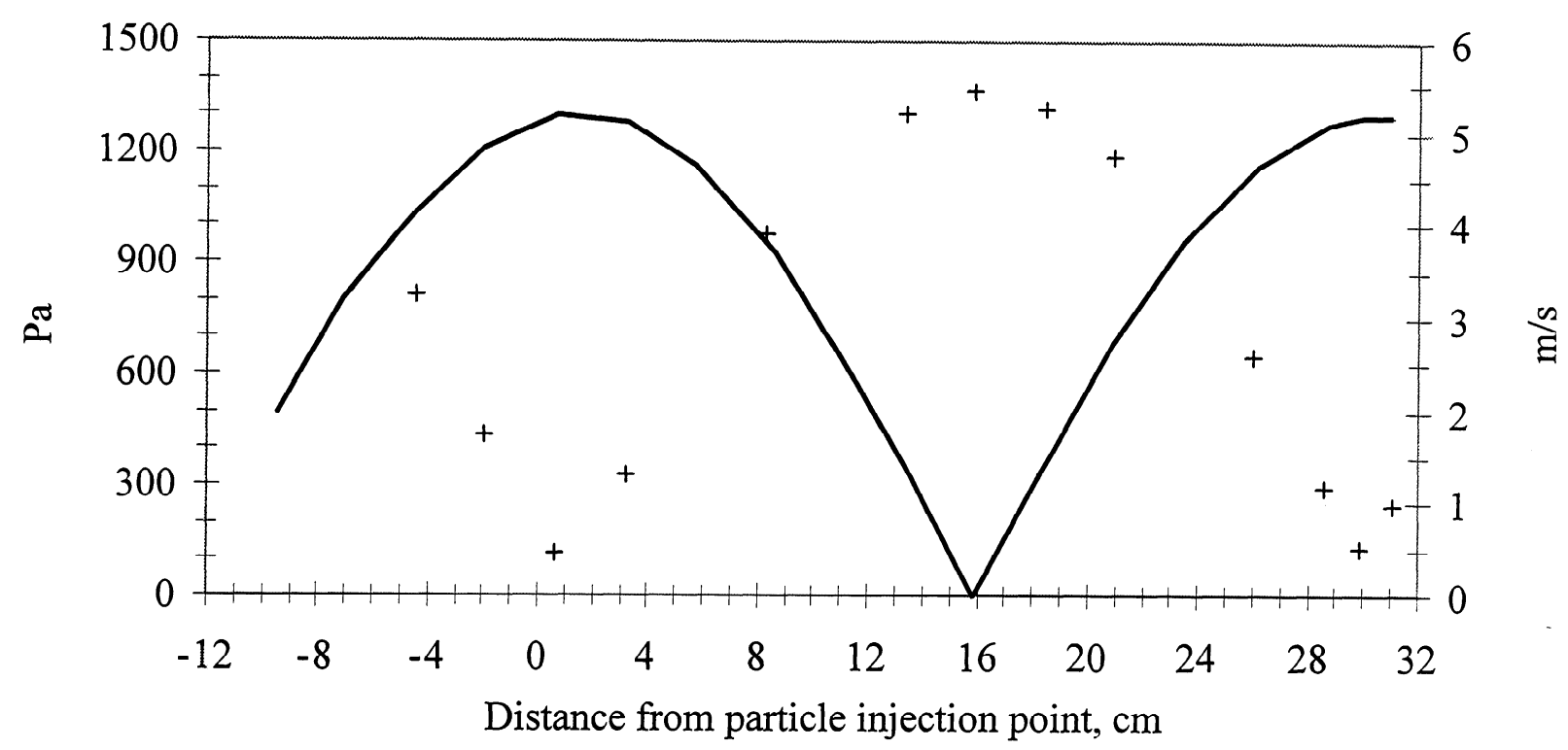

Figure A8.2. Profiles of the measured acoustic pressure amplitude $(+)$ and the calculated acoustic velocity amplitude $(-)$ in the pyrolysis tube obtained with an acoustic field of $154 \mathrm{~dB}$ and $970 \mathrm{~Hz}$ (RAC1009) under reactor conditions of $400^{\circ} \mathrm{C}, 0.81 \mathrm{~m}$ pyrolysis tube heated length, $1.10 \mathrm{~s}$ particle residence time, and $1.70 \mathrm{~s}$ secondary gas space-time.

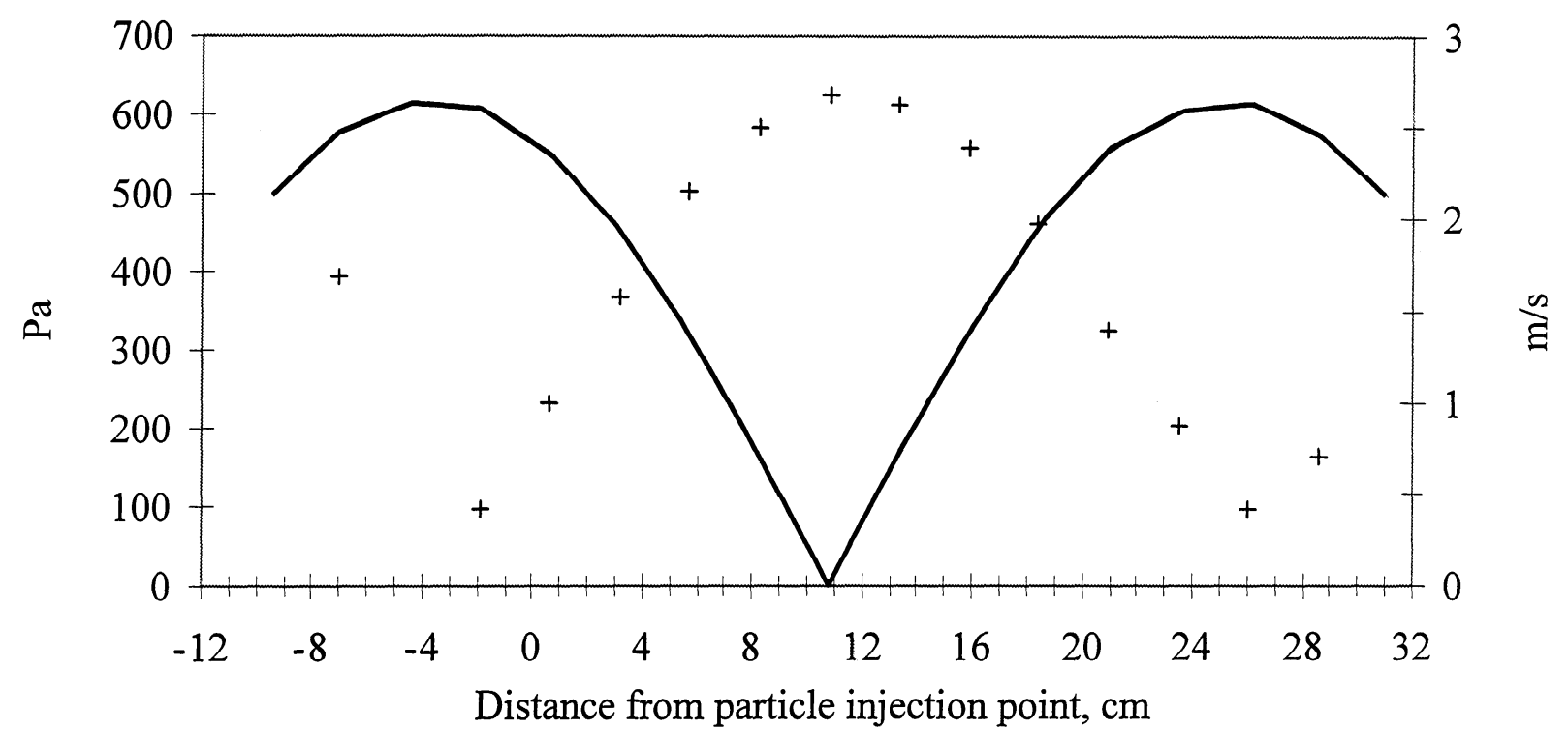

Figure A8.3. Profiles of the measured acoustic pressure amplitude $(+)$ and the calculated acoustic velocity amplitude ( - in the pyrolysis tube obtained with an acoustic field of $146 \mathrm{~dB}$ and $1000 \mathrm{~Hz}$ (RAC925) under reactor conditions of $550^{\circ} \mathrm{C}, 0.81 \mathrm{~m}$ pyrolysis tube heated length, $1.23 \mathrm{~s}$ particle residence time, and $1.72 \mathrm{~s}$ secondary gas space-time. 


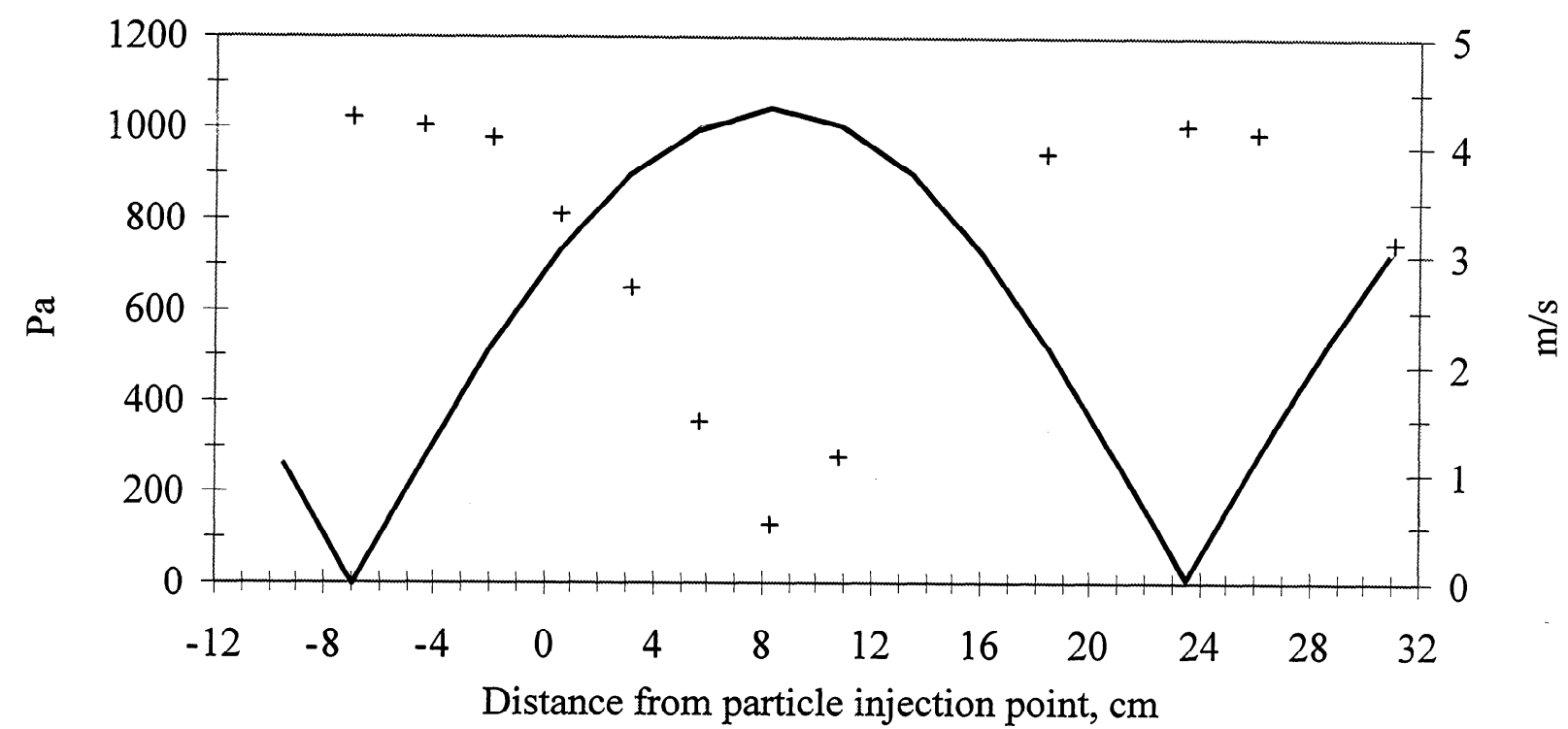

Figure A8.4. Profiles of the measured acoustic pressure amplitude $(+)$ and the calculated acoustic velocity amplitude $(\rightarrow$ in the pyrolysis tube obtained with an acoustic field of $151 \mathrm{~dB}$ and $950 \mathrm{~Hz}$ (RAC1106) under reactor conditions of $550^{\circ} \mathrm{C}, 0.18 \mathrm{~m}$ pyrolysis tube heated length, and $0.38 \mathrm{~s}$ secondary gas space-time.

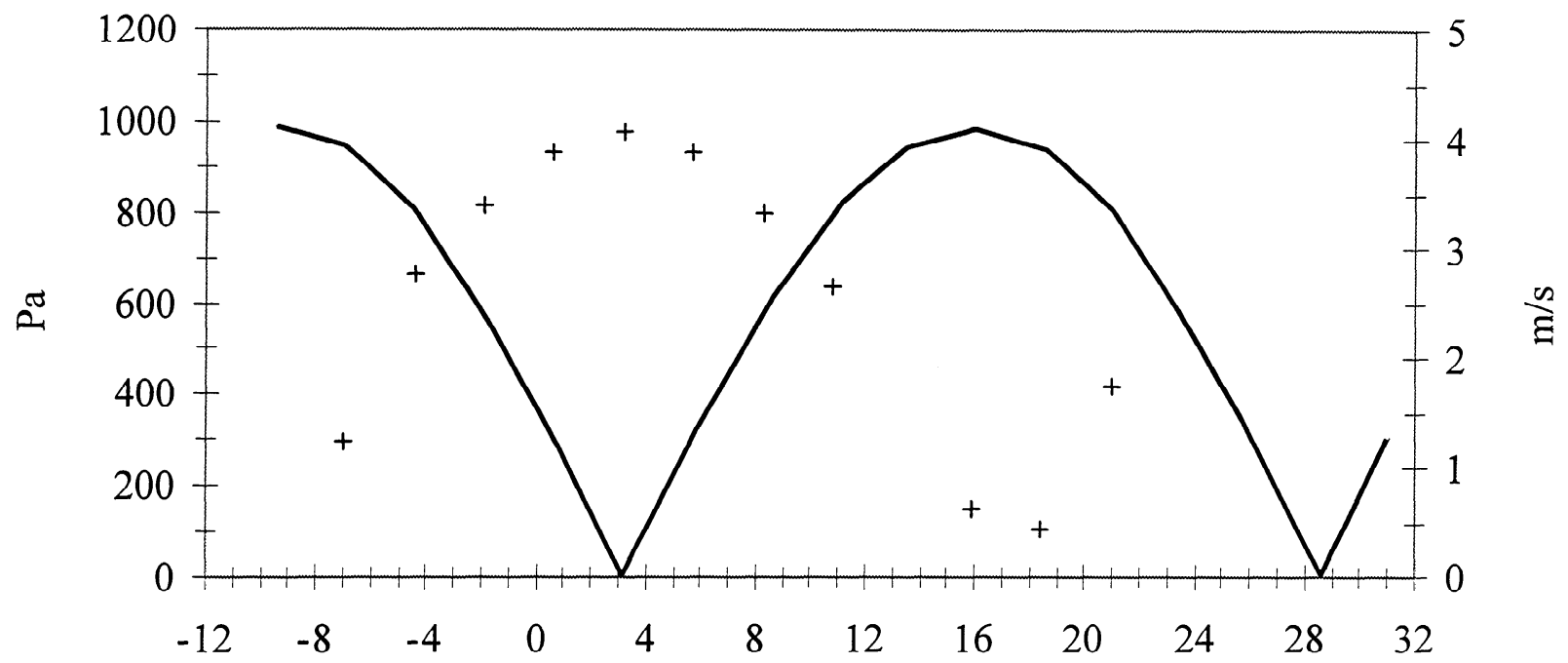

Distance from particle injection point, $\mathrm{cm}$

Figure A8.5. Profiles of the measured acoustic pressure amplitude $(+)$ and the calculated acoustic velocity amplitude (-) in the pyrolysis tube obtained with an acoustic field of $151 \mathrm{~dB}$ and $1000 \mathrm{~Hz}(\mathrm{RAC1} 107)$ under reactor conditions of $550^{\circ} \mathrm{C}$, $0.18 \mathrm{~m}$ pyrolysis tube heated length, $0.27 \mathrm{~s}$ particle residence time, and $0.38 \mathrm{~s}$ secondary gas space-time. 


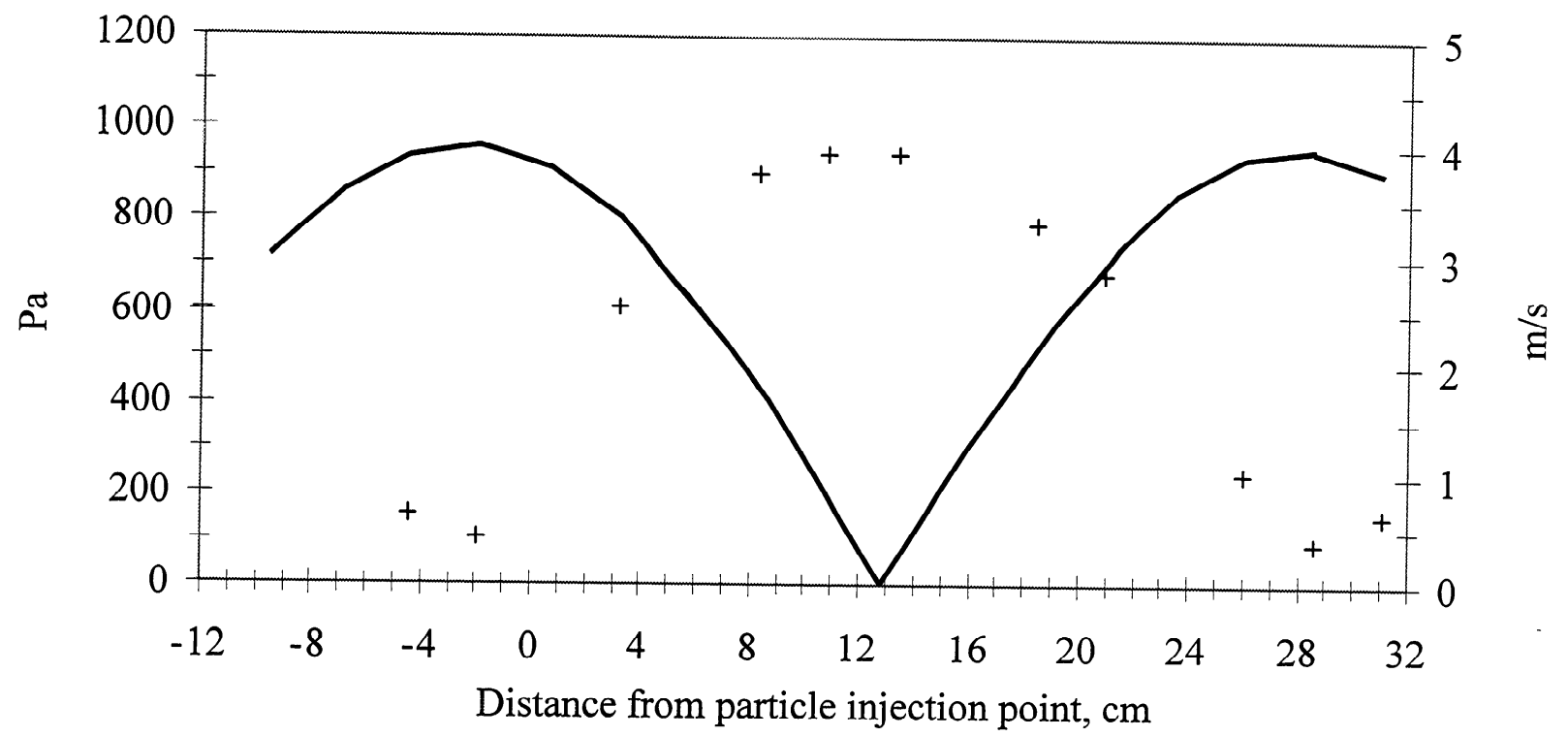

Figure A8.6. Profiles of the measured acoustic pressure amplitude $(+)$ and the calculated acoustic velocity amplitude $(-)$ in the pyrolysis tube obtained with an acoustic field of $151 \mathrm{~dB}$ and $970 \mathrm{~Hz}$ (RAC1108) under reactor conditions of $550^{\circ} \mathrm{C}, 0.48 \mathrm{~m}$ pyrolysis tube heated length, 0.70 particle residence time, and $1.02 \mathrm{~s}$ secondary gas space-time.

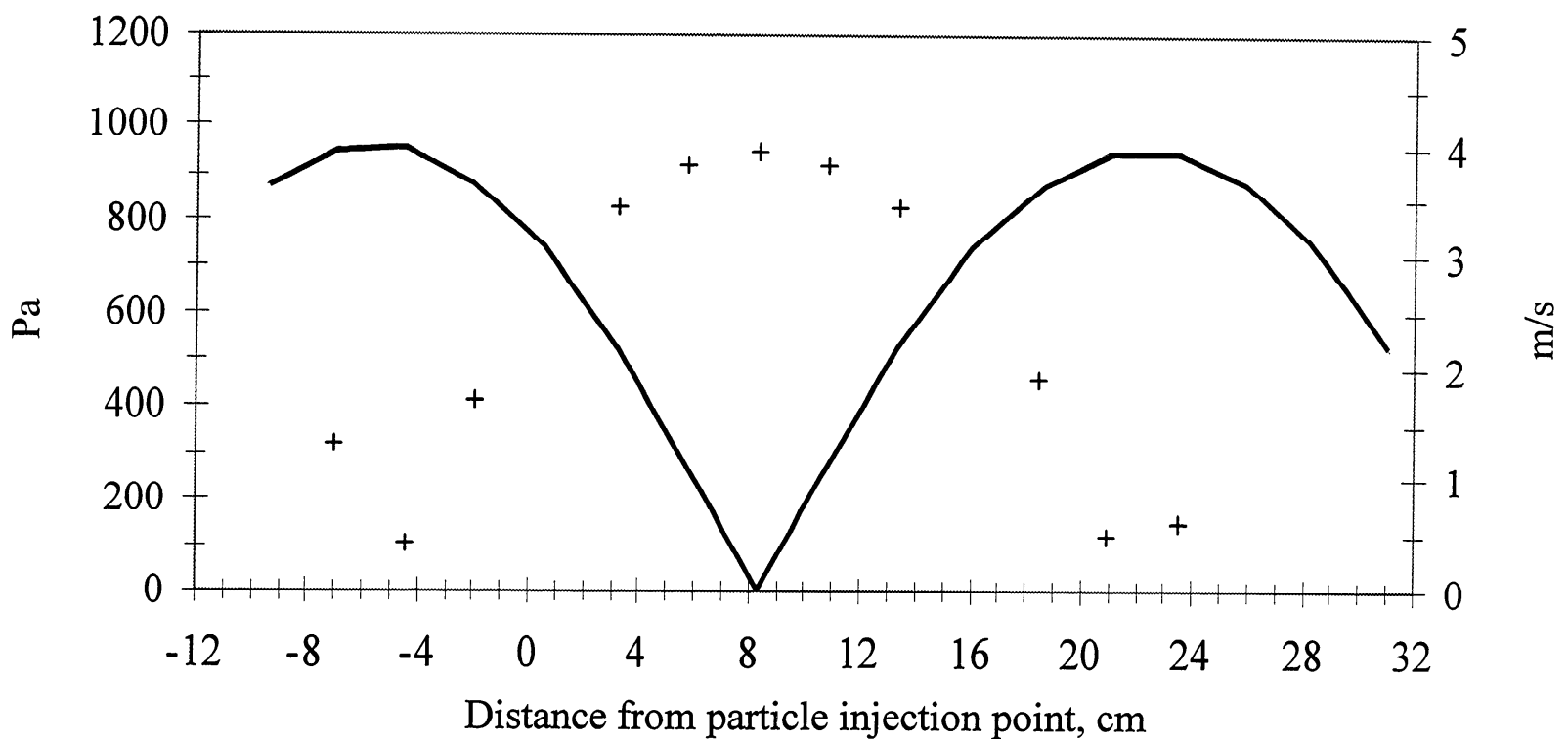

Figure A8.7. Profiles of the measured acoustic pressure amplitude $(+)$ and the calculated acoustic velocity amplitude $(-)$ in the pyrolysis tube obtained with an acoustic field of $151 \mathrm{~dB}$ and $990 \mathrm{~Hz}$ (RAC925B) under reactor conditions of $550^{\circ} \mathrm{C}$, $0.81 \mathrm{~m}$ pyrolysis tube heated length, $1.26 \mathrm{~s}$ particle residence time, and $1.72 \mathrm{~s}$ secondary gas space-time. 


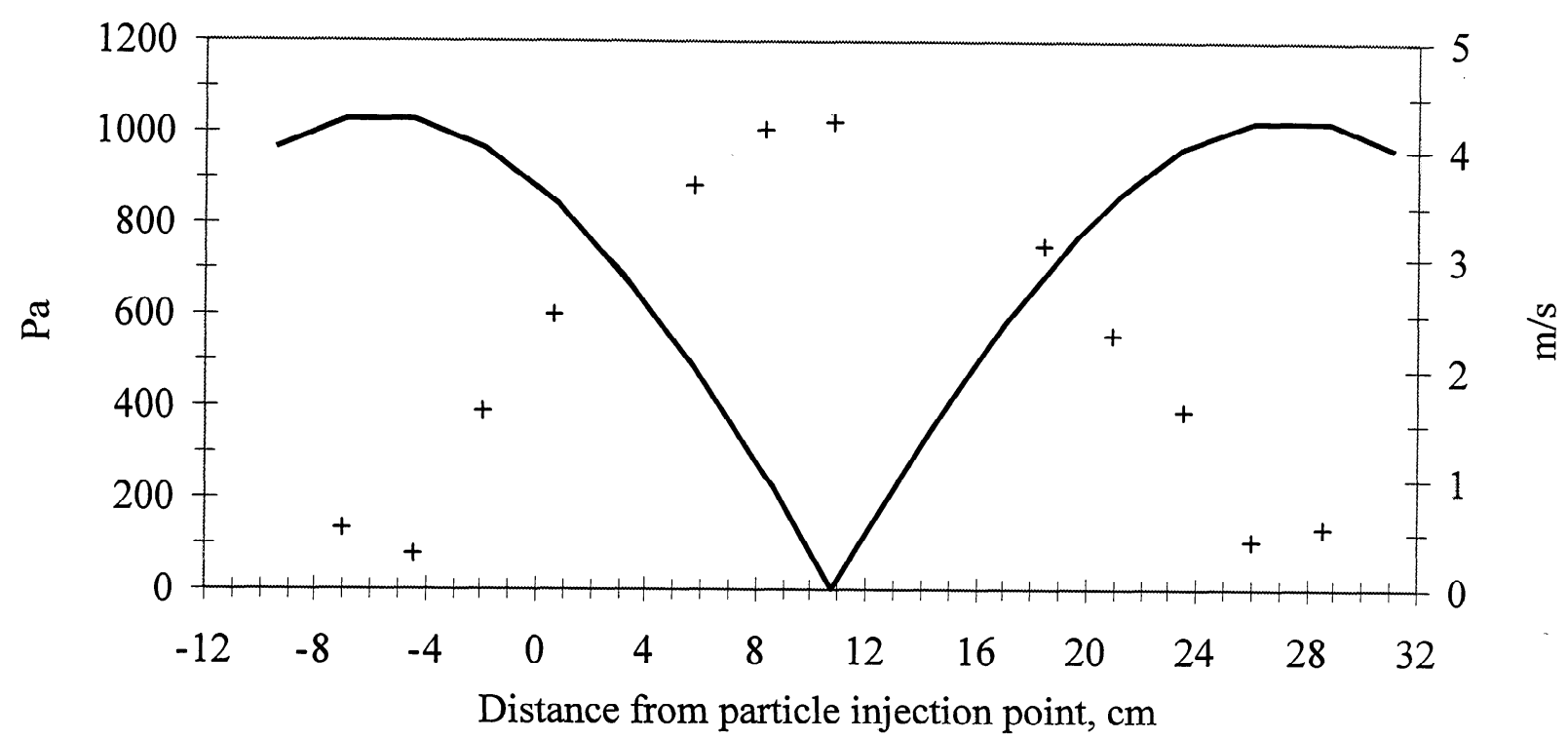

Figure A8.8. Profiles of the measured acoustic pressure amplitude $(+)$ and the calculated acoustic velocity amplitude $(-)$ in the pyrolysis tube obtained with an acoustic field of $151 \mathrm{~dB}$ and $980 \mathrm{~Hz}(\mathrm{RAC1230 \textrm {B }})$ under reactor conditions of $550^{\circ} \mathrm{C}$, $0.81 \mathrm{~m}$ pyrolysis tube heated length, $2.22 \mathrm{~s}$ particle residence time, and $3.39 \mathrm{~s}$ secondary gas space-time.

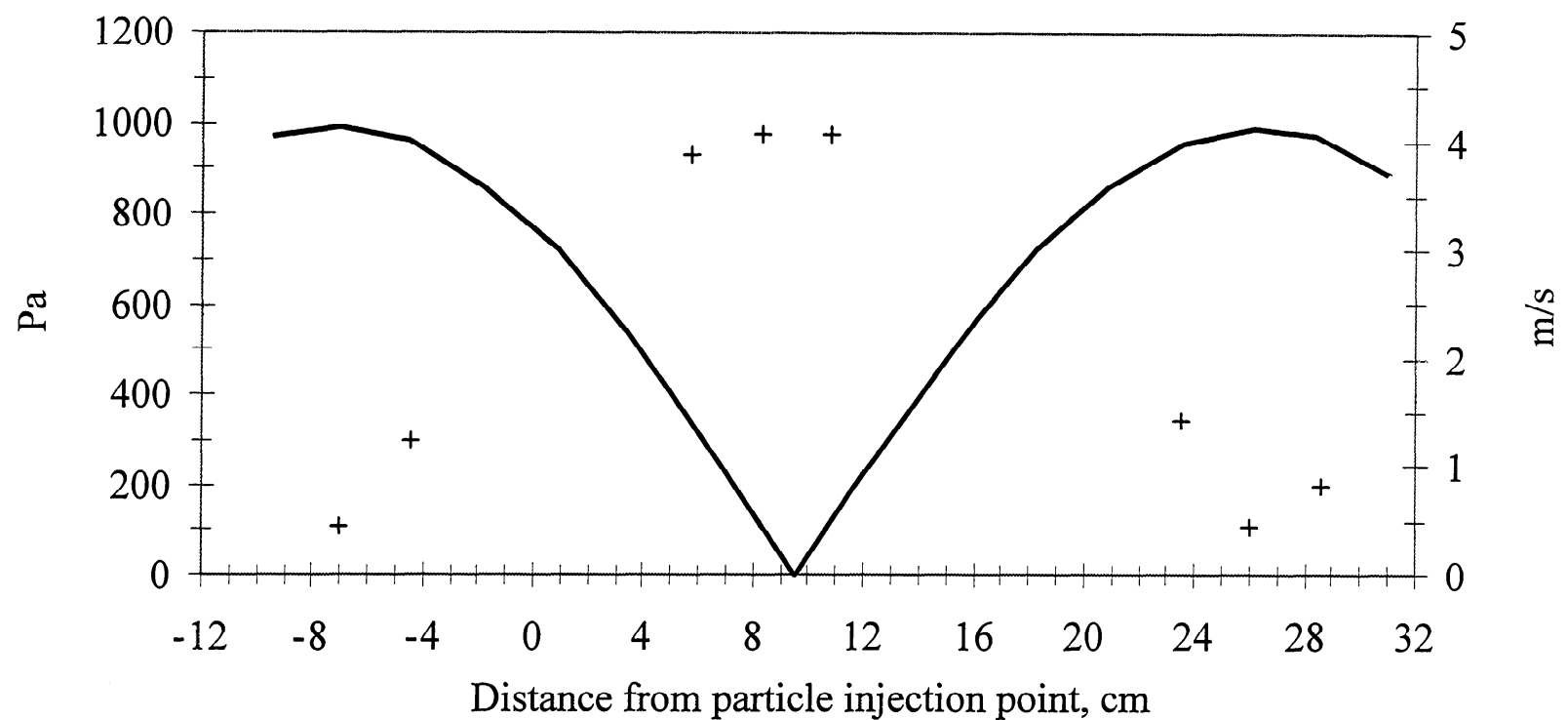

Figure A8.9. Profiles of the measured acoustic pressure amplitude $(+)$ and the calculated acoustic velocity amplitude $(-)$ in the pyrolysis tube obtained with an acoustic field of $151 \mathrm{~dB}$ and $980 \mathrm{~Hz}$ (RAC1226) under reactor conditions of $550^{\circ} \mathrm{C}, 0.81 \mathrm{~m}$ pyrolysis tube heated length, $3.69 \mathrm{~s}$ particle residence time, and $6.59 \mathrm{~s}$ secondary gas space-time. 


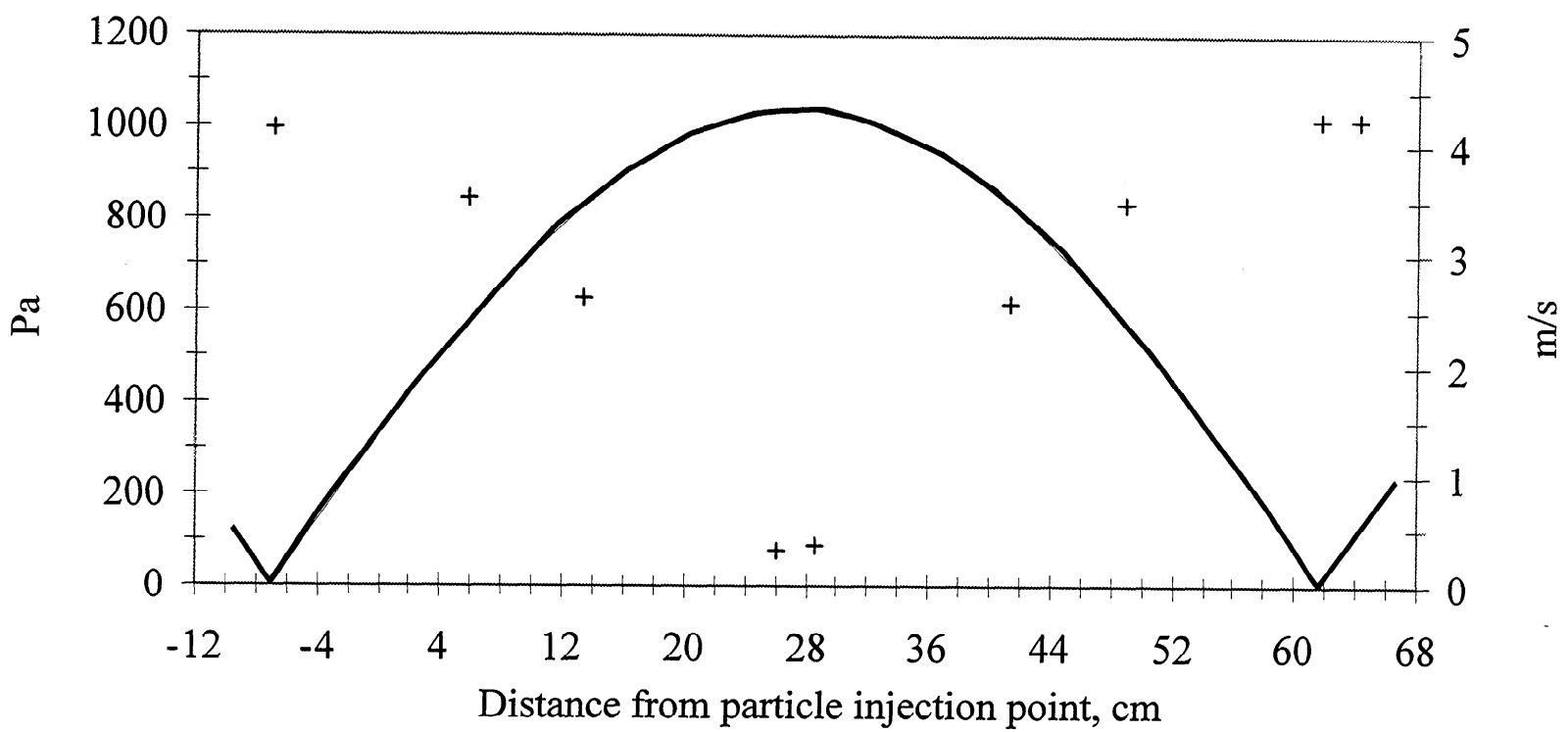

Figure A8.10. Profiles of the measured acoustic pressure amplitude (+) and the calculated acoustic velocity amplitude $(-)$ in the pyrolysis tube obtained with an acoustic field of $151 \mathrm{~dB}$ and $310 \mathrm{~Hz}(\mathrm{RAC1} 231 \mathrm{~A})$ under reactor conditions of $550^{\circ} \mathrm{C}$, $0.81 \mathrm{~m}$ pyrolysis tube heated length, $1.26 \mathrm{~s}$ particle residence time, and $1.72 \mathrm{~s}$ secondary gas space-time.

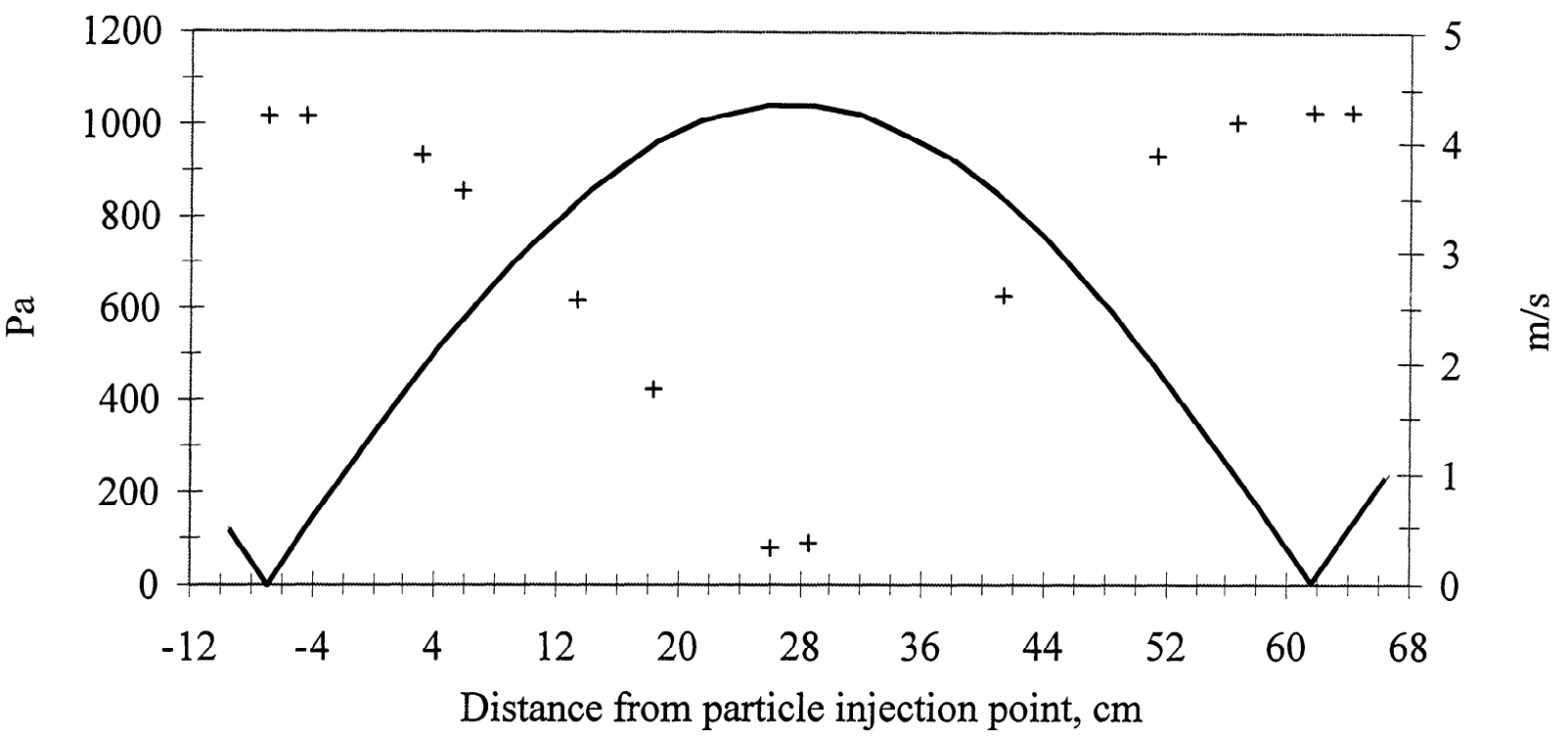

Figure A8.11. Profiles of the measured acoustic pressure amplitude (+) and the calculated acoustic velocity amplitude ( - in the pyrolysis tube obtained with an acoustic field of $151 \mathrm{~dB}$ and $310 \mathrm{~Hz}(\mathrm{RAC} 1231 \mathrm{~B})$ under reactor conditions of $550^{\circ} \mathrm{C}$, $0.81 \mathrm{~m}$ pyrolysis tube heated length, $2.18 \mathrm{~s}$ particle residence time, and $3.39 \mathrm{~s}$ secondary gas space-time. 


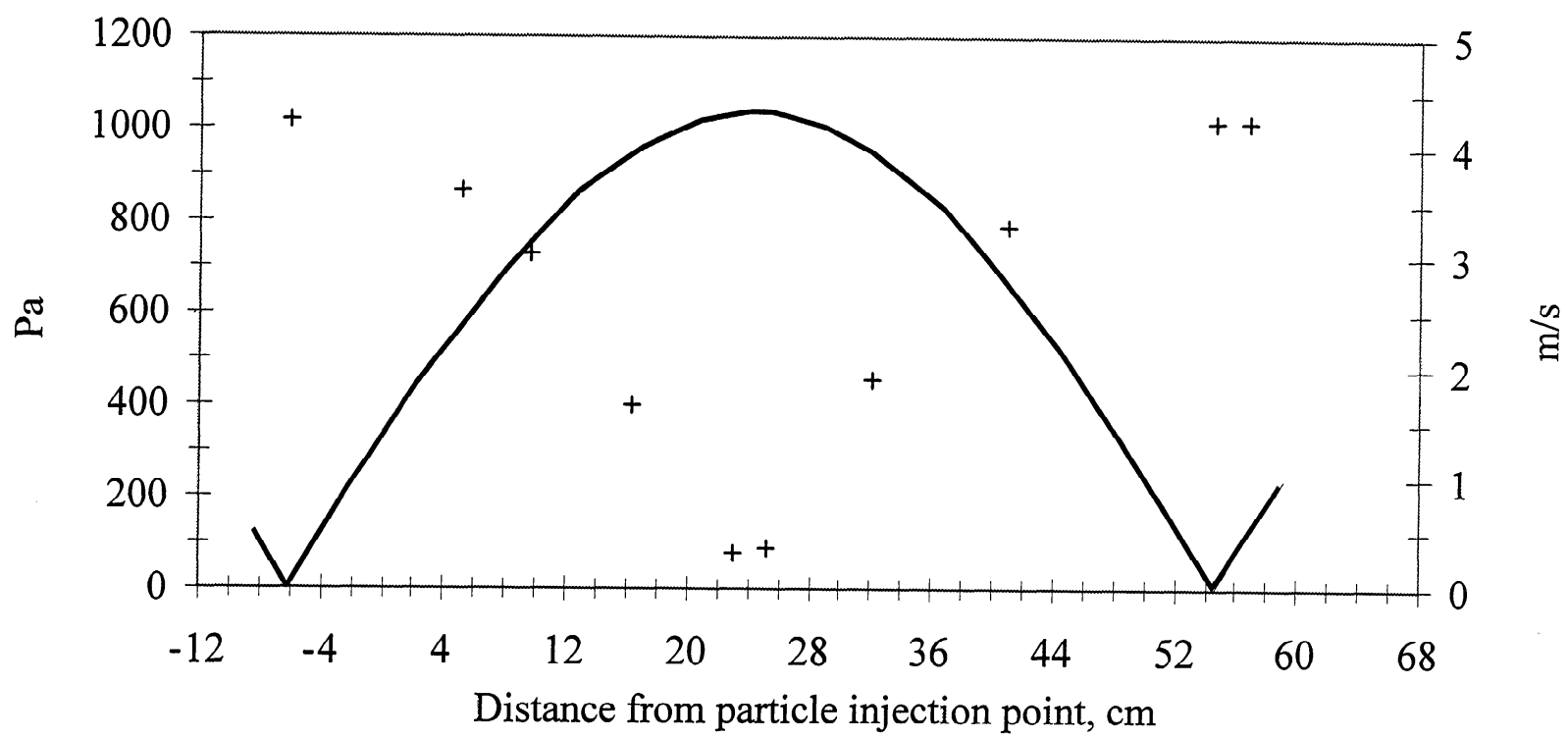

Figure A8.12. Profiles of the measured acoustic pressure amplitude $(+)$ and the calculated acoustic velocity amplitude $(-)$ in the pyrolysis tube obtained with an acoustic field of $151 \mathrm{~dB}$ and $310 \mathrm{~Hz}\left(\mathrm{RAC1231 \textrm {C } )}\right.$ under reactor conditions of $550^{\circ} \mathrm{C}$, $0.81 \mathrm{~m}$ pyrolysis tube heated length, $3.57 \mathrm{~s}$ particle residence time, and $6.59 \mathrm{~s}$ secondary gas space-time.

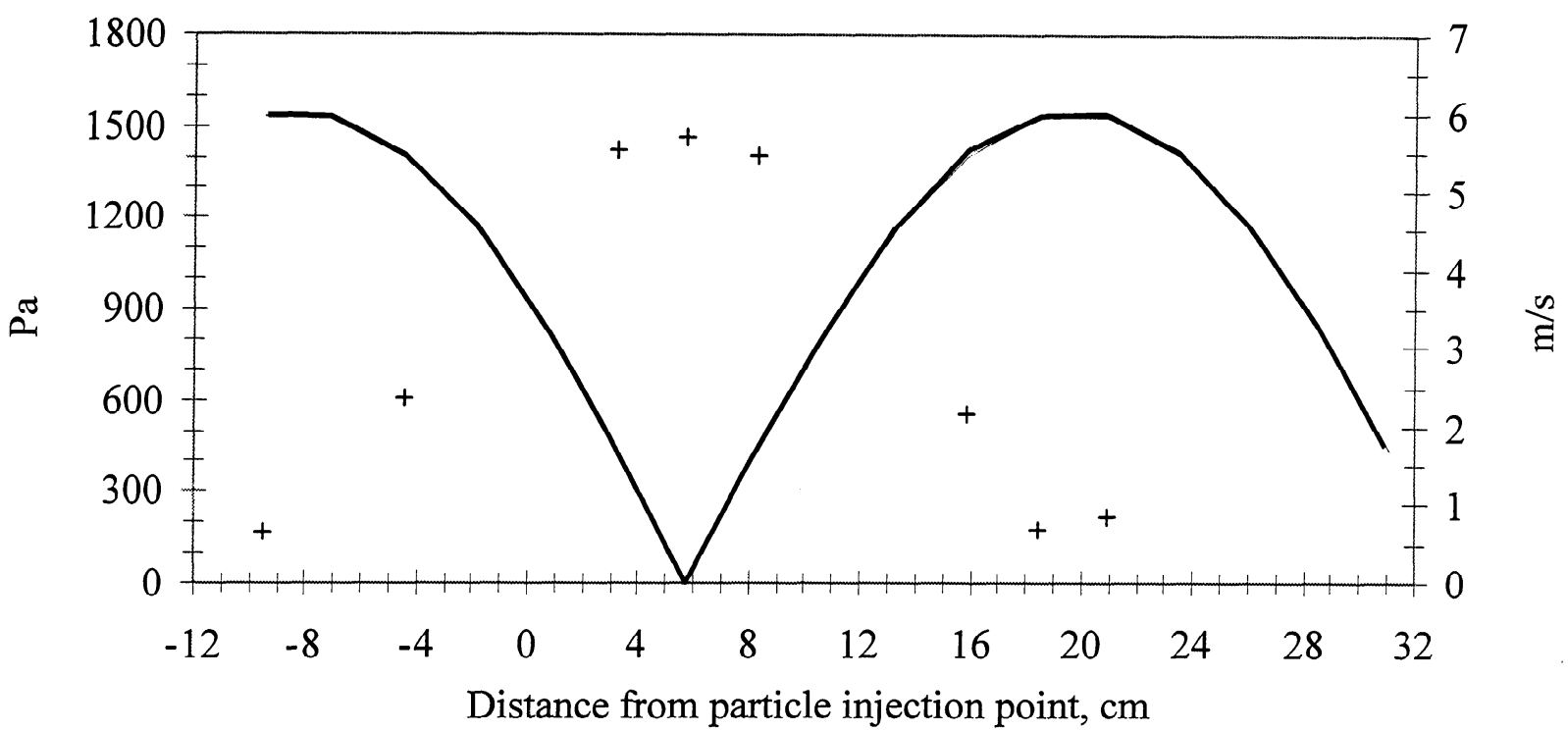

Figure A8.13. Profiles of the measured acoustic pressure amplitude $(+)$ and the calculated acoustic velocity amplitude $(-)$ in the pyrolysis tube obtained with an acoustic field of $154 \mathrm{~dB}$ and $1010 \mathrm{~Hz}$ (RAC1028) under reactor conditions of $550^{\circ} \mathrm{C}$, $0.18 \mathrm{~m}$ pyrolysis tube heated length, and $0.38 \mathrm{~s}$ secondary gas space-time. 


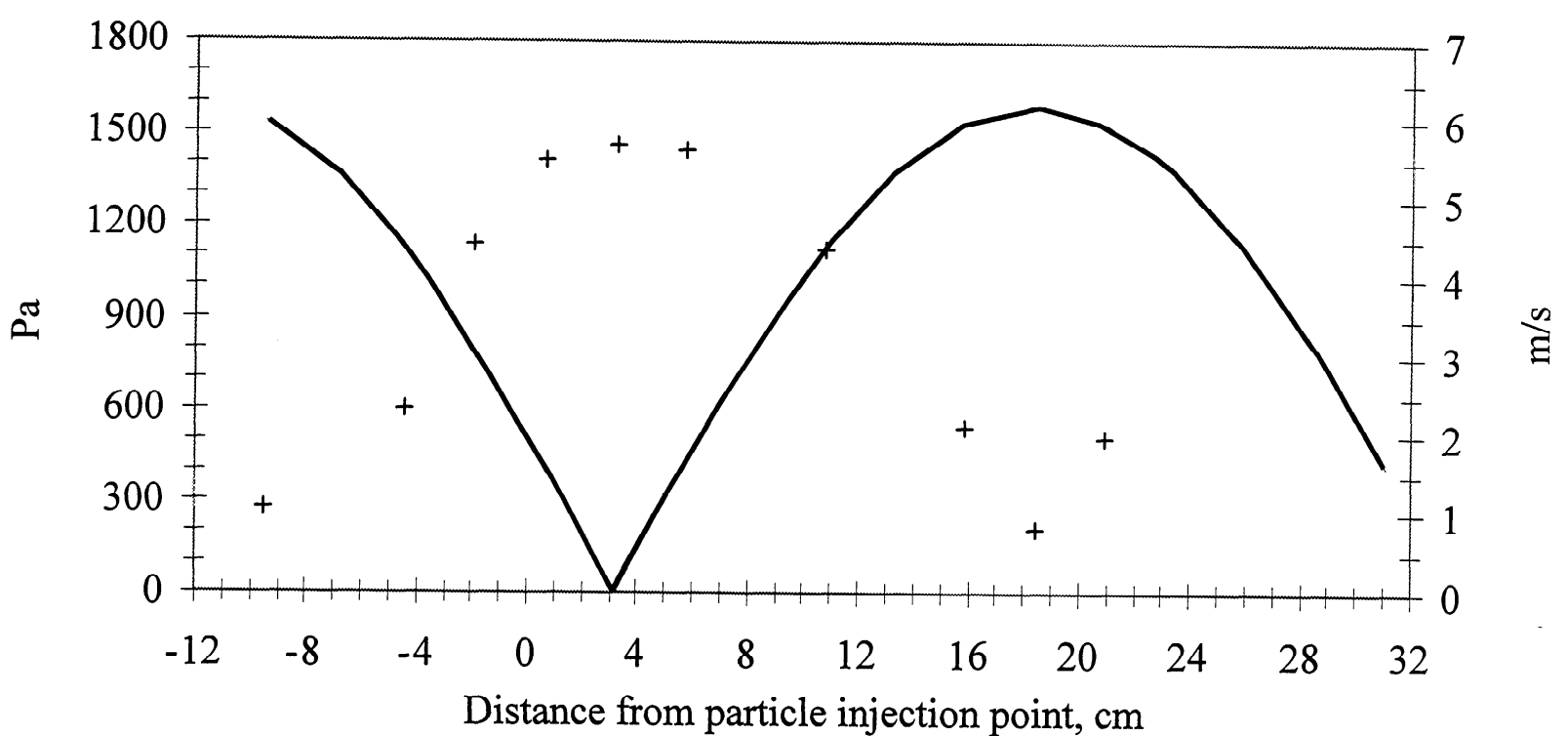

Figure A8.14. Profiles of the measured acoustic pressure amplitude $(+)$ and the calculated acoustic velocity amplitude $(-)$ in the pyrolysis tube obtained with an acoustic field of $154 \mathrm{~dB}$ and $950 \mathrm{~Hz}$ (RAC912) under reactor conditions of $550^{\circ} \mathrm{C}, 0.81 \mathrm{~m}$ pyrolysis tube heated length, $1.29 \mathrm{~s}$ particle residence time, and $1.72 \mathrm{~s}$ secondary gas space-time.

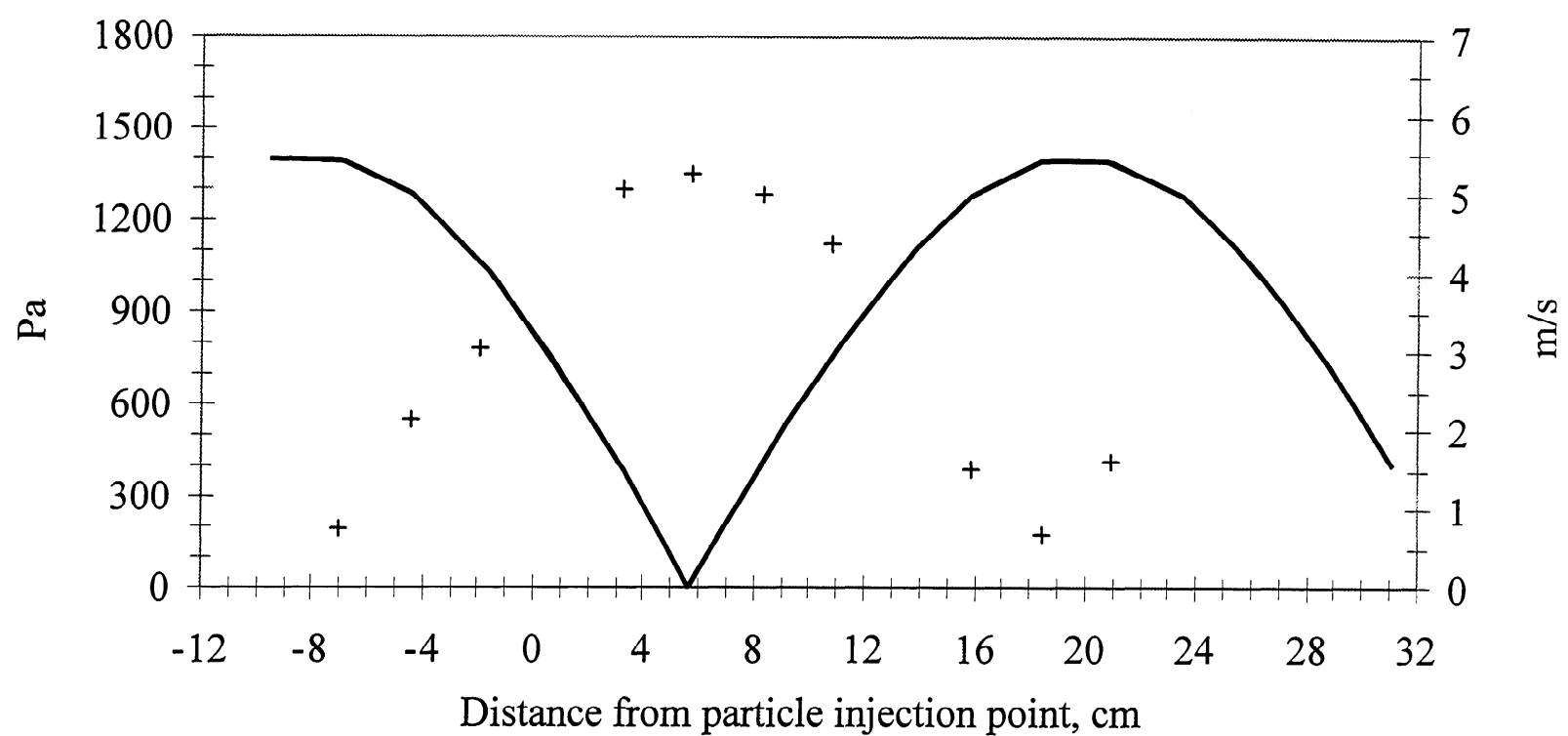

Figure A8.15. Profiles of the measured acoustic pressure amplitude $(+)$ and the calculated acoustic velocity amplitude ( - in the pyrolysis tube obtained with an acoustic field of $154 \mathrm{~dB}$ and $990 \mathrm{~Hz}$ (RAC926) under reactor conditions of $550^{\circ} \mathrm{C}, 0.81 \mathrm{~m}$ pyrolysis tube heated length, $1.29 \mathrm{~s}$ particle residence time, and $1.72 \mathrm{~s}$ secondary gas space-time. 


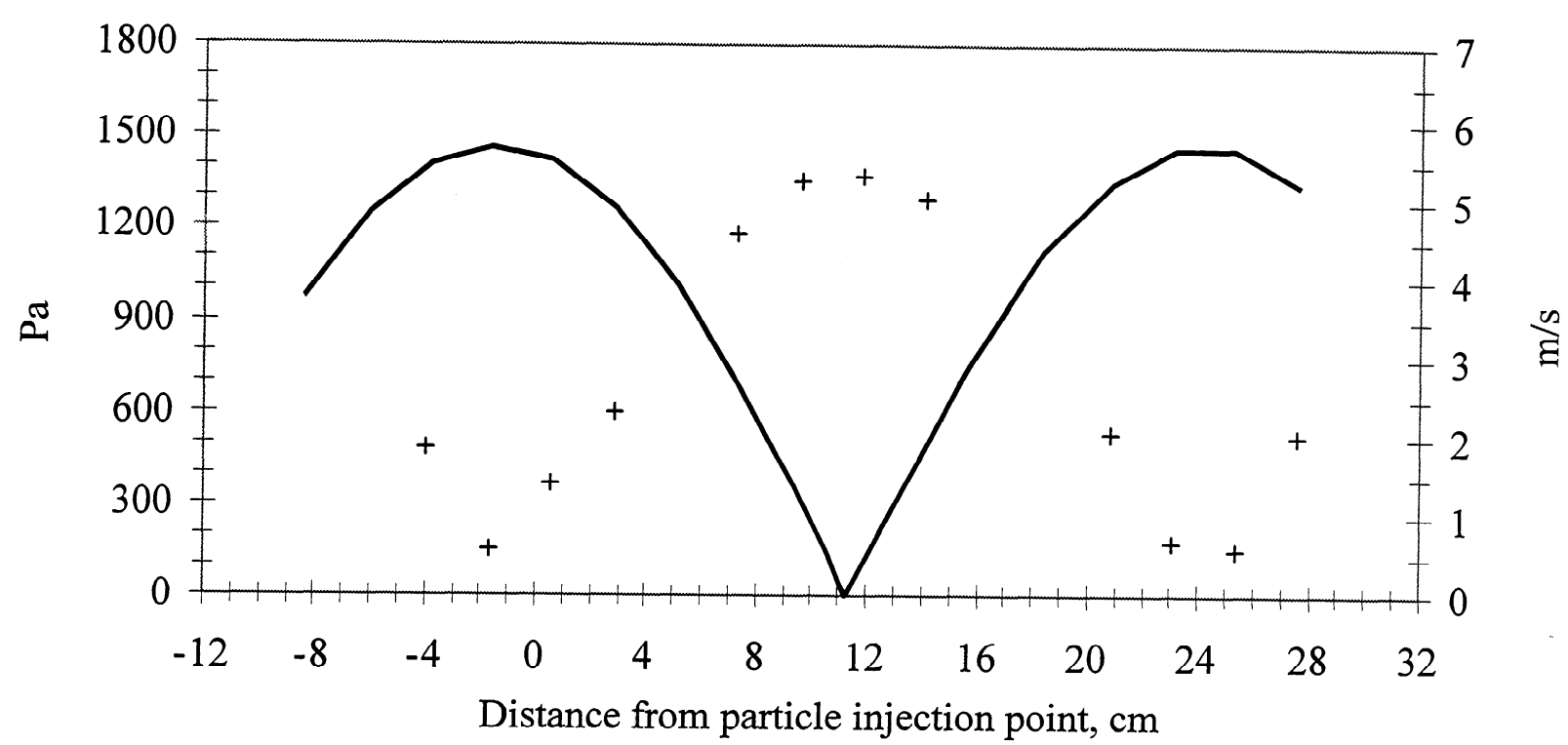

Figure A8.16. Profiles of the measured acoustic pressure amplitude $(+)$ and the calculated acoustic velocity amplitude $(-)$ in the pyrolysis tube obtained with an acoustic field of $154 \mathrm{~dB}$ and $1000 \mathrm{~Hz}(\mathrm{RACl014})$ under reactor conditions of $530^{\circ} \mathrm{C}$, $0.81 \mathrm{~m}$ pyrolysis tube heated length, $1.29 \mathrm{~s}$ particle residence time, and $1.76 \mathrm{~s}$ secondary gas space-time.

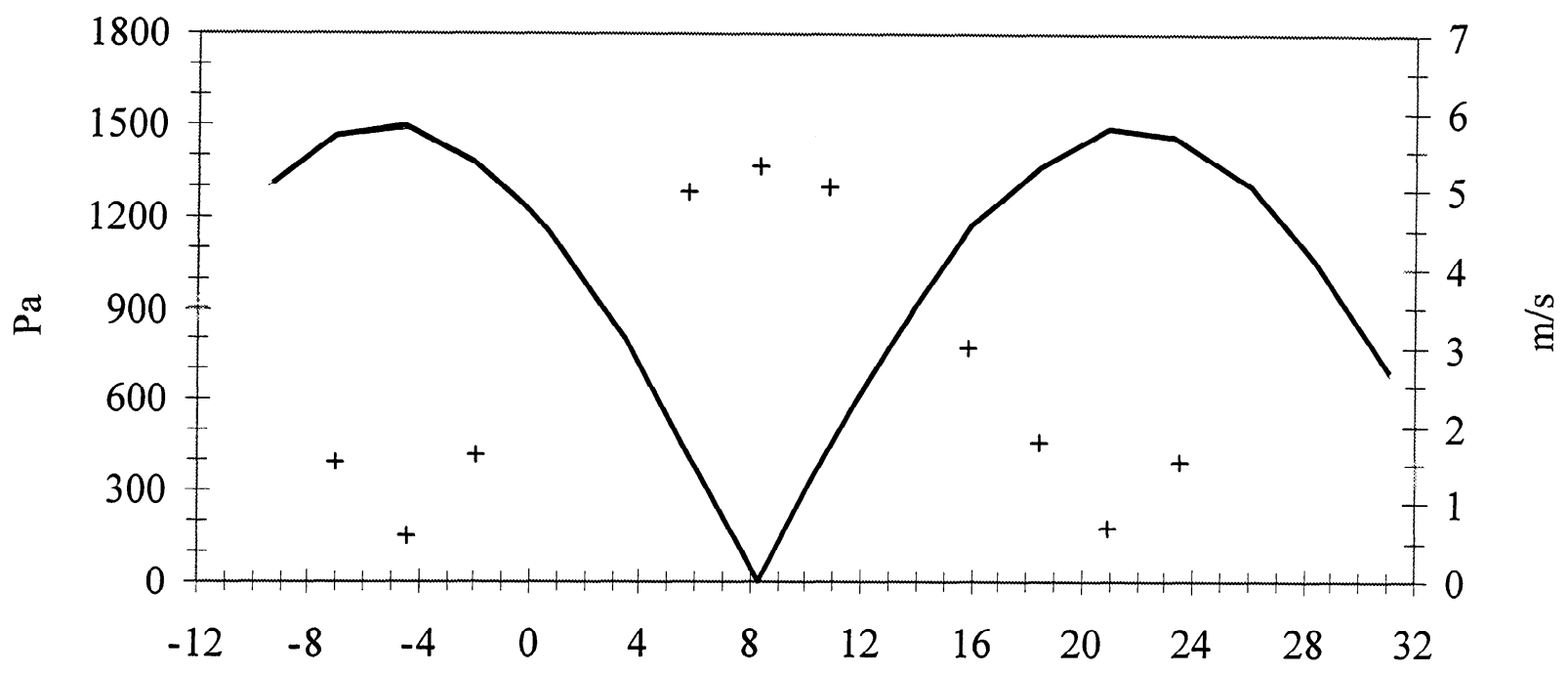

Distance from particle injection point, $\mathrm{cm}$

Figure A8.17. Profiles of the measured acoustic pressure amplitude $(+)$ and the calculated acoustic velocity amplitude (-) in the pyrolysis tube obtained with an acoustic field of $154 \mathrm{~dB}$ and $990 \mathrm{~Hz}$ (RAC930) under reactor conditions of $550^{\circ} \mathrm{C}, 0.81 \mathrm{~m}$ pyrolysis tube heated length, $2.27 \mathrm{~s}$ particle residence time, and $3.39 \mathrm{~s}$ secondary gas space-time. 


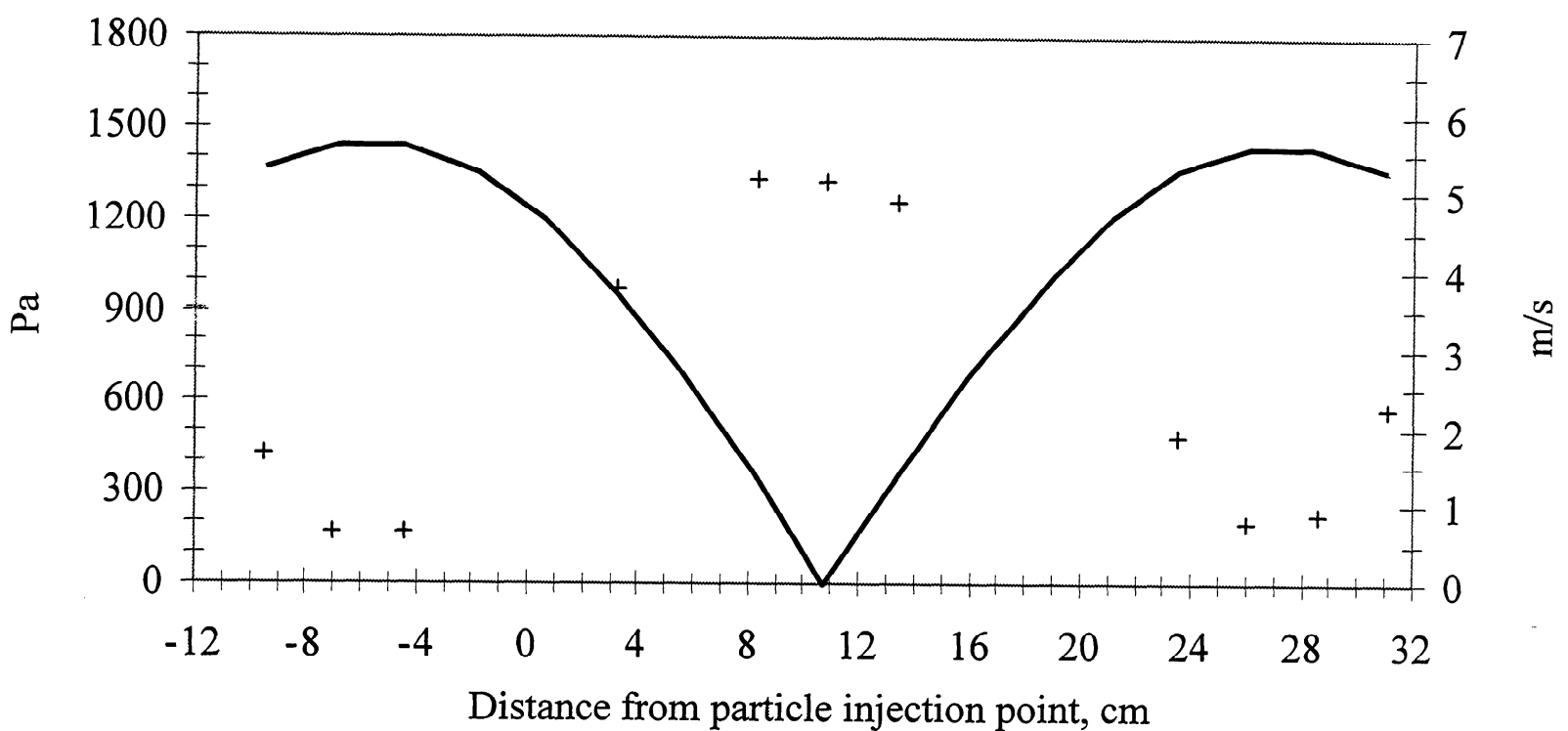

Figure A8.18. Profiles of the measured acoustic pressure amplitude $(+)$ and the calculated acoustic velocity amplitude $(-)$ in the pyrolysis tube obtained with an acoustic field of $154 \mathrm{~dB}$ and $960 \mathrm{~Hz}(\mathrm{RACl} 227 \mathrm{~A})$ under reactor conditions of $550^{\circ} \mathrm{C}$, $0.81 \mathrm{~m}$ pyrolysis tube heated length, $3.88 \mathrm{~s}$ particle residence time, and $6.59 \mathrm{~s}$ secondary gas space-time.

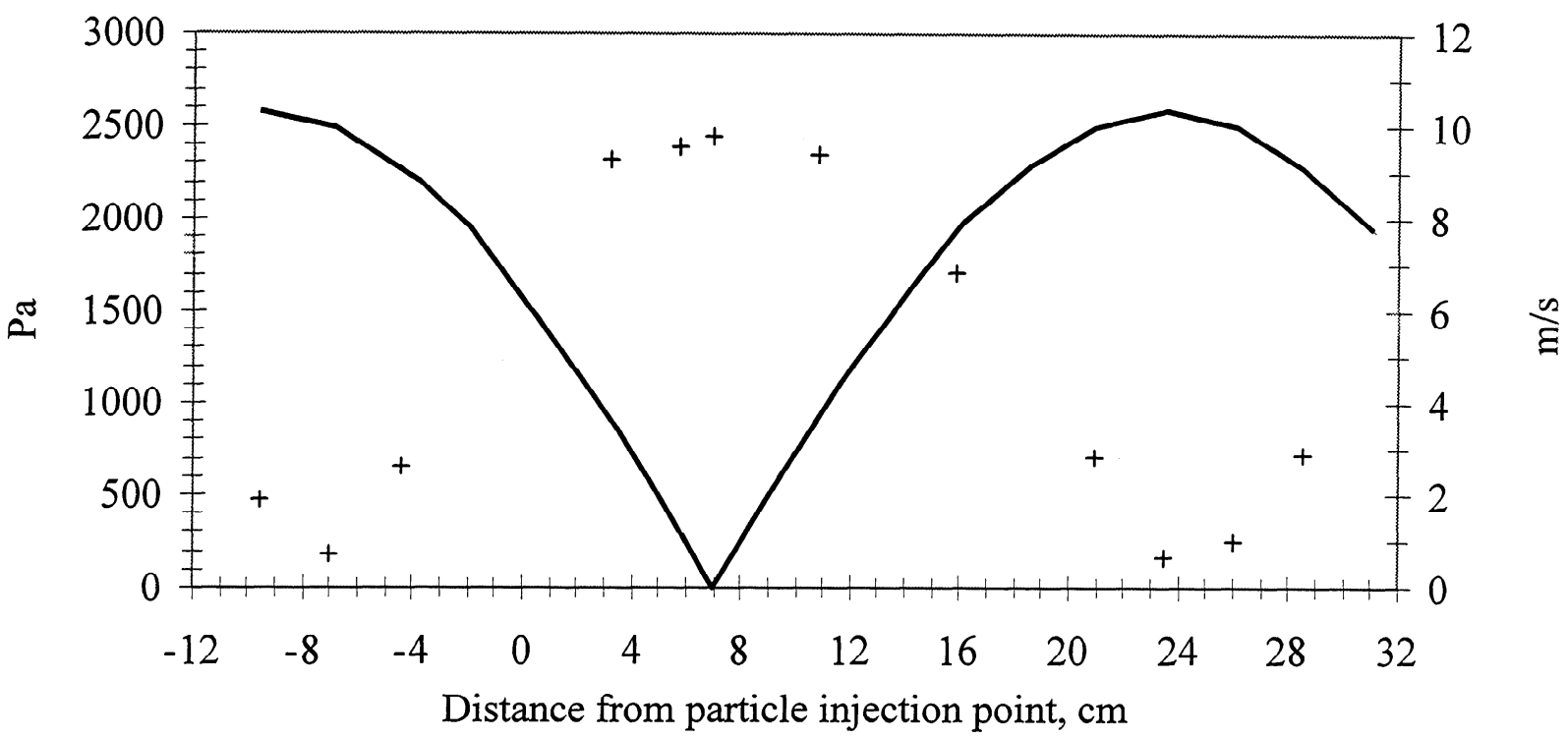

Figure A8.19. Profiles of the measured acoustic pressure amplitude $(+)$ and the calculated acoustic velocity amplitude ( $\rightarrow$ in the pyrolysis tube obtained with an acoustic field of $158 \mathrm{~dB}$ and $970 \mathrm{~Hz}$ (RAC1207) under reactor conditions of $550^{\circ} \mathrm{C}, 0.81 \mathrm{~m}$ pyrolysis tube heated length, at least $1.37 \mathrm{~s}$ particle residence time, and $1.72 \mathrm{~s}$ secondary gas space-time. 


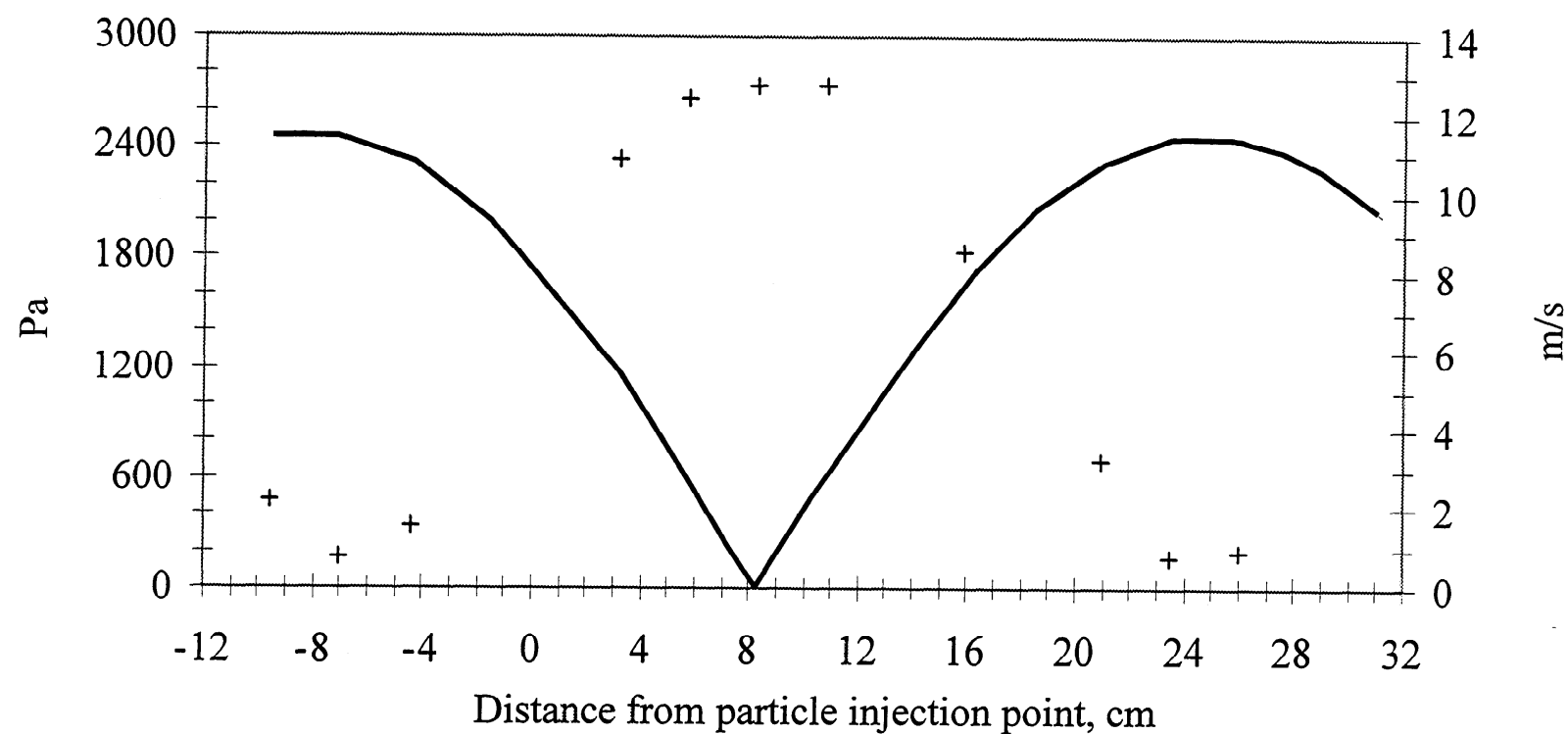

Figure A8.20. Profiles of the measured acoustic pressure amplitude $(+)$ and the calculated acoustic velocity amplitude ( - ) in the pyrolysis tube obtained with an acoustic field of $159.5 \mathrm{~dB}$ and $970 \mathrm{~Hz}$ (RAC1227B) under reactor conditions of $550^{\circ} \mathrm{C}$, $0.81 \mathrm{~m}$ pyrolysis tube heated length, at least $3.91 \mathrm{~s}$ particle residence time, and $3.39 \mathrm{~s}$ secondary gas space-time.

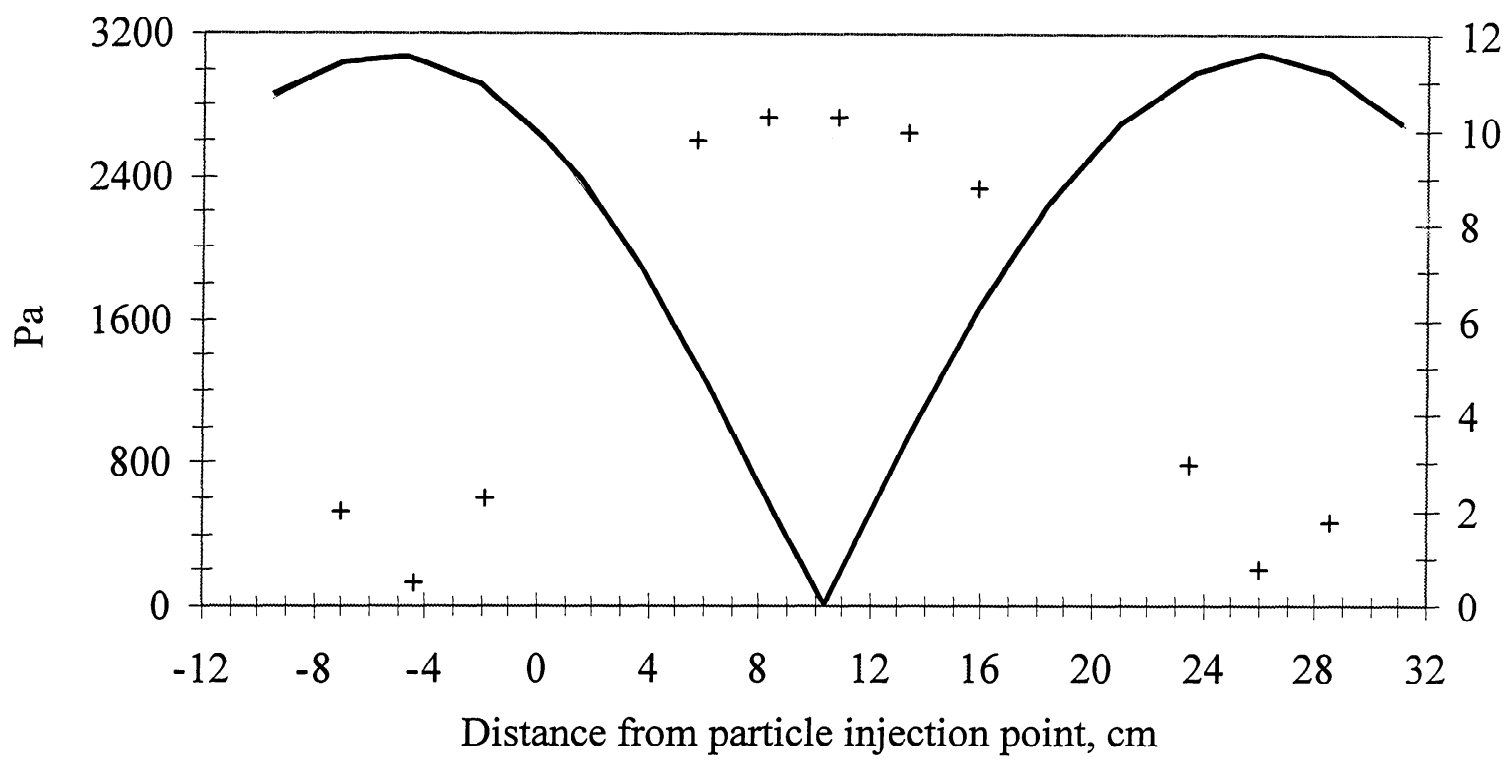

Figure A8.21. Profiles of the measured acoustic pressure amplitude $(+)$ and the calculated acoustic velocity amplitude ( - in the pyrolysis tube obtained with an acoustic field of $159.5 \mathrm{~dB}$ and $970 \mathrm{~Hz}$ (RAC1230) under reactor conditions of $550^{\circ} \mathrm{C}$, $0.81 \mathrm{~m}$ pyrolysis tube heated length, at least $3.91 \mathrm{~s}$ particle residence time, $3.39 \mathrm{~s}$ secondary gas space-time, and pulsed feeding of BLS particles. 


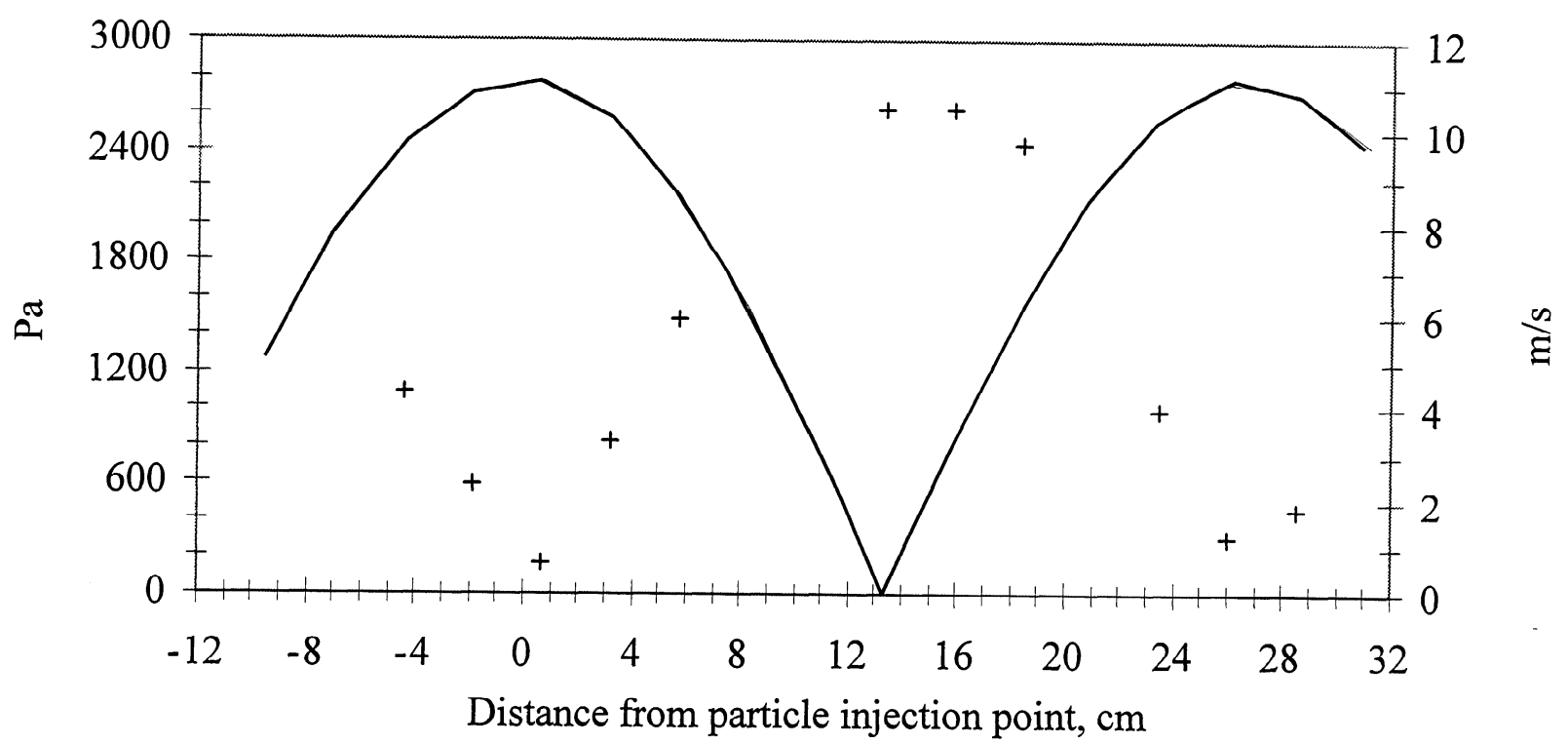

Figure A8.22. Profiles of the measured acoustic pressure amplitude $(+)$ and the calculated acoustic velocity amplitude $(-)$ in the pyrolysis tube obtained with an acoustic field of $158 \mathrm{~dB}$ and $970 \mathrm{~Hz}$ (RAC1224) under reactor conditions of $550^{\circ} \mathrm{C}, 0.81 \mathrm{~m}$ pyrolysis tube heated length, very long particle residence time, and $6.59 \mathrm{~s}$ secondary space-time.

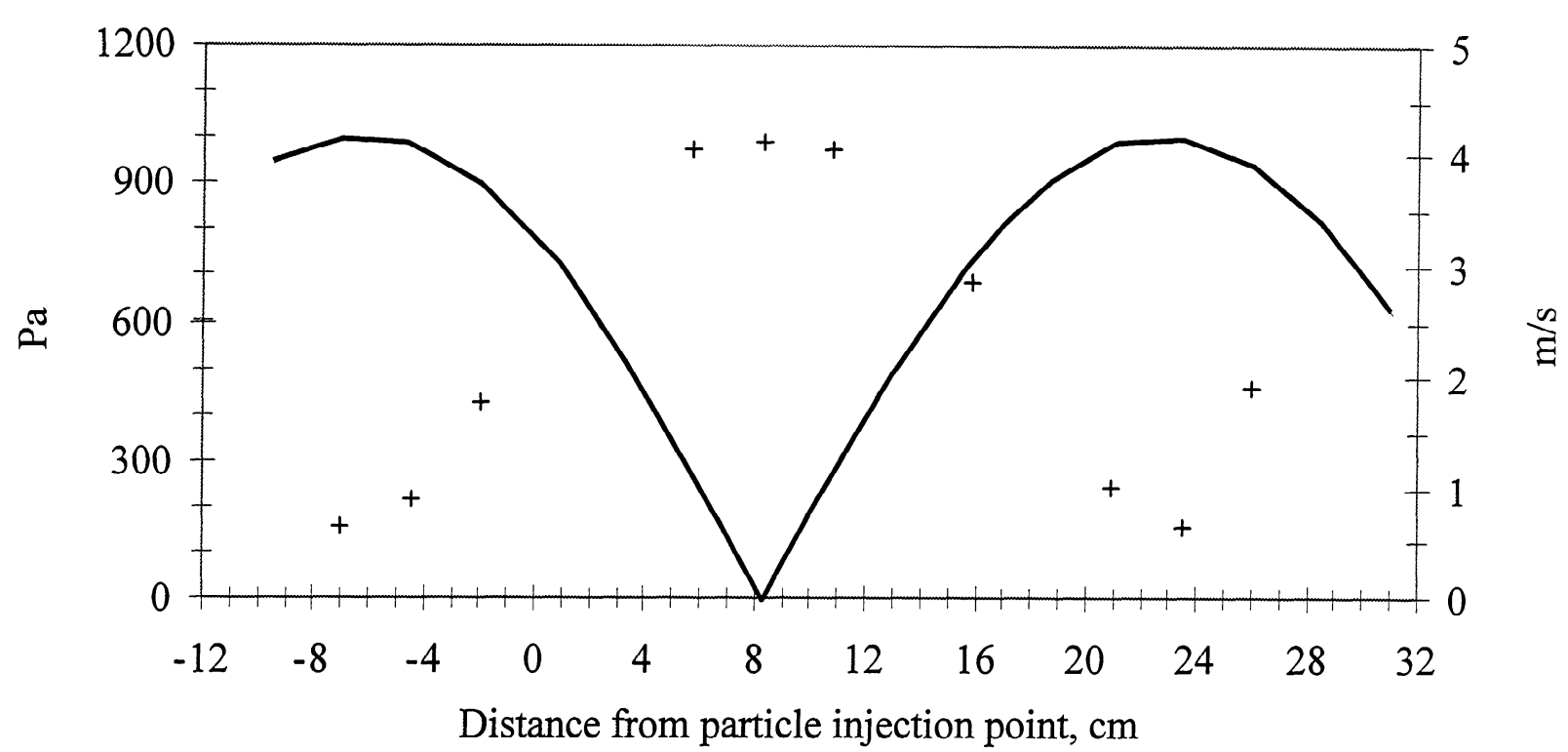

Figure A8.23. Profiles of the measured acoustic pressure amplitude $(+)$ and the calculated acoustic velocity amplitude $(-)$ in the pyrolysis tube obtained with an acoustic field of $151 \mathrm{~dB}$ and $960 \mathrm{~Hz}$ (RAC1206) and a steel-wool plug located at $0.75 \mathrm{~m}$ under reactor conditions of $550^{\circ} \mathrm{C}, 0.81 \mathrm{~m}$ pyrolysis tube heated length, very long particle residence time, and $3.39 \mathrm{~s}$ secondary gas space-time. 


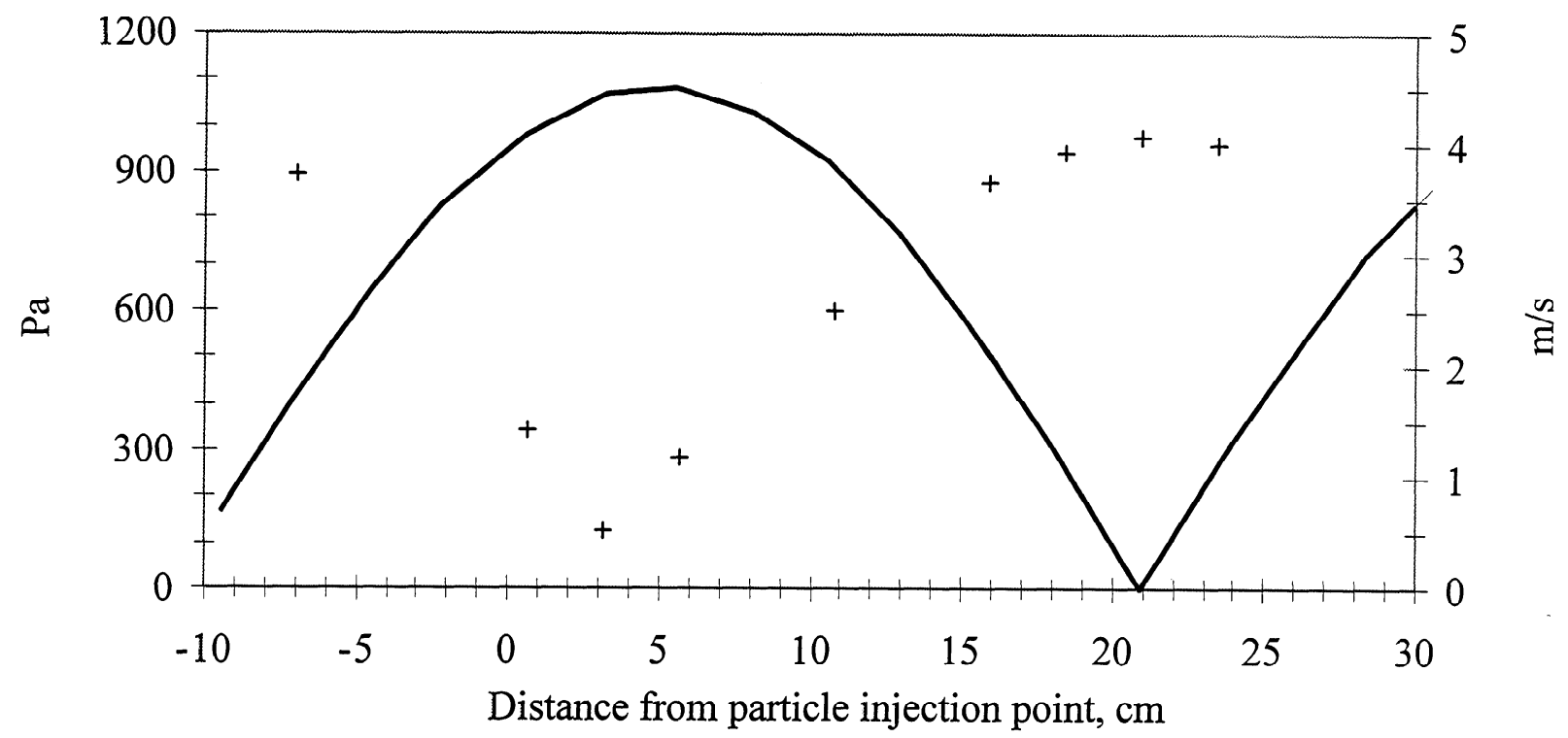

Figure A8.24. Profiles of the measured acoustic pressure amplitude $(+)$ and the calculated acoustic velocity amplitude $(-)$ in the pyrolysis tube obtained with an acoustic field of $151 \mathrm{~dB}$ and $960 \mathrm{~Hz}(\mathrm{RAC1} 126 \mathrm{~A})$ under reactor conditions of $700^{\circ} \mathrm{C}$, $0.18 \mathrm{~m}$ pyrolysis tube heated length, $0.25 \mathrm{~s}$ particle residence time, and $0.32 \mathrm{~s}$ secondary gas space-time.

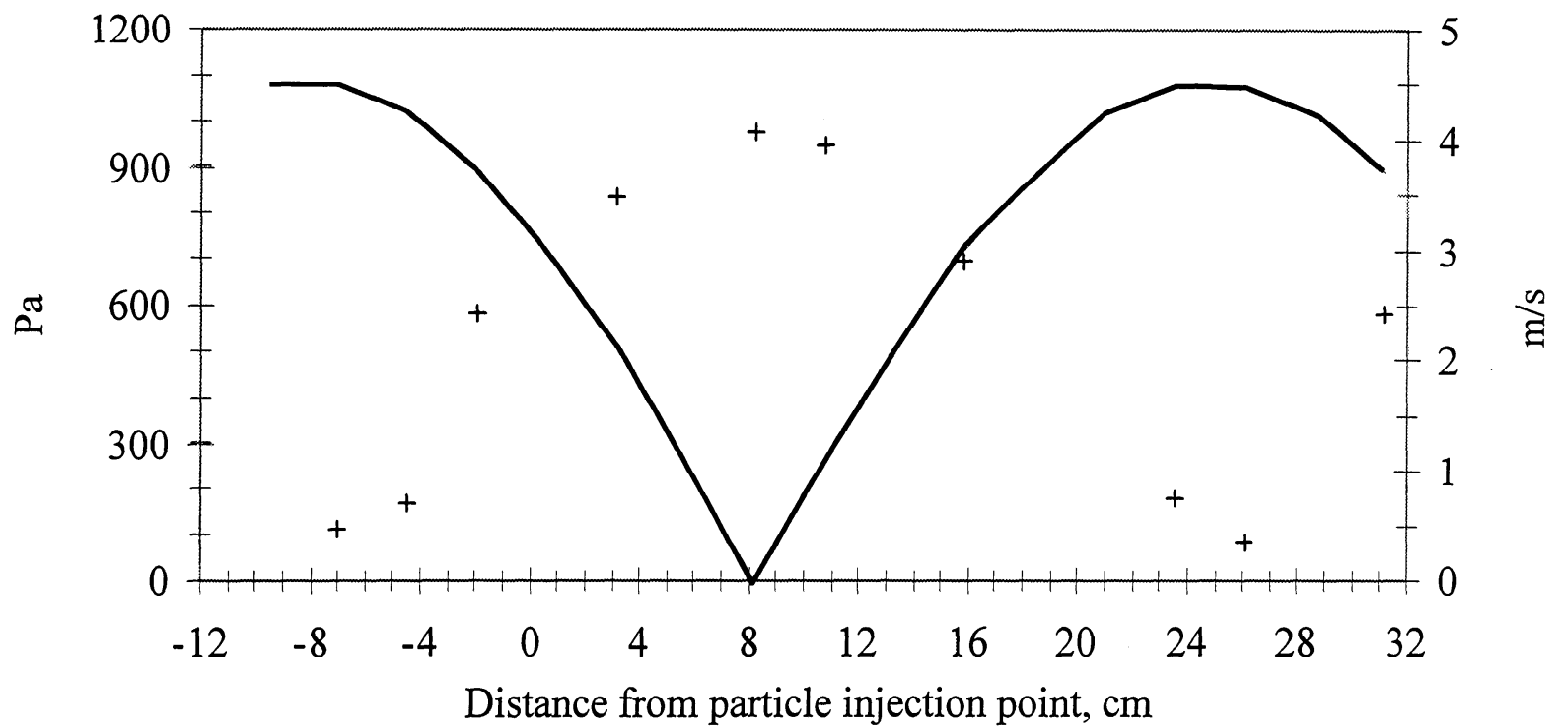

Figure A8.25. Profiles of the measured acoustic pressure amplitude $(+)$ and the calculated acoustic velocity amplitude $(-)$ in the pyrolysis tube obtained with an acoustic field of $151 \mathrm{~dB}$ and $990 \mathrm{~Hz}(\mathrm{RAC1} 127)$ under reactor conditions of $700^{\circ} \mathrm{C}, 0.48 \mathrm{~m}$ pyrolysis tube heated length, $0.64 \mathrm{~s}$ particle residence time, and $0.86 \mathrm{~s}$ secondary gas space-time. 


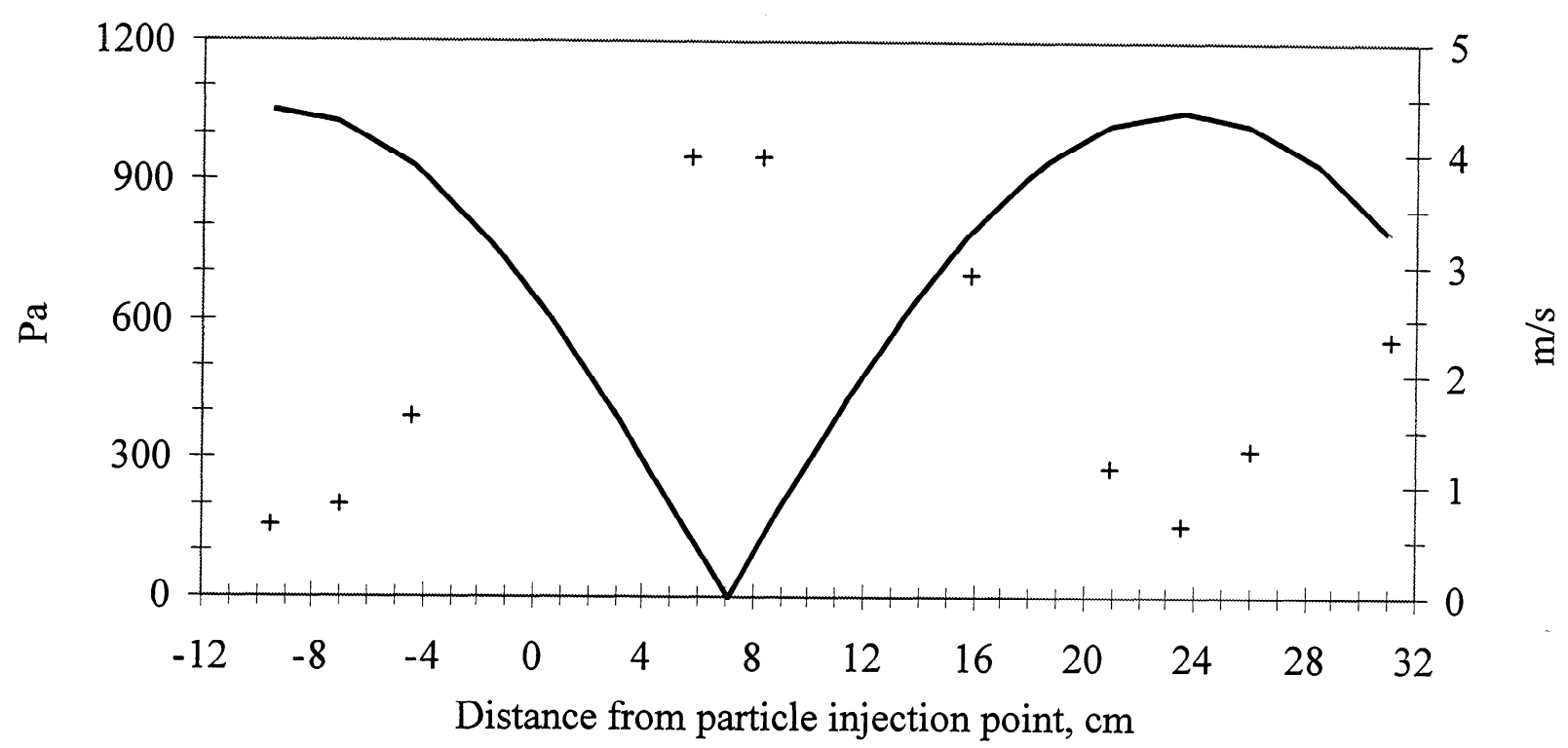

Figure A8.26. Profiles of the measured acoustic pressure amplitude $(+)$ and the calculated acoustic velocity amplitude ( - ) in the pyrolysis tube obtained with an acoustic field of $151 \mathrm{~dB}$ and $990 \mathrm{~Hz}$ (RAC1130) under reactor conditions of $700^{\circ} \mathrm{C}, 0.48 \mathrm{~m}$ pyrolysis tube heated length, $0.64 \mathrm{~s}$ particle residence time, and $0.86 \mathrm{~s}$ secondary gas space-time.

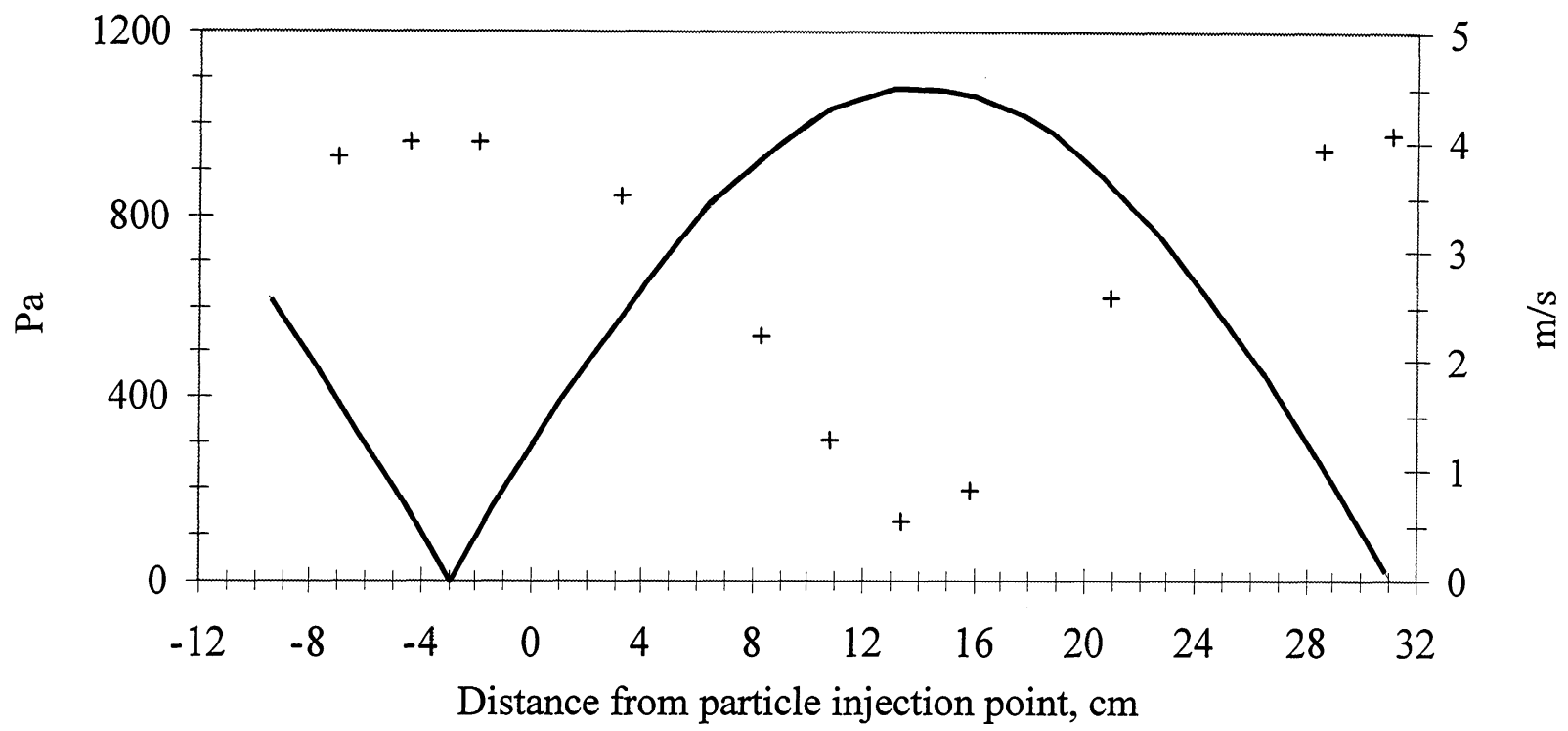

Figure A8.27. Profiles of the measured acoustic pressure amplitude $(+)$ and the calculated acoustic velocity amplitude $(-)$ in the pyrolysis tube obtained with an acoustic field of $151 \mathrm{~dB}$ and $950 \mathrm{~Hz}$ (RAC1126B) under reactor conditions of $700^{\circ} \mathrm{C}$, $0.81 \mathrm{~m}$ pyrolysis tube heated length, $1.15 \mathrm{~s}$ particle residence time, and $1.46 \mathrm{~s}$ secondary gas space-time. 


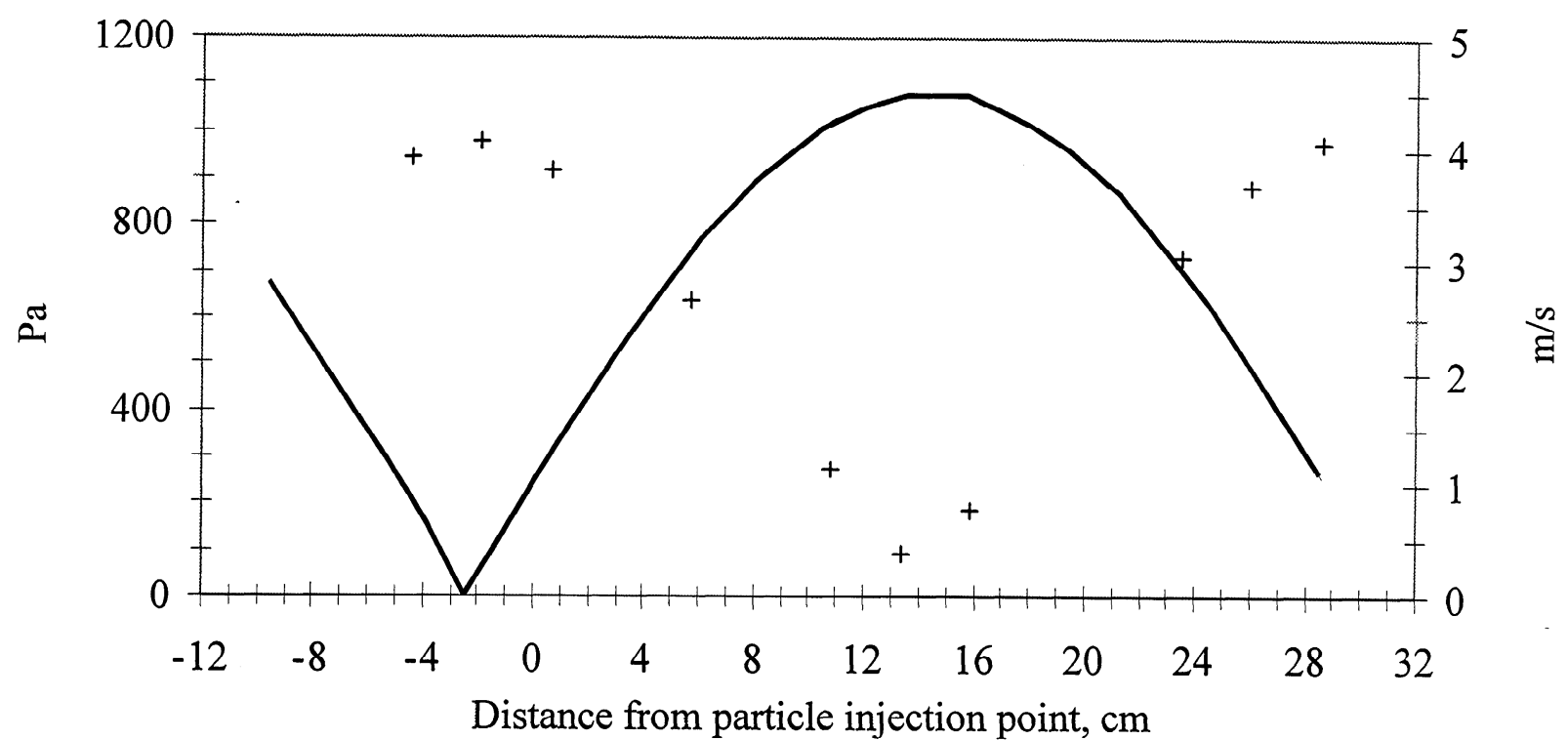

Figure A8.28. Profiles of the measured acoustic pressure amplitude $(+)$ and the calculated acoustic velocity amplitude $(-)$ in the pyrolysis tube obtained with an acoustic field of $151 \mathrm{~dB}$ and $950 \mathrm{~Hz}(\mathrm{RAC1} 130 \mathrm{~B})$ under reactor conditions of $700^{\circ} \mathrm{C}$, $0.81 \mathrm{~m}$ pyrolysis tube heated length, $1.15 \mathrm{~s}$ particle residence time, and $1.46 \mathrm{~s}$ secondary gas space-time.

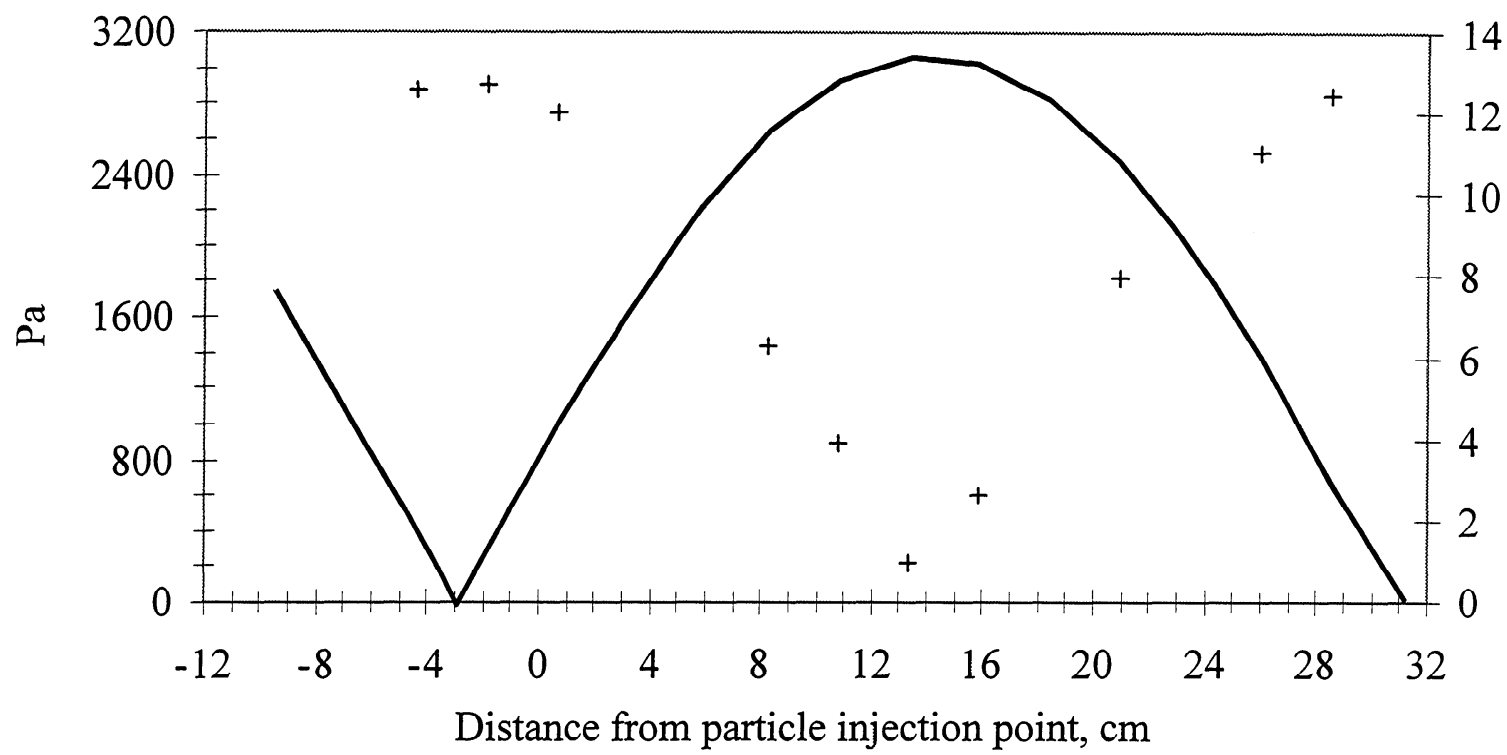

Figure A8.29. Profiles of the measured acoustic pressure amplitude $(+)$ and the calculated acoustic velocity amplitude $(-)$ in the pyrolysis tube obtained with an acoustic field of $160 \mathrm{~dB}$ and $950 \mathrm{~Hz}(\mathrm{RACl} 130 \mathrm{C})$ under reactor conditions of $700^{\circ} \mathrm{C}$, $0.81 \mathrm{~m}$ pyrolysis tube heated length, very long particle residence time, and $1.46 \mathrm{~s}$ secondary gas space-time. 


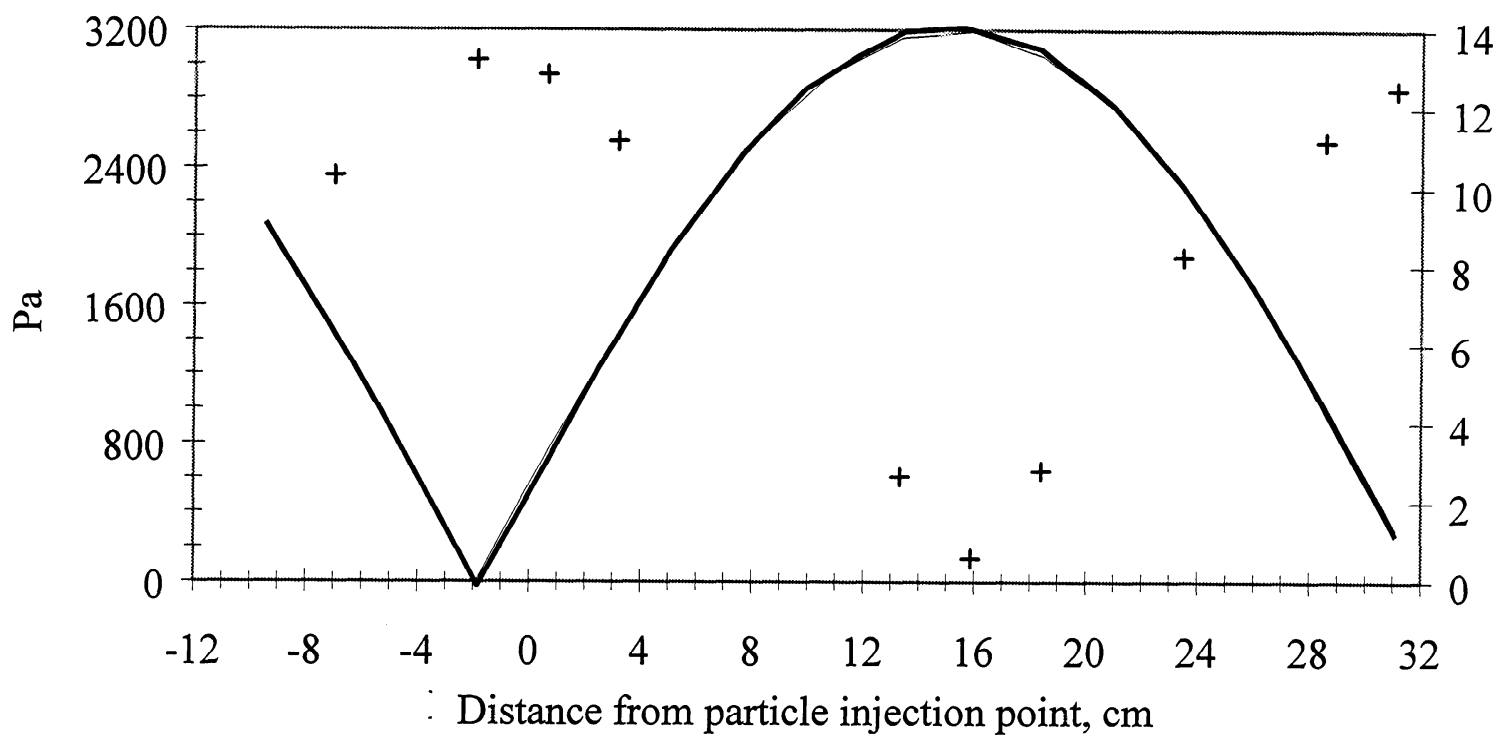

Figure A8.30. Profiles of the measured acoustic pressure amplitude $(+)$ and the calculated acoustic velocity amplitude ( $\longrightarrow$ ) in the pyrolysis tube obtained with an acoustic field of $160 \mathrm{~dB}$ and $950 \mathrm{~Hz}$ (RAC1205) under reactor conditions of $700^{\circ} \mathrm{C}, 0.81 \mathrm{~m}$ pyrolysis tube heated length, very long particle residence time, and $2.87 \mathrm{~s}$ secondary gas space-time. 


\section{[A9] APPENDIX 9. MEASURED PARTICLE RESIDENCE TIMES IN THE PYROLYSIS TUBE IN COLD FLOW EXPERIMENTS}

\section{[A9.1] ESTIMATION OF CHAR PARTICLE DENSITY}

The particle density is necessary to calculate the velocities of inflight particles using the numerical particle residence time model in Appendix 10. Parameters in the particle residence time model were adjusted to ensure that the time- and space-averaged particle velocities estimated using the model best matched those obtained from high-speed video particle imaging experiments. Char particles used in the high-speed video experiments were produced with and without acoustics using a gas temperature of $400^{\circ} \mathrm{C}$. The density of a single char particle can be expressed as,

$$
\rho_{p}=\frac{6 m_{p}}{\pi d_{p}{ }^{3}},
$$

where $m_{p}$ and $d_{p}$ are the mass and diameter of individual char particles, respectively. For $400^{\circ} \mathrm{C}$ experiments conducted with or without acoustics (RNAC1113 and RAC1119), char particle diameters ranged from 125-300 $\mu \mathrm{m}$ with an average diameter of about $150 \mu \mathrm{m}$ (obtained from SEM Analysis), and the average char yield was about $95 \mathrm{wt} \%$ of BLS. The mass of a 125-300 $\mu \mathrm{m}$ diameter char particle obtained from $400^{\circ} \mathrm{C}$ experiments was assumed to be $95 \%$ of the mass of a dry, $115 \mu \mathrm{m}$ diameter BLS particle. The bulk density of dry 106-125 $\mu \mathrm{m}$ diameter BLS particles was $855 \mathrm{~kg} / \mathrm{m}^{3}$. The bulk density was measured by weighing a known volume of dry BLS particles that had been loosely packed into a graduated cylinder. Taking possible void space into consideration, this compares well with the $940 \mathrm{~kg} / \mathrm{m}^{3}$ density of dry BLS reported by Adams and Frederick (1988). Using Eq. A9.1, the mass of a $115 \mu$ m diameter BLS is 
$7.4855 \times 10^{-10} \mathrm{~kg}$. The densities of 125,150 , and $300 \mu \mathrm{m}$ diameter char particles, calculated using a BLS density of $940 \mathrm{~kg} / \mathrm{m}^{3}$, are 695,402 , and $50 \mathrm{~kg} / \mathrm{m}^{3}$, respectively.

\section{[A9.2] AMPLITUDES OF MEASURED ACOUSTIC PRESSURE AND CALCULATED ACOUSTIC VELOCITY IN THE PYROLYSIS TUBE}

Figs. A9.1-A9.4 show profiles of the measured acoustic pressure amplitude and the calculated acoustic velocity amplitude inside the pyrex tube obtained with an acoustic field of 151 and $158 \mathrm{~dB}_{\mathrm{rms}}$ and frequencies of 340 and $970 \mathrm{~Hz}$ during gas and particle flow imaging experiments. The secondary air flowrate was 14 slpm while acoustic pressures were measured. Acoustic velocity amplitudes were calculated from the measured acoustic pressure amplitudes using Eqs. A8.1 and A8.2 in Appendix 8.

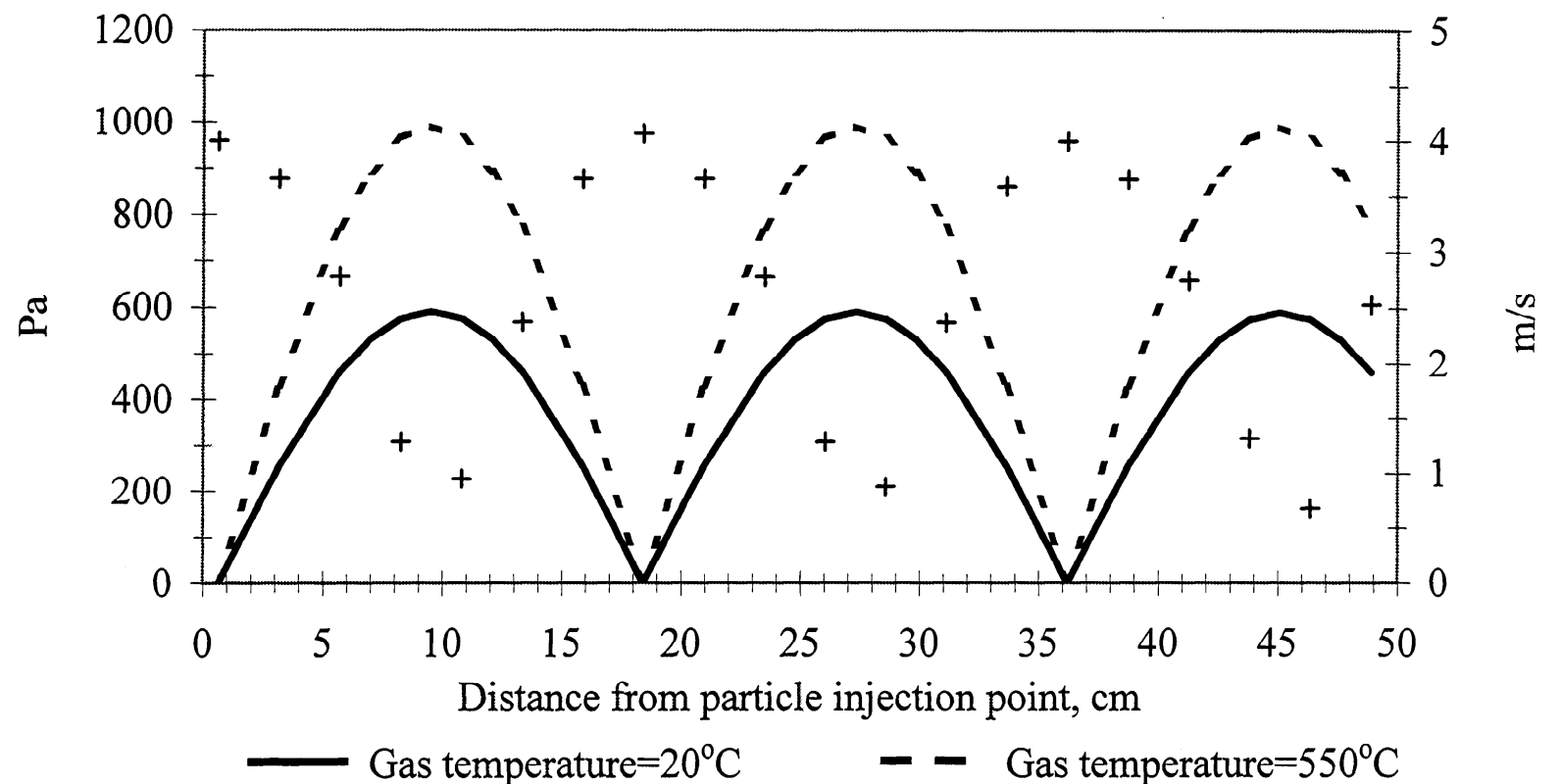

Figure. A9.1. Profiles of the measured acoustic pressure amplitude and the calculated acoustic velocity amplitude inside the pyrex tube obtained with an acoustic field of $151 \mathrm{~dB}_{\text {rms }}$ and frequency of $970 \mathrm{~Hz}$. 


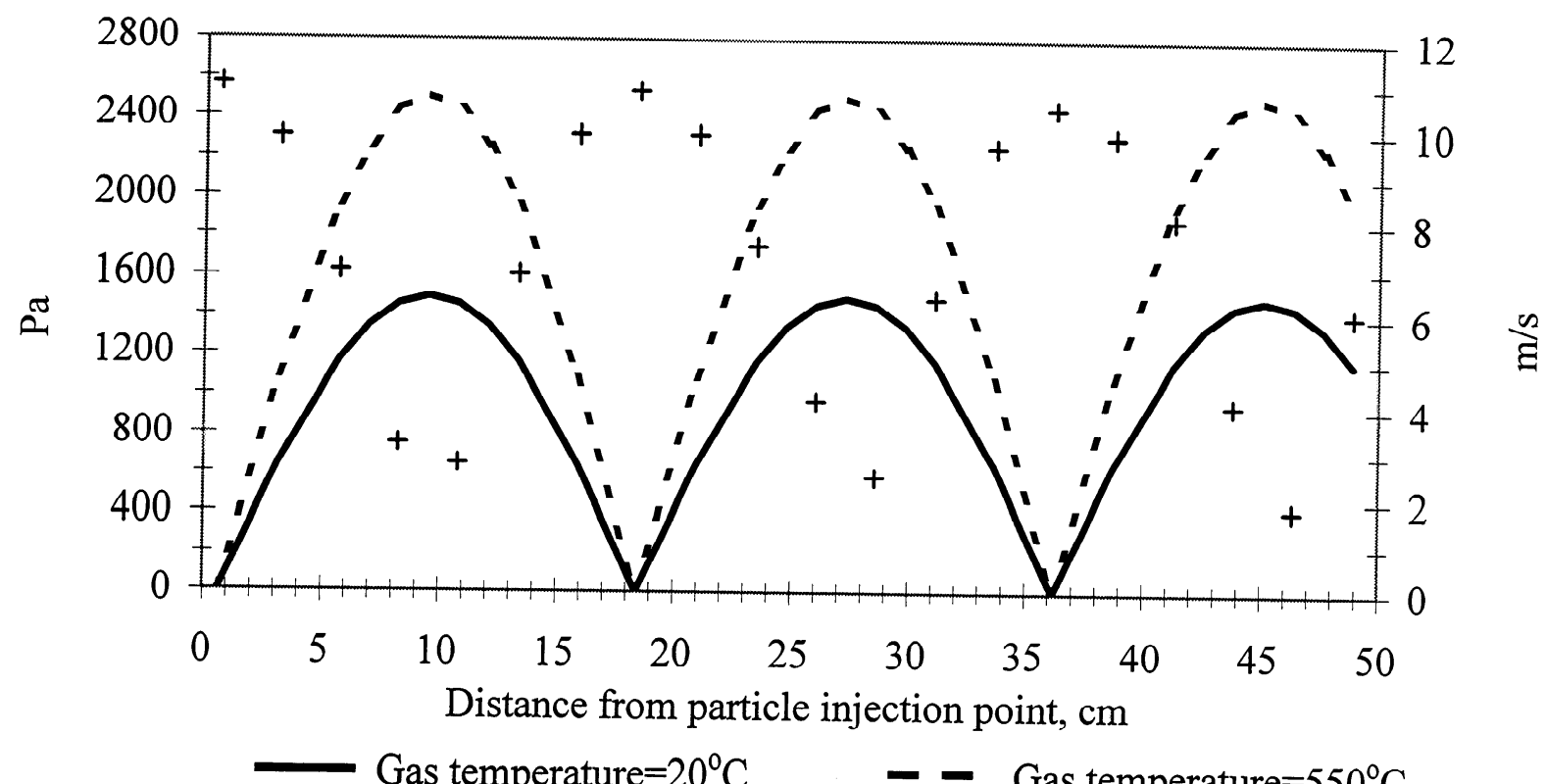

Figure. A9.2. Profiles of the measured acoustic pressure amplitude and the calculated acoustic velocity amplitude inside the pyrex tube obtained with an acoustic field of $159 \mathrm{~dB}_{\mathrm{rms}}$ and frequency of $970 \mathrm{~Hz}$.

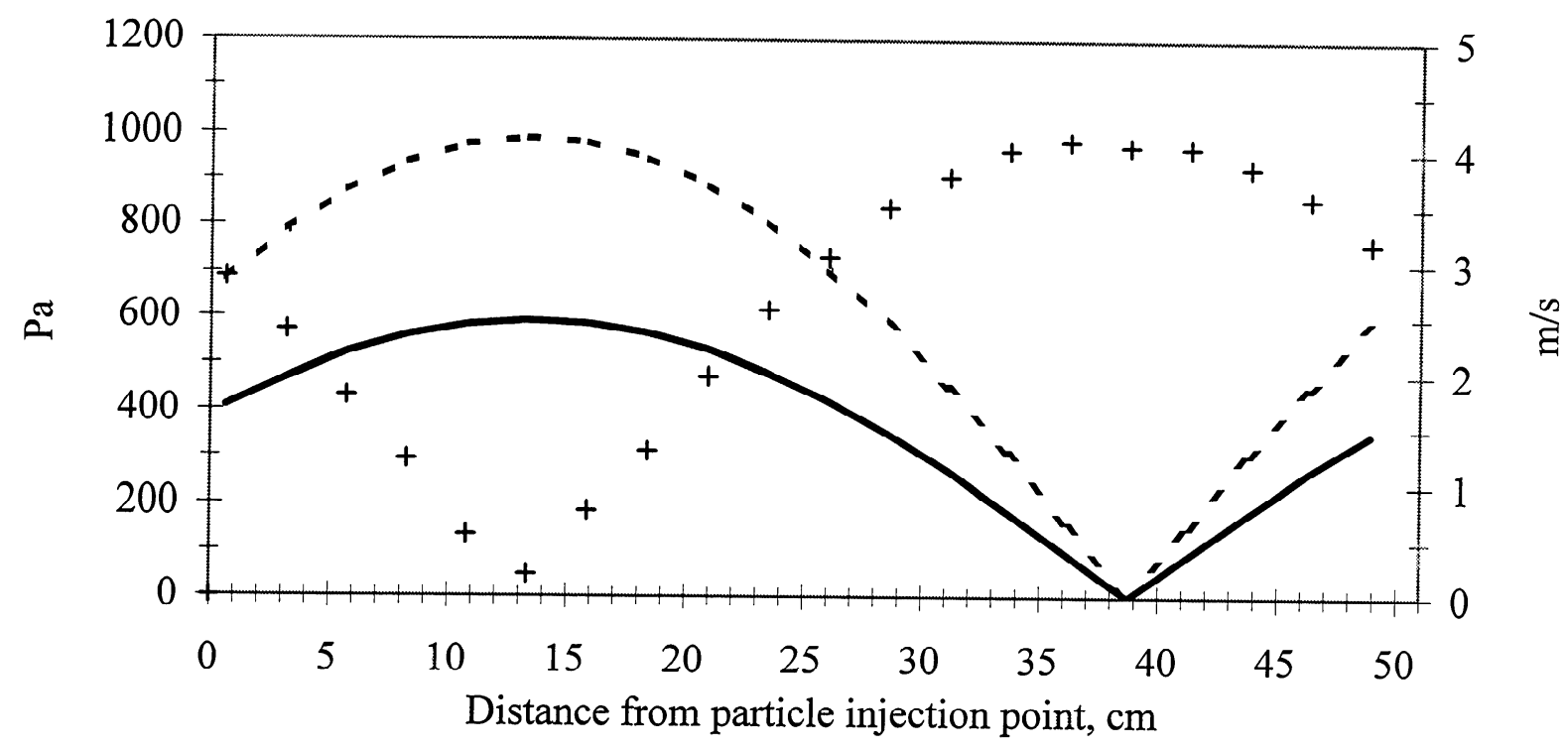

- Gas temperature $=20^{\circ} \mathrm{C} \quad$ - - Gas temperature $=550^{\circ} \mathrm{C}$

Figure. A9.3. Profiles of the measured acoustic pressure amplitude and the calculated acoustic velocity amplitude inside the pyrex tube obtained with an acoustic field of $151 \mathrm{~dB}_{\mathrm{mms}}$ and frequency of $340 \mathrm{~Hz}$. 


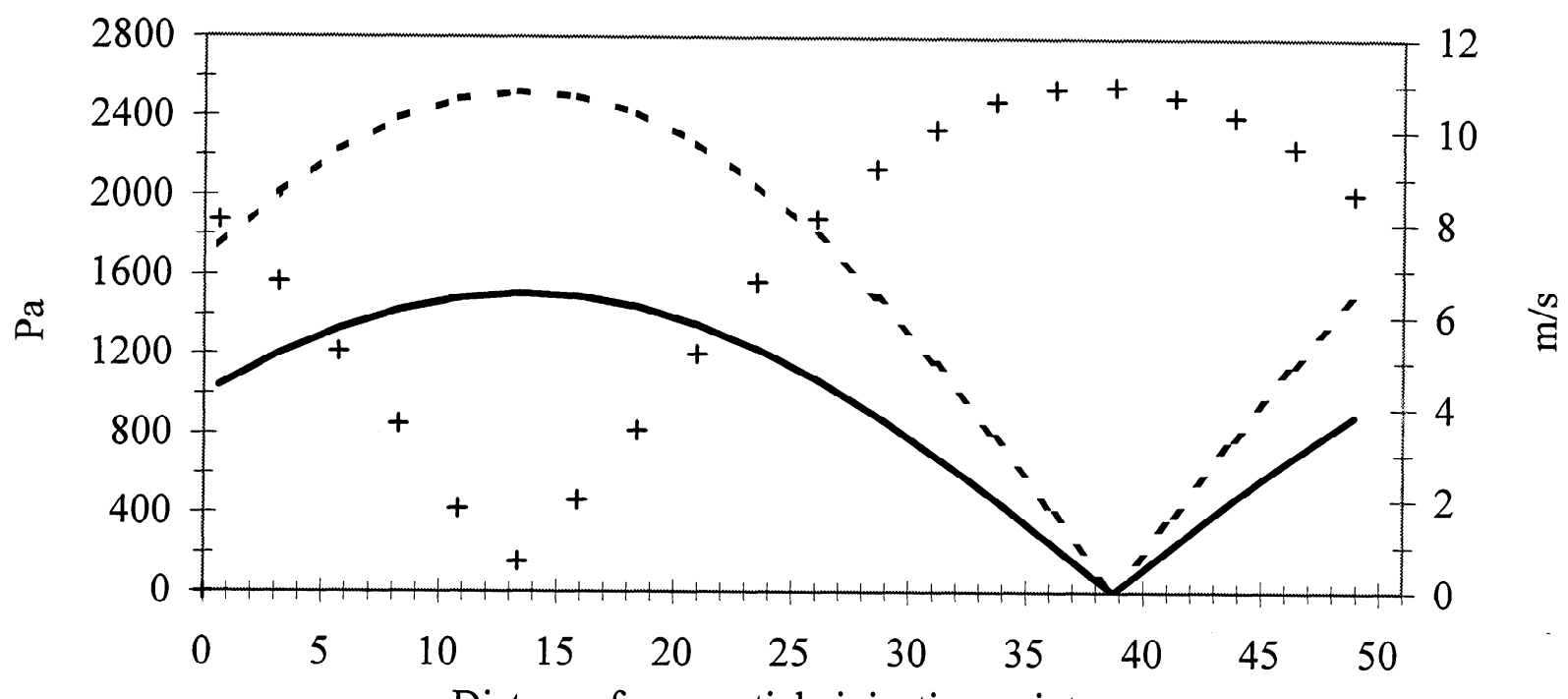

Distance from particle injection point, $\mathrm{cm}$

- Gas temperature $=20^{\circ} \mathrm{C} \quad$ - $\quad$ Gas temperature $=550^{\circ} \mathrm{C}$

Figure. A9.4. Profiles of the measured acoustic pressure amplitude and the calculated acoustic velocity amplitude inside the pyrex tube obtained with an acoustic field of $159 \mathrm{~dB}_{\mathrm{rms}}$ and frequency of $340 \mathrm{~Hz}$.

\section{[A9.3] MEASURED PARTICLE RESIDENCE TIMES}

Table A9.1 lists the residence time of several individual pulses of BLS particles in the $0.95 \mathrm{~m}$ pyrolysis tube that were measured using the diode laser system. Measurements were performed with and without acoustics using a secondary air flowrate of 56 slpm.

Table A9.1. Residence times of a pulse of BLS particles in the $0.95 \mathrm{~m}$ pyrolysis tube obtained with and without acoustics using a secondary air flowrate of $56 \mathrm{slpm}$.

\begin{tabular}{|c|c|c|c|}
\hline Acoustic field conditions & $\begin{array}{l}\text { Measured residence times } \\
\text { of pulses, } s\end{array}$ & $\begin{array}{l}\text { Average } \\
\text { residence time } \\
\text { of pulses, } s \\
\end{array}$ & $\begin{array}{l}\text { Standard deviation } \\
\text { of pulses, } \mathrm{s}\end{array}$ \\
\hline No acoustics, $20^{\circ} \mathrm{C}$ & $\begin{array}{r}1.03,1.10,1.11,1.17,1.20 \\
1.25\end{array}$ & 1.14 & 0.079 \\
\hline $146 \mathrm{~dB}$ and $970 \mathrm{~Hz}, 20^{\circ} \mathrm{C}$ & $1.50,1.50,1.64,1.75$ & 1.60 & 0.12 \\
\hline $154 \mathrm{~dB}$ and $970 \mathrm{~Hz}, 20^{\circ} \mathrm{C}$ & $\begin{array}{r}1.20,1.40,1.44,1.89 \\
\text { several at } 1.70\end{array}$ & - & - \\
\hline
\end{tabular}


Tables A9.2-A9.4 list individual particle velocities in the pyrex, simulated pyrolysis tube at distances of $0.45-0.85,0.05-0.175$, and $0.145-0.185 \mathrm{~m}$ downstream from the particle injection point with and without an acoustic field of 151 or $159 \mathrm{~dB}$ and $970 \mathrm{~Hz}$ using secondary air flowrates between 14-56 slpm. It is pointed out that the same particle may not have been tracked from one section to another. The particle velocities in each section are listed arbitrarily, with no correspondence between columns by the row. Table A9.5 lists the mean particle residence times in the $0.18 \mathrm{~m}$ simulated pyrolysis tube calculated using the mean particle velocities between 0.05-0.175 $\mathrm{m}$ downstream of the particle injection point with and without an acoustic field of 151 or $159 \mathrm{~dB}$ and $970 \mathrm{~Hz}$ using secondary air flowrates between 14-56 slpm. 
Table A9.2. Mean velocities of individual particles in the pyrex, simulated pyrolysis tube at distances of $0.045-0.085,0.05-0.175$, and $0.145-0.185 \mathrm{~m}$ from the particle injection point obtained with and without an acoustic field of $151 \mathrm{~dB}$ and $970 \mathrm{~Hz}$ using a secondary air flowrate of $56 \mathrm{slpm}$.

\begin{tabular}{|c|c|c|c|c|c|}
\hline \multicolumn{3}{|c|}{ No acoustics } & \multicolumn{3}{|c|}{$151 \mathrm{~dB}$ and $970 \mathrm{~Hz}$} \\
\hline Velocity in & yrolysis tube st & ction, $\mathrm{m} / \mathrm{s}$ & Velocity in & pyrolysis tube $\mathrm{s}$ & ection, $\mathrm{m} / \mathrm{s}$ \\
\hline $0.045-0.085 \mathrm{~m}$ & $0.145-0.185 \mathrm{~m}$ & $0.05-0.175 \mathrm{~m}$ & $0.045-0.085 \mathrm{~m}$ & $0.145-0.185 \mathrm{~m}$ & $0.05-0.175 \mathrm{~m}$ \\
\hline 1.13 & 1.13 & 0.973 & 0.95 & 0.89 & 0.8 \\
\hline 1.13 & 1.36 & 1.02 & 0.95 & 0.89 & 0.98 \\
\hline 0.89 & 1.01 & 1.22 & 0.84 & 1.04 & 0.93 \\
\hline 0.89 & 1.32 & 1.08 & 0.67 & 0.85 & 1.04 \\
\hline 0.75 & 1.16 & 0.97 & 0.95 & 1.23 & 0.82 \\
\hline 0.75 & 1.41 & 1.13 & 0.95 & 1.23 & 1.01 \\
\hline 0.75 & 1.24 & 1.16 & 0.72 & 0.97 & 0.96 \\
\hline 0.69 & 1.13 & 1.29 & 0.72 & 0.98 & 0.92 \\
\hline 0.69 & 1.05 & 1.1 & 0.72 & 0.89 & 0.83 \\
\hline 0.80 & 1.10 & 1.05 & 0.82 & 0.98 & 0.86 \\
\hline 0.80 & 1.31 & 1.21 & 0.87 & 0.98 & 0.93 \\
\hline 0.86 & 1.08 & 1.19 & 0.99 & 0.87 & 0.93 \\
\hline 0.86 & 1.12 & 1.23 & 0.99 & 1.05 & 0.93 \\
\hline 0.78 & 1.09 & 1.05 & 0.89 & 0.92 & 0.98 \\
\hline 0.78 & 1.23 & 1.08 & 0.89 & 0.98 & 0.86 \\
\hline 0.71 & 1.23 & 1.05 & 0.95 & 0.92 & 0.98 \\
\hline 0.71 & 1.15 & 1.16 & 0.95 & 1.05 & \\
\hline 0.74 & 1.18 & 1.13 & 0.87 & 0.98 & - \\
\hline 0.74 & 0.98 & 1.1 & 0.78 & 0.98 & \\
\hline 0.74 & 1.02 & 1.1 & 0.78 & 1.05 & \\
\hline 0.74 & 1.27 & -1 & 0.84 & 1.05 & - \\
\hline 0.95 & 1.14 & - & 0.84 & 1.04 & - \\
\hline 0.86 & 1.03 & - & 0.84 & 1.02 & - \\
\hline 0.86 & 1.03 & - & 0.84 & 1.02 & \\
\hline 0.85 & 1.08 & - & 0.69 & 0.89 & \\
\hline 0.85 & 1.24 & - & 0.69 & 0.89 & - \\
\hline 0.86 & 1.22 & - & 0.84 & 0.98 & \\
\hline 0.86 & 1.13 & - & 0.84 & 0.98 & - \\
\hline 0.83 & 1.09 & - & 0.82 & 1.18 & \\
\hline 0.83 & 1.00 & - & 0.82 & 1.09 & - \\
\hline Avg.: & 1.15 & 1.11 & 0.84 & 1.00 & 0.92 \\
\hline S.D.: & 0.11 & 0.09 & 0.09 & 0.10 & 0.07 \\
\hline
\end{tabular}


Table A9.3. Mean velocities of individual particles in the pyrex, simulated pyrolysis tube at distances of $0.045-0.085,0.05-0.175$, and $0.145-0.185 \mathrm{~m}$ from the particle injection point obtained with and without an acoustic field of $151 \mathrm{~dB}$ and $970 \mathrm{~Hz}$ using a secondary air flowrate of $14 \mathrm{slpm}$.

\begin{tabular}{|c|c|c|c|c|c|}
\hline \multicolumn{3}{|c|}{ No acoustics } & \multicolumn{3}{|c|}{$151 \mathrm{~dB}$ and $970 \mathrm{~Hz}$} \\
\hline Velocity in & pyrolysis tube & ection, $\mathbf{m} / \mathbf{s}$ & Velocity in & pyrolysis tube $s$ & ection, $\mathrm{m} / \mathrm{s}$ \\
\hline $0.45-0.085 \mathrm{~m}$ & $0.145-0.185 \mathrm{~m}$ & $0.05-0.175 \mathrm{~m}$ & $0.045-0.085 \mathrm{~m}$ & $0.145-0.185 \mathrm{~m}$ & $0.05-0.175 \mathrm{~m}$ \\
\hline 0.59 & 0.58 & 0.43 & 0.60 & 0.64 & 0.62 \\
\hline 0.63 & 0.64 & 0.43 & 0.45 & 0.64 & 0.55 \\
\hline 0.75 & 0.61 & 0.44 & 1.13 & 0.58 & 0.61 \\
\hline 0.70 & 0.61 & 0.46 & 0.65 & 0.58 & 0.51 \\
\hline 0.70 & 0.61 & 0.48 & 0.58 & 0.56 & 0.46 \\
\hline 0.55 & 0.61 & 0.48 & 0.46 & 0.53 & 0.474 \\
\hline 0.59 & 0.46 & 0.49 & 0.59 & 0.39 & 0.55 \\
\hline 0.61 & 0.64 & 0.52 & 0.69 & 0.39 & 0.62 \\
\hline 0.61 & 0.62 & 0.55 & 0.53 & 0.57 & 0.54 \\
\hline 0.45 & 0.38 & 0.58 & 0.46 & 0.53 & 0.45 \\
\hline 0.66 & 0.38 & 0.58 & 0.60 & 0.62 & 0.45 \\
\hline 0.57 & 0.53 & 0.59 & 0.60 & 0.62 & 0.54 \\
\hline 0.57 & 0.53 & 0.59 & 0.56 & 0.48 & 0.54 \\
\hline 0.50 & 0.55 & 0.61 & 0.60 & 0.48 & 0.61 \\
\hline 0.50 & 0.55 & 0.61 & 0.60 & 0.48 & 0.61 \\
\hline 0.65 & 0.46 & 0.61 & 0.56 & 0.58 & 0.62 \\
\hline 0.59 & 0.46 & 0.63 & 0.56 & 0.58 & 0.55 \\
\hline 0.59 & 0.45 & 0.67 & 0.50 & 0.48 & 0.55 \\
\hline 0.66 & 0.45 & 0.67 & 0.50 & 0.48 & 0.46 \\
\hline 0.60 & 0.43 & 0.7 & 0.62 & 0.53 & 0.51 \\
\hline 0.60 & 0.43 & 0.72 & 0.44 & 0.53 & \\
\hline 0.68 & 0.50 & 0.73 & 0.44 & 0.43 & \\
\hline 0.64 & 0.54 & 0.75 & 0.58 & 0.43 & \\
\hline 0.59 & 0.54 & 0.76 & 0.52 & 0.46 & - \\
\hline 0.64 & 0.54 & 0.77 & 0.44 & 0.40 & \\
\hline 0.53 & 0.51 & 0.79 & 0.44 & 0.36 & \\
\hline 0.72 & 0.51 & - & 0.56 & 0.36 & - \\
\hline 0.63 & 0.69 & - & 0.47 & 0.60 & - \\
\hline 0.66 & 0.49 & - & 0.58 & 0.60 & 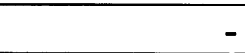 \\
\hline 0.57 & 0.36 & - & 0.57 & 0.60 & - \\
\hline Avg: & 0.52 & 0.60 & 0.56 & 0.52 & 0.54 \\
\hline $\mathbf{0 . 0 7}$ & $\mathbf{0 . 0 8}$ & 0.11 & 0.13 & .09 & 0.06 \\
\hline
\end{tabular}


Table A9.4. Mean velocities of individual particles in the pyrex, simulated pyrolysis tube at distances of $0.045-0.085,0.05-0.175$, and $0.145-0.185 \mathrm{~m}$ from the particle injection point obtained with an acoustic field of $159 \mathrm{~dB}$ and $970 \mathrm{~Hz}$ using a secondary air flowrate of $56 \mathrm{slpm}$.

\begin{tabular}{|c|c|c|}
\hline \multicolumn{3}{|c|}{$159 \mathrm{~dB}$ and $970 \mathrm{~Hz}$} \\
\hline Velocity i & pyrolysis tube sec & $\mathbf{n}, \mathbf{m} / \mathbf{s}$ \\
\hline 0.045-0.085 m & $0.145-0.185 \mathrm{~m}$ & $0.05-0.175 \mathrm{~m}$ \\
\hline 1.37 & 1.20 & 1.19 \\
\hline 0.96 & 1.15 & 1.24 \\
\hline 1.11 & 1.03 & 1.24 \\
\hline 1.06 & 1.37 & 1.24 \\
\hline 0.91 & 1.03 & 1.03 \\
\hline 0.93 & 1.08 & 1.03 \\
\hline 0.93 & 1.02 & 1.03 \\
\hline 1.01 & 0.94 & 0.98 \\
\hline 1.11 & 0.94 & 0.98 \\
\hline 0.94 & 0.91 & 0.98 \\
\hline 0.94 & 0.91 & 0.98 \\
\hline 1.31 & 0.80 & 1.09 \\
\hline 0.88 & 0.80 & 0.93 \\
\hline 0.87 & 0.80 & 0.93 \\
\hline 0.67 & 1.30 & 0.93 \\
\hline 1.00 & 1.30 & 0.93 \\
\hline 1.00 & 1.13 & 1.12 \\
\hline 1.03 & 1.00 & 1.12 \\
\hline 1.06 & 1.00 & 1.15 \\
\hline 0.78 & 1.17 & 1.15 \\
\hline 0.86 & 1.34 & 0.83 \\
\hline 0.78 & 0.96 & - \\
\hline 0.91 & 1.08 & - \\
\hline 0.95 & 0.61 & - \\
\hline 0.68 & 1.26 & - \\
\hline 0.96 & 0.91 & - \\
\hline 1.19 & 1.32 & - \\
\hline 1.36 & 0.86 & - \\
\hline 0.51 & 1.16 & - \\
\hline 0.48 & 0.86 & - \\
\hline Avg.: & 1.04 & 1.05 \\
\hline 0.21 & 0.19 & 0.12 \\
\hline
\end{tabular}


Table A9.5. Mean particle residence times in the $0.18 \mathrm{~m}$ simulated pyrolysis tube calculated using the mean particle velocities between $0.05-0.175 \mathrm{~m}$ downstream of the particle injection point with and without an acoustic field of 151 or $159 \mathrm{~dB}$ and $970 \mathrm{~Hz}$ using secondary air flowrates between 14-56 slpm.

\begin{tabular}{|l|r|}
\hline Acoustic field conditions & Mean particle residence time, $\mathbf{s}$ \\
\hline No acoustics, 14 slpm air at $20^{\circ} \mathrm{C}$ & 0.30 \\
\hline No acoustics, 56 slpm air at $20^{\circ} \mathrm{C}$ & 0.162 \\
\hline $151 \mathrm{~dB}, 970 \mathrm{~Hz}, 14$ slpm air at $20^{\circ} \mathrm{C}$ & 0.333 \\
\hline $151 \mathrm{~dB}, 970 \mathrm{~Hz}, 56$ slpm air at $20^{\circ} \mathrm{C}$ & 0.196 \\
\hline $159 \mathrm{~dB}, 970 \mathrm{~Hz}, 56$ slpm air at $20^{\circ} \mathrm{C}$ & 0.171 \\
\hline
\end{tabular}




\section{APPENDIX 10. ESTIMATION OF MEAN PARTICLE RESIDENCE TIME AND RATE OF PARTICLE HEATUP IN PYROLYSIS TUBE}

\section{[A10.1] PURPOSE AND LIMITATIONS OF NUMERICAL MODELS}

It was discussed in the Pyrolysis Results and Gas and Particle Flow Analysis sections that particle residence times were longer and the rates of particle heatup were higher in acoustics experiments. The degree to which a resonant acoustic field can increase the particle residence time and particle heatup rate depends on the sound pressure level. A model was developed to estimate the mean particle residence time in the pyrolysis tube that were used to present the data in this dissertation and the relative rates of particle heatup with and without acoustics. The assumed empirical parameters used in the model were validated using the mean particle velocities in the pyrex tube section between $0.045-0.085$ and $0.145-0.185 \mathrm{~m}$ downstream from the particle injection point measured by high-speed imaging studies of cold flows, as shown in Tables A9.2-A9.4. It should be pointed out that accurate prediction of residence time of an inflight pyrolyzing particle is very difficult, which is beyond the scope of this dissertation.

Therefore, a simplified empirical model was used in this study.

\section{[A10.2] FORMULATION OF MODEL TO ESTIMATE MEAN PARTICLE RESIDENCE TIME IN PYROLYSIS TUBE}

The velocities of particles exiting the particle injection probe and passing through the pyrolysis tube were estimated using Eq. 25. Pressure gradient term, apparent mass term, and Basset history term were neglected as suggested by Rudinger (1980), so that it can be expressed as,

$$
\frac{1}{6} \pi d_{p}^{3} \rho_{p} \frac{d U_{p}}{d t}=\frac{1}{8} \pi d_{p}^{2} \rho_{g} C_{\mathrm{D}}\left(U_{g}-U_{p}\right)\left|U_{g}-U_{p}\right|+\frac{1}{6} \pi d_{p}^{3} \rho_{p} g+\text { external force, (A10.1) }
$$


where $C_{\mathrm{D}}=\left(24 / \operatorname{Re}_{p}\right)\left(1+\operatorname{Re}_{p}^{2 / 3} / 6\right)$ for $\operatorname{Re}_{p}$ between $0.01-1000$ (Fuchs, 1964). The pressure drag can be reduced due to delayed flow separation by the surface roughness on particles. To correct total drag on a rough particle, $C_{\mathrm{D}}$ can be estimated by calculating the drag for a smooth sphere that can be inscribed within the rough particle (Clift et al, 1978). As observed in SEM images of $150 \mu \mathrm{m}$ or larger diameter char particles, the thickness of the rough surface layer typically varies between $10-15 \mu \mathrm{m}$. For a $150 \mu \mathrm{m}$ diameter char particle having a surface roughness of $12 \mu \mathrm{m}, C_{\mathrm{D}}$ was calculated to be about $80 \%$ of that estimated for the same diameter smooth sphere (Fuchs, 1964). Eq. A10.1 was solved in Microsoft Excel using a fourth order Runga-Kutta integration scheme (Canale and Chapra, 1988) with a time increment $\Delta t_{z}=0.0001 \mathrm{~s}$. Velocities and gravitational acceleration are positive in the downward direction. The external force that caused particles to levitate at high sound pressure level and low flowrate was equal to the acoustic radiation pressure force.

Particles were injected from the $4.572 \mathrm{~mm}$ I.D. particle injection tube into the $52.51 \mathrm{~mm}$ I.D. pyrolysis tube. Gas temperature in the particle injection tube was $20^{\circ} \mathrm{C}$ for cold flow studies and $77^{\circ} \mathrm{C}$ for hot flow studies. The average particle injection velocity was assumed to equal the sum of the average carrier gas flow velocity and the particle terminal velocity. The average carrier gas velocity was assumed because particles were observed flowing out across almost the entire diameter of the particle injection tube. The gas flow was assumed to be laminar in the particle injection tube. The average velocity of the carrier gas $\bar{U}_{g}$ can be expressed as,

$$
\bar{U}_{g}=\frac{4 V_{S T P}}{\pi d_{t}^{2}}\left(\frac{1 \mathrm{~min}}{60 \mathrm{~s}}\right)\left(\frac{1 \mathrm{~m}^{3}}{1000 \mathrm{~L}}\right)\left(\frac{T_{g}}{273.15 \mathrm{~K}}\right),
$$


where $V_{S T P}$ is the volumetric flowrate of $\mathrm{N}_{2}(\mathrm{slpm}), d_{t}$ is the I.D. of the particle injection tube (in meters), and $T_{g}$ is the temperature of the carrier gas. The average carrier gas velocity was $0.415 \mathrm{~m} / \mathrm{s}$ for a carrier gas flowrate 0.32 and $0.38 \mathrm{slpm} \mathrm{N}_{2}$ at a temperature of 77 and $20^{\circ} \mathrm{C}$, respectively for hot and cold flow experiments.

In the model, the total distance traversed by a particle $z\left(t_{z}\right)$ from injection to a time $t_{z f}$ can be expressed as,

$$
z\left(t_{z}\right)=\sum_{t_{z}=0}^{t_{z}=t_{z f}} U_{p}\left(t_{z}\right) \Delta t_{z}
$$

The mean diameters of BLS particles that were fed to the reactor were assumed to be $115 \mu \mathrm{m}$ and $150 \mu \mathrm{m}$ for hot and cold flow studies, respectively. The initial density of BLS particles fed to the reactor in hot flow studies was assumed to be $940 \mathrm{~kg} / \mathrm{m}^{3}$ (Adams and Frederick, 1988) and $402 \mathrm{~kg} / \mathrm{m}^{3}$ in cold flow studies.

In the model, fractional pyrolytic mass losses from an individual particle were assumed to be the same as those obtained from hot flow experiments. Mass loss $m_{p}(z)$ was assumed to occur linearly with distance $z$ traveled and can be expressed as,

$$
m_{p}(z)=M_{p}\left(z_{0}\right)-\frac{\left(M_{p}\left(z_{1}\right)-M_{p}\left(z_{0}\right) z\right.}{z_{1}-z_{0}} \text { for } z_{0} \leq z \leq z_{1},
$$

where $M_{p}\left(z_{0}\right)$ and $M_{p}\left(z_{1}\right)$ are the fractions of the initial particle mass $m_{p}(0)$ at the beginning $z=z_{0}$ and end $z=z_{1}$ of a section of the pyrolysis tube, respectively. The average particle diameter $d_{p}(z)$ was assumed to increase linearly due to swelling and can be expressed as, 


$$
d_{p}(z)=D_{p}\left(z_{0}\right)+\frac{\left(D_{p}\left(z_{1}\right)-D_{p}\left(z_{0}\right) z\right.}{z_{1}-z_{0}} \text { for } z_{0} \leq z \leq z_{1}
$$

where $D_{p}\left(z_{0}\right)$ and $D_{p}\left(z_{1}\right)$ are the particle diameters at the beginning $z=z_{0}$ and end $z=z_{1}$ of a the pyrolysis tube section. Particle density $\rho_{p}$ can be expressed as,

$$
\rho_{p}(z)=\frac{6 m_{p}(z)}{\pi\left(d_{p}(z)\right)^{3}}
$$

At a secondary air flowrate of $56 \mathrm{slpm}$ without acoustics, particle dispersion from the centerline $r_{d}(z)$ was observed to be about 0.25 times the pyrolysis tube radius at a distance $0.15 \mathrm{~m}$ downstream from the particle injection tube exit. The maximum particle dispersion radius at $z=0.81 \mathrm{~m}$ was assumed to be the average radius of the pile of particles observed at the bottom of the decoupler, which corresponds to a distance of $0.013 \mathrm{~m}$ or about 0.5 times the tube radius. At the same secondary air flowrate of $56 \mathrm{slpm}$ with acoustics, particle dispersion was about 0.7 times the pyrolysis tube radius at a distance $z=0.15 \mathrm{~m}$. With acoustics $r_{d}(z)$ was assumed to be the radius of the pyrolysis tube at $z=0.81 \mathrm{~m}$. The radial dispersion distance can be expressed as,

$$
\begin{aligned}
& r_{d}(z)=\frac{r_{d}(0.15) z}{0.15} \text { for } 0<z \leq 0.15 \\
& r_{d}(z)=\frac{r_{d}(0.66) z}{0.66} \text { for } 0.15<z \leq 0.81 .
\end{aligned}
$$

The gas flow was assumed to have a Gaussian velocity profile at $z=0$ for a particle carrier gas jet (Pai, 1954) and have a parabolic velocity profile of a laminar pipe flow at $z>z m l$. The instantaneous mean gas velocity experienced by particles during mixing of the 
carrier gas jet with the secondary gas stream was assumed to either increase or decrease linearly from the mean carrier gas velocity at $z=0 \mathrm{~m}$ to the velocity of the completely mixed gas stream at $z_{m l}=0.15 \mathrm{~m}$. All particles were assumed to experience the same instantaneous mean gas velocity because the radial particle mass distribution could not be measured. All particles were assumed to be inflight at the pyrolysis tube radius in which the average gas velocity is attained between the centerline and $r_{d}(z)$ for $z \geq z_{m l}$. By assuming a parabolic velocity profile for $z \geq z_{m l}$, the instantaneous mean gas velocity $U_{g}(z)$ experienced by all particles can be expressed as,

$$
\bar{U}_{g}(z)=\frac{2 \pi\left(2 \bar{U}_{g}\right) \int_{0}^{r d(z)}\left[1-\left(\frac{r}{r_{t}}\right)^{2}\right] r d r}{\pi r^{2}}=2 \bar{U}_{g}\left(1-\frac{\left(r_{d}(z)\right)^{2}}{2 r_{t}{ }^{2}}\right),
$$

where $r$ is radial distance from the pyrolysis tube centerline and $r t$ is the radius of the pyrolysis tube (Bird et al, 1960).

Acoustic radiation pressure is suggested to be responsible for particle levitation and longer residence times because levitational zones occurred periodically in the pyrolysis tube. Oseen-type drag forces are probably not the cause of particle levitation, because levitation was not observed near the acoustic velocity anti-nodes of the resonant axial acoustic field where the Oseen-type drag force would be the greatest. The acoustic radiation pressure acting on 115-300 $\mu \mathrm{m}$ diameter char particles levitated with an acoustic field of $159 \mathrm{~dB}$ and $970 \mathrm{~Hz}$ using a secondary air flowrate of $14 \mathrm{slpm}$ was calculated using an expression derived by Doinikov (1996) and was found to be 9 orders of magnitude higher than the sum of the gravitational and the steady flow drag forces exerted on the levitated particle. The radiation 
pressure calculated with King's equation (King, 1934) was too low and in the wrong direction to levitate particles.

The levitational force can be calculated from the force balance, as shown in Fig. A10.1, regardless of the theoretically predicted magnitudes. The levitational force exerted on a $300 \mu \mathrm{m}$ diameter char particle having a density of $50 \mathrm{~kg} / \mathrm{m}^{3}$ using an acoustic field of $159 \mathrm{~dB}$ and $970 \mathrm{~Hz}$ and a secondary air flowrate of $14 \mathrm{slpm}$ represents the greatest levitational force for the range of particle diameters and densities used in the cold flow studies. At a secondary gas flowrate of 14 slpm, the maximum downward steady flow drag force on a stationary char particle was calculated using the assumed parabolic velocity distribution with a centerline velocity of $0.223 \mathrm{~m} / \mathrm{s}$.

Steady flow drag force $=$ $\frac{1}{8} \rho d_{p}^{2} r_{g} C_{D}\left(U_{g}-U_{p}\right)\left|U_{g}-U_{p}\right|$,
$C_{D}=\left(24 / \operatorname{Re}_{p}\right)\left(1+\frac{1}{6} \operatorname{Re}_{p}^{2 / 3}\right)$

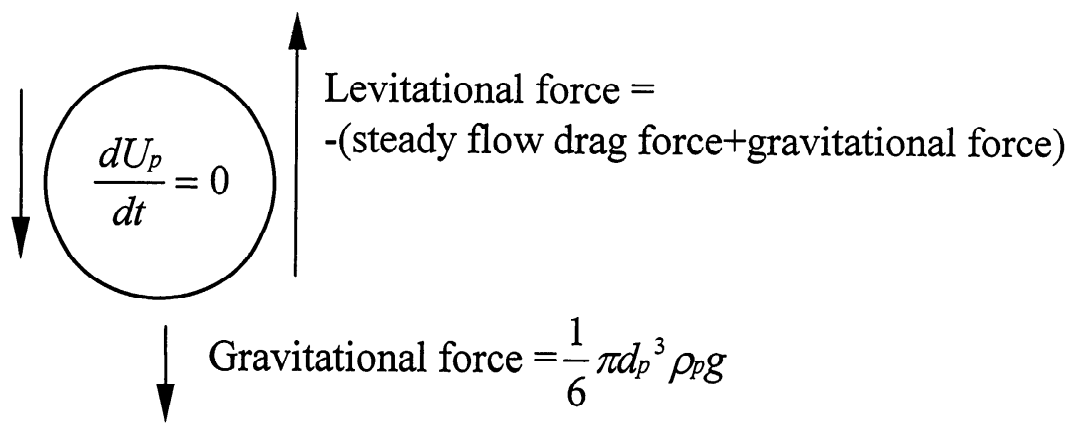

Figure A10.1. A schematic diagram of the gravitational, downward steady flow drag, and levitational forces exerted on levitating particle.

The direction of the levitational force was that given by Doinikov (1996). The empirical time-mean levitational force $F_{l}(z)$, can be expressed as,

$$
F_{l}(z)=-\frac{\rho_{g}}{\rho_{o}}\left(\frac{\hat{u}_{g}}{\hat{u}_{o}}\right)^{2} F_{o} \sin \left[\frac{4 \pi f(z-z d)}{c}\right],
$$


where $F_{o}$ is the calculated mean levitational force shown in Fig. A10.1, $\rho_{o}$ is the density of the cold air $\left(1.175 \mathrm{~kg} / \mathrm{m}^{3}\right), \hat{u}_{o}$ is the acoustic velocity amplitude at a cold air temperature of $20^{\circ} \mathrm{C}$, and $z d$ is the distance between the particle injection point and the nearest downstream acoustic pressure anti-node. Fig. 10.2 illustrates the relationship between the levitational force, acoustic pressure, and the approximate regions of particle levitation in the pyrolysis tube.

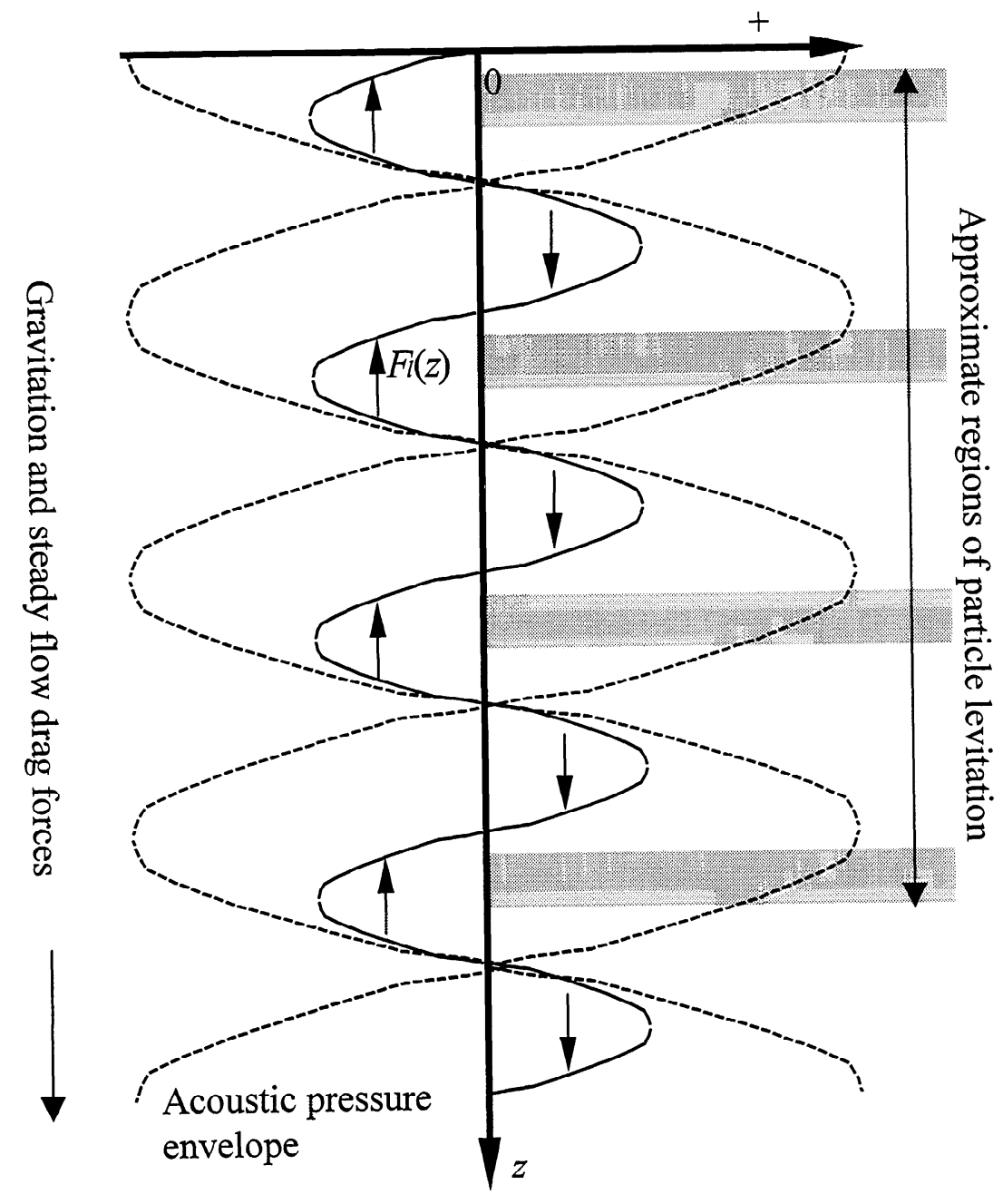

Figure A10.2. A schematic diagram of the levitational force, acoustic pressure, and approximate regions of particle levitation in the pyrolysis tube. 
[10.2.1] Model Estimation of Mean Char Particle Residence Time in the Pyrex Tube Measured During Gas and Particle Flow Imaging Studies

Integration of Eq. A10.1 indicated that $150 \mu \mathrm{m}$ diameter char particles attained a terminal velocity of $0.262 \mathrm{~m} / \mathrm{s}$ in the particle injection tube using a carrier gas flowrate of $0.32 \operatorname{slpm~} \mathrm{N}_{2}$ at a temperature of $77^{\circ} \mathrm{C}$. The char particle injection velocity into the pyrolysis tube was $0.677 \mathrm{~m} / \mathrm{s}$ assuming a mean carrier gas velocity of $0.415 \mathrm{~m} / \mathrm{s}$. Particle velocity, travel distance, and gas velocity were calculated for cold flows as shown in Figs. A10.3-A10.8. The model best estimated the mean char particle velocities measured between $0.045-0.085$ and 0.145-0.185 $\mathrm{m}$ downstream from the particle injection point, as shown in Tables A9.2-A9.4, when $z=0.15 \mathrm{~m}$. However, with exception to the experimental observations, the model predicted that char particles would be almost levitated between 0.04-0.08 $\mathrm{m}$ downstream of the particle injection tube exit with an acoustic field of $159 \mathrm{~dB}$ and $970 \mathrm{~Hz}$ and a secondary gas flowrate of $56 \mathrm{slpm}$. This did not occur in experiments because the acoustic pressure may have been reduced due to partial reflection of the acoustic wave at the particle injection tube exit and the flow vain attached to the $90^{\circ}$ elbow section. 


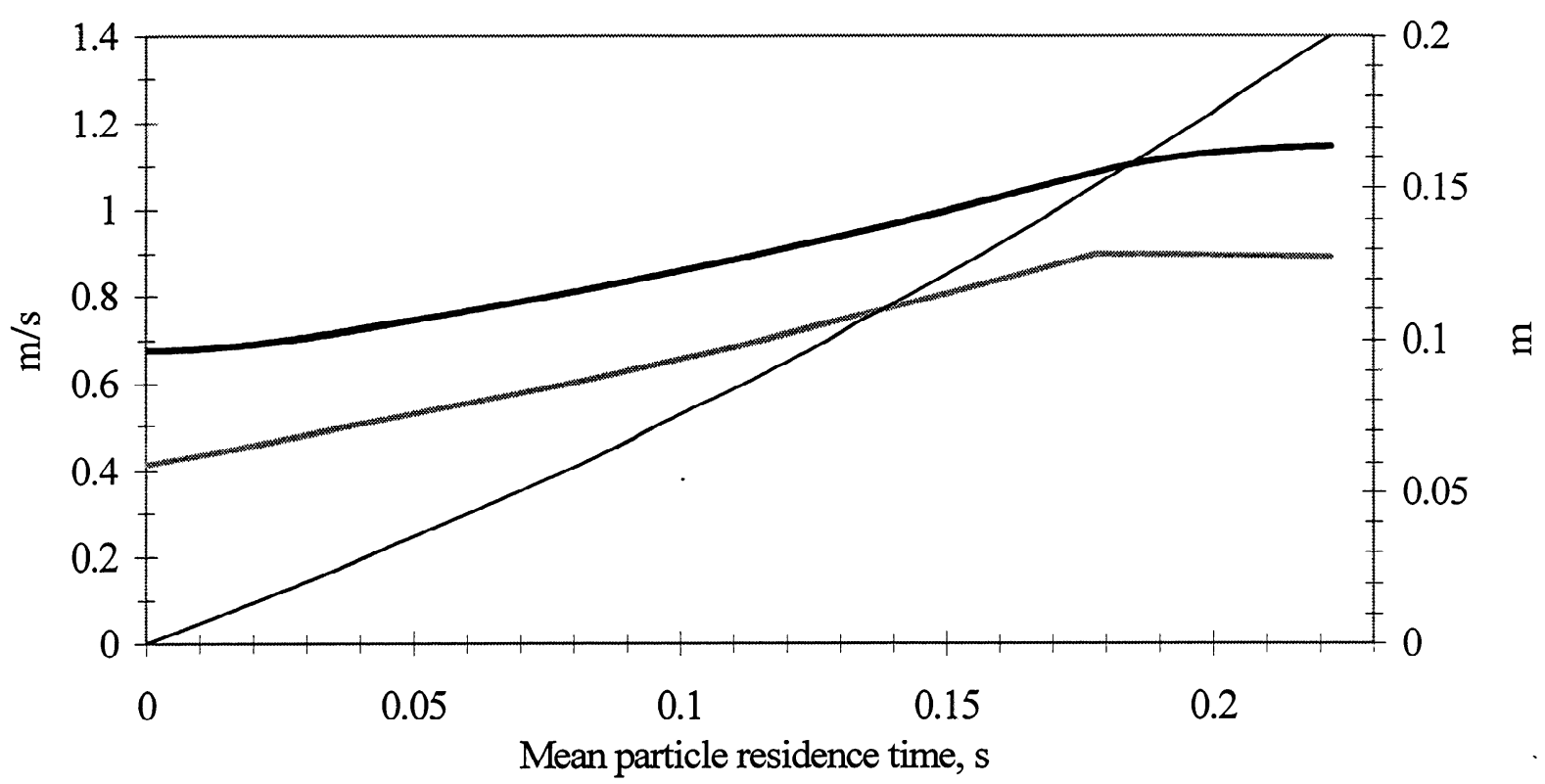

Mean particle velocity - Mean gas velocity — Distance traveled by particle

Figure A10.3. Model predicted dynamics of inflight char particles in pyrolysis tube obtained without acoustics for $V_{S T P}=56 \mathrm{slpm}$ air, $T_{g}=20^{\circ} \mathrm{C}, \rho_{g}=1.175 \mathrm{~kg} / \mathrm{m}^{3}$, $v_{g}=1.535 \times 10^{-5} \mathrm{~m}^{2} / \mathrm{s}, m_{p}(z)=7.11 \times 10^{-10} \mathrm{~kg}, d_{p}(z)=150 \mu \mathrm{m}$, and $\rho_{p}(z)=402 \mathrm{~kg} / \mathrm{m}^{3}$.

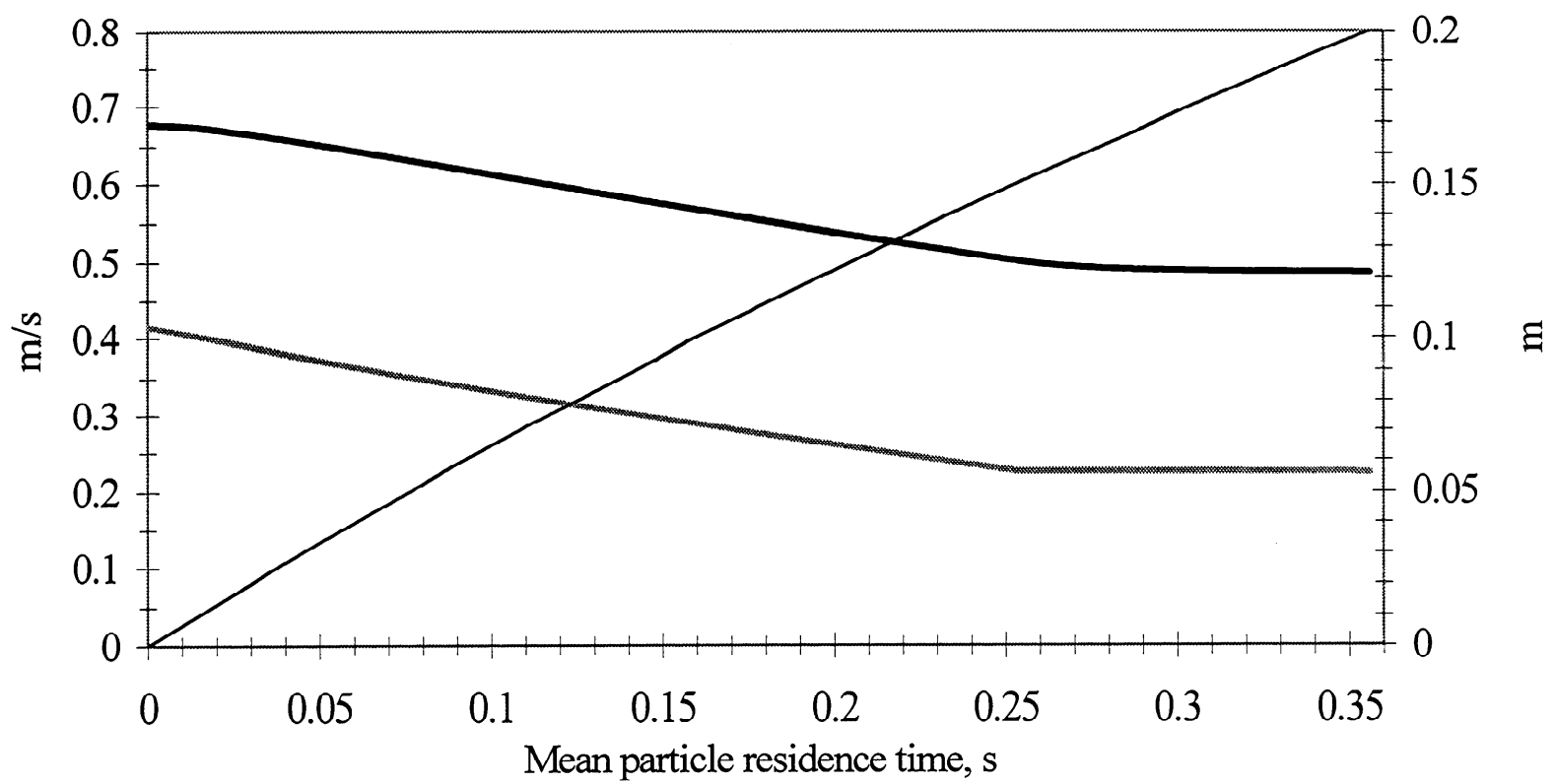

- Mean particle velocity - Mean gas velocity — Distance traveled by particle

Figure A10.4. Model predicted dynamics of inflight char particles in pyrolysis tube obtained without acoustics for $V_{S T P}=14 \mathrm{slpm}$ air, $T_{g}=20^{\circ} \mathrm{C}, \rho_{g}=1.175 \mathrm{~kg} / \mathrm{m}^{3}$, $v_{g}=1.535 \times 10^{-5} \mathrm{~m}^{2} / \mathrm{s}, m_{p}(z)=7.11 \times 10^{-10} \mathrm{~kg}, d_{p}(z)=150 \mu \mathrm{m}$, and $\rho_{p}(z)=402 \mathrm{~kg} / \mathrm{m}^{3}$. 


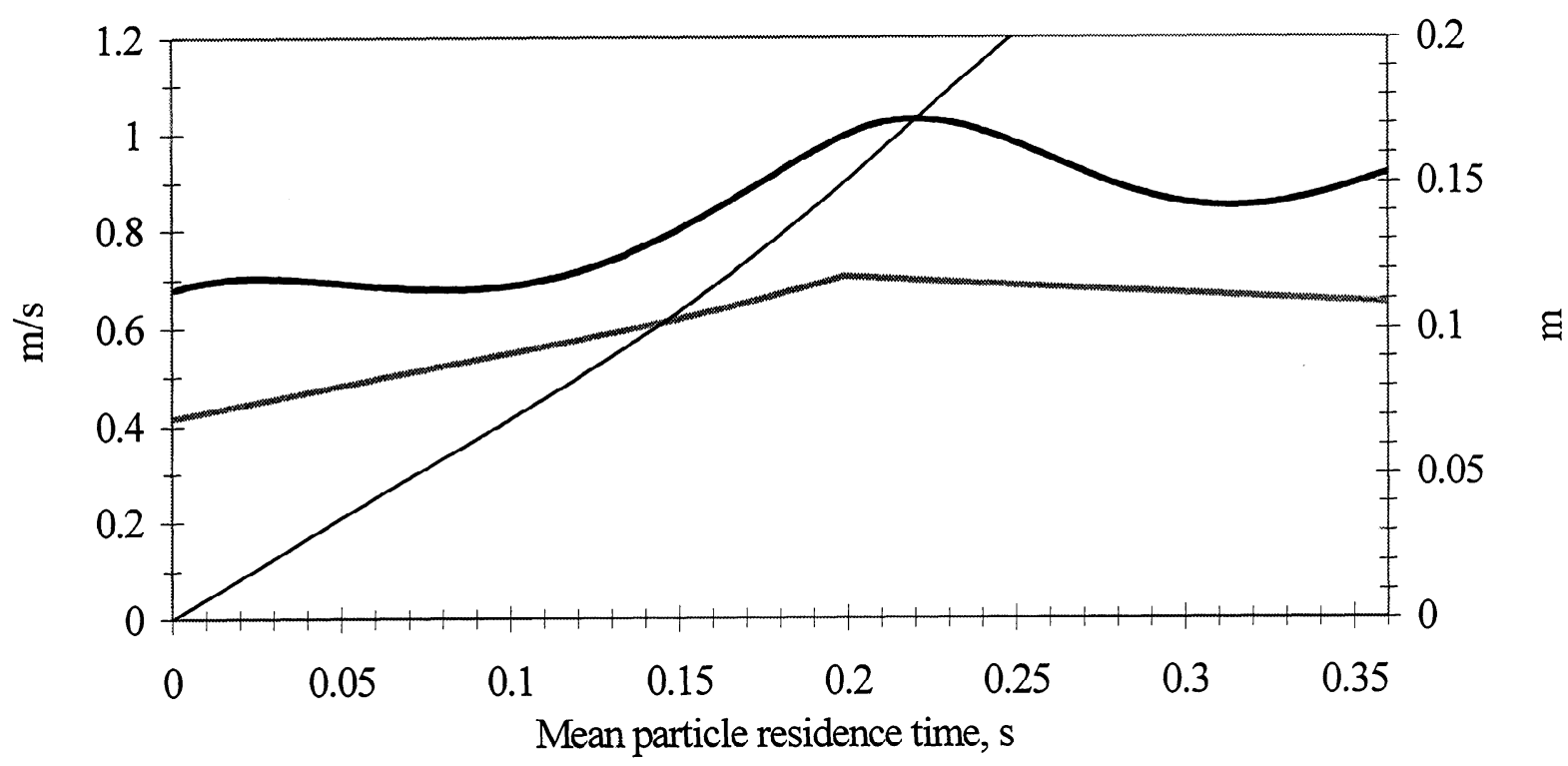

- Mean particle velocity - Mean gas velocity - Distance traveled by particle

Figure A10.5. Model predicted dynamics of inflight char particles in pyrolysis tube obtained with an acoustic field of $151 \mathrm{~dB}\left(\hat{u}_{g}=2.5 \mathrm{~m} / \mathrm{s}\right)$ and $970 \mathrm{~Hz}$ for $V_{S T P}=56 \mathrm{slpm}$ air, $T_{g}=20^{\circ} \mathrm{C}, \rho_{g}=1.175 \mathrm{~kg} / \mathrm{m}^{3}, v_{g}=1.535 \times 10^{-5} \mathrm{~m}^{2} / \mathrm{s}, m_{P}(z)=7.11 \times 10^{-10} \mathrm{~kg}$, $d_{p}(z)=150 \mu \mathrm{m}$, and $\rho_{p}(z)=402 \mathrm{~kg} / \mathrm{m}^{3}$.

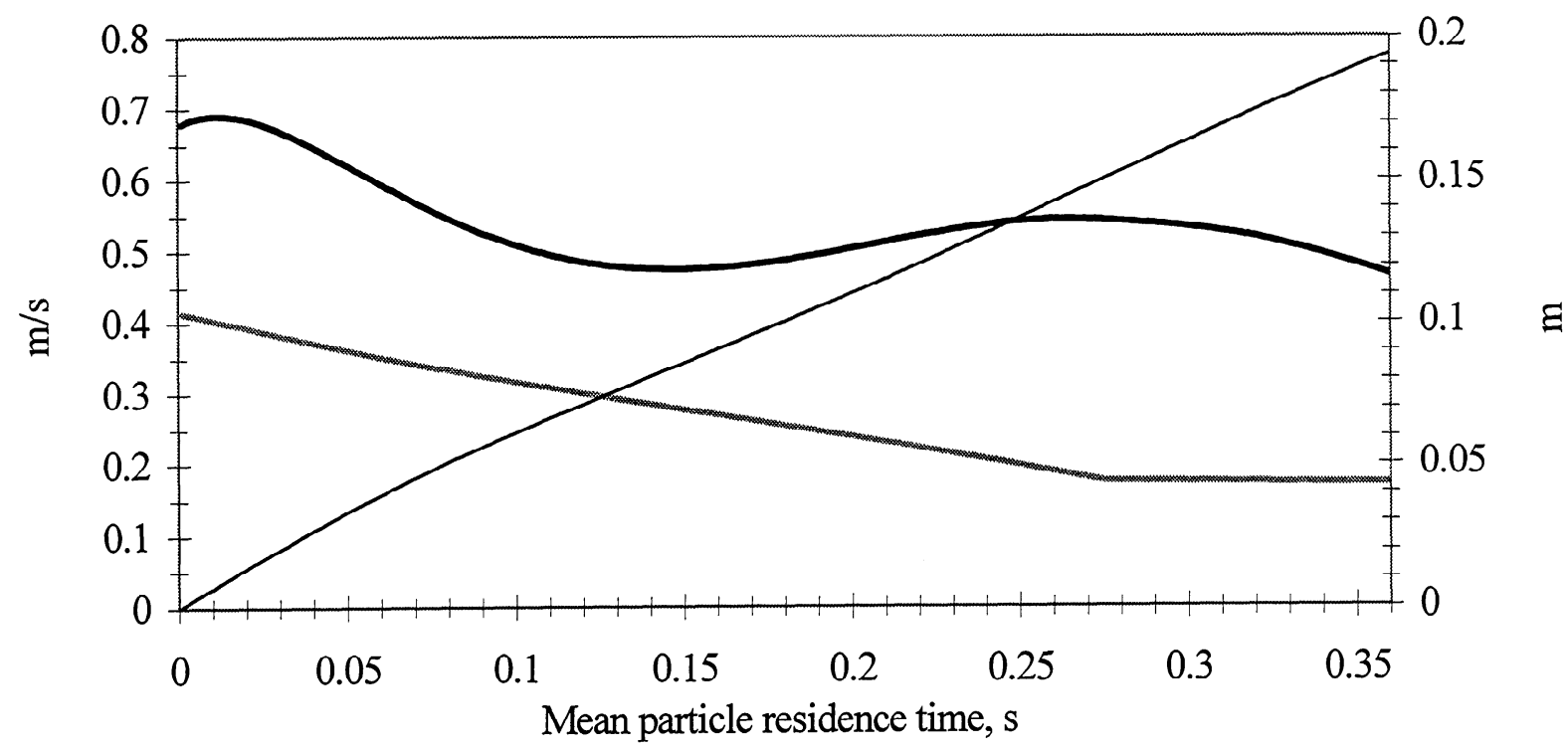

- Mean particle velocity - Mean gas velocity — Distance traveled by particle

Figure A10.6. Model predicted dynamics of inflight char particles in pyrolysis tube obtained with an acoustic field of $151 \mathrm{~dB}\left(\hat{u}_{g}=2.5 \mathrm{~m} / \mathrm{s}\right)$ and $970 \mathrm{~Hz}$ for $V_{\text {STP }}=14 \mathrm{slpm}$ air, $T_{g}=20^{\circ} \mathrm{C}, \rho_{g}=1.175 \mathrm{~kg} / \mathrm{m}^{3}, v_{g}=1.535 \times 10^{-5} \mathrm{~m}^{2} / \mathrm{s}, m_{P}(z)=7.11 \times 10^{-10} \mathrm{~kg}$, $T_{g} d_{p}(z)=150 \mu \mathrm{m}$, and $\rho_{p}(z)=402 \mathrm{~kg} / \mathrm{m}^{3}$. 


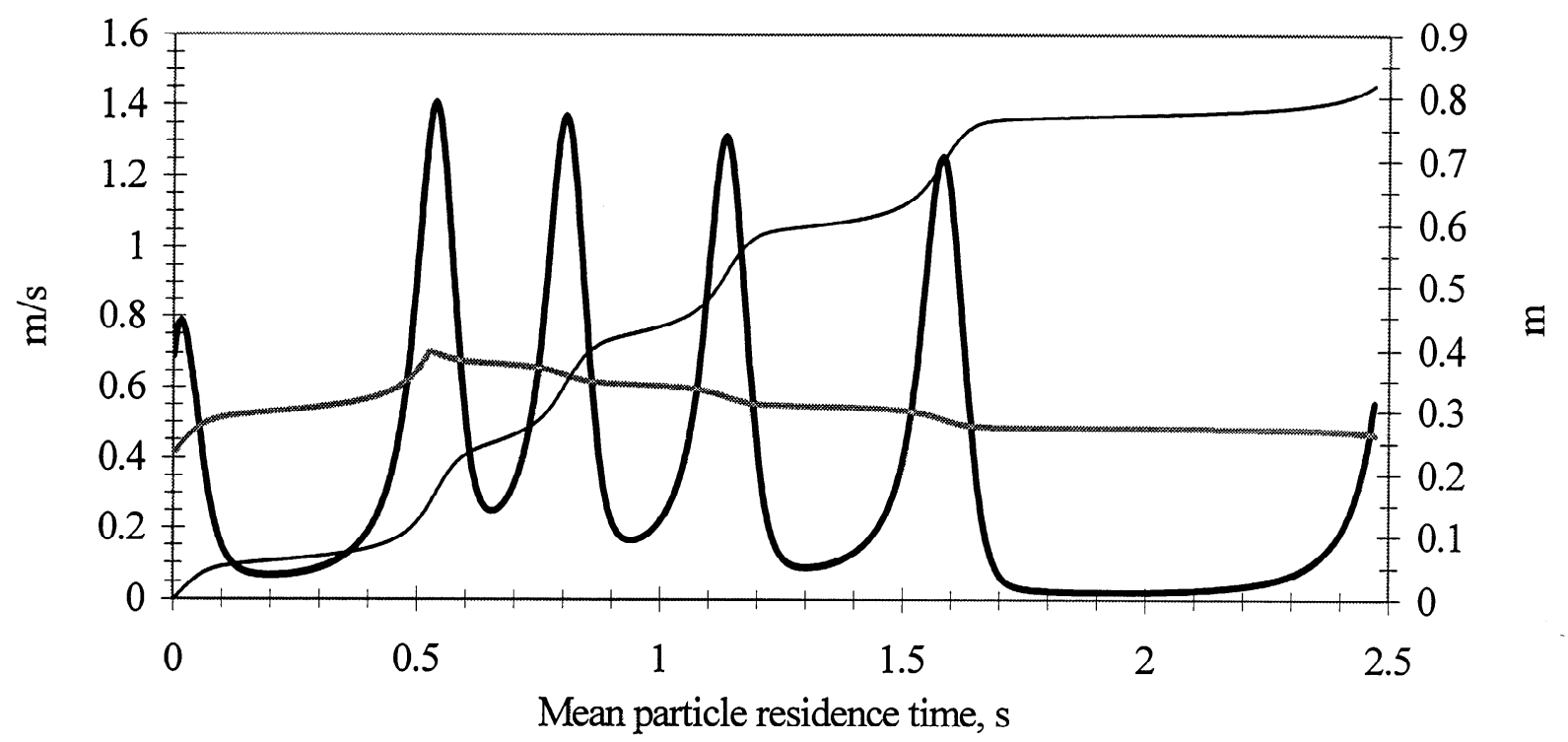

- Mean particle velocity - Mean gas velocity _ Distance traveled by particle

Figure A10.7. Model predicted dynamics of inflight char particles in pyrolysis tube obtained with an acoustic field of $159 \mathrm{~dB}\left(\hat{u}_{g}=6.4 \mathrm{~m} / \mathrm{s}\right)$ and $970 \mathrm{~Hz}$ for $V_{S T P}=56 \mathrm{slpm}$ air, $T_{g}=20^{\circ} \mathrm{C}, \rho_{g}=1.175 \mathrm{~kg} / \mathrm{m}^{3}, v_{g}=1.535 \times 10^{-5} \mathrm{~m}^{2} / \mathrm{s}, m_{p}(z)=7.11 \times 10^{-10} \mathrm{~kg}$, $d_{p}(z)=150 \mu \mathrm{m}$, and $\rho_{p}(z)=402 \mathrm{~kg} / \mathrm{m}^{3}$.

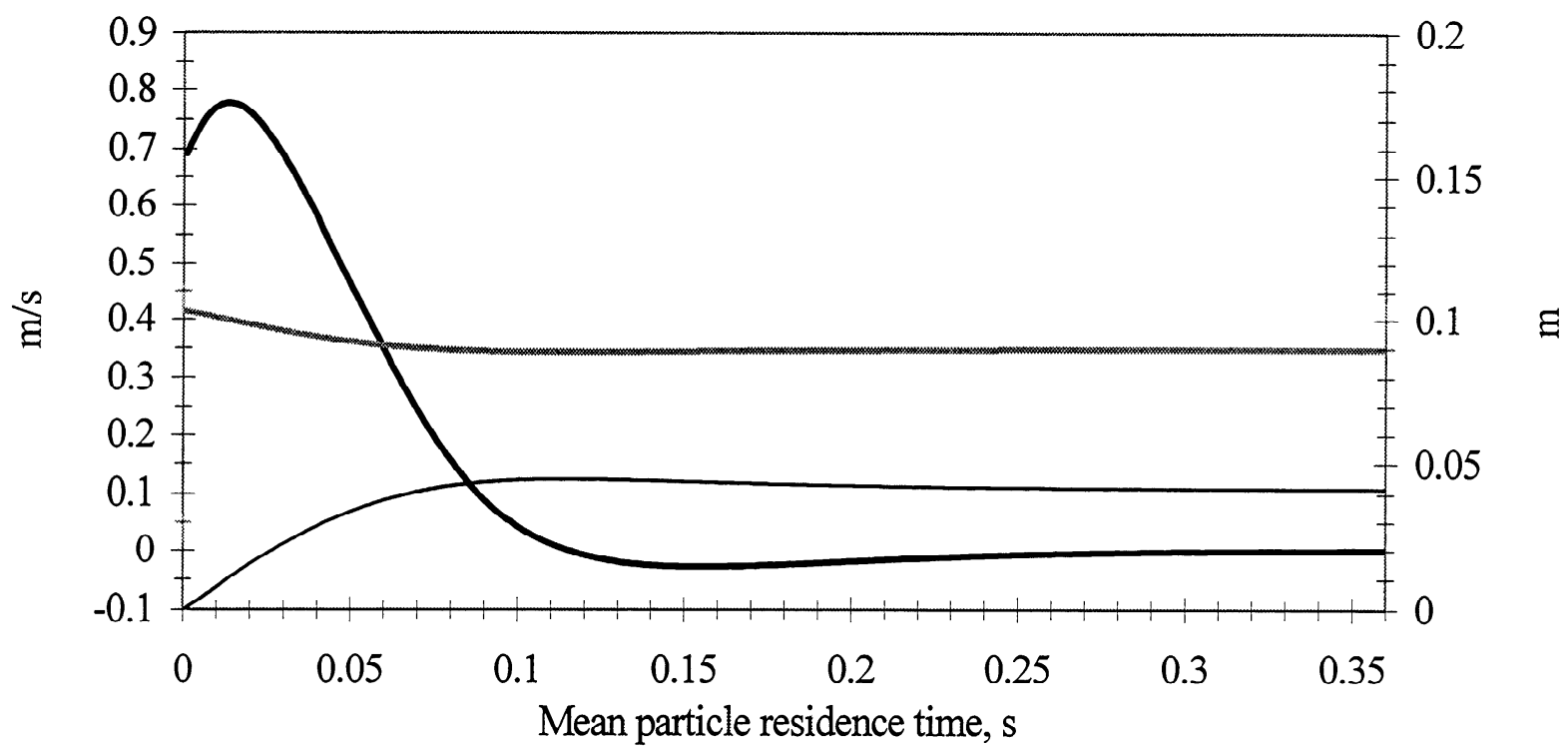

- Mean particle velocity - Mean gas velocity - Distance traveled by particle

Figure A10.8. Model predicted dynamics of inflight char particles in pyrolysis tube obtained with an acoustic field of $159 \mathrm{~dB}\left(\hat{u}_{g}=6.4 \mathrm{~m} / \mathrm{s}\right)$ and $970 \mathrm{~Hz}$ for $V_{S T P}=14 \mathrm{slpm}$ air, $T_{g}=20^{\circ} \mathrm{C}, \rho_{g}=1.175 \mathrm{~kg} / \mathrm{m}^{3}, v_{g}=1.535 \times 10^{-5} \mathrm{~m}^{2} / \mathrm{s}, m_{p}(z)=7.11 \times 10^{-10} \mathrm{~kg}$, $d_{p}(z)=150 \mu \mathrm{m}$, and $\rho_{p}(z)=402 \mathrm{~kg} / \mathrm{m}^{3}$. 


\section{[A10.2.2] Model Estimation of Mean Particle Residence Time in the Heated Pyrolysis Tube During Pyrolysis Experiments}

Figs. 10.9-10.29 show particle velocity, distance traveled by the particle, and gas velocity calculated using the model under pyrolysis experimental conditions. The extent of particle pyrolytic mass loss and swelling in hot flow was the same as that observed within 0.18 , 0.48 , and $0.81 \mathrm{~m}$ pyrolysis tube heated lengths. For acoustics experiments conducted under conditions of $151 \mathrm{~dB}$ and $310 \mathrm{~Hz}$, or 154 and $159 \mathrm{~dB}$ and $950-1000 \mathrm{~Hz}$ that used only the 0.81 $\mathrm{m}$ pyrolysis tube heated length, the initial particle pyrolytic mass loss and swelling values were approximated by those obtained at $z=0.18 \mathrm{~m}$ using an acoustic field of $151 \mathrm{~dB}$ and $970 \mathrm{~Hz}$. Experimentally measured axial acoustic velocities were used to calculate the levitational force exerted on the particle. Particle dispersion parameters $r d(0.15)$ and $r d(0.81)$ were the same as those used to model cold flow. 


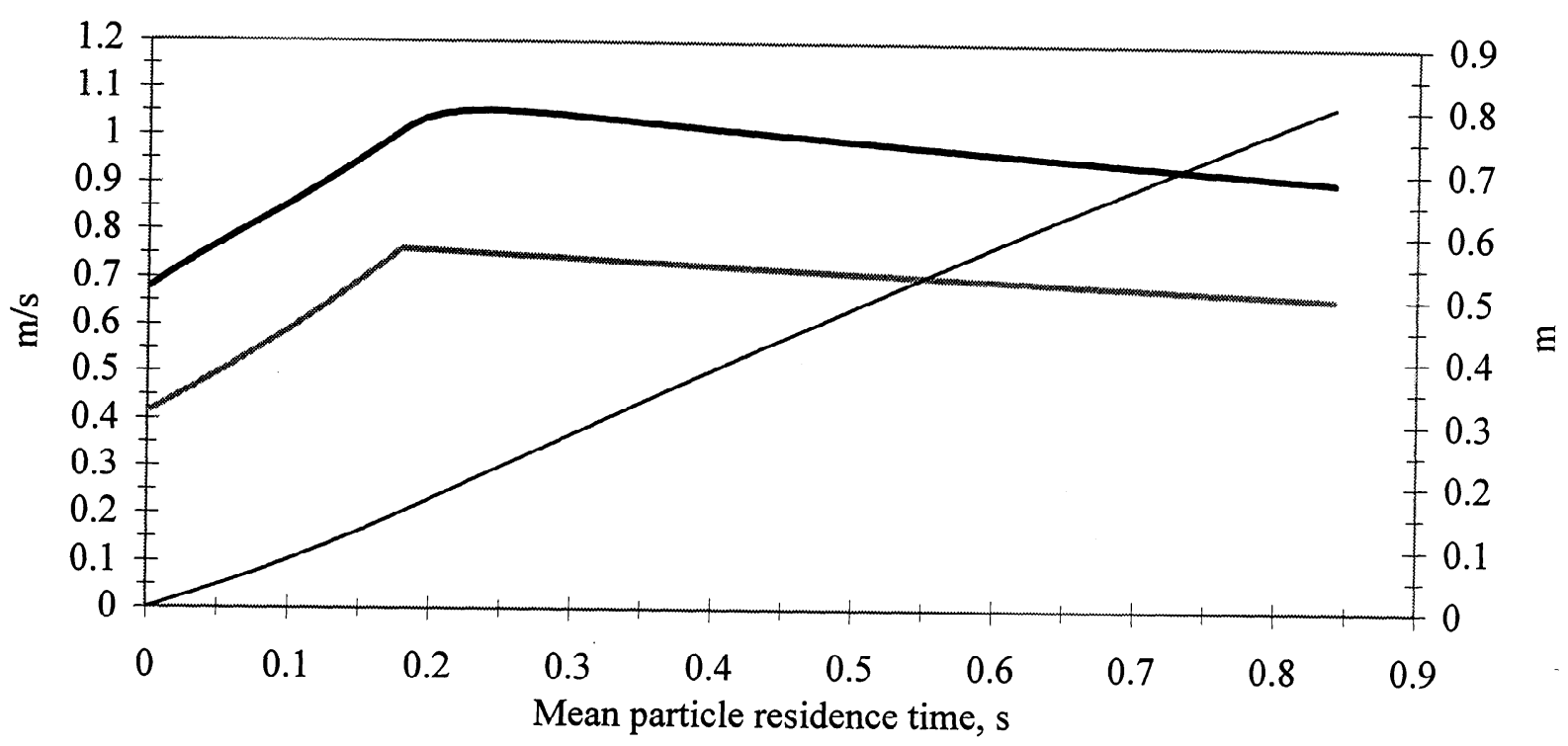

- Mean particle velocity - Mean gas velocity — Distance traveled by particle

Figure A10.9. Model predicted dynamics of inflight BLS particles in pyrolysis tube obtained without acoustics (RNAC1113) for $V_{S T P}=20 \mathrm{slpm} \mathrm{N}, T_{g}=400^{\circ} \mathrm{C}$, $\rho_{g}=0.5028 \mathrm{~kg} / \mathrm{m}^{3}, \nu_{g}=3.484 \times 10^{-5} \mathrm{~m}^{2} / \mathrm{s}, d_{P}(0)=115 \mu \mathrm{m}, m_{P}(0)=7.4855 \times 10^{-10} \mathrm{~kg}$, $\rho_{p}(0)=940 \mathrm{~kg} / \mathrm{m}^{3}, D_{p}(0.81)=150 \mu \mathrm{m}$, and $M_{P}(0.81)=0.96$.

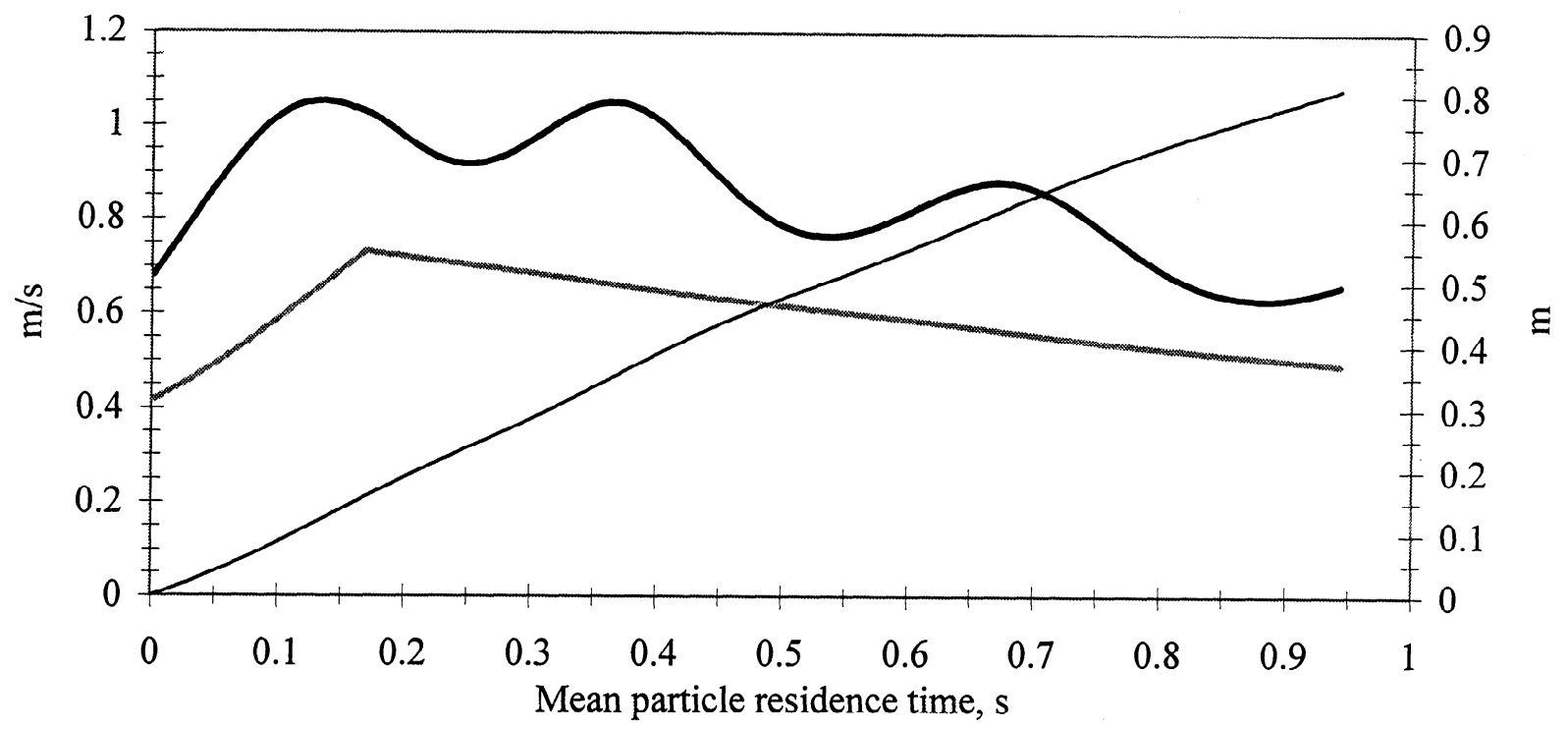

Mean particle velocity - Mean gas velocity — Distance traveled by particle

Figure A10.10. Model predicted dynamics of inflight BLS particles in pyrolysis tube obtained with an acoustic field of $151 \mathrm{~dB}\left(\hat{u}_{g}=3.9 \mathrm{~m} / \mathrm{s}\right.$ for RAC1119) and $970 \mathrm{~Hz}$ for $V_{S T P}=20 \mathrm{slpm} \mathrm{N} \mathrm{N}_{2}, T_{g}=400^{\circ} \mathrm{C}, \rho_{g}=0.5028 \mathrm{~kg} / \mathrm{m}^{3}, v_{g}=3.484 \times 10^{-5} \mathrm{~m}^{2} / \mathrm{s}$, $d_{p}(0)=115 \mu \mathrm{m}, m_{p}(0)=7.4855 \times 10^{-10} \mathrm{~kg}, \rho_{p}(0)=940 \mathrm{~kg} / \mathrm{m}^{3}, D_{p}(0.81)=225 \mu \mathrm{m}$, and $M_{p}(0.81)=0.934$. 


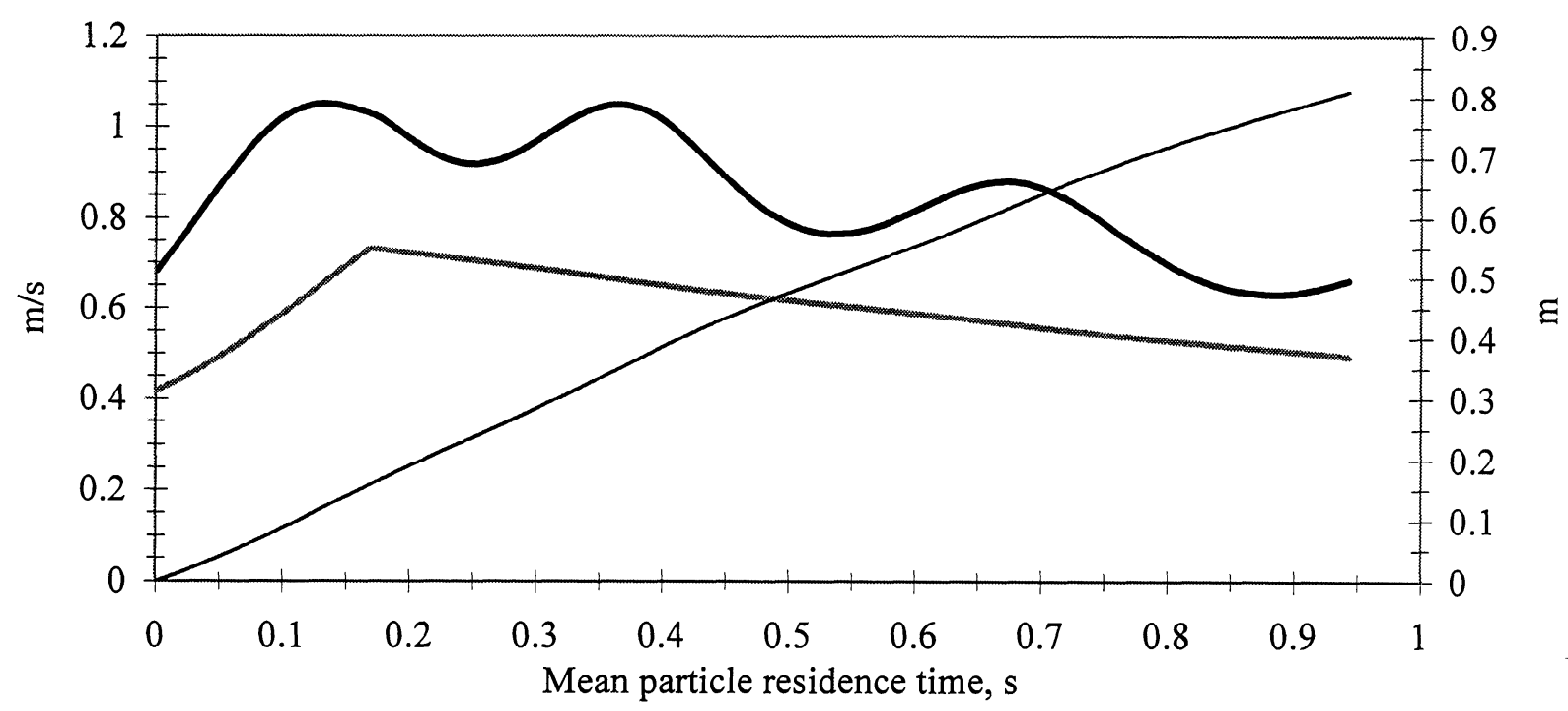

Mean particle velocity - Mean gas velocity - Distance traveled by particle

Figure A10.11. Model predicted dynamics of inflight BLS particles in pyrolysis tube obtained with an acoustic field of $151 \mathrm{~dB}$ ( $\hat{u}_{g}=3.9 \mathrm{~m} / \mathrm{s}$ for RAC1009) and $970 \mathrm{~Hz}$ for $V_{S T P}=24.9 \mathrm{slpm} \mathrm{N}_{2}, T_{g}=400^{\circ} \mathrm{C}, \rho_{g}=0.5028 \mathrm{~kg} / \mathrm{m}^{3}, v_{g}=3.484 \times 10^{-5} \mathrm{~m}^{2} / \mathrm{s}$, $d_{p}(0)=115 \mu \mathrm{m}, m_{p}(0)=7.4855 \times 10^{-10} \mathrm{~kg}, \rho_{p}(0)=940 \mathrm{~kg} / \mathrm{m}^{3}, D_{p}(0.81)=225 \mu \mathrm{m}$, and $M_{p}(0.81)=0.934$ (assumed to be the same as RAC11119; char yield could not be obtained because some particles stuck to pyrolysis tube wall).

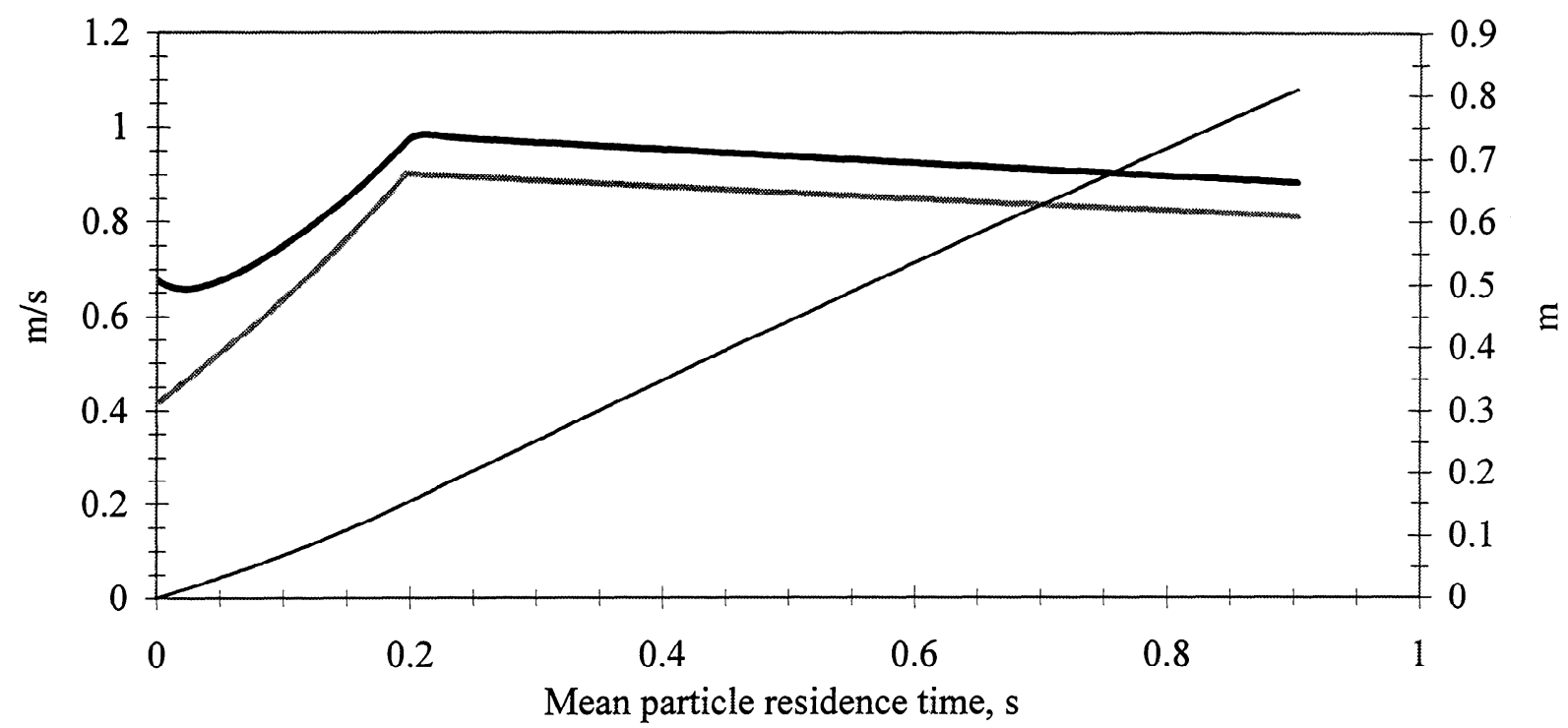

- Mean particle velocity - Mean gas velocity _ Distance traveled by particle

Figure A10.12. Model predicted dynamics of inflight BLS particles in pyrolysis tube obtained without acoustics for $V_{S T P}=20 \mathrm{slpm} \mathrm{N}{ }_{2}, T_{g}=550^{\circ} \mathrm{C}, \rho_{\mathcal{g}}=0.4103 \mathrm{~kg} / \mathrm{m}^{3}$, $v_{g}=8.69 \times 10^{-5} \mathrm{~m}^{2} / \mathrm{s}, d_{p}(0)=115 \mu \mathrm{m}, m_{p}(0)=7.4855 \times 10^{-10} \mathrm{~kg}, \quad \rho_{p}(0)=940 \mathrm{~kg} / \mathrm{m}^{3}$, $D_{p}(\geq 0.18)=275 \mu \mathrm{m}, M_{p}(0.18)=0.847, M_{p}(0.48)=0.806$, and $M_{p}(0.81)=0.772$. 


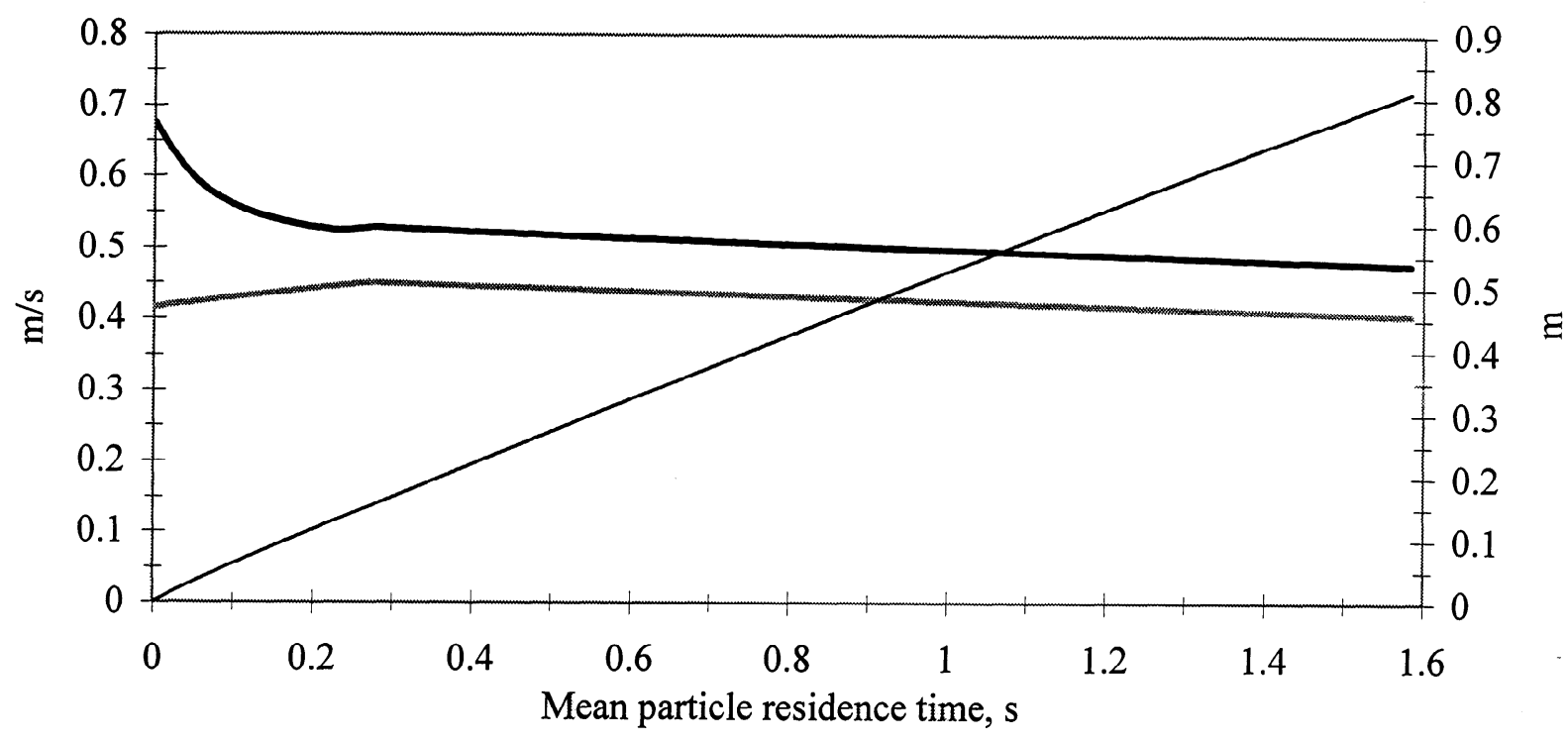

- Mean particle velocity - Mean gas velocity — Distance traveled by particle

Figure 10.13. Model predicted dynamics of inflight BLS particles in pyrolysis tube obtained without a acoustics for $V_{S T P}=10 \mathrm{slpm} \mathrm{N}, T_{g}=550^{\circ} \mathrm{C}, \rho_{g}=0.4103 \mathrm{~kg} / \mathrm{m}^{3}$, $\nu_{g}=8.69 \times 10^{-5} \mathrm{~m}^{2} / \mathrm{s}, d_{p}(0)=115 \mu \mathrm{m}, m_{p}(0)=7.4855 \times 10^{-10} \mathrm{~kg}, \rho_{p}(0)=940 \mathrm{~kg} / \mathrm{m}^{3}$, $D_{p}(\geq 0.103)=275 \mu \mathrm{m}, M_{p}(0.18)=0.834, M_{p}(0.48)=0.788$, and $M_{p}(0.81)=0.756$.

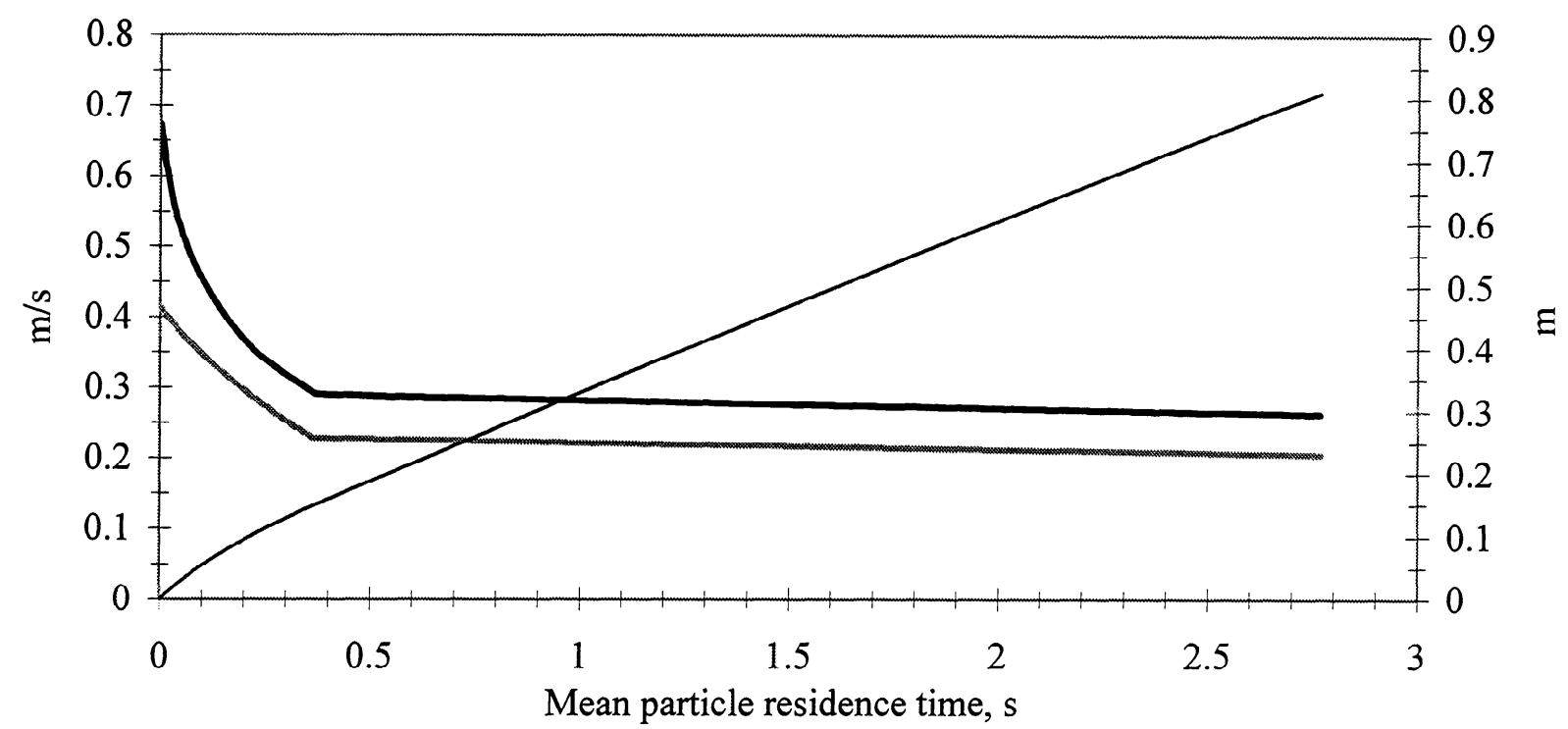

Mean particle velocity - Mean gas velocity — Distance traveled by particle

Figure A10.14. Model predicted dynamics of inflight BLS particles in pyrolysis tube obtained without acoustics for $V_{S T P}=5 \mathrm{slpm} \mathrm{N}, T_{g}=550^{\circ} \mathrm{C}, \rho_{g}=0.4103 \mathrm{~kg} / \mathrm{m}^{3}$, $v_{8}=8.69 \times 10^{-5} \mathrm{~m}^{2} / \mathrm{s}, d_{p}(0)=115 \mu \mathrm{m}, m_{P}(0)=7.4855 \times 10^{-10} \mathrm{~kg}, \rho_{p}(0)=940 \mathrm{~kg} / \mathrm{m}^{3}$, $D_{p}(z \geq 0.076)=275 \mu \mathrm{m}, M_{p}(0.18)=0.814, M_{p}(0.48)=0.783$, and $M_{p}(0.81)=0.756$. 


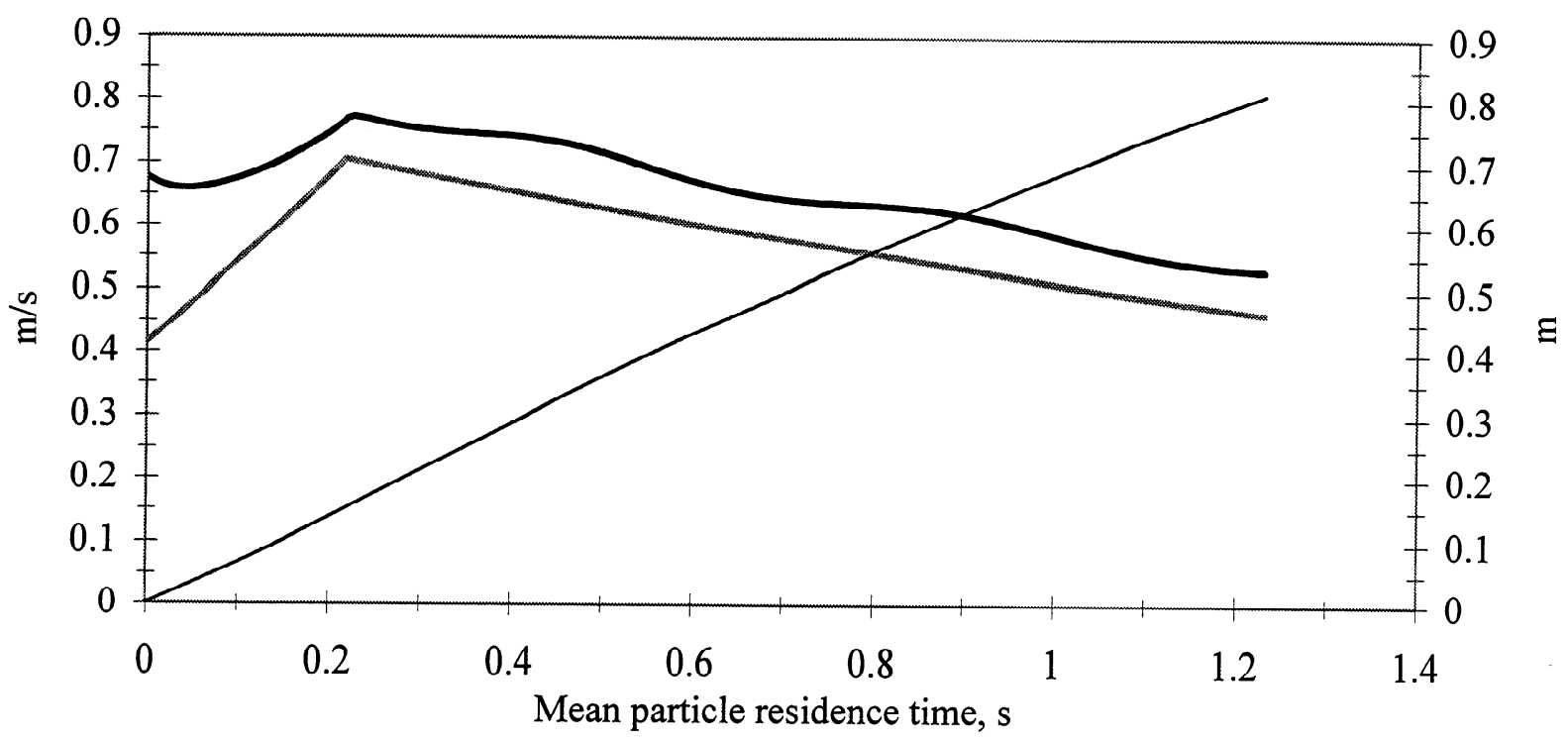

- Mean particle velocity - Mean gas velocity — Distance traveled by particle

Figure A10.15. Model predicted dynamics of inflight BLS particles in pyrolysis tube obtained with an acoustic field of $146 \mathrm{~dB}\left(\hat{u}_{g}=4.1 \mathrm{~m} / \mathrm{s}\right.$ for RAC1107) and $1000 \mathrm{~Hz}$ for $V_{S T P}=20 \mathrm{slpm} \mathrm{N}, T_{g}=550^{\circ} \mathrm{C}, \rho_{g}=0.4103 \mathrm{~kg} / \mathrm{m}^{3}, v_{g}=8.69 \times 10^{-5} \mathrm{~m}^{2} / \mathrm{s}$, $d_{p}(0)=115 \mu \mathrm{m}, m_{P}(0)=7.4855 \times 10^{-10} \mathrm{~kg}, \rho_{p}(0)=940 \mathrm{~kg} / \mathrm{m}^{3}$, $D_{P}(\geq 0.136)=275 \mu \mathrm{m}, M_{P}(0.18)=0.843, M_{P}(0.48)=0.794$, and $M_{P}(0.81)=0.751$.

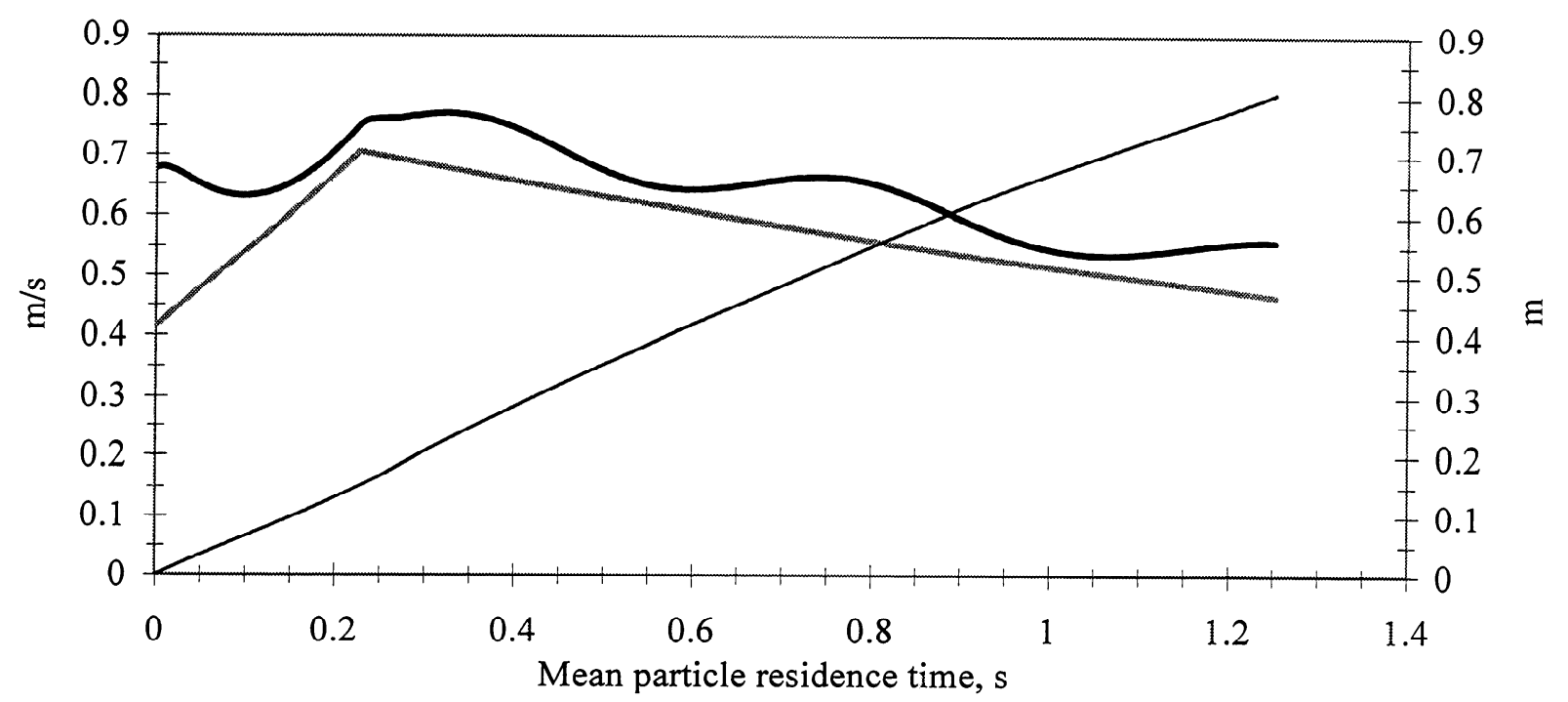

- Mean particle velocity - Mean gas velocity _ Distance traveled by particle

Figure A10.16. Model predicted dynamics of inflight BLS particles in pyrolysis tube obtained with an acoustic field of $151 \mathrm{~dB}\left(\hat{u}_{g}=4.1 \mathrm{~m} / \mathrm{s}\right.$ for RAC1107) and $1000 \mathrm{~Hz}$ for $V_{S T P}=20 \mathrm{slpm} \mathrm{N} \mathrm{N}_{2}, T_{g}=550^{\circ} \mathrm{C}, \rho_{g}=0.4103 \mathrm{~kg} / \mathrm{m}^{3}, v_{g}=8.69 \times 10^{-5} \mathrm{~m}^{2} / \mathrm{s}$, $d_{p}(0)=115 \mu \mathrm{m}, m_{p}(0)=7.4855 \times 10^{-10} \mathrm{~kg}, \rho_{p}(0)=940 \mathrm{~kg} / \mathrm{m}^{3}$, $D_{p}(\geq 0.18)=300 \mu \mathrm{m}, M_{p}(0.18)=0.762, M_{p}(0.48)=0.723$, and $M_{p}(0.81)=0.706$. 


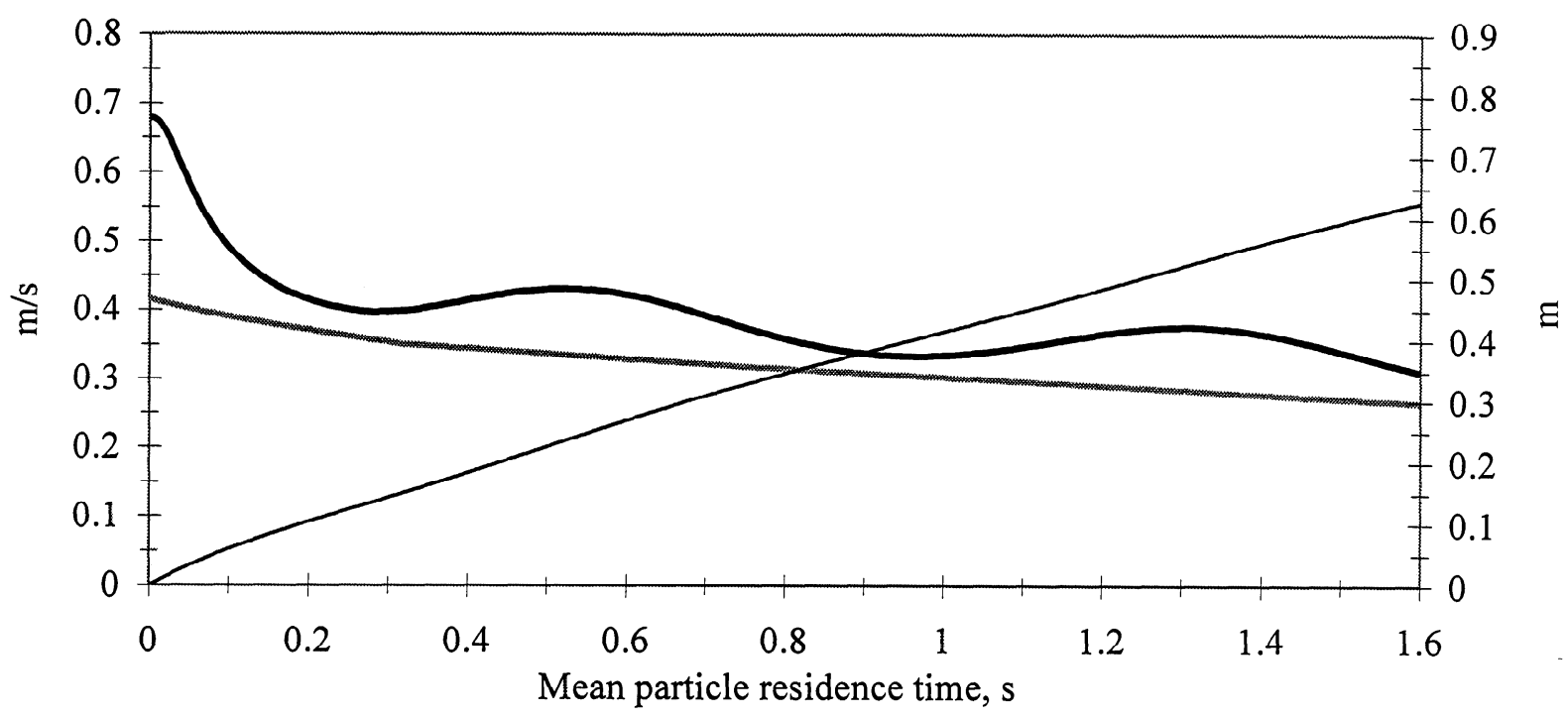

- Mean particle velocity - Mean gas velocity - Distance traveled by particle

Figure A10.17. Model predicted dynamics of inflight BLS particles in pyrolysis tube obtained with an acoustic field of $151 \mathrm{~dB}\left(\hat{u}_{g}=4.1 \mathrm{~m} / \mathrm{s}\right.$ for RAC1107) and $1000 \mathrm{~Hz}$ for $V_{S T P}=10 \mathrm{slpm} \mathrm{N}, T_{g}=550^{\circ} \mathrm{C}, \rho_{g}=0.4103 \mathrm{~kg} / \mathrm{m}^{3}, \nu_{g}=8.69 \times 10^{-5} \mathrm{~m}^{2} / \mathrm{s}$, $d_{p}(0)=115 \mu \mathrm{m}, m_{p}(0)=7.4855 \times 10^{-10} \mathrm{~kg}, \rho_{p}(0)=940 \mathrm{~kg} / \mathrm{m}^{3}$, $D_{p}(\geq 0.129)=300 \mu \mathrm{m}, M_{p}(0.18)=0.751, M_{p}(0.48)=0.706$, and $M_{p}(0.81)=0.673$.

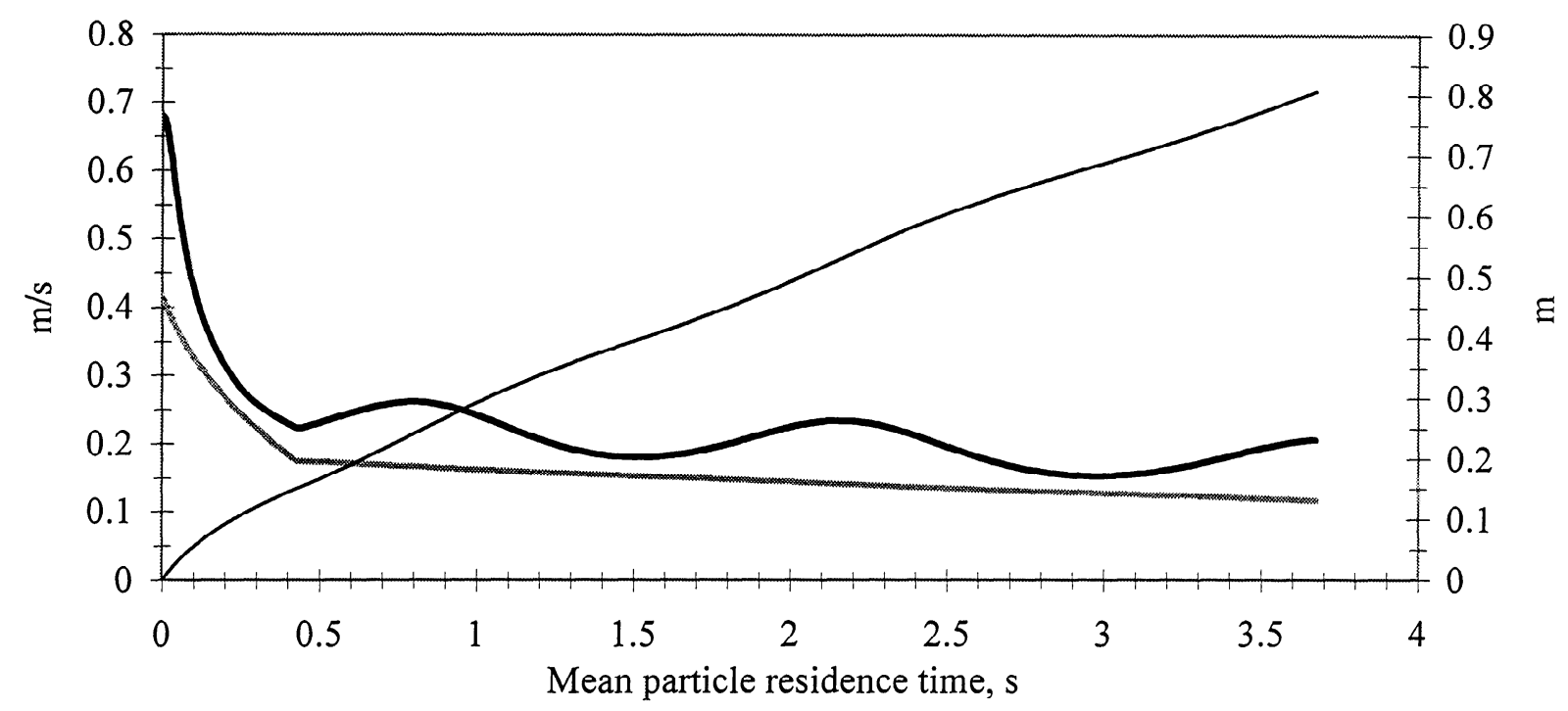

Mean particle velocity - Mean gas velocity - Distance traveled by particle

Figure A10.18. Model predicted dynamics of inflight BLS particles in pyrolysis tube obtained with an acoustic field of $151 \mathrm{~dB}\left(\hat{u}_{g}=4.1 \mathrm{~m} / \mathrm{s}\right.$ for RAC1107) and $1000 \mathrm{~Hz}$ for $V_{S T P}=5 \mathrm{slpm} \mathrm{N}, T_{g}=550^{\circ} \mathrm{C}, \rho_{g}=0.4103 \mathrm{~kg} / \mathrm{m}^{3}, \nu_{g}=8.69 \times 10^{-5} \mathrm{~m}^{2} / \mathrm{s}$, $d_{p}(0)=115 \mu \mathrm{m}, m_{P}(0)=7.4855 \times 10^{-10} \mathrm{~kg}, \rho_{p}(0)=940 \mathrm{~kg} / \mathrm{m}^{3}, M_{P}(0.18)=0.735$, $M_{p}(0.48)=0.706, M_{p}(0.81)=0.687$, and $D_{p}(z \geq 0.111)=300 \mu \mathrm{m}$. 


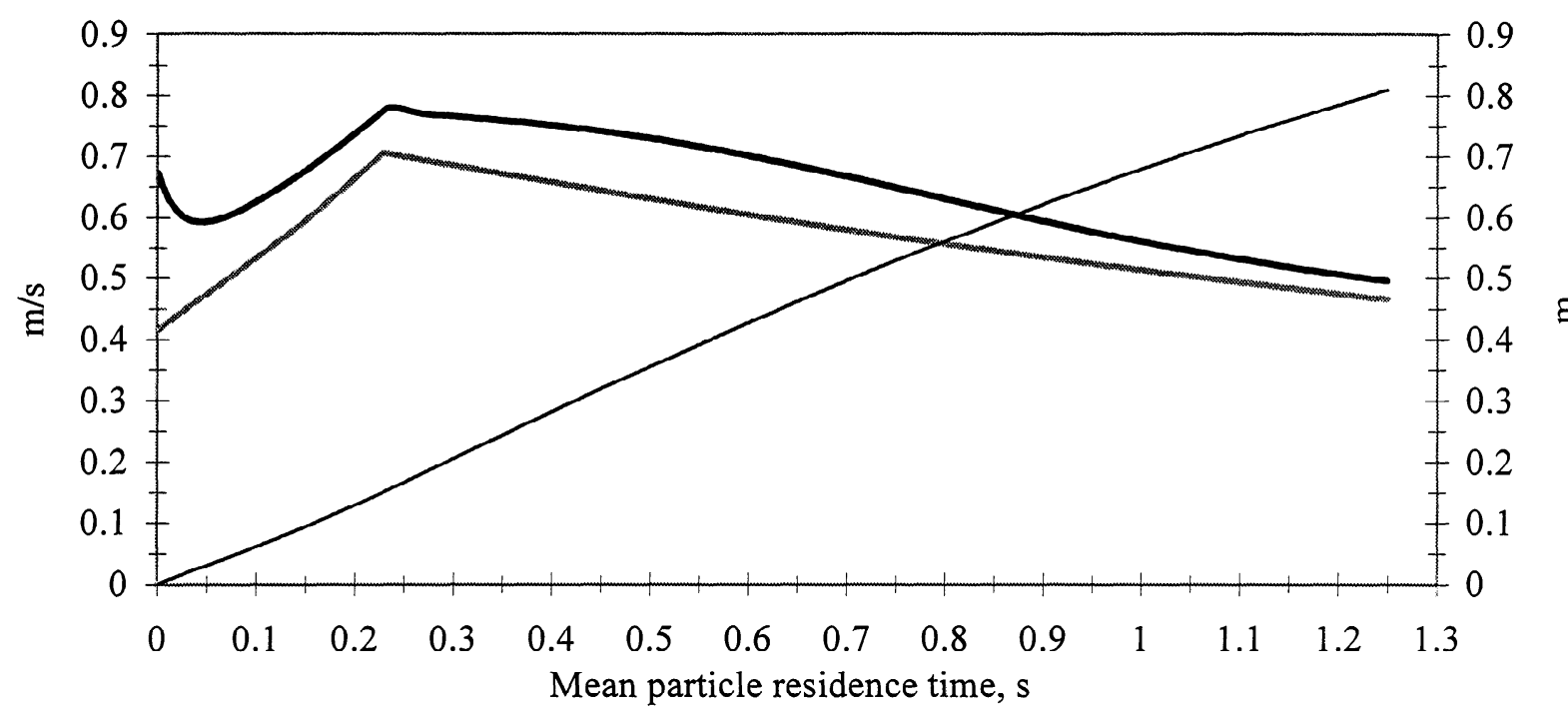

- Mean particle velocity - Mean gas velocity - Distance traveled by particle

Figure A10.19. Model predicted dynamics of inflight BLS particles in pyrolysis tube obtained with an acoustic field of $151 \mathrm{~dB}\left(\hat{u}_{g}=4.1 \mathrm{~m} / \mathrm{s}\right.$ for RAC1231A) and $310 \mathrm{~Hz}$ for $V_{S T P}=20 \mathrm{slpm} \mathrm{N}{ }_{2}, T_{g}=550^{\circ} \mathrm{C}, \rho_{g}=0.4103 \mathrm{~kg} / \mathrm{m}^{3}, v_{g}=8.69 \times 10^{-5} \mathrm{~m}^{2} / \mathrm{s}$, $d_{p}(0)=115 \mu \mathrm{m}, m_{p}(0)=7.4855 \times 10^{-10} \mathrm{~kg}, \rho_{p}(0)=940 \mathrm{~kg} / \mathrm{m}^{3}, M_{p}(0.18)=0.762$ $M_{p}(0.48)=0.745, M_{p}(0.81)=0.728$, and $D_{p}(z \geq 0.176)=300 \mu \mathrm{m}$.

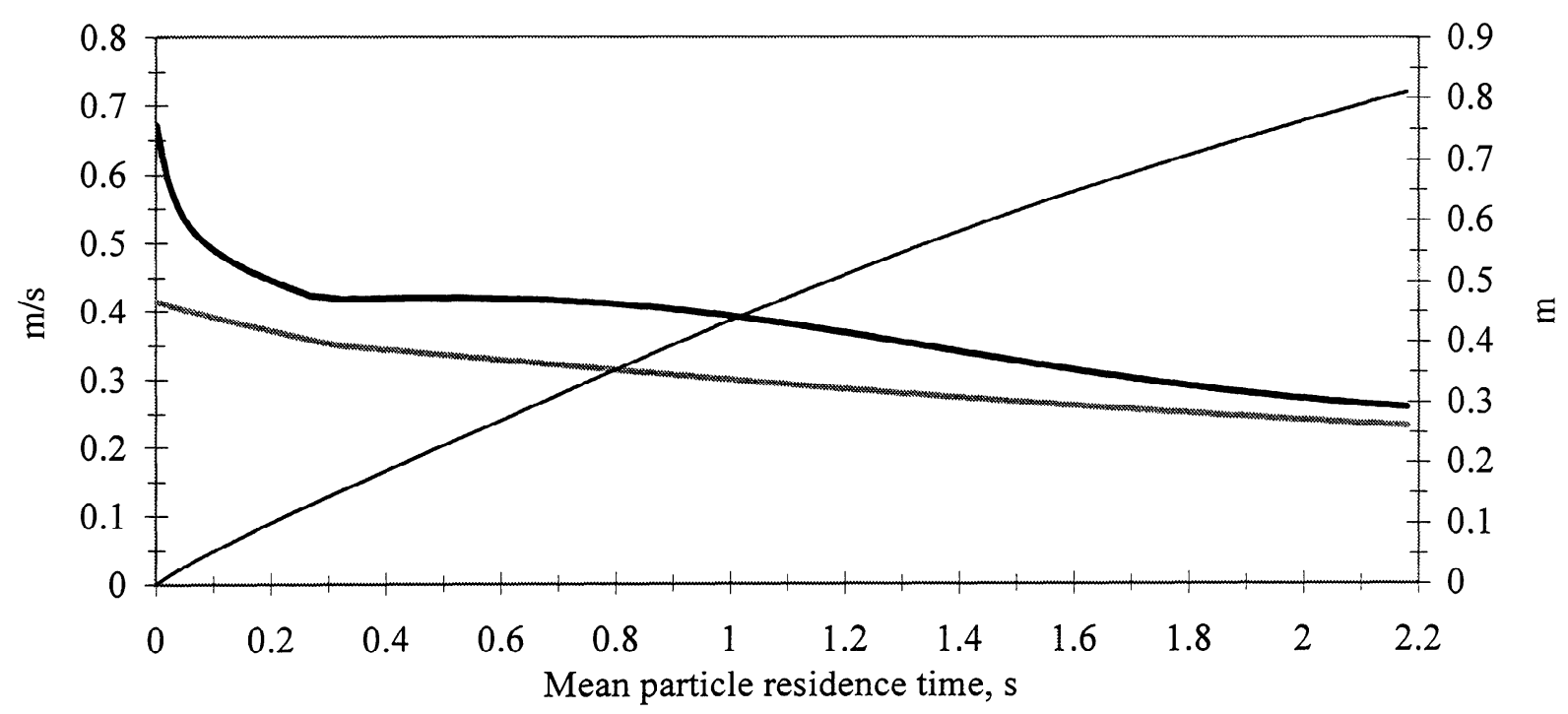

Mean particle velocity - Mean gas velocity — Distance traveled by particle

Figure A10.20. Model predicted dynamics of inflight BLS particles in pyrolysis tube obtained with an acoustic field of $151 \mathrm{~dB}\left(\hat{u}_{g}=4.1 \mathrm{~m} / \mathrm{s}\right.$ for RAC1231B) and $310 \mathrm{~Hz}$ for $V_{S T P}=10 \mathrm{slpm} \mathrm{N} \mathrm{N}_{2}, T_{g}=550^{\circ} \mathrm{C}, \rho_{g}=0.4103 \mathrm{~kg} / \mathrm{m}^{3}, v_{g}=8.69 \times 10^{-5} \mathrm{~m}^{2} / \mathrm{s}$, $d_{p}(0)=115 \mu \mathrm{m}, m_{p}(0)=7.4855 \times 10^{-10} \mathrm{~kg}, \rho_{p}(0)=940 \mathrm{~kg} / \mathrm{m}^{3}, M_{p}(0.18)=0.758$, $M_{p}(0.48)=0.733, M_{p}(0.81)=0.705$, and $D_{p}(z \geq 0.128)=300 \mu \mathrm{m}$. 


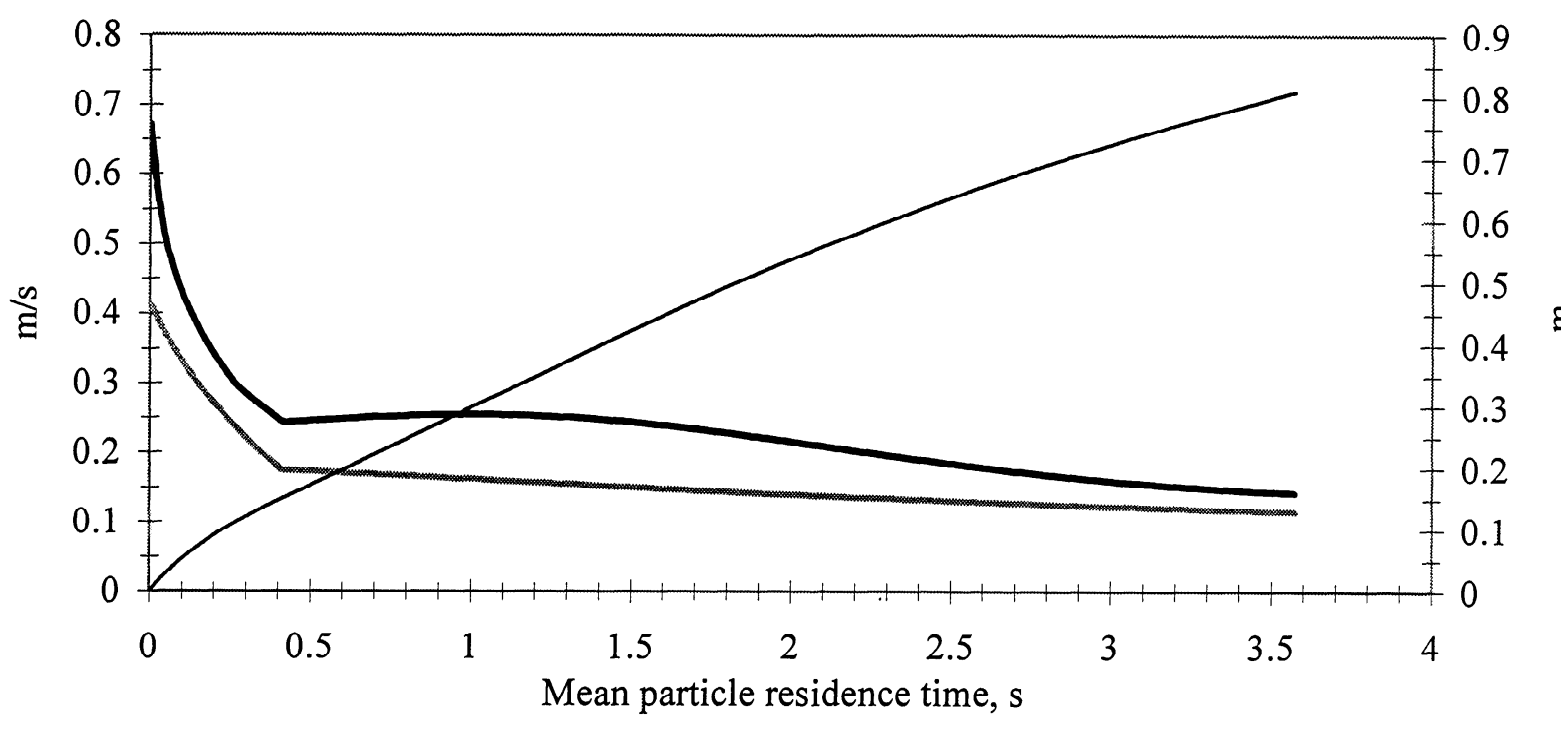

- Mean particle velocity - Mean gas velocity — Distance traveled by particle

Figure A10.21. Model predicted dynamics of inflight BLS particles in pyrolysis tube obtained with an acoustic field of $151 \mathrm{~dB}\left(\hat{u}_{g}=4.1 \mathrm{~m} / \mathrm{s}\right.$ for RAC1231C) and $310 \mathrm{~Hz}$ for $V_{S T P}=5 \mathrm{slpm} \mathrm{N} \mathrm{N}_{2}, T_{g}=550^{\circ} \mathrm{C}, \rho_{g}=0.4103 \mathrm{~kg} / \mathrm{m}^{3}, v_{g}=8.69 \times 10^{-5} \mathrm{~m}^{2} / \mathrm{s}$, $d_{p}(0)=115 \mu \mathrm{m}, m_{p}(0)=7.4855 \times 10^{-10} \mathrm{~kg}, \rho_{p}(0)=940 \mathrm{~kg} / \mathrm{m}^{3}, M_{p}(0.18)=0.757$, $M_{p}(0.48)=0.735, M_{p}(0.81)=0.711$, and $D_{p}(z \geq 0.109)=300 \mu \mathrm{m}$.

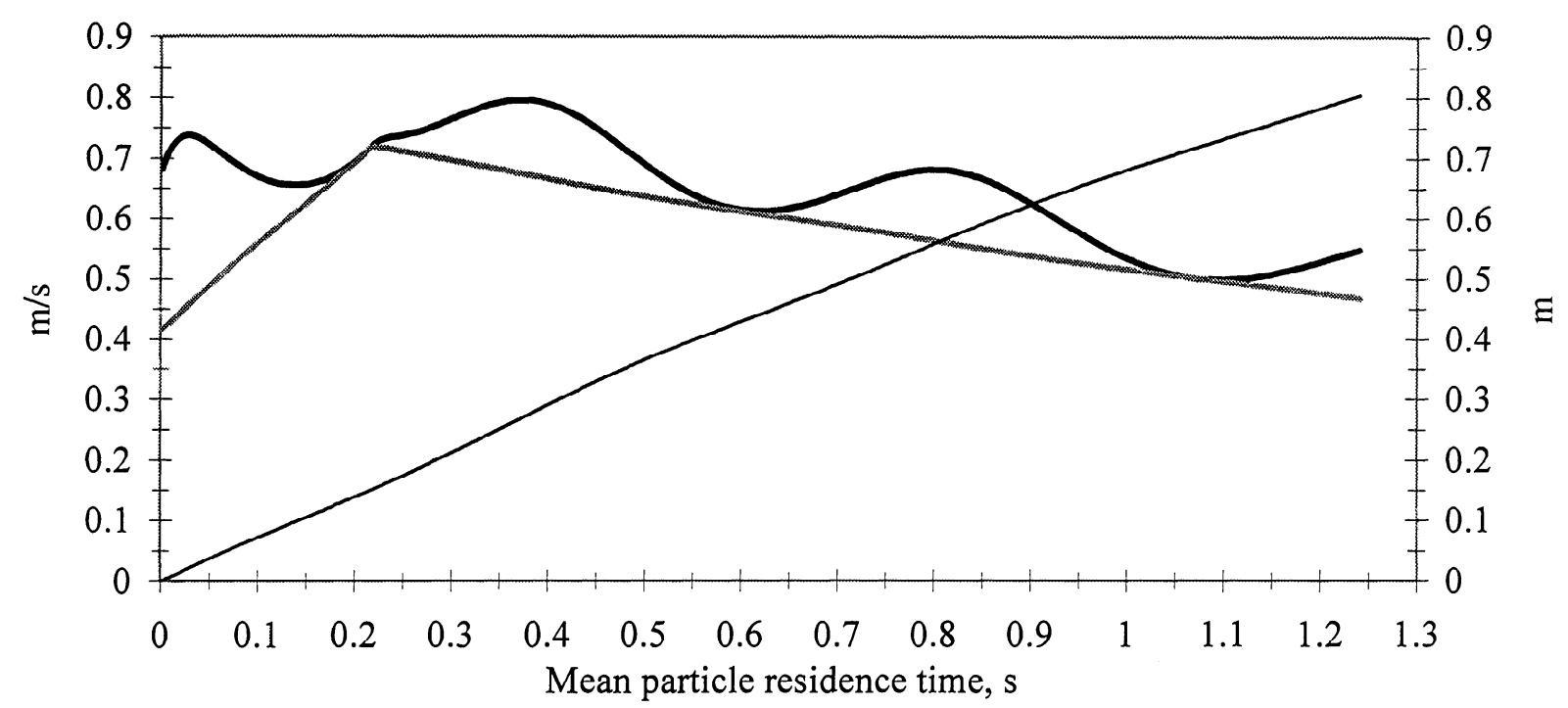

Mean particle velocity - Mean gas velocity - Distance traveled by particle

Figure A10.22. Model predicted dynamics of inflight BLS particles in pyrolysis tube obtained with an acoustic field of $154 \mathrm{~dB}\left(\hat{u}_{g}=5.5 \mathrm{~m} / \mathrm{s}\right.$ for RAC926) and $990 \mathrm{~Hz}$ for $V_{S T P}=20 \mathrm{slpm} \mathrm{N} N_{2}, T_{g}=550^{\circ} \mathrm{C}, \rho_{g}=0.4103 \mathrm{~kg} / \mathrm{m}^{3}, v_{g}=8.69 \times 10^{-5} \mathrm{~m}^{2} / \mathrm{s}$, $d_{p}(0)=115 \mu \mathrm{m}, m_{p}(0)=7.4855 \times 10^{-10} \mathrm{~kg}, \rho_{p}(0)=940 \mathrm{~kg} / \mathrm{m}^{3}, M_{p}(0.18)=0.768$, $M_{p}(0.48)=0.73, M_{p}(0.81)=0.695$, and $D_{p}(z \geq 0.185)=300 \mu \mathrm{m}$. 


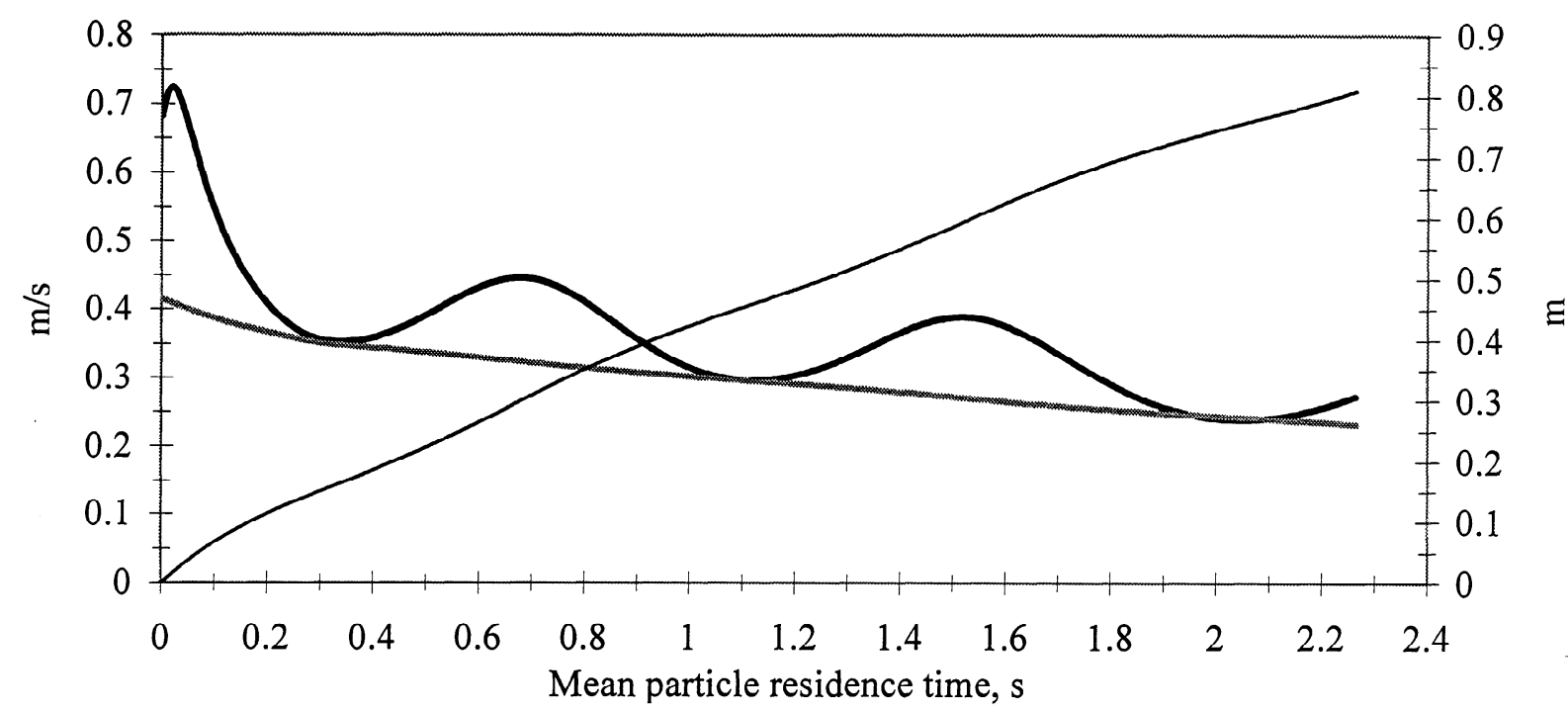

- Mean particle velocity - Mean gas velocity — Distance traveled by particle

Figure A10.23. Model predicted dynamics of inflight BLS particles in pyrolysis tube obtained with an acoustic field of $154 \mathrm{~dB}\left(\hat{u}_{g}=5.5 \mathrm{~m} / \mathrm{s}\right.$ for RAC930) and $990 \mathrm{~Hz}$ for $V_{S T P}=10 \mathrm{slpm} \mathrm{N}, T_{g}=550^{\circ} \mathrm{C}, \rho_{g}=0.4103 \mathrm{~kg} / \mathrm{m}^{3}, v_{g}=8.69 \times 10^{-5} \mathrm{~m}^{2} / \mathrm{s}$, $d_{p}(0)=115 \mu \mathrm{m}, m_{p}(0)=7.4855 \times 10^{-10} \mathrm{~kg}, \rho_{p}(0)=940 \mathrm{~kg} / \mathrm{m}^{3}, M_{p}(0.18)=0.756$, $M_{p}(0.48)=0.716, M_{p}(0.81)=0.673$ and $D_{p}(z \geq 0.135)=300 \mu \mathrm{m}$.

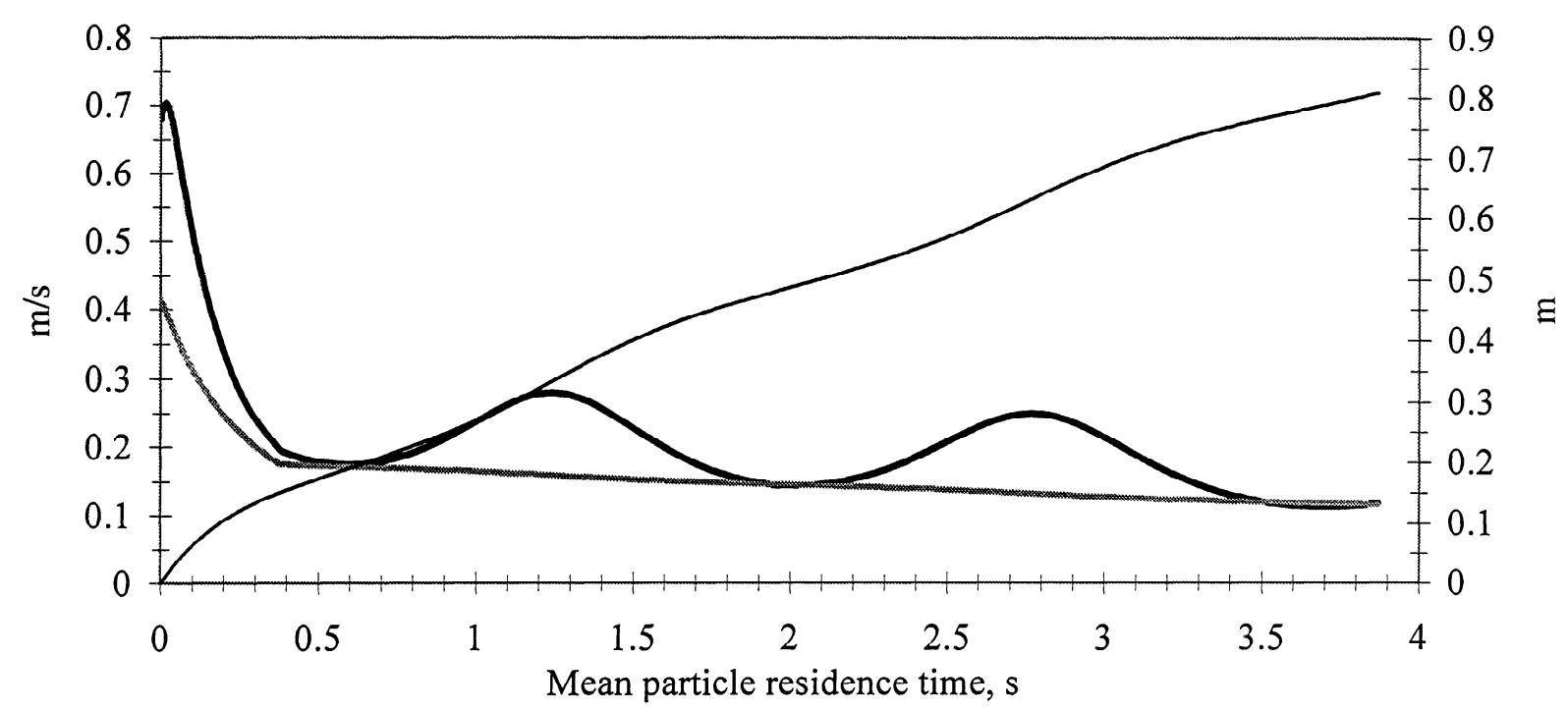

- Mean particle velocity - Mean gas velocity _ Distance traveled by particle

Figure A10.24. Model predicted dynamics of inflight BLS particles in pyrolysis tube obtained with an acoustic field of $154 \mathrm{~dB}\left(\hat{u}_{g}=5.5 \mathrm{~m} / \mathrm{s}\right.$ for RAC1227A) and $960 \mathrm{~Hz}$ for $V_{\text {STP }}=5 \mathrm{slpm} \mathrm{N}, T_{g}=550^{\circ} \mathrm{C}, \rho_{g}=0.4103 \mathrm{~kg} / \mathrm{m}^{3}, v_{g}=8.69 \times 10^{-5} \mathrm{~m}^{2} / \mathrm{s}$, $d_{p}(0)=115 \mu \mathrm{m}, m_{p}(0)=7.4855 \times 10^{-10} \mathrm{~kg}, \rho_{p}(0)=940 \mathrm{~kg} / \mathrm{m}^{3}, M_{p}(0.18)=0.755$, $M_{p}(0.48)=0.716, M_{p}(0.81)=0.673$, and $D_{p}(z \geq 0.124)=300 \mu \mathrm{m}$. 


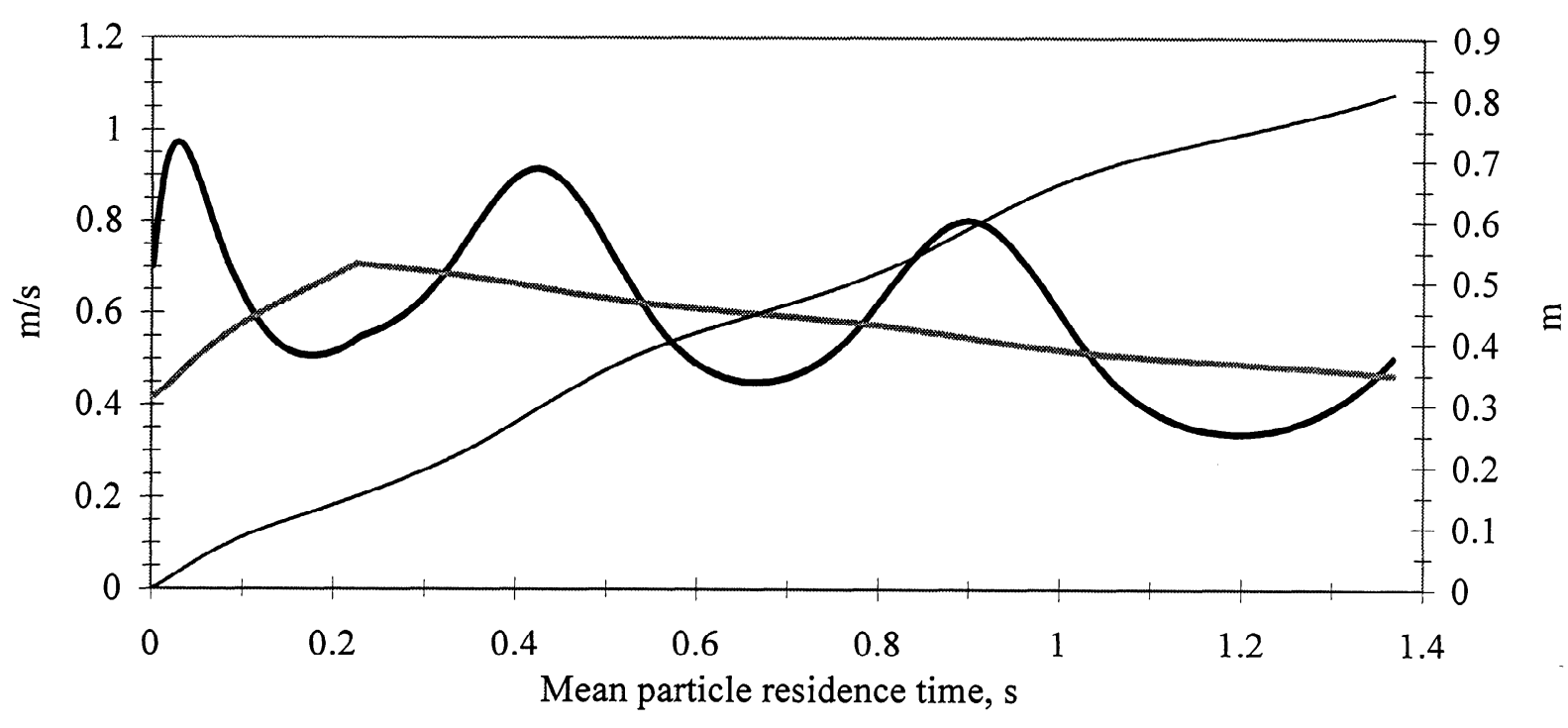

- Mean particle velocity - Mean gas velocity _ Distance traveled by particle

Figure A10.25. Model predicted dynamics of inflight BLS particles in pyrolysis tube obtained with an acoustic field of $158 \mathrm{~dB}\left(\hat{u}_{g}=10.3 \mathrm{~m} / \mathrm{s}\right.$ for RAC1207) and $970 \mathrm{~Hz}$ for $V_{S T P}=20 \mathrm{slpm} \mathrm{N} \mathrm{N}_{2}, T_{g}=550^{\circ} \mathrm{C}, \rho_{g}=0.4103 \mathrm{~kg} / \mathrm{m}^{3}, \nu_{g}=8.69 \times 10^{-5} \mathrm{~m}^{2} / \mathrm{s}$, $d_{p}(0)=115 \mu \mathrm{m}, m_{p}(0)=7.4855 \times 10^{-10} \mathrm{~kg}, \rho_{p}(0)=940 \mathrm{~kg} / \mathrm{m}^{3}, M_{p}(0.18)=0.761$, $M_{p}(0.48)=0.708, M_{p}(0.81)=0.651$, and $D_{p}(z \geq 0.173)=300 \mu \mathrm{m}$.

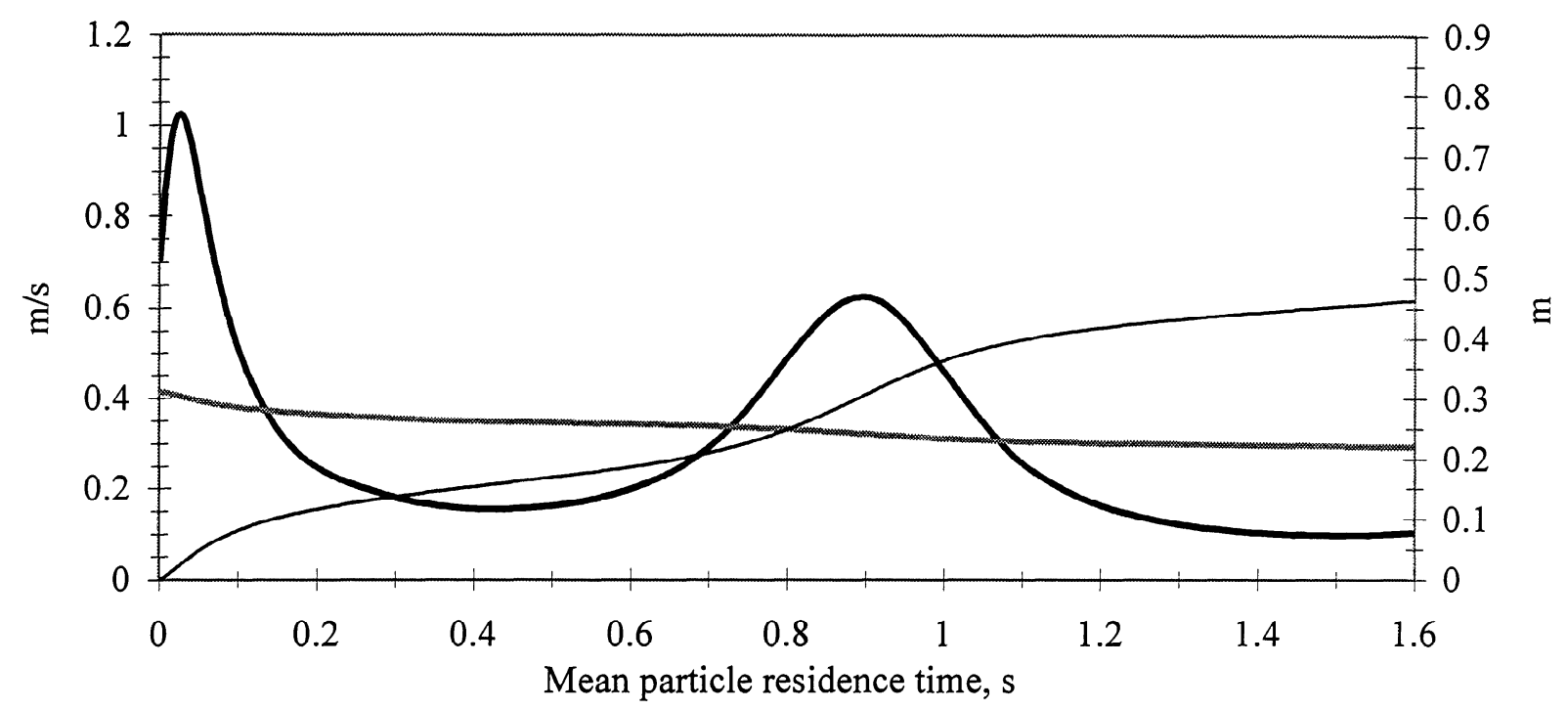

- Mean particle velocity - Mean gas velocity — Distance traveled by particle

Figure A10.26. Model predicted dynamics of inflight BLS particles in pyrolysis tube obtained with an acoustic field of $159.5 \mathrm{~dB}\left(\hat{u}_{g}=11.5 \mathrm{~m} / \mathrm{s}\right.$ for RAC1227B) and $970 \mathrm{~Hz}$ for $V_{S T P}=10 \mathrm{slpm} \mathrm{N}, T_{g}=550^{\circ} \mathrm{C}, \rho_{g}=0.4103 \mathrm{~kg} / \mathrm{m}^{3}, v_{g}=8.69 \times 10^{-5} \mathrm{~m}^{2} / \mathrm{s}$, $d_{p}(0)=115 \mu \mathrm{m}, m_{p}(0)=7.4855 \times 10^{-10} \mathrm{~kg}, \rho_{p}(0)=940 \mathrm{~kg} / \mathrm{m}^{3}, M_{p}(0.18)=0.753$, $M_{p}(0.48)=0.70, M_{p}(0.81)=0.642$, and $D_{p}(z \geq 0.129)=300 \mu \mathrm{m}$. 


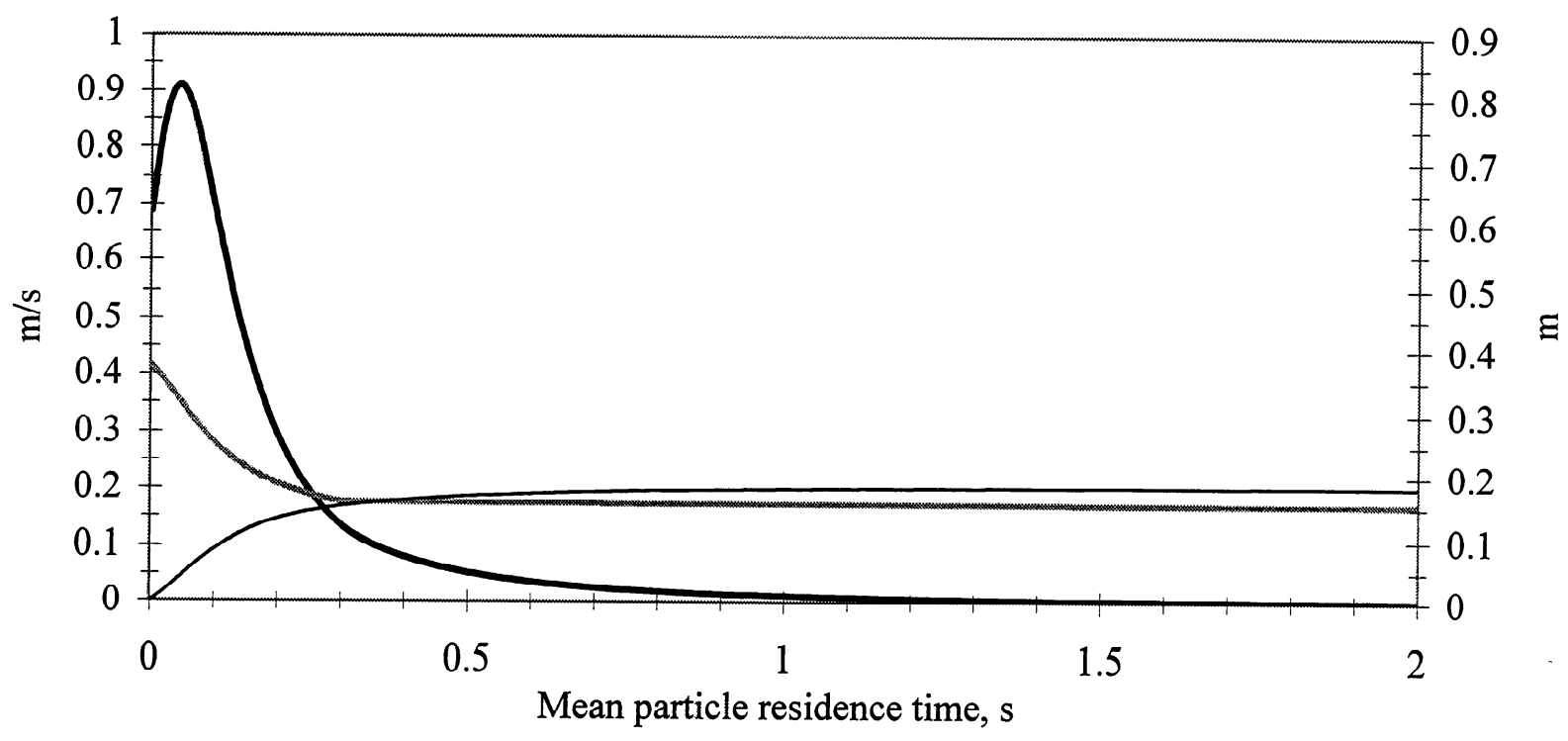

- Mean particle velocity - Mean gas velocity — Distance traveled by particle

Figure A10.27. Model predicted dynamics of inflight BLS particles in pyrolysis tube obtained with an acoustic field of $159.5 \mathrm{~dB}\left(\hat{u}_{g}=11.5 \mathrm{~m} / \mathrm{s}\right.$ for RAC1224) and $970 \mathrm{~Hz}$ for $V_{S T P}=5 \mathrm{slpm} \mathrm{N}, T_{g}=550^{\circ} \mathrm{C}, \rho_{g}=0.4103 \mathrm{~kg} / \mathrm{m}^{3}, v_{g}=8.69 \times 10^{-5} \mathrm{~m}^{2} / \mathrm{s}$, $d_{p}(0)=115 \mu \mathrm{m}, m_{p}(0)=7.4855 \times 10^{-10} \mathrm{~kg}, \rho_{p}(0)=940 \mathrm{~kg} / \mathrm{m}^{3}, M_{p}(0.18)=0.758$, $M_{p}(0.81)=0.629$, and $D_{p}(z \geq 0.0 .98)=300 \mu \mathrm{m}$.

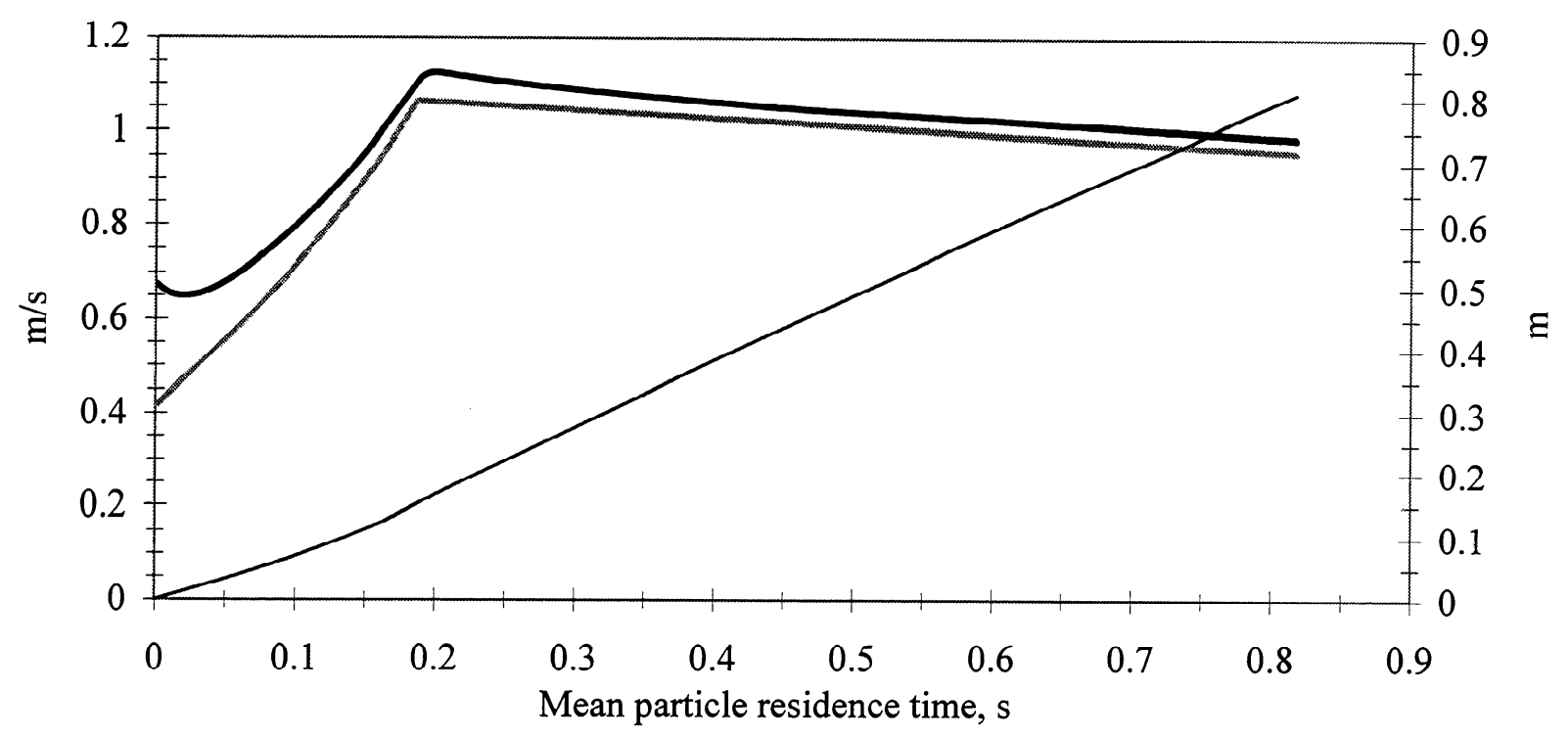

- Mean particle velocity - Mean gas velocity — Distance traveled by particle

Figure A10.28. Model predicted dynamics of inflight BLS particles in pyrolysis tube obtained without acoustics for $V_{S T P}=20 \mathrm{slpm} \mathrm{N} N_{2}, T_{g}=700^{\circ} \mathrm{C}, \rho_{g}=0.3469 \mathrm{~kg} / \mathrm{m}^{3}$, $\nu_{g}=1.14 \times 10^{-4} \mathrm{~m}^{2} / \mathrm{s}, d_{p}(0)=115 \mu \mathrm{m}, m_{p}(0)=7.4855 \times 10^{-10} \mathrm{~kg}, \rho_{p}(0)=940 \mathrm{~kg} / \mathrm{m}^{3}$, $D_{p}(0.18)=300 \mu \mathrm{m}, D_{p}(\geq 0.48)=600 \mu \mathrm{m}, M_{p}(0.18)=0.76, M_{p}(0.48)=0.705$, and $M_{p}(0.81)=0.688$. 


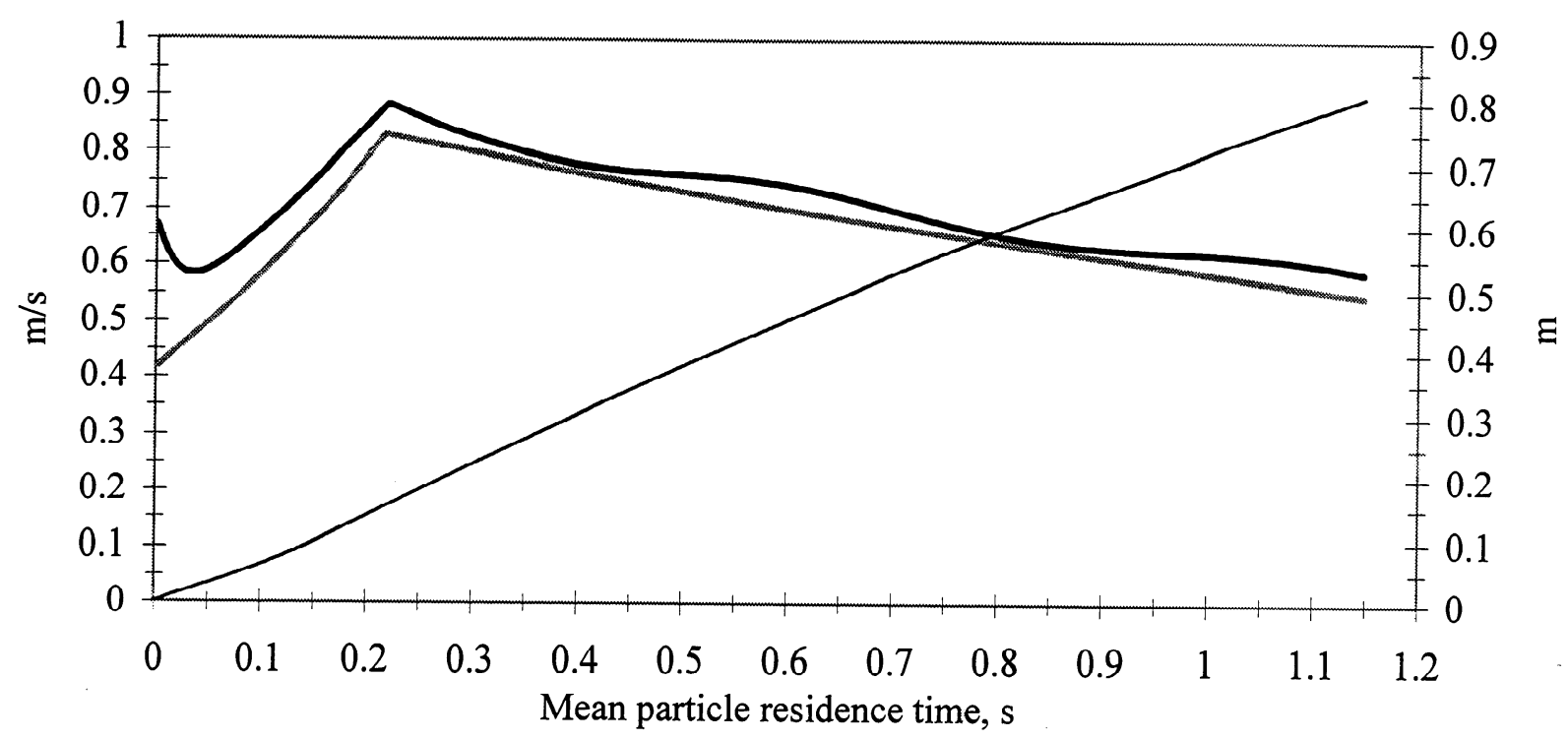

- Mean particle velocity - Mean gas velocity — Distance traveled by particle

Figure A10.29. Model predicted dynamics of inflight BLS particles in pyrolysis tube obtained with an acoustic field of $151 \mathrm{~dB}\left(\hat{u}_{g}=4.5 \mathrm{~m} / \mathrm{s}\right.$ for RAC1126A) and $960 \mathrm{~Hz}$ for $V_{S T P}=20 \mathrm{slpm} \mathrm{N} \mathrm{N}_{2}, T_{g}=700^{\circ} \mathrm{C}, \rho_{g}=0.3469 \mathrm{~kg} / \mathrm{m}^{3}, v_{g}=1.14 \times 10^{-4} \mathrm{~m}^{2} / \mathrm{s}$, $d_{p}(0)=115 \mu \mathrm{m}, m_{p}(0)=7.4855 \times 10^{-10} \mathrm{~kg}, \rho_{p}(0)=940 \mathrm{~kg} / \mathrm{m}^{3}, D_{p}(0.18)=550 \mu \mathrm{m}$, $D_{p}(\geq 0.48)=600 \mu \mathrm{m}, M_{p}(0.18)=0.738, M_{p}(0.48)=0.687$, and $M_{p}(0.81)=0.668$.

\section{[A10.3] FORMULATION OF MODEL TO ESTIMATE PARTICLE HEATUP RATES TO PEAK GAS TEMPERATURE}

The rates of particle heatup to peak gas temperatures of 400,550 , and $700^{\circ} \mathrm{C}$ were estimated for pyrolysis experiments with and without an acoustic field of 151 or $159 \mathrm{~dB}$ and $970 \mathrm{~Hz}$ within the $0.18 \mathrm{~m}$ pyrolysis tube heated length. $106-125 \mu \mathrm{m}$ diameter BLS particles were assumed to be heated uniformly throughout. Biot numbers $<0.1$ as calculated using Eq. A.11 justified this assumption.

The energy equation for a particle heated by convection and radiation can be expressed as,

$$
\frac{\pi}{6} d_{p}^{3} \rho_{p} c_{p p} \frac{d T_{p}}{d t}=\pi \mathrm{Nu} k_{g} d_{p}\left(T_{g}-T_{p}\right)+\pi \sigma \varepsilon d_{p}{ }^{2}\left(T_{w}{ }^{4}-T_{p}{ }^{4}\right),
$$


where $c_{p p}$ is the heat capacity of the BLS particle, $T_{w}$ is the temperature of the pyrolysis tube wall, $\sigma$ is the Stefan-Boltzmann constant, and $\varepsilon$ is the emissivity of the stainless steel pyrolysis tube (0.4). The net heat of reaction was assumed to be zero (Shafizadeh, 1985). Because of the numerous tar compounds released from the particle, the latent heat of vaporization of tar is not known and is assumed to be zero. Eq. 10.11 was solved along with Eq. 10.1 in Microsoft Excel using a fourth order Runga-Kutta integration scheme (Canale and Chapra, 1988) with a time step $\Delta_{t z}=0.0001 \mathrm{~s}$. Particle diameter, density, and distance traveled and steady flow gas velocity for each time step were obtained from the mean particle residence time model for the studied cases in Figs. A10.9, A10.10, A10.11, A10.15, A10.27, and A10.28.

The heat capacity of a BLS particle can be expressed as (Frederick and Hupa, 1993),

$$
c_{p p}=1675+3.31 T_{s}
$$

The temperature of the pyrolysis tube wall was measured be $10-20^{\circ} \mathrm{C}$ higher than the peak gas temperature. The gas viscosity $v_{g}\left(T_{g}\right)$ and thermoconductivity $k_{g}\left(T_{g}\right)$ can be expressed as a linear function of temperature (De Witt and Incropera, 1990),

$$
\begin{aligned}
& v_{g}\left(T_{g}\right)=1.366 \times 10^{-7} T_{g}+2.738 \times 10^{-5} . \\
& k_{g}\left(T_{g}\right)=5.739 \times 10^{-5} T_{g}+9.330 \times 10^{-3}
\end{aligned}
$$

$\mathrm{Nu}$ without acoustics is given by Eq. 21 . The Nusselt number with acoustics $\mathrm{Nu} a c$ can be calculated using the time- and space-averaged Nu number factor given by Eq. 24, 


$$
\mathrm{Nu} a c=2+(\mathrm{Nu}-2)\left(0.7268 \sqrt{\frac{\hat{u}_{g}(z)}{\left|U_{g}-U_{p}\right|}}+0.1372\right)
$$

where $\hat{u}_{g}(z)$ is the amplitude of the axial acoustic velocity oscillations at a distance $z$ downstream from the particle injection point. The axial acoustic velocity amplitude can be expressed as,

$$
\hat{u}_{g}(z)=\hat{u}_{s w} \sin \left[\frac{2 \pi f\left(z-z_{d}\right)}{c}\right]
$$

where $\hat{u}_{s w}$ is the amplitude of the standing wave acoustic velocity obtained from Figs A8.1A8.30 in Appendix 8.

Centerline gas temperatures measured by a thermocouple were corrected for radiation and conduction errors were used as the gas temperature in Eq. A10.11. Measured gas temperatures shown in Table A7.2 were corrected for radiation and conduction errors using values in Table A7.5. It was found that the measured centerline gas temperature $T_{g}(z)$ increased to the peak gas temperature in two linear segments which can be expressed as,

$$
T_{g}(z)=T_{g}\left(z_{0}\right)+\frac{\left(T_{g}\left(z_{1}\right)-T_{g}\left(z_{0}\right)\right)}{z_{1}-z_{0}} \text { for } z_{0} \leq z \leq z_{1},
$$

where $T_{g}\left(z_{0}\right)$ and $T_{g}\left(z_{1}\right)$ are the gas temperatures at the beginning $z=z_{0}$ and end $z=z_{1}$ of a section of the pyrolysis tube, respectively.

Fig. A10.30 shows the gas temperature profile and the model prediction of particle temperature versus time for pyrolysis experiments conducted without and with an acoustic field 
of $151 \mathrm{~dB}$ and $960 \mathrm{~Hz}$ for a secondary gas flowrate of $20 \operatorname{slpm~} \mathrm{N}_{2}$ preheated to $400^{\circ} \mathrm{C}$. The increase of the ambient gas temperature experienced by a particle was lower with acoustics than without acoustics. Faster moving particles (without acoustics) will experience larger temperature gradients as a function of time than slower moving particles (with acoustics). The increased particle heatup rate with acoustics was the result of higher $\mathrm{Nu}$ number.

A computational model that can accurately predict two-phase particle reacting flows using the energy equation and Navier-Stokes equations is required to accurately predict the rate of particle heatup. Development of this was beyond the scope of this dissertation. To estimate the most rapid particle heatup case with acoustics, the carrier gas jet was assumed to be entirely mixed with the preheated $\mathrm{N}_{2}$, so that particles experienced a gas temperature of $400^{\circ} \mathrm{C}$ immediately upon injection into the pyrolysis tube. This shows an increased particle heatup rate primarily at temperatures that are lower than the substrate temperature of $200^{\circ} \mathrm{C}$ necessary to initiate pyrolysis. For pyrolysis experiments with acoustics, particles experienced higher gas temperatures due to dispersion from the centerline of particle carrier gas jet core flow into the surrounding hot secondary gas stream. For pyrolysis experiments without acoustics, particles remained nearer to the pyrolysis tube centerline and experienced the centerline gas temperature profile that was measured using thermocouples. 


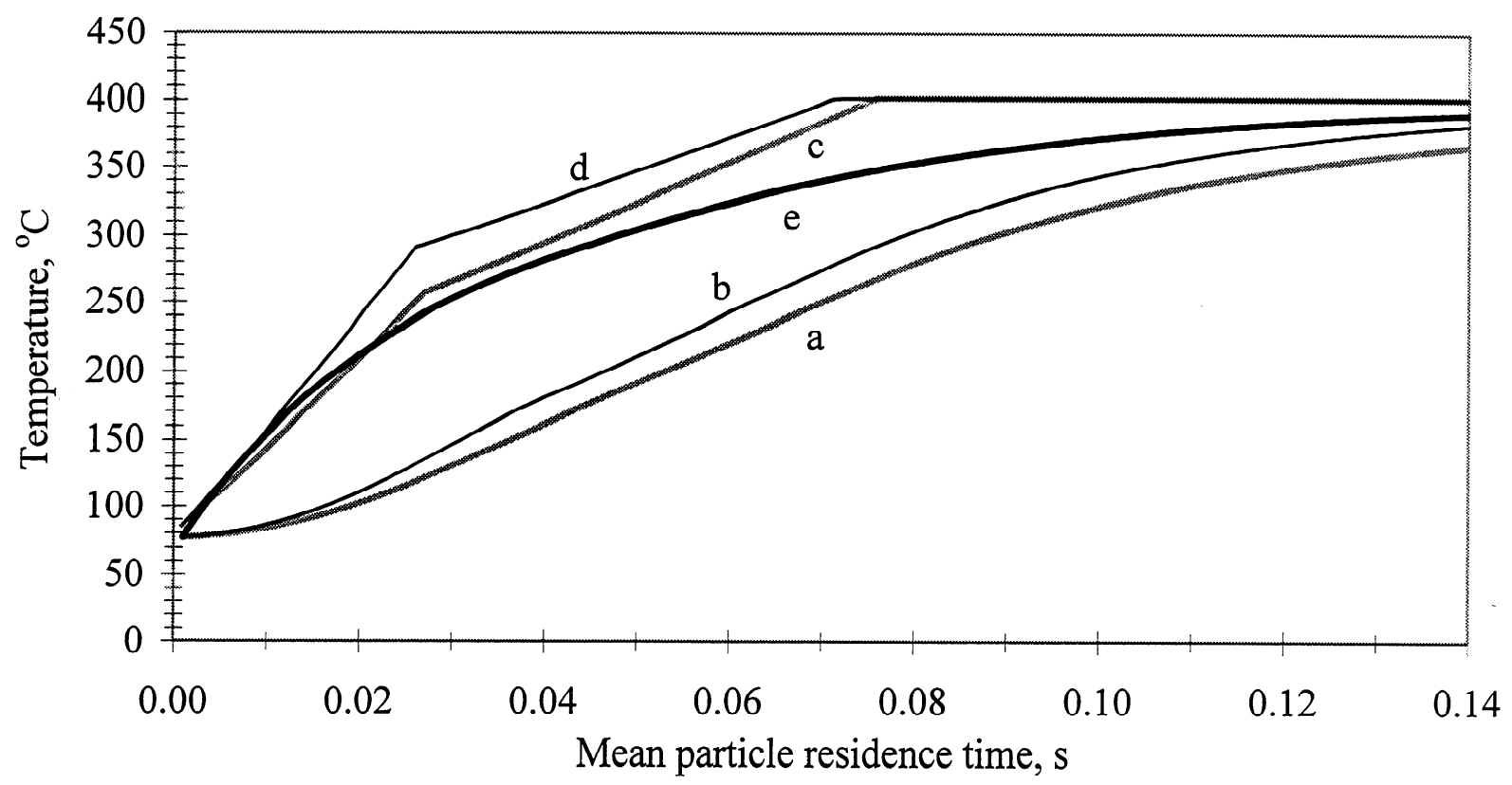

Figure A10.30. Model predicted heatup of inflight BLS particles to a peak temperature of $400^{\circ} \mathrm{C}$. (a) Particle temperatures estimated without acoustics (RNAC1113) using measured gas temperature (d). (b) Particle temperatures estimated with an acoustic field of $151 \mathrm{~dB}$ and $960 \mathrm{~Hz}$ (RAC1119) using measured gas temperature (c). (e) Particle temperature estimated assuming a uniform gas temperature of $400^{\circ} \mathrm{C}$ and an acoustic field of $151 \mathrm{~dB}$ and $960 \mathrm{~Hz}$.

Fig. A10.31 shows the gas temperature and the estimated particle temperature versus time for pyrolysis experiments with and without an acoustic field of 151 and $159 \mathrm{~dB}$ and $1000 \mathrm{~Hz}$ using a secondary gas flowrate of $20 \mathrm{slpm} \mathrm{N}_{2}$ preheated to $550^{\circ} \mathrm{C}$. The estimated particle heatup rates were similar with and without an acoustic field of $151 \mathrm{~dB}$. The particle heatup rate was substantially increased at temperatures between $200-450^{\circ} \mathrm{C}$ when $T_{g}(z)=550^{\circ} \mathrm{C}$. Increased particle heatup rate is significant because most of the pyrolysis reactions proceed between temperatures of $200-450^{\circ} \mathrm{C}$. For a sound pressure level of $151 \mathrm{~dB}$, the time-mean acoustic velocity amplitude was near its minima at the particle injection point. Fig. A10.32 shows that $\mathrm{Nu}$ ac was decreasing to its minima, which was lower than the steady flow $\mathrm{Nu}$, and would not begin to increase until the particle traversed several centimeters downstream. Fig. A10.32 also 
shows that the maximum value of $\mathrm{Nu}$ ac estimated with an acoustic field of $159 \mathrm{~dB}$ and $1000 \mathrm{~Hz}$, in which the wave was shifted so that the acoustic velocity amplitude was at its maxima near the particle injector exit, can be significantly increased at high sound pressure levels.

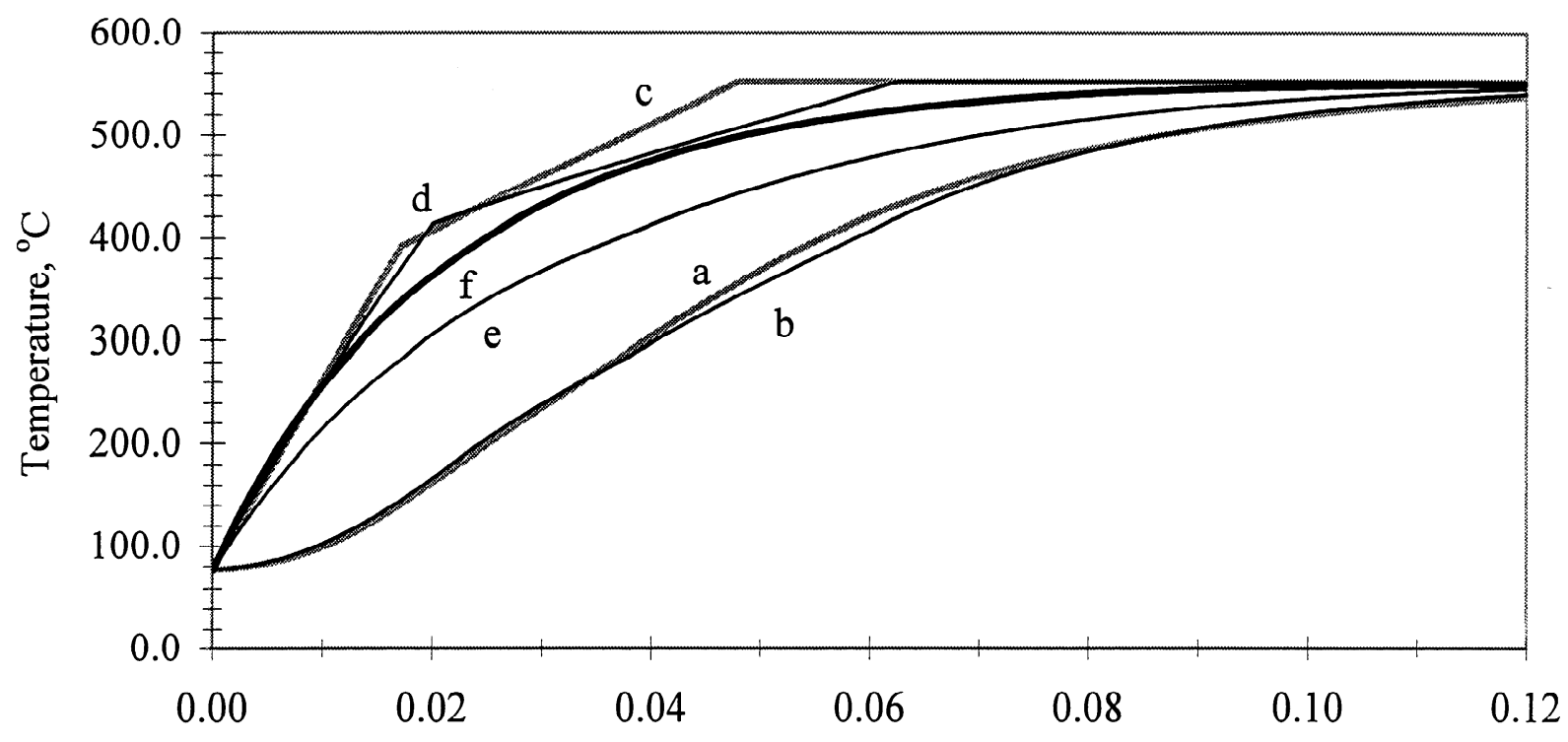

Average particle residence time, $\mathrm{s}$

Figure A10.31. Model predicted heatup of inflight BLS particles to a peak temperature of $550^{\circ} \mathrm{C}$.

(a) Particle temperatures calculated without (RNAC1105) using gas temperatures measured without acoustics (d). (b) Particle temperatures calculated with an acoustic field of $151 \mathrm{~dB}$ and $1000 \mathrm{~Hz}$ (RAC1107) using gas temperatures measured with acoustics (d). (e) Particle temperature calculated assuming $T_{g}(z)=550^{\circ} \mathrm{C}, \varepsilon=0.4$, and an acoustic field of $151 \mathrm{~dB}$ and $1000 \mathrm{~Hz}$. (f) Particle temperature calculated assuming $T_{g}(z)=550^{\circ} \mathrm{C}, \varepsilon=0.4$, and an acoustic field of $159 \mathrm{~dB}$ and $970 \mathrm{~Hz}$. 


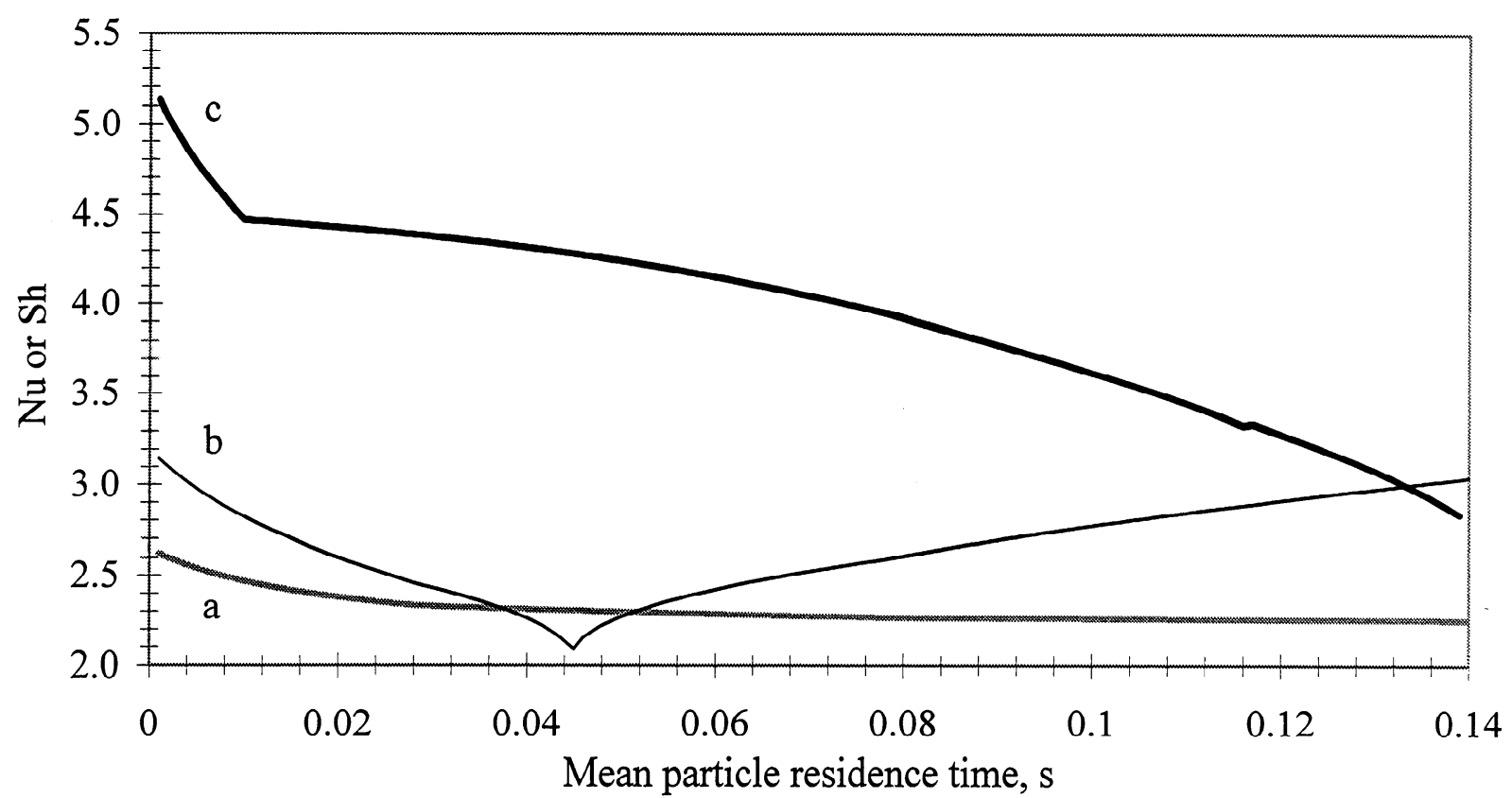

Figure A10.32. Model predicted (a) Nu or Sh without acoustics, (b) $\mathrm{Nu}_{a c}$ or $\mathrm{Sh}_{a c}$ with an acoustic field of $151 \mathrm{~dB}$ and $1000 \mathrm{~Hz}$ (RAC1107), and (c) Nuac or Shac with an acoustic field of $159 \mathrm{~dB}$ and $970 \mathrm{~Hz}$ in which $\hat{u}_{s w}$ occurred at the particle injection point, during particle heatup to a peak gas temperature of $550^{\circ} \mathrm{C}$. Measured gas temperatures were used for all cases.

Fig. A10.33 shows that radiative heating contributed very little to particle heatup.

Because $\mathrm{Nu}$ ac was not significantly higher than $\mathrm{Nu}$ without acoustics at a gas temperature of $550^{\circ} \mathrm{C}$ and that particle heatup rates were only significantly increased due to increased ambient gas temperature with acoustics, it is concluded that increased particle heatup rate with acoustics is caused by better mixing of the carrier gas jet and BLS particles with the hot secondary gas stream. Better mixing of the two streams and particles was confirmed by high- and low-speed video imaging studies of gas and particle flows. 


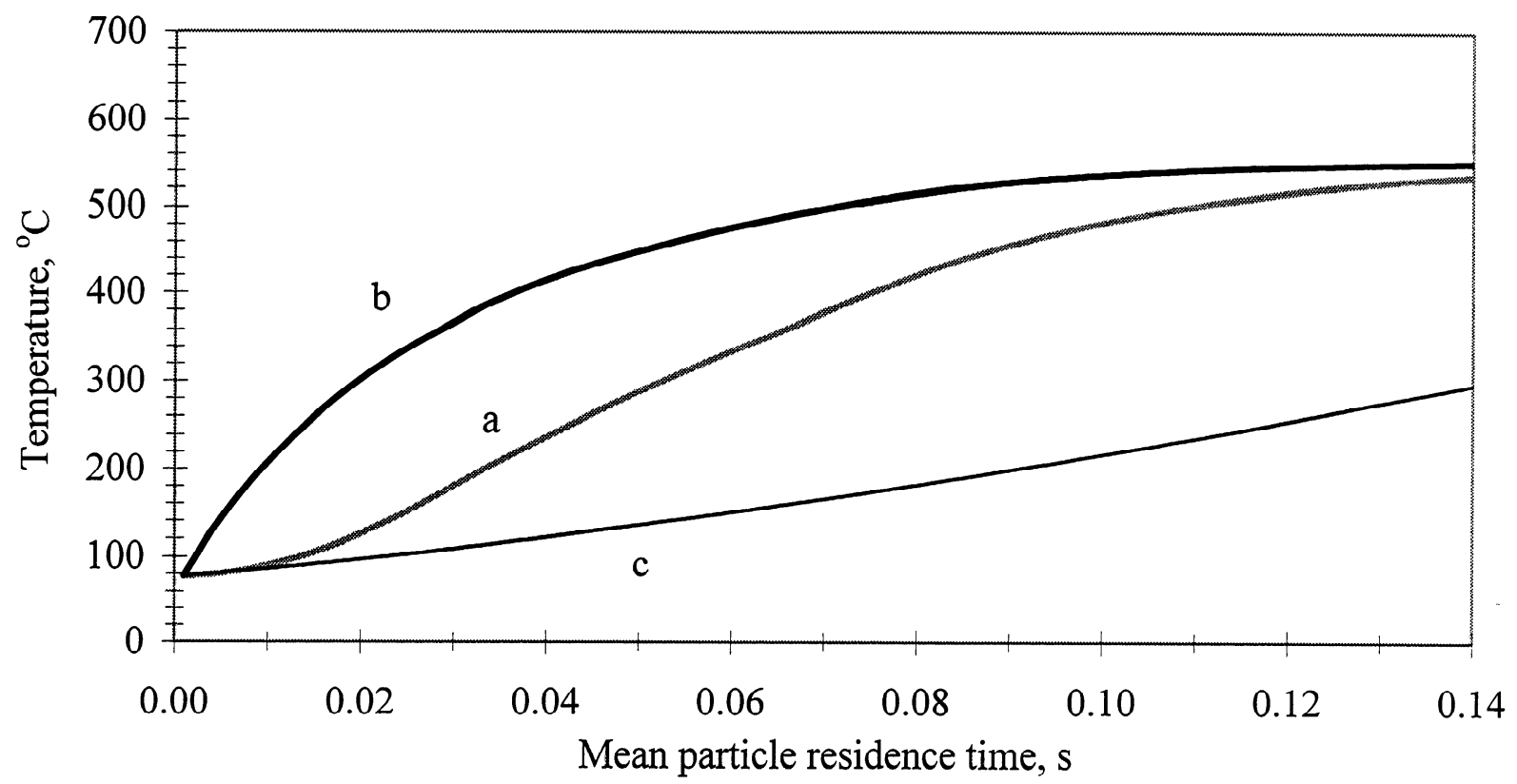

Figure A10.33. Model predicted heatup of inflight BLS particles to a peak temperature of $550^{\circ} \mathrm{C}$. Particle temperatures estimated (a) without acoustics (RNAC1105) using experimental gas temperatures; (b) with an acoustic field of $151 \mathrm{~dB}$ and $1000 \mathrm{~Hz}$ (RAC1 107), assuming $T_{\mathcal{B}}(z)=550^{\circ} \mathrm{C}$ and $\varepsilon=1$; and (c) due to radiative heating using a pyrolysis tube wall temperature of $570^{\circ} \mathrm{C}$ and $\varepsilon=1$.

Fig. A10.34 shows the centerline gas temperature and estimated particle temperature versus time for pyrolysis experiments with and without an acoustic field of 151 and $159 \mathrm{~dB}$ and $950-960 \mathrm{~Hz}$ using secondary gas flowrate of $20 \mathrm{slpm} \mathrm{N}_{2}$ preheated to $700^{\circ} \mathrm{C}$. The particle heatup rate estimated with an acoustic field of $151 \mathrm{~dB}$ and $960 \mathrm{~Hz}$ was higher than that without an acoustics. BLS particles were injected into a region of high acoustic velocity, which increased $\mathrm{Nu}_{a c}$. 


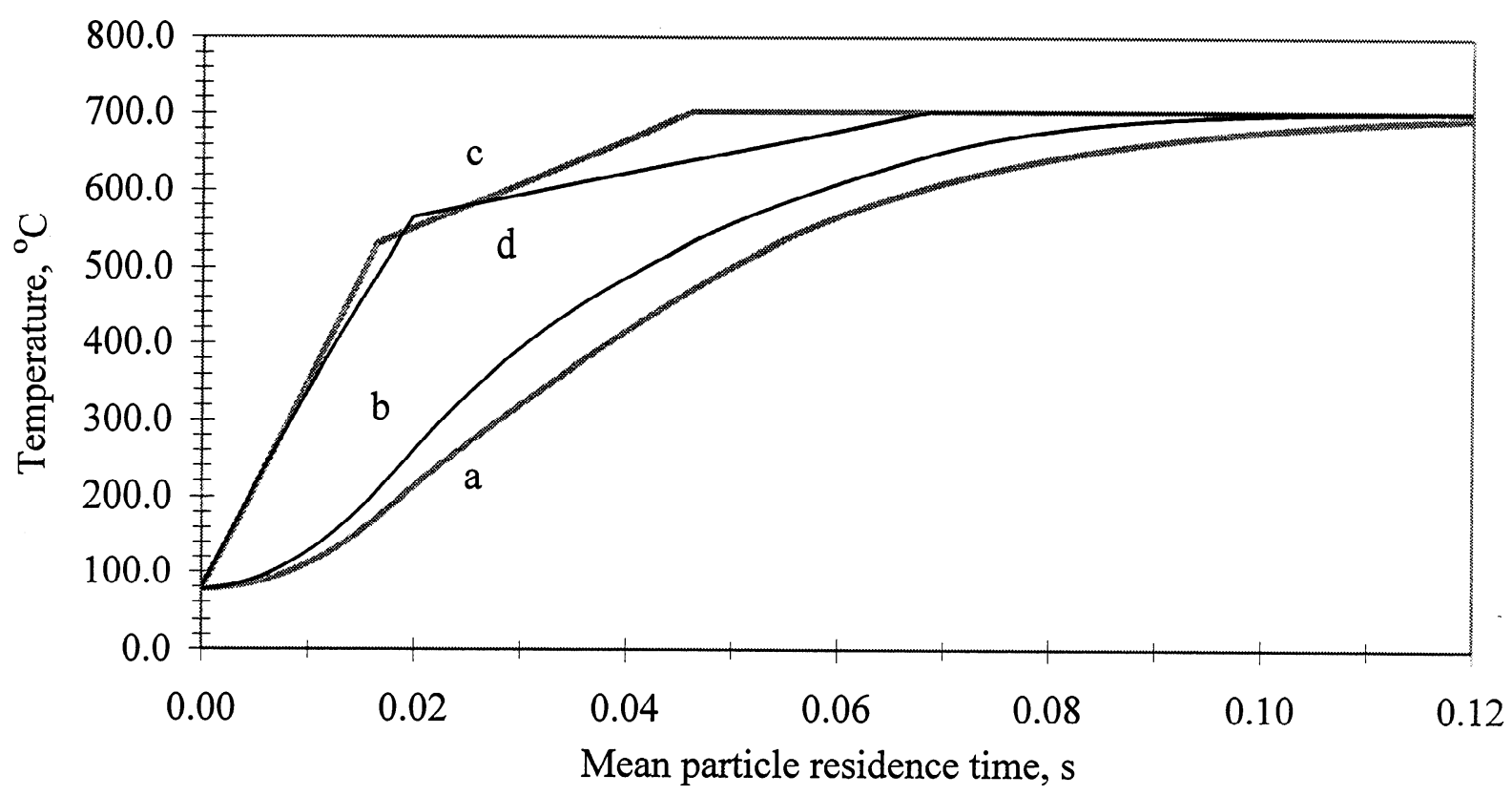

Figure A10.34. Model predicted heatup of inflight BLS particles to a peak gas temperature of $700^{\circ} \mathrm{C}$. Particle temperatures calculated (a) without acoustics (RNAC1123) and (b) with an acoustic field of $151 \mathrm{~dB}$ and $960 \mathrm{~Hz}$ (RAC1126A) using gas temperatures measured (c) with and (d) without acoustics.

\section{[A10.4] FORMULATION OF KINETIC MODEL TO ESTIMATE CARBON CONVERSION TO CHAR AND VOLATILES}

A kinetic model formulated by Howard et al. (1977) was used to test whether it was kinetically feasible to obtain the measured percent of the carbon in BLS as carbon in the char due to increased the rates of particle cracking reactions relative to the rates of particle polymerization reactions under rapid particle heating. Particles were rapidly heated under conditions of $151 \mathrm{~dB}$ at a gas temperature of $550^{\circ} \mathrm{C}$ or with and without acoustics at $700^{\circ} \mathrm{C}$. The model assumes pyrolysis proceeds by two parallel, first-order, irreversible reactions. One reaction proceeds at low temperatures and produces more carbon residue and less carbon volatiles. The other reaction proceeds only at higher temperatures and produces less carbon residue and more carbon volatiles. The two reactions can be expressed as, 


$$
\begin{aligned}
& C_{C B L S} \stackrel{k_{1}}{\longrightarrow}\left(1-Y_{1}\right) S_{1}+Y_{1} V_{1} \\
& C_{C B L S} \stackrel{k_{2}}{\longrightarrow}\left(1-Y_{1}\right) S_{1}+Y_{1} V_{1},
\end{aligned}
$$

where $C_{C B L S}$ is the concentration of unreacted carbon in the BLS particle $\left(\mathrm{kg} / \mathrm{m}^{3}\right) ; S_{1}$ and $S_{2}$ are the concentrations of unreactive carbon formed that remains in the BLS particle, e.g., carbon that forms a char residue; $V_{1}$ and $V_{2}$ are the concentrations of the carbon volatile that are released from the BLS particle; $Y_{1}$ and $Y_{2}$ are the devolatization coefficients of reactions 1 and 2, and $k_{1}$ and $k_{2}$ are Arrhenius-type rate coefficients that can be expressed as,

$$
\begin{aligned}
& k_{1}=A_{1} \exp \left(-E_{1} / R T\right) \\
& k_{2}=A_{2} \exp \left(-E_{2} / R T\right),
\end{aligned}
$$

where $A_{1}$ and $A_{2}$ and $E_{1}$ and $E_{2}$ are the frequency factors and activation energies for reactions 1 and 2, respectively. The rate equations can be expressed as,

$$
\begin{aligned}
& \frac{d C_{C B L S}}{d t}=-\left(k_{1}+k_{2}\right) C_{C B L S} \\
& \frac{d V}{d t}=\frac{d V_{1}+d V_{2}}{d t}=\left(Y_{1} k_{1}+Y_{2} k_{2}\right) C_{C B L S} \\
& \frac{d S}{d t}=\frac{d S_{1}+d S_{2}}{d t}=\left[\left(1-Y_{1}\right) k_{1}+\left(1-Y_{2}\right) k_{2}\right] C_{C B L S .} .
\end{aligned}
$$

Eqs. A10.22-A10.24 were solved in Microsoft Excel using an Euler integration scheme (Canale and Chapra, 1988) with a time step of $\Delta t z=0.001 \mathrm{~s}$. The fraction of carbon in BLS as volatiles $V_{(i)}$ and unreactive carbon $S_{(i)}$ at the current time step can be expressed as, 


$$
\begin{aligned}
& V_{(i)}=V_{(i-1)}+\frac{d V}{d t} \Delta t z \\
& S_{(i)}=S_{(i-1)}+\frac{d S}{d t} \Delta t z .
\end{aligned}
$$

The concentration of carbon in the BLS particle that can still react after the current time step can be expressed as,

$$
C_{C B L S(i)}=C_{C B L S(i-1)}-\left(\frac{d V}{d t}+\frac{d S}{d t}\right) \Delta t z
$$

The concentration of total carbon remaining in the BLS particle $C_{T C(i)}$ after the current time step can be expressed as,

$$
C_{T C(i)}=C_{B L S(i)}+S_{(i)}
$$

$Y_{1}=0.15$ was chosen to be that achieved under the slowest particle heatup rate to a peak temperature of $550^{\circ} \mathrm{C}$, which was obtained without acoustics (RNAC1105) at $0.23 \mathrm{~s}$ particle residence time in the $0.18 \mathrm{~m}$ pyrolysis tube heated length. $Y_{2}=0.6$ was chosen to be that achieved under the fastest particle heatup rate and longest particle residence time to a peak temperature of $700^{\circ} \mathrm{C}$, which was obtained with acoustics (RAC1130B) at 1.15 s particle residence time in the $0.81 \mathrm{~m}$ pyrolysis tube heated length.

Temperatures of BLS particles during the heatup period were calculated using the numerical particle heatup model in Appendix 10. For cases without acoustics at a peak gas temperature of $550^{\circ} \mathrm{C}(\mathrm{RNAC1} 105)$ and with and without acoustics at $700^{\circ} \mathrm{C}(\mathrm{RAC} 1126 \mathrm{~A}$ and RNAC1127), particle temperatures during the heatup period were calculated assuming that 
particles experienced ambient gas temperatures that were measured along the pyrolysis tube centerline, as listed in Appendix 7. For the case with acoustics at a peak gas temperature of $550^{\circ} \mathrm{C}$ ( $\mathrm{RAC1107),} \mathrm{particle} \mathrm{temperatures} \mathrm{during} \mathrm{the} \mathrm{heatup} \mathrm{period} \mathrm{were} \mathrm{calculated} \mathrm{assuming} \mathrm{that}$ particles experienced an ambient gas temperature of $550^{\circ} \mathrm{C}$. This was done to account for the best possible increased mixing of the carrier gas jet and particles into the hot secondary gas.

The model best estimated the amount of char carbon obtained with and without acoustics at temperatures of 550 and $700^{\circ} \mathrm{C}$ when $E_{1} / R=0, E_{2} / R=7000, A_{1}=1.5$ and $A_{2}=10,000$. 


\section{[A11] APPENDIX 11. MISCELLANEOUS CALCULATIONS}

\section{[A11.1] SECONDARY GAS ACTUAL SPACE-TIME}

The secondary gas actual space-time $\Gamma$ in the reactor can be expressed as,

$$
\Gamma=\frac{V_{r}}{\dot{V}_{a}}
$$

where $V_{r}$ is the reactor volume which is the product of the pyrolysis tube heated length and the tube cross-sectional area $\left(0.0021656 \mathrm{~m}^{2}\right)$ and $\dot{V}_{a}$ is the actual volumetric feedrate of gas $\left(\mathrm{m}^{3} / \mathrm{s}\right)$ at an absolute temperature $T_{r}$, which can be expressed as,

$$
\dot{V}_{a}=\dot{V}_{S T P}\left(\frac{\min }{60 \mathrm{~s}}\right)\left(\frac{\mathrm{m}^{3}}{1000 \mathrm{~L}}\right) \frac{T_{r}}{273.15 \mathrm{~K}},
$$

where $\dot{V}_{S T P}$ is the total volumetric flowrate (slpm) under conditions of 1.01325 bar and $273.15 \mathrm{~K}$.

\section{[A11.2] ACOUSTIC CONDITIONS FOR A QUASI STEADY-STATE FLOW FIELD AROUND 106-125 $\mu \mathrm{m}$ DIAMETER PARTICLES}

A quasi steady-state flow field exists when the ratio of the displacement amplitude $\hat{a}$ of the oscillating flow to the sphere diameter $d_{p}$ is greater than 0.75 (Al Taweel and Landau, 1976). Using Eq. 8 and 10, the acoustic displacement amplitude can be expressed as,

$$
\hat{a}=\frac{\hat{p}}{2 \pi f \rho_{g} c}>0.75 d_{p} .
$$


The product of the velocity of sound and $\mathrm{N}_{2}$ density will be greatest at the minimum pyrolysis temperature of $400^{\circ} \mathrm{C}$ studied in this dissertation. $c=523 \mathrm{~m} / \mathrm{s}$ and $\rho_{g}=0.5028 \mathrm{~kg} / \mathrm{m}^{3}$ at a gas temperature of $400^{\circ} \mathrm{C}$. A quasi steady-state flow field will exist around $106-125 \mu \mathrm{m}$ diameter particles when $\hat{p}>154.9 \mathrm{~Pa}$ or $134.8 \mathrm{~dB}_{\mathrm{rms}}$ for $f \leq 1000 \mathrm{~Hz}$ at gas temperatures between $400-700^{\circ} \mathrm{C}$.

\section{[A11.3] BIOT NUMBER}

The Biot number provides a measure of the temperature drop in a solid relative to the temperature difference between the solid and the fluid (DeWitt and Incropera, 1990). When the Biot number is less than about 0.1 , the resistance to conduction in the solid is much less than the resistance to convection across the fluid boundary layer. The Biot number Bi for a sphere can be expressed as ,

$$
\mathrm{Bi}=\frac{h d_{p}}{6 k_{B L S}},
$$

where $h$ is the convection coefficient for a sphere and $k_{B L S}=0.335 \mathrm{~W} / \mathrm{m} \bullet \mathrm{K}$ is the thermoconductivity of dry BLS. The thermoconductivity was assumed to be one-half that of water (Adams and Frederick, 1988) at $77^{\circ} \mathrm{C}$, which was the temperature of particles at the exit of the particle injection tube. The Biot number was calculated for a $125 \mu \mathrm{m}$ diameter dry soda-AQ black liquor particle exposed to $\mathrm{N}_{2}$ at temperatures of 550 and $700^{\circ} \mathrm{C}$. The relative slip velocity between the particle and the gas was assumed to be the maximum acoustic velocity at sound pressure levels of 151 and $158 \mathrm{~dB}$, approximately $4.3 \mathrm{~m} / \mathrm{s}$ and $11 \mathrm{~m} / \mathrm{s}$, respectively. Biot numbers for all cases were near or slightly under the criterion of $<0.1$ for assuming that 
temperature resistance to conduction in the solid is much less than the resistance to convection across the fluid boundary layer, as shown in Table A11.1.

Table A11.1. Biot number of $125 \mu \mathrm{m}$ diameter BLS particles calculated at temperatures of 550 and $700^{\circ} \mathrm{C}$ and relative slip velocities between $4.3-11 \mathrm{~m} / \mathrm{s}$.

\begin{tabular}{|l|r|r|r|r|}
\hline Variable & \multicolumn{2}{|c|}{$\mathbf{5 5 0}^{\mathbf{0}} \mathbf{C}$} & \multicolumn{2}{|c|}{$\mathbf{7 0 0}^{\mathbf{0}} \mathbf{C}$} \\
\hline$U_{r}, \mathrm{~m} / \mathrm{s}$ & 4.3 & 11 & 4.3 & 11 \\
\hline$k_{g}, \mathrm{~W} / \mathrm{m} \bullet \mathrm{K}$ & 0.05593 & 0.05593 & 0.06335 & 0.06335 \\
\hline$\rho_{g}, \mathrm{~kg} / \mathrm{m}^{3}$ & 0.4103 & 0.4103 & 0.3469 & 0.3469 \\
\hline$\mu_{g}, \mathrm{~N} \bullet \mathrm{s} / \mathrm{m}^{2}$ & 0.0000355 & 0.0000355 & 0.0000393 & 0.0000393 \\
\hline $\mathrm{Pr}$ & 0.716 & 0.716 & 0.721 & 0.721 \\
\hline$h, \mathrm{~W} / \mathrm{m}^{2} \bullet \mathrm{K}$ & 1492 & 1850 & 1606 & 1961 \\
\hline $\mathrm{Bi}$ & 0.093 & 0.115 & 0.10 & 0.122 \\
\hline
\end{tabular}




\section{[A12] APPENDIX 12. DESIGN OF EJECTOR}

The ejector design used a convergent-divergent nozzle inside of a tube. Under conditions of maximum vacuum, pumping air was designed to flow through the throat at sonic velocity, accelerate to supersonic velocities through the nozzle, and exit the nozzle with an abrupt transition from supersonic to subsonic velocity, generating a normal shock wave that propagates through the tube in the direction of flow (Street and Venard, 1982). The normal shock wave causes the pressure at the exit of the nozzle to jump from a lower to a higher value. Low pressure at the nozzle exit pumps pyrolysis product gas through the annulus between the nozzle and the tube. The pumped gas is entrained in the jet of air that exits the nozzle at high subsonic velocities. When the velocity of the pumping air through the nozzle is subsonic, gas is pumped through the annulus by entrainment in the jet.

The divergent nozzle cone is typically expanded at 15 degrees relative to its center axis (Vertzberger, 1994) as shown in a schematic diagram of the ejector in Fig. A12.1. Precise construction of the divergent section of a very small nozzle can be very difficult. Therefore, the ejector was over-sized, beyond the capacity necessary to vacuum the small quantity of pyrolysis product gas, so that it could be constructed precisely and easily, using standard-size tubing and fittings. The over-sized ejector was designed to be small enough so that it could operate at supersonic velocities, if required, with a pumping air flowrate of $\sim 50 \mathrm{~g} / \mathrm{s}$ and an absolute pressure of $7.68 \mathrm{kPa}$, which was the maximum pressure of the laboratory air system. Temperature of the laboratory air was approximately $20^{\circ} \mathrm{C}$. A high mass flowrate of air was used to ensure that pyrolysis product gases would be quickly diluted and carried through the $10 \mathrm{~cm}$ O.D., $15 \mathrm{~m}$ length, interior exhaust duct. An absolute pressure at the nozzle exit of $0.275 \mathrm{kPa}$ was designed 
to be obtained under conditions of maximum pumping air flowrate and pressure. The nozzle throat diameter $d_{t}$ can be calculated by,

$$
d_{t}=\frac{4 \dot{m}}{\pi p_{a}}\left[\frac{\gamma M}{R T_{g}}\left(\frac{2}{\gamma+1}\right)^{(\gamma+1) /(\gamma-1)}\right]^{-1 / 2},
$$

where $\dot{m}$ is the mass flowrate of pumping air and $p_{a}$ is the pressure of the pumping air. The throat diameter was calculated to be $5.86 \mathrm{~mm}$. The divergent section exit diameter $d_{e}$ can be calculated by,

$$
d_{e}=\frac{4 \dot{m}}{\pi p_{a}}\left\{\frac{2 \gamma M}{R T_{g}(\gamma-1)}\left[\left(\frac{p_{e}}{p_{a}}\right)^{2 / y}-\left(\frac{p_{e}}{p_{a}}\right)^{(\gamma+1) / y}\right]\right\}^{-1 / 2},
$$

where $p_{e}$ is the pressure at the nozzle exit. The divergent section exit diameter was calculated to be $11 \mathrm{~mm}$. The outer diameter of the nozzle body was chosen to be $13 \mathrm{~mm}$. A standard-size, 19.05 mm O.D. by $17.27 \mathrm{~mm}$ I.D., $304 \mathrm{SS}$ tube was placed around the nozzle body, which formed a $2.135 \mathrm{~mm}$ annulus between the nozzle body and the tube. The straight length of the 19.05 mm O.D. tube was $170 \mathrm{~mm}$, typically designed to be at least ten times longer than the inside diameter of the tube (Vertzberger, 1994). Pyrolysis product gas was introduced into the annulus through a $73.03 \mathrm{~mm}$ O.D. (2.5" IPS) tee-section. 


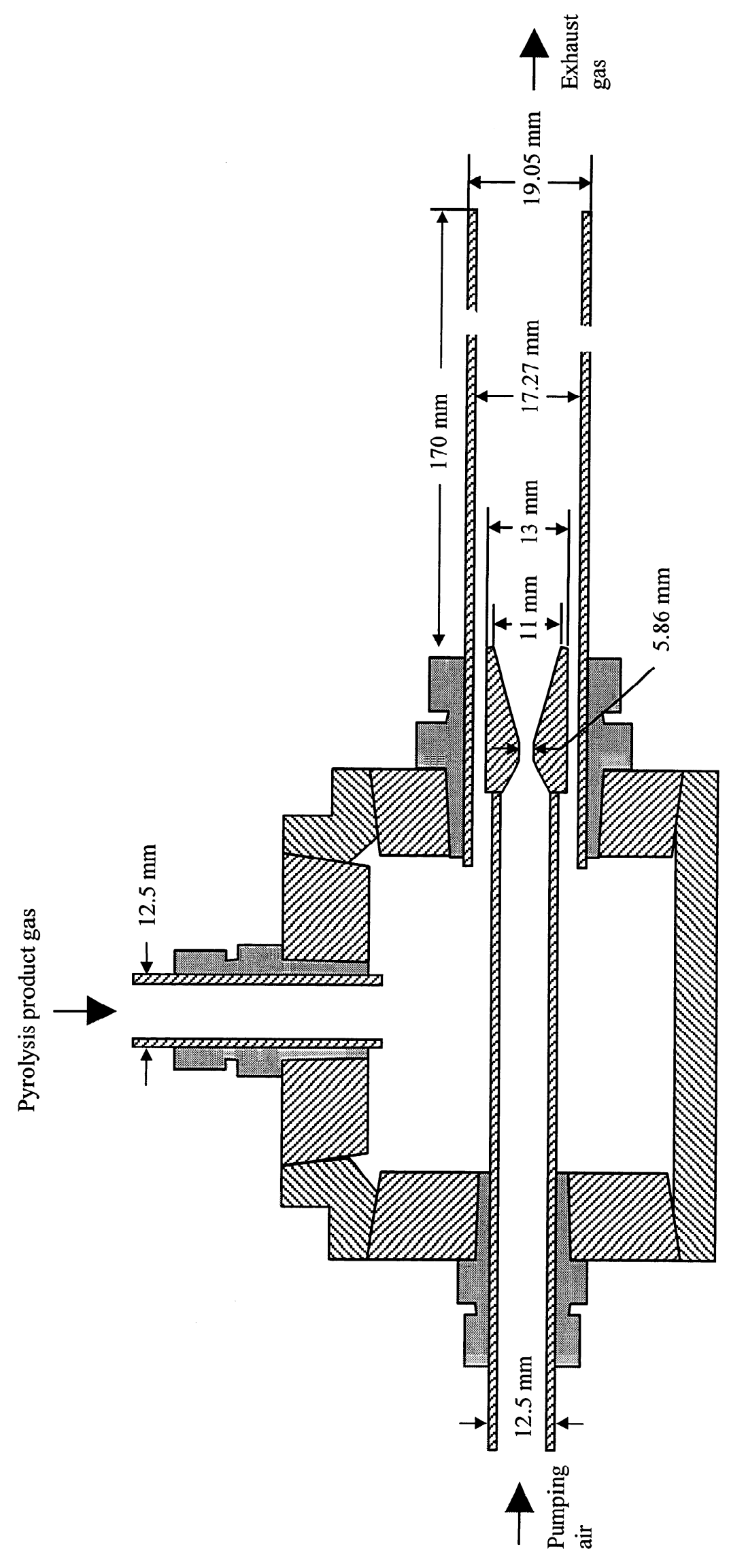

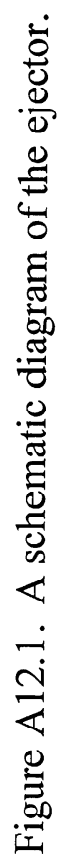



